\title{
$Q \mathrm{QL}$ \\ 444 \\ M33E33 \\ 1890 INVZ
}

incon

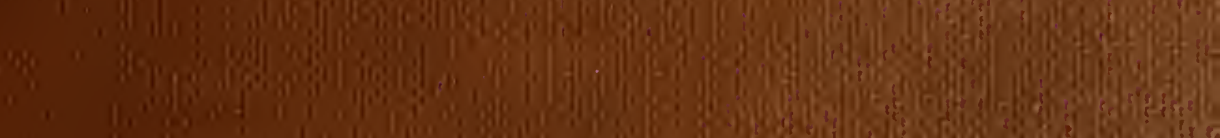




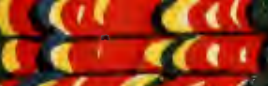
$\operatorname{coc}(\mathrm{C})$

(Q)

4

161

c aria

c a id

icirice

crect

icerec

(c)

cactices

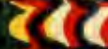

ias (is

- vir ce réco

$1 / \cos (6)$

cor a

cir suras race

cilce

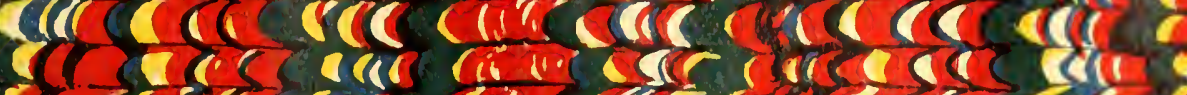

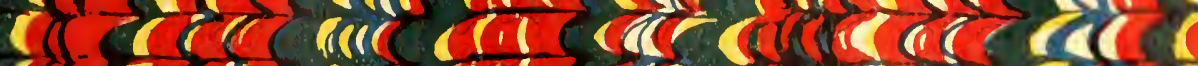

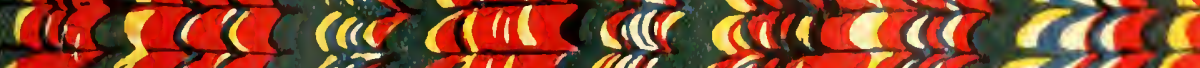

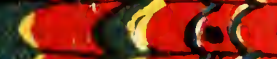

res cor

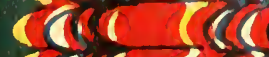

$\operatorname{sich}$

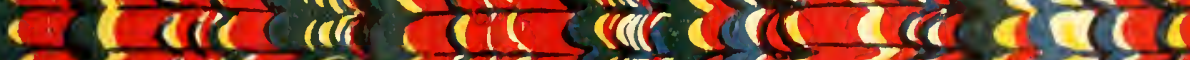

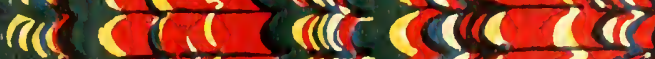

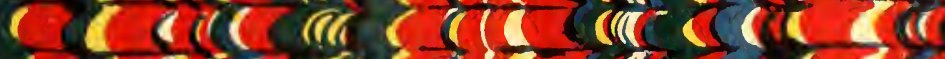

aciscos $x$

ब(ce $140<$

$\operatorname{lol}_{1}$

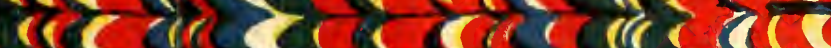

(c)

cinesicin

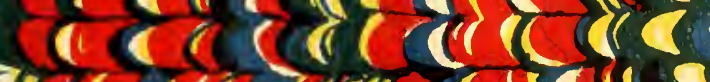

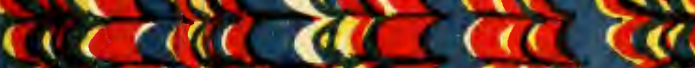

cicisece

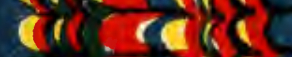

$\cos \cos$

$\cos <10$

rice are réte

ircere

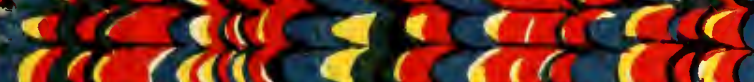

(lic) rec(i)

crer is

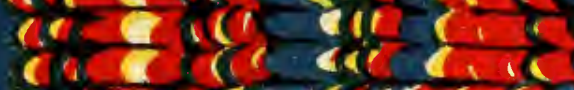

$c i s)^{2}$

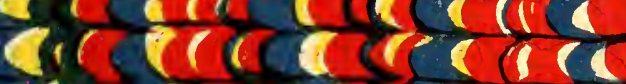

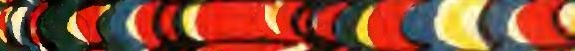

(a) a race coses

$\sum_{0}^{2}$

(a)

(

(c) C

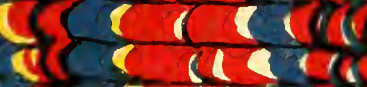

(C)

(c) 1

c

exerese

(in)

ceras

$x_{C}>-1$

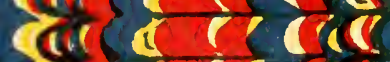

$\operatorname{sic}\left(\frac{1}{4}\right.$

(ii) a care

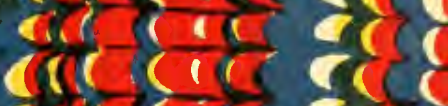

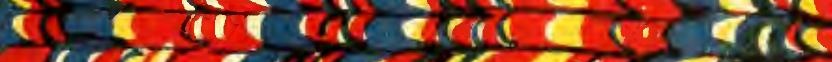

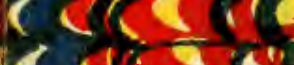
$\Rightarrow \operatorname{cis} 410$ iा

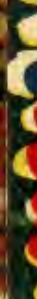

112

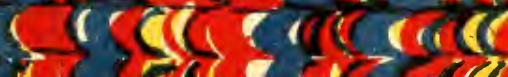

ca
cer
ara
aser
ice

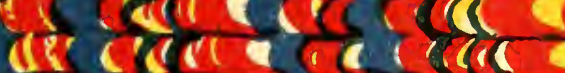

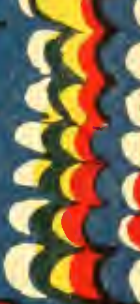
तार? 10

ar bug a ma

-

cerarar जो का? ise ic

काषि 710

तो दो

if

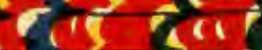

ivir curit

it 2110 दi

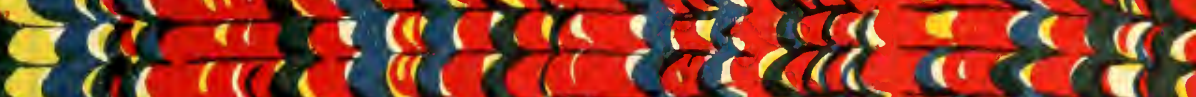

araras

Qदि

विiिa $\operatorname{coc} \mathrm{cos}$ arisica

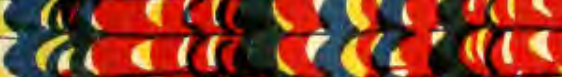

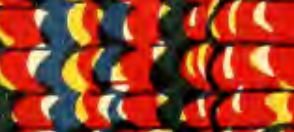

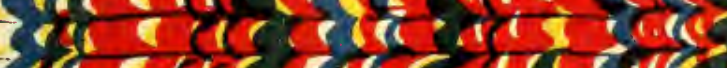

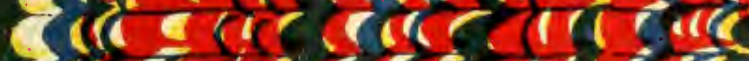

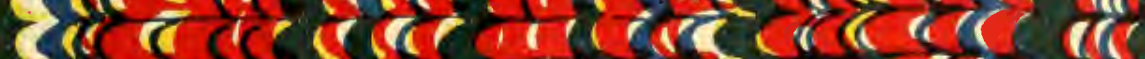

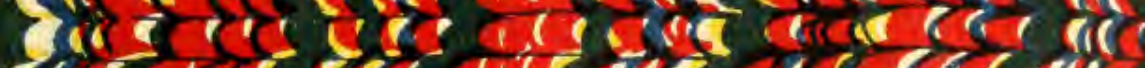

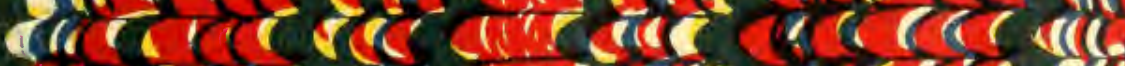

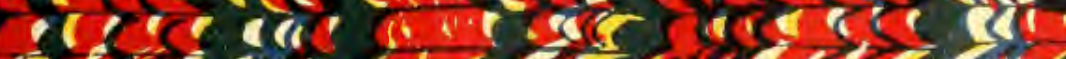

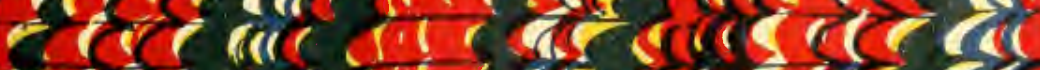
ire

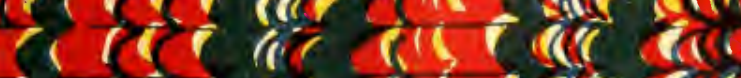
$\cos x \cos$

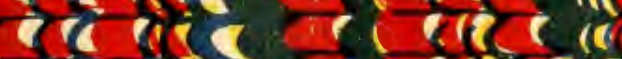

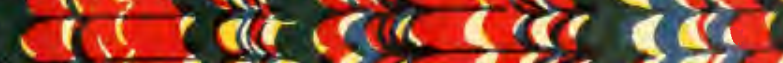

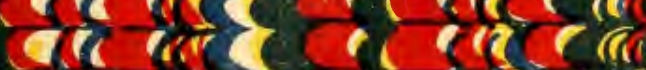
tis? sur $\cos 2$ $\rightarrow 2$ all 1 - 


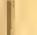





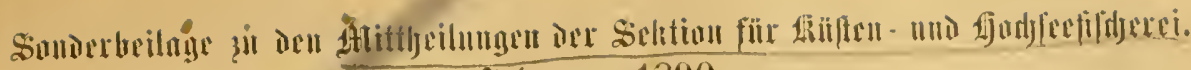

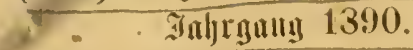

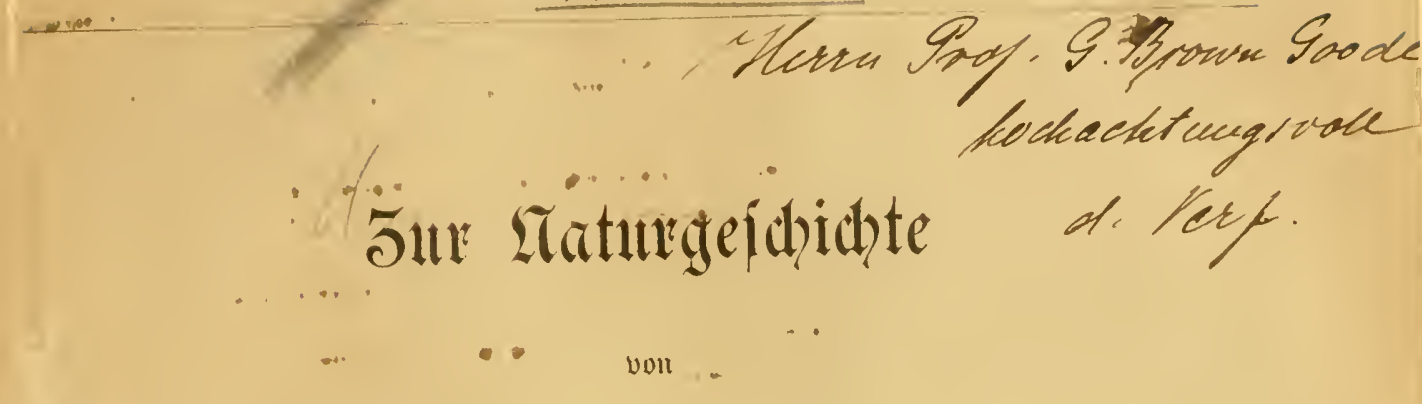

\section{Crangon vullgaris Fabr.}

Etuster über bau, Entwittung, Sebensweife und

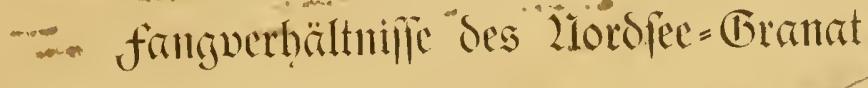

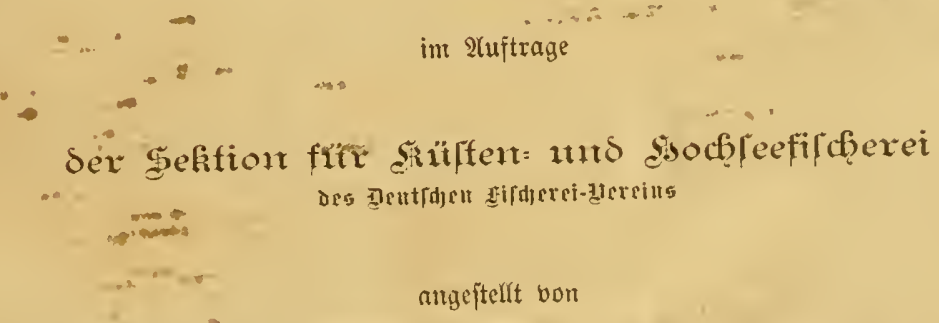

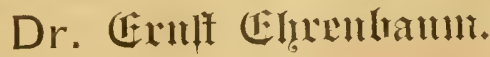

Berfit 1890.

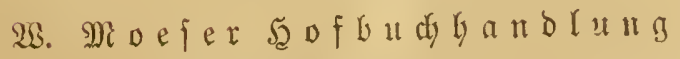

ङtallidureiber $=$ Etrape 34.35 . 



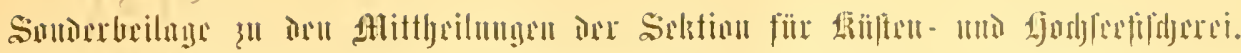
Inlyrgnn!y 1890.

\section{oum Saturge ibidible}

WoIt

\section{Crangon vulgaris Fabr.}

Stubicn übor bon, Entwitthno, Schensmeife mo

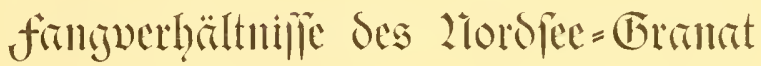

int $\mathfrak{2}(\mathfrak{u} \mathfrak{f t r a g e}$

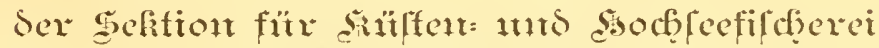

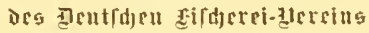

ongeftellt bon

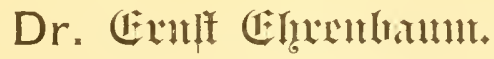

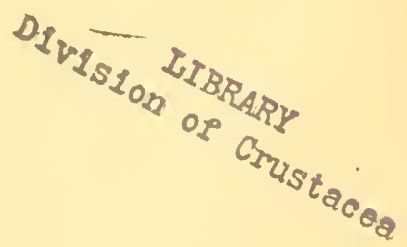

Bicrlin 1890.

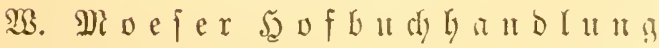





\title{
Dent hodnersienten förderer
}

\author{
ber
}

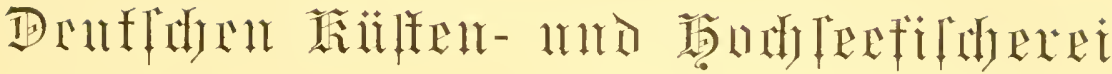

Königlichen Klofterkanmerbircftor

\section{Soctil sorwig}

in Danfbarfeit mo chrfurd)tswoll gewiomet

vom

Dexfallex. 



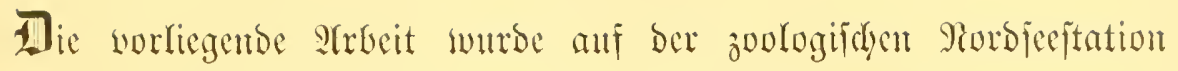
angefertigt, weldye int Frühjaly 1888 anf 3 seranlajilutg Der Eeftion für

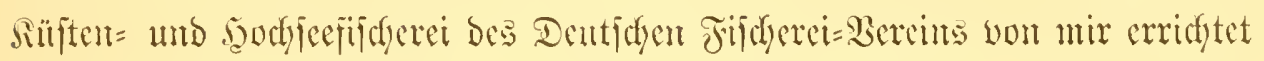
worben ijt.

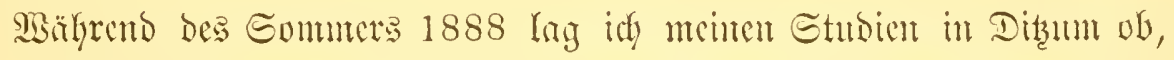
einem fleinem fiffyerborfe anf ber linfen Eeite Der Ems unweit Des

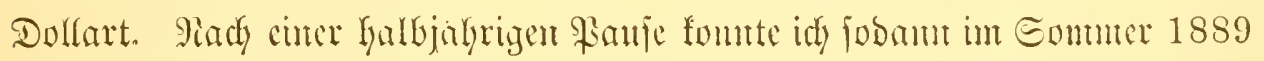

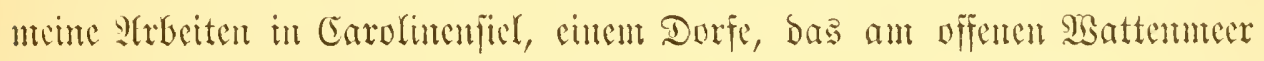
ber Jufel

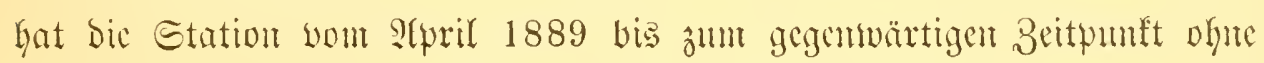
Innterbredjung Durdh Den WBinter ifyen Sis gehabt.

Earolimetifiel, bu 1. Mai 1890.

Dr. Ëgrenbnum. 



\section{Inllultsinllurlindt.}

હiutcitumg ................ E)

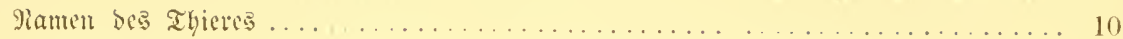

\$erbreituty ......................................... 10

Syjtematijus Eterlung ................................ 10

Berivanste Begleiter des Granat ............................ 11

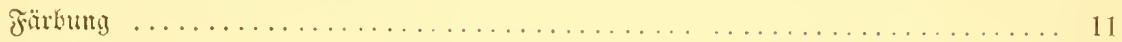

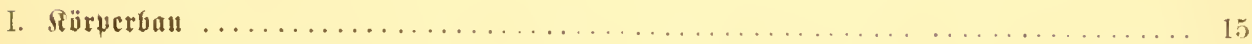

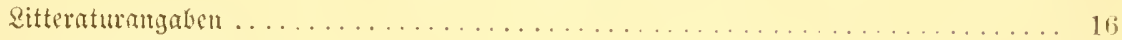

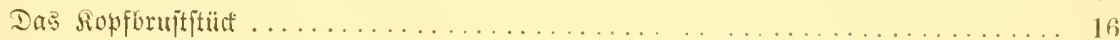

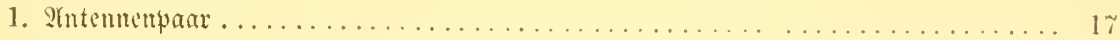

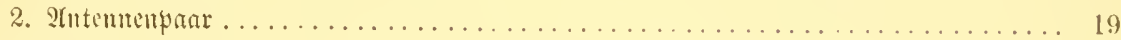

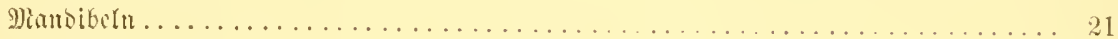

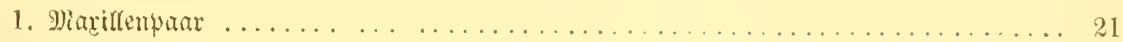

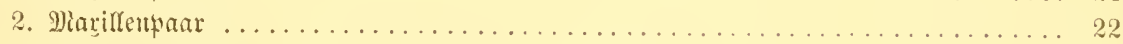

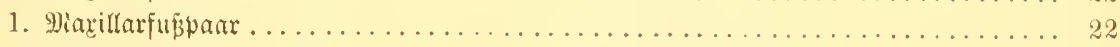

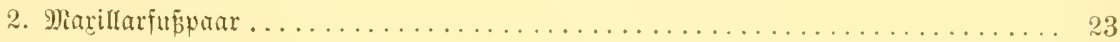

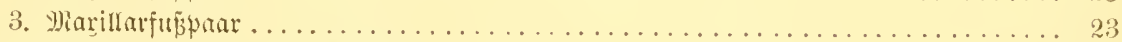

Dic Gangbeine mit ben Siemen .............................. 24

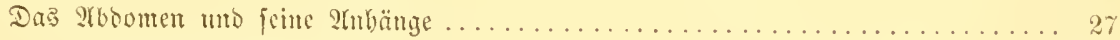

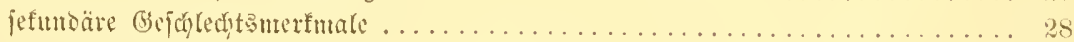

Эerbaung gatwerf

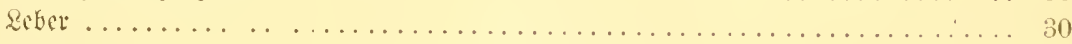

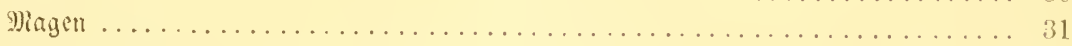

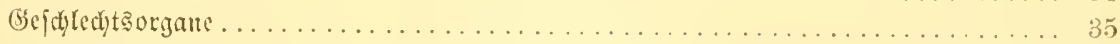

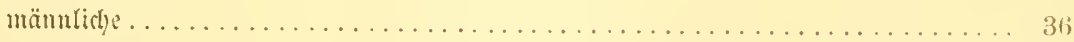

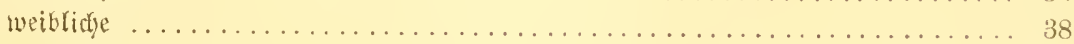

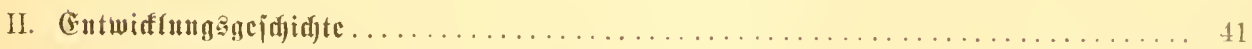

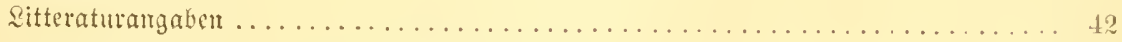

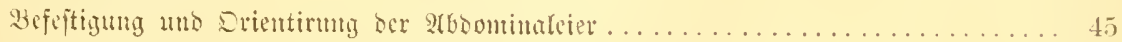

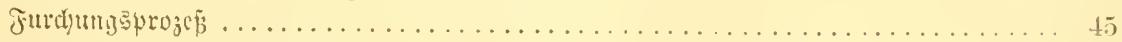

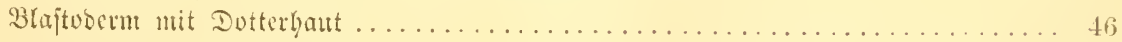

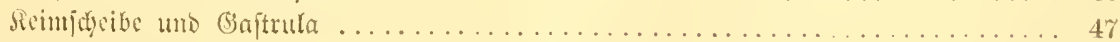

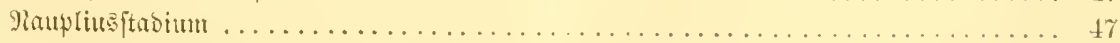

Embryo mit alten Earvengliesmapen ....................... 49

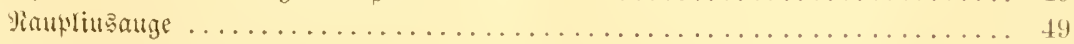

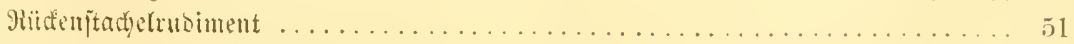

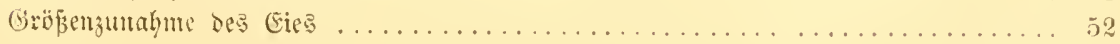


Siti

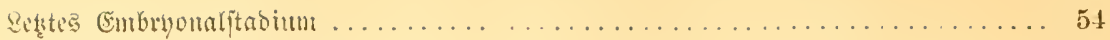

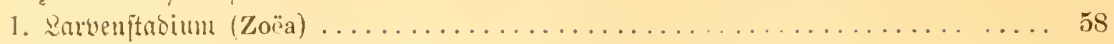

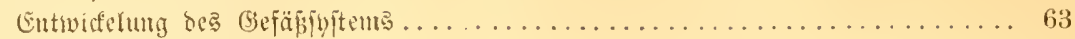

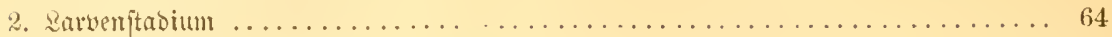

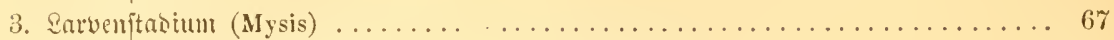

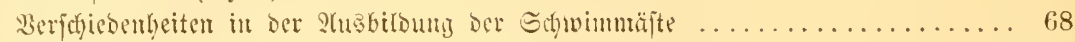

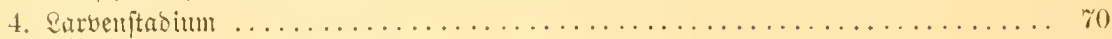

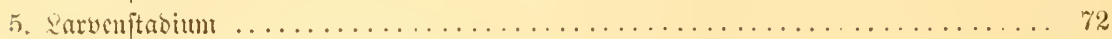

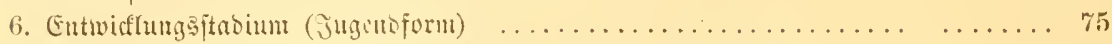

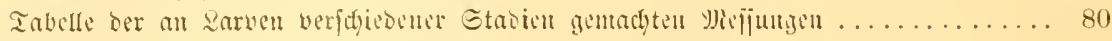

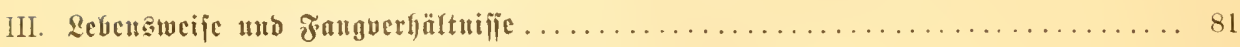

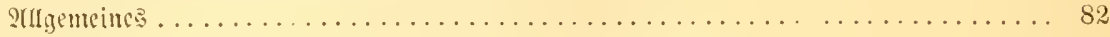

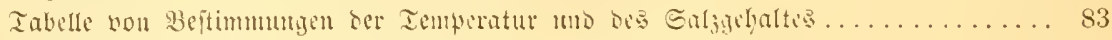

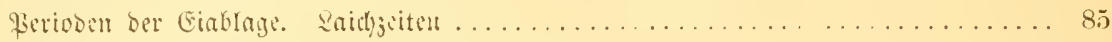

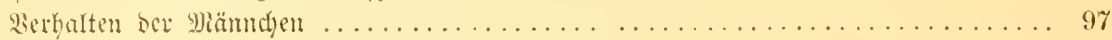

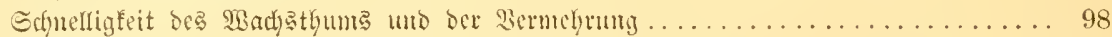

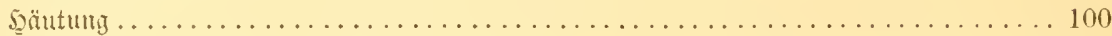

Erhaltung Des Granatbejtanse. . . . . . . . . . . . . . . . . . . 102

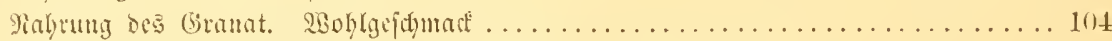

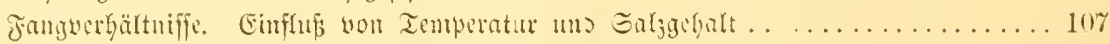

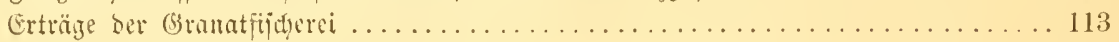

Anljuly.

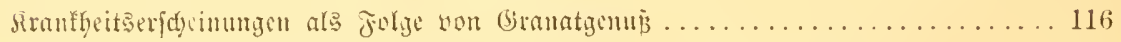

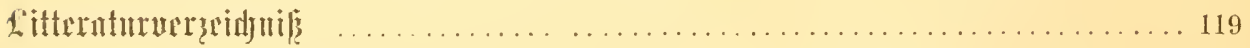

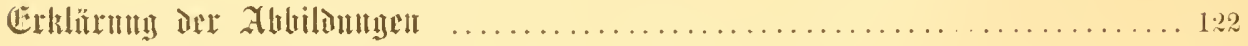




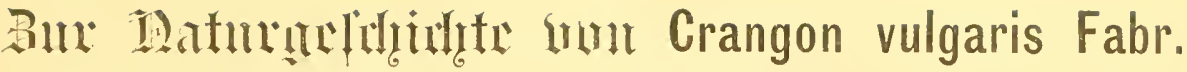

\author{
选i
}

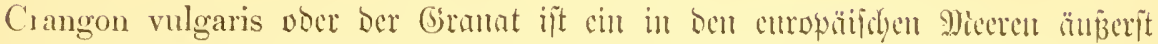

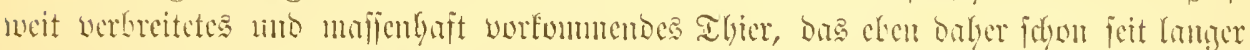

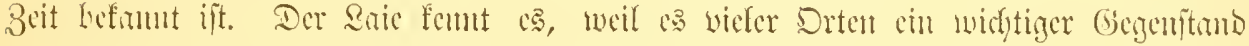

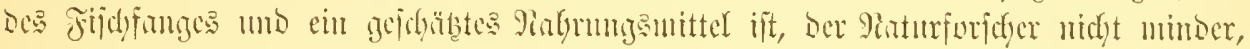

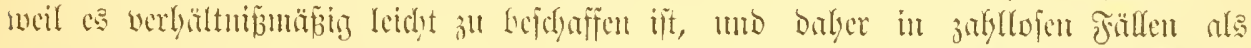

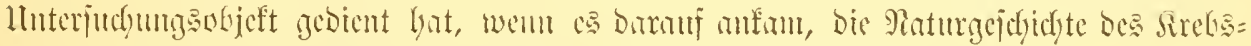

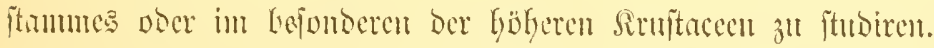

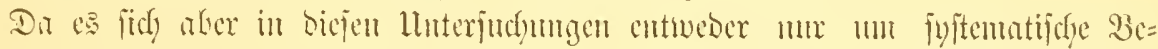

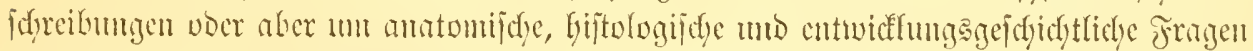

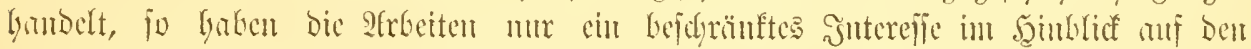

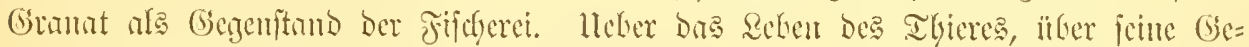

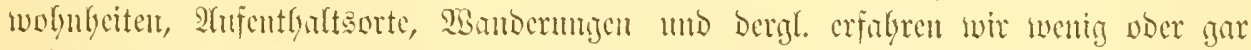

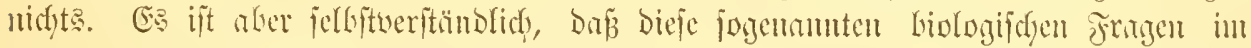

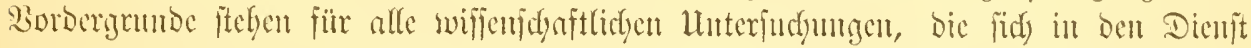

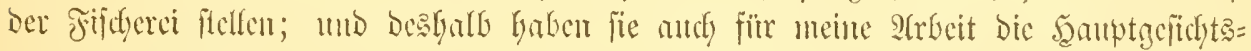
pumfte abgegelent.

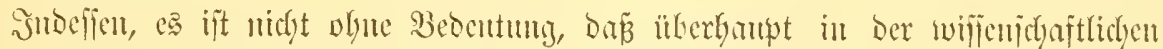

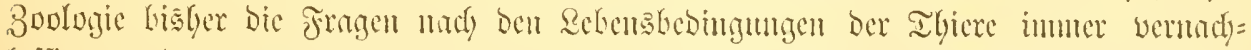

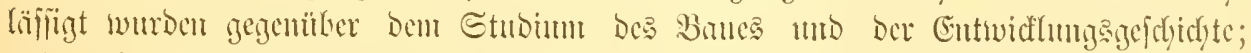

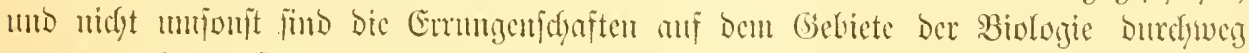

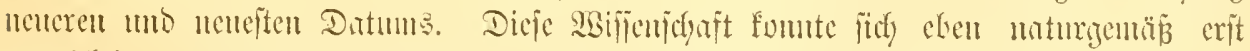

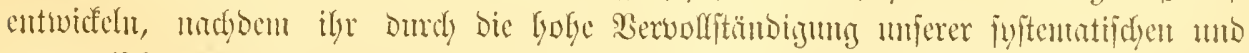

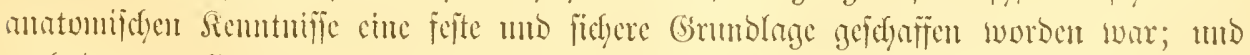

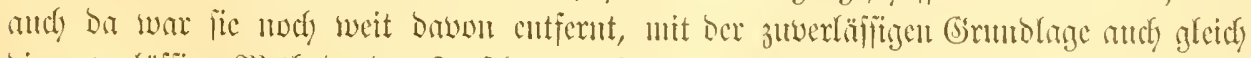

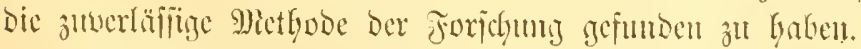

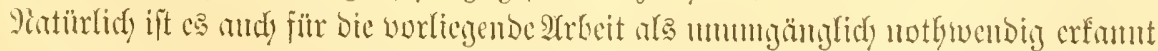

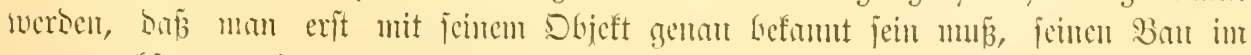

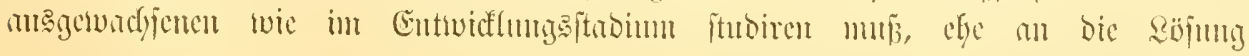




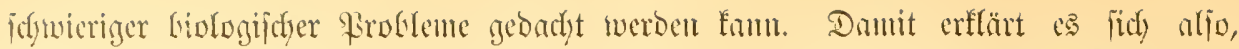

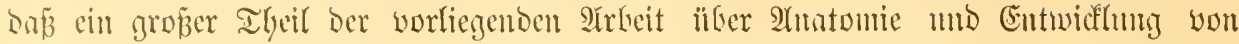

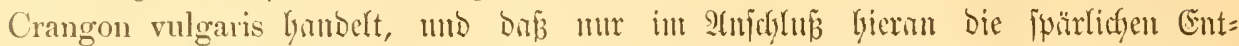

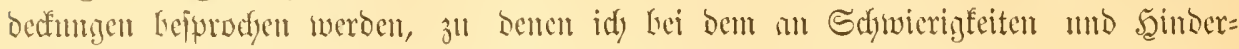

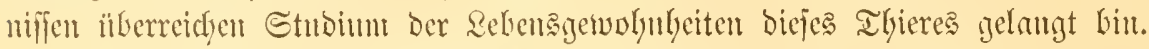

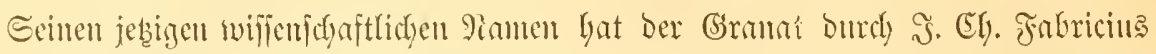

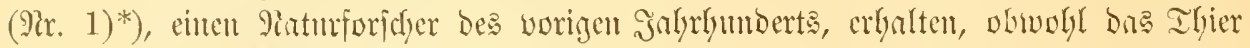

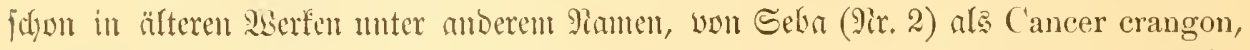

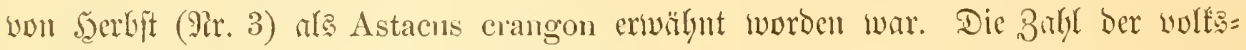

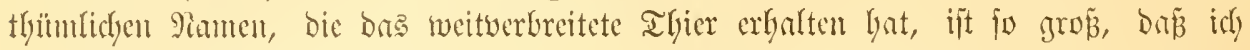

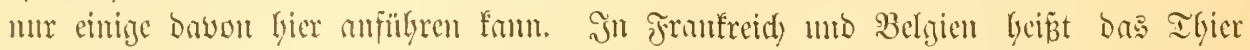
Crevette, in Englinto shrimp, and wolgl sand shrimp ober gray shrimp,

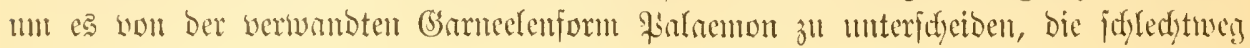

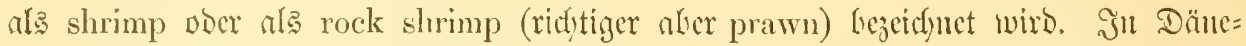

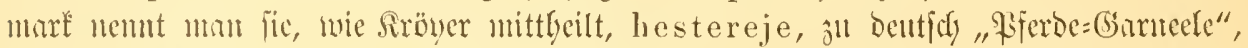

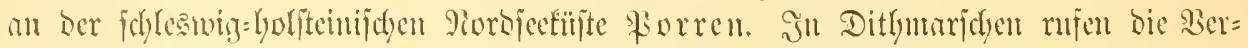

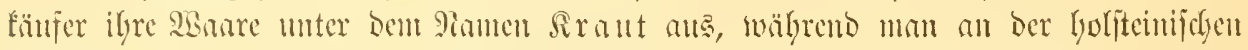

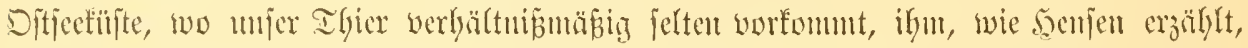

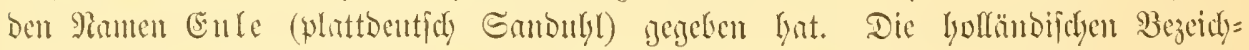

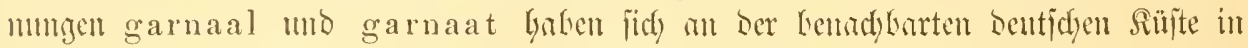

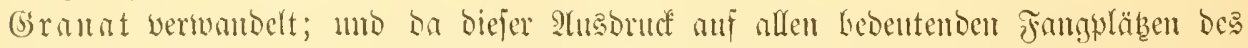

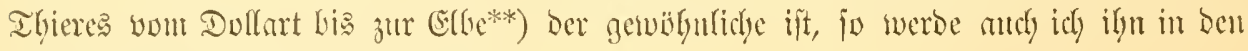
nadyfolgenden Şrättern getrandyen.

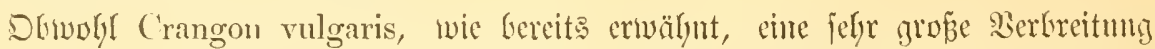

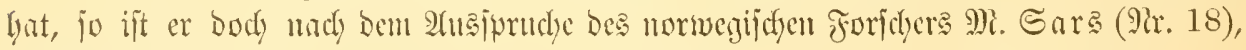

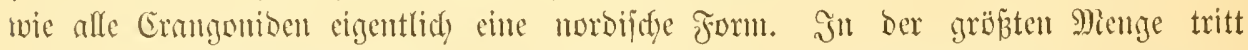

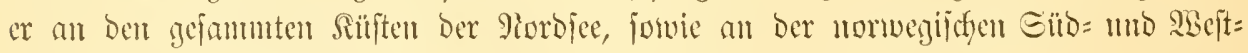

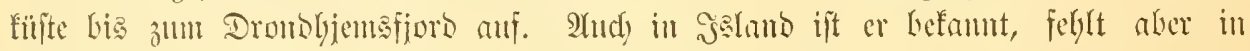

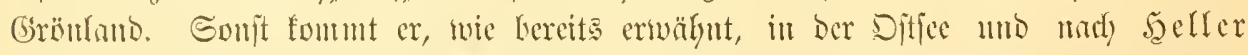

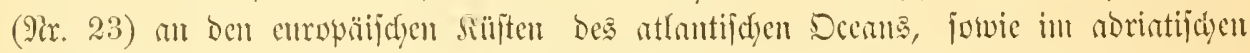

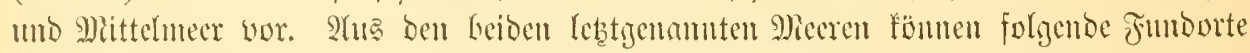

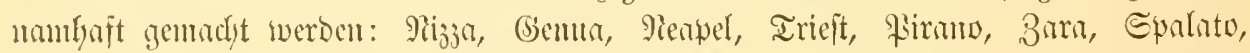

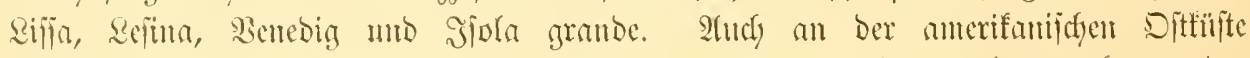

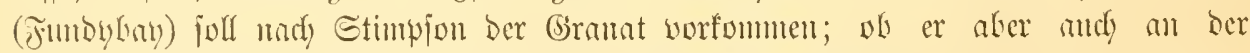

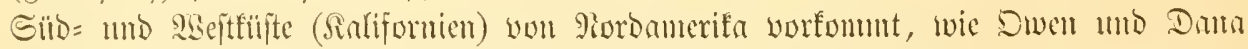

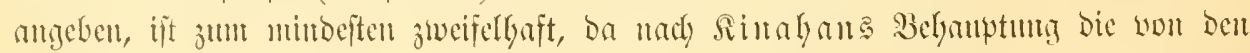

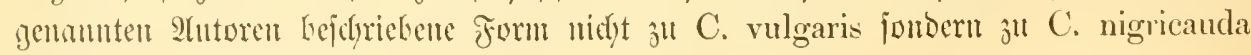
Stimpson jull reclynen ift.

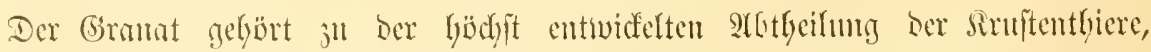

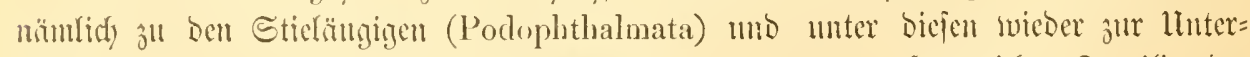

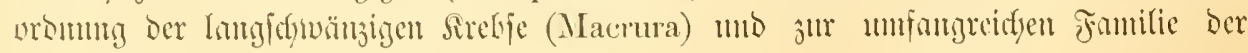

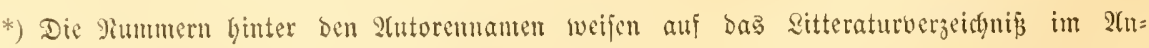
bang hitr.

**) Str ber êbe bezeidfnet mar bie Granat meijt ebcufo wie die Ditjeeganeelen (Palaemon)

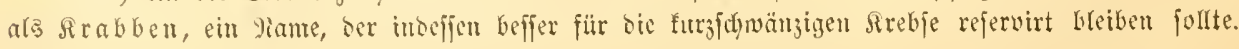




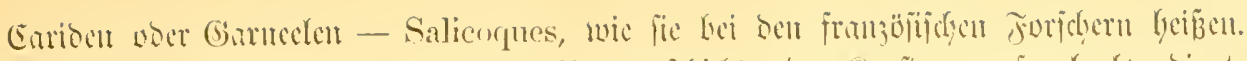

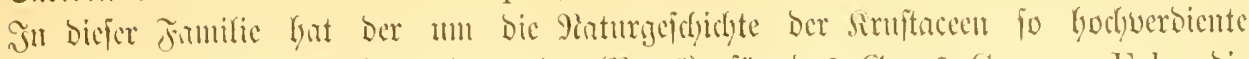

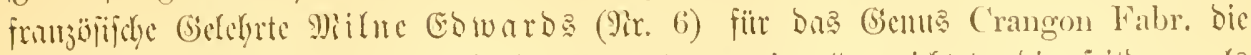

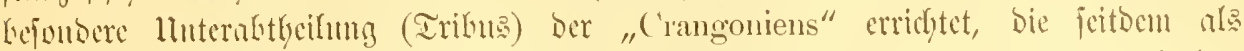
Crangoninae ober, wie man bäufiger ficft, ('rangonidae bunt ber Selftemntif bei=

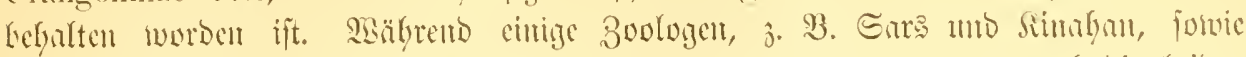

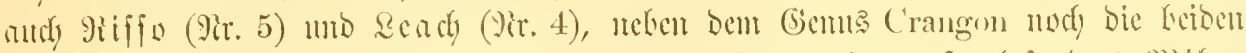
Ginttungen Egeon umb Pontophílus anfitelfen, find andere, fo befunbers Mitue EDbaros geneigt, affe bieje forment afs C'rangon jul vereinigen.

Sier intereffiren indejen felleft bie nädjfen Serwanoten won C. vulgaris mur

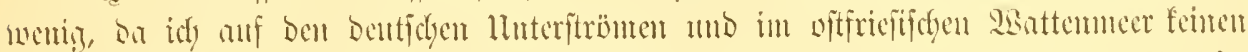

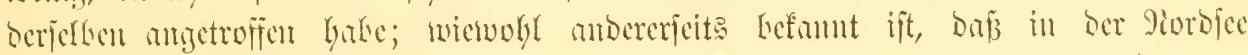
C. Allmanni Kinahan, ( . nanus líröyer uno ( . trispinosus Ilailstone vorfoumuten.

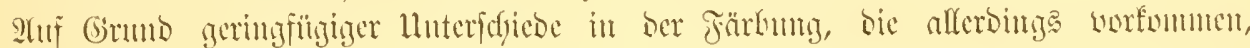

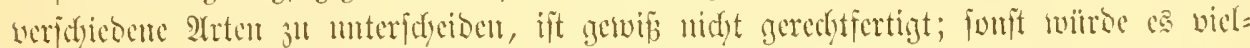

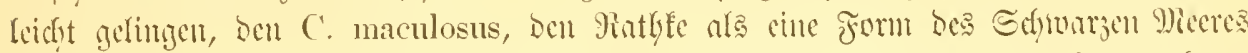

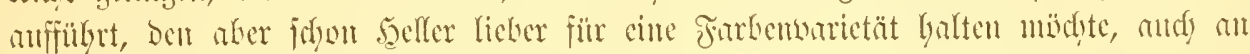
Der Porbfectiifte ivicberzufintioen.

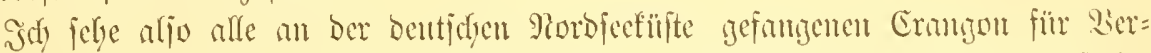

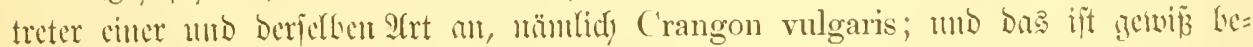

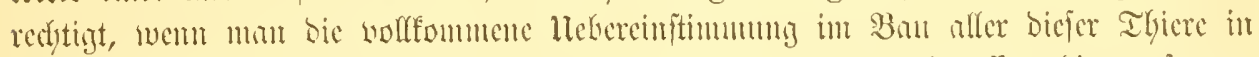

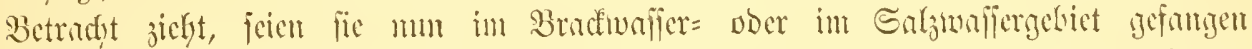

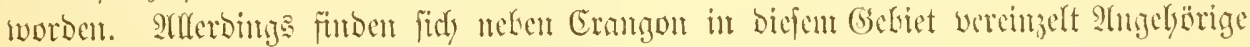

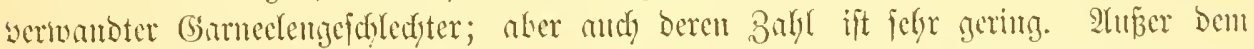

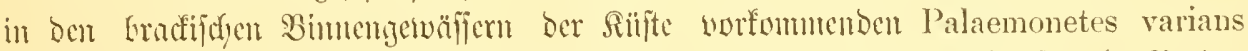

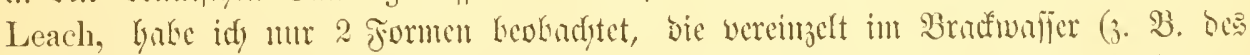

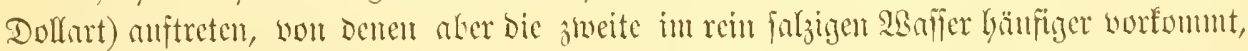

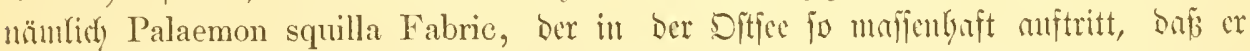
als Gejenftand Der Fijdyerei bort ben Erangon vertritt, unb Pandalus annulicornis Leach.

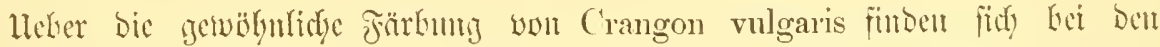

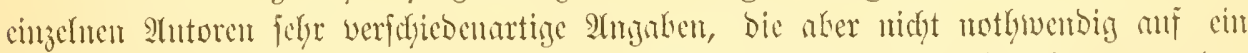

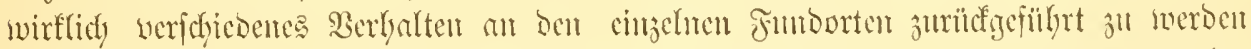

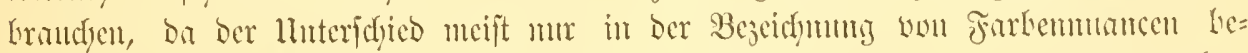

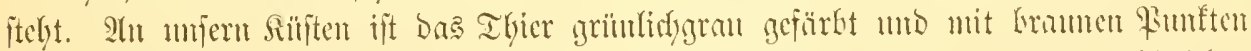

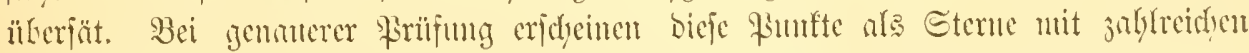

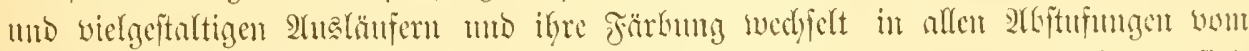

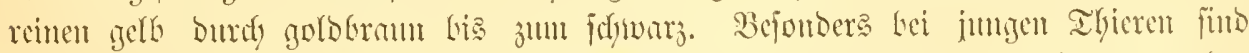

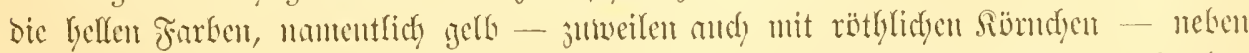

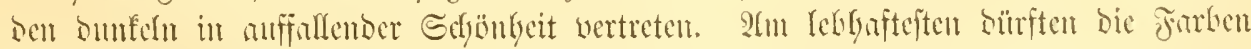

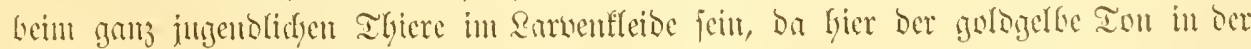

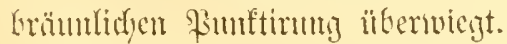

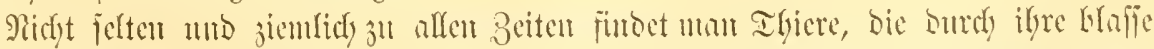

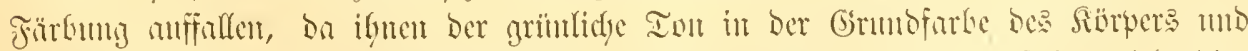

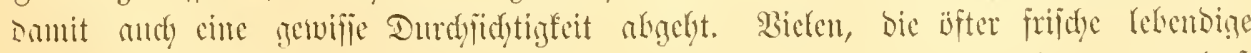

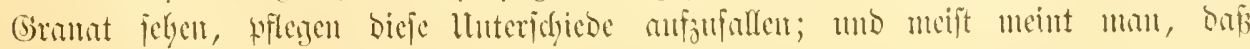




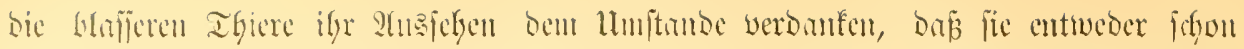

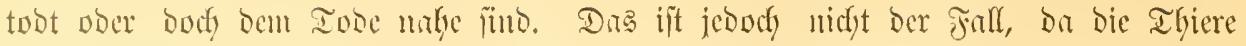

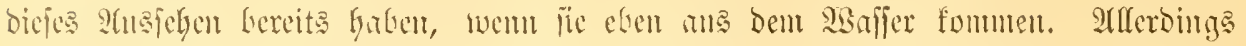

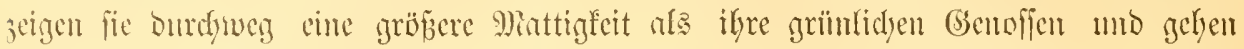

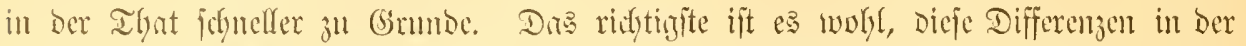

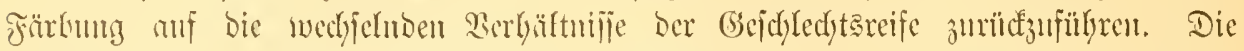
btaffen Gramat tringen niemale Eier an Sainterteib - jebr bereinzeft fanden fids

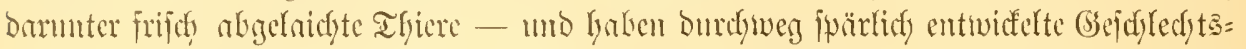

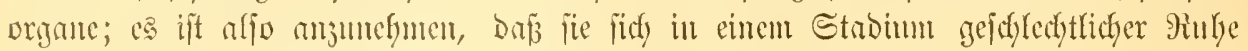

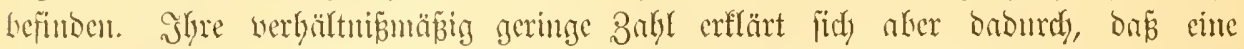

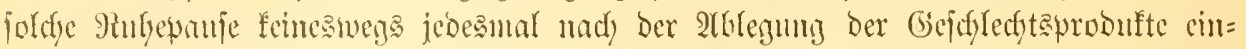

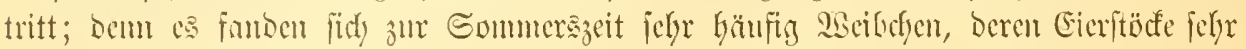

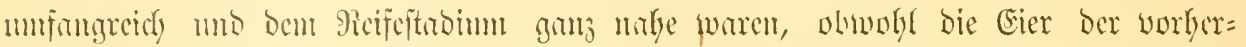

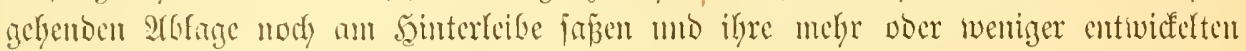

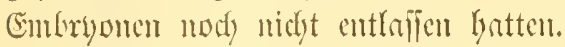

Bei ber Mebrzabl unjerer (Sranat, aber uidyt bei allen, finben fid) mner ben

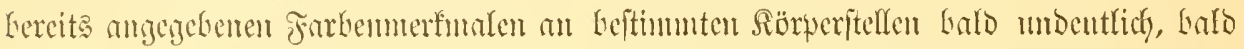

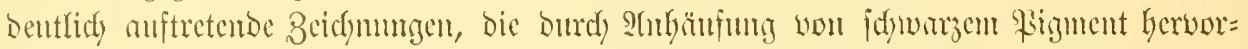

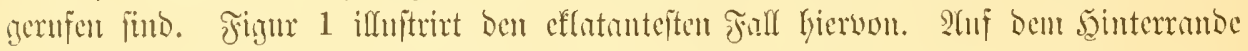

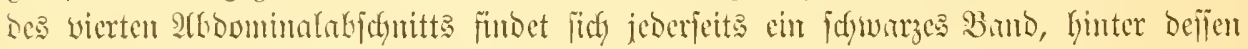

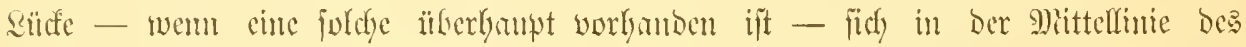

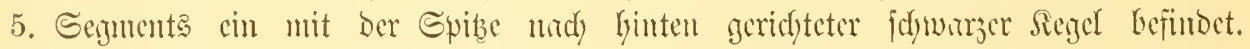

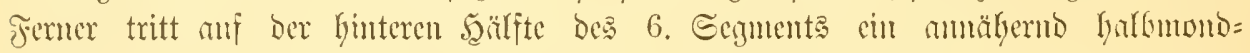

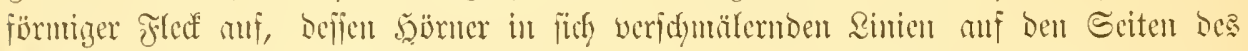

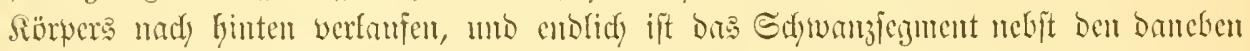

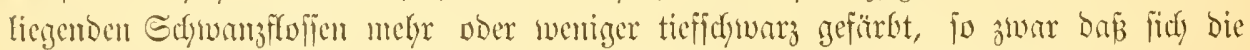

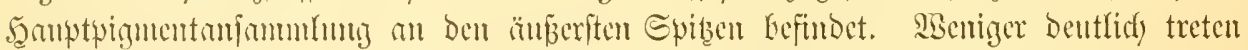

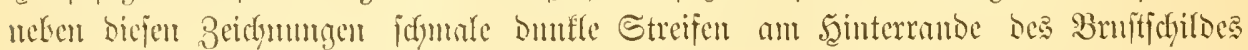

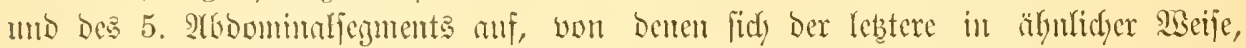

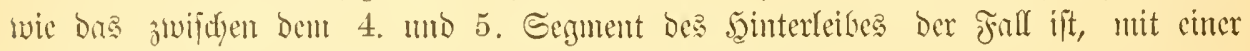
feiten Spibe anf bas nächiffolgende 6. Eegunent fortiebt.

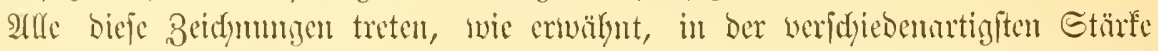

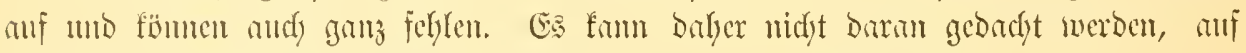

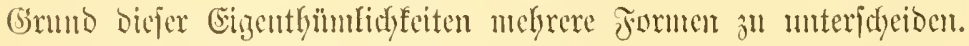

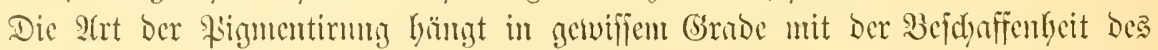

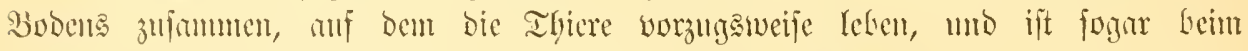

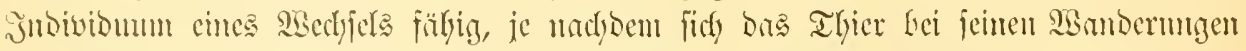

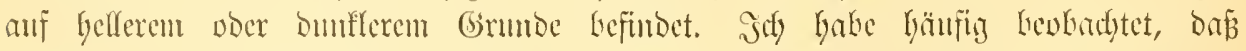

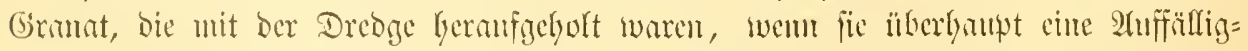

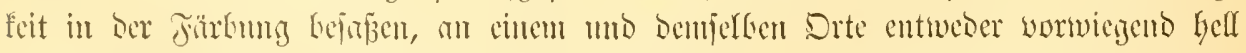

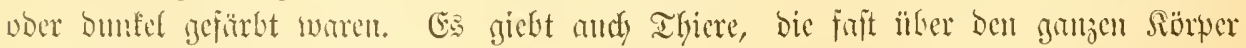
bidgt ichusirs pligmentirt jün.

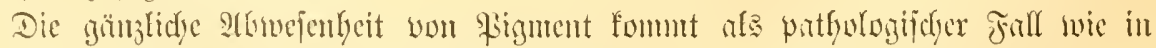

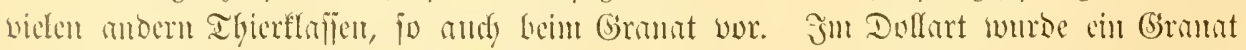

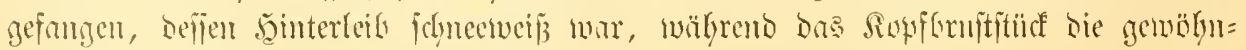
lidge Füroung gatte. 


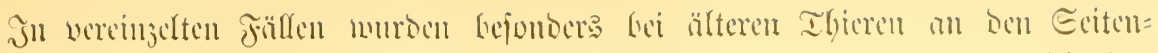

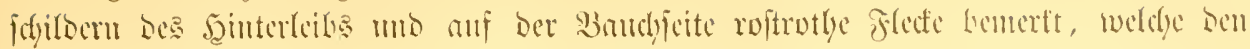

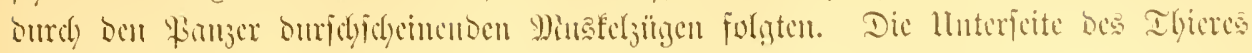

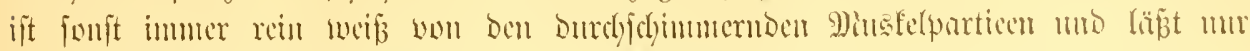

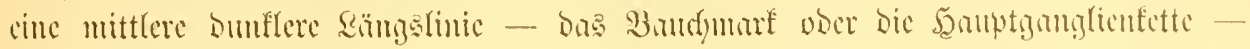
arfemint.

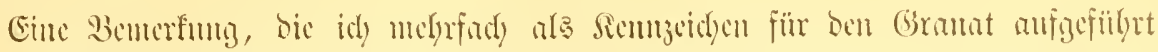

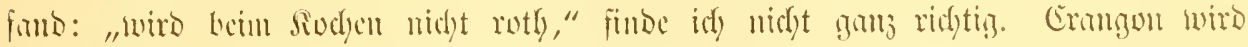

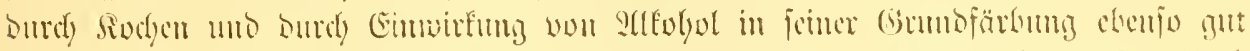

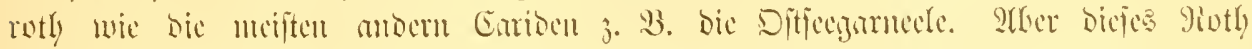

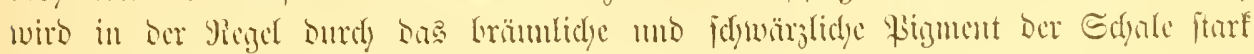

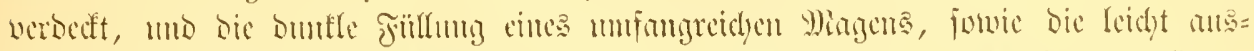

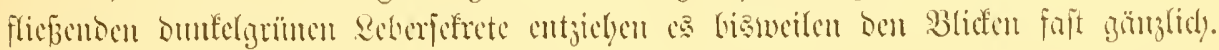



I. Sïrperfan. 


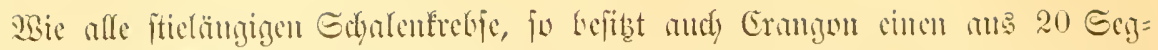

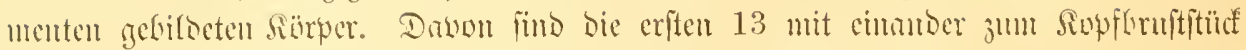

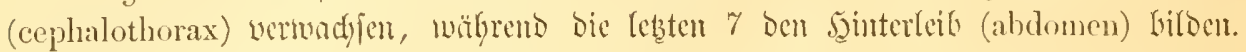

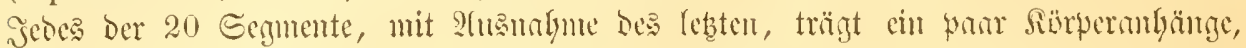

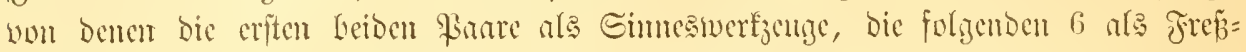

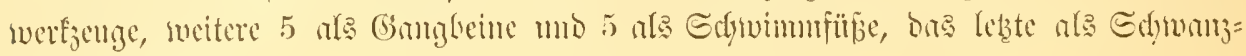
floffe funftionits.

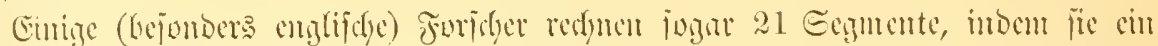

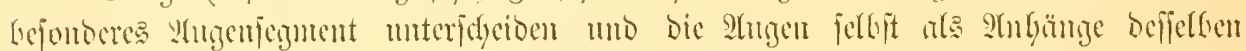

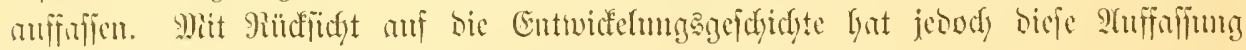
Ecute Lejondere sieredytigumis.

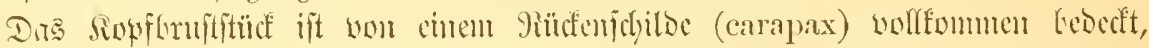

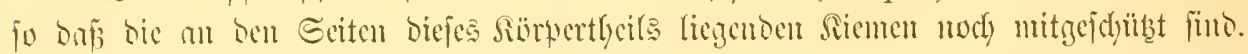

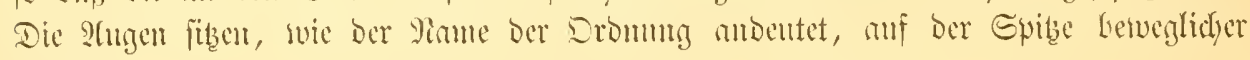
Eticle.

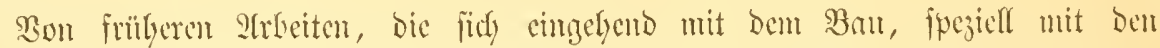

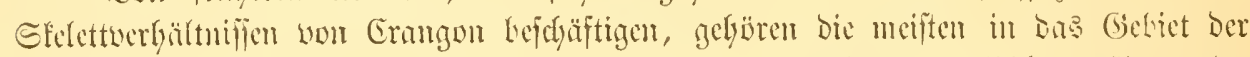

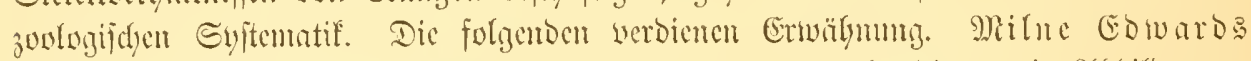

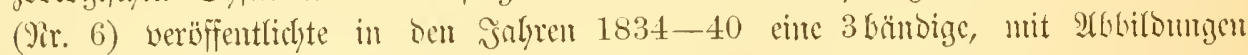

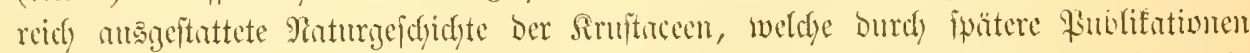
in ben Annales des sciences naturelles III. série (30. X, 1848, 200. XVIII, 1852, 3D. XX, 1853) wervollitündigt wurbe. Bon Den bereits mehrfach erwäbnten bäni=

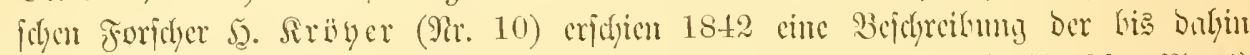

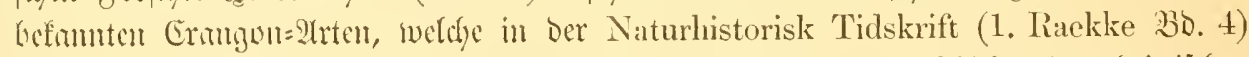

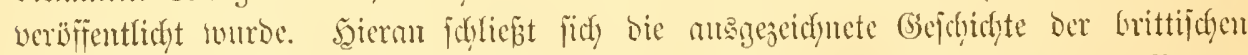

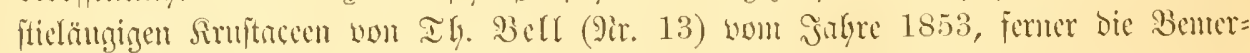

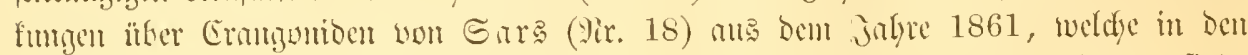
Forhandlinger i Videnskabs Selskabet i Cristiania (Aar 1860) erferienen fint;

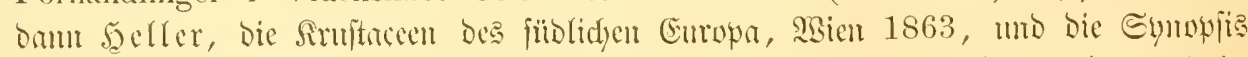

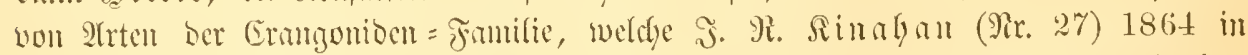
ben Proceedings of the Royal Irish Academy (BD. S) zu Dublin bcroffentlicyt Gatt.

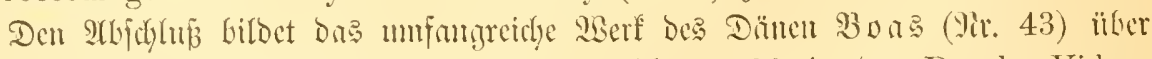
Dic Berwandichaftbezielyungen Der Defapooen, weldyes 1880 in ben Danske Videnskibernes Selskabs Skrifter (6. Raekke I, 2) erficicucu iit.

Dą Siouforujtjuild (carapax).

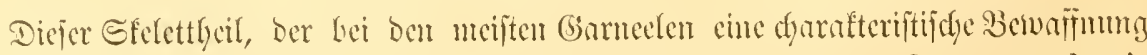

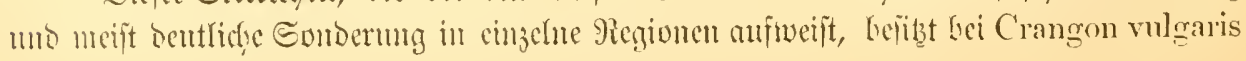




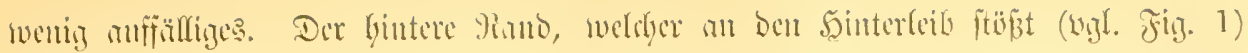

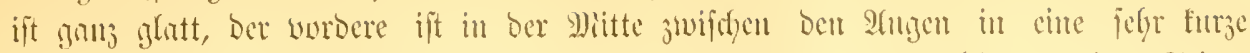

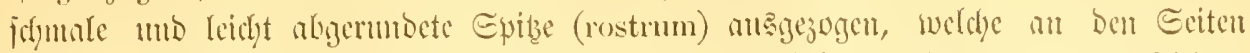

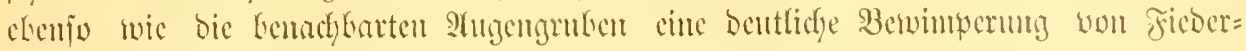
furften refibt.

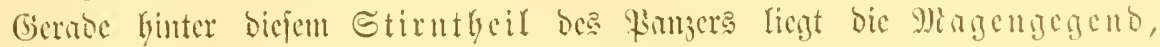

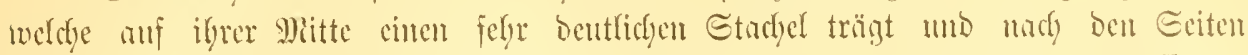

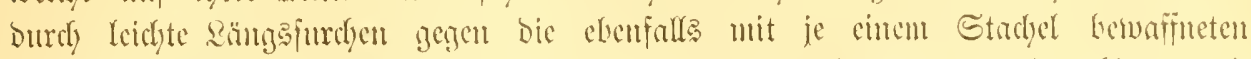

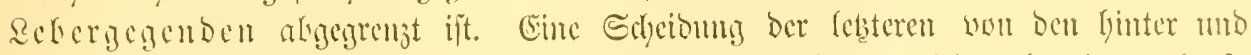

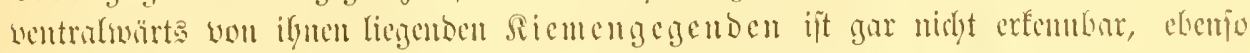

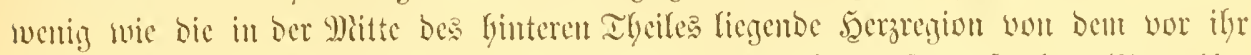

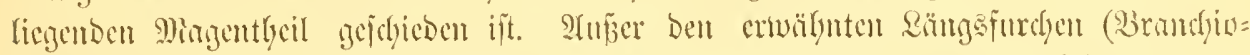

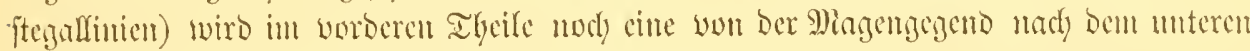

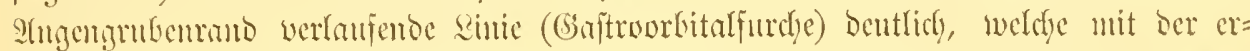

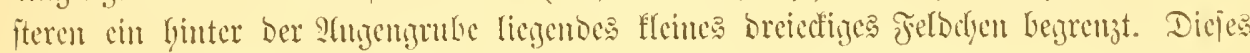

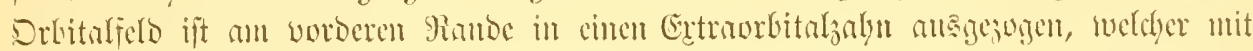

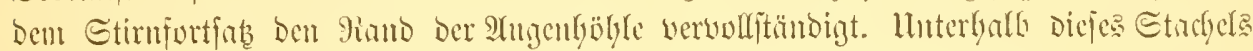

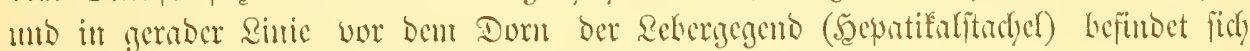

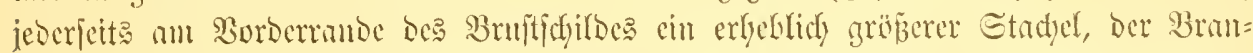

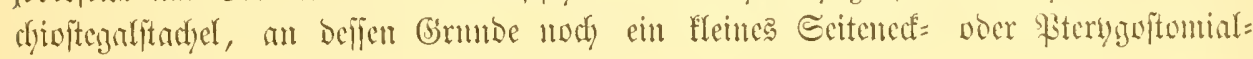
zälunct)en itbet.

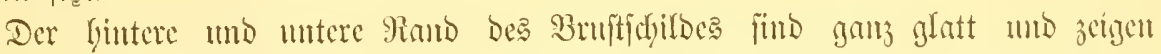

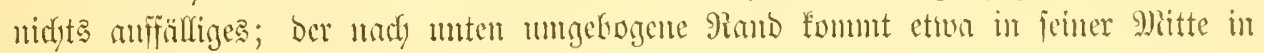

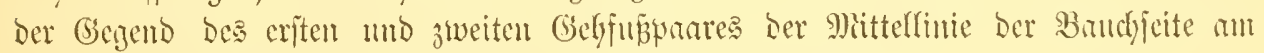

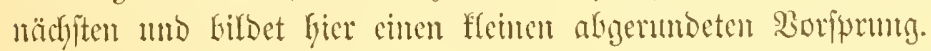

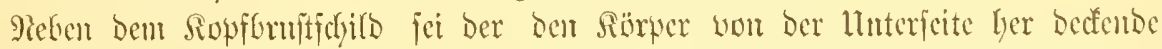

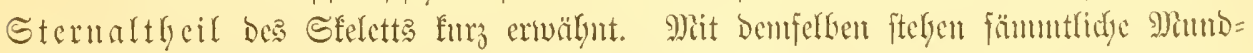

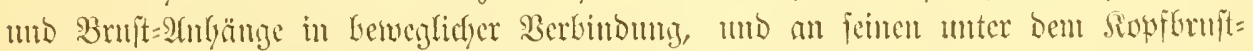

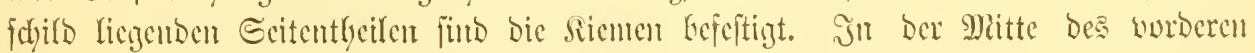

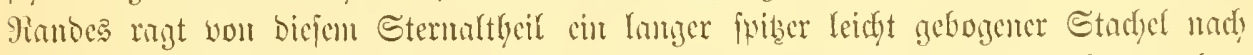

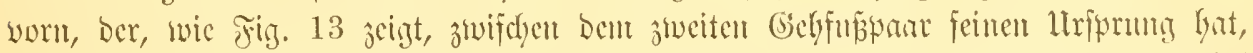

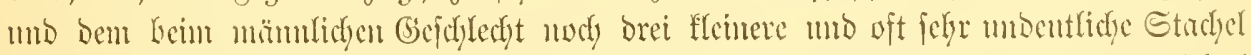

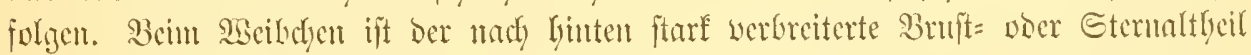
bes Sfelets wollfommen glatt.

\section{Die গ̛lüuge ocr Sopforult (cephalothorax).}

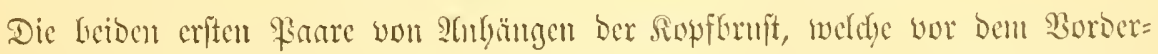

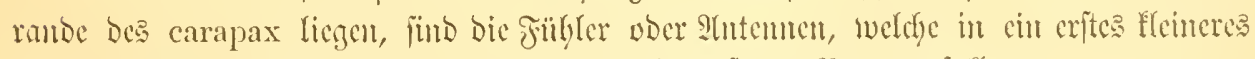

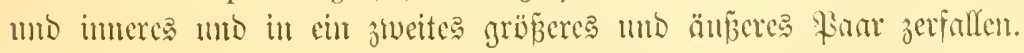

\section{Das 1. 2tutenneunat. $\quad\left(A_{1}.\right)$ Fig. 3.}

Dic immeren antemen ruben fait in ibrer gamzen sänge anf einer grof̧en

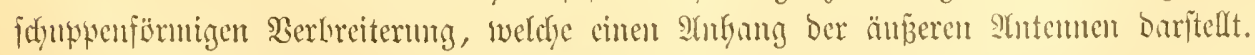

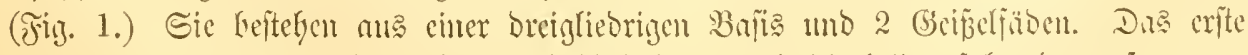

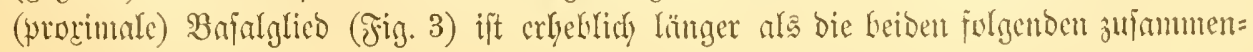




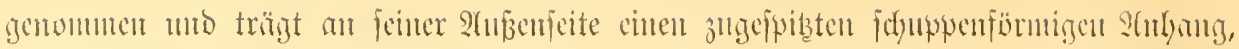

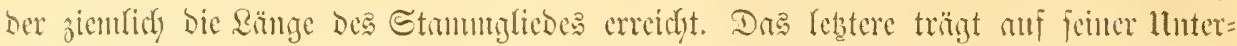
feite ente Seifte, Die in cinen ftonfen Dorn embet, und anf jeiner Dferfeite cine SBer=

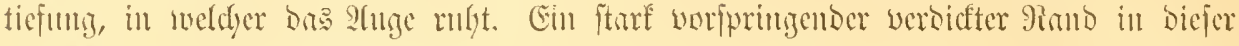

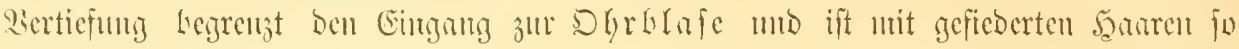

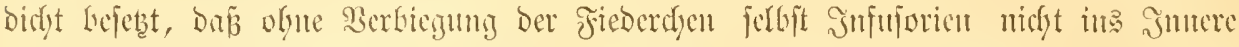

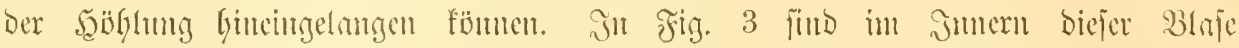

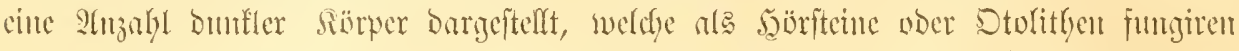

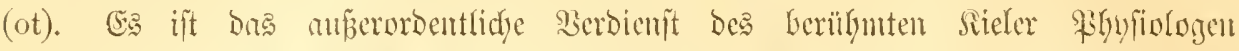

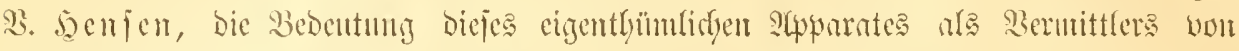

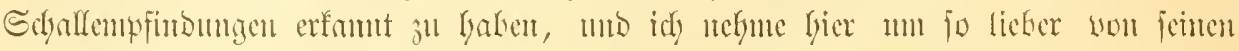

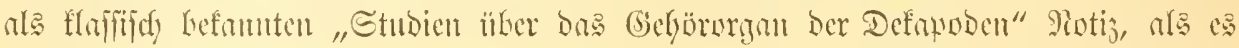

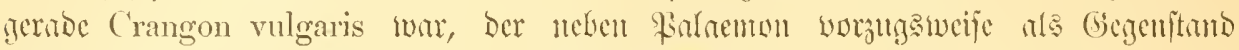

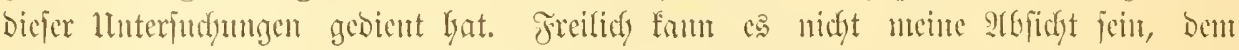

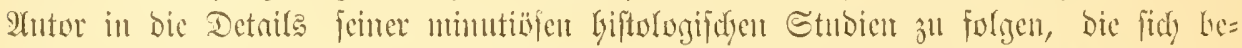

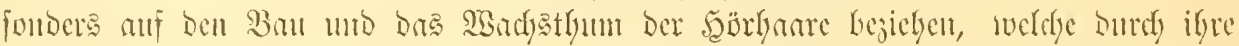

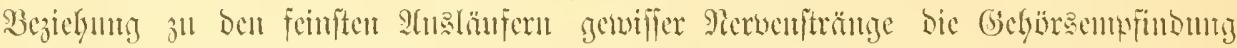

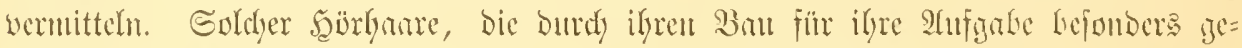

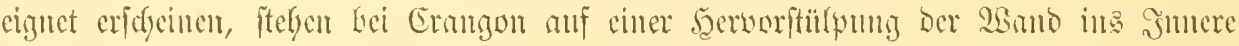

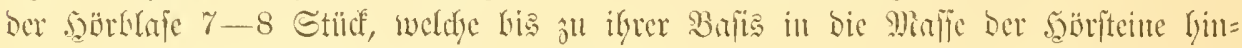

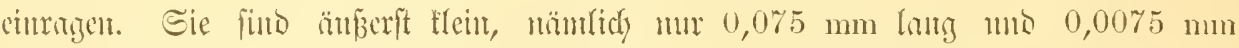

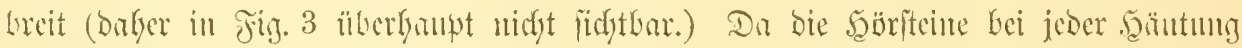

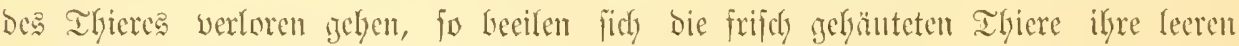

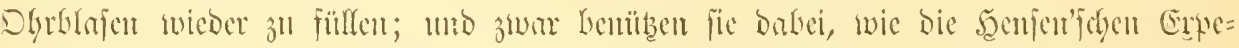

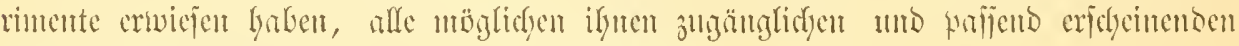

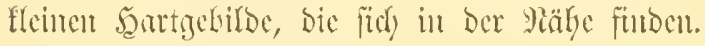

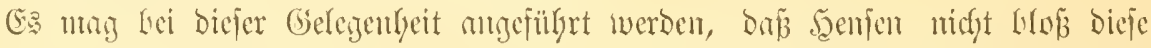

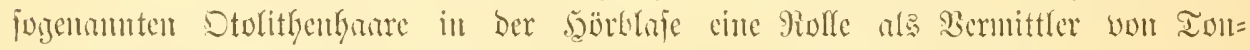

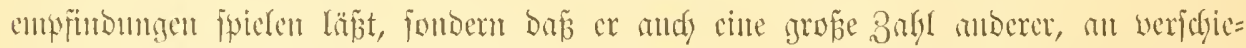

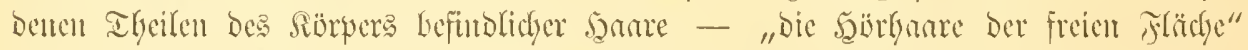

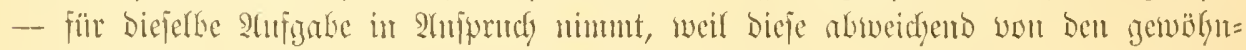

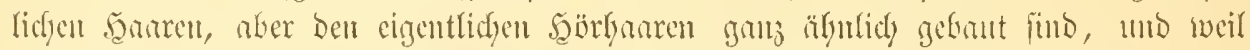

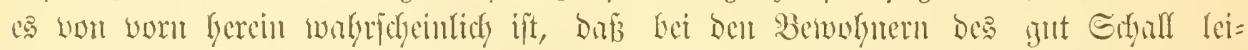

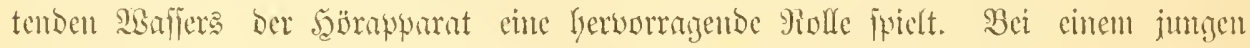

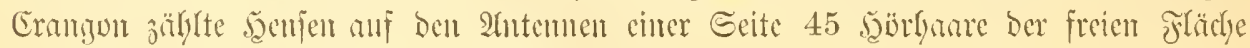

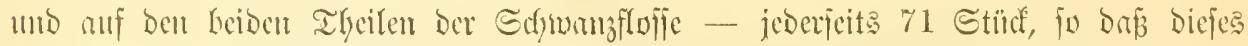

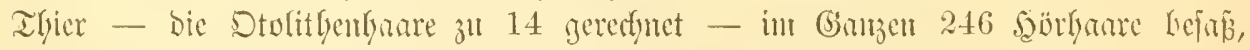

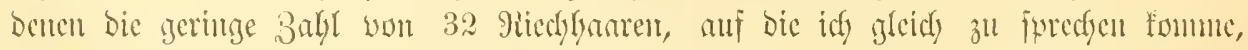
gegeniliferiftruto.

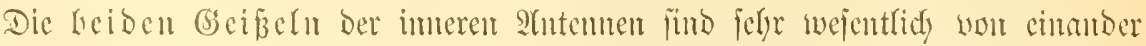

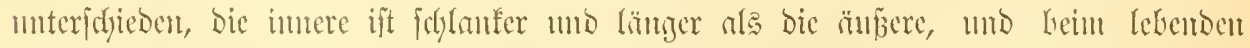

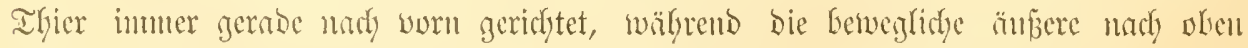

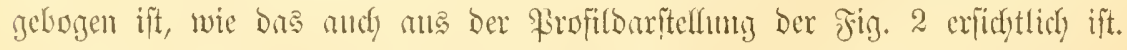

Der frärfer pigntutirte Snnenaft ift in ben unteren $2 / 3$, feiner Ränge leiber= feits mit Fieberborften bejez̧t, yon benen bie anf Der mebialen Seite aur längfiten

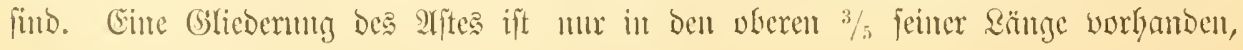




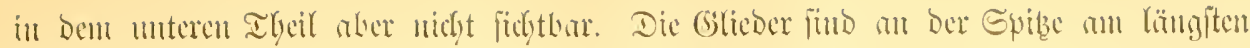

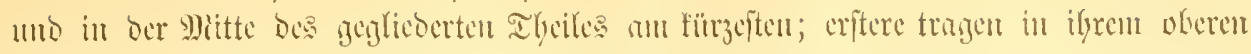

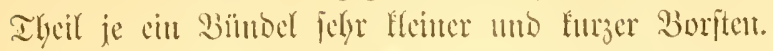

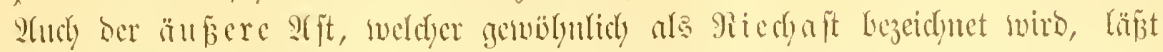

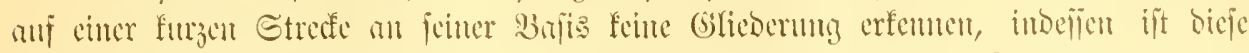

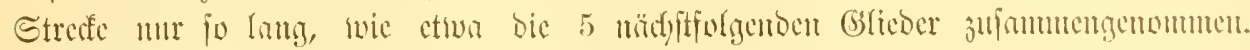

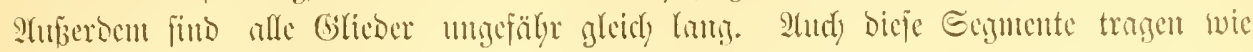

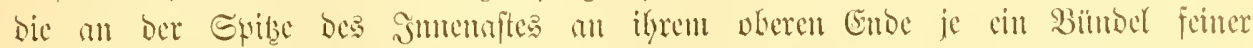

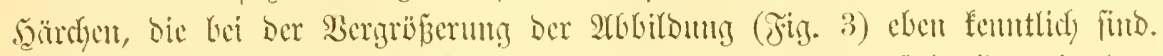

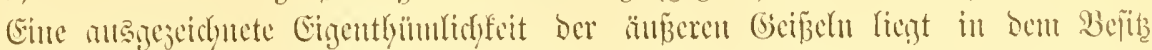

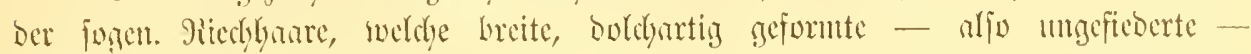

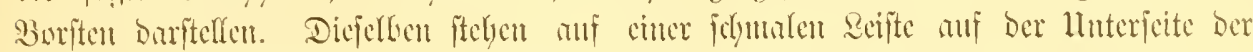

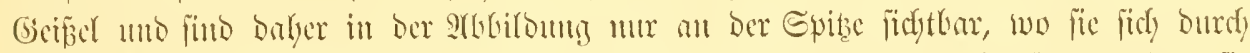

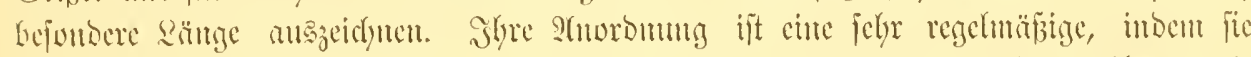
bie unteriten 5 Eegmente ctiva jeeifajemb anf jobem Segment in 2 Duerreilyen ju je $3-5$ itchen.

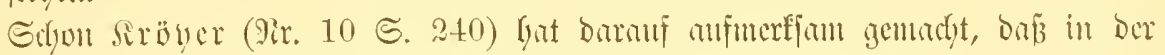

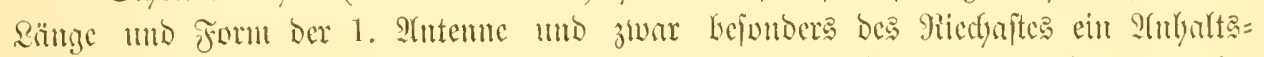

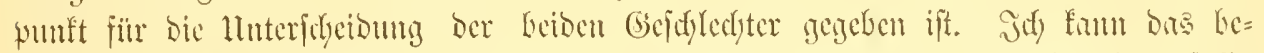

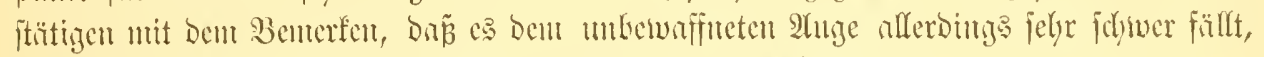

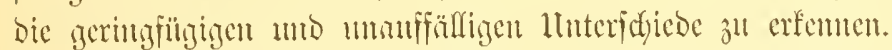

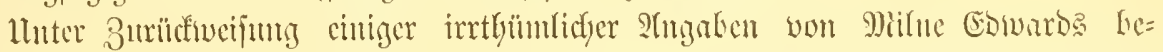

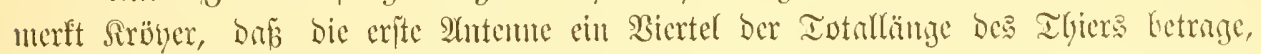

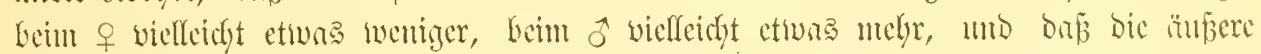

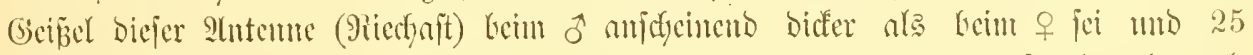

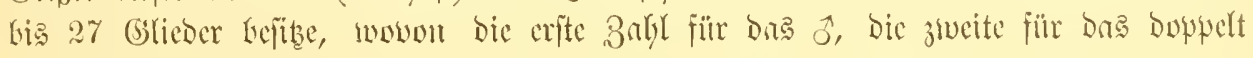
fo grofe + gelte.

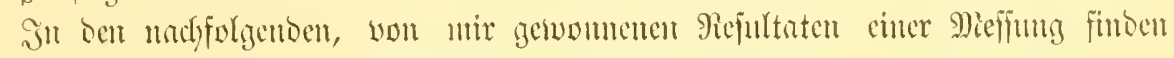

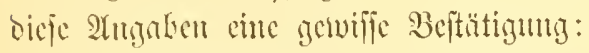

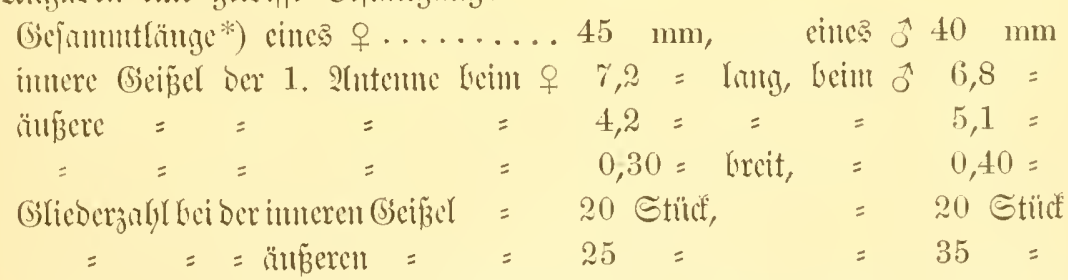

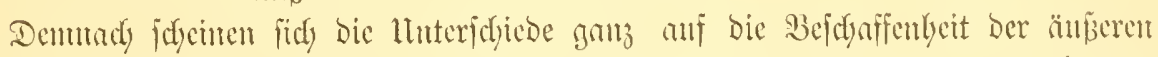

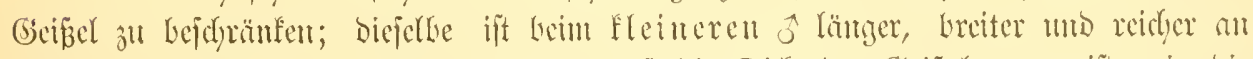

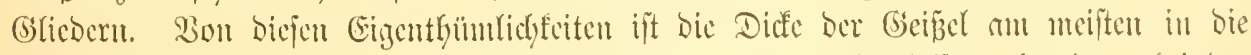

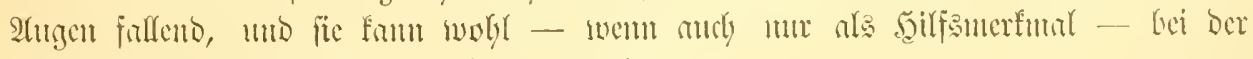

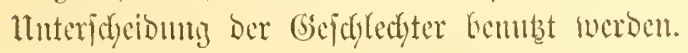

Das 2. Autenuentar. $\left(\mathrm{A}_{2}\right)$ Fig. 4.

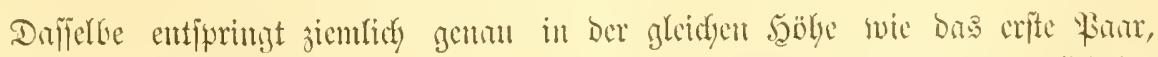

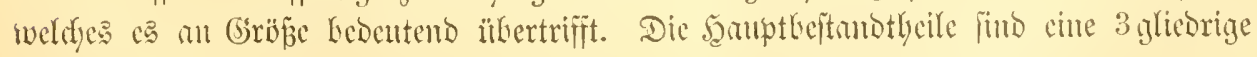

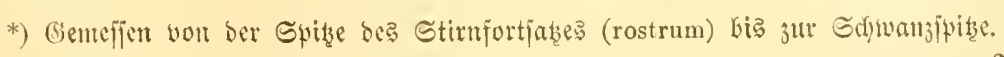




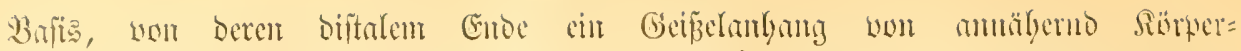

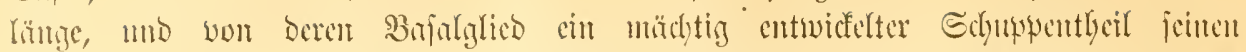

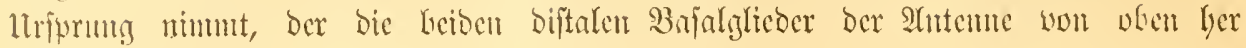
wibllig bebedt.

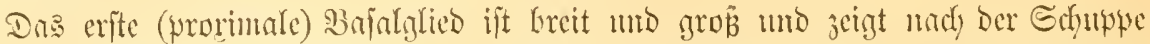

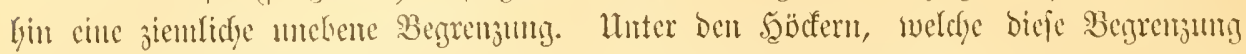

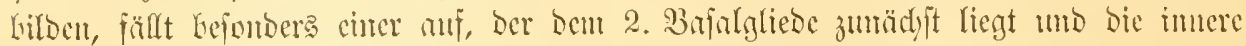

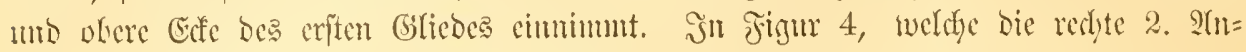

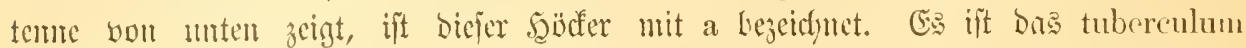

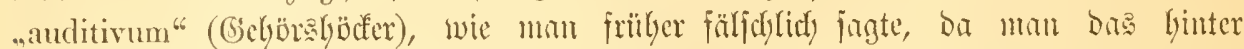

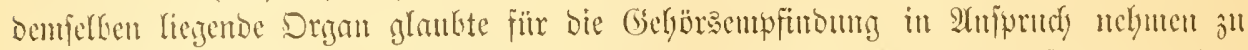

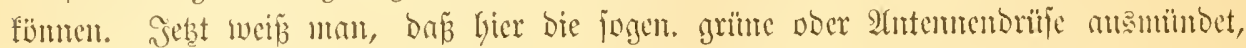

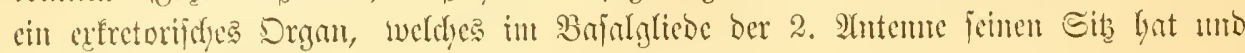
bei ben Siruftrcen bie Etelfe ber Rieren vertritt.

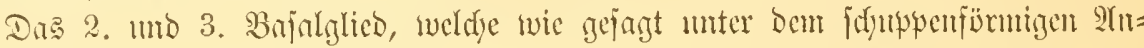

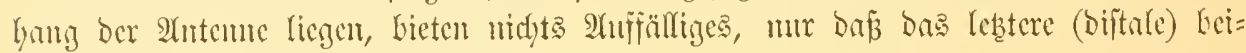
nahe boppelt fo lang ift ale bas vorige.

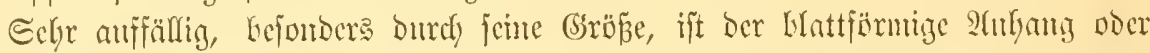

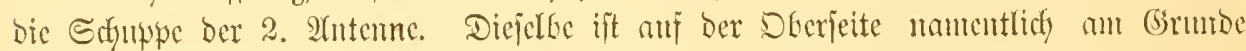

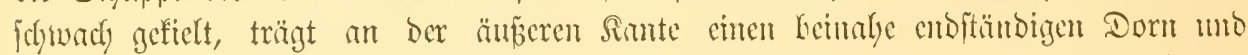

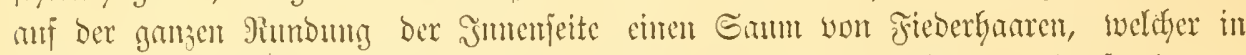

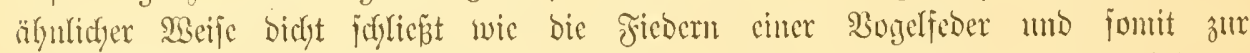

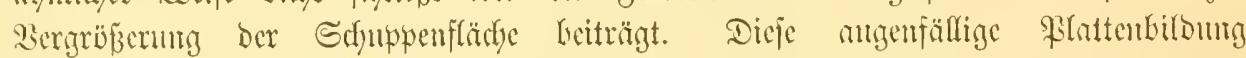

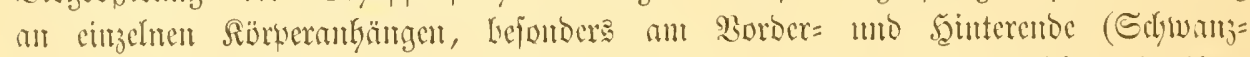

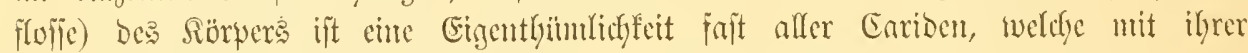

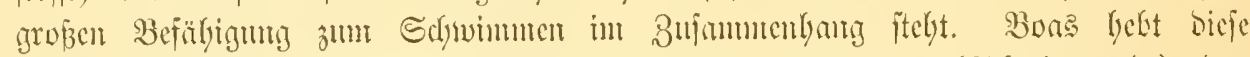

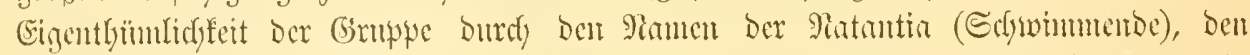
er ibr gegeben bat, Gerwor und bejeidynet bie ülrigen Definpoben als gieptintia (sitieclyentide).

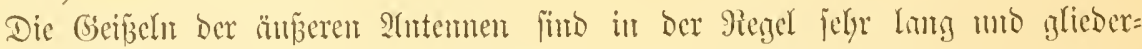

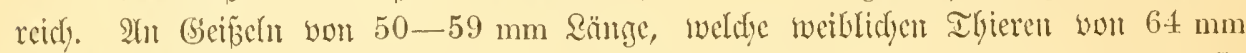

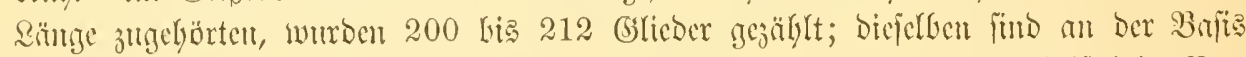

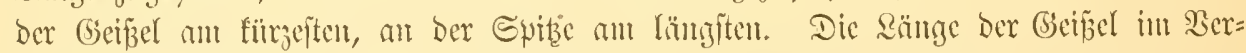

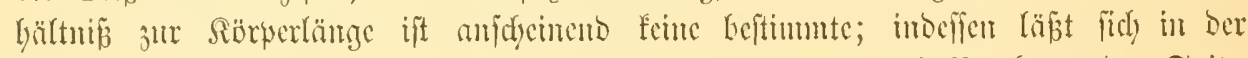

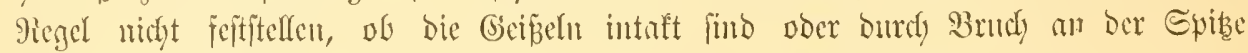

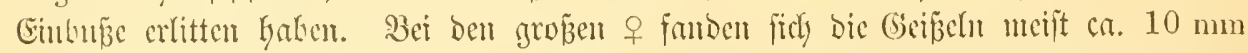

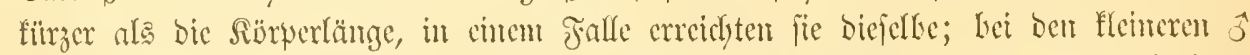

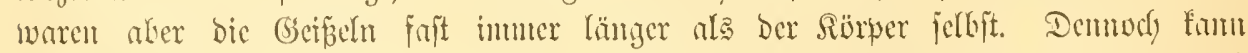

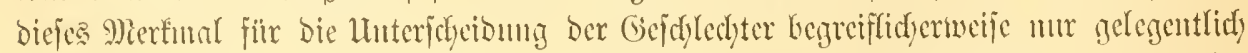

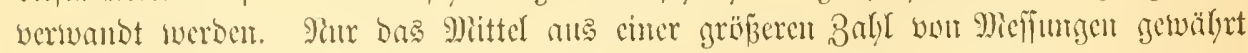

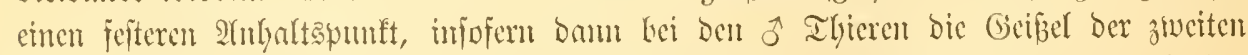

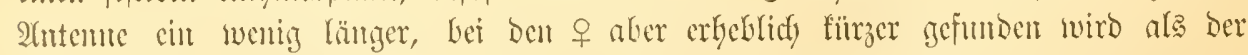
Sï̈rper. Bei 10 o von 50-68 mm Ränge war bei einer mittleren Rürperlänge von $59,3 \mathrm{~mm}$ bie Geipel int Mittel $50,5 \mathrm{~mm}$ lang; bei 10 o yon $29-32 \mathrm{~mm}$ Rärge

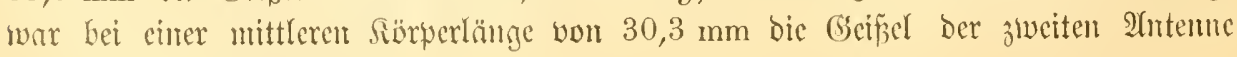
im Mittel $31,1 \mathrm{~mm}$ lang. 


\section{Die gimbtgeile.}

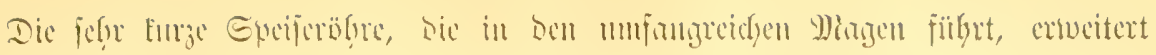

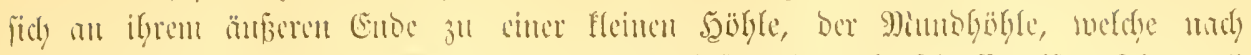

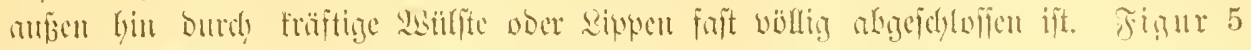

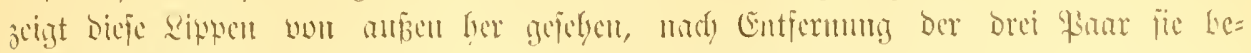

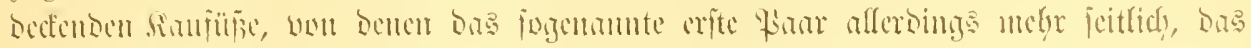

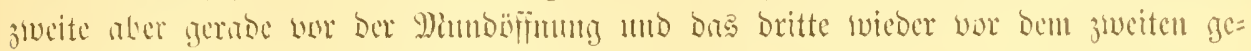
latgert ifit.

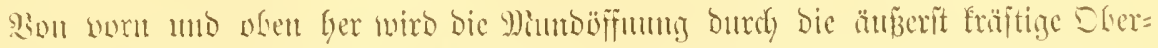

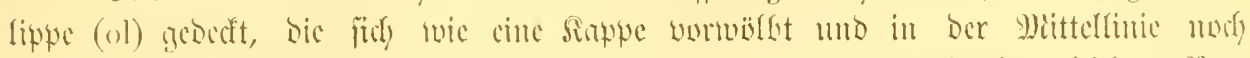

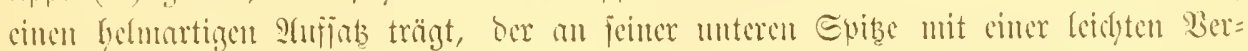

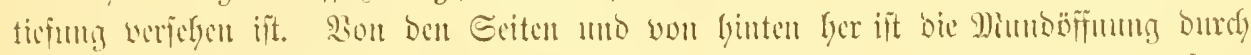

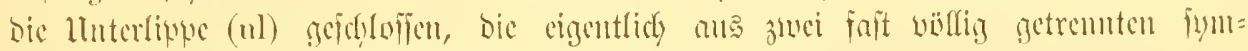

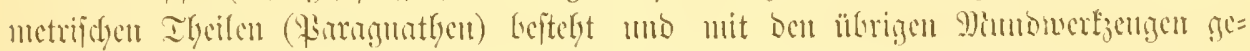

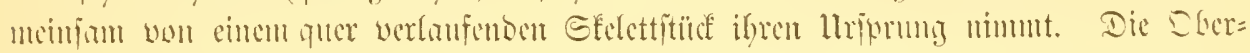

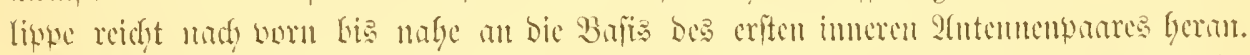

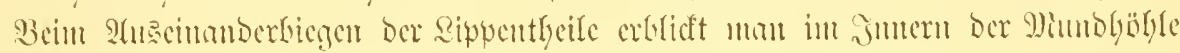

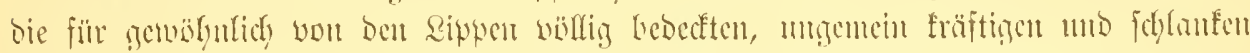

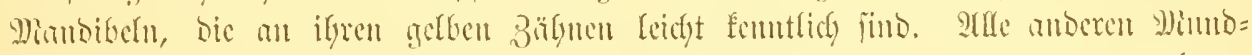

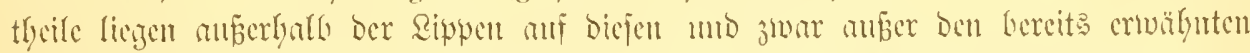

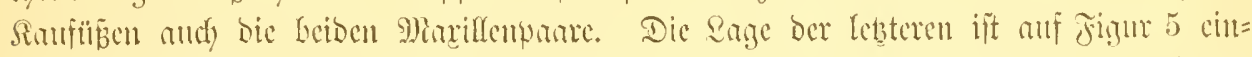

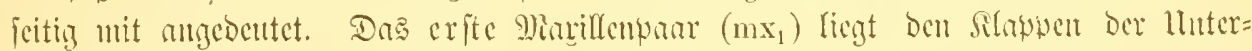

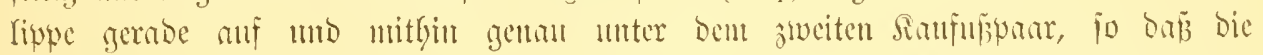

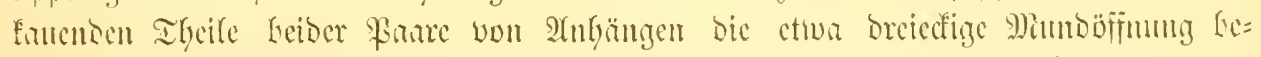

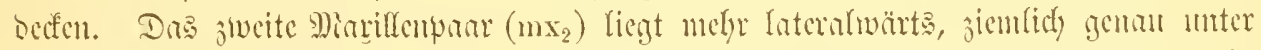

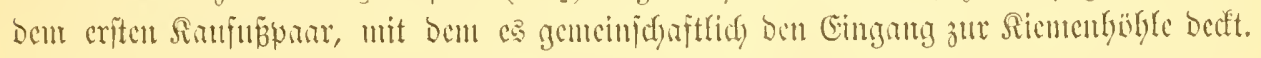

\section{Dic Mandifelu (md). Fig. 6.}

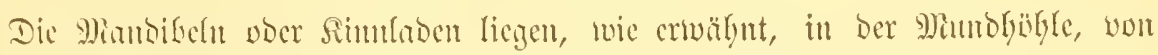

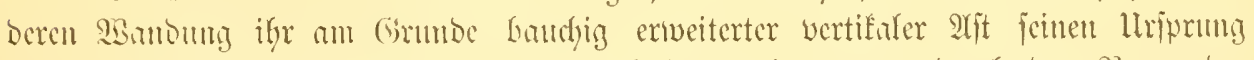

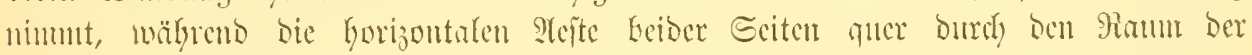

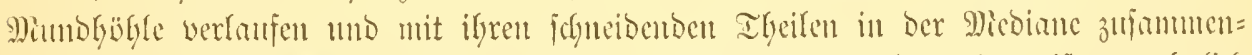

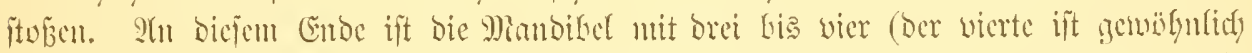

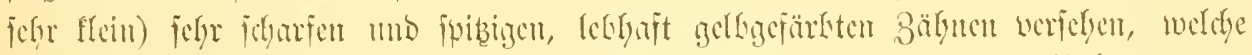

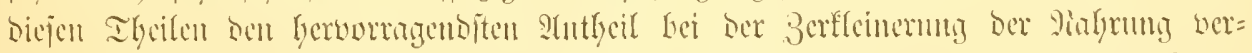

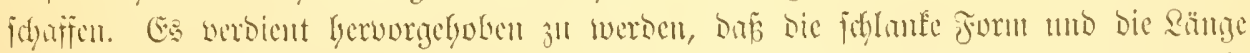

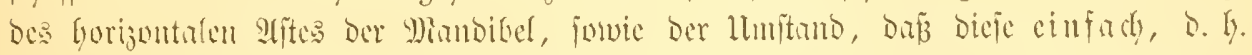

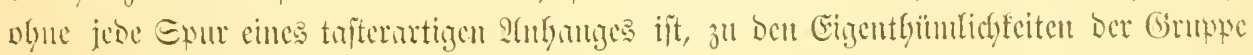
Der Cranguniben gehürt.

\section{Das 1. Miariflempar $\left(\mathrm{mx}_{1}\right)$. Fig. 7.}

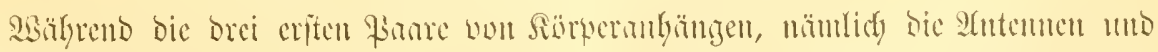

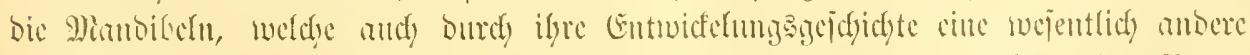

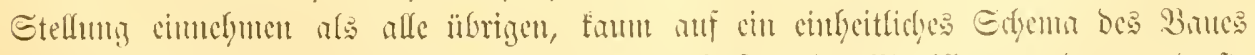

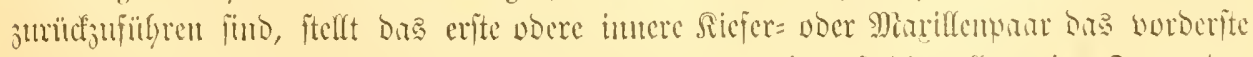

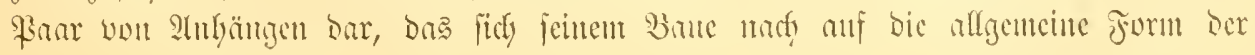




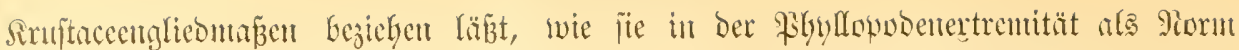

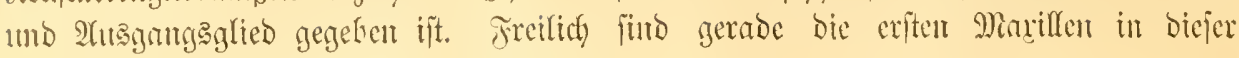
Seirificht als bejoutiors rebucirt arzulielyent.

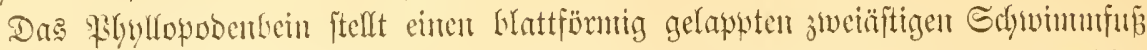
bar: anf einen furrzen Bajalabjdyntt folgt Der lä̈tgere eigentliche Stanum, wedder

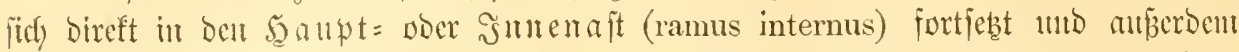

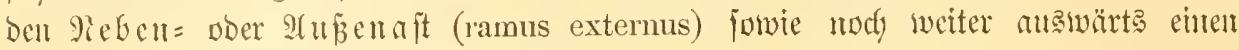
Sieutu= ober Enipodialantang trägt.

Jim vorliegenten Falfe Des 1. Mariffentaares ift Bajal= mo Stamuglieb

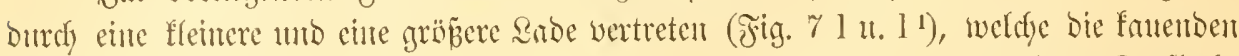

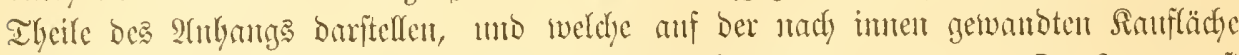

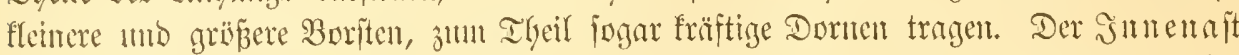

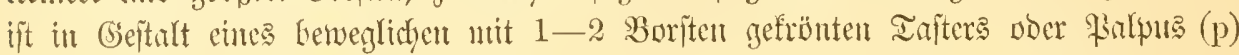

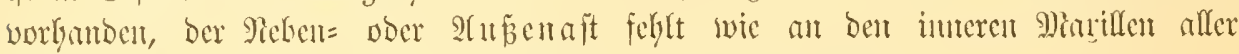
Mialafoitrafen. 2huch cin Eptpobialantyang ijt nicht worbanden.

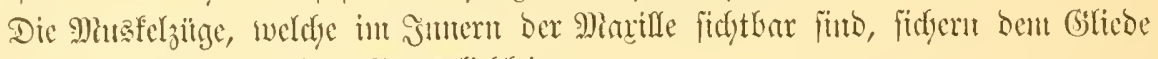
bie für feine gunftion nöthige Beweglidjéfeit.

\section{Das 2. Marilleman $\left(\mathrm{mx}_{2}\right)$. Fig. 8 .}

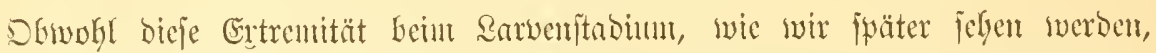

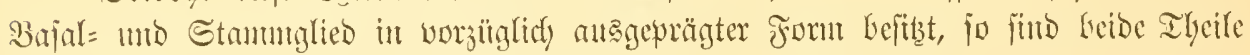

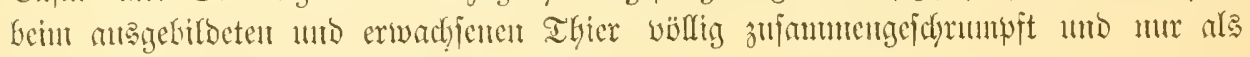

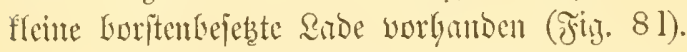

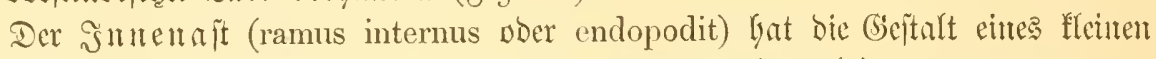
am Sïrper uno aut Der Spibe mit Borjten verfelyenten Infters (p) angenommen.

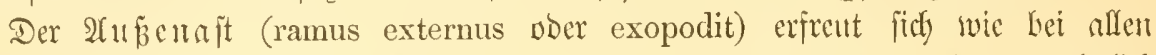

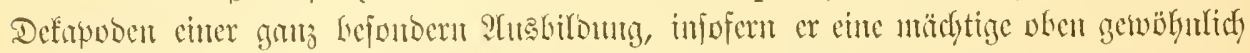

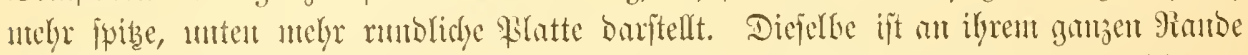

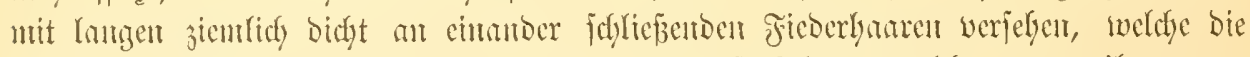

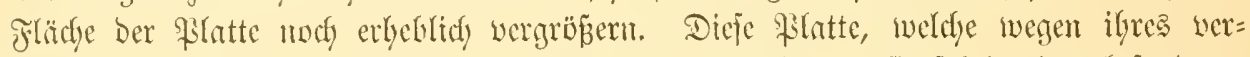

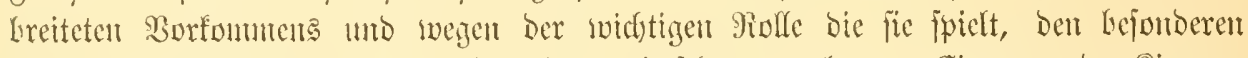

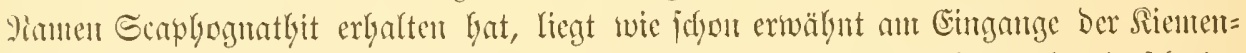

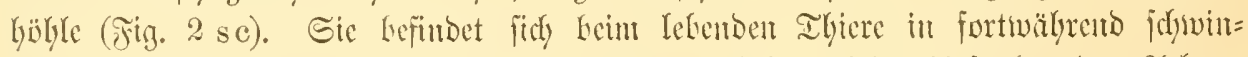

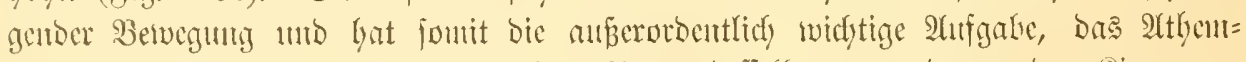

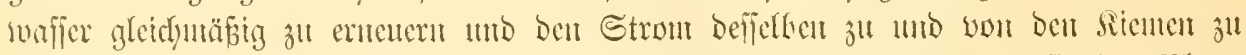

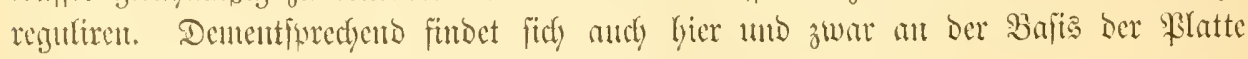

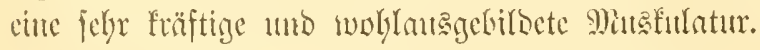

\section{Das 1. Miarillarfupanar (mp $\mathrm{p}_{1}$. Fig. 9 .}

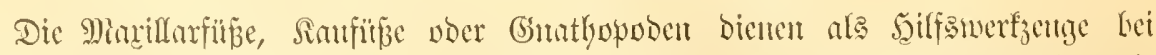

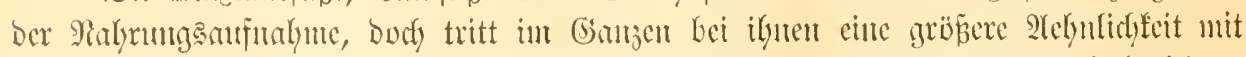

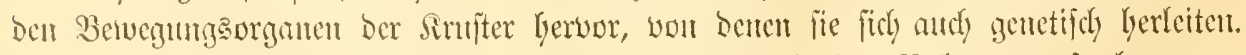

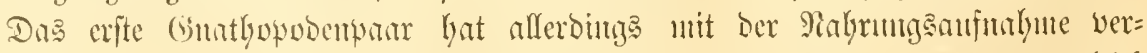

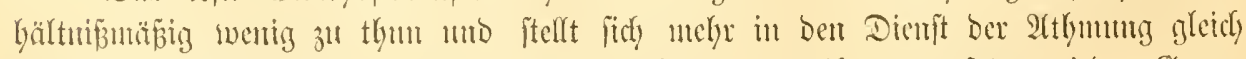

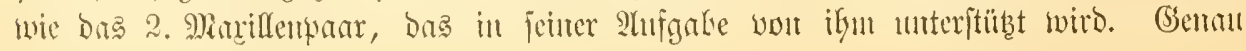




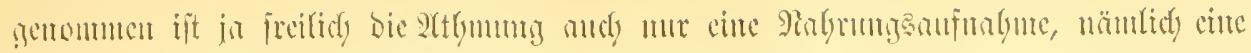

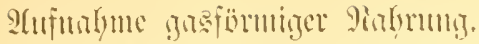

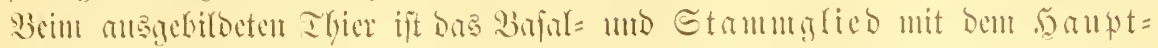

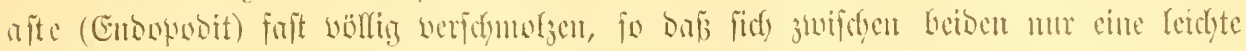

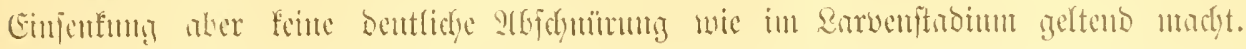

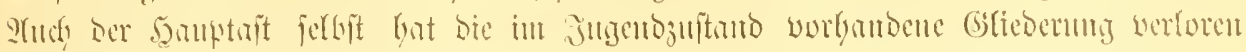

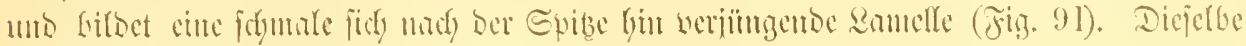

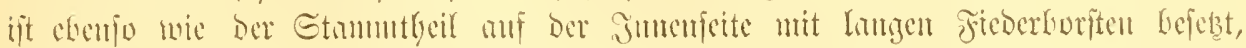

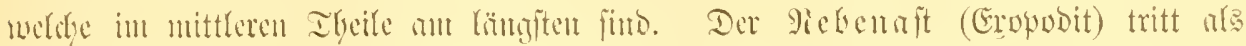

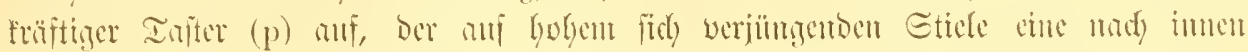

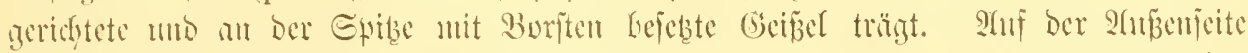

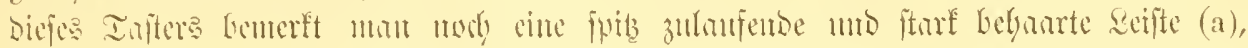

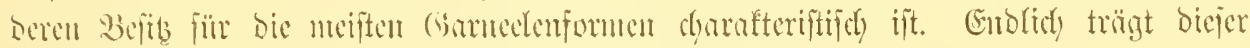

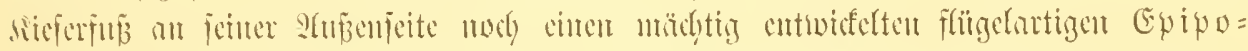

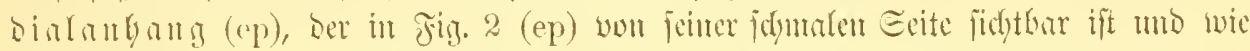

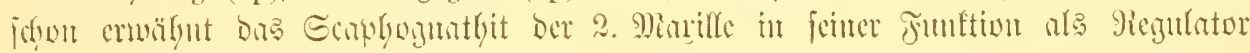

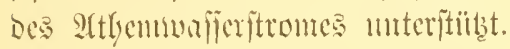

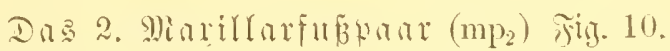

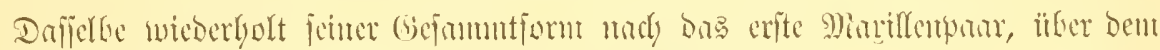

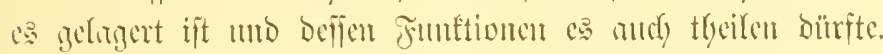

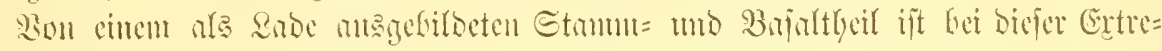

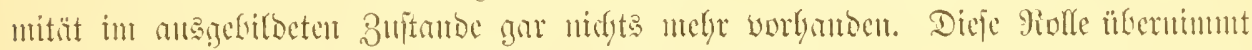

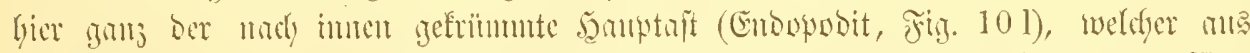

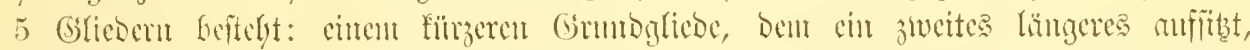

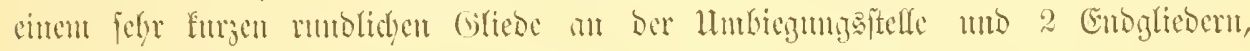

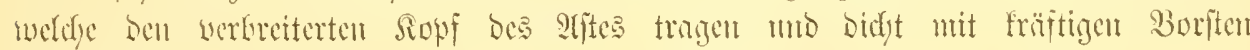
lejeçit juito.

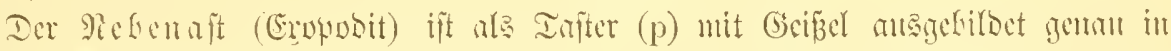

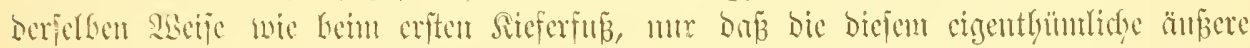
bebuarte serifte bier foblt.

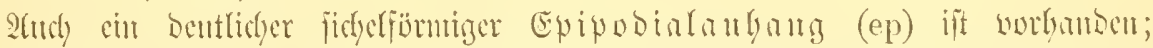

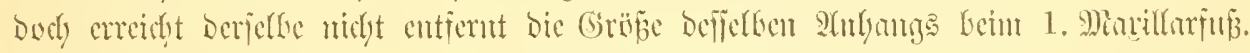

\section{Das 3. Miariflarfubarar $\left(\mathrm{mp}_{3}\right)$. Fig. 11.}

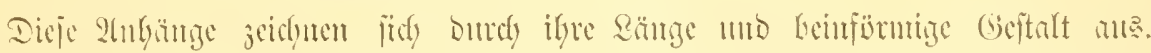

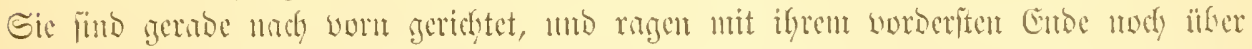

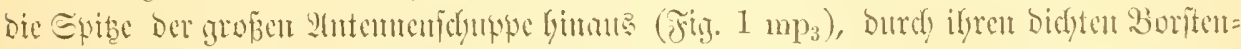

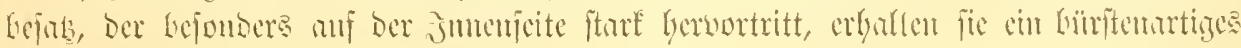
2uâteren.

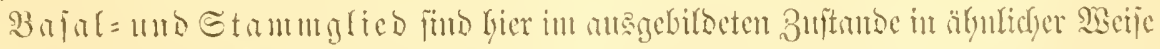

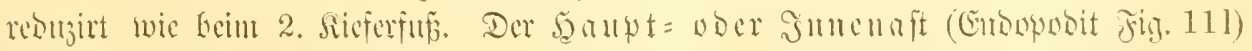

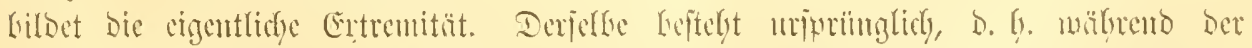

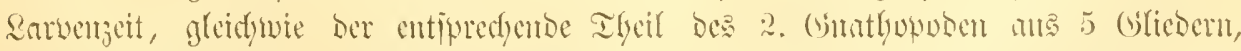

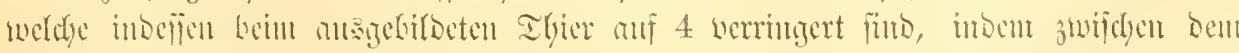

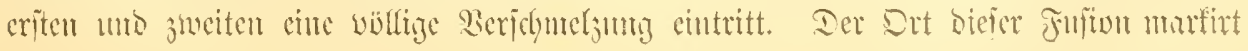




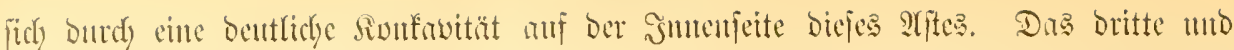

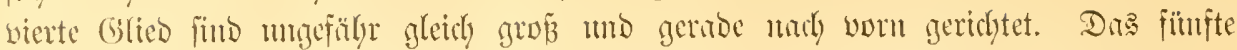

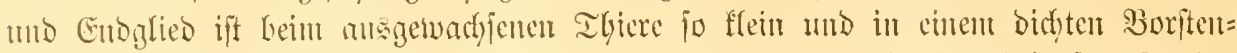

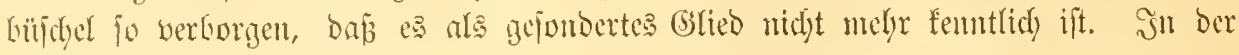
Sitgent ift es aber Deutlicher.

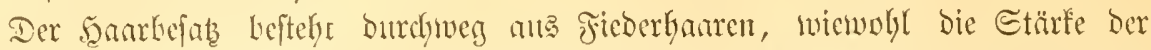

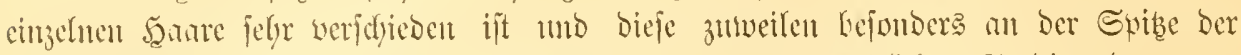

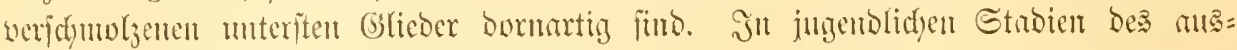

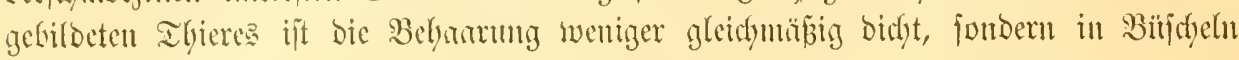
georonet.

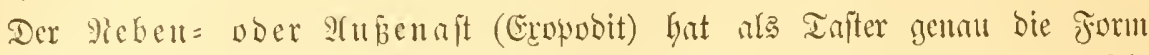

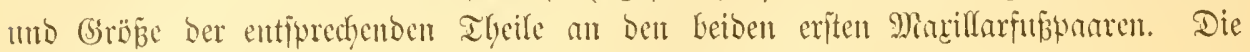
(beijel ift ebenfo wie bei jencen naty imen gebogen (p).

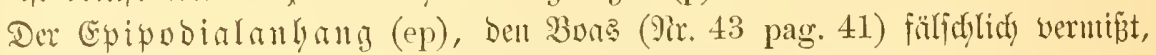

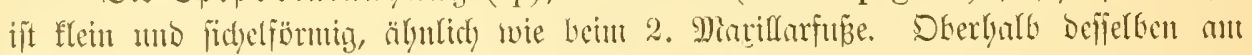

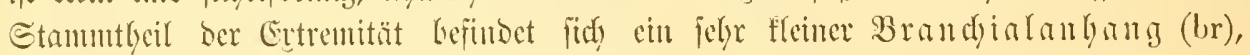

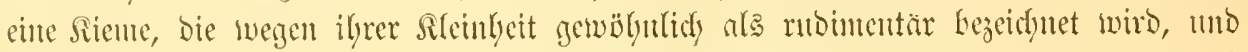

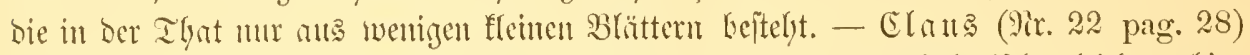

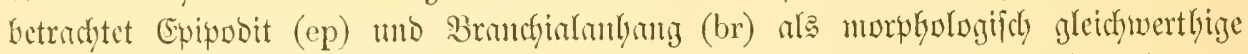

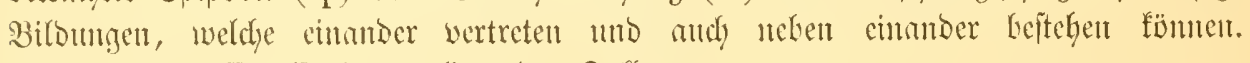
Das lebtere trifft aljo im worliegenton Falle jul.

\section{Die Gintgbente.}

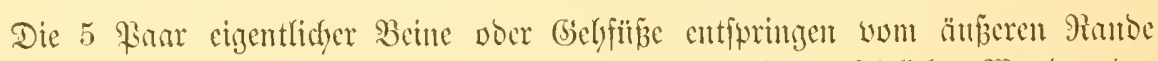

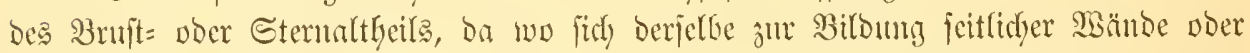

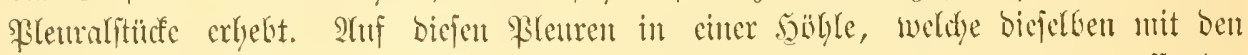

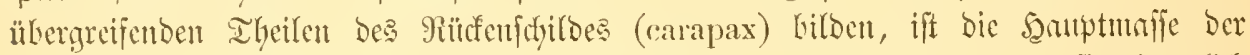

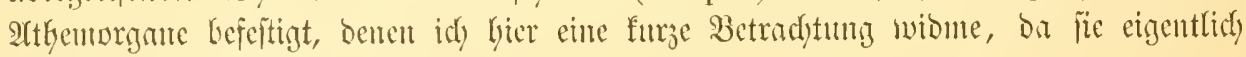

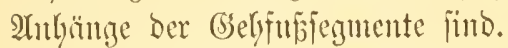

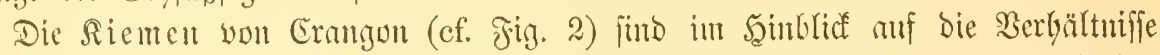

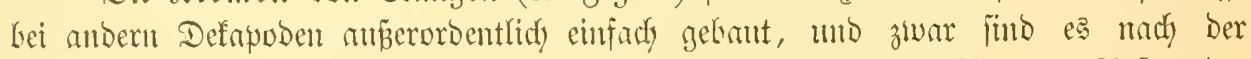

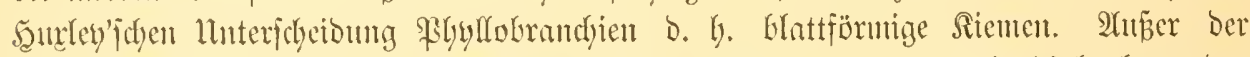

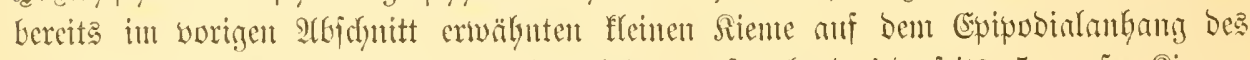

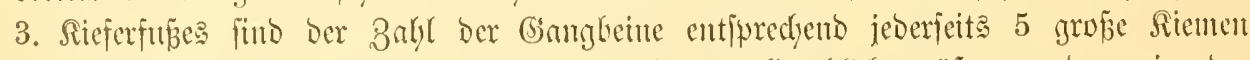

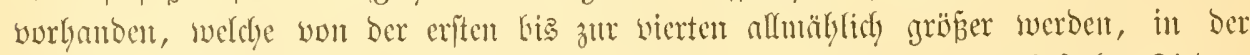
lebten aber wieber ctwas almelynen. Jebe Sicme hat Den Ban ciner einfarben Fieder:

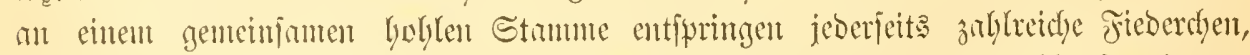
weldye aber nidft fabenfürming (we bei ben Iridgubrandfien) fondern blattfürmig ge=

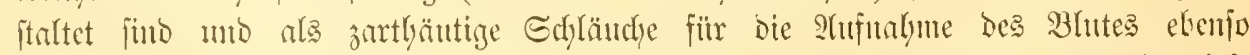

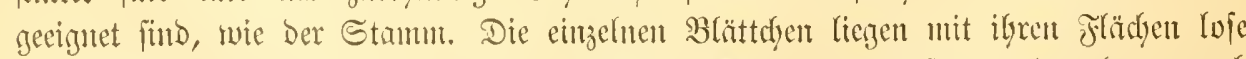

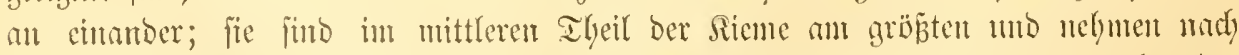

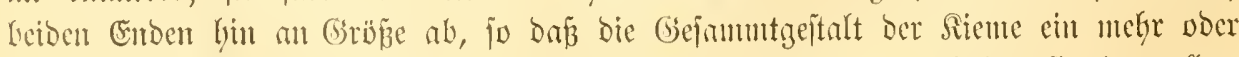

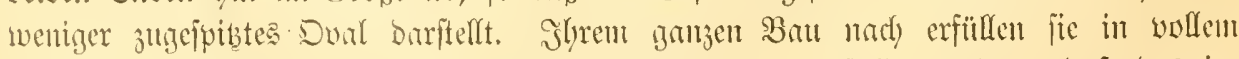

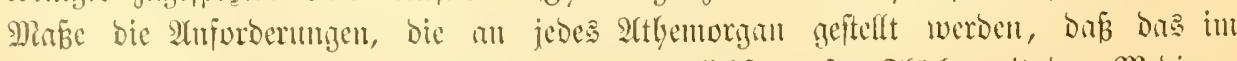

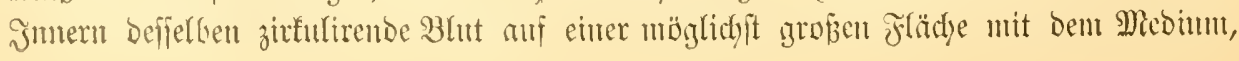




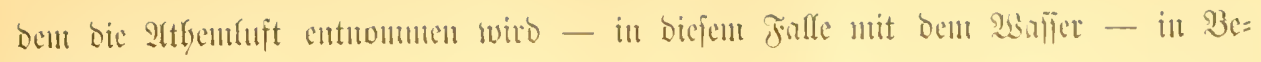
riibrumity tritt.

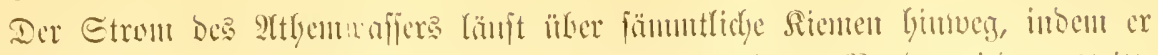

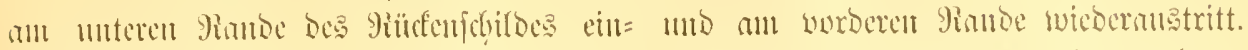

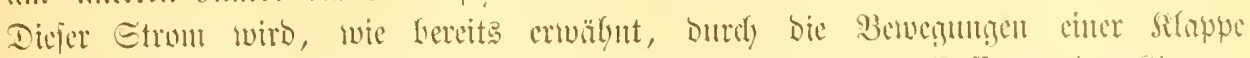

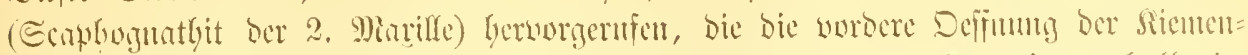

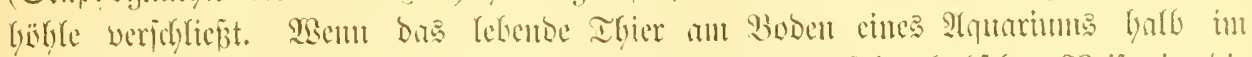

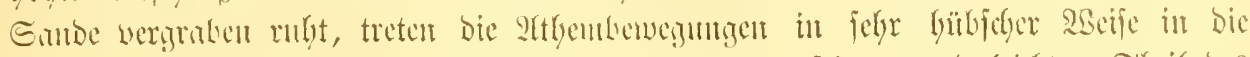

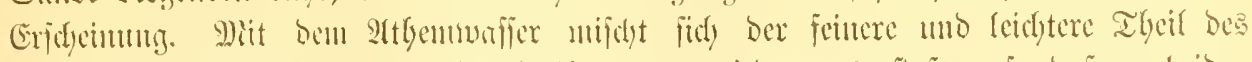

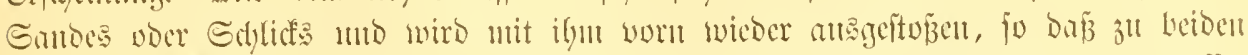

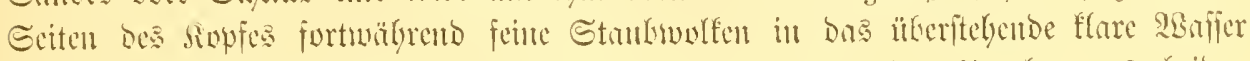

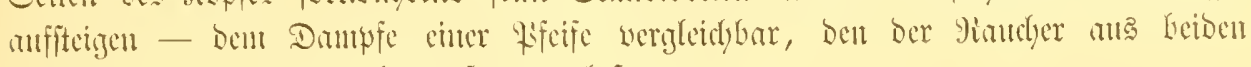

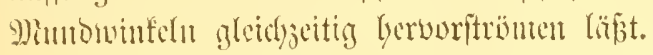

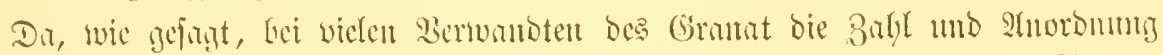

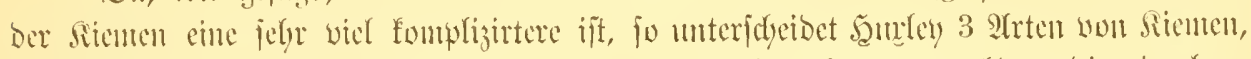

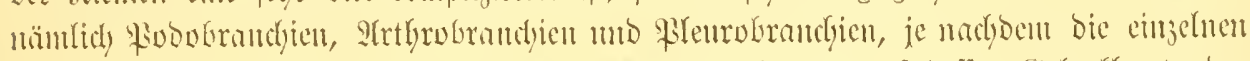

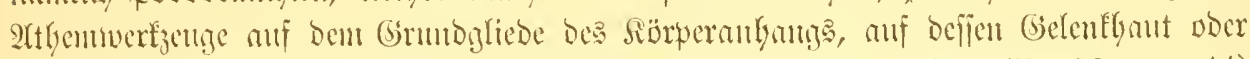

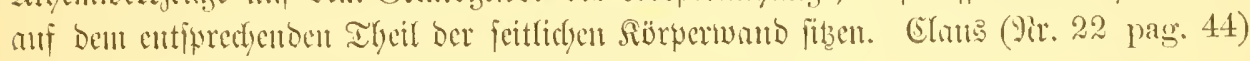
neutut fie prorimale, mittleve uno biftule.

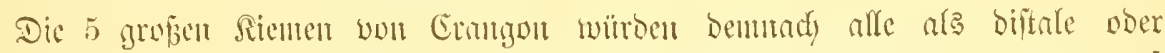

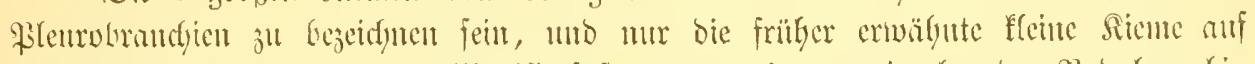

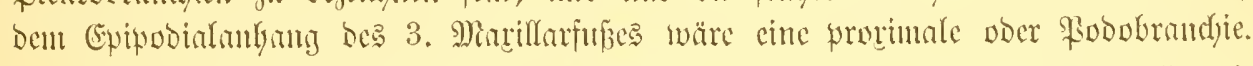

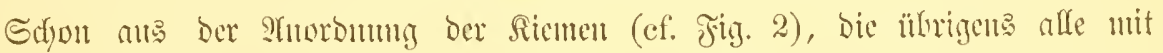
ifyer 9)itte anf flemen Erbebungen der Pleuren Gefeftigt füb, mo nod mely ans

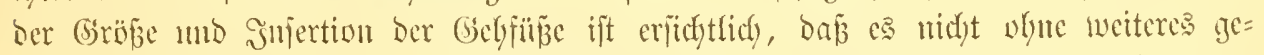

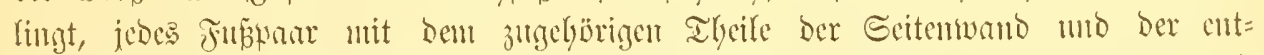

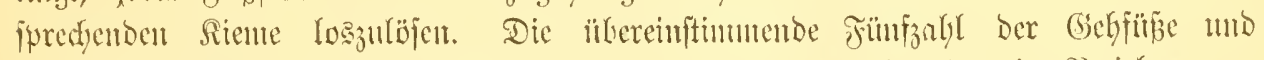

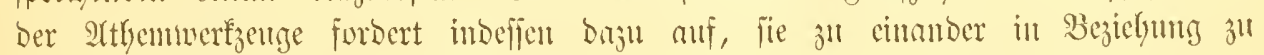

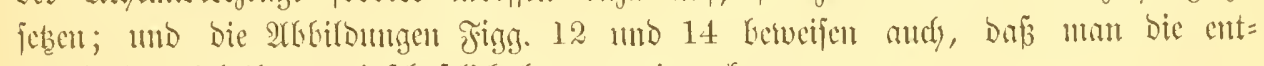
fpredyenden Theile gencinfdyaftlidy Iosprïpariren fam.

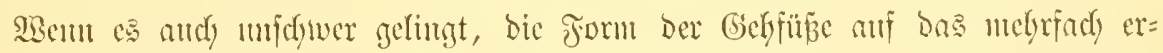

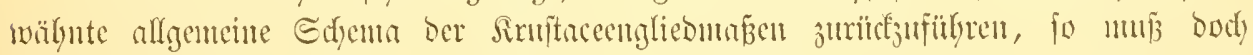

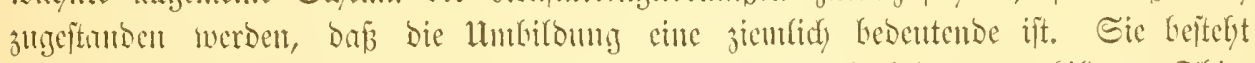

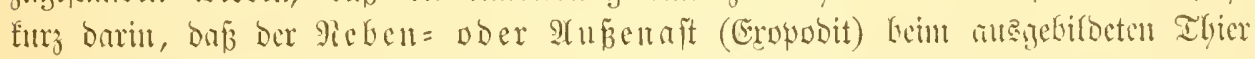

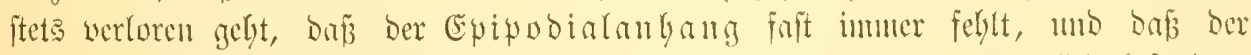

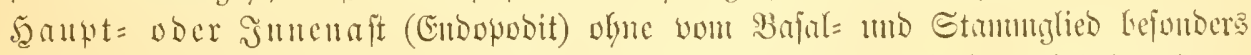

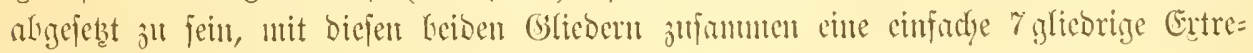
unitüt biloct.

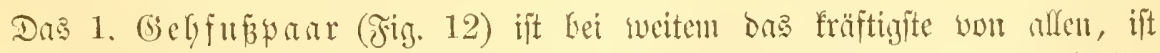

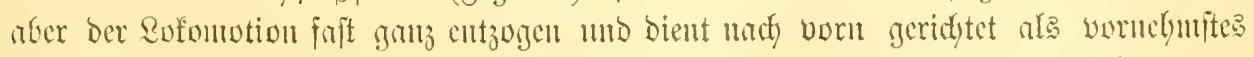

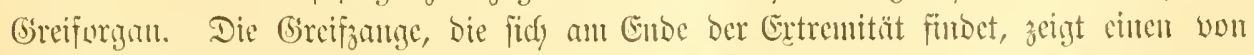

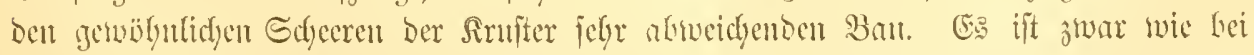

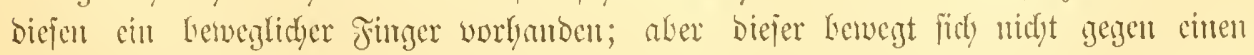
andern feiten Fintger, fondern gegen ben jurrägen Endrmb Des werbreiterten worlebten 


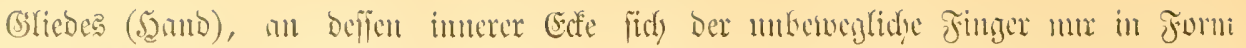
cincs fleinen Dornes worfübet.

Dicjer jogen. Falphe Edferumfun (pes subcheliformis) giebt mit Das befte Er=

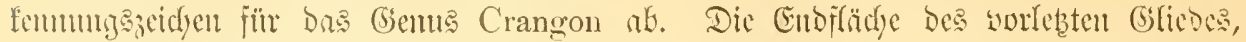

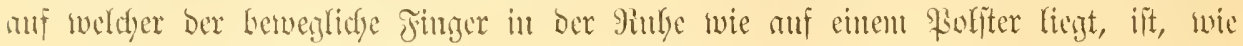

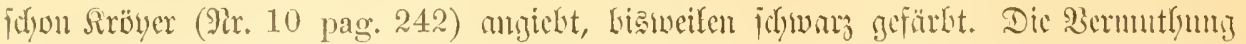

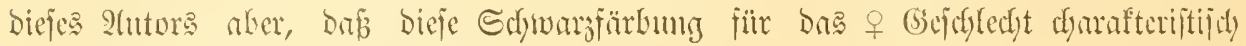
feiu bürfte, fond idy nidyt beftütigt.

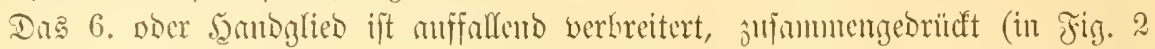

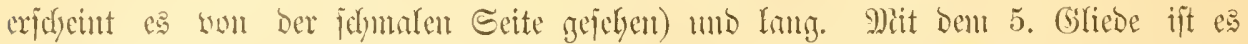

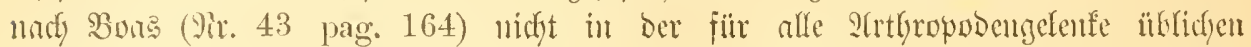

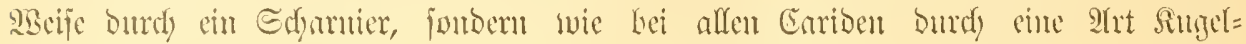

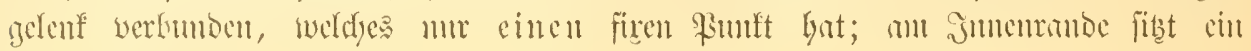
Hleinex Dorn.

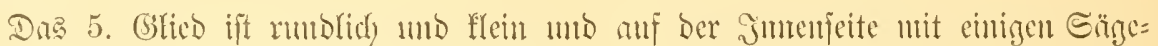

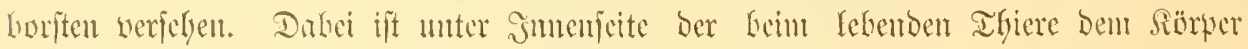

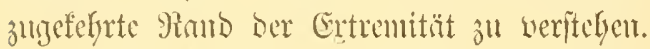

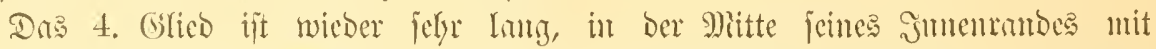

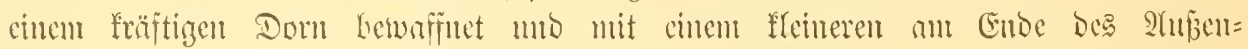
rmulde.

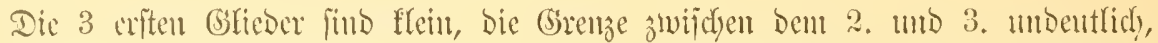

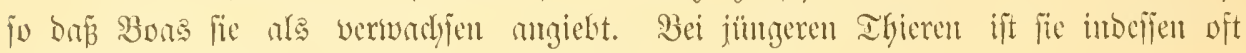

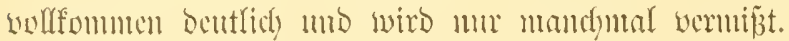

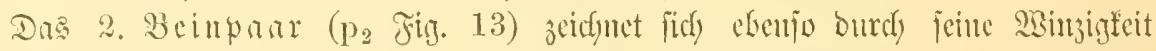

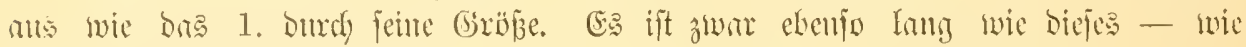

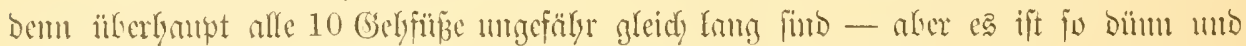

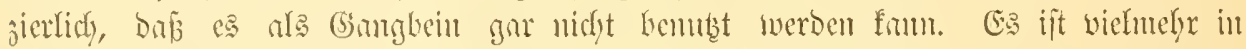

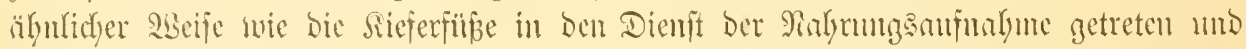

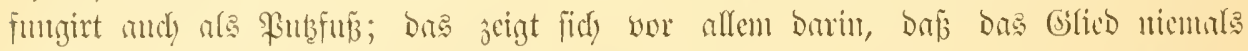

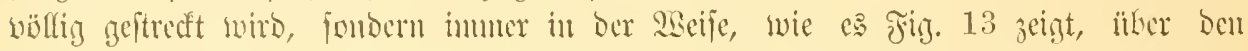

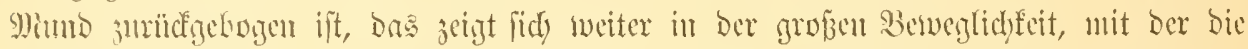

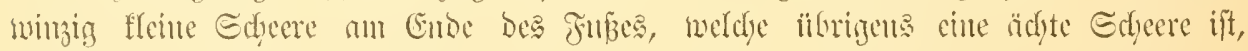

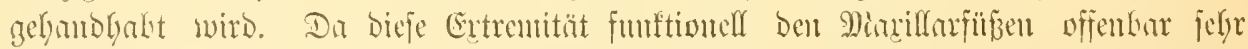

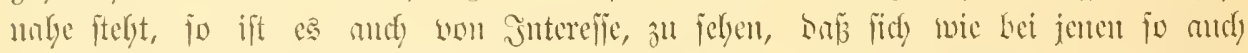

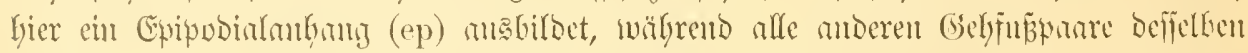

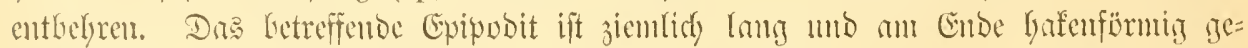

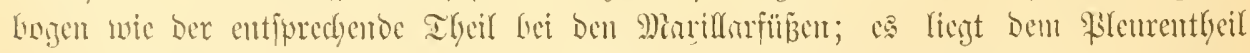

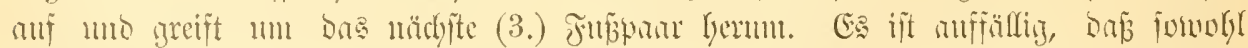

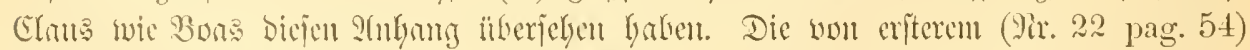

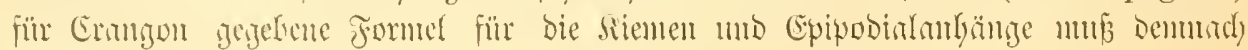
geälioert fruten: $4 \mathrm{E}_{1}+(1+5) \mathrm{K}$.

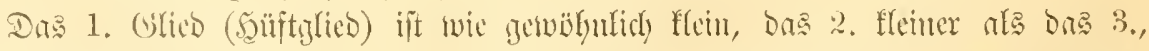

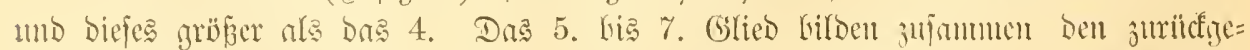

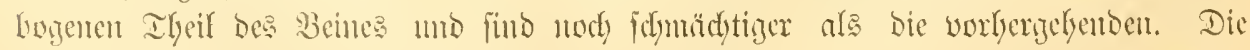

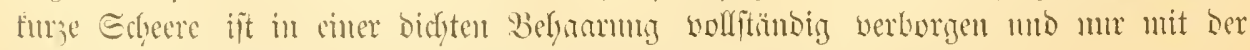

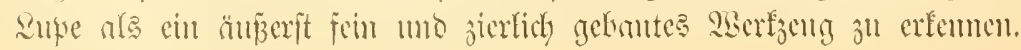




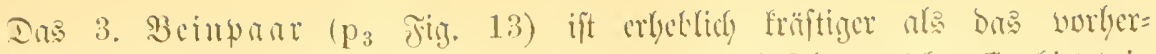

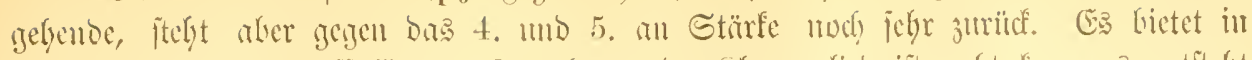

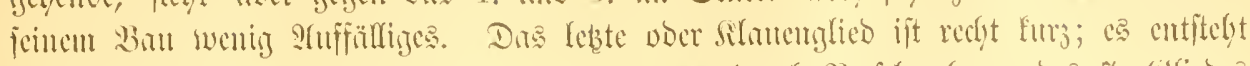

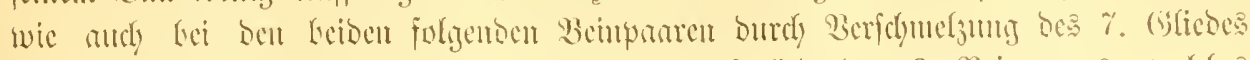

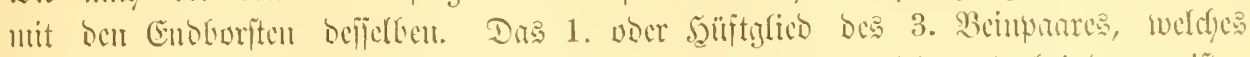

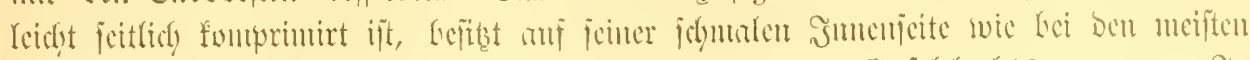

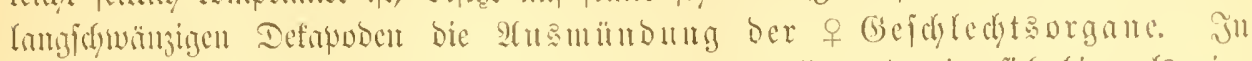

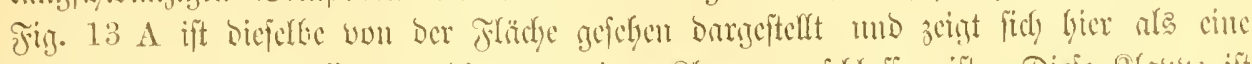

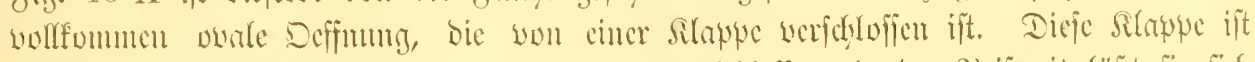

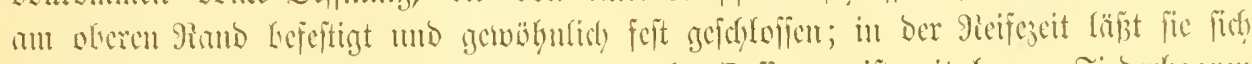

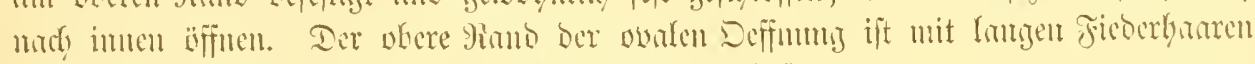

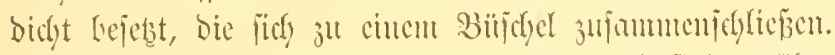

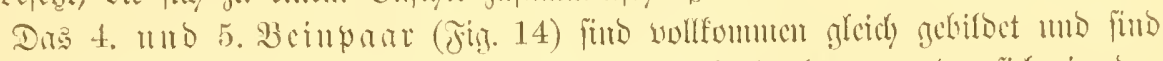

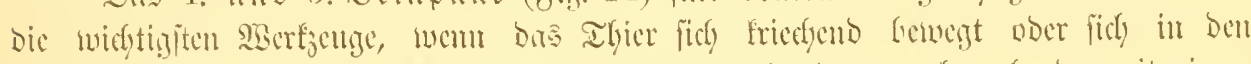

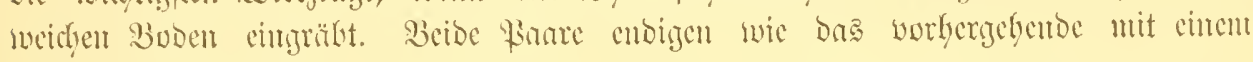
cimfadien Rilamenylicos.

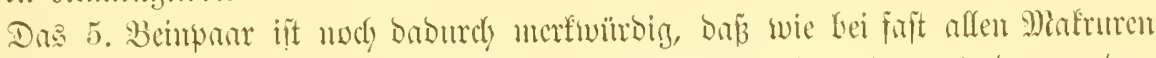

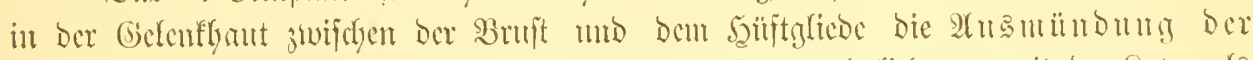

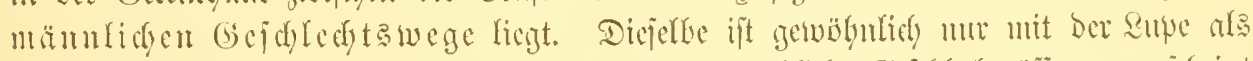

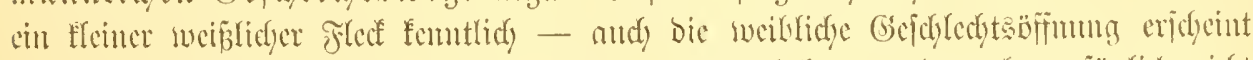

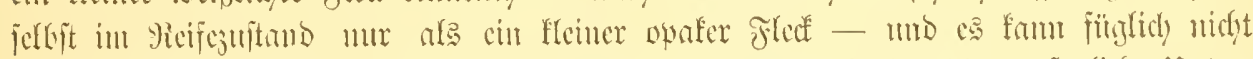

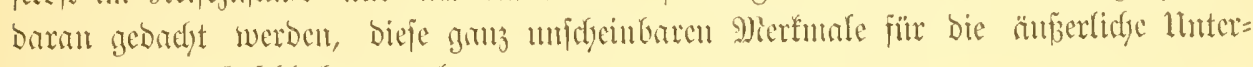

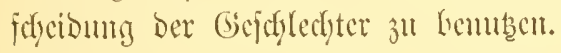

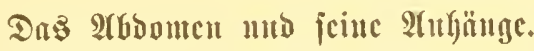

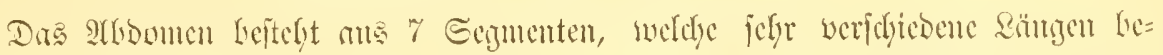

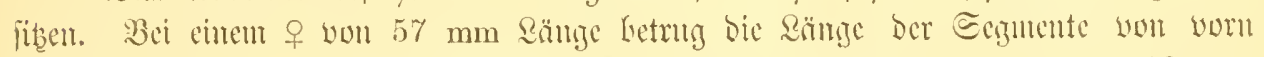

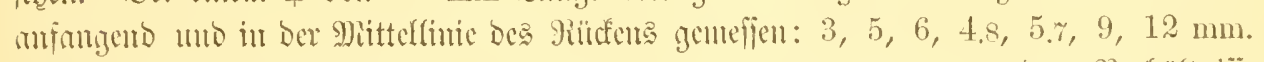

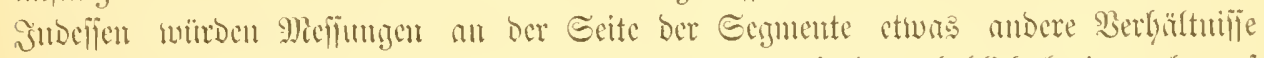

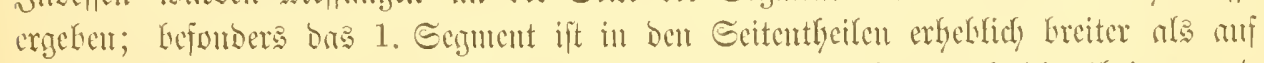

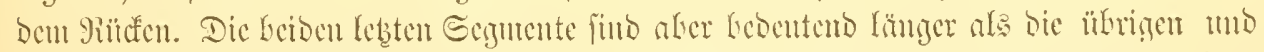

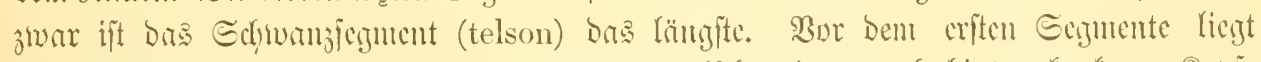

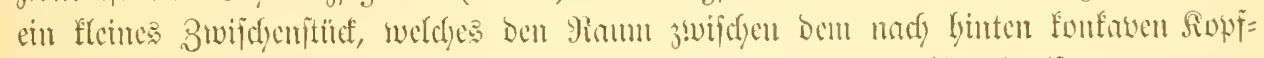

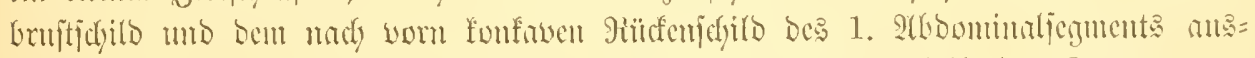

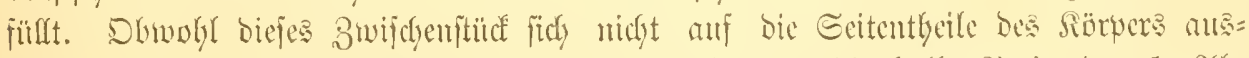

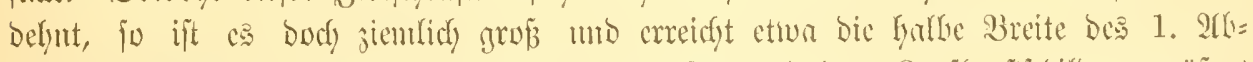

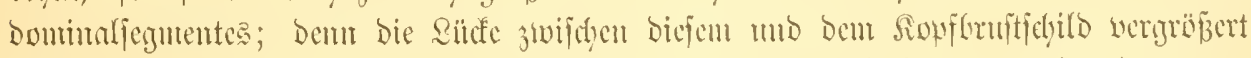

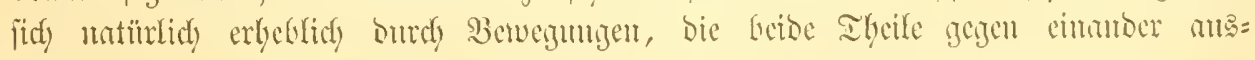
fïlyren.

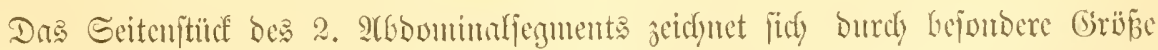

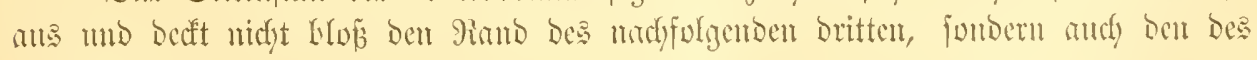
1. Eejullits.

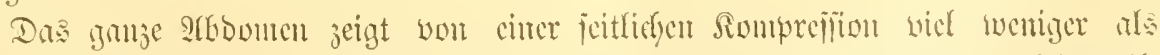

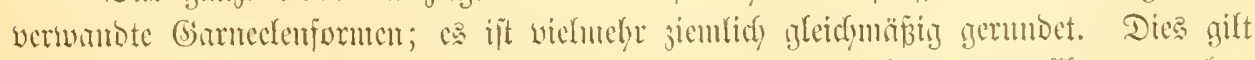

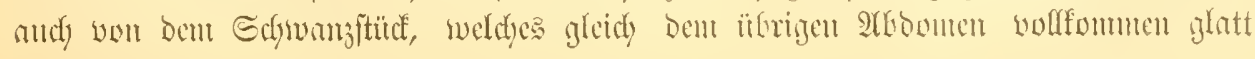




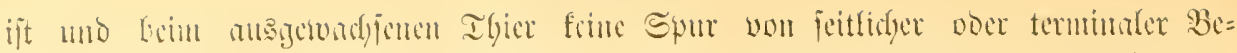

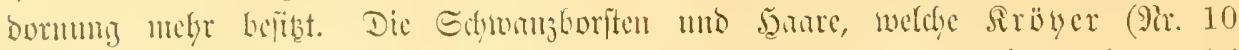

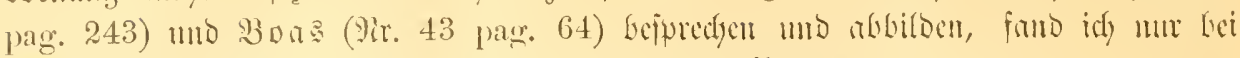
jugenolidgen Formen, morauf idf soeiter unten zurïdfonme.

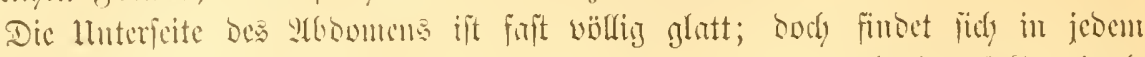

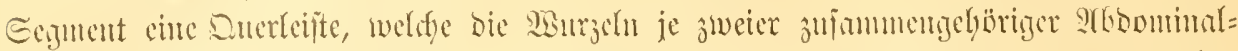

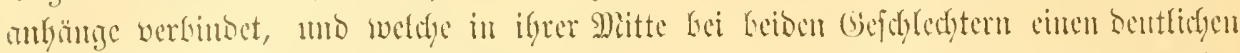

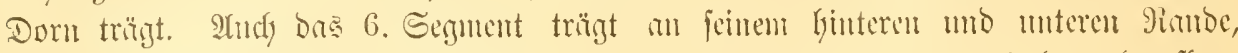

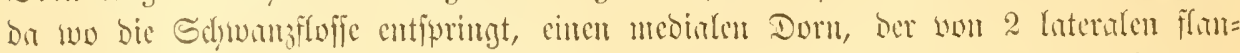

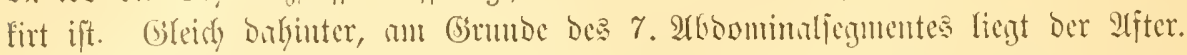

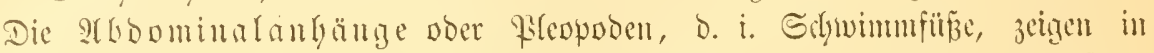

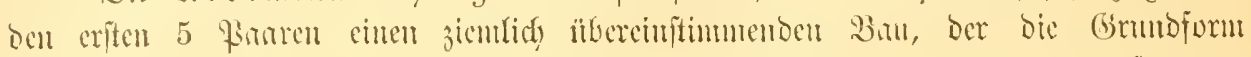

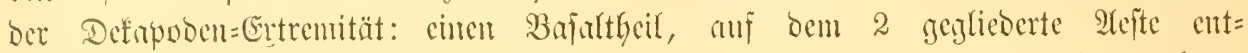

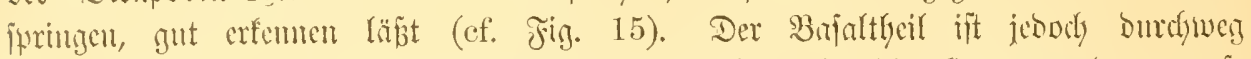

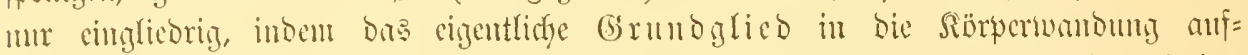
genommen ift, mo fonit mu bas fefre mmiangreidye rmberartig fomprimirte

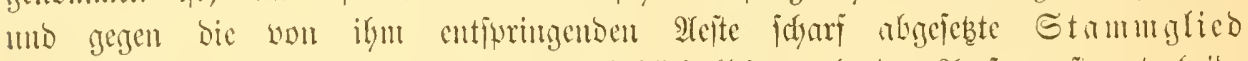

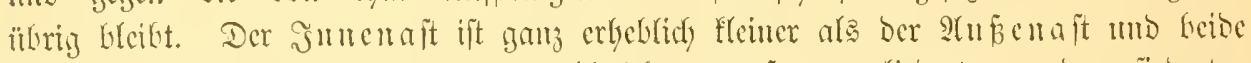
find in ifyer ganjen sänge mit jublrcidyen grof̈en geglieberten mo gefieberten

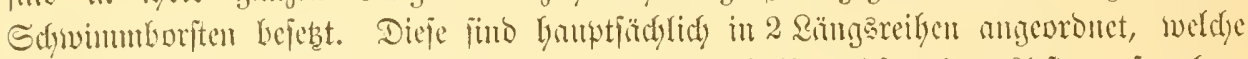

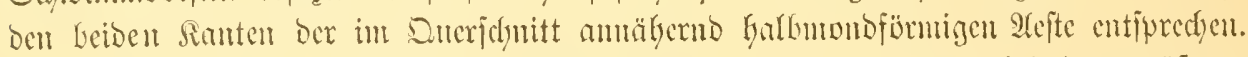

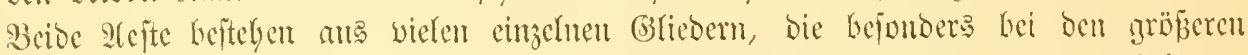

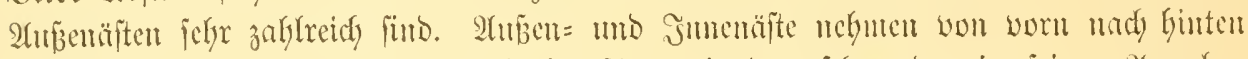

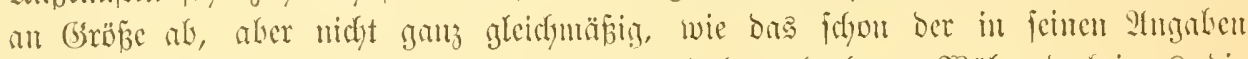

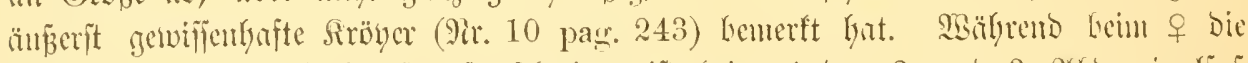

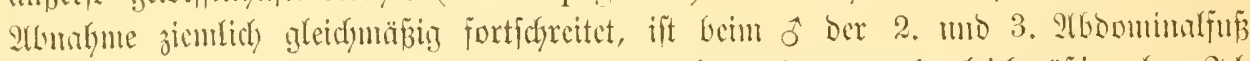

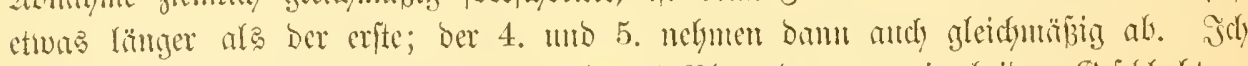
fand ate Dinßze für bie ganze sünge ber 5 Pledpodenpare in Gerben Gejdyledyterm folgende Barblen in Millimetern:

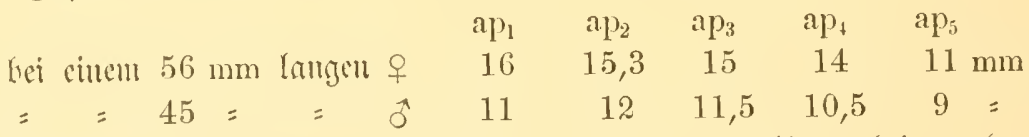

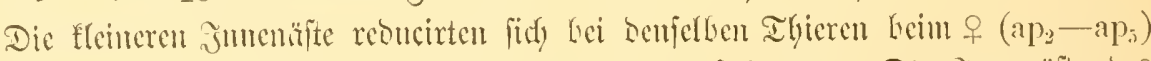

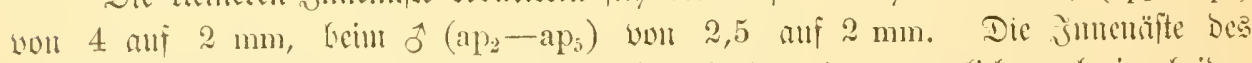

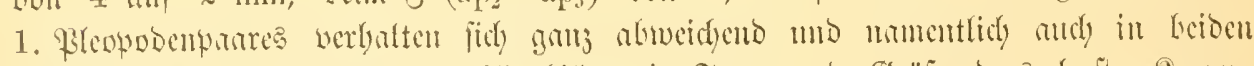

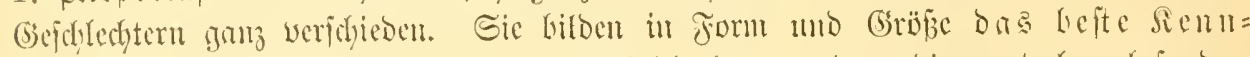

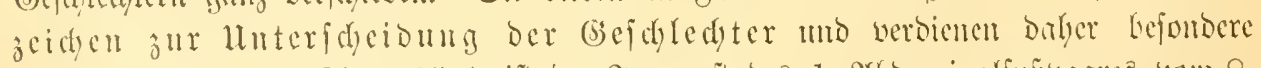

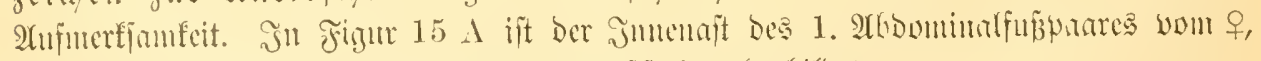

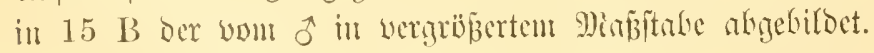

Die Samptiadye ifit: beim o bejibt biejer Jumenaft eime anferorbent=

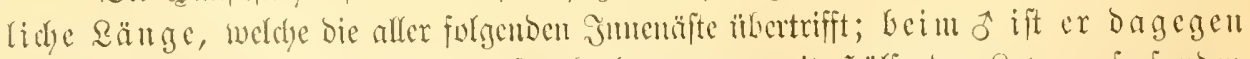

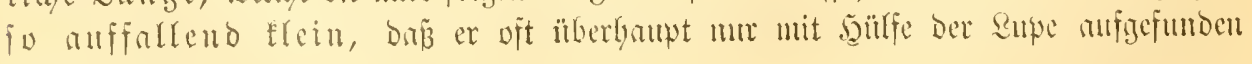
inerden fallu.

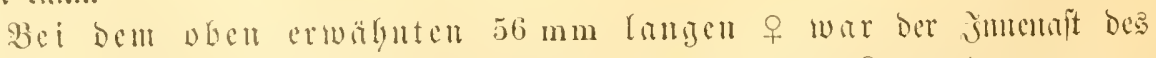

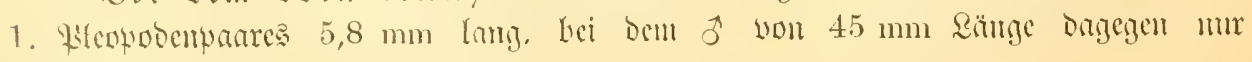
1,3 $\mathrm{mm}$. 


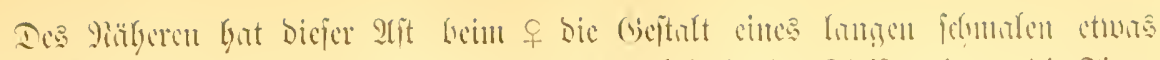

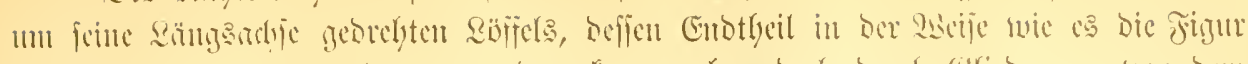

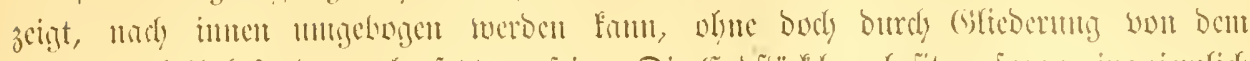

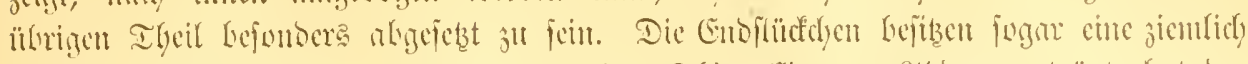

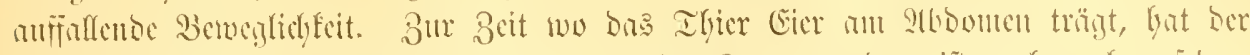

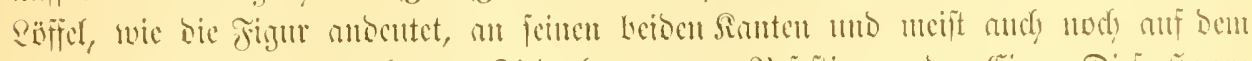

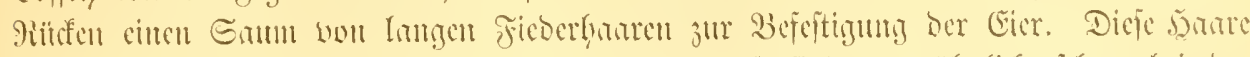

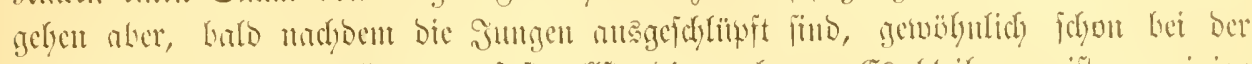

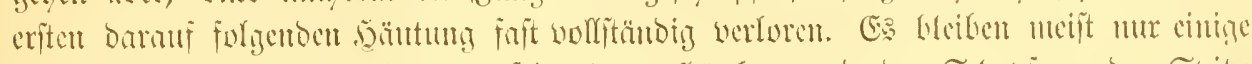

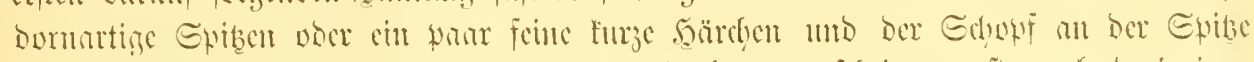

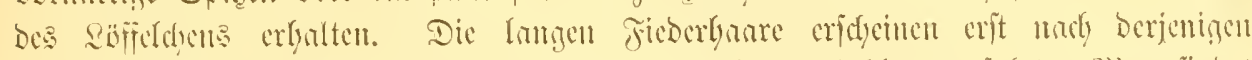

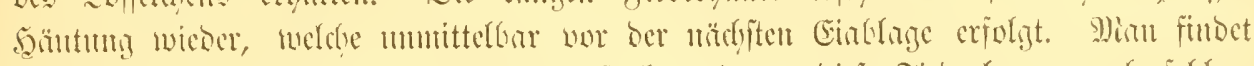

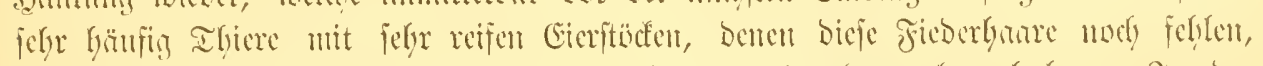

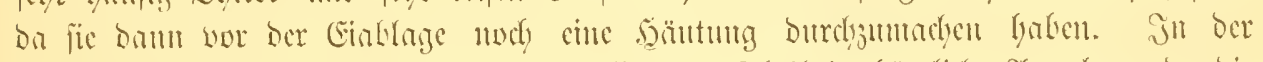

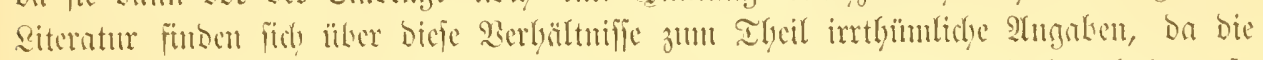

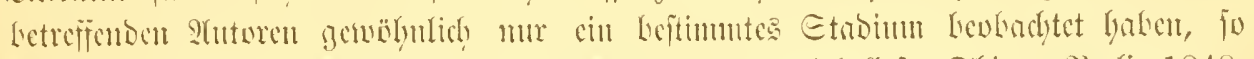

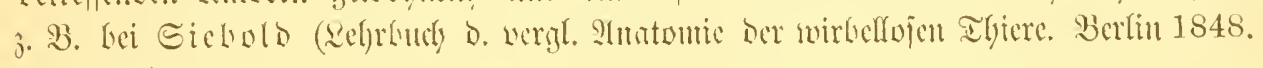
pag. 500).

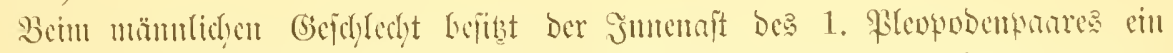

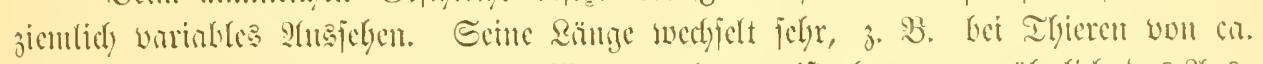

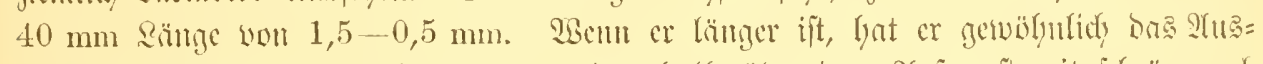

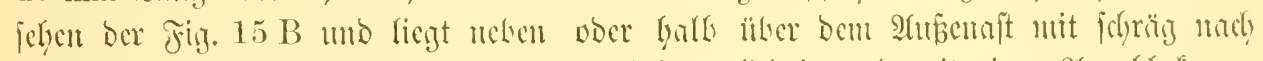

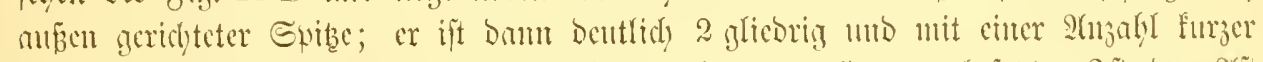

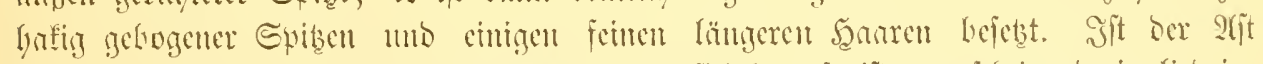

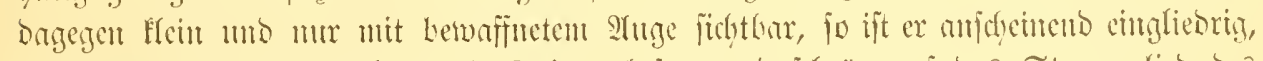

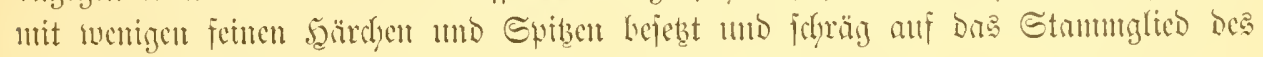
Sleopoden juriefigetrogen, bicjent fejt aufliegent.

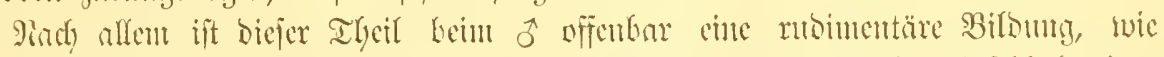

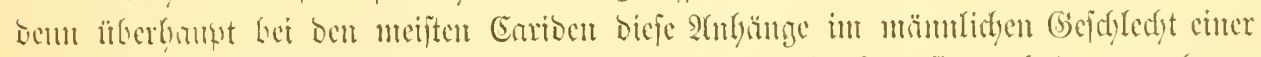

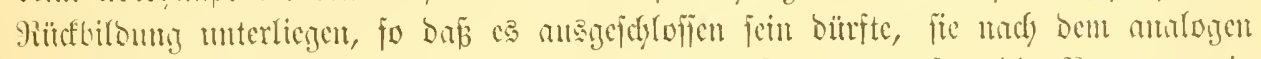

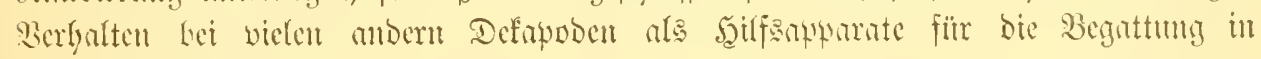
?tripruthy 3u nelymen.

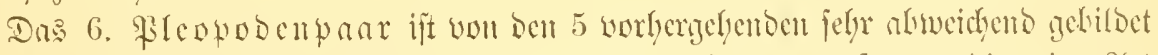

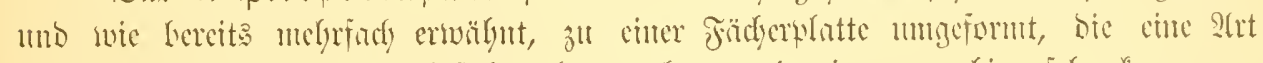

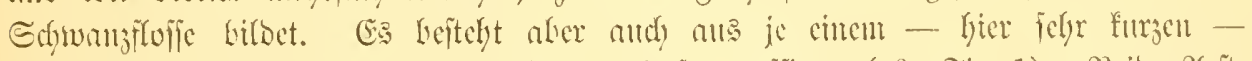

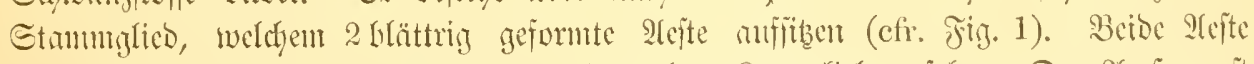

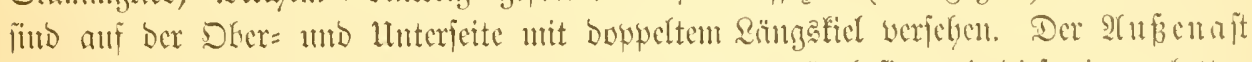

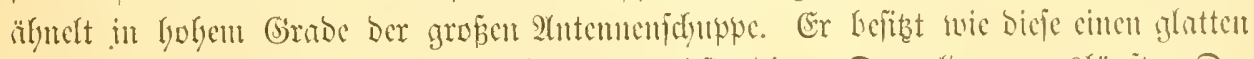

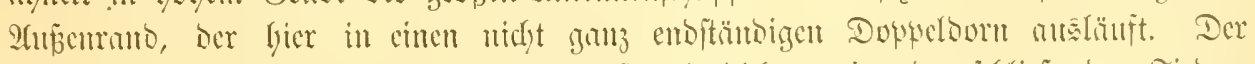

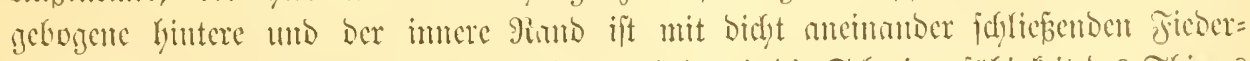

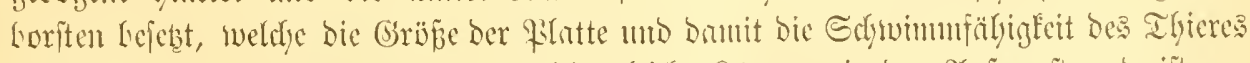

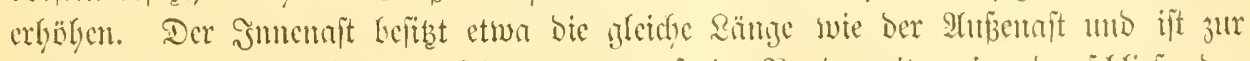

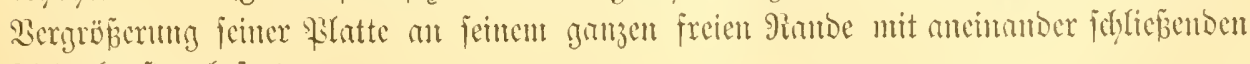
Ficoerfuriten Lejeģt. 


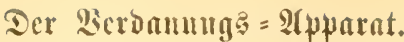

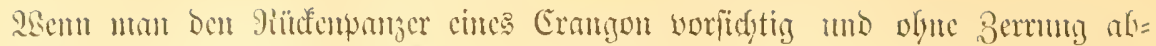

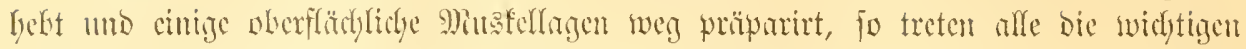

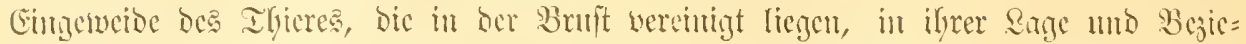

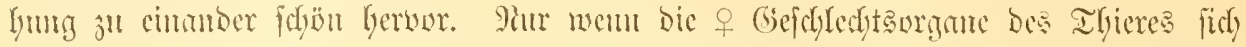

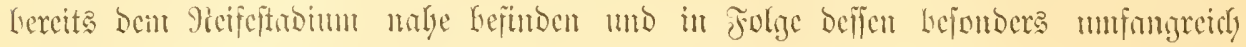
geworben find, beocefen fie fajt alfe übrigen Theile volfoumen.

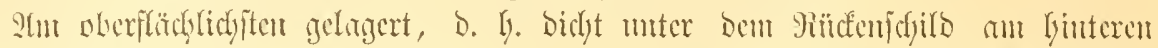

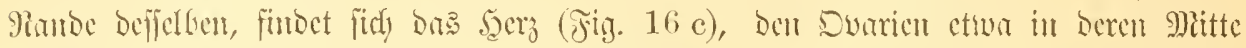

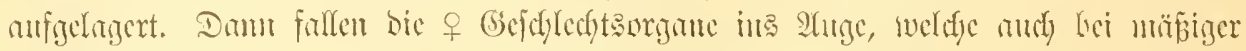

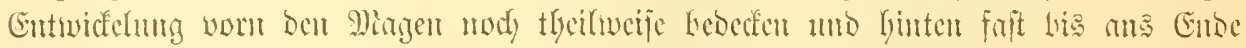

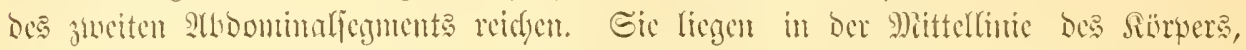

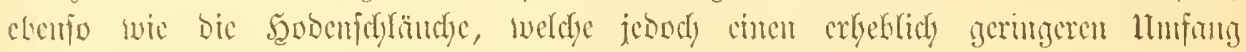
Lecitizct.

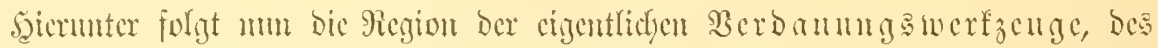

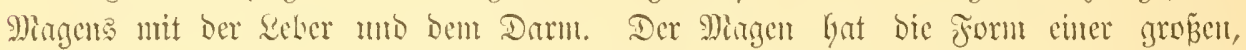

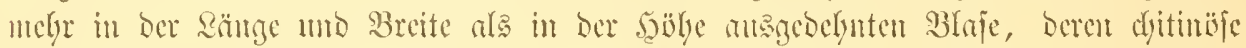

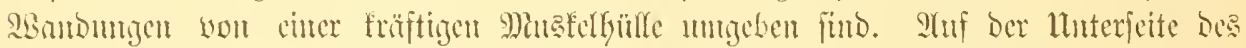

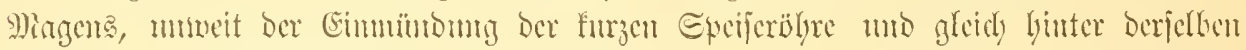

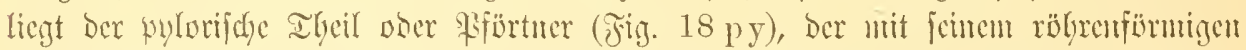

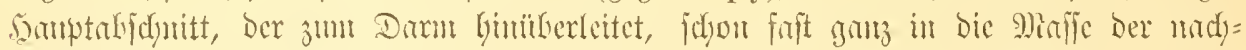
Folgenten Refer cingehettet ift; Da ber vorbere Theil ber Reber als folfiter für Den

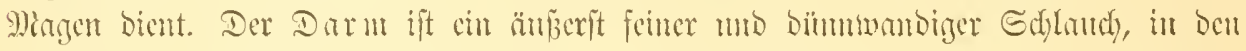

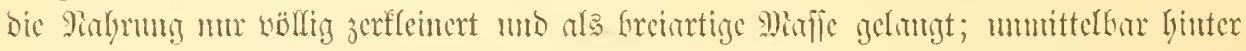

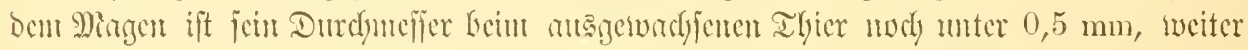

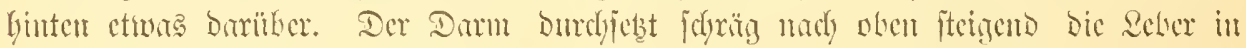

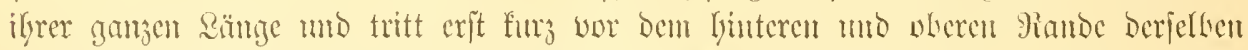

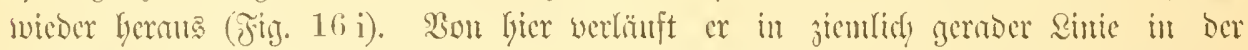

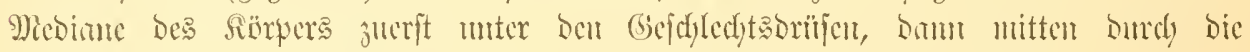

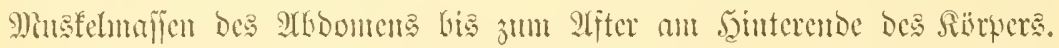

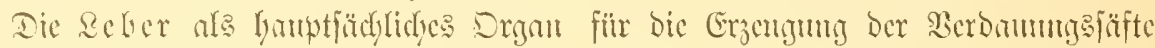

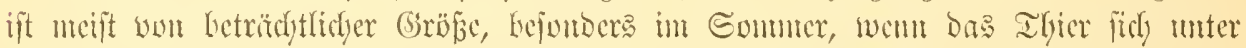

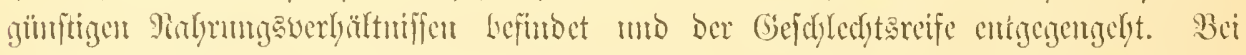

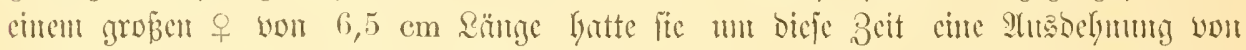

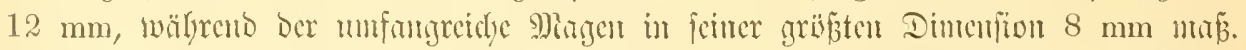

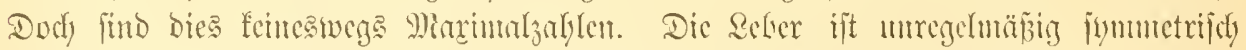

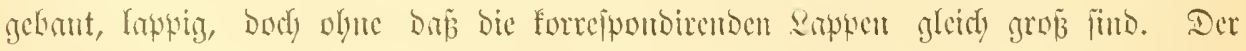
worbere motere Iheif, ben ber Magen anfliegt, ift jeocrfeits in brei ctwa gleich grobe

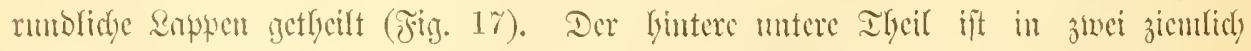

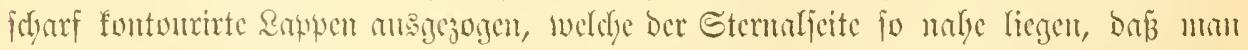

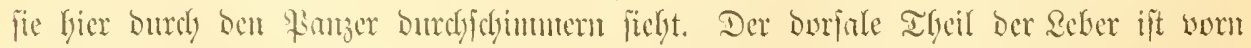

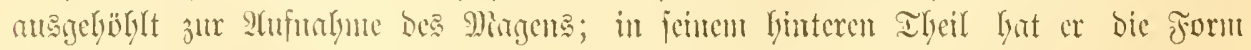

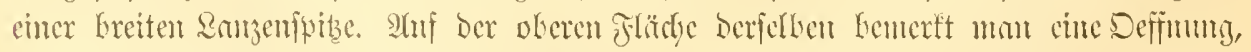

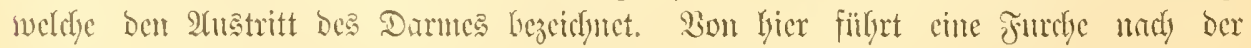

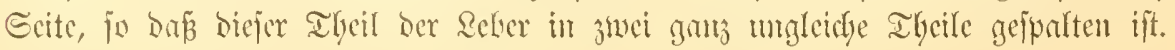




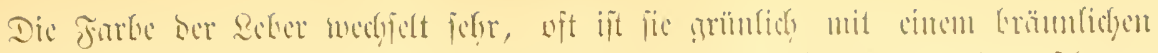

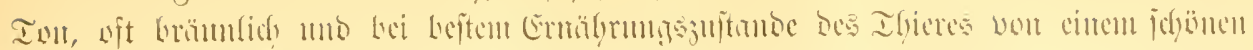

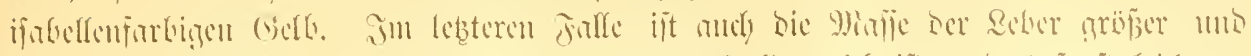

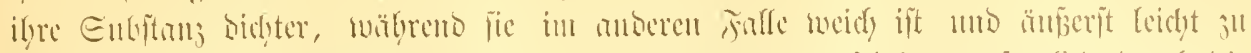

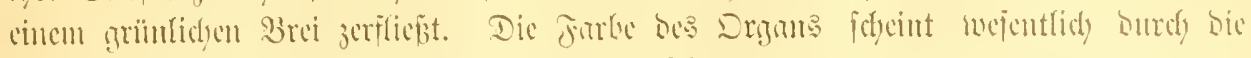

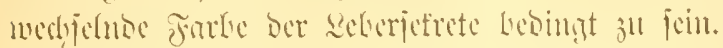

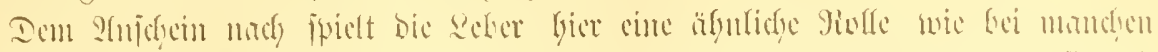

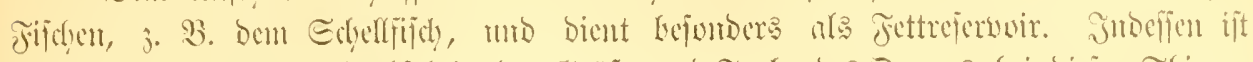

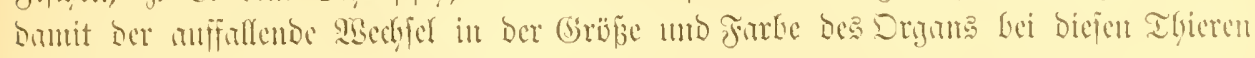

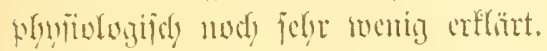

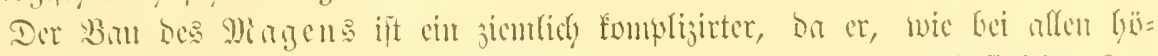

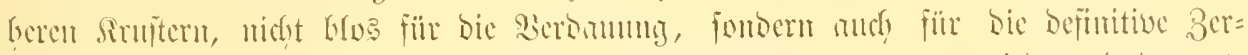

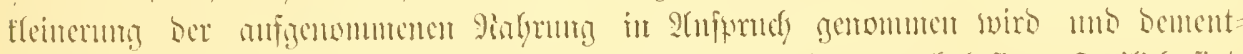

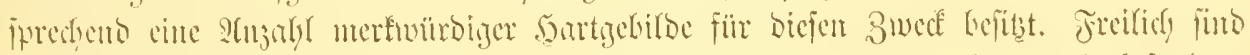

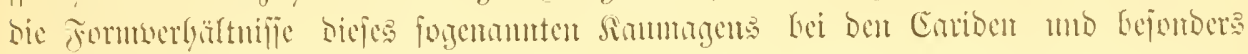

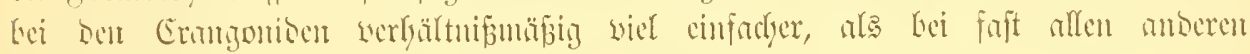
Defirposert.

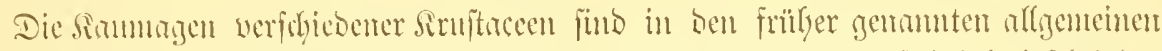

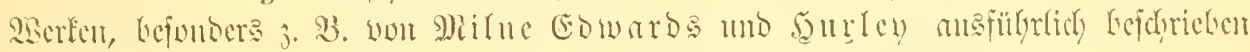

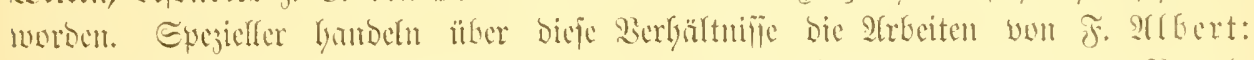

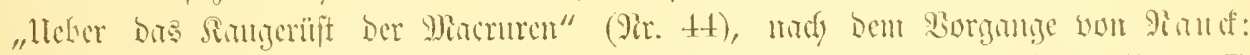

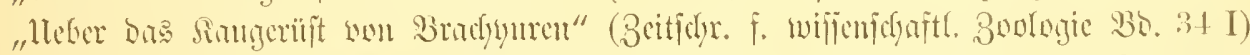
und wen $\mathcal{F}$. Mioc

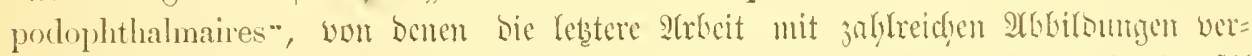

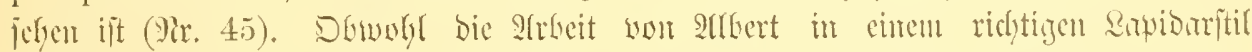

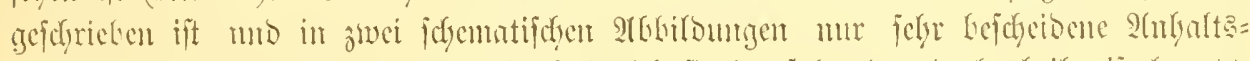

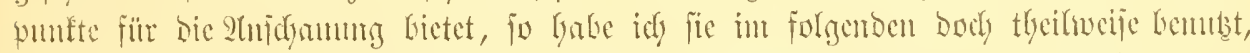

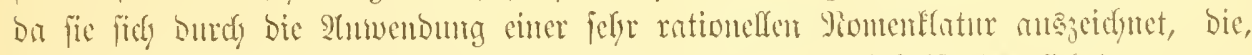

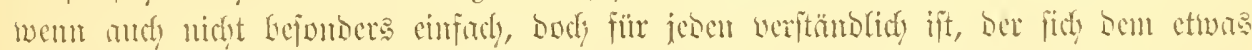

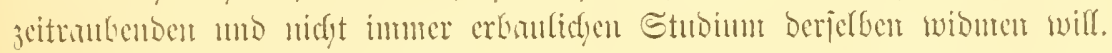

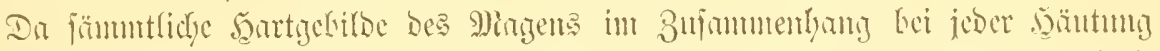

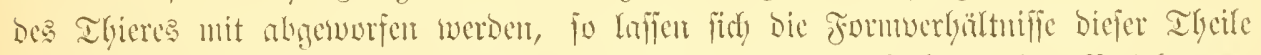

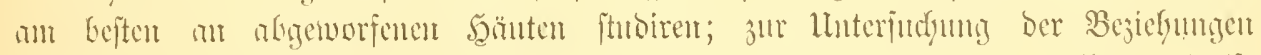

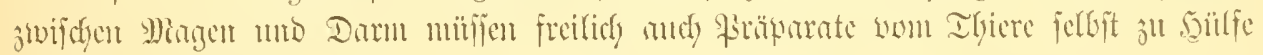
genomแน werben.

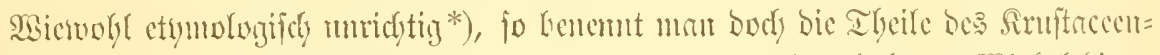

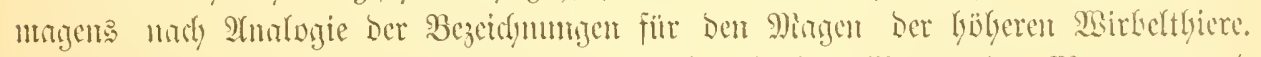

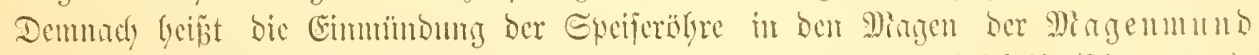

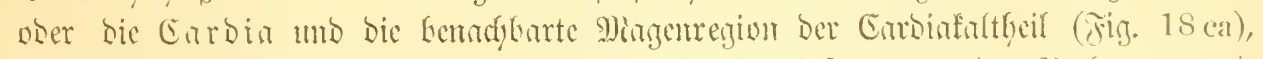

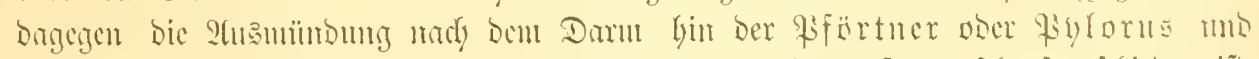

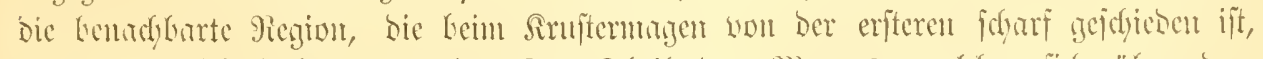

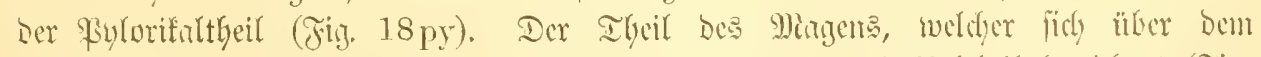

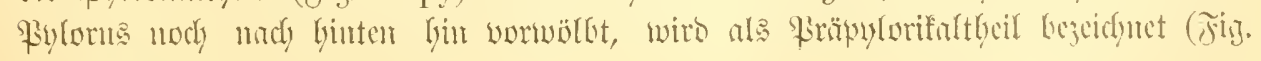

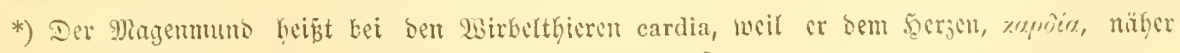

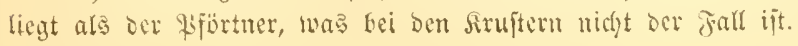


18pp). Diejer lebetere ift gerabe an Ermgommagen bejombers ansgebilbet mo ïber=

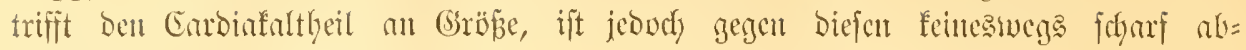
gegrenzt.

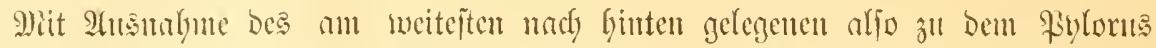

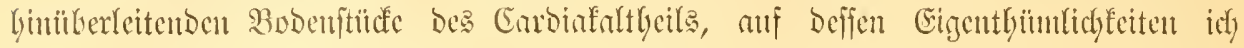

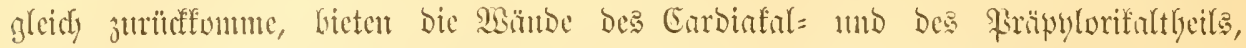

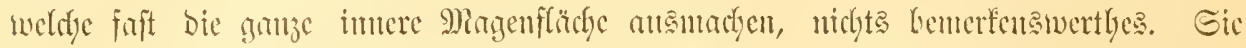

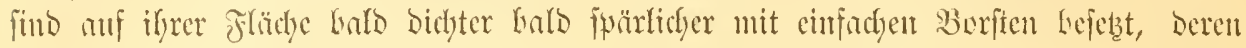

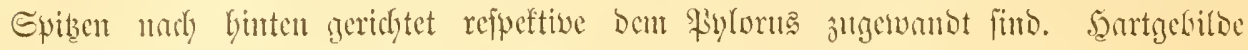

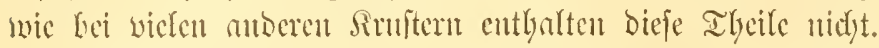

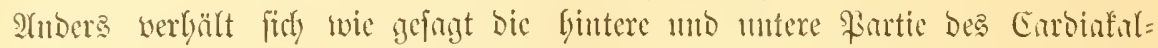

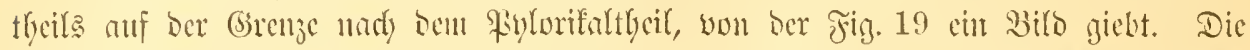

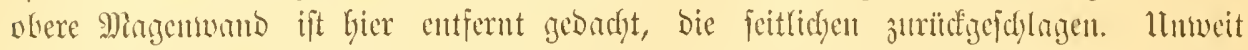

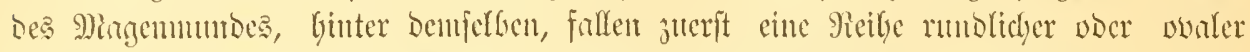

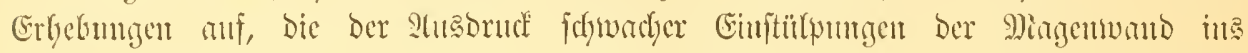

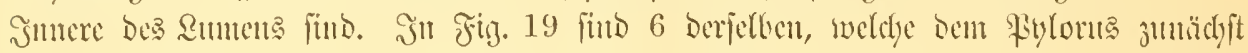
liegen, Dargeftellt. Sie fund bidfter als bie mugebendent Ibeile mit Borften Gejebt, Deren Spiben Den Fylorus jugefebrt füb; body cutbalten fie feinc Sartgebilde.

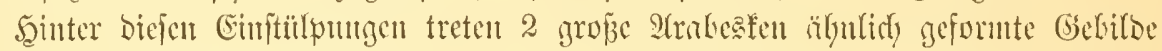

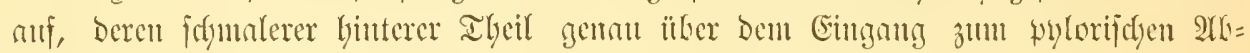

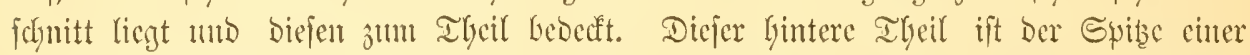

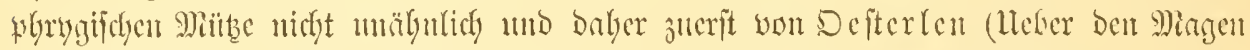

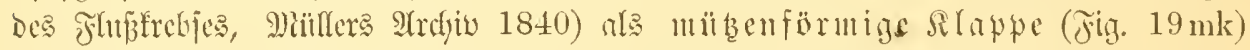

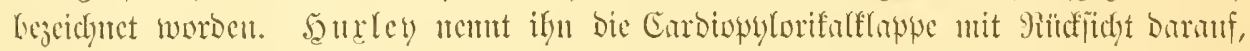

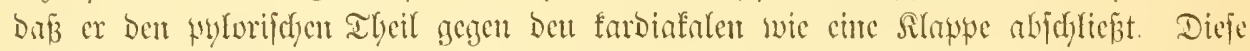
Silappe ift jedody bei Erangon nidfte weiter ale einc - an einigen Stellen boptelt

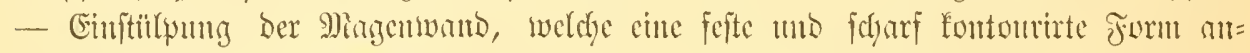

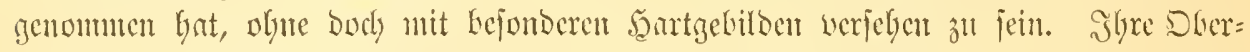

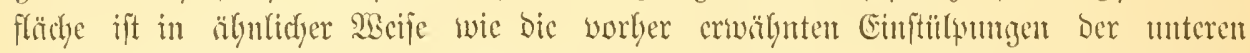

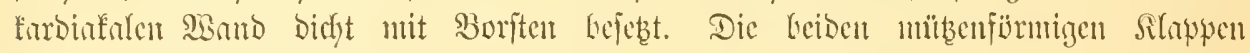

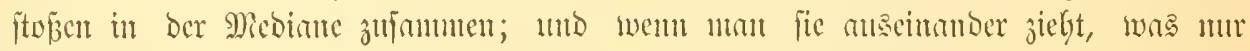

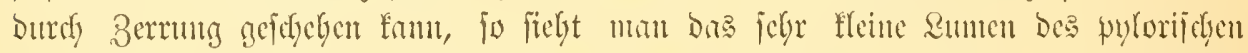

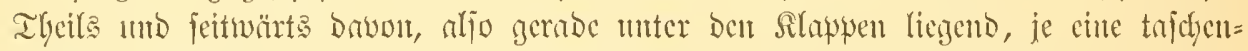

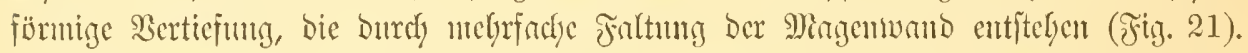

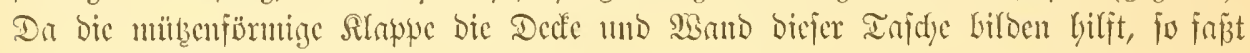

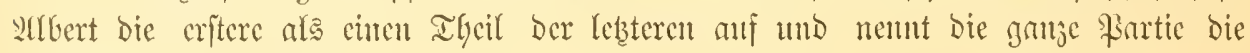
Suferonediantaidy.

Bor ben mübenförmigen Silapsen funden fich in Der unteren Carbinfaluano

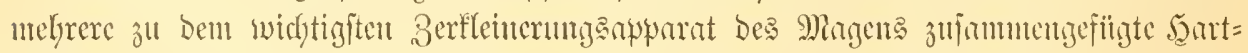

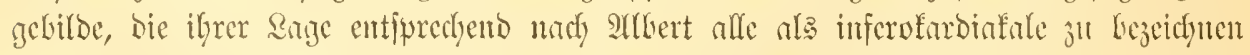

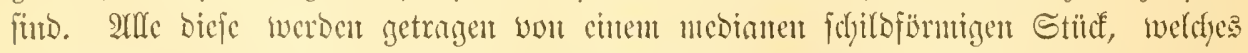

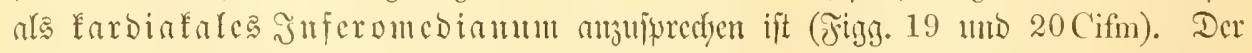

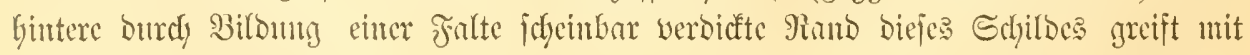

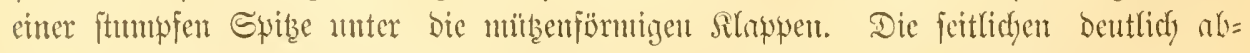

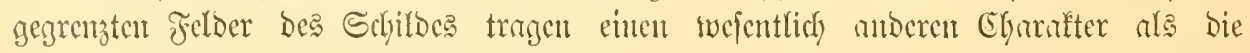

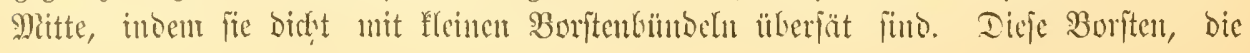




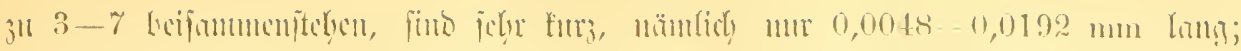

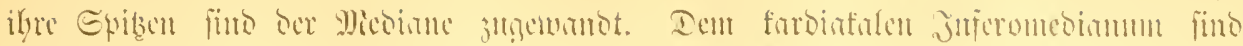

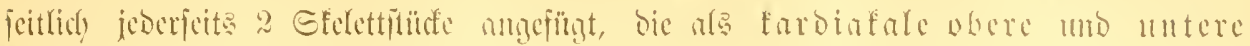

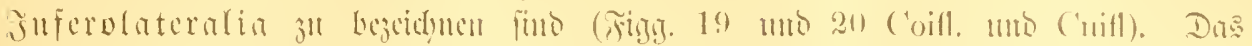
lestere lisctet im

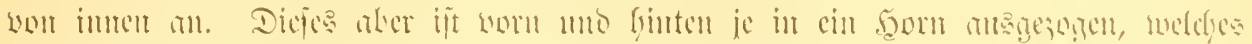

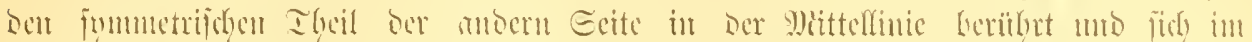

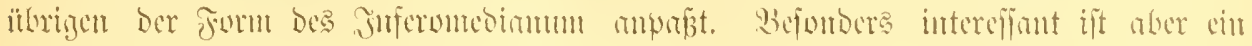

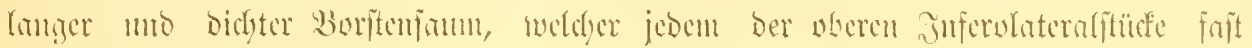

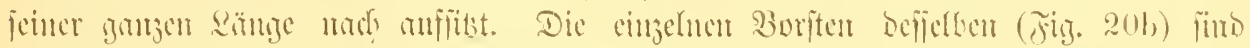

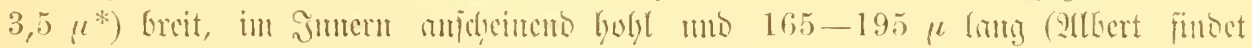

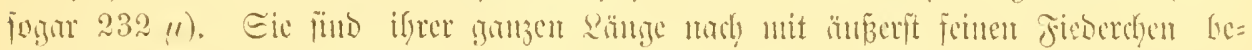

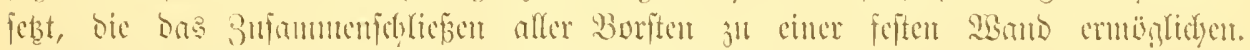

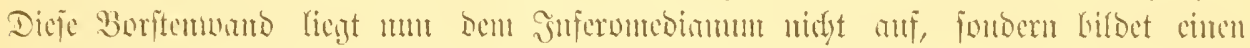

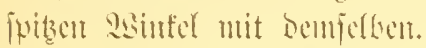

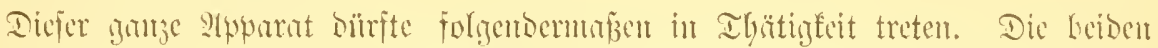

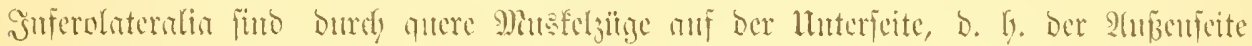

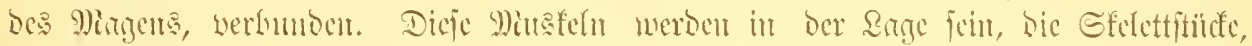

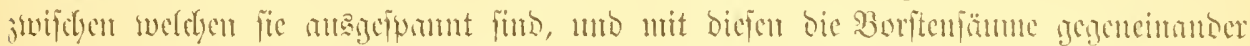

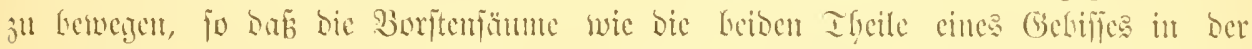

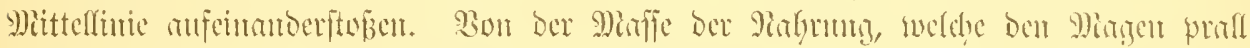

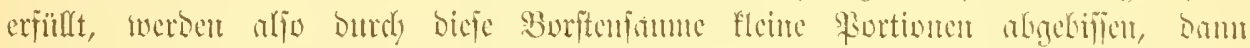

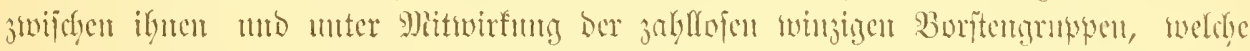

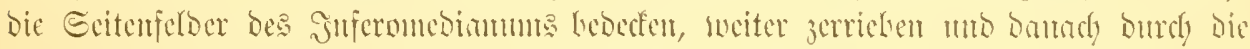

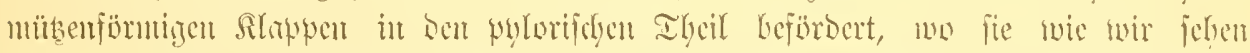

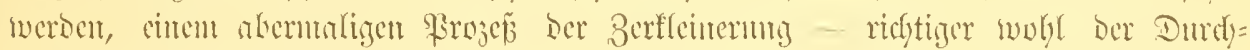
Filfung - unterworjen werben.

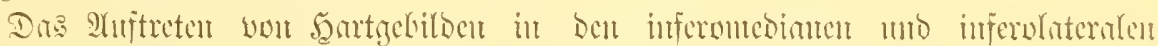

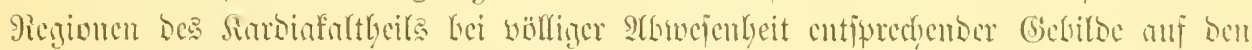

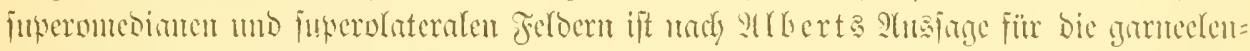

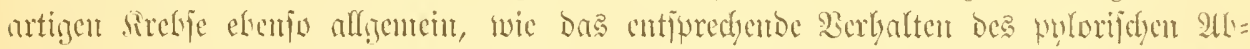

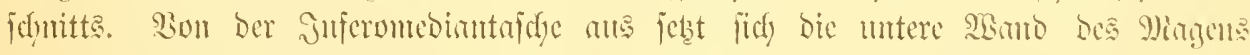

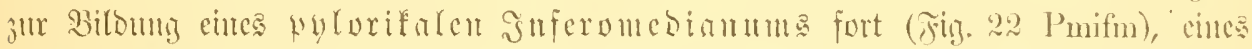

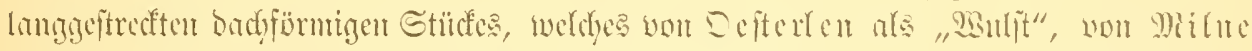
EDW

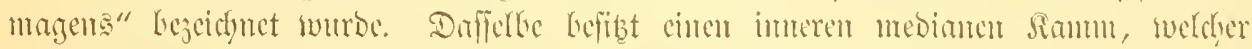

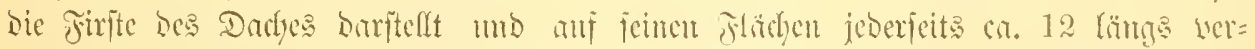

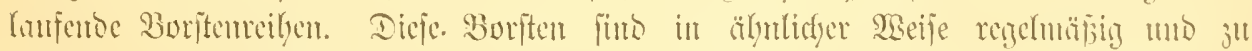

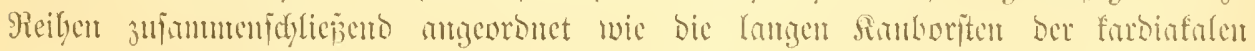

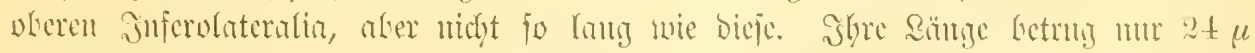

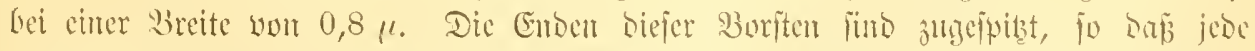

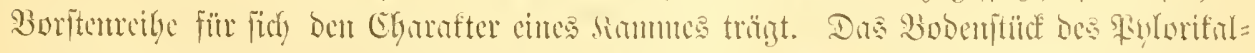

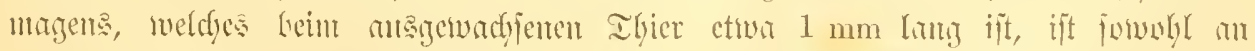

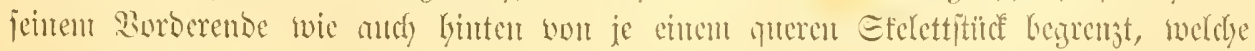




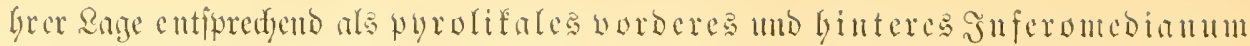

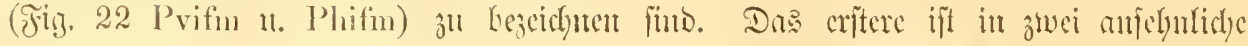

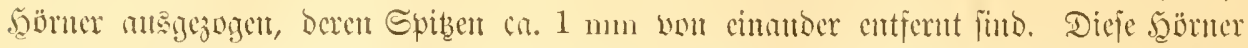

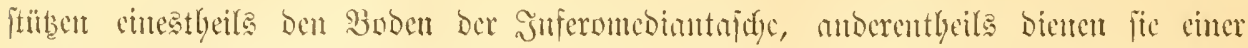

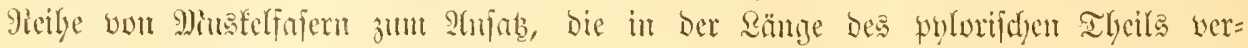

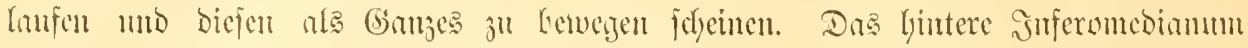

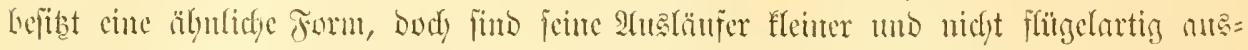

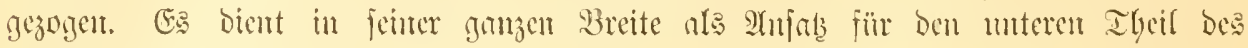

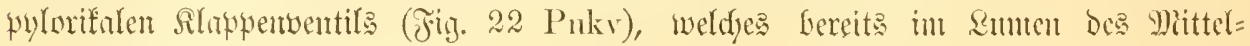
Darmis (i) licigt,

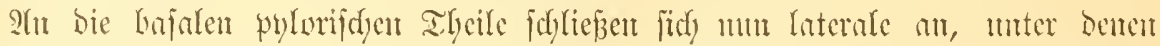
wieder das mittlere Snferolaterale duref feinc Gröbe bie erfte Stelle chmmunt.

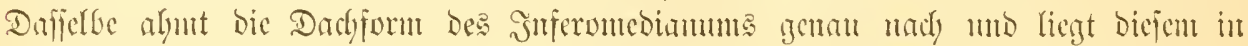

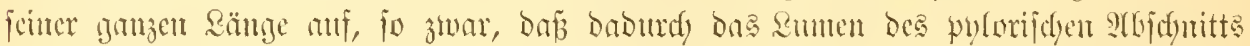

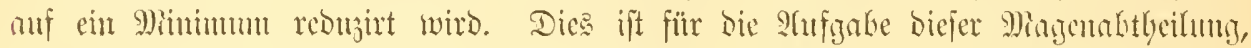

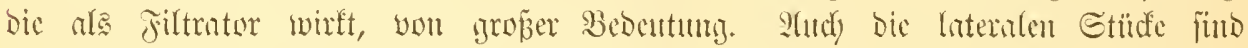

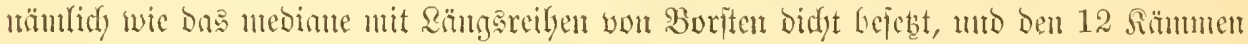

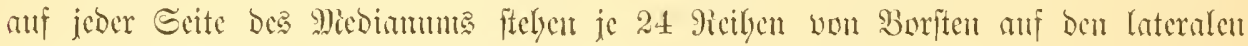
Stüden gegenïber. Dieje lebteren Borjten füb aber länger als bic criteren mis

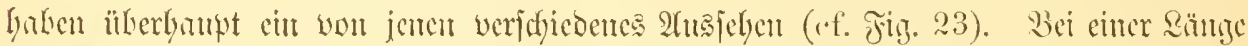

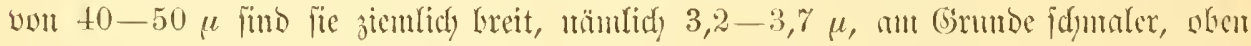

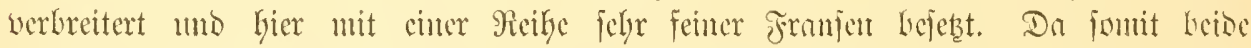

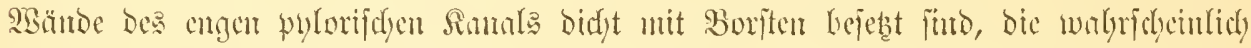

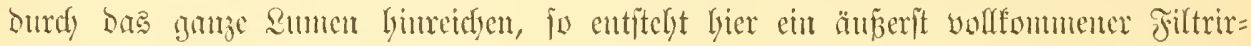

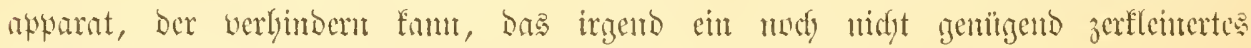
Bathrungetbeildyen ben Sieg mady bent Darme finden mödyte.

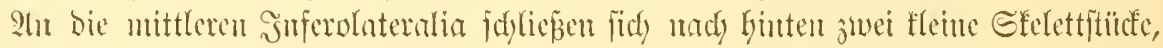

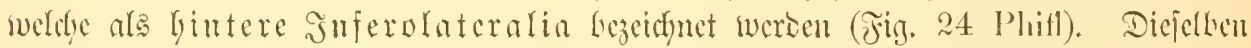

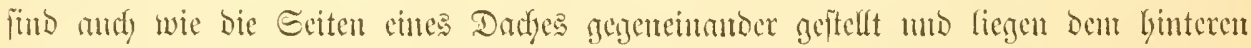

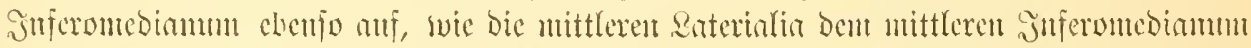

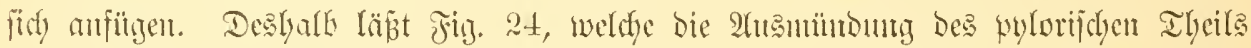

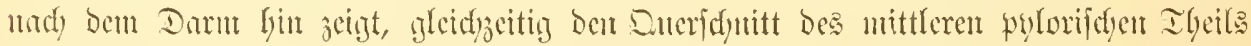

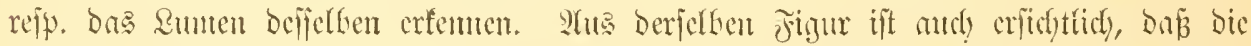

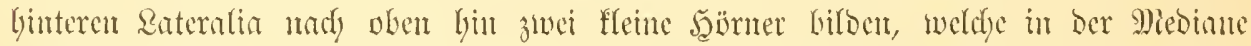

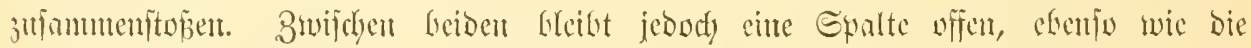

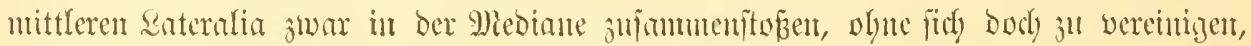

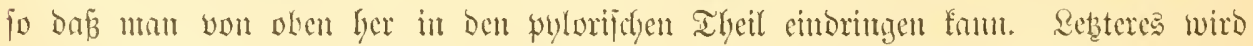

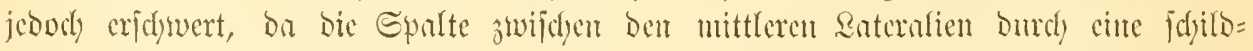

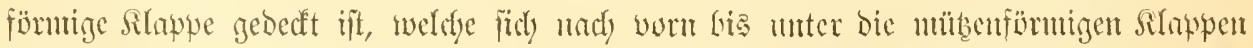

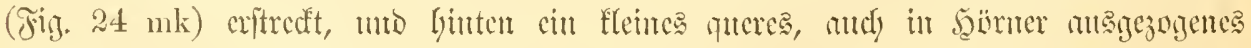

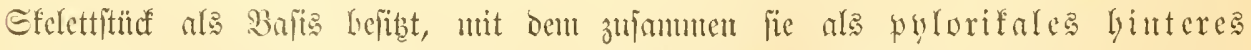

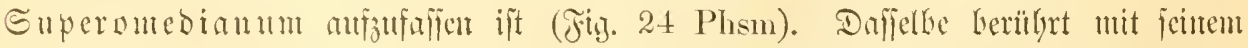

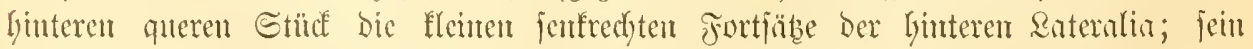

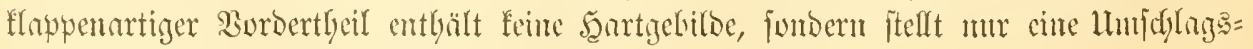
falte der vberen häutigen Magentwand Dar.

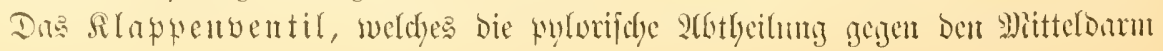




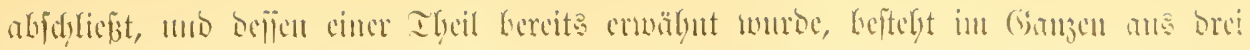

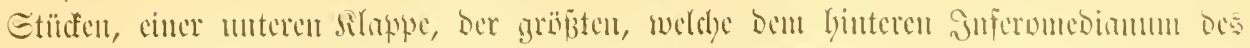

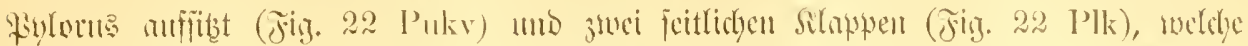

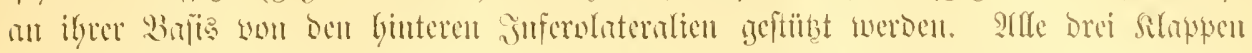

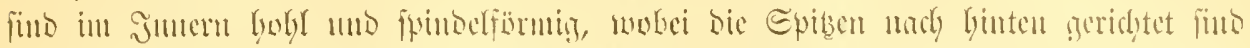

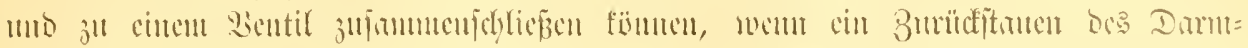

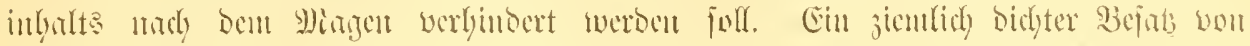

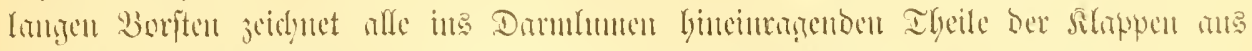

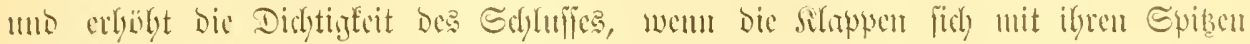
зијанแntenlegzent.

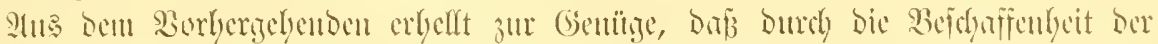

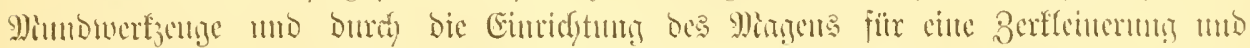

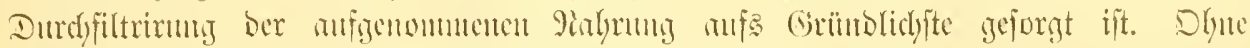

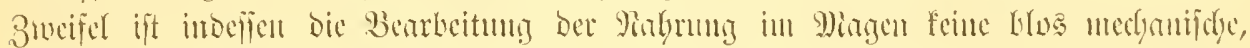

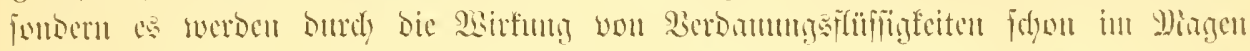

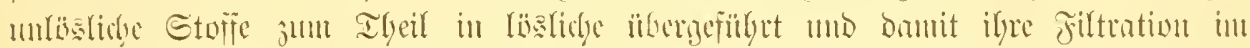

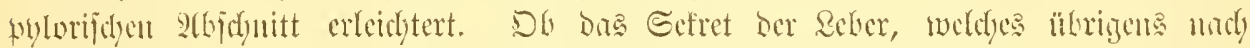

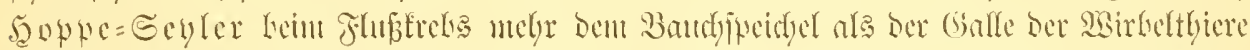

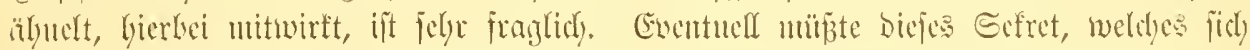

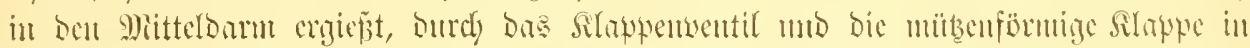

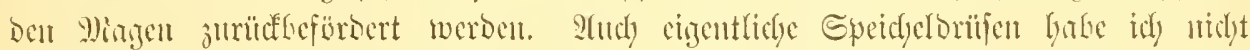

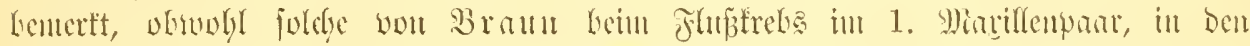

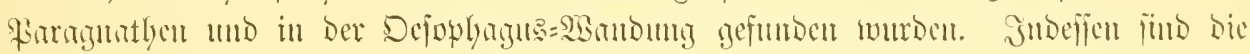

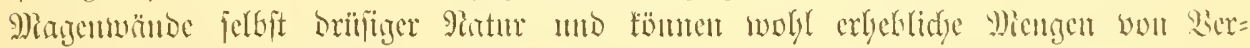
Daum!gâfüten lieferu.

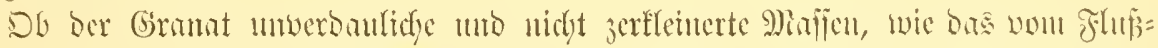

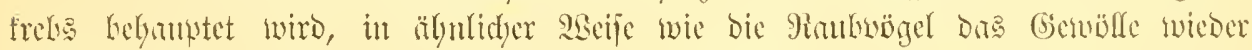

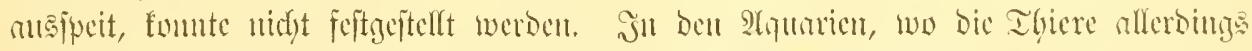

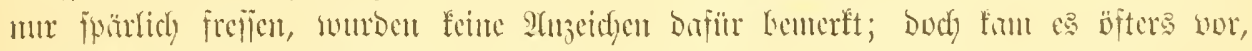

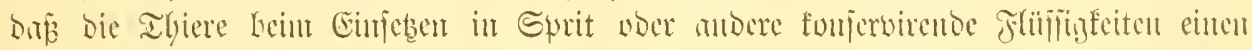

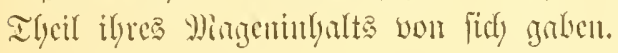

\section{Dic Gicjuledjêrgauc.}

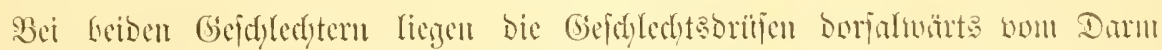

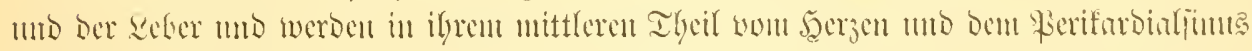

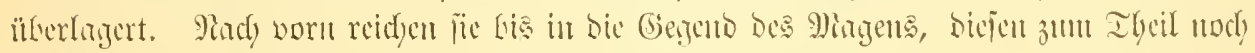

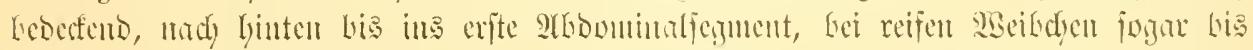

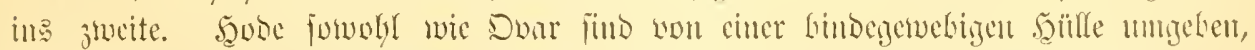

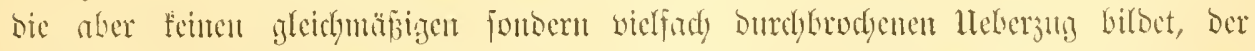

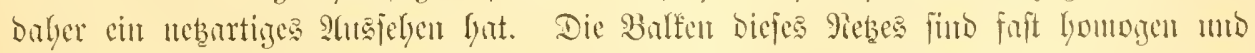

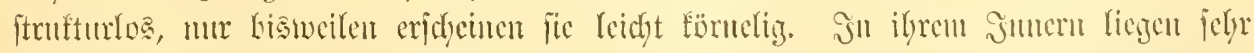

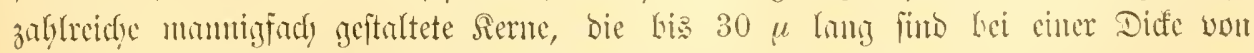
$6-9 \mu$. Die Diebsalfen laben eine Breite you $20-70 \mu$. 


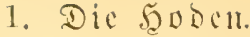

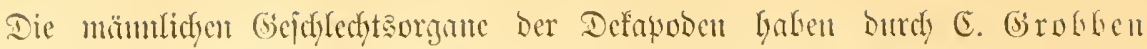

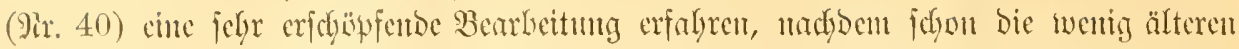

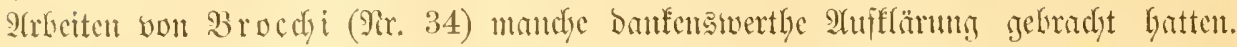

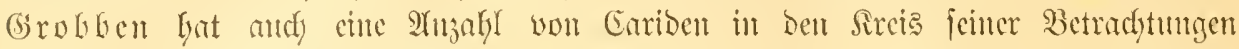

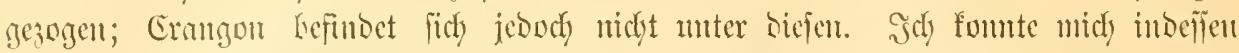

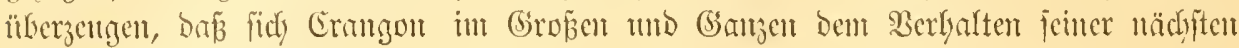
Sertwanoten anforliefist.

Figutr 25 giebt cinc Sorftellumg wou ber Geftalt ber Soben Leim Granat.

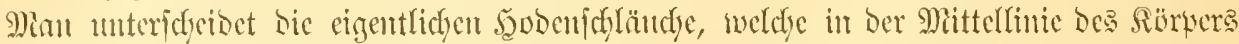

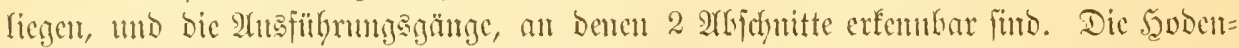

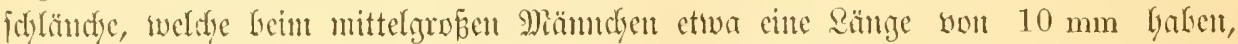

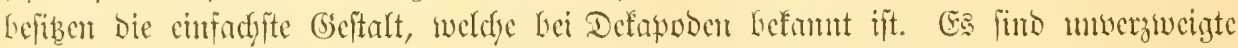

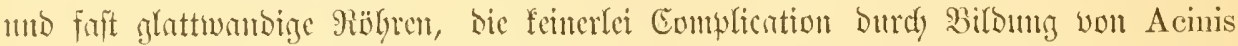
(wic bei verwanden Formten) anfweifen. Dic Schländye ber beidu Geiten fund afuer

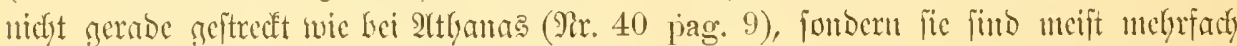

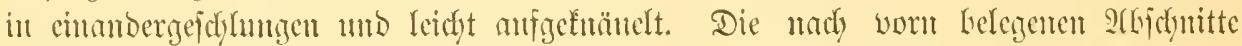

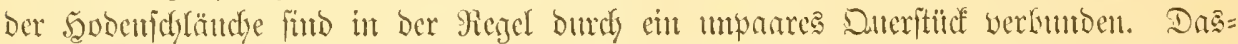
ferbe feblt aber aucly bänfig, wie idy anf Grumb zablecidyer und forgfialtiger

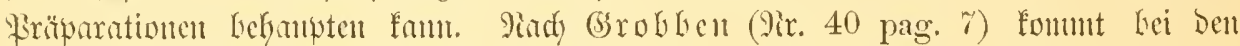

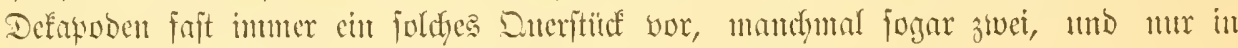
felyr jeltenen Fällen wird es wermifint z. 23. Gei Pagurus.

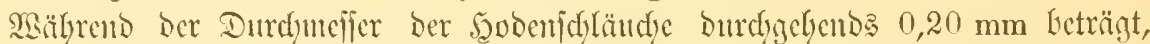

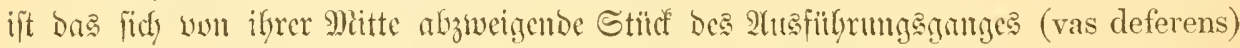

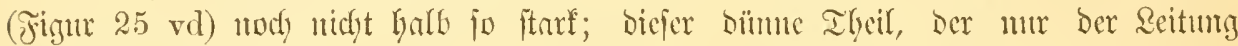

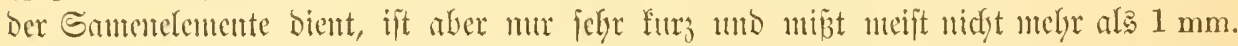

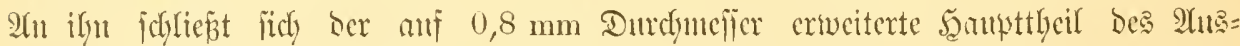

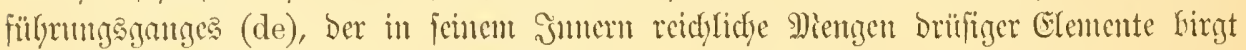

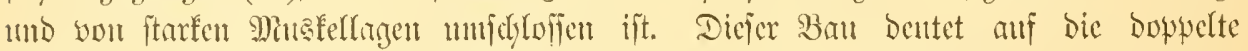

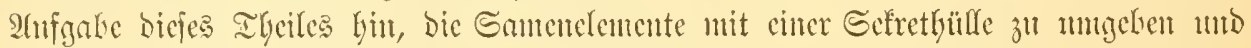

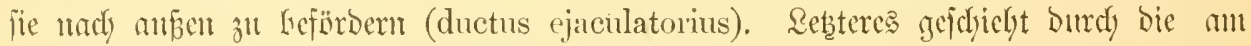
Ende Des Gantges befindidye Deffmmig (o), weldye anf der S̈menjeite des 5. Gely=

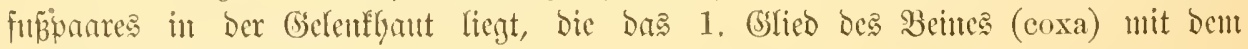
Brnftftïd wertindet.

Die Sobonfaländye fint bidyt angefüllt von den Samenzellen, die cinen Durdy=

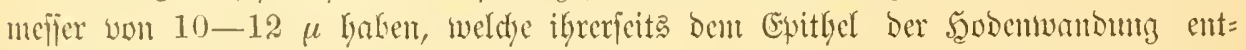

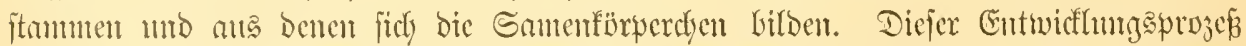

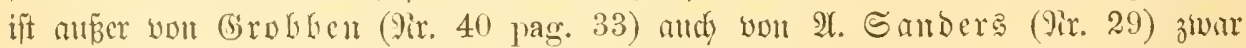

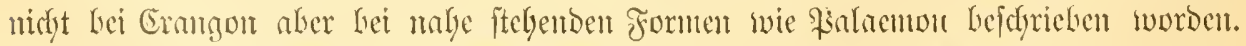
Ex verläuft Lei Crangon in ganz älunlidyer sBeife. Dic Gamenzellen (Jig. 26A)

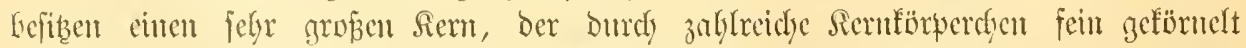

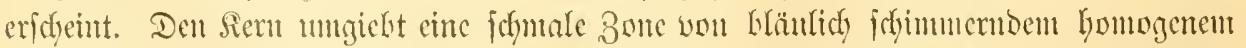

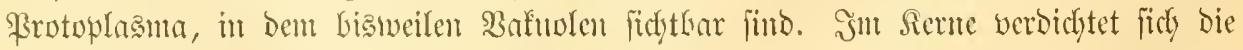

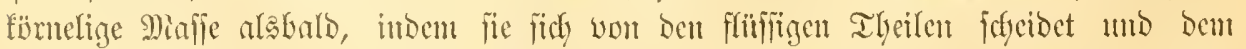

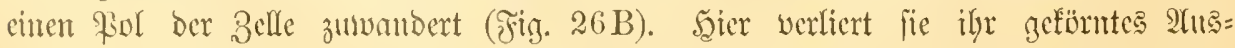

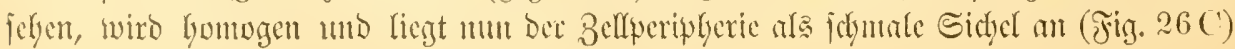




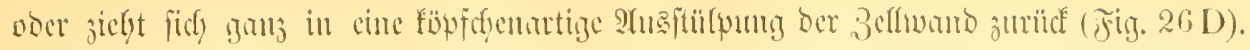

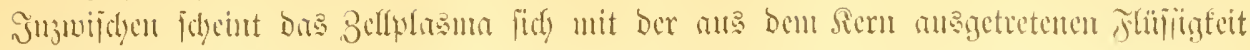

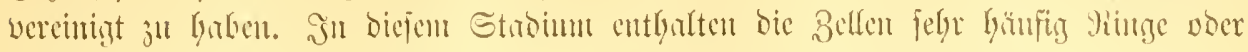

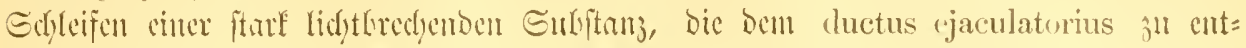

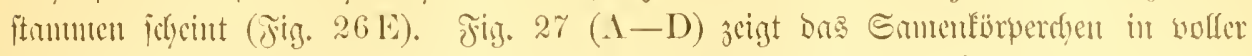

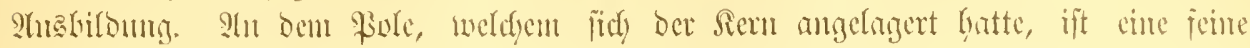

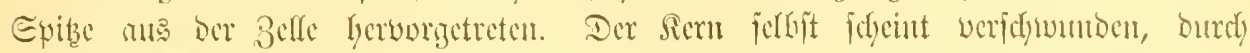

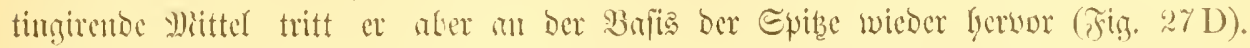

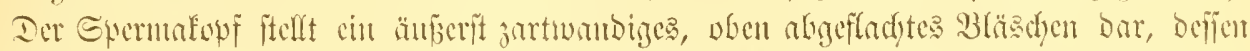

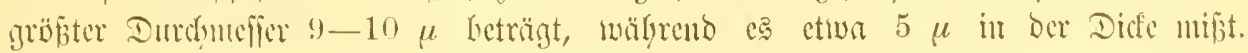

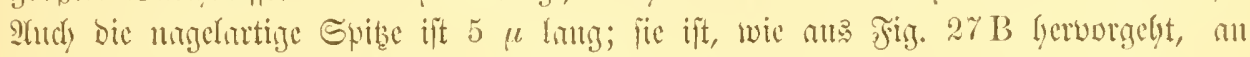

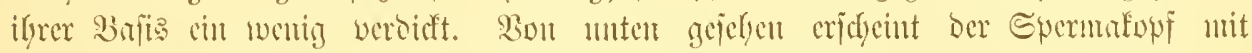

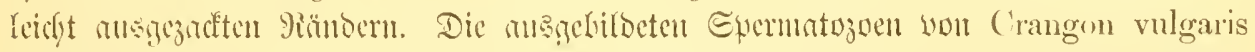

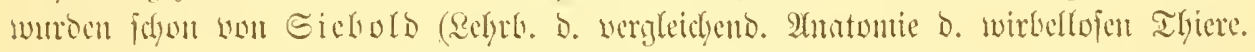

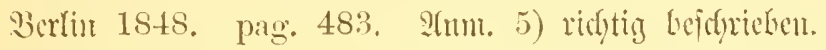

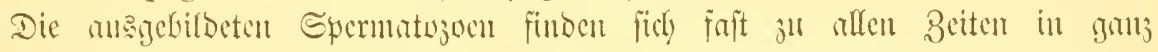

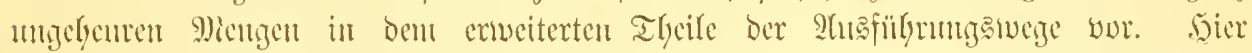

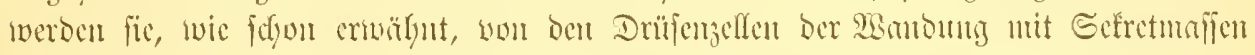

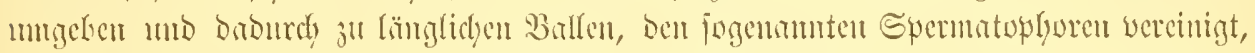

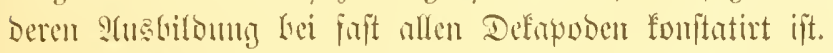

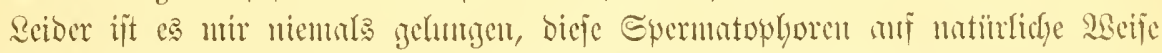

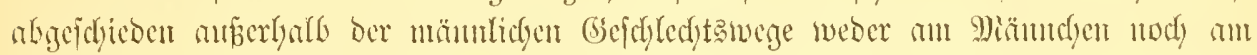

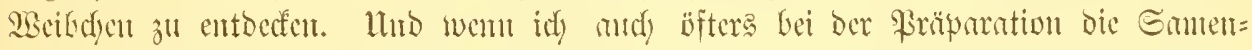

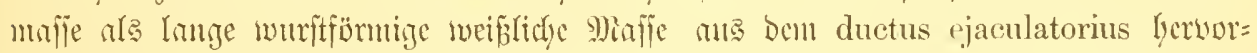

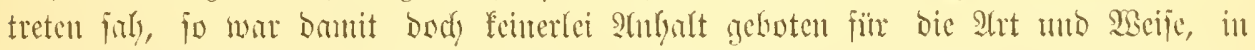

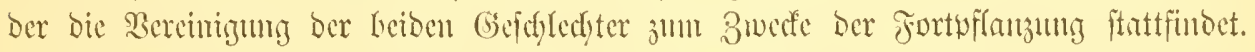

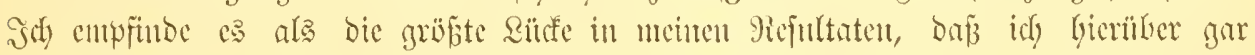

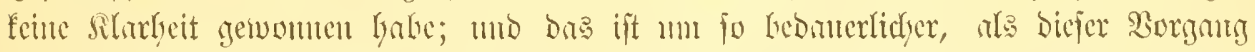

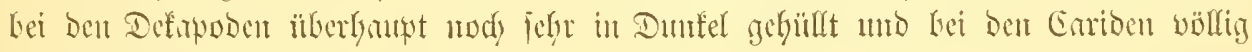
untsefimut ijt.

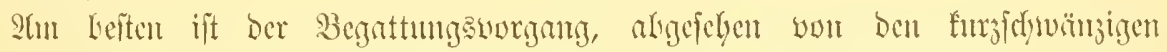

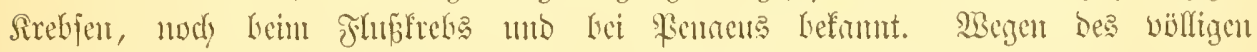

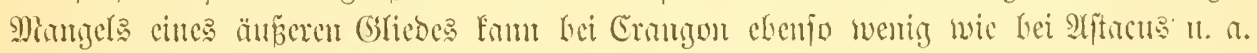

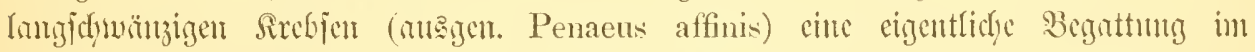

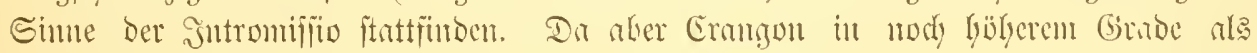

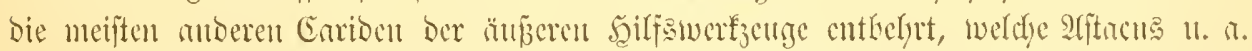

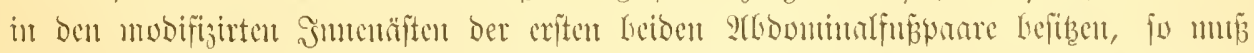

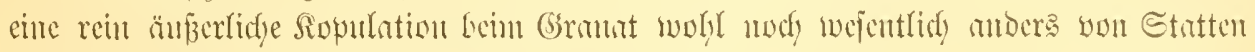

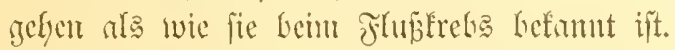

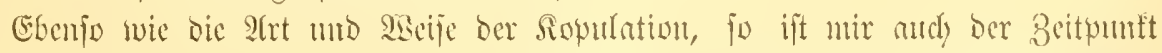

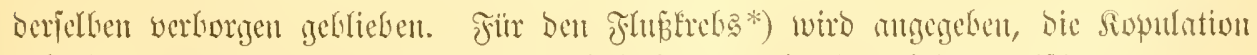

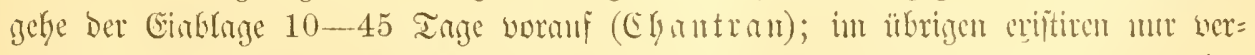

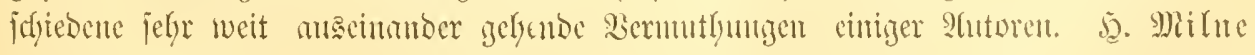

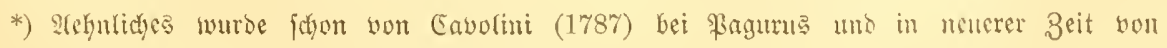

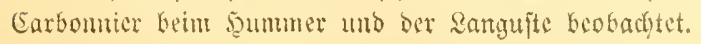




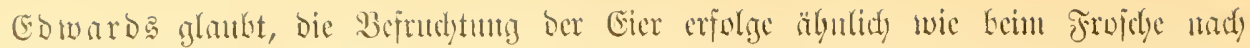

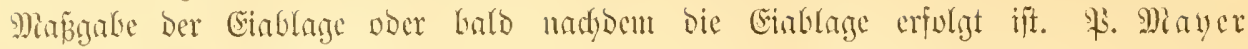

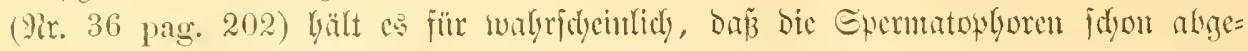

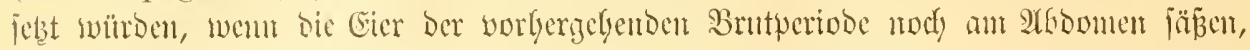

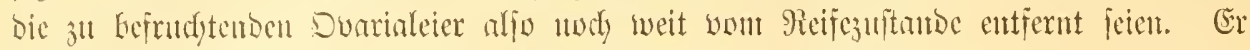

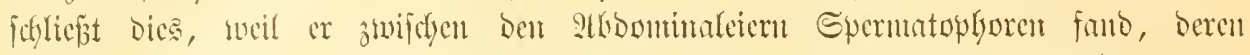

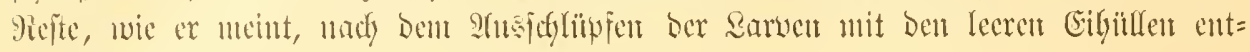
ferut würoden.

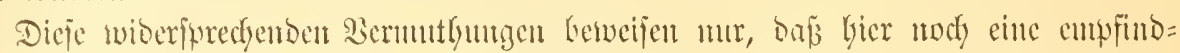

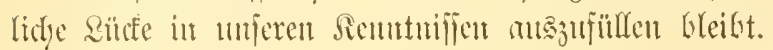

\section{Der Eieritod.}

Das Duarimn ift ebenjo jumnetrifdy gebant wic bie mämulidyen Gejdyledyts:

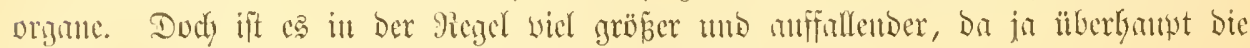

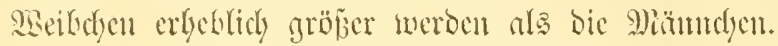

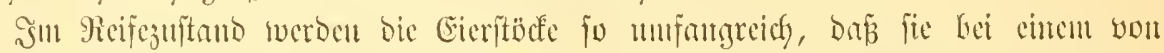

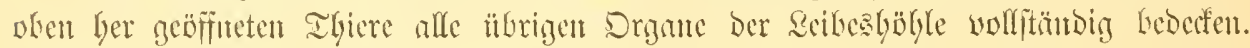

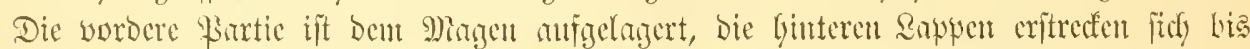

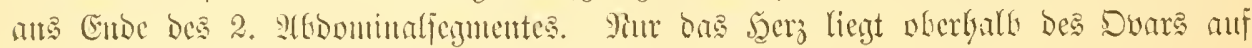
Der sorberen Ђälfte Deffelben (c.f. Jig. 16).

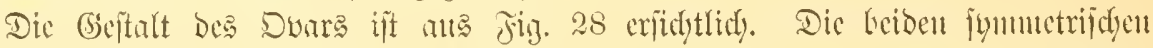

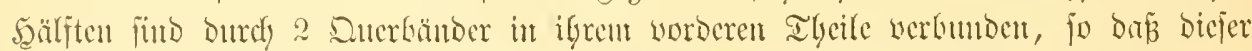

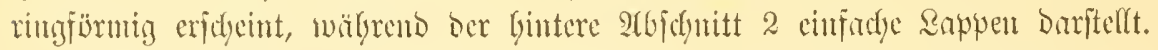

Eine bellere Rinie, weldye man burdy bie Mitte beiber Dvarbälften berlanfen

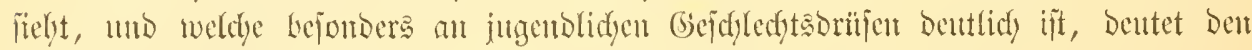

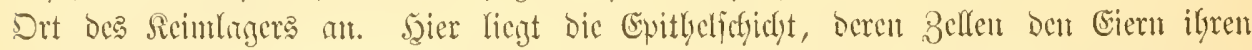

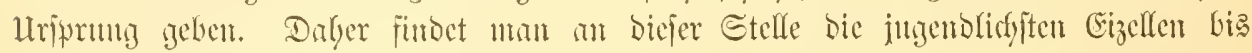
berab zu cincur Durufutejer un $3 \mu$.

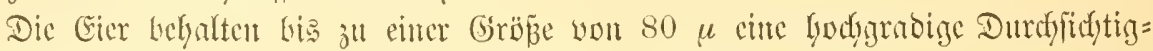

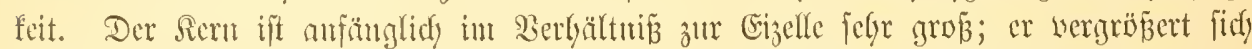

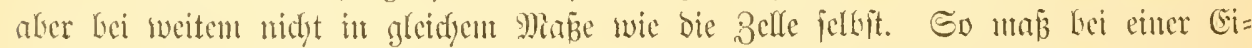

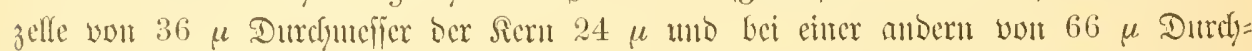
mefier mu $30 \mu$. Buerft ift bas Plasma ber Belle fajt Gomogen und feljr bell, der

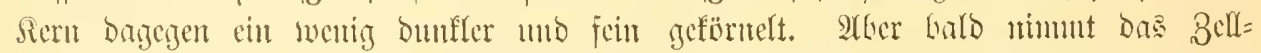

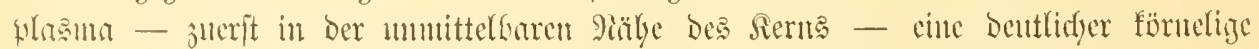

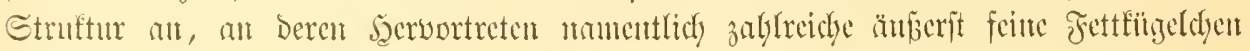

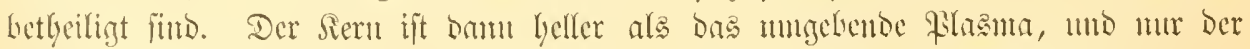

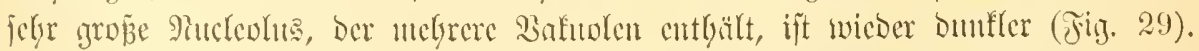

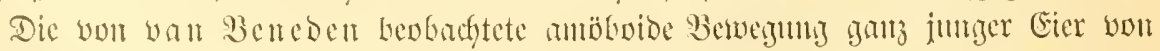
Crangon vulgaris bube idy ebenjo wentig gejeben wie \$s. Miancr, ben biefelfen andy worgelegen baben.

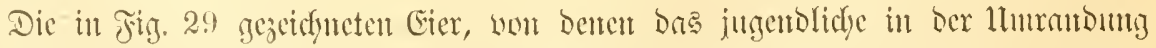

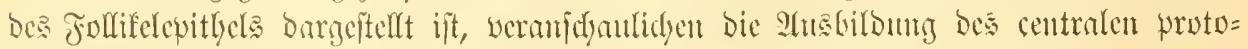

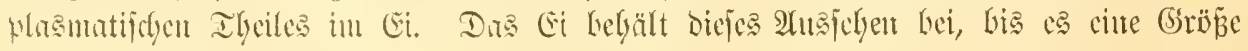

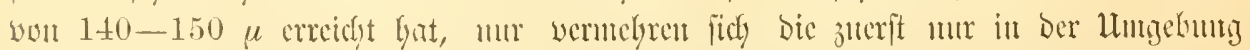
Des Serms anftretendon Jettröpfäyen und serbreiten fidy über bie gange Belle. Die 


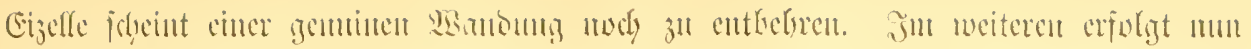

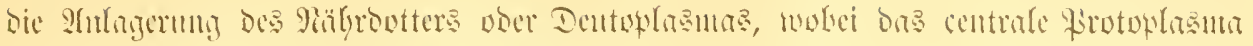

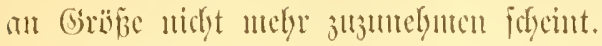

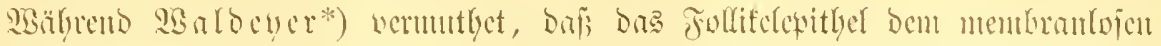

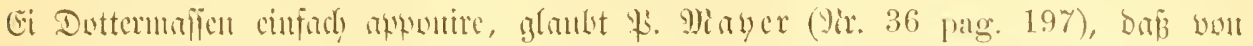

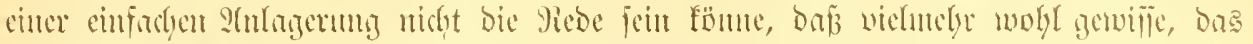

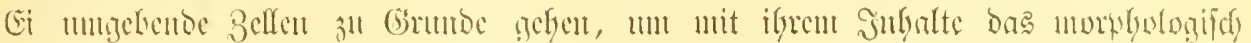

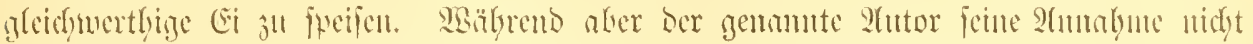

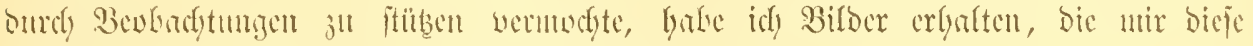

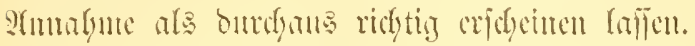

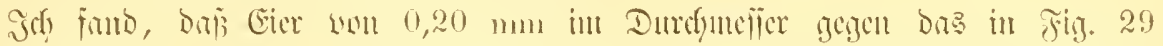

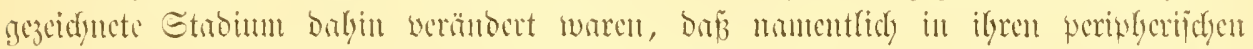

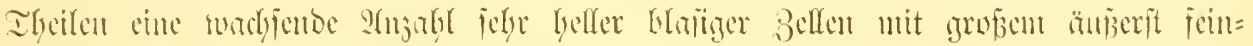

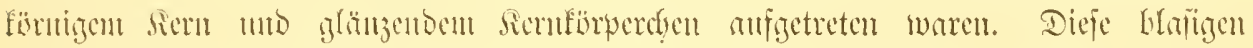

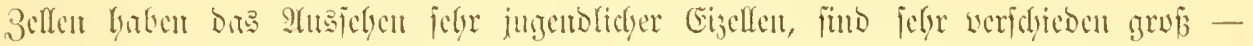

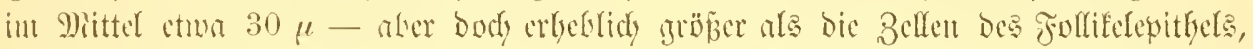
io baß

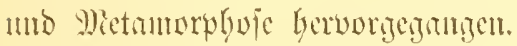

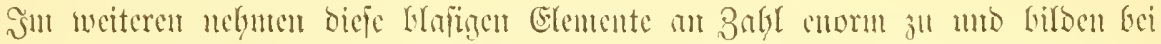

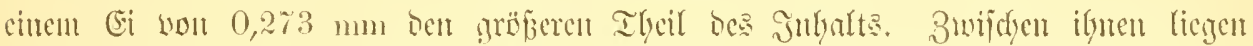

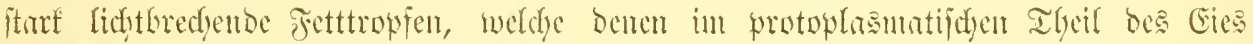

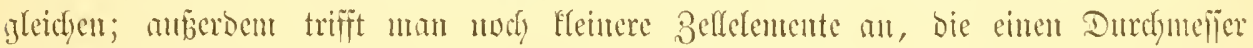

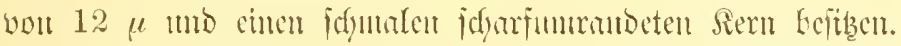

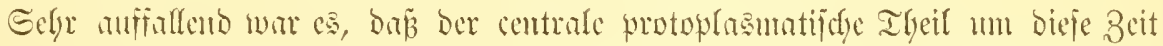

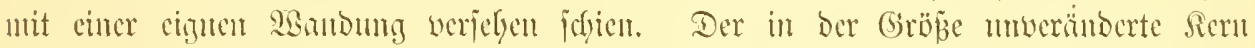

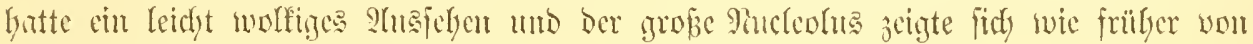
Bafluden Durdjict. (Jig. 30.)

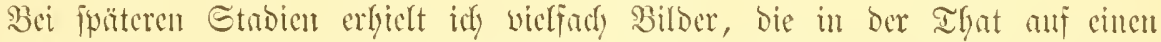

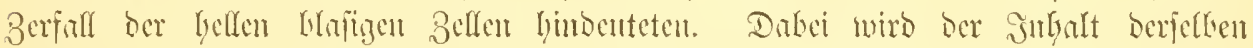

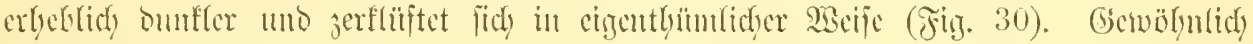

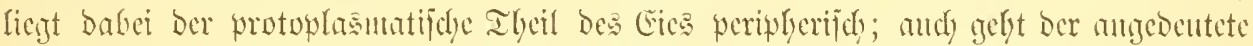

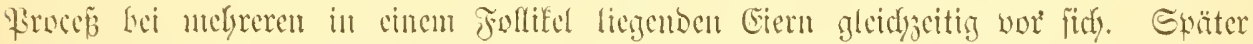

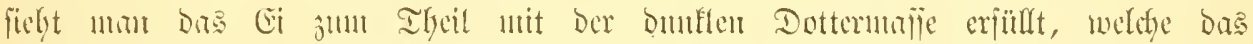

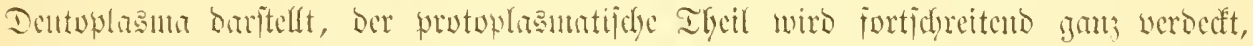

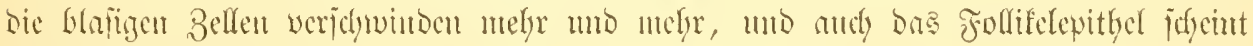
morkint jll werben.

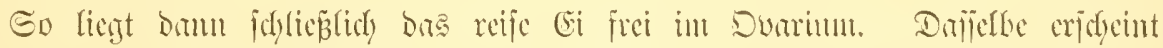

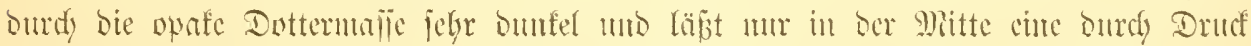

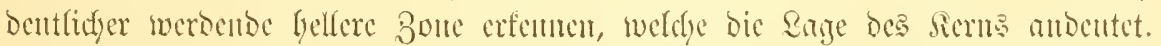

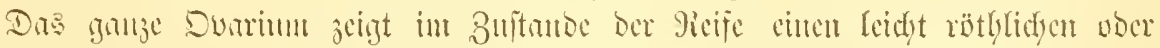

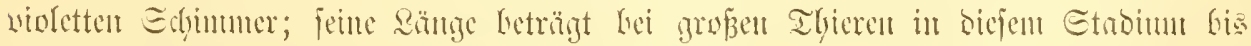

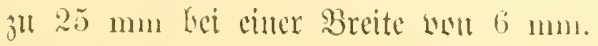

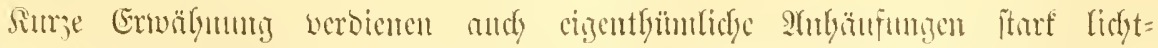

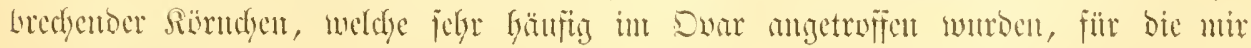

*) 2Ealdeyer, Evieritodf unb (či. 1870 pag. 85 , 


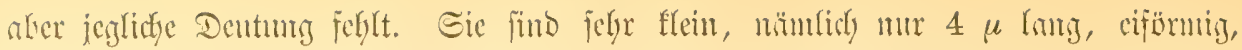

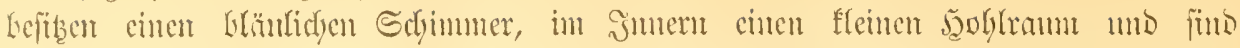

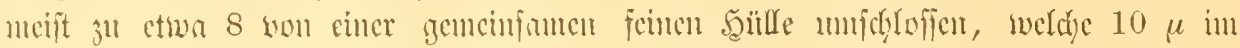

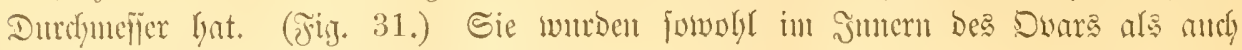

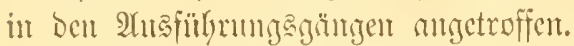

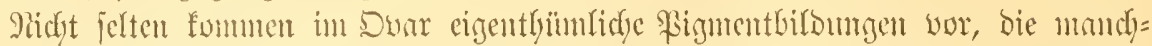

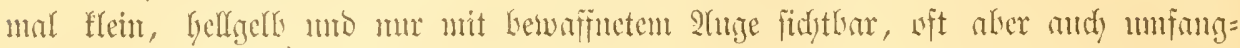

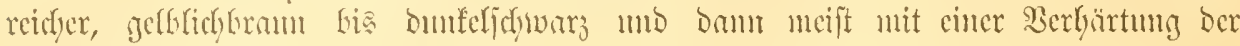

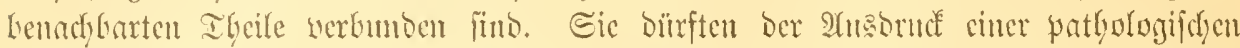

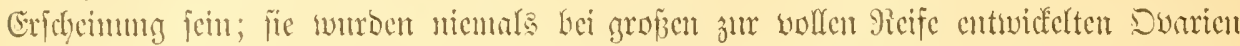

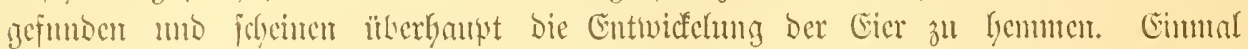

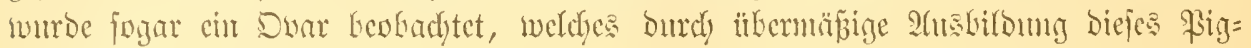
mente sollfig petrificirt war.

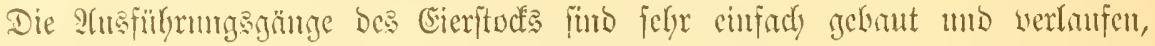

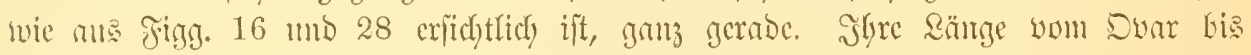

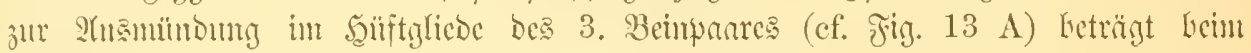

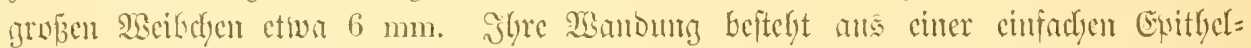

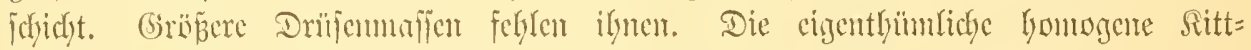

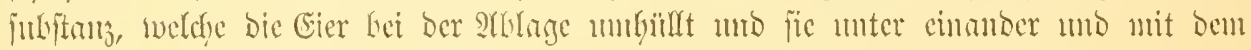

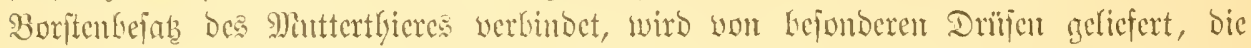

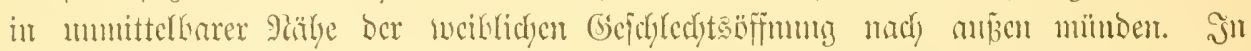
ben 2(bonmintulfüben, wo Brann (9ir. 35) bei andern Defapoben Sittbrïjen antraf,

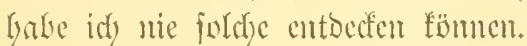

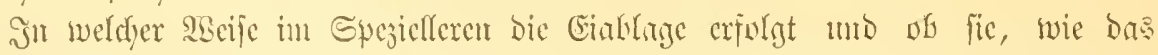

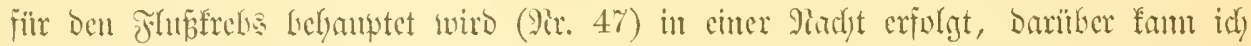

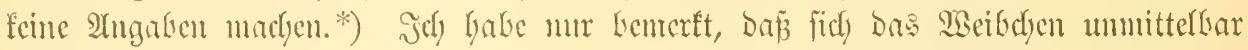

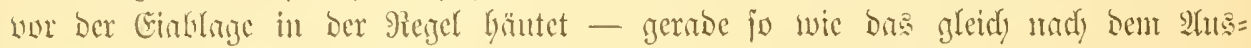

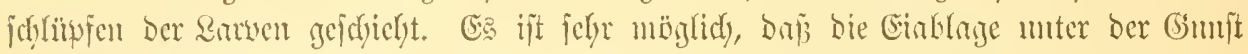

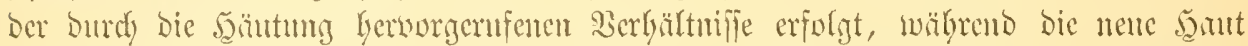

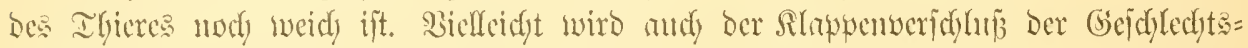

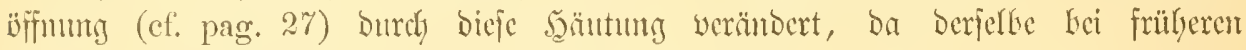

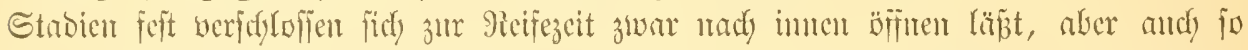

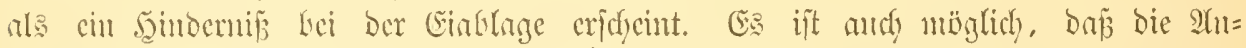

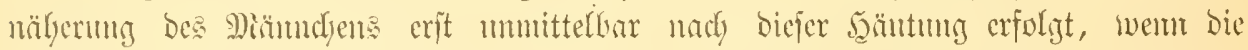

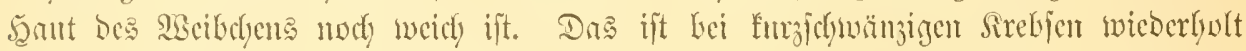
beobadytet worocm, zuerft won Eavolini (178\%) an Carcinus Maenas (cf. Fir. 34

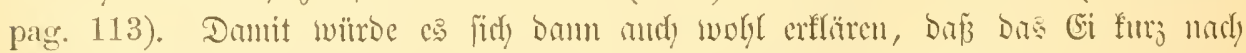

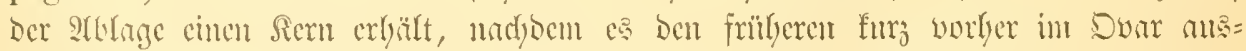

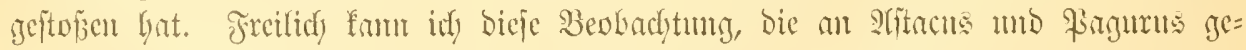

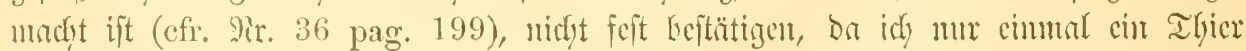

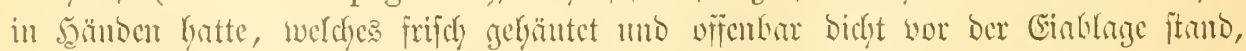
Gei ben idy in Den Dustalciern cutueder gar feine ober mur wanoftianbige - aljo

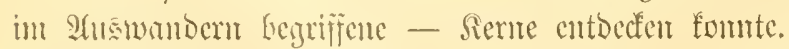

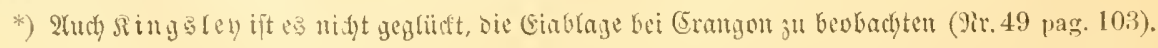




\section{Enttwidf(ntugsgejdyidyte.}




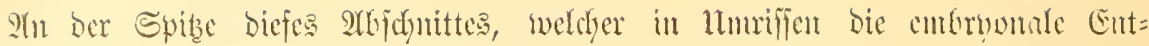

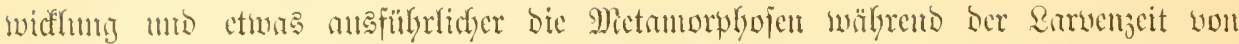

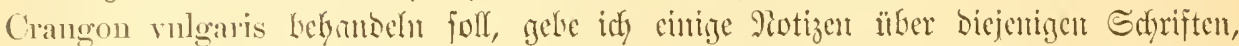

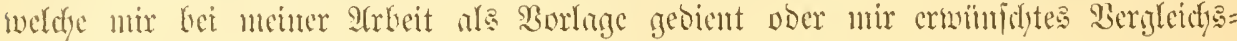

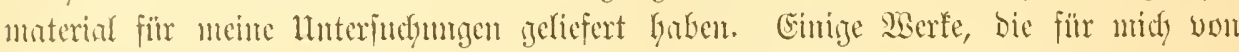

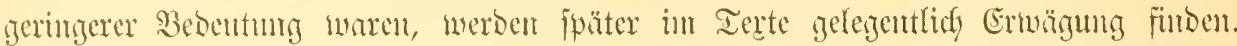

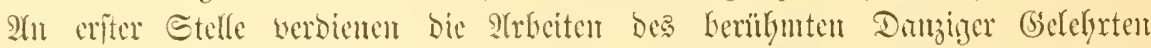

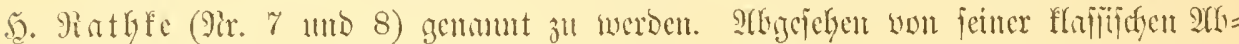

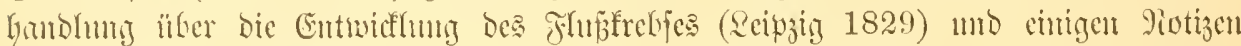

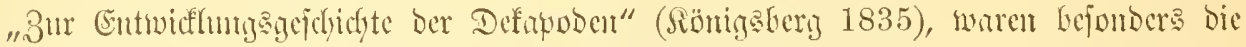

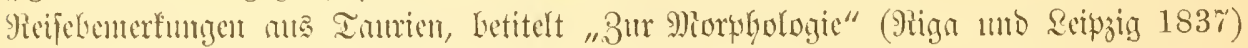

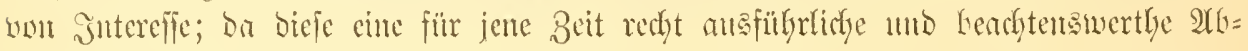

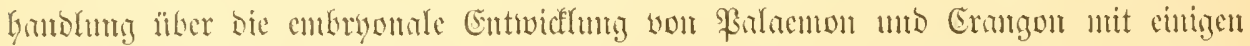

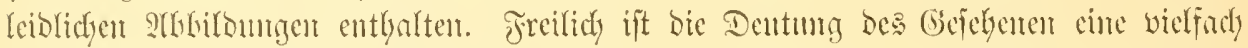

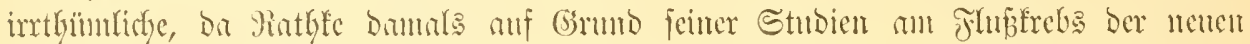

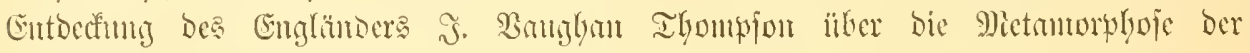

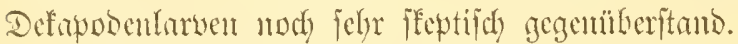

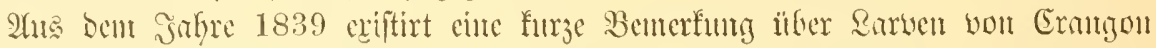
mb Palacnton (gencint ift Palaemonetes varians Leach), weldye ber Santiäu Du Eane (9ir. 9) in Den Amuals of natural history giebt mo mit einigen bürftigen atbrillomigen liegleitet.

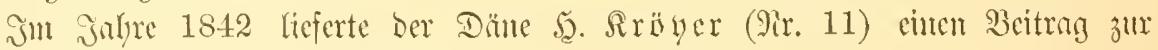
Entividfungegeffyidyte Der Definpoen.

2rre erite wertbwollere 9)iontographie Ḧber bie Entwidfung emes Eariben ift bic Arbeit wou 9)i. Joly (9ir. 12) ïber Caridina Desmarestii iu bon Annales des

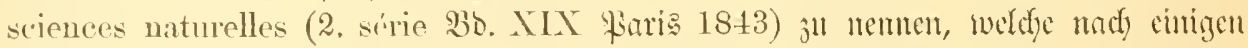

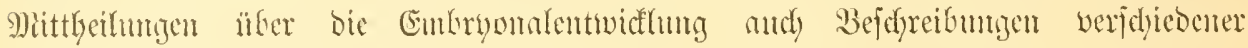

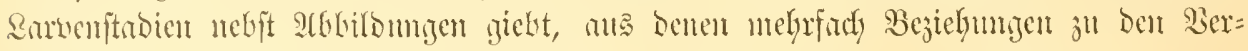

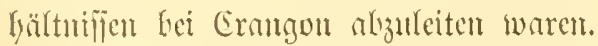

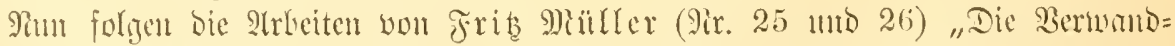

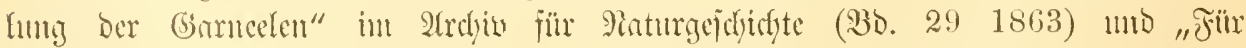

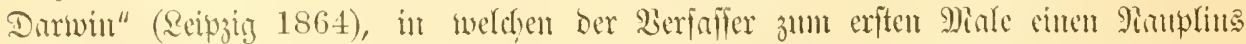

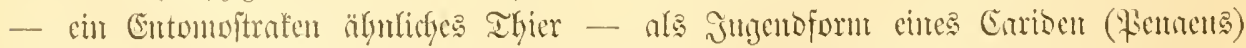

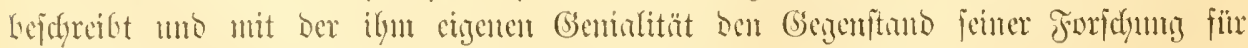

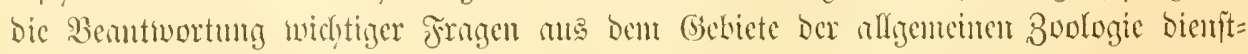
brit madit.

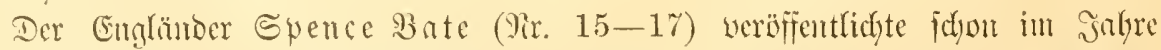
1859 ciuc 2 rbeit .. On the Development of Decapod C'mstacea" (Pliblos. Transact. 


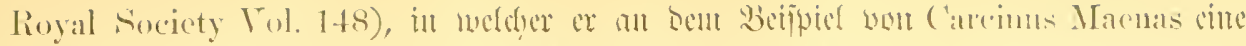

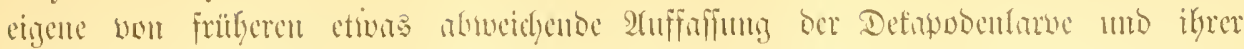

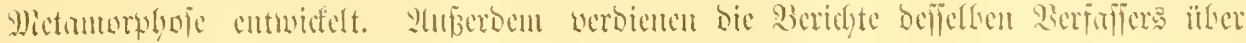

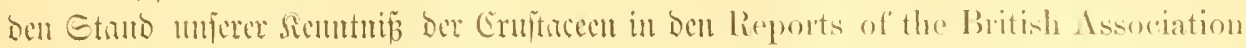

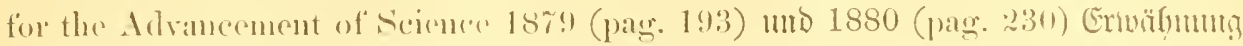

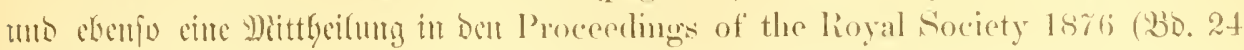

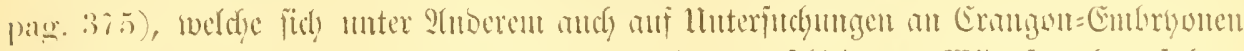

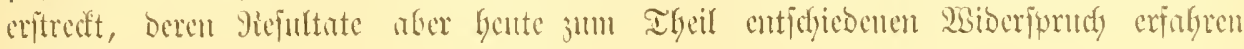
miiijicl.

(E. CIa

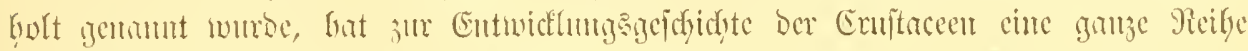

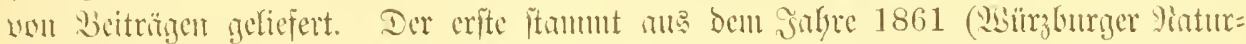

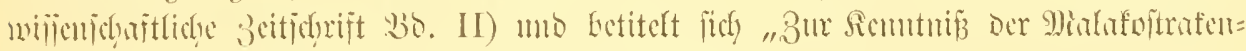

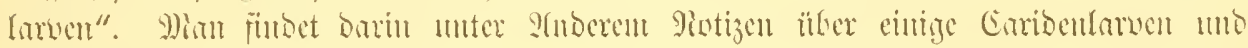

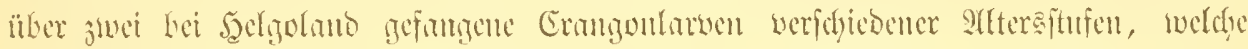

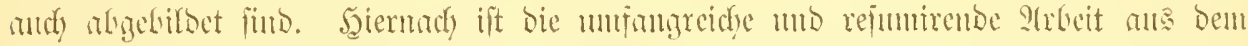

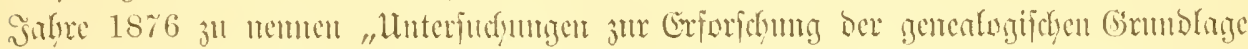

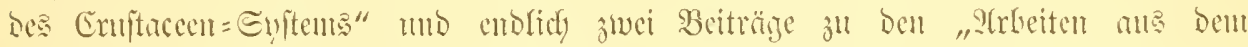

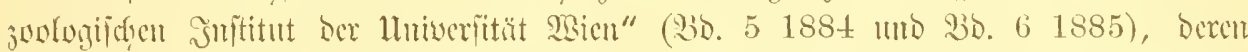

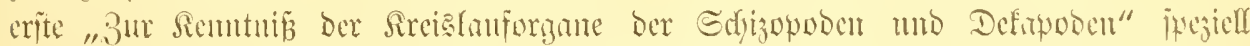

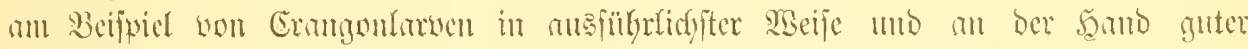

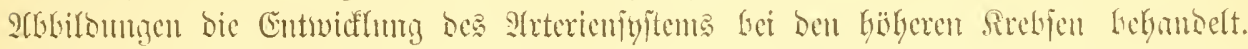

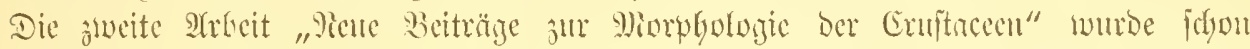

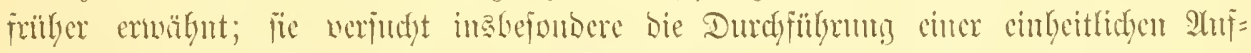

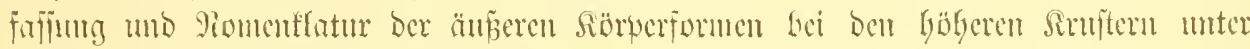

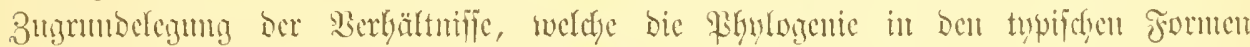

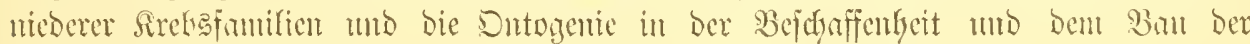
Bintwenformen Darbietet.

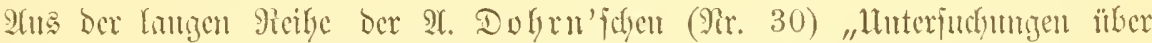

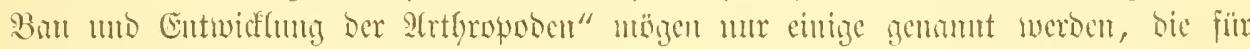

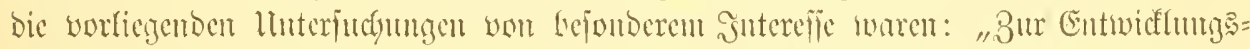

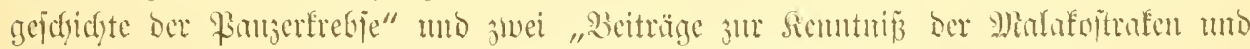

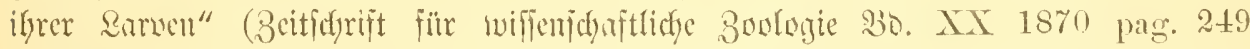

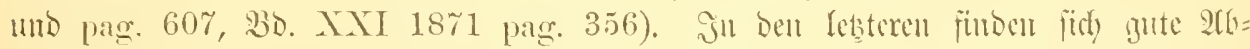

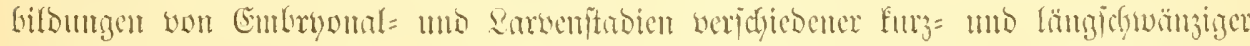

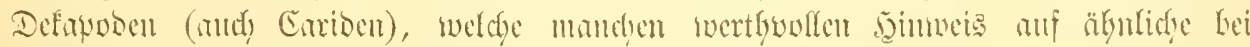

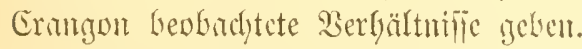

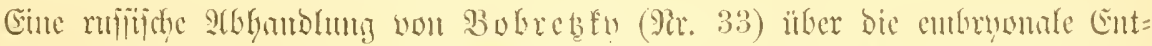

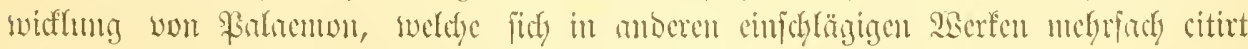

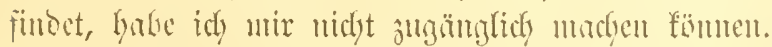

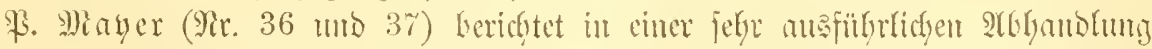

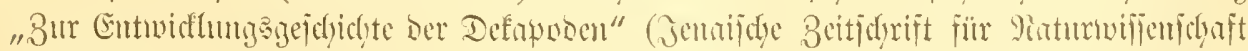

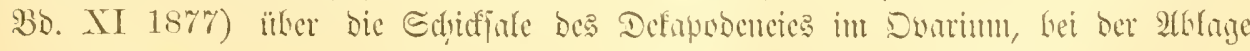

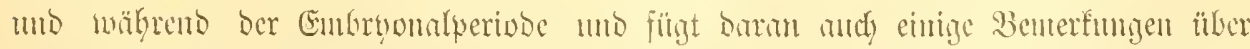

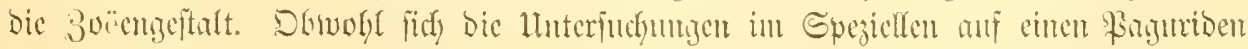

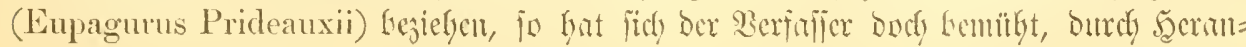




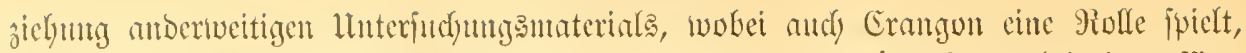

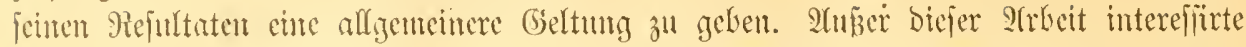

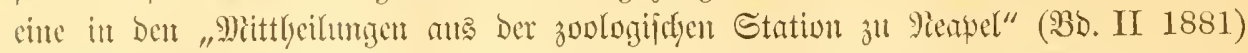

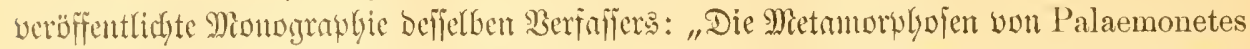
varians Leach." Dieje Unterfudfungen bilben eine willfonmente Ergänzung ž cinter

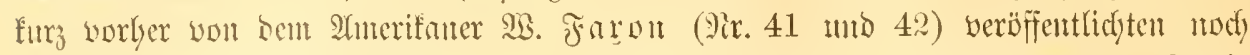
amofitibrtideren Mionographic: On the Development of Palaemonetes vulgaris (Bullet. of the Museum of Comparative Zoology, Harvard College in Cambridge.

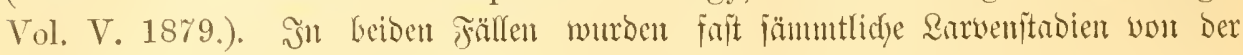

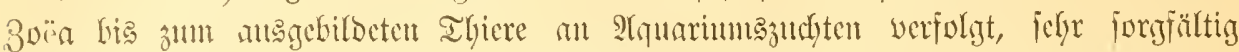

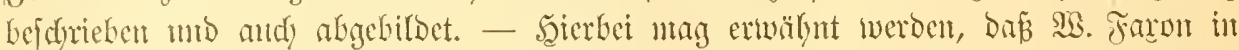

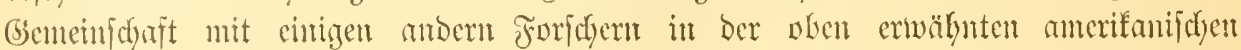

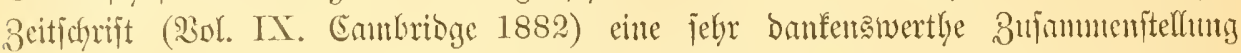

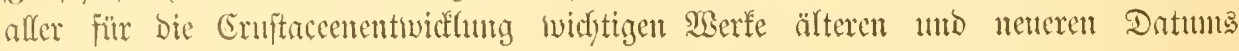
fublicirt bat.

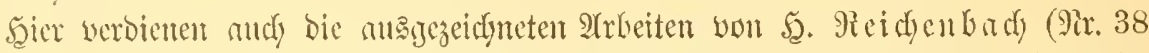

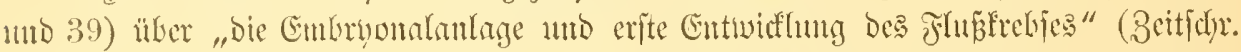

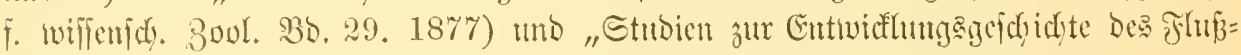

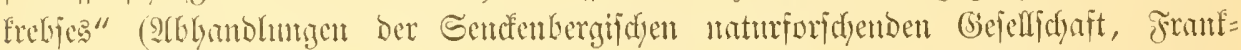

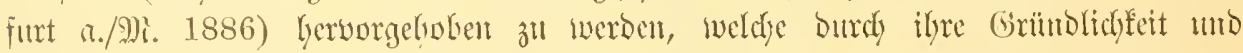

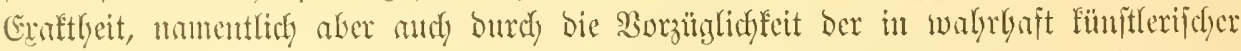

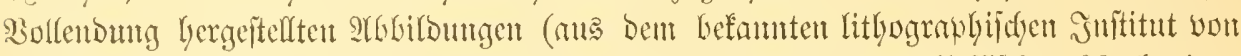

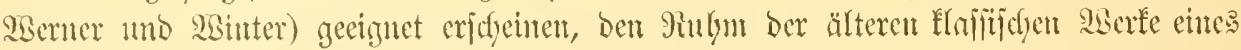
Ratlyfe und sereboullet zu verdunfeln.

Fermer mirg Der "Bidrag til kundskaben om Dekapodernes forvandlinger"

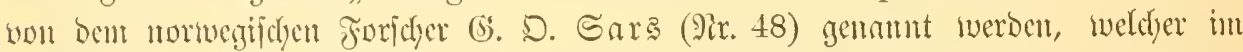

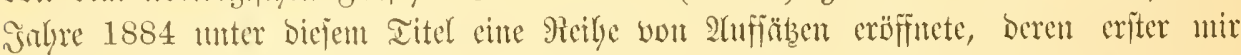

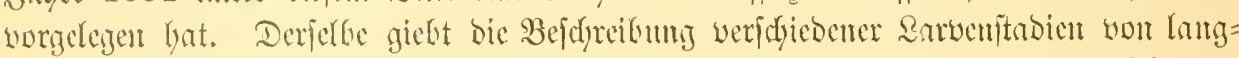

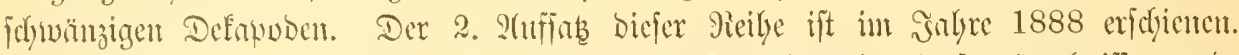

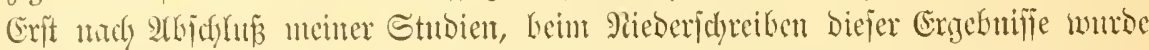

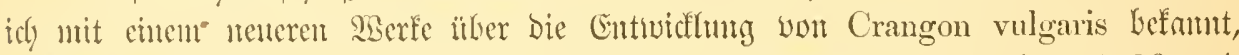

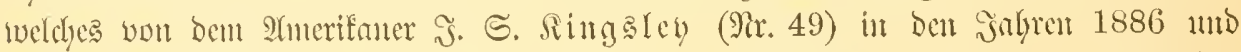
1889 in bem Bulletin of the Essex Institute veröffentlidyt wurbe. Da Diefe Artucit

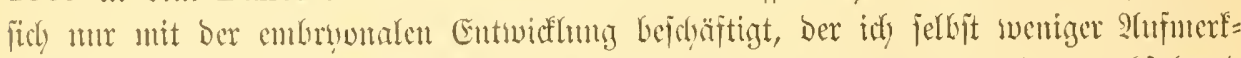

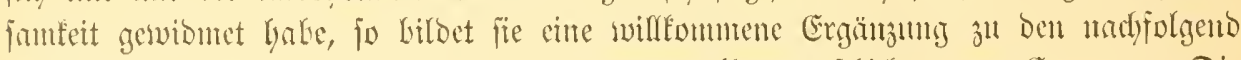

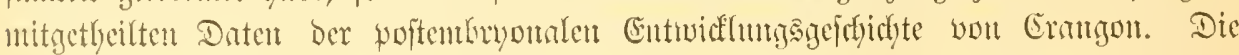

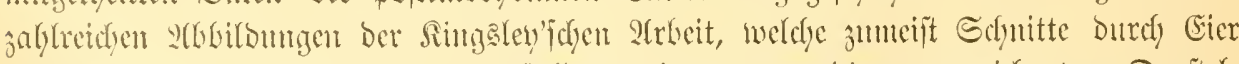

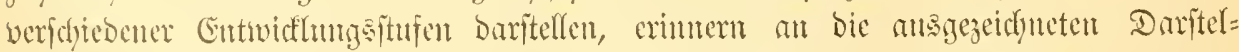

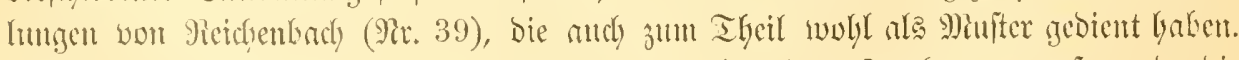

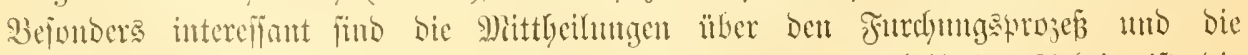

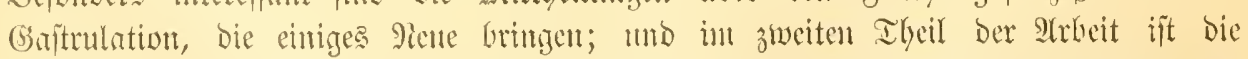

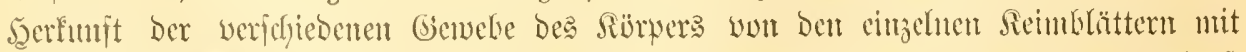

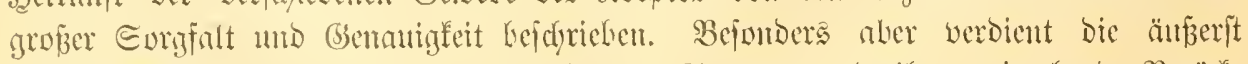

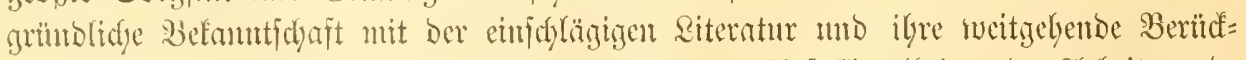

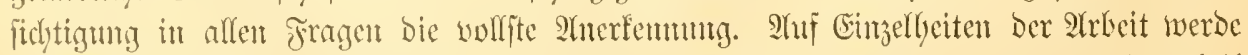

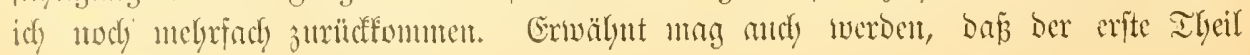




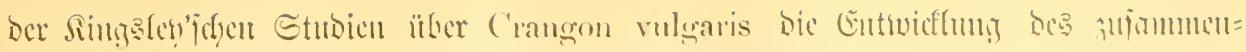

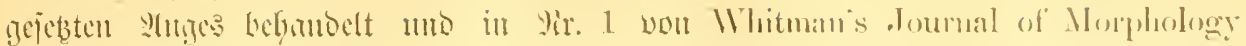
erifficten ijt.

\section{Befejtigung แ⿰氵 Drientirung Der Hbouminalcier.}

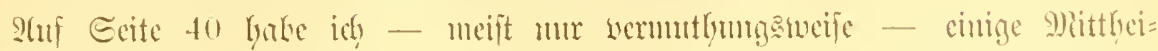

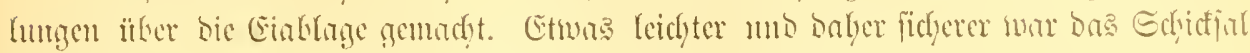

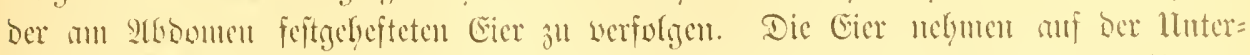

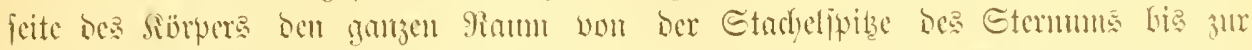

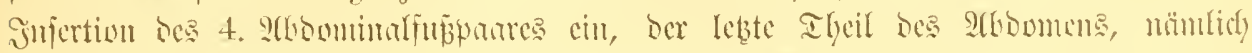

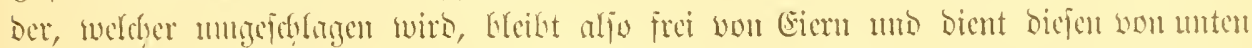

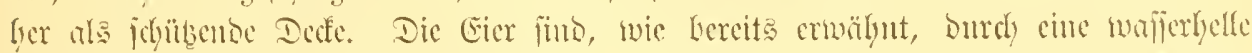

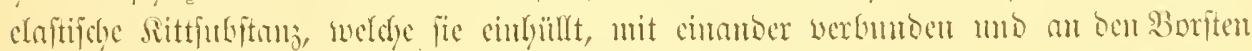

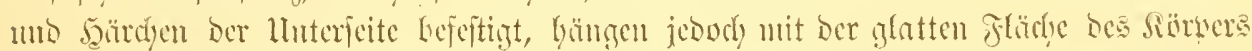

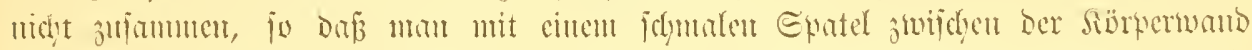

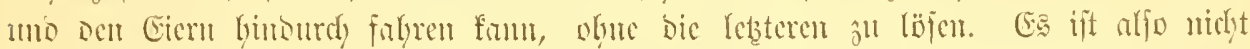

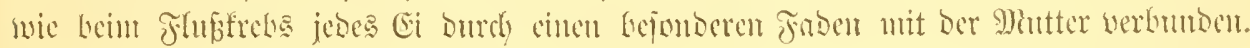

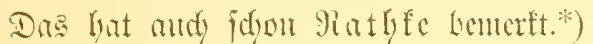

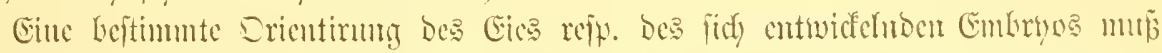

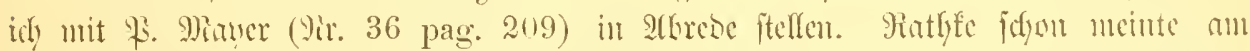

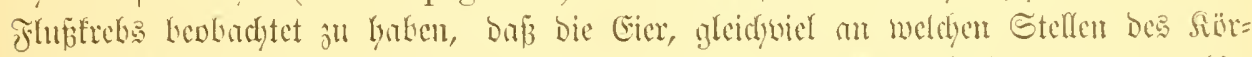

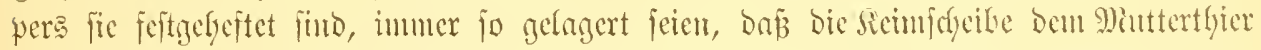

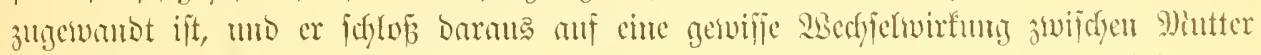

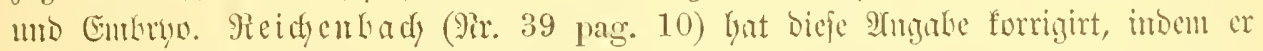

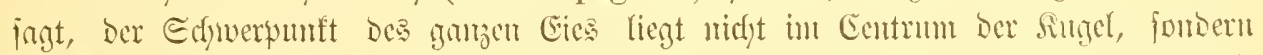

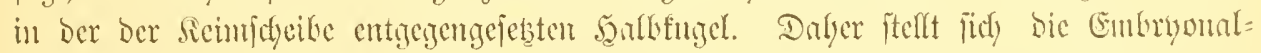

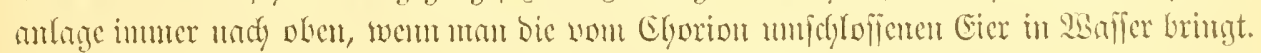

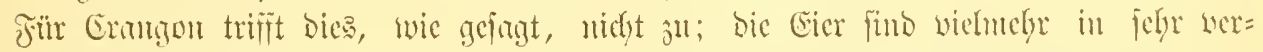

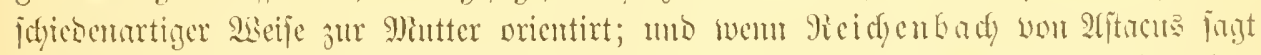

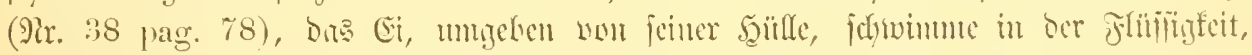

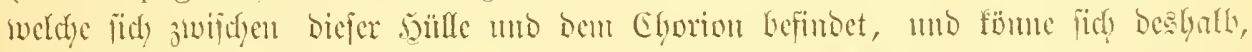

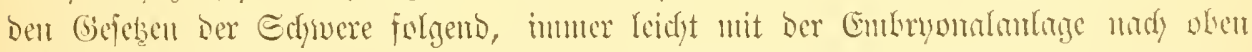

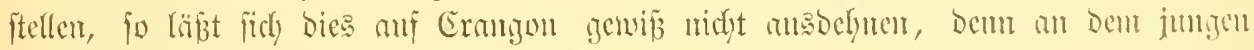

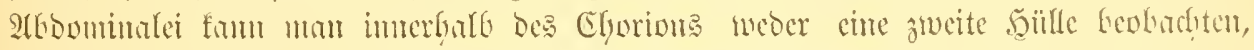

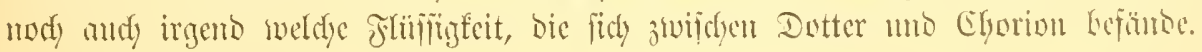

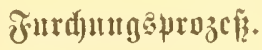

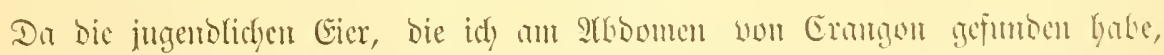

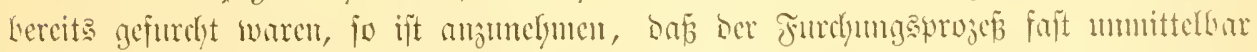

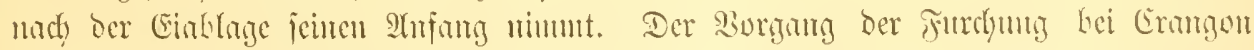

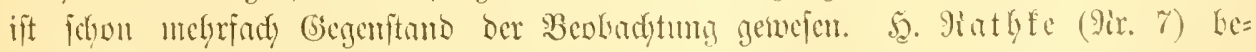

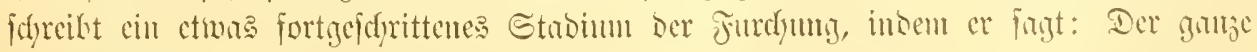

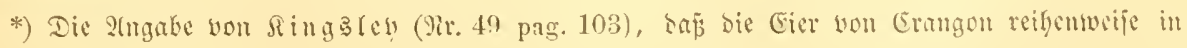
langen jtrufturlofen Siälgren jib̨en, if̣t mir nidut redjt verjtänblid̦. 


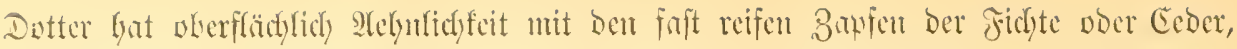

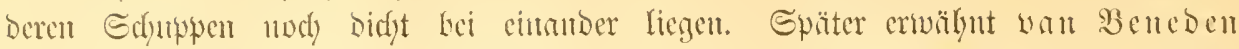

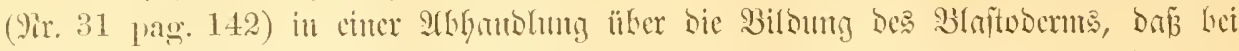

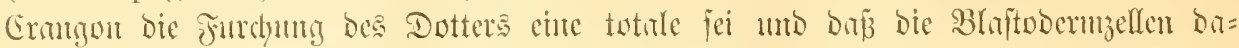

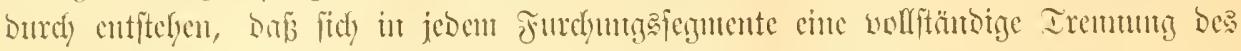

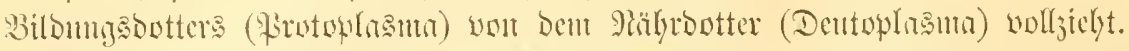

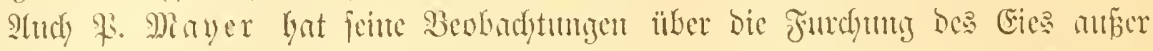

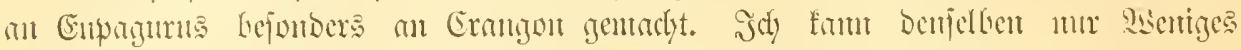

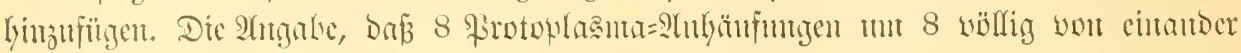

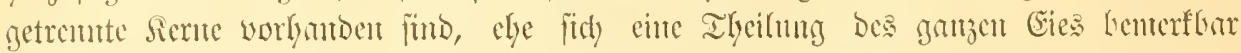

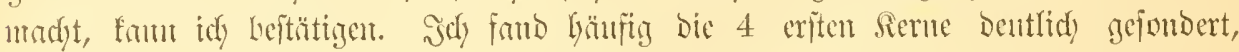

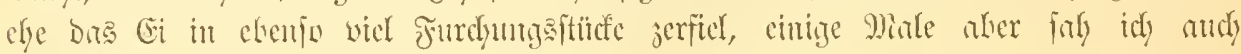

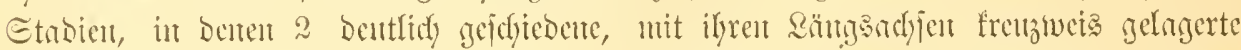

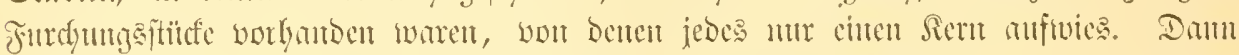

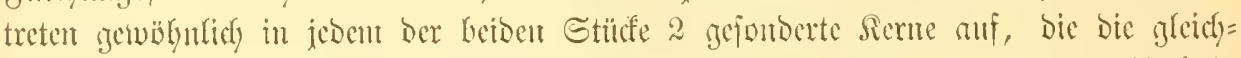

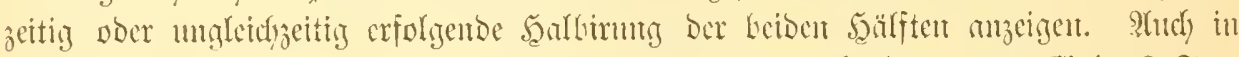

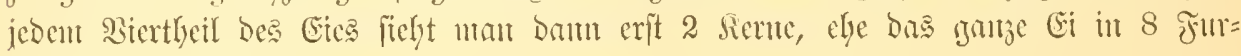
dyungefugelı zorfänt.

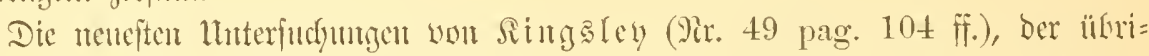

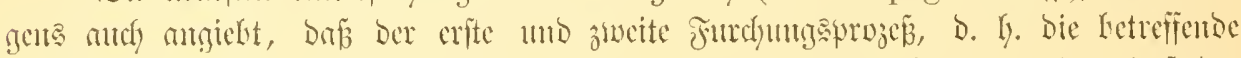

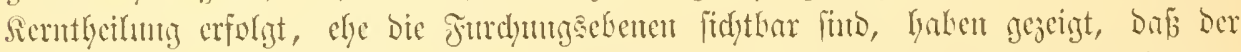

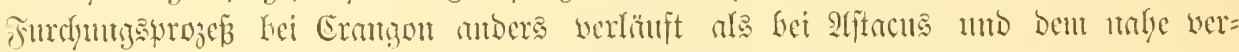

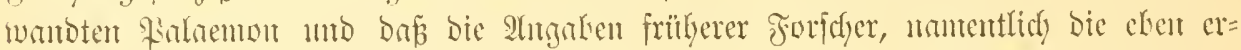

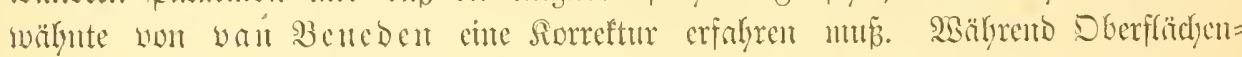

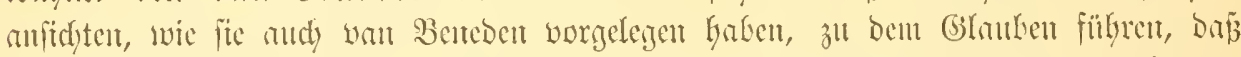

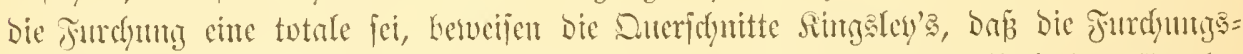

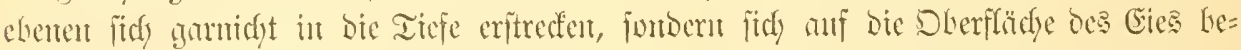

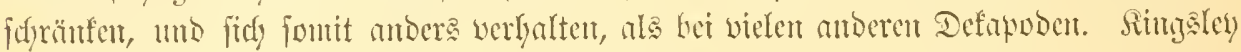

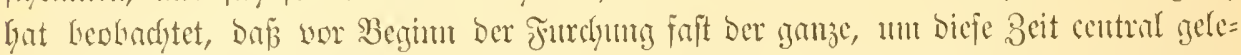

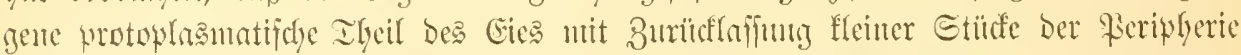

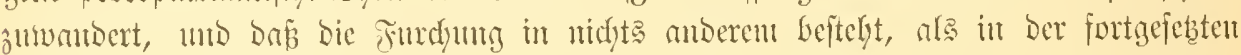

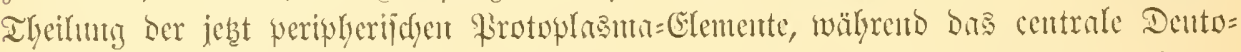

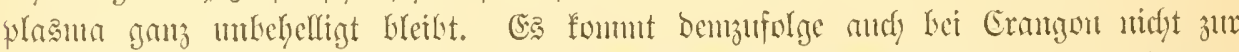

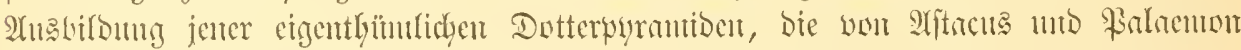

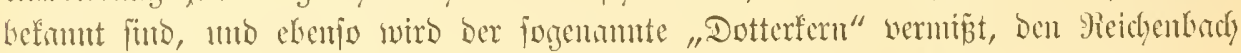

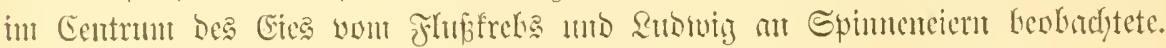

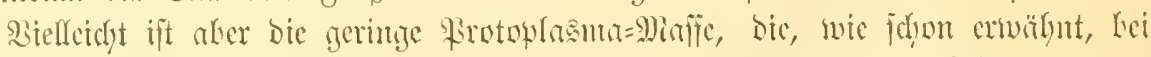

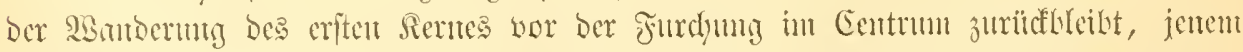

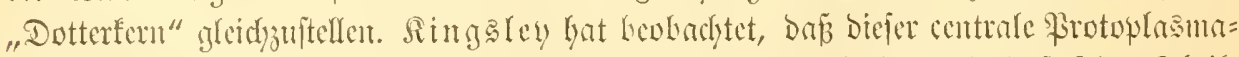

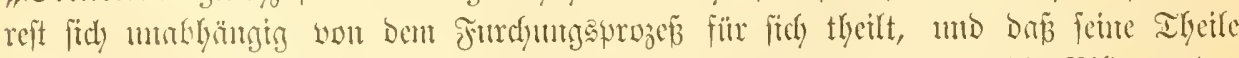

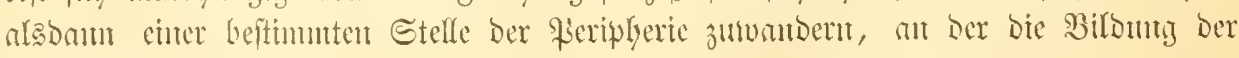
Siciuradocile exfolgt.

\section{BIajtoderm uto Dotterfant=(Ǵajtrula.}

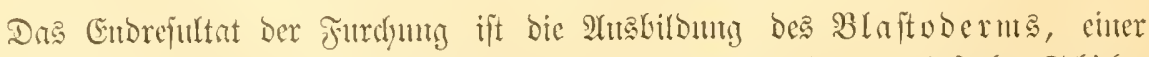

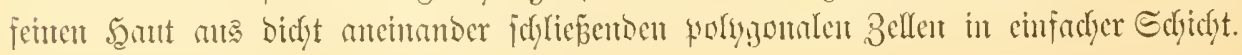




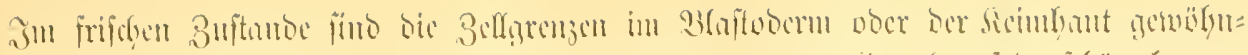

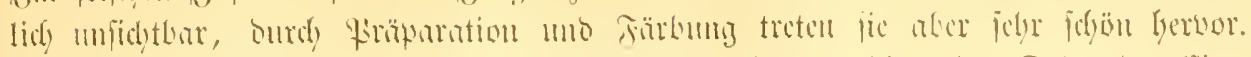

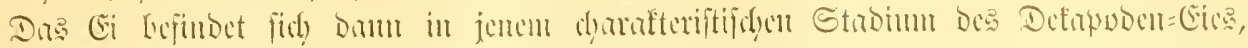

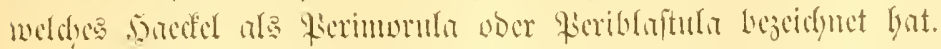

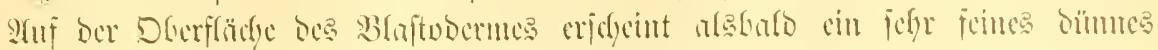

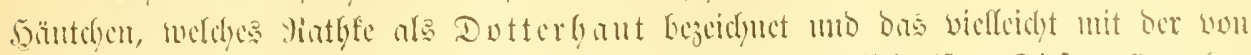

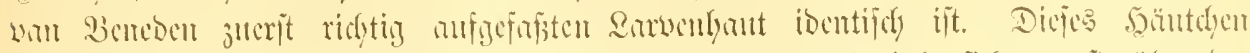

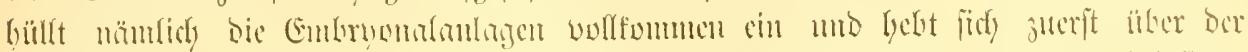

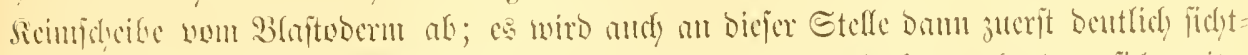

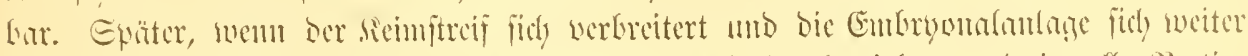

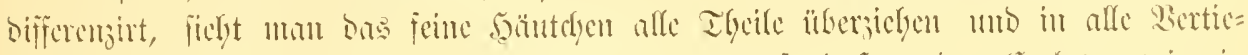

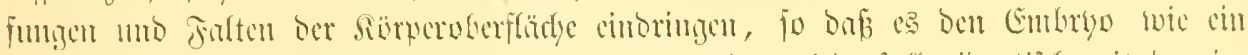

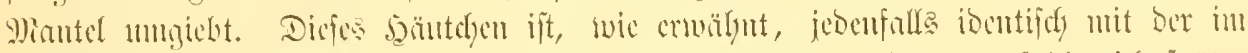
Mionente bes 2 (4)

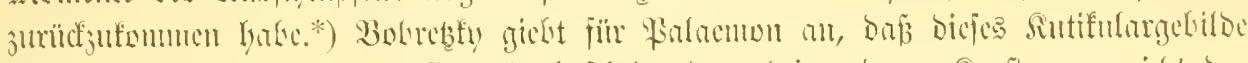

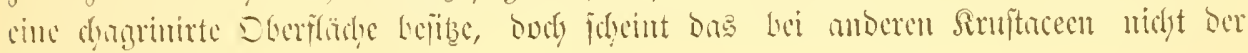
Frall jull jint.

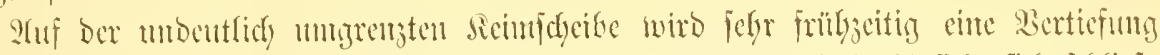

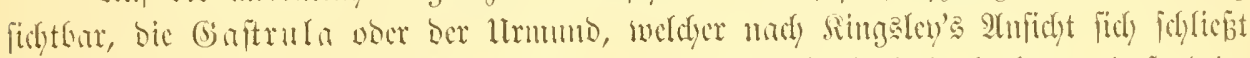

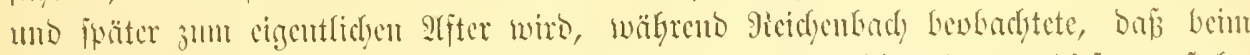

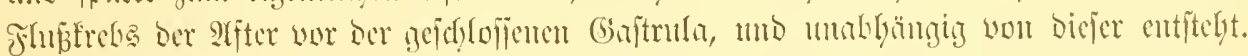

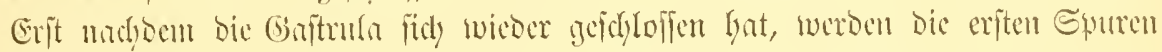

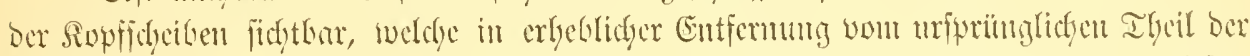

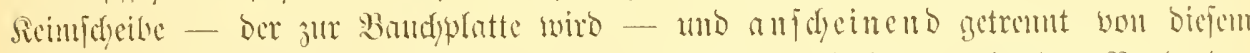

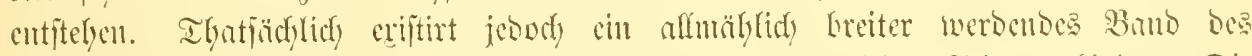

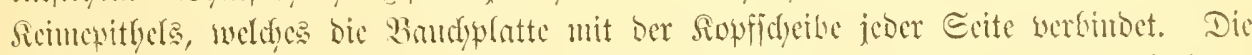

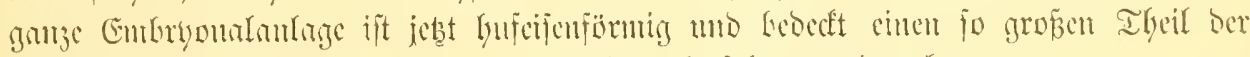

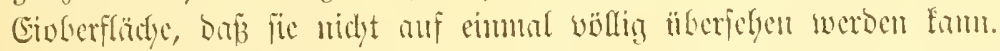

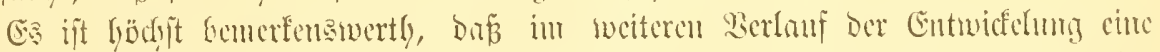

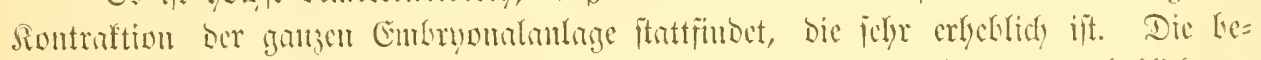

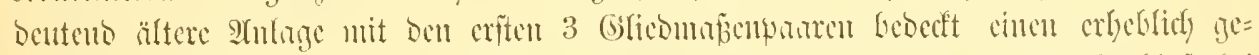

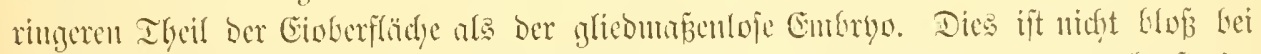

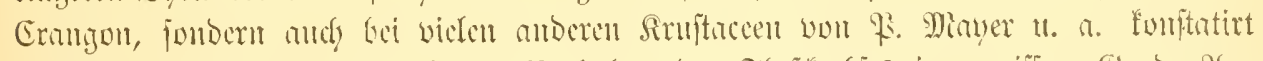

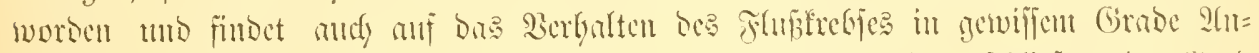

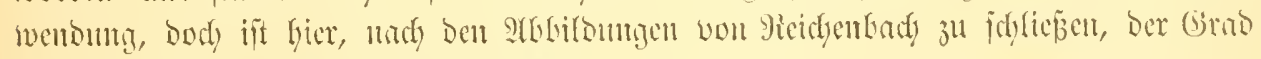
Der Sontraftion ein erbeblicly geringerer.

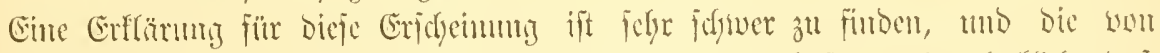

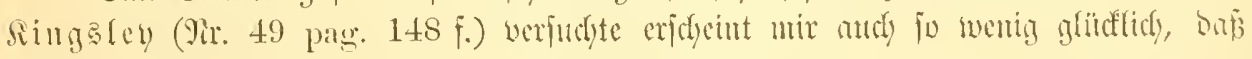
id nidyt näber barmuf eingelye.

\section{Manpling̈tabium.}

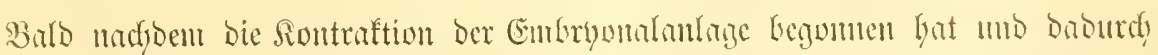
bie Sopfiplatten einmoer und Der Baudyplatte genälyert find, treten furz linter

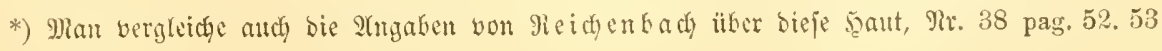
uno Mir. 39 pag. 9. 


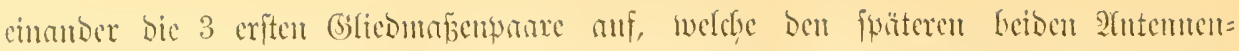

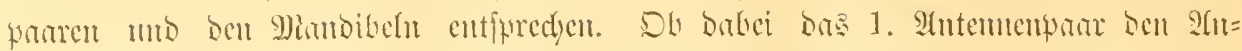

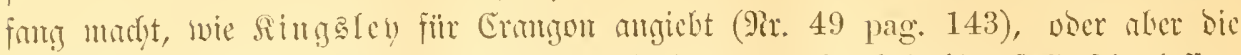

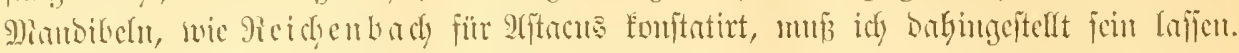

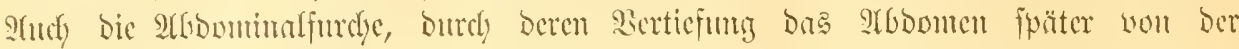
Bandywlatte abgefdyürt wirb, ift fefre zeitig angebeutet, binter berfelfen ift bie ur=

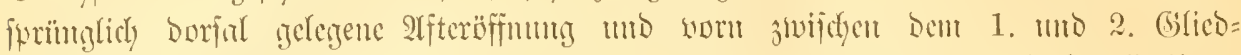

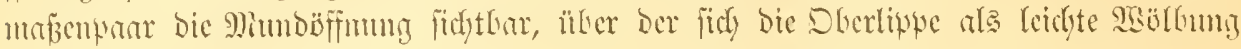
erkelit.

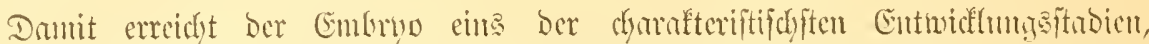

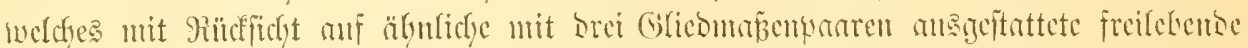

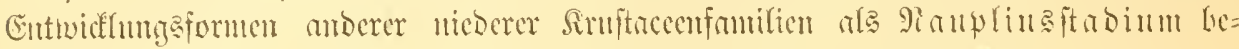
zeidfutet worben ift. Man trifft bicies Etnbinm in ber Entwidelumg wohl allex

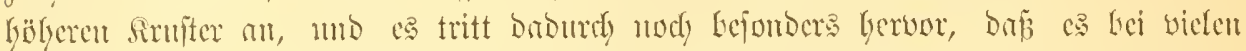

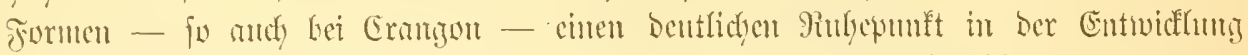

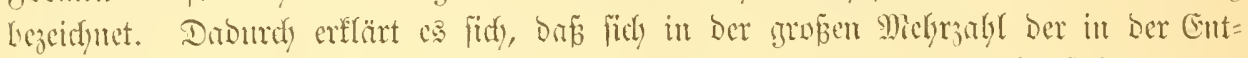

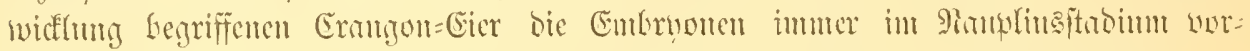

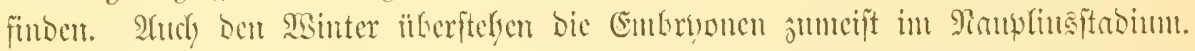

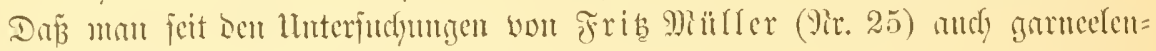

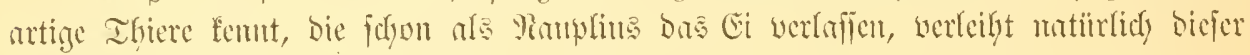

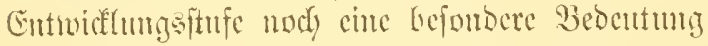

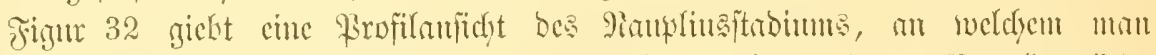

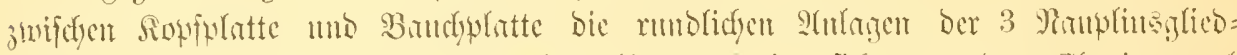

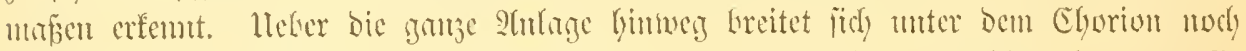

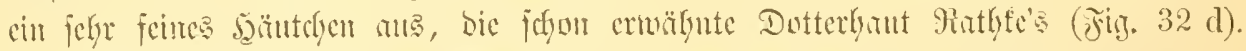

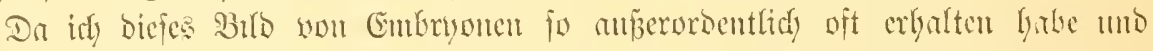

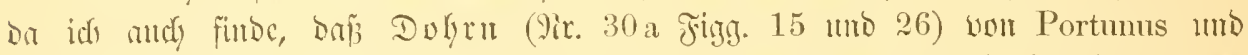

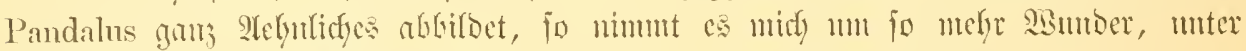

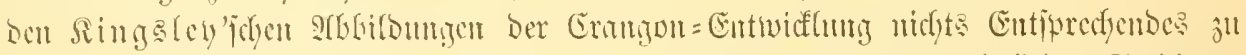

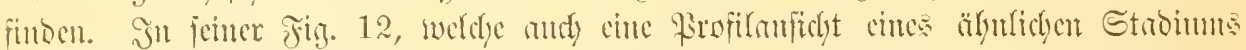

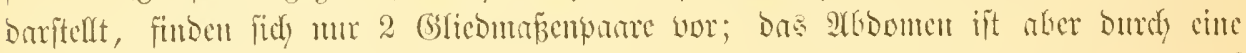

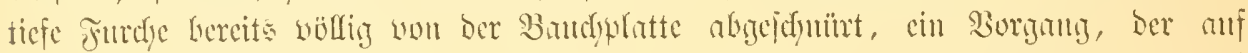

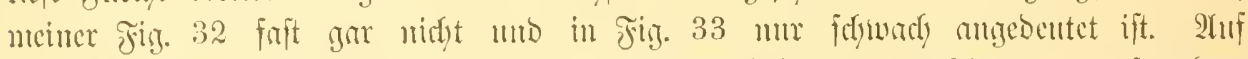

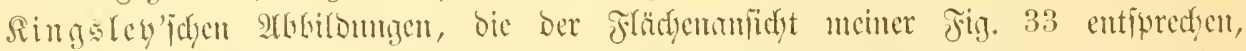

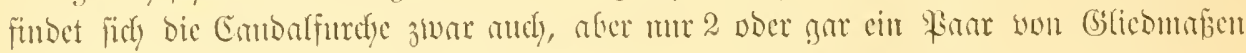

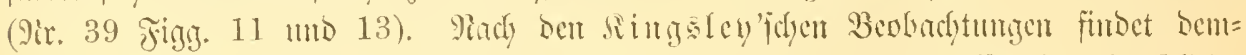

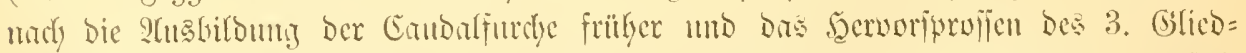

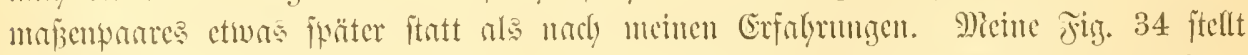

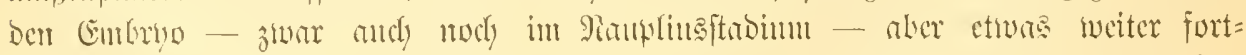

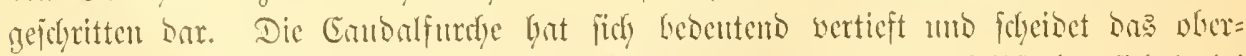

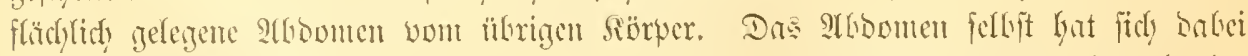

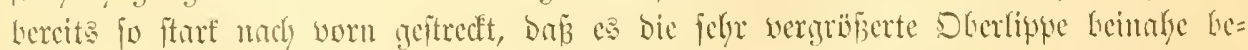

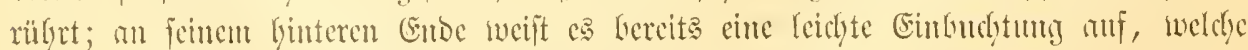

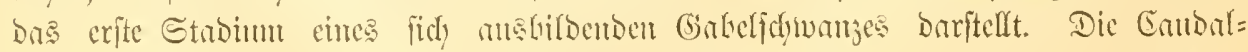

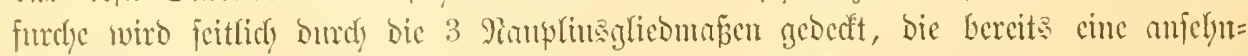

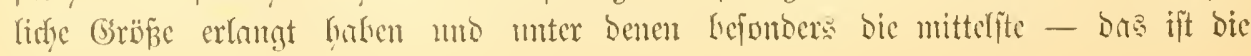




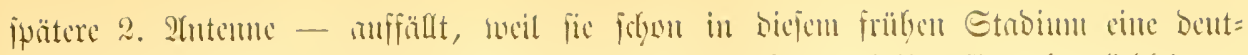

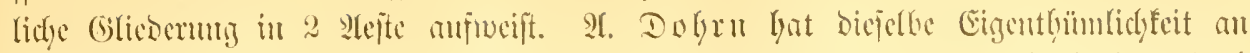

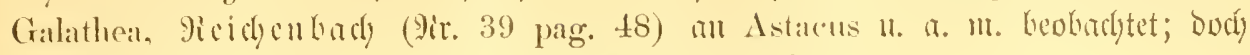

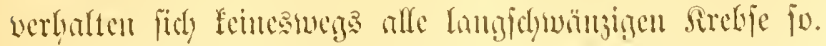

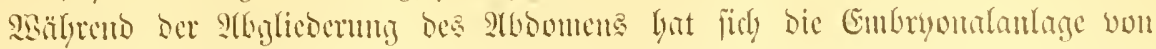

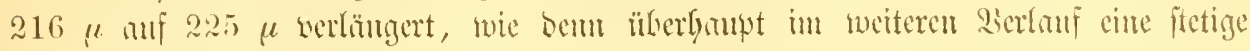
Giribenjunalyme ju leobadyten ift.

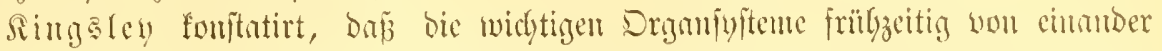

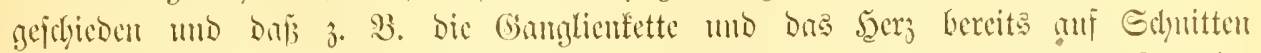

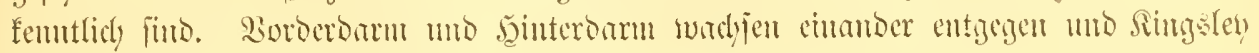

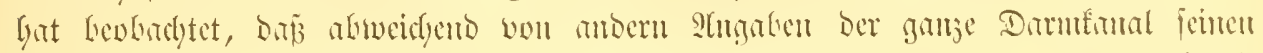

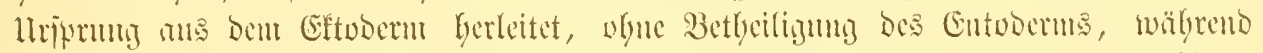

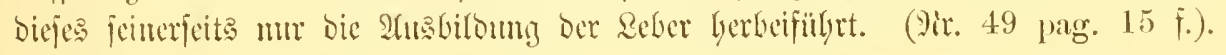

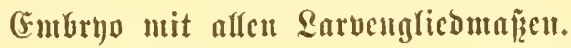

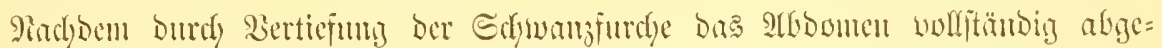

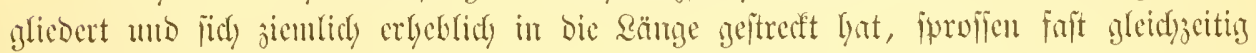

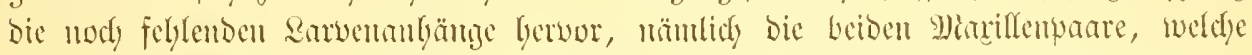

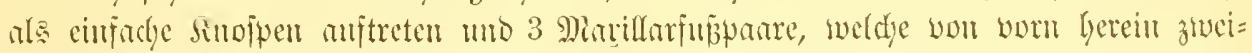

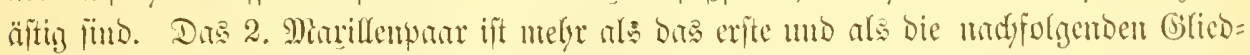

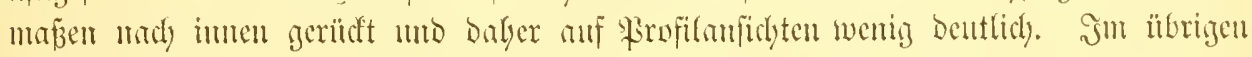

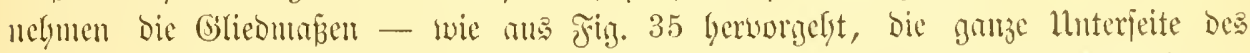

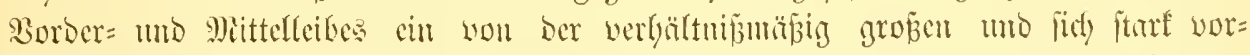

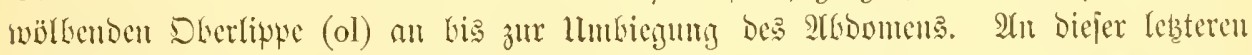

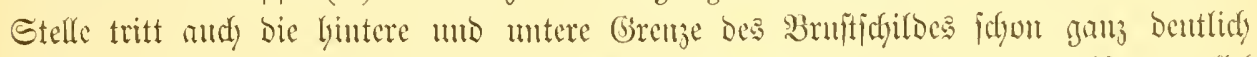

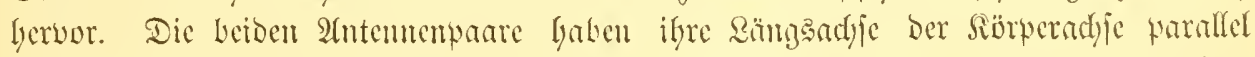

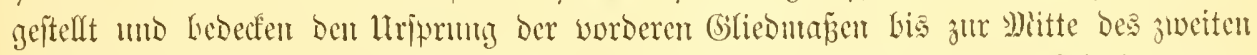

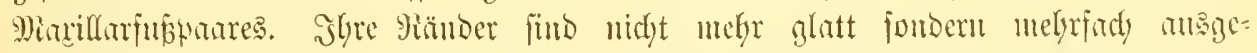

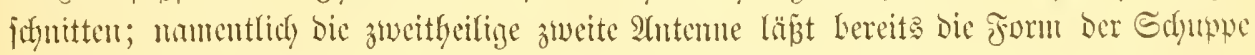

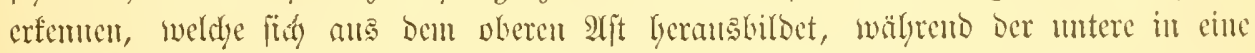

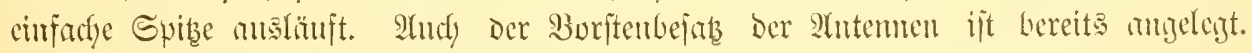

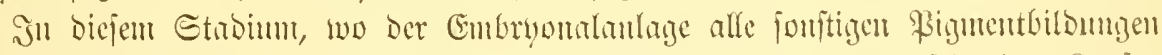

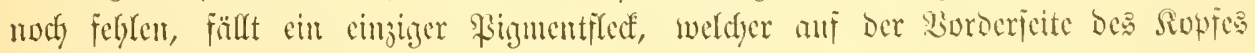

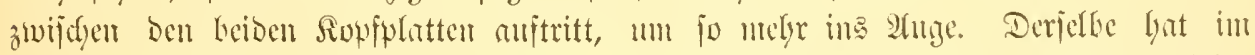

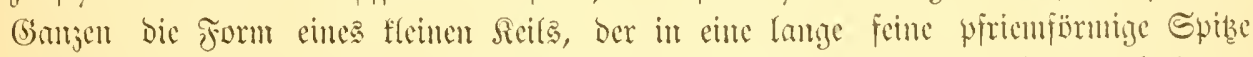

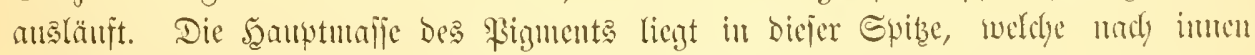

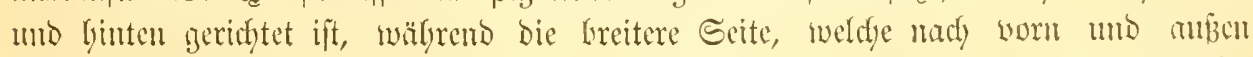

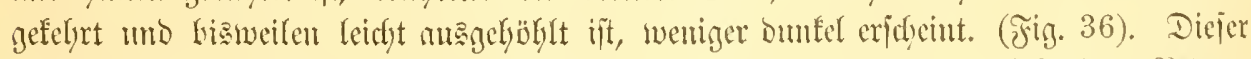
Pigmentfled lyat für Die Stammesgejdyidfte Der lyögeren Sirebje cine bejombere BcDen=

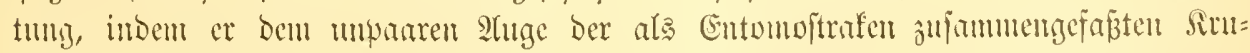

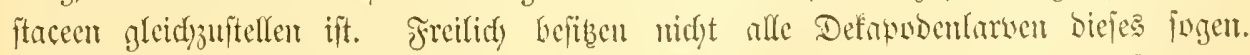

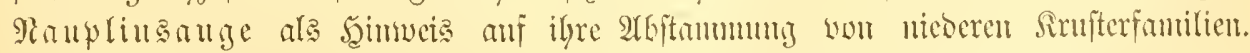

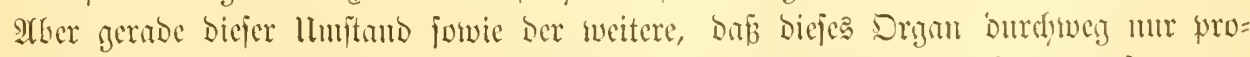
viforifd auftritt mb wälyrend ber Rarvenjeit - ober viclleidyt audy etwas fpäter -

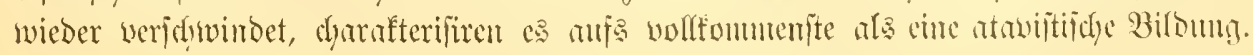




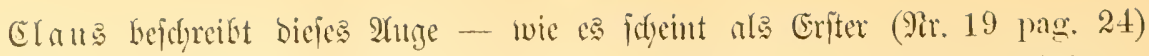

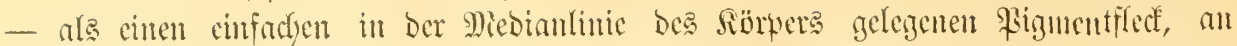

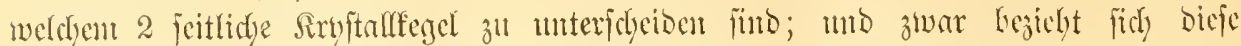

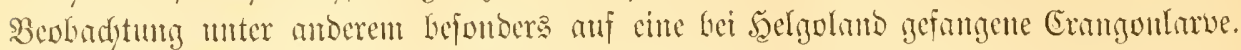

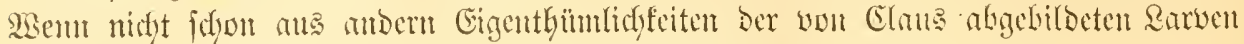

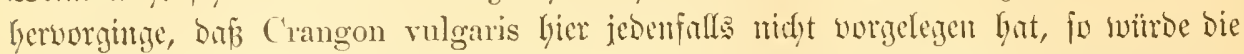

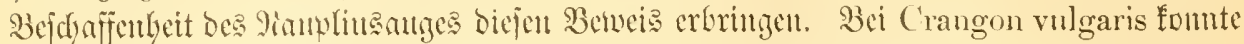

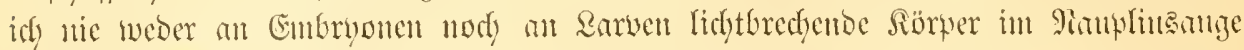

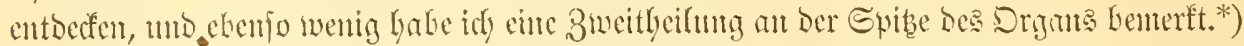

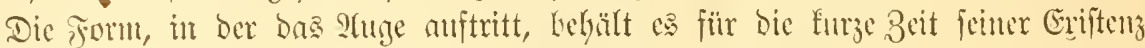

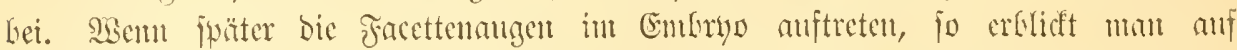

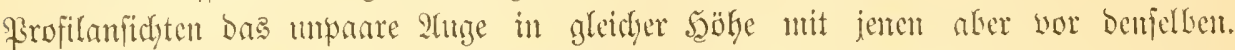

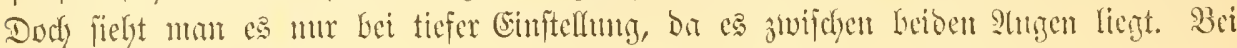

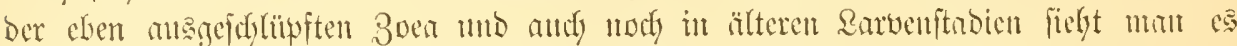

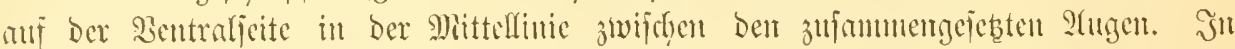
Der Fig. 36 i it bas Rampliusange ijolint abigebiloet.

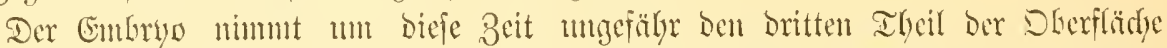

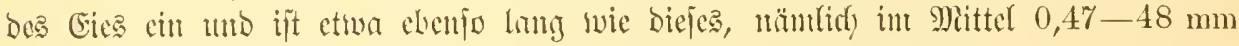
frei cinter 3 reite von $0,41 \mathrm{~mm}$.

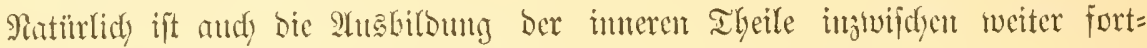
gefdyritten, bod) geche id barmf nidyt nälyer cilt.

Figur 37 zeigt cinten etwas weiter cutwidfelten Embryo bon ber Bandffeife ber.

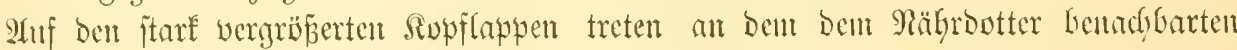

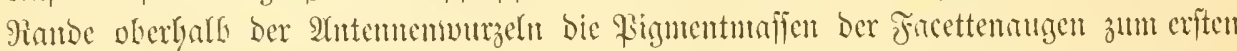

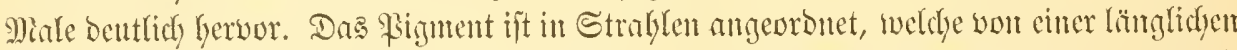

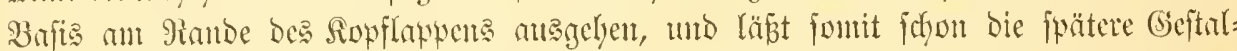

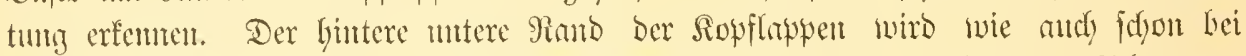

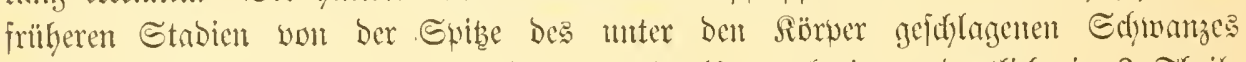

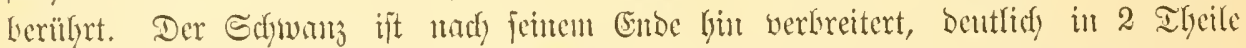

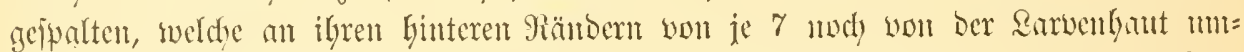

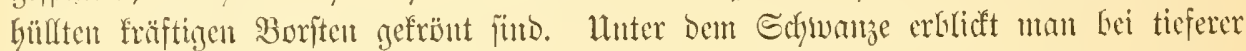
Einjtellturg bie jelyr grope Dberlippe, weldye in Der Mittellnie Des Sïrpers lient,

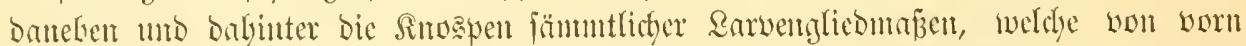

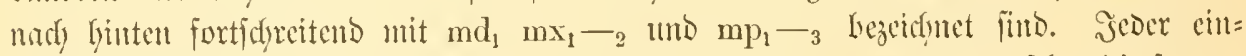

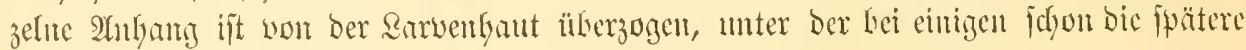
Gsicberung fidlthar wirb.

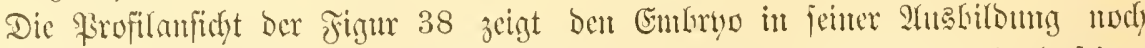
erberlich weiter worgefdritten. Der Riälyoutter ift anf ein fleines Drittel feiner

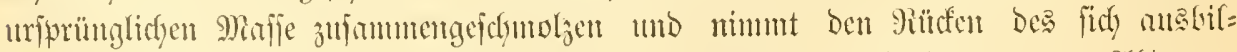

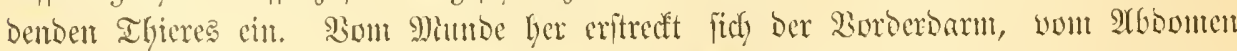

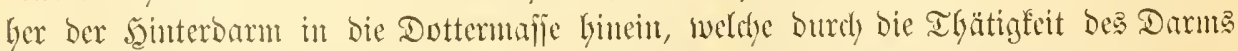
gewiffermañen verbant wirb. Die an weiteften nady finten gelegenen Theile bes

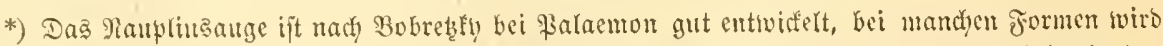

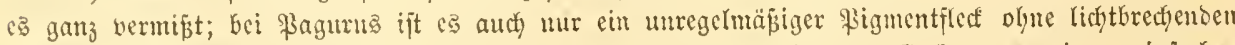
Rörper (cfr. Miayer 9ir, 36 pag. 245). Ringăley biloct bei Erangon=Enbrbonen einen einfadyen fleinen Rrijtalfegel $a b$, ber jeovds im Ierte nidjt weiter crwähnt wirb. 


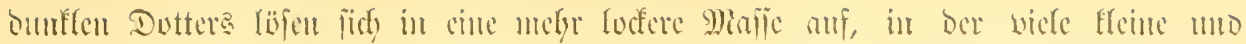

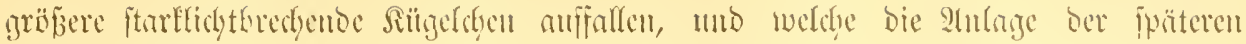
Retier biritellt.

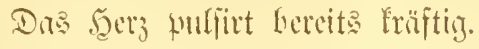

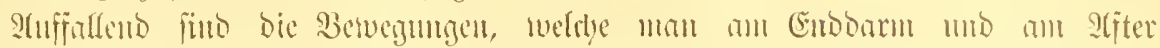

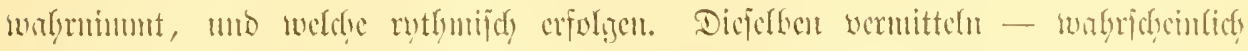

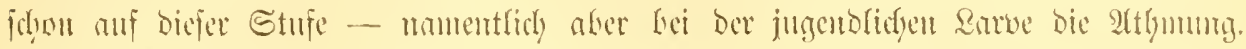

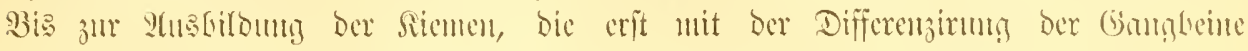

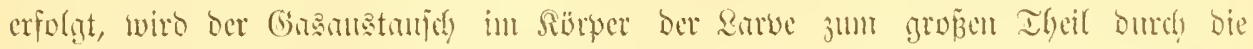

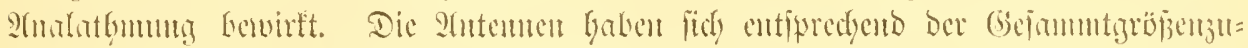

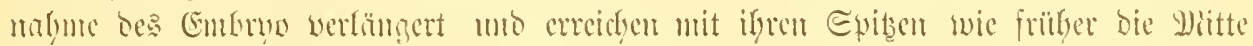

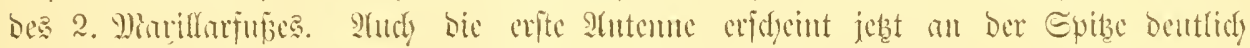

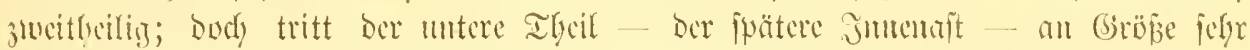

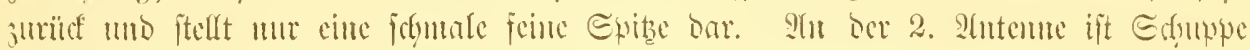

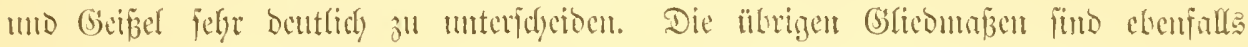

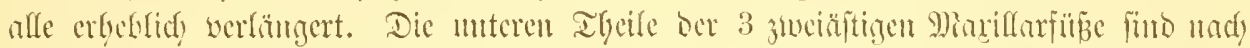

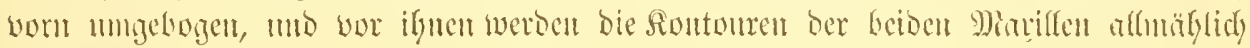
Dentlidyer.

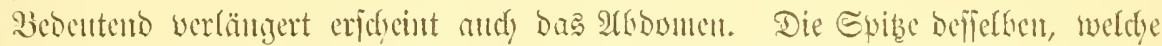

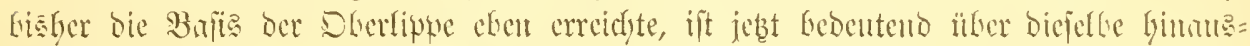

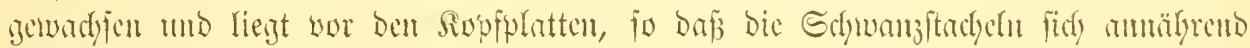

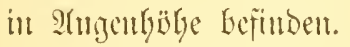

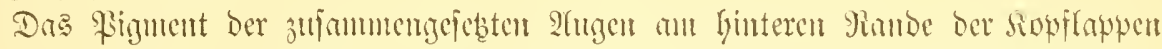

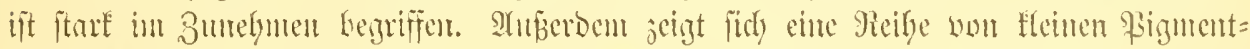

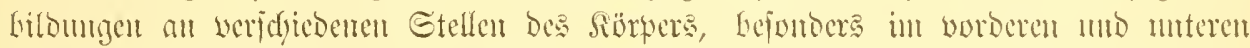

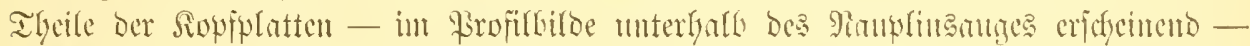

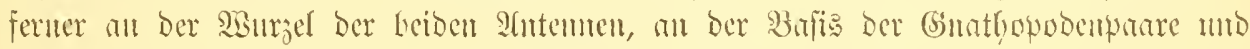

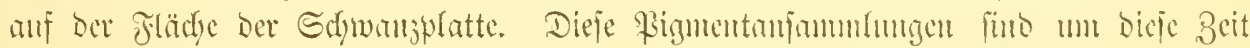

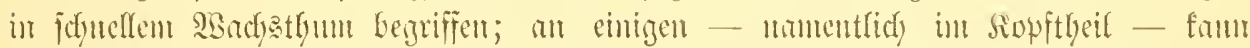

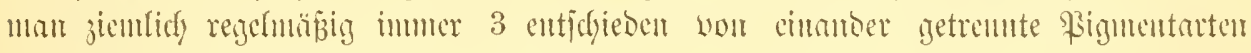

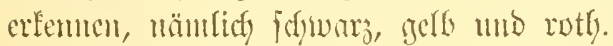

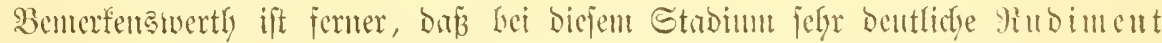

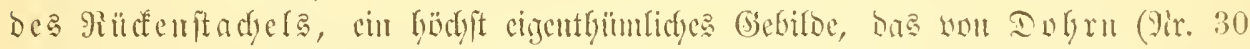

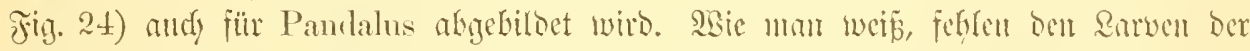

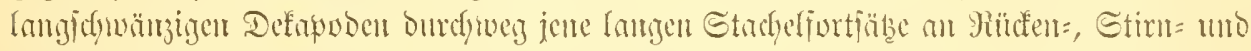

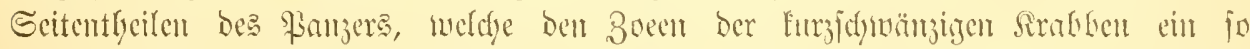

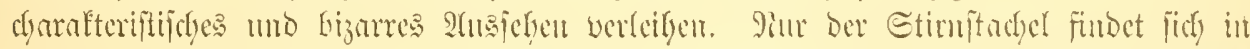

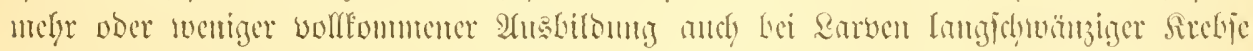

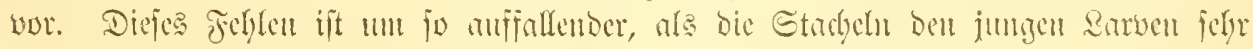

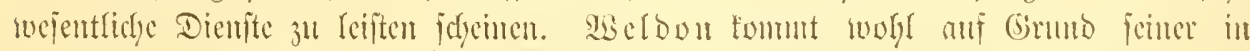

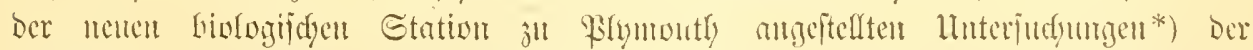

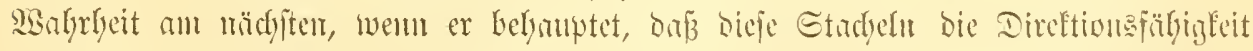

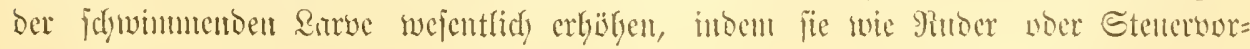

*) efr. Journal of the marine biological Association of the United Kingdom New. Ser. Vol. I. No. 2. pag. 169. London 1 SS9. 
ridftungen funltioniren. TBenn man mun junge Crangonlarwen in ibren Sdyminme

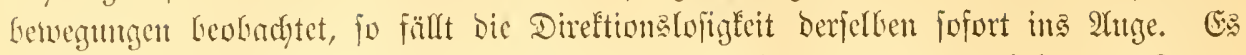

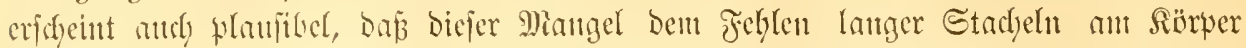

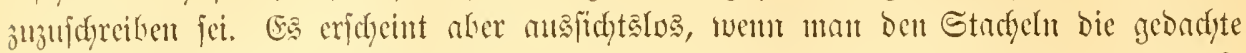
Bebutung zuerfennt, anjunclumen, fie fönnten in sanfe Der Benerationen in Siampfe

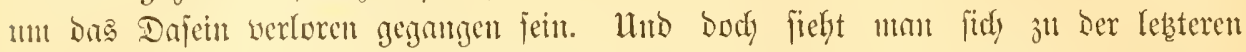

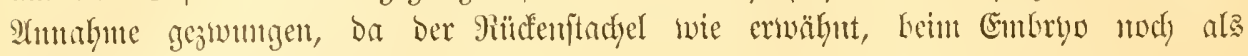
Bindiment worlyandon ift.

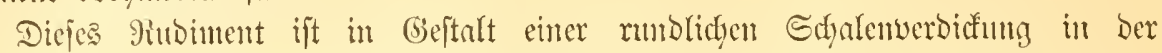

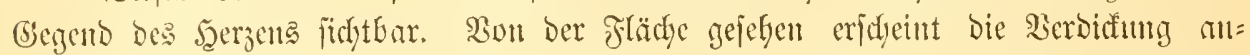

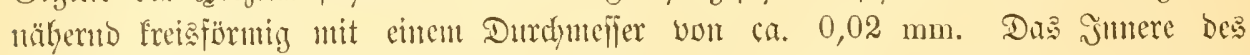

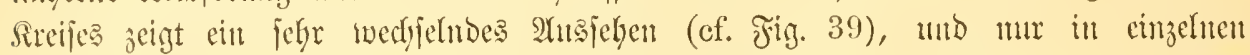

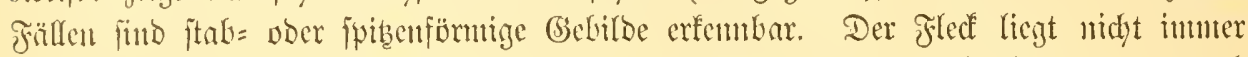

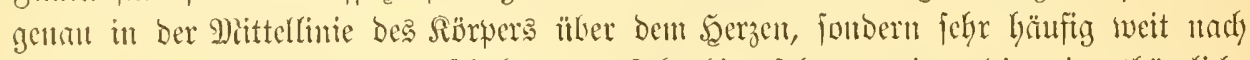

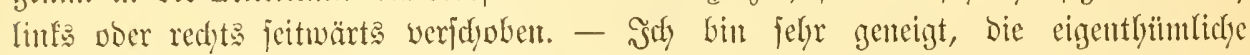

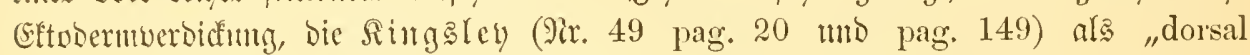

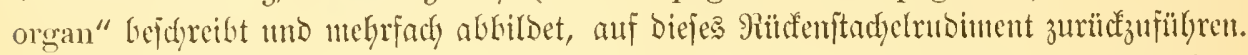

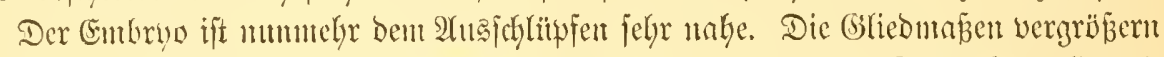
(itd) noch ein ivenig mo man benrerft an ibren Enden unter ber sarvenfyant liegend

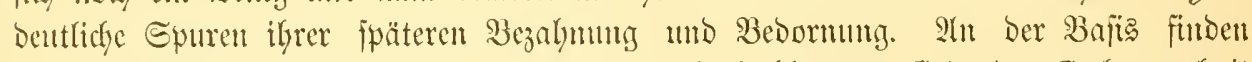
fid Pigmentanfanmlungen, die an Sirö̈̈e und Babl gegen Ende Der Embruonalgeit jelyr zunefmen. Bejonders anf Der Sternaljeite Des Eutoryos zeigen fidy einige गieu=

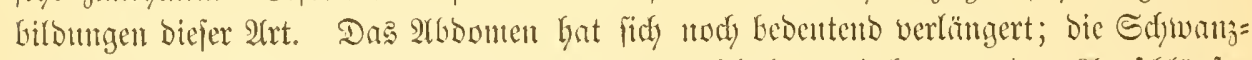

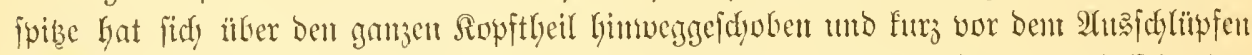

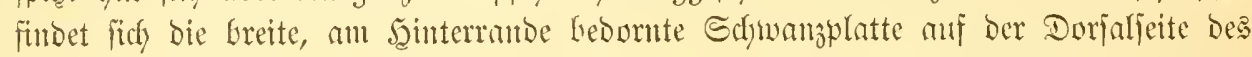
Embryo fafon fo weit mady lyinten gerüdt, Daj bie Sdywanjitadyeln lyinter Der Mitte Des gindents etiwa ïber Der Rebcranlage angetroffent werden.

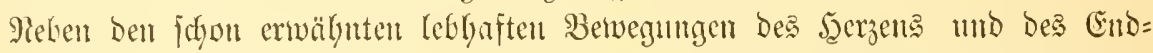
Darms, bie beibe rbytbmifh exfolgen, beobadytet man aud an ben Gsfiedmañen mo

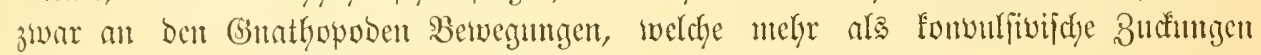
auftreten.

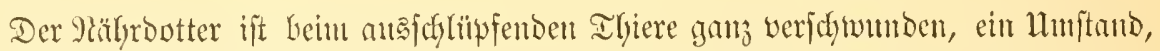
ber bervorgeboben zu werben verbient, Da nabe werwambte Formen mody mehr oder

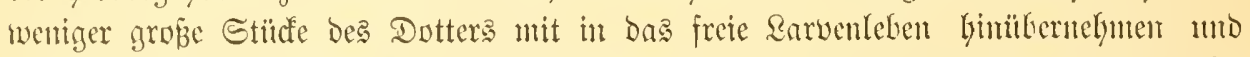

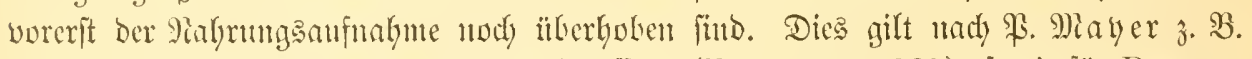

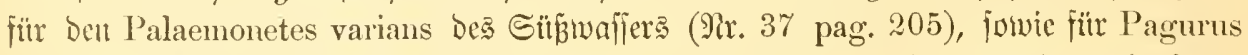

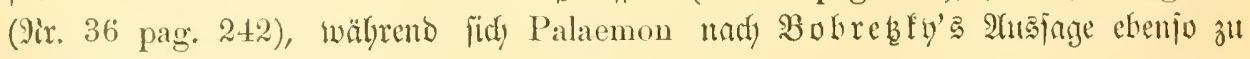
verbalten fobent wie Crangon.

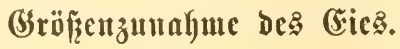

Das Ei bnt un dieje Beit jeinen bedentendfen llufang crreidyt. Dáp dic

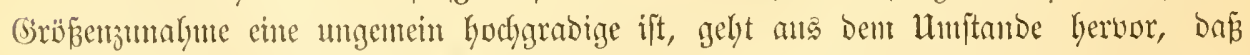

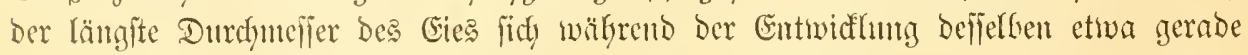

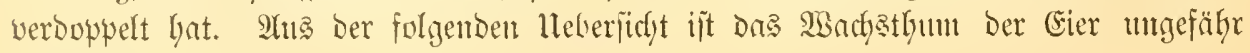
erïichtlidi. 


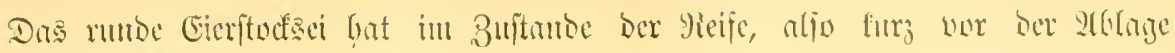
cincu Durdyutefer von .

Eier im F⿱艹

$0,32-35 \mathrm{~mm}$

Girftrulaftabium maßen . in ber \&innge 0,37-38 in ber Breite $0,3: 3$ "

unit glicomañenlojer EmLryos=

anlinge maźetr. . .

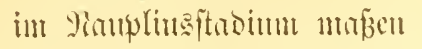

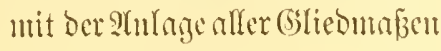

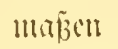

"Den erifen Erumen Der

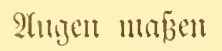

" grofient âtugen tmo biel

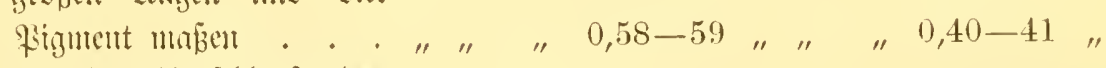

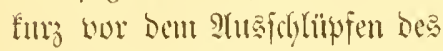

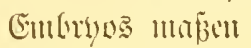

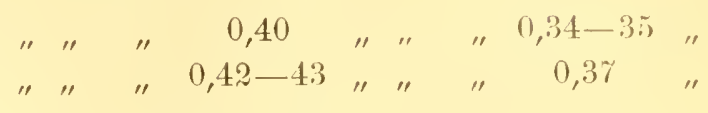

$0,47-48, "$ " 0,42

$0,50-52, "$ " $0,42-43 \quad$ "

$0,60-61 "$ " " $0,35-36$ "

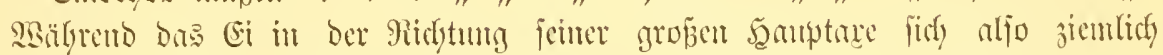

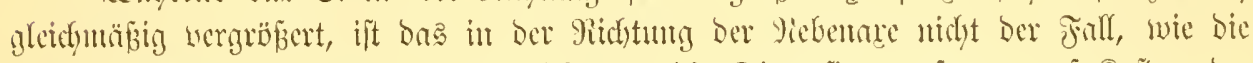

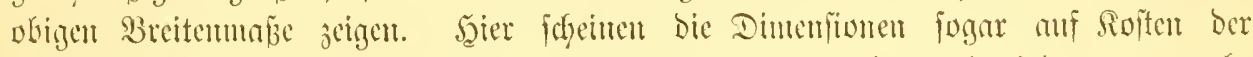

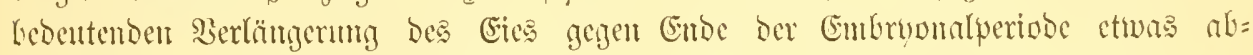

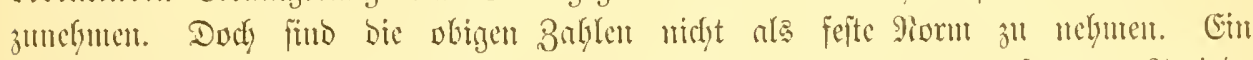

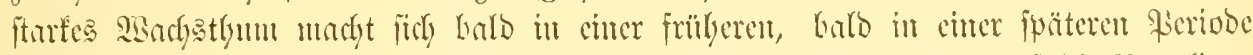

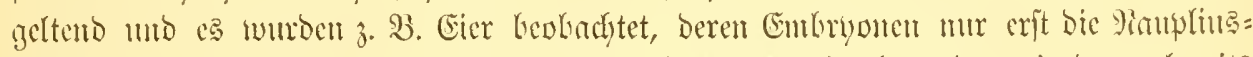

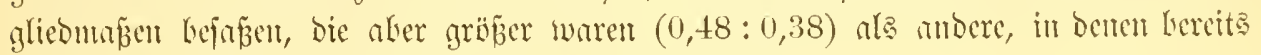
affe sarvengliebma

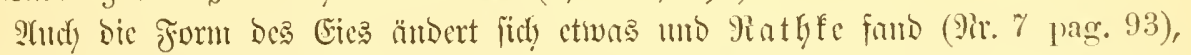

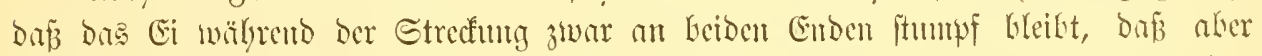

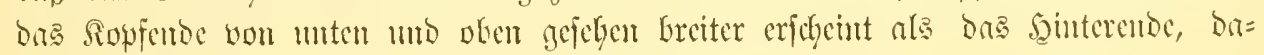
gegen fdyutaler, wemt man eine Profilamildyt lyat.

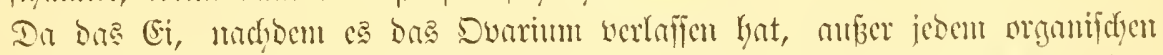

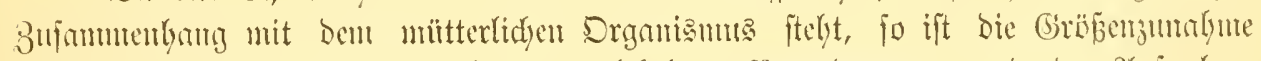

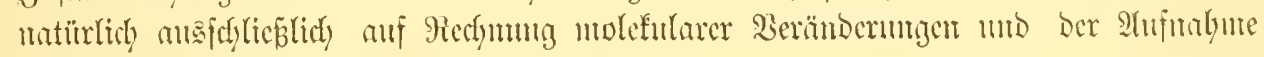
von Micerwafficr ju feţen.

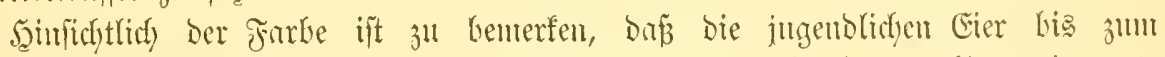

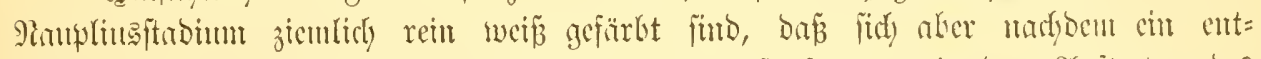

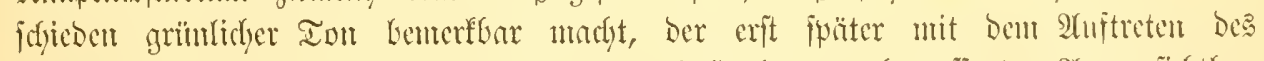

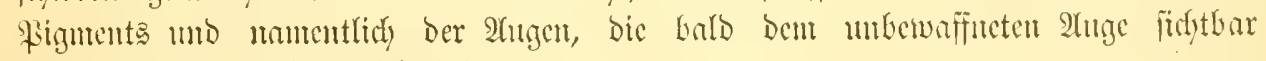
werben, wieber melyr verffywindet.

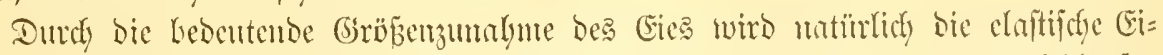

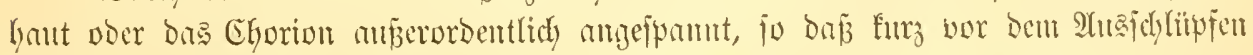

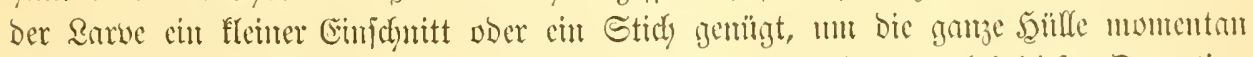

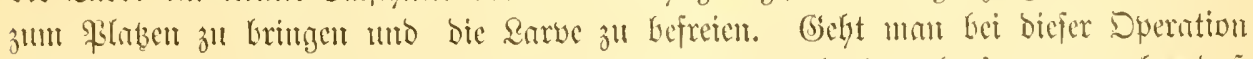

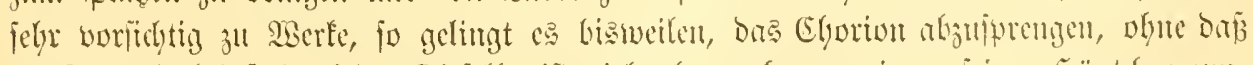
bie Rnrve babei frei wird. Diejelbe ift vielmelyr nody von eimem feinen Sä̈utdyen mut=

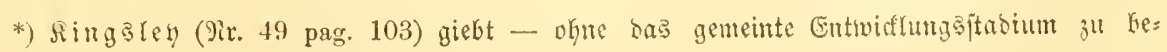

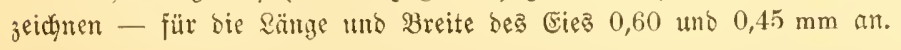




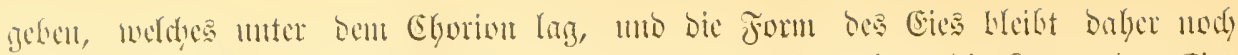

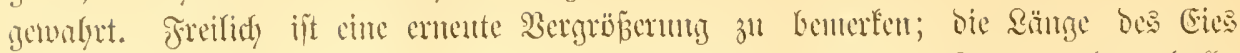

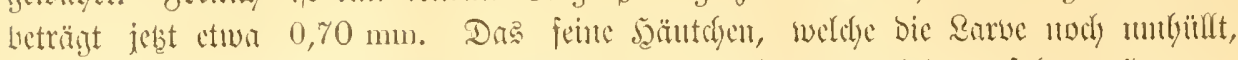

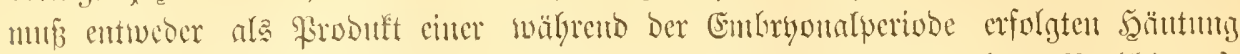

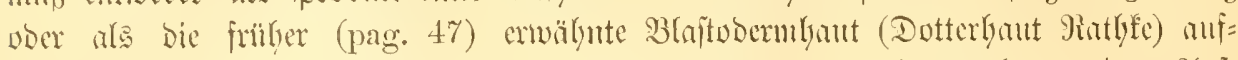

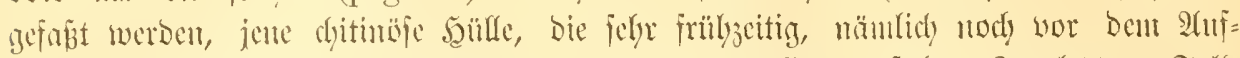

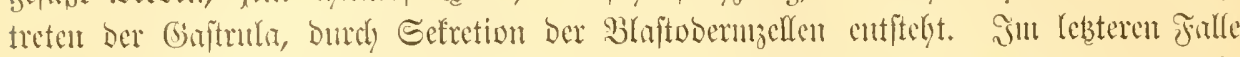

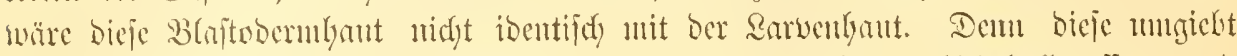

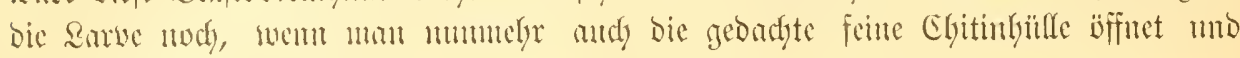
bie surve unllents hefreit.

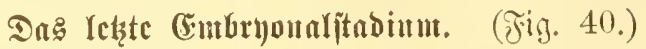

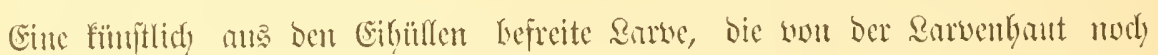

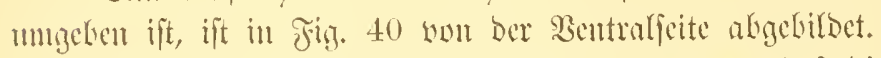

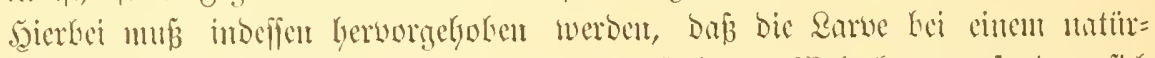

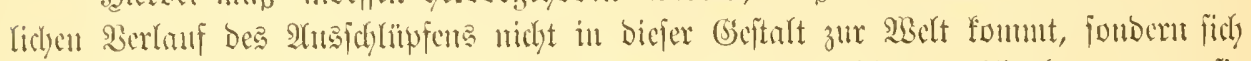

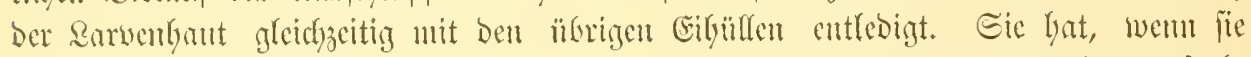

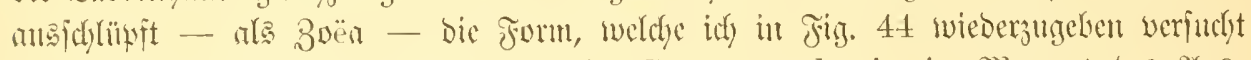

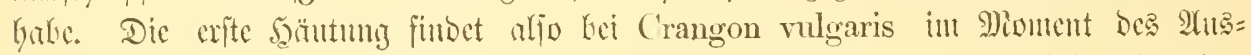

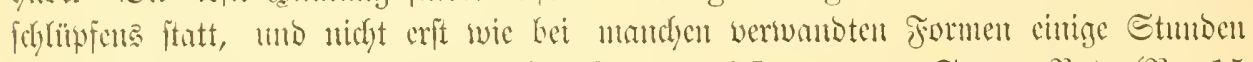
ipuäter. Der Yetetere Foll ijt 3 . 3. für Carcinus Maenas won Epence Bate (Mir. 15

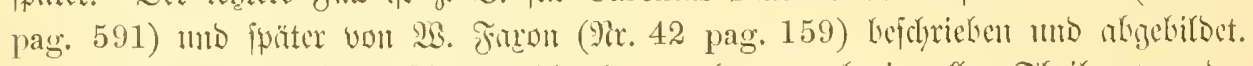

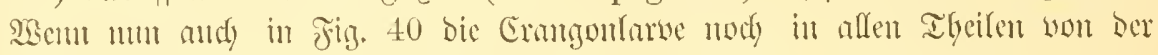

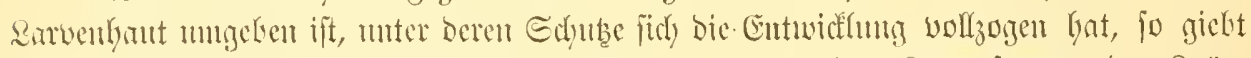

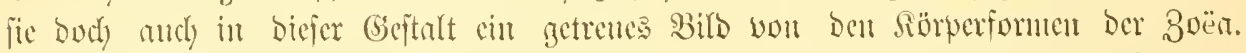

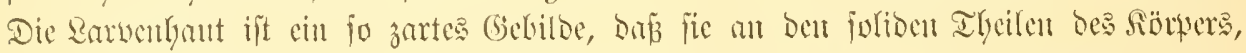
benen fie feft anliegt, nicht fidfthar ift und mur als llutyüllung ber Borften, weldye

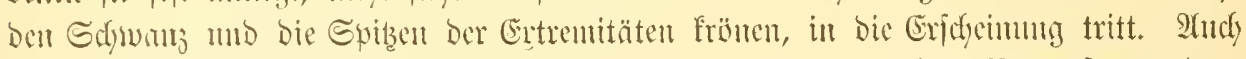

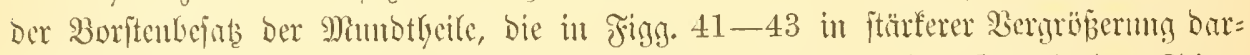

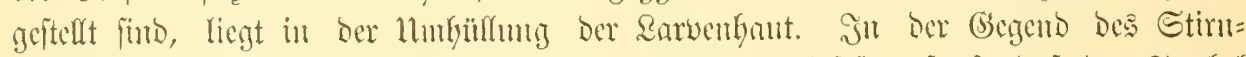

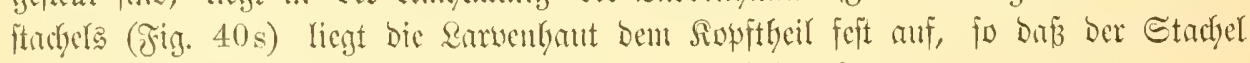

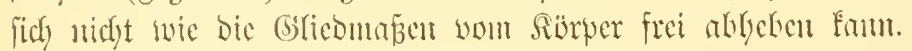

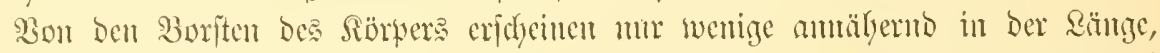

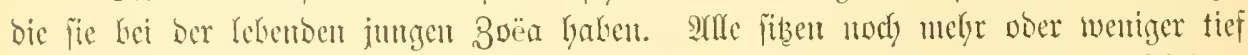

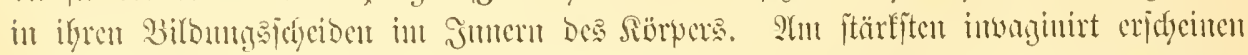
bie Boriten an Der Epibe Der 3 Gnathopodentware, weniger bie an ben Stutemen IIIL an Der S(f)wanzplatte.

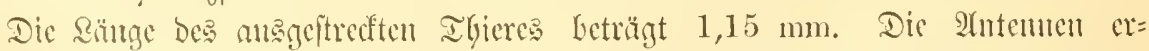

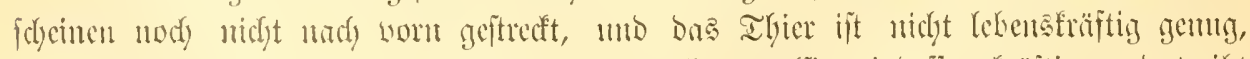

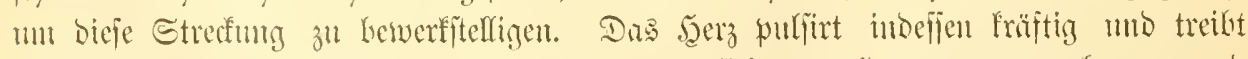

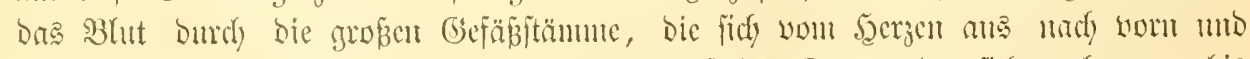

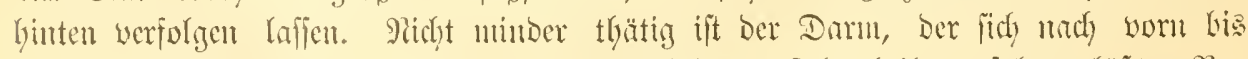

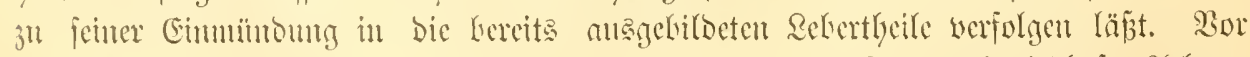

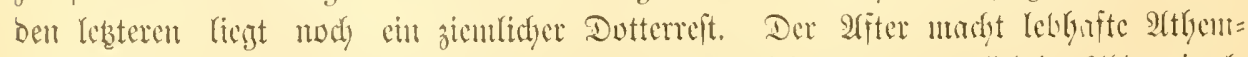

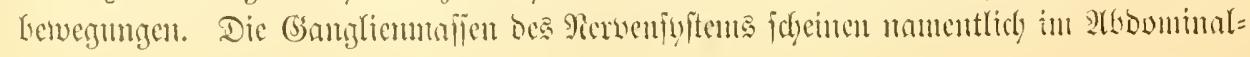




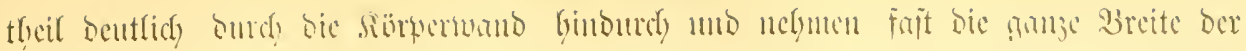

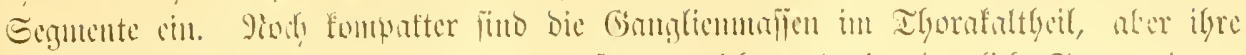

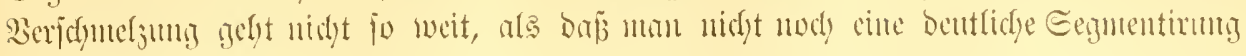
wallnutymen fïmute.

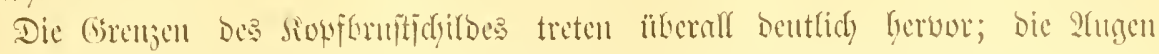

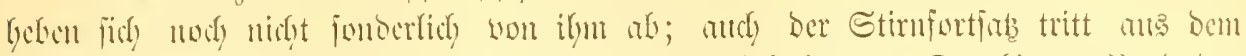

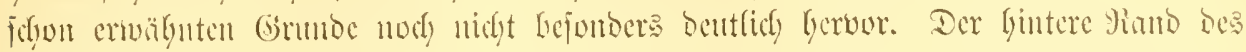

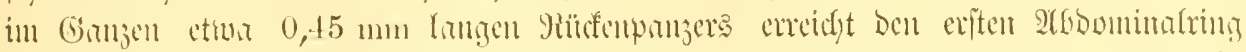

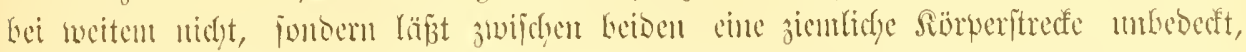

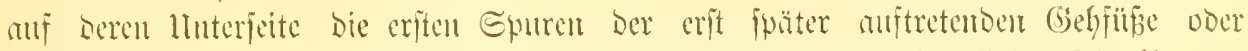

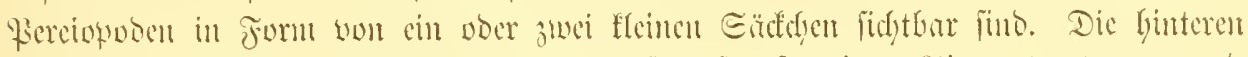

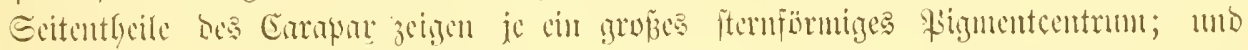

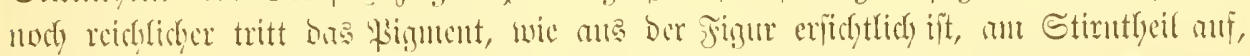

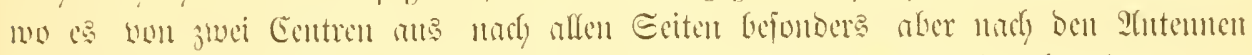

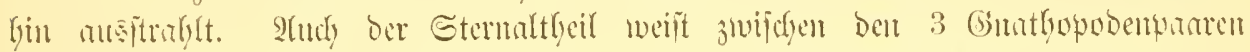

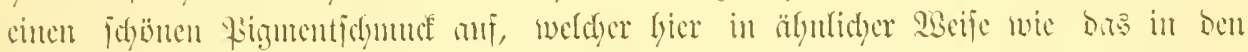

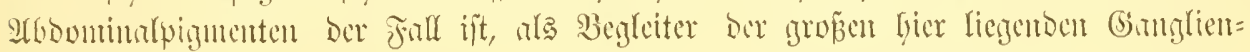
majןat anitritt.

Das 1. Antenuenpar jeigt zwar anf cinem ungegliederten Stanuntgeil jofou

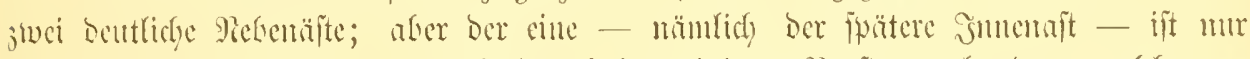

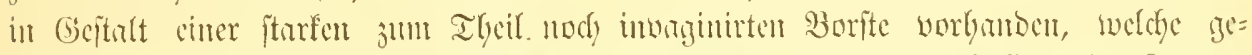

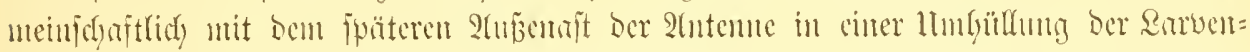

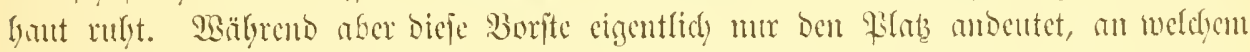

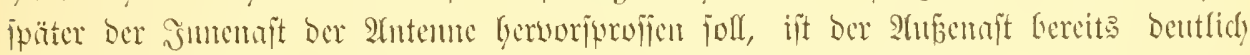

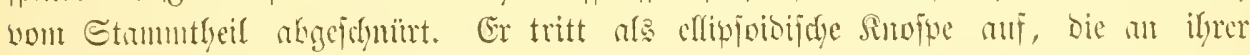

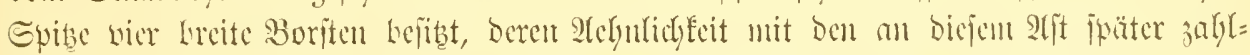

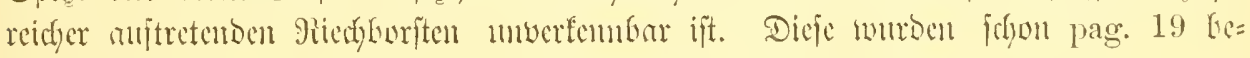
idricten.

3ei anderen Cariben, 3. B. Wei Palaemonetes varians (cfr. Iir. 37 pag. 207), Eei Palaemonetes vulgaris ( $9 \mathrm{ir}, 41$ pag. 310), Gei Caridina Desmarestii ( $) 12$

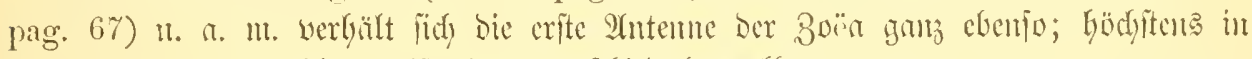

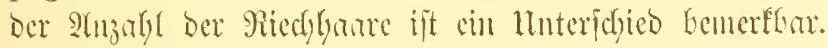

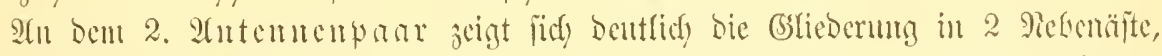

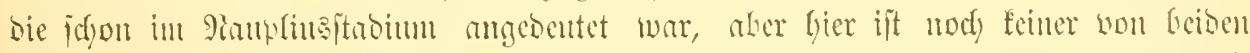

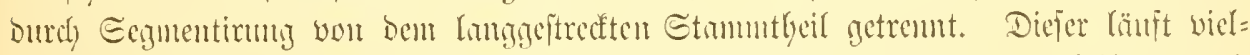

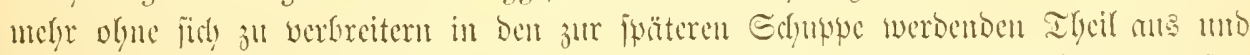

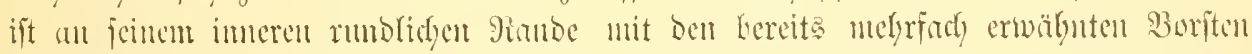

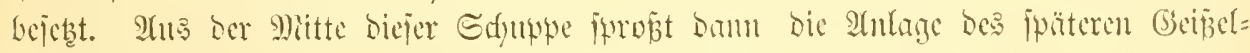

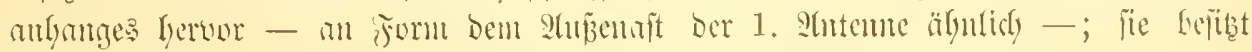
an ilyer Epitze cimen cimjigen groben Dorn.

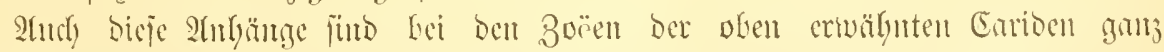

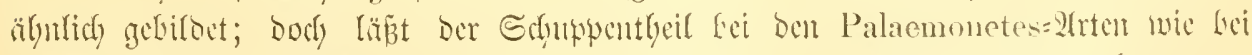

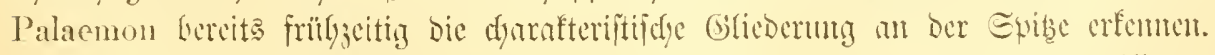

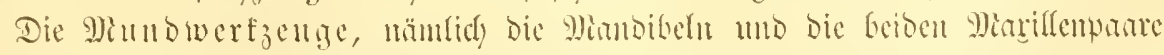

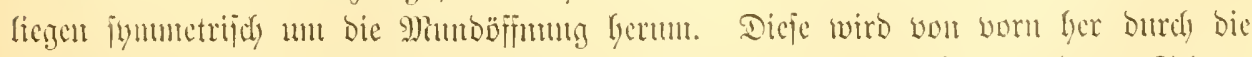

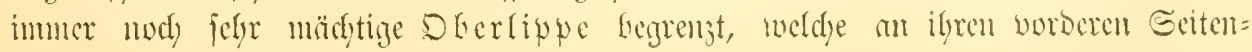




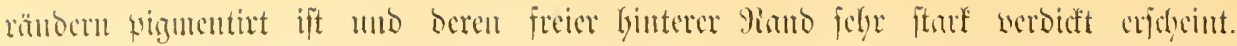

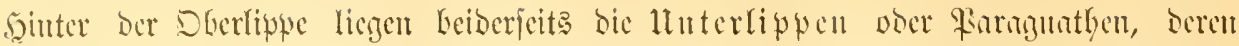

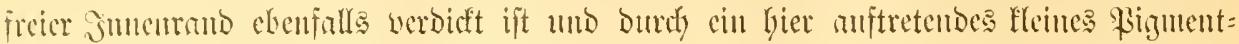
centrum bie ange biejer Ibeile Dentrich madyt.

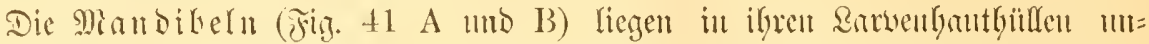

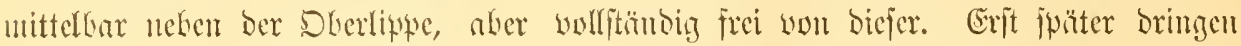

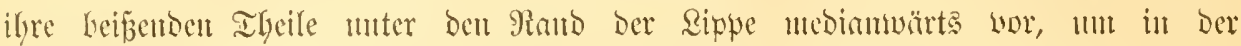

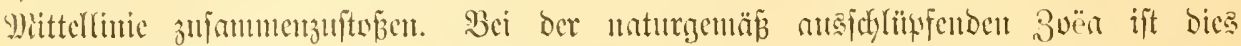

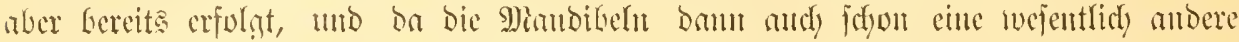

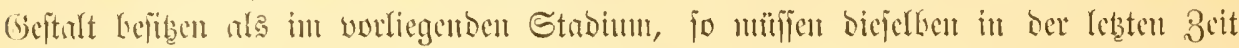

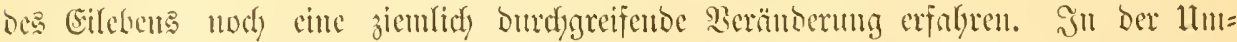

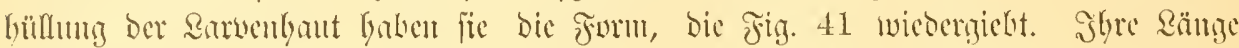

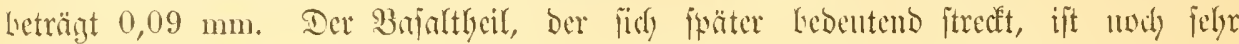

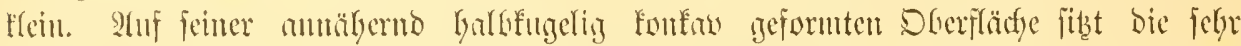

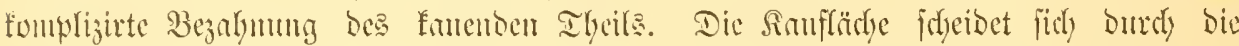

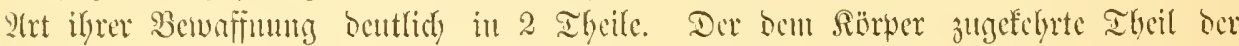

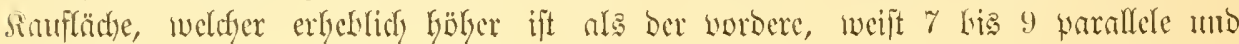

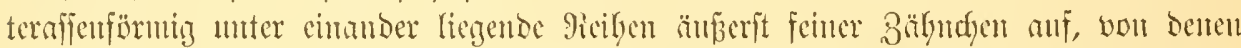

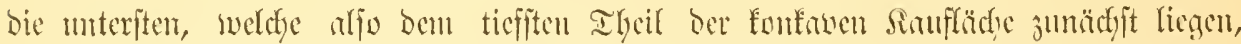

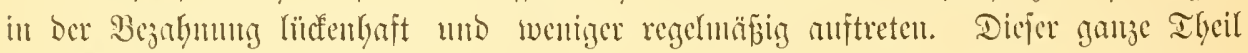

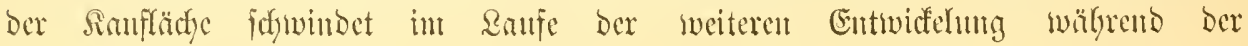
Rarbenjeit.

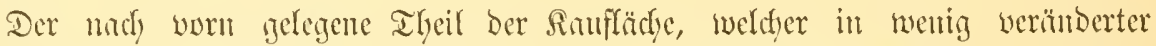

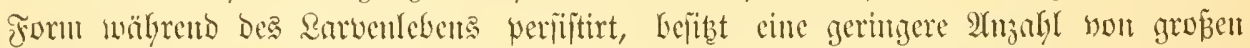

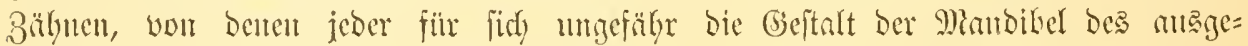
bilbeten Ibieres bat (cf. Fig. 6). Rebteres gilt manentlin won bent gröbten 3alyn,

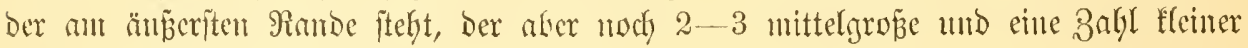

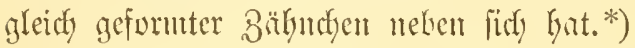

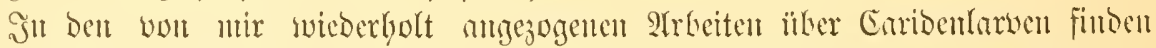

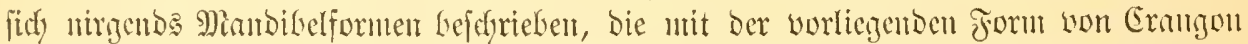

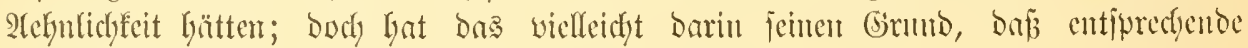

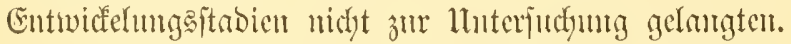

Ulmuttelbar Ginter Den Mandibelı, bie Barje Derferben nod, vollitinbing mit

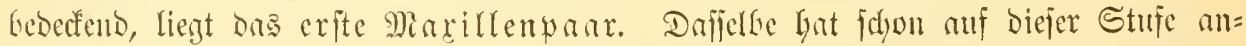

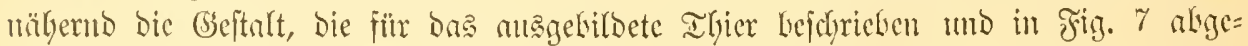
bildet murbe. Jig. 42 jeigt bieje Miarifle in ber llubitflung ber sarventant; ibre

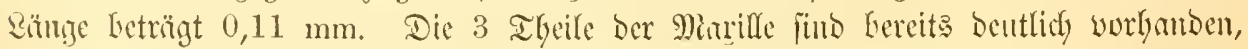

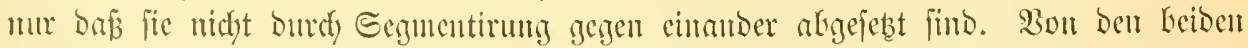

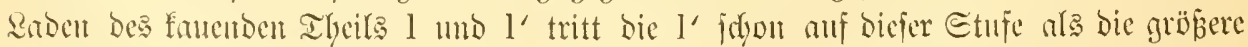

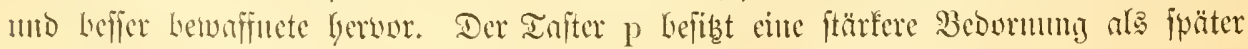
bein anggelibdeten I I jier (cf. Fing. 7).

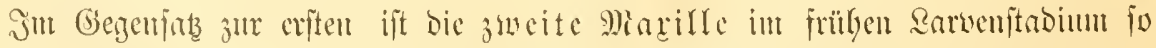
abucidyend gebant vou ber Form, bie fie beim anghebildeten Thiere bat (cf. Fig. 8),

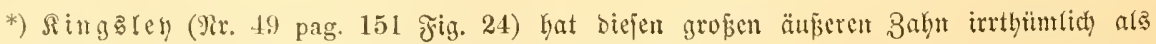

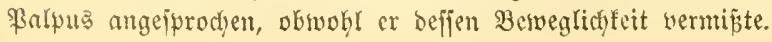




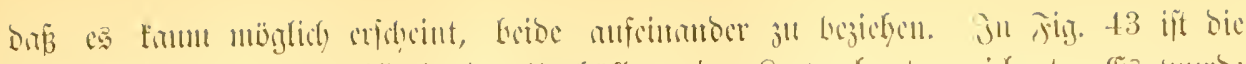

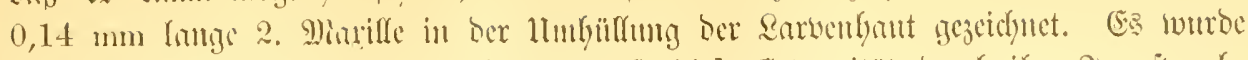

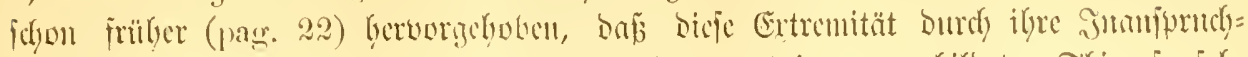

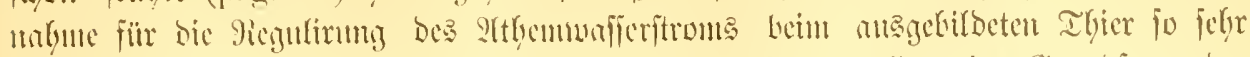

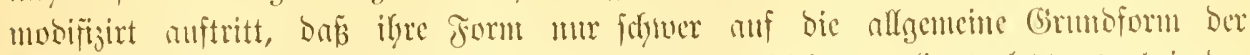

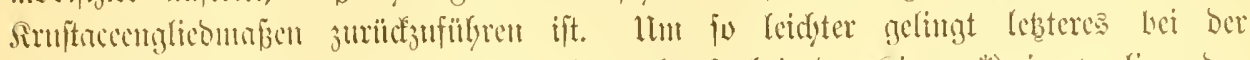

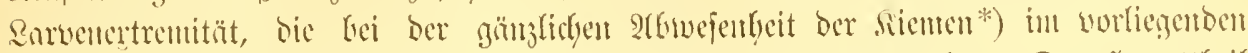

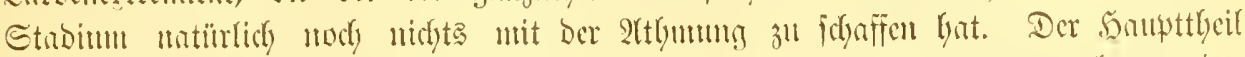

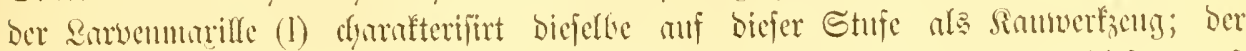

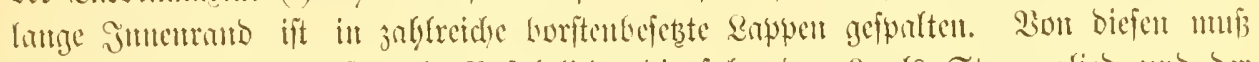
ser unterite mo ruteitefte als Bajulglied, bie folgenden 3 als Etanmmglied und ber

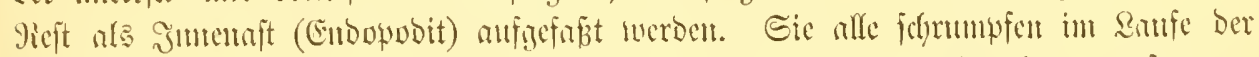

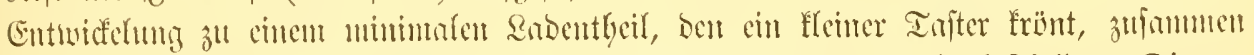

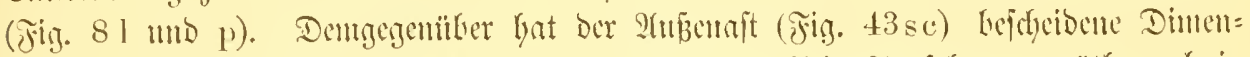

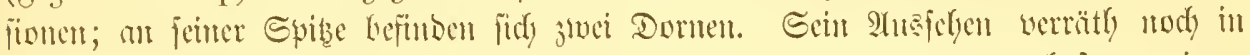

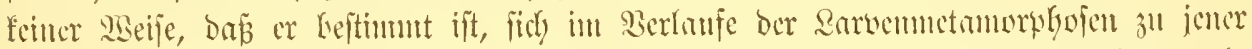

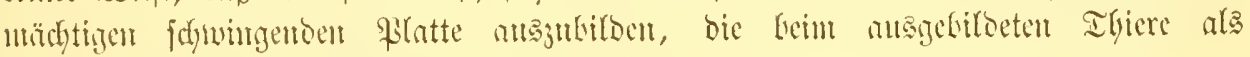
Ecoplyoguntbit beflyrieben ivurde (pag. 22).

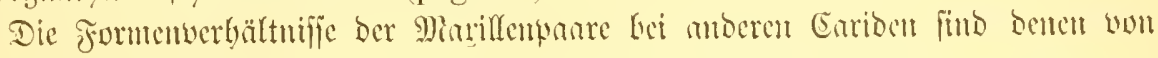
Errmgun jobr äfulidy.

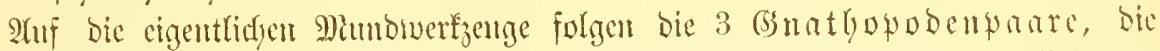

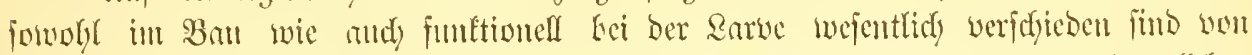

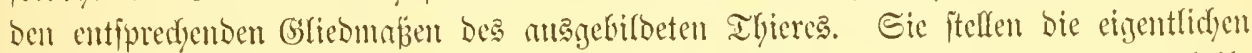

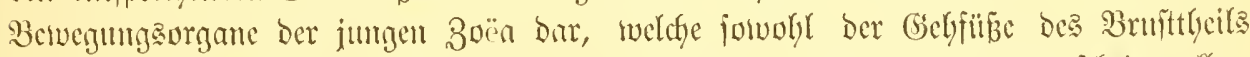

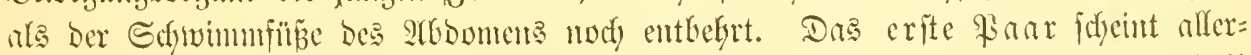

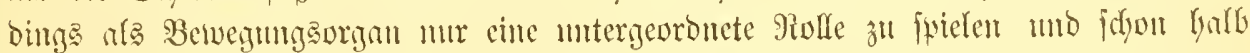

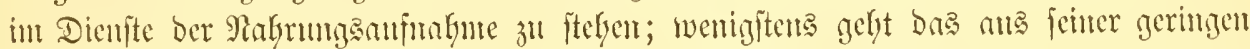

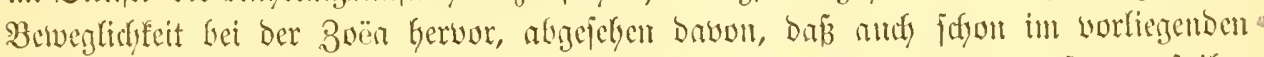

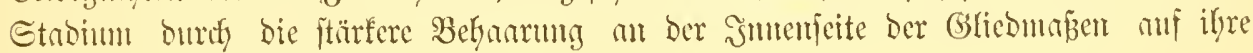
Funtion bingewicjen svirb.

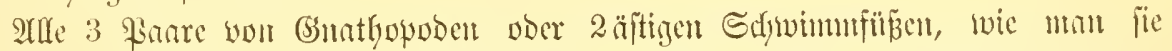

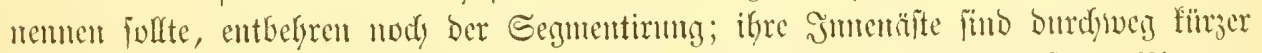

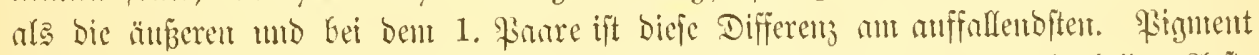

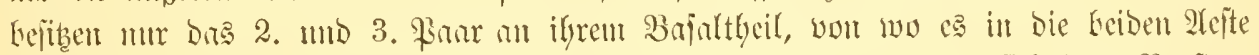

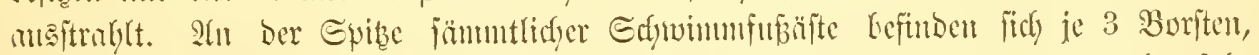

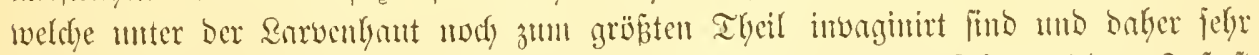

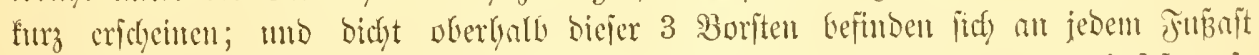

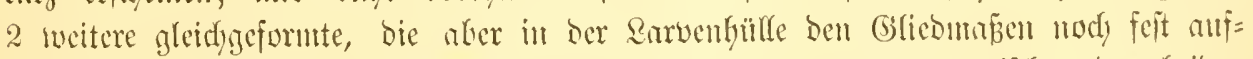
riegen. Shre Snfertion entipridyt Der fpriter muftretenben Grenje juifdyen ben beiben

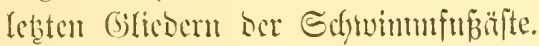

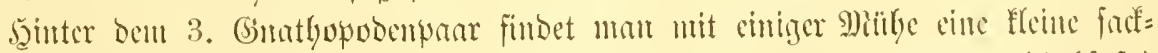

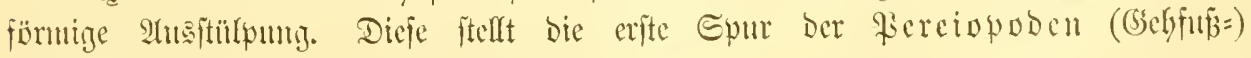
Anlauge onx.

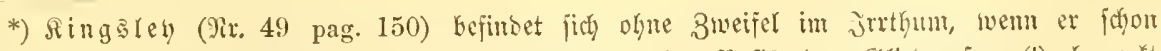

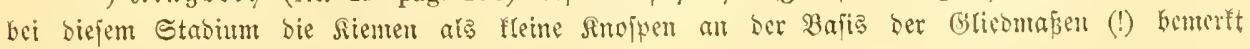
haben will. 


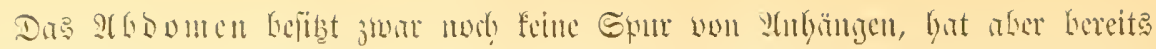

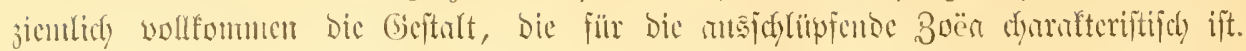

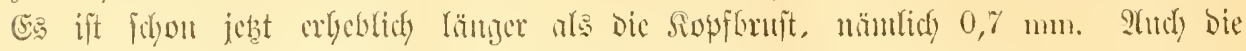

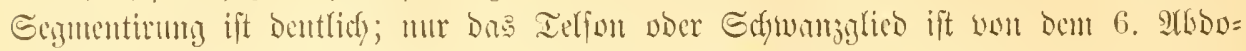

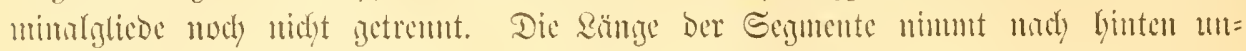

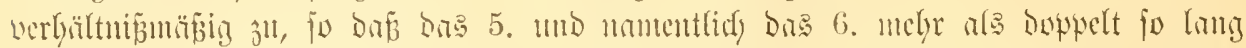

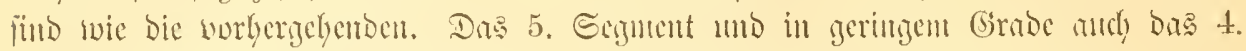

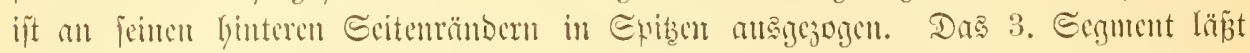

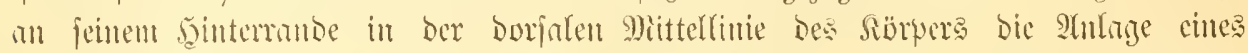

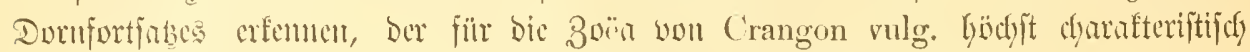
ift. Der Dorn liegt aher unter ber Barwentyunt Dem Rörper und feft anf.

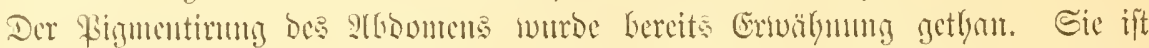

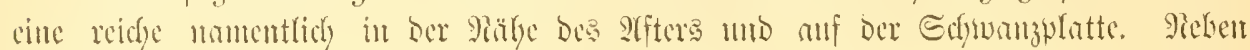

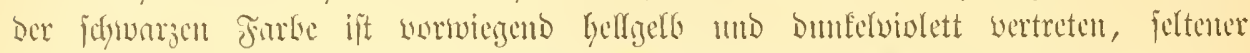

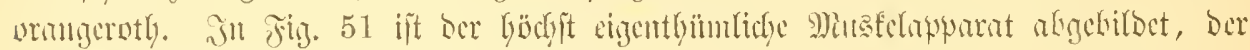

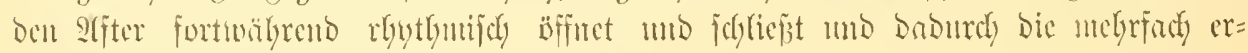

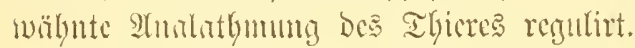

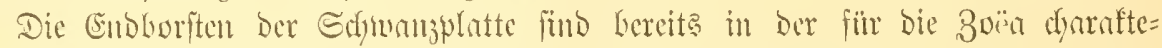

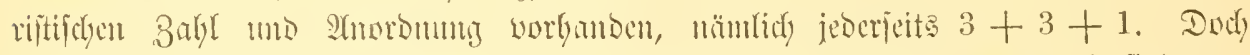

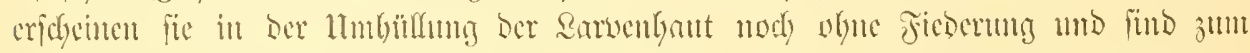

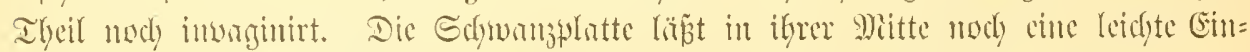

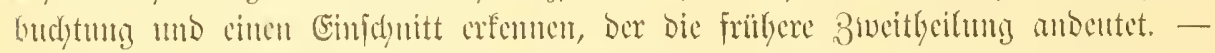

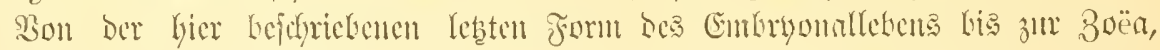

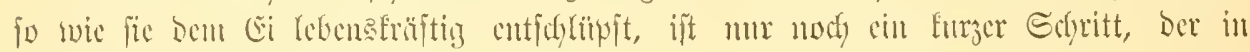

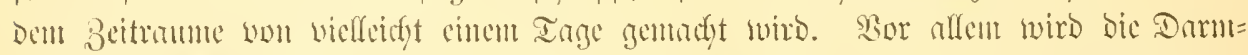

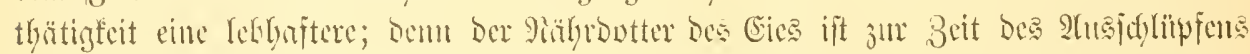

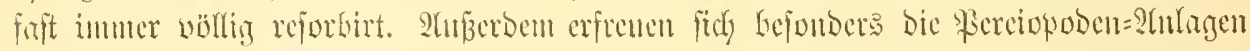
mod) ciner ettuas weitergelyenden Entmidefmig.

\section{Dic 3oën.}

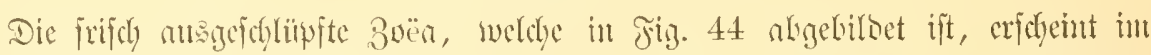

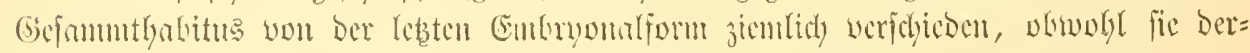

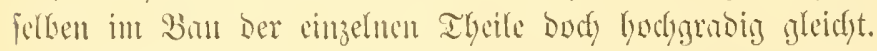

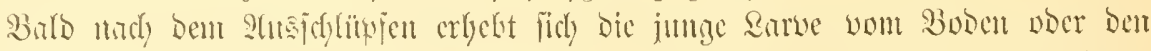

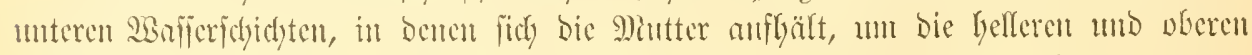

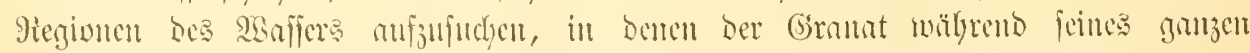

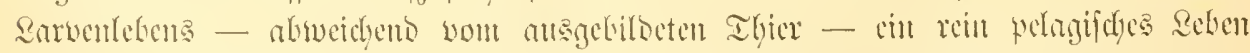

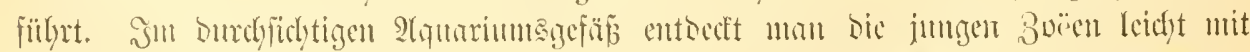

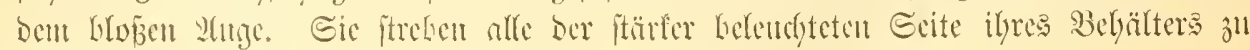
und bilben bier cin Didytes Gerwimmel.

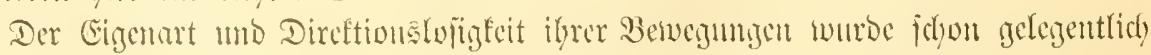

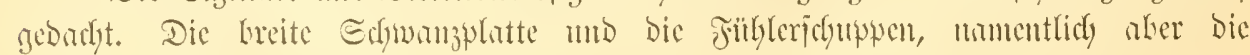

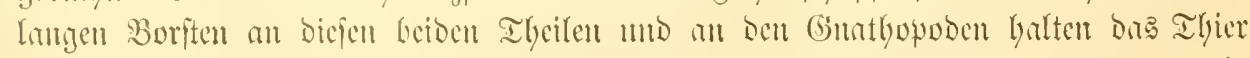

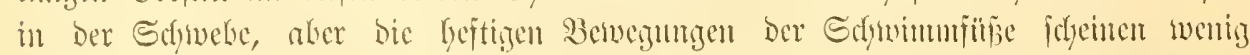

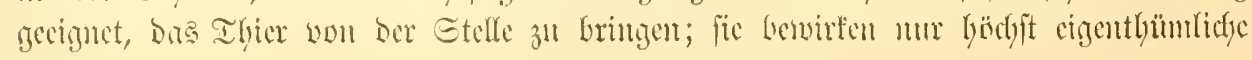




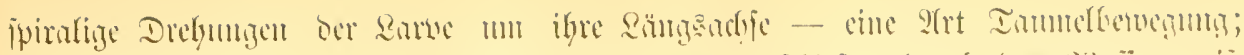

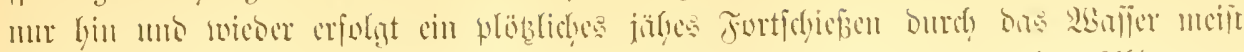

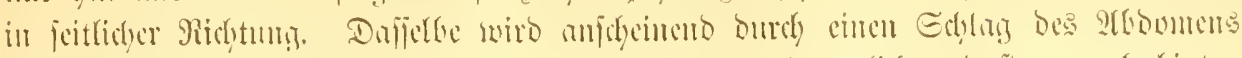

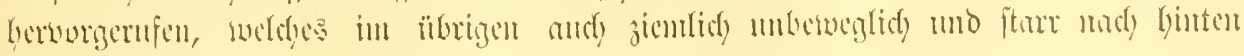
geftredt eridecint.

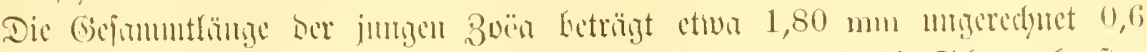

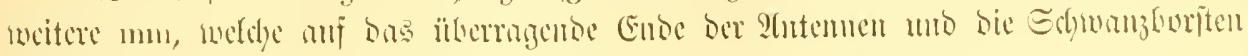
entianten.

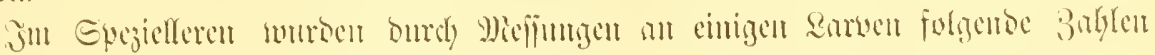
gefumbett: *)

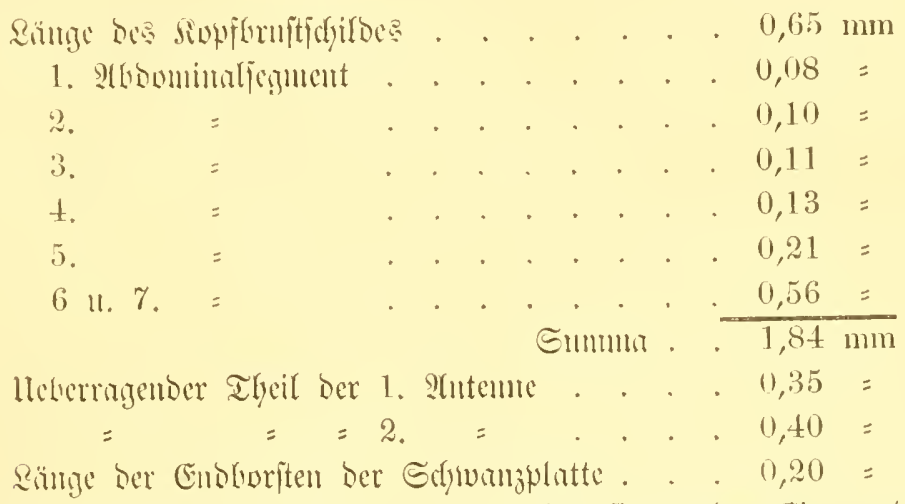

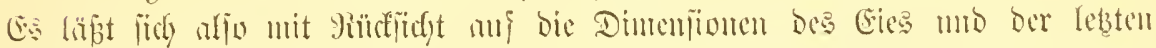

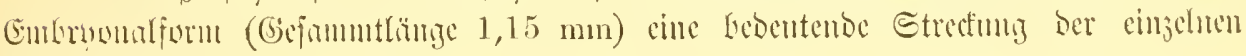
Iheile Eunftatiren.

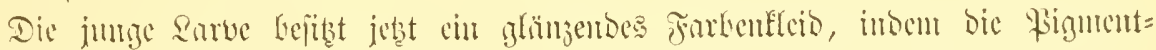

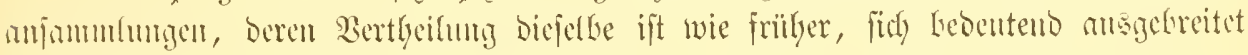
und grellere Furbentöne angenoumen baben.

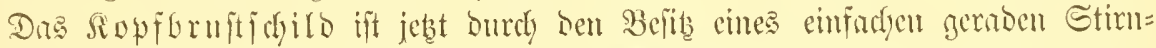

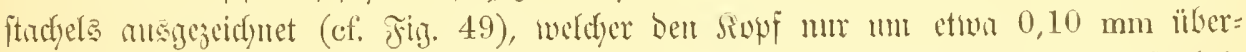

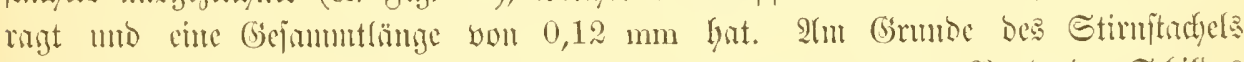

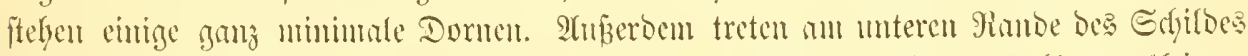

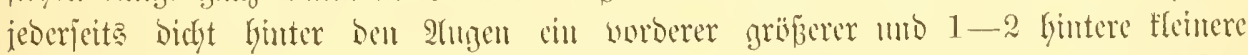

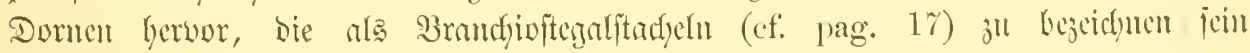
mürben.

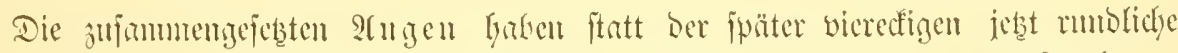

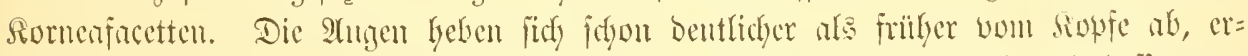

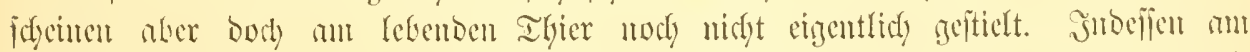

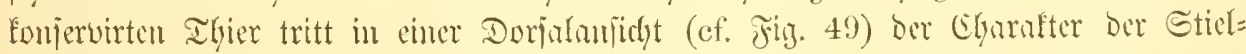

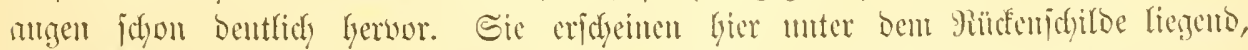

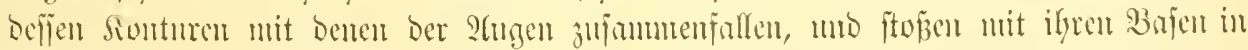

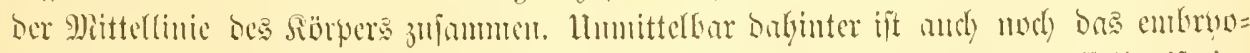

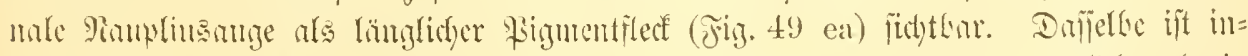

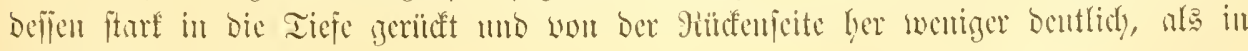
einer Bentrilunjicht.

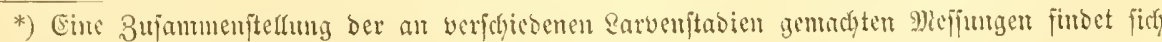
in ber Tabelle auf pag. 80. 


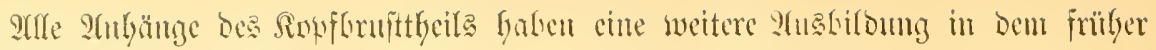
angedenteten Eimue cringreu.

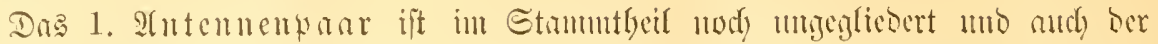

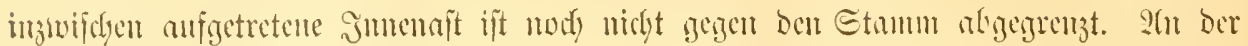

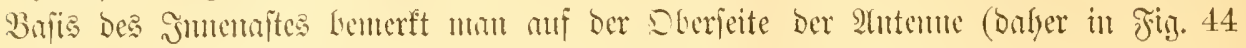

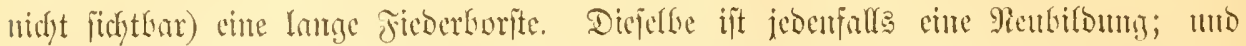

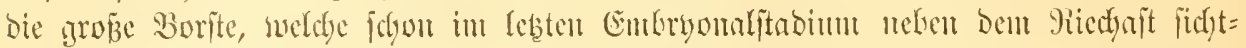

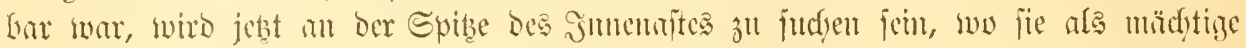

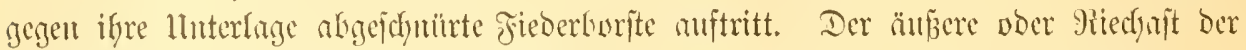

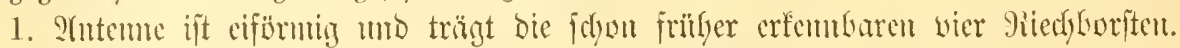

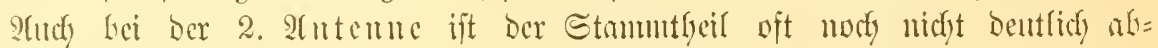

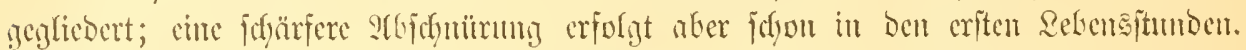

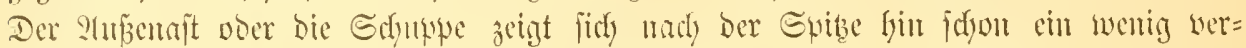

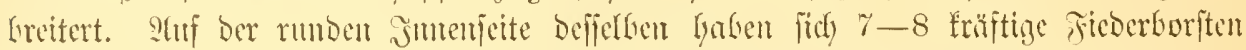

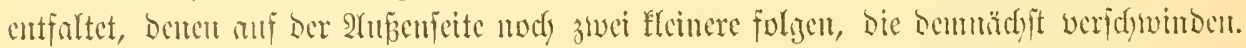

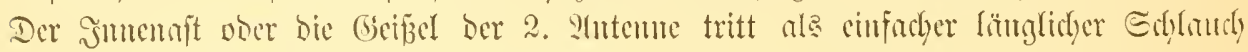

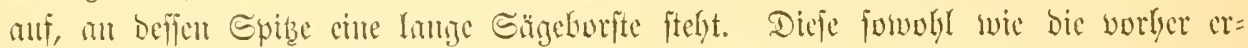

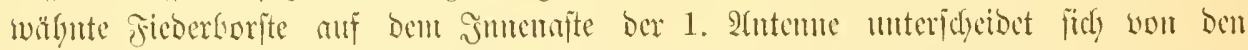

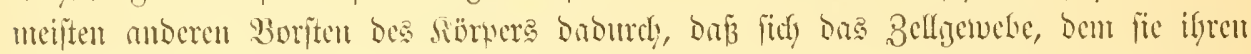

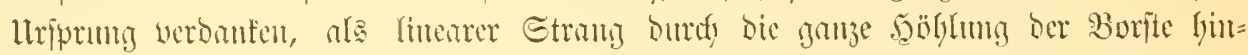

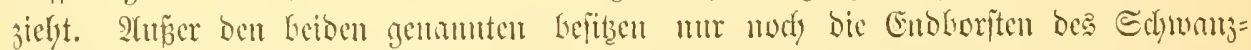

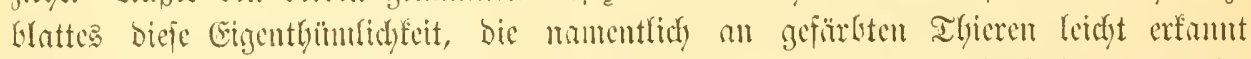

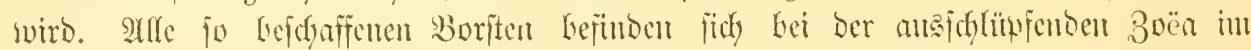

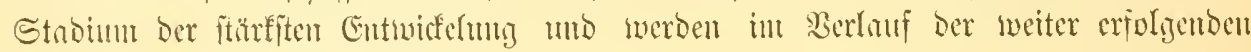
Metanurphojen jurrüfigebildoet.

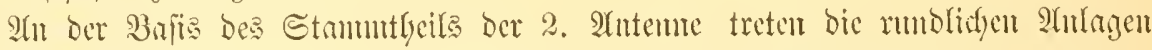

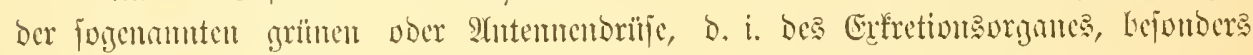
Deutticly Gervor.

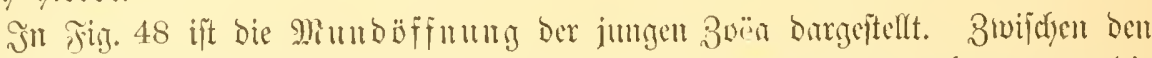

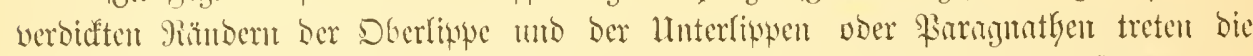

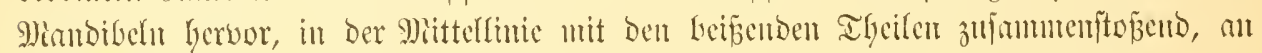

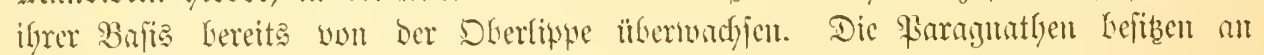

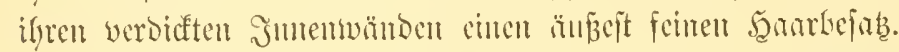

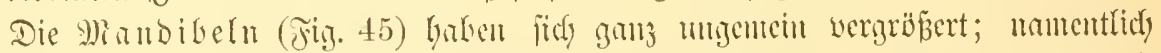

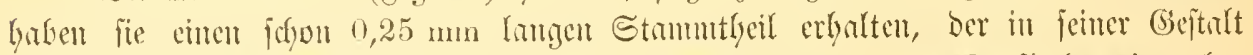

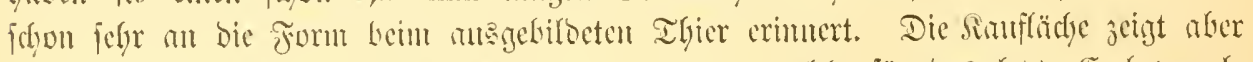

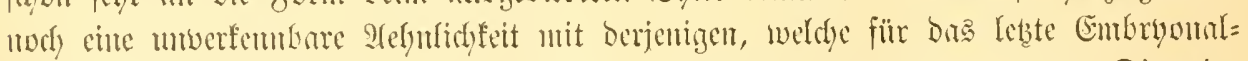

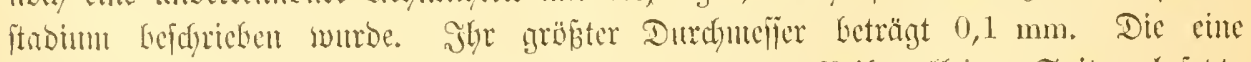

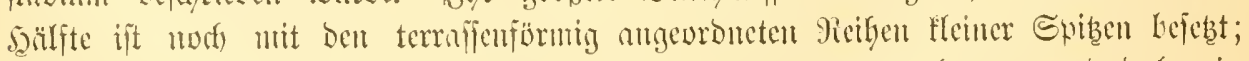

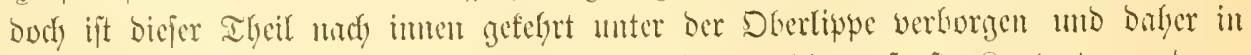

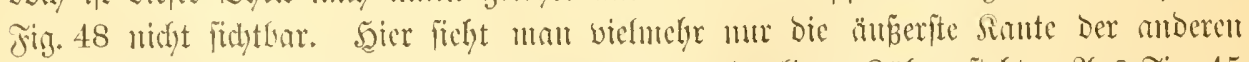

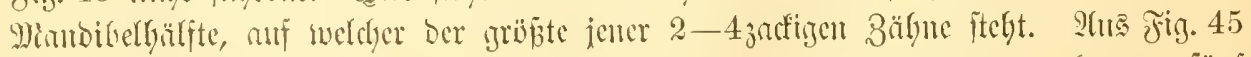

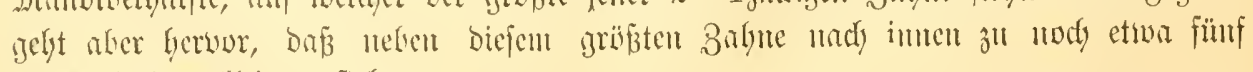
gleidagejtaltete fleinere ftelyen.

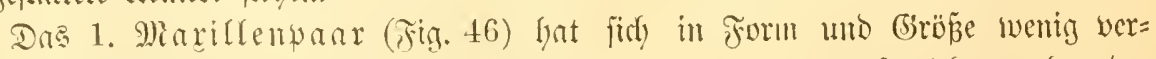

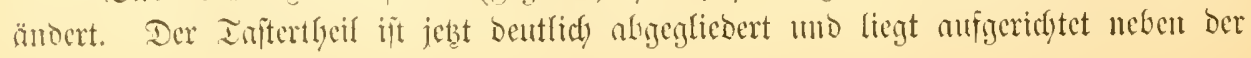




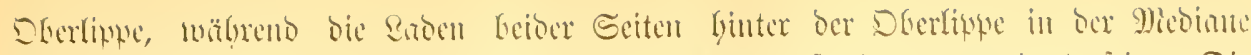

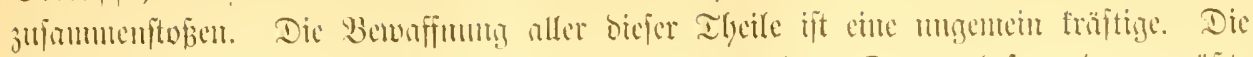

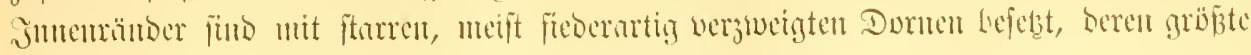
muf bent Tofler eine Ränge you 0,063 nm Lefiber.

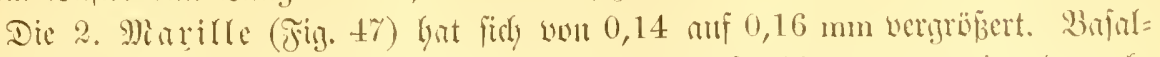

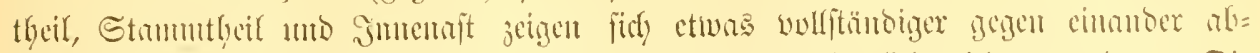

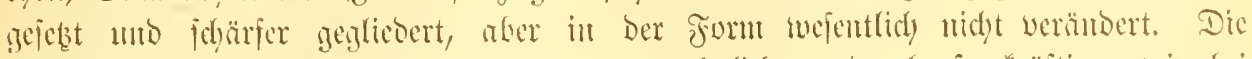

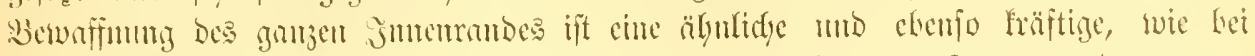

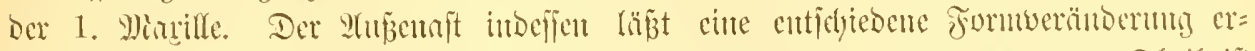

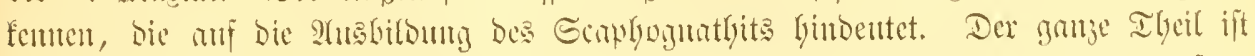

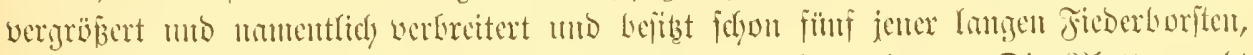

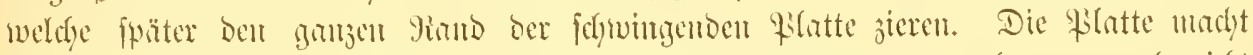

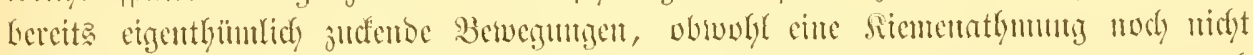

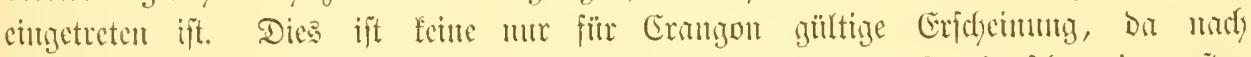
9. Farou (9ir. 41 pag. 311) andy bei Palaemonetes vulgaris jofyn in cxiten

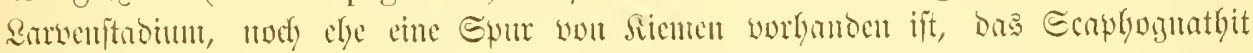

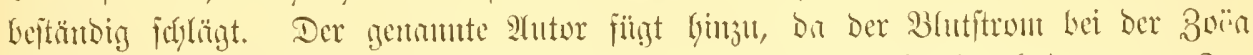

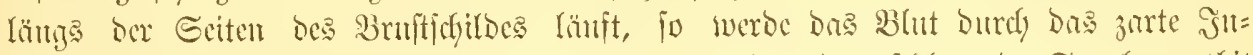

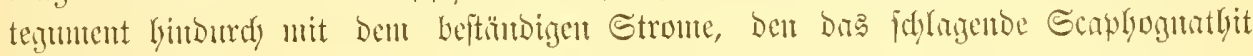
erzentegt, geliejtet.

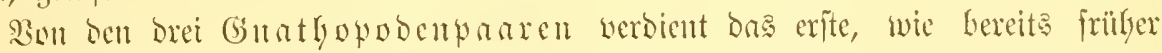

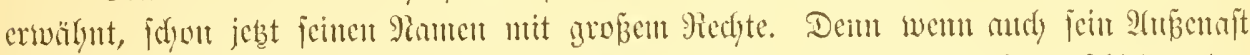

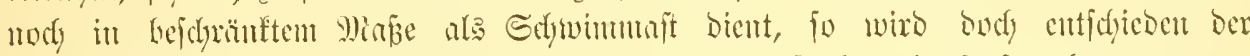

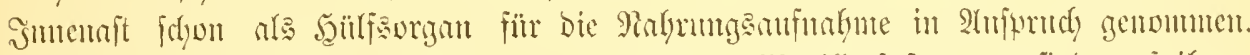

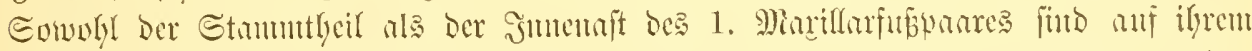

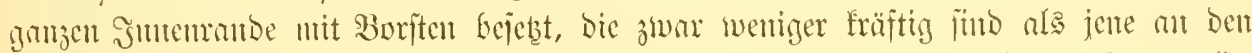

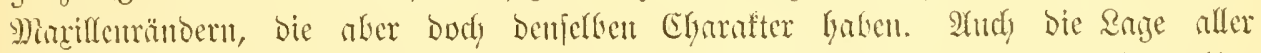

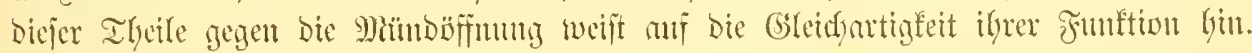

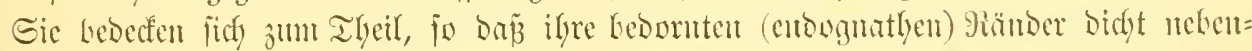

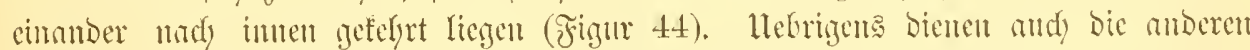

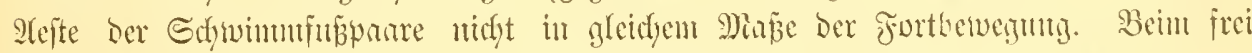

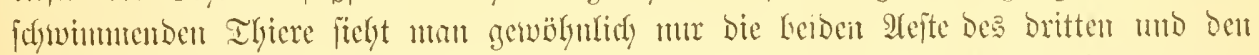

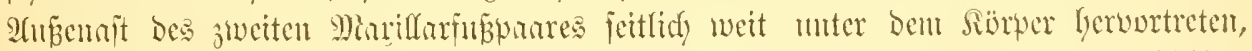
während bie Bewegungen der üLrigen Theile melgr voer wentiger bextorgen berben unb bulfer aud midyt fo fräftig fein werben.

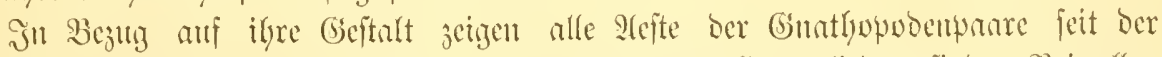

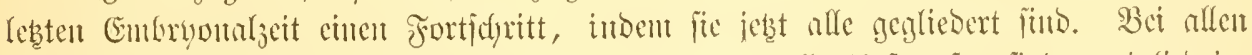

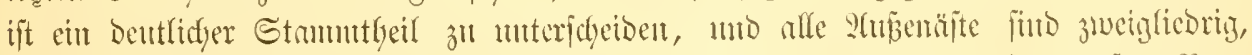

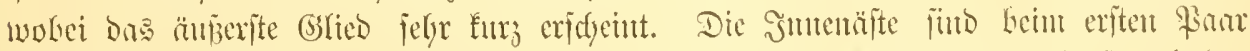

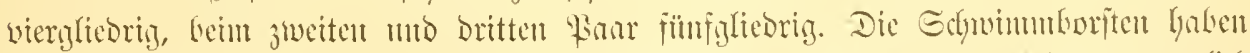

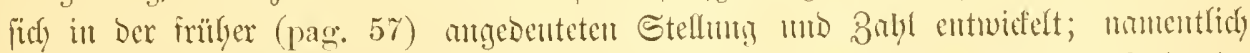

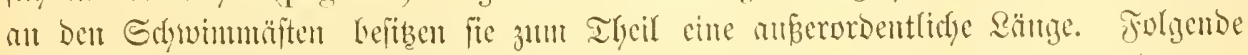

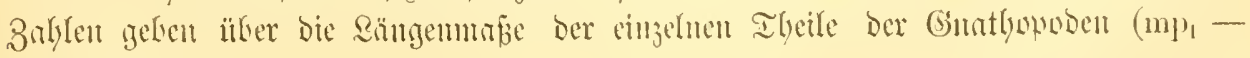
$\mathrm{mp}_{3}$ ) 2(ufíd) 


$\left.\begin{array}{l}\text { 3ajaltgeil } \\ \mathrm{mp}_{1} \\ \mathrm{mp}_{3}\end{array}\right\} 0,135-0,150 \mathrm{~mm}\left\{\begin{array}{ccc}\text { Jumenajt } & \text { Anpenajt } & \begin{array}{c}\text { Iängite } \\ \text { Sdfuimmborite }\end{array} \\ 0,11 & 0,23 & 0,33 \\ 0,18 & 0,34 & 0, \pm 0 \\ 0,26 & 0,34 & 0,45\end{array}\right.$

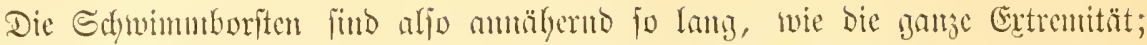

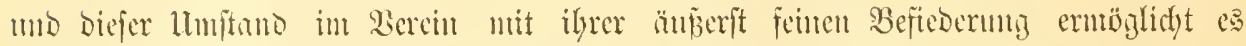

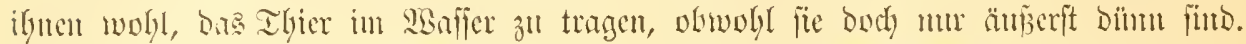

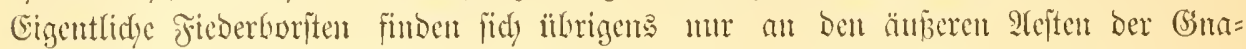

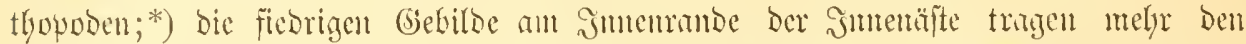

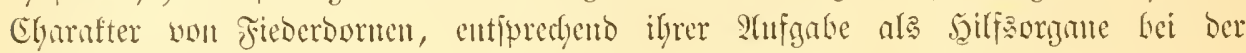

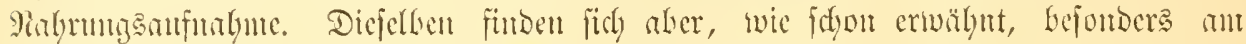
criten Ginatlyownocnpar, an ben mberen gants wereingelt.

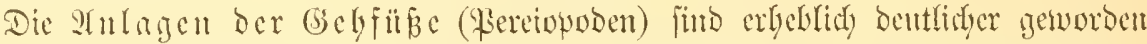
gegen frïlyer; gewöhnlidy treten bie eriten brei, biendeilen and bie erften vier Fante

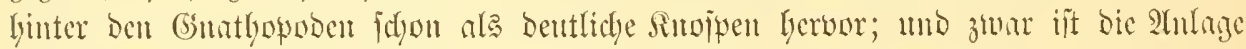

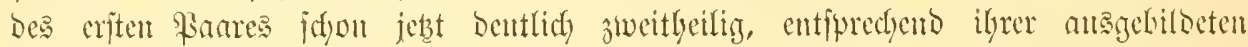

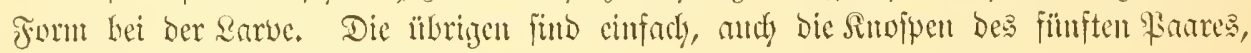
bie felyr bald barnuf erjacinen.

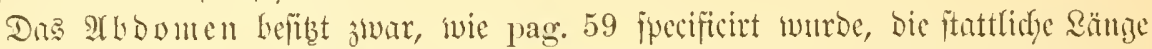
von $1,2 \mathrm{~mm}$, läjt aber nody feine Spur Der \$reopodent:2tulagen erfenten. Die idfou frillyer crwäblytte charnfteriftifdye Bewaffinug, nümlidy der borfale Dorn an 3. Sey=

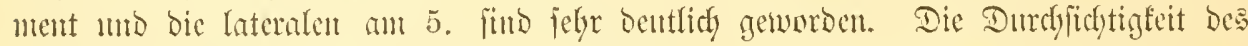

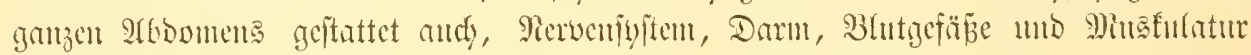

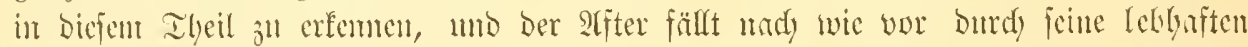

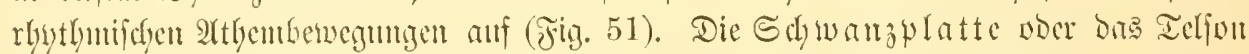

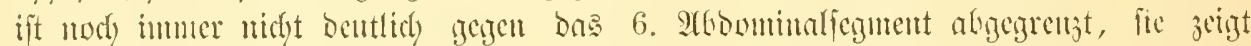

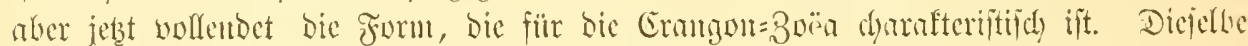

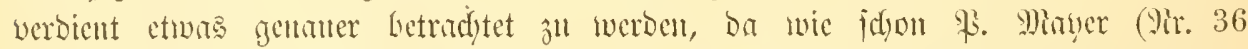

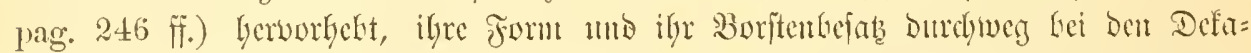

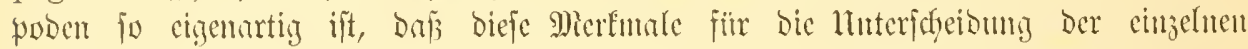

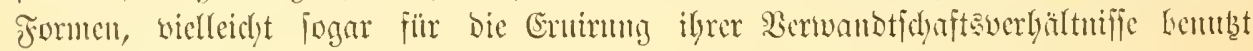
werben fömnen.

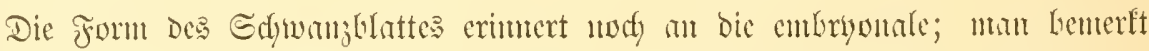

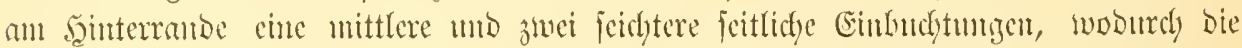

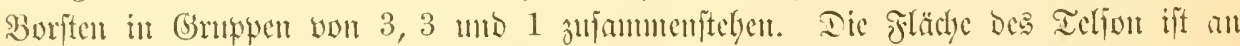

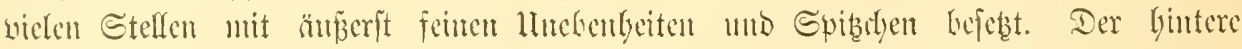

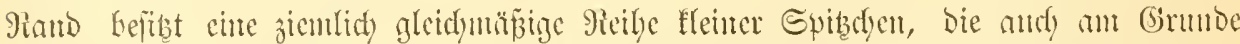

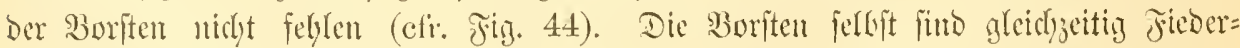

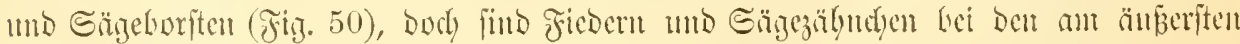

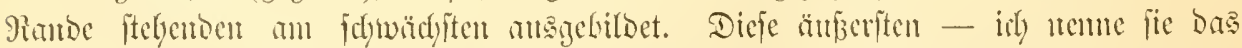

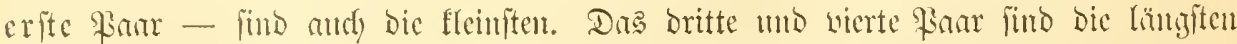
utb unter bicfen wieber bas britte, weldyes cine Ränge won $0,27 \mathrm{~mm}$ crrectfyt. Die

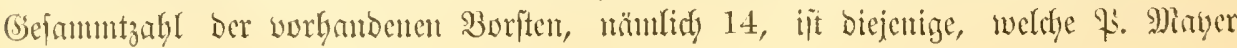

*) Jut gitg. 44 fino fie wegen igrer gropen Bartheit midyt mitgejeichnet. 


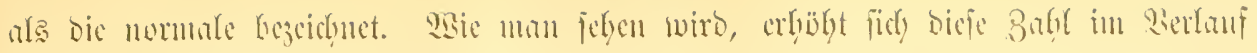
Der Inciteren Entwidelum nod) แแn 2.

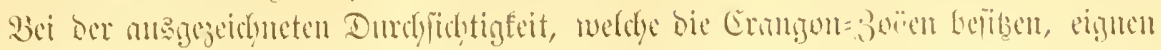

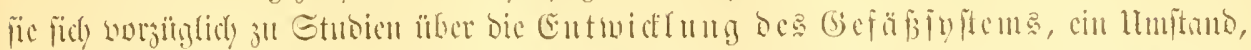

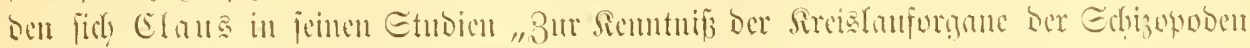

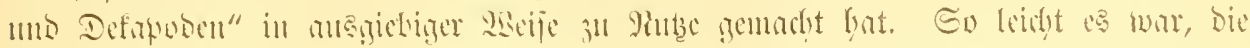

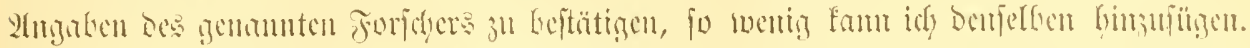

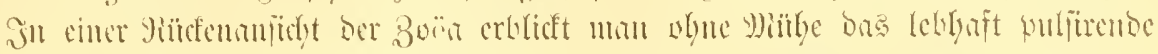

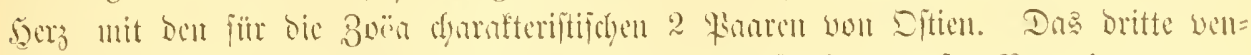

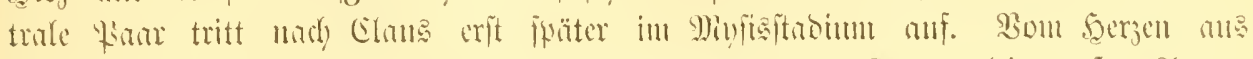

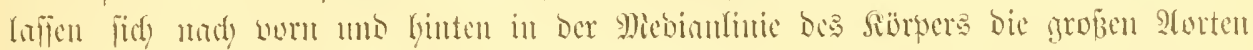

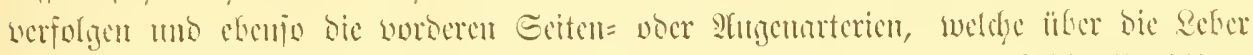

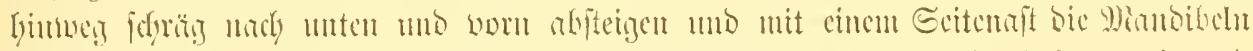

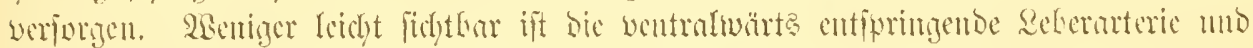

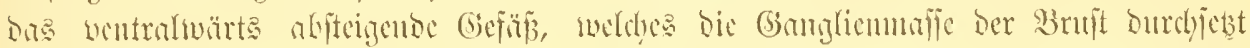

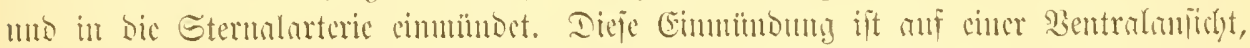

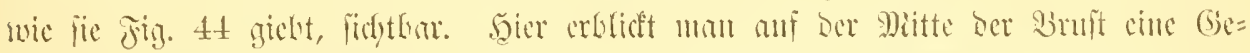

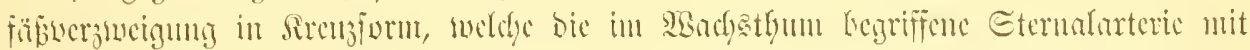

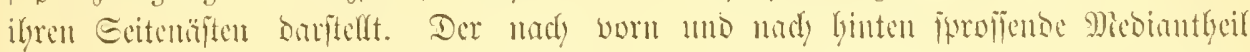

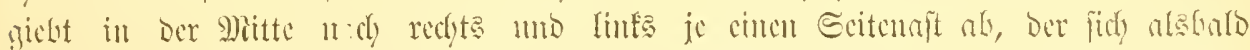

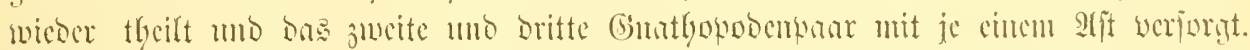

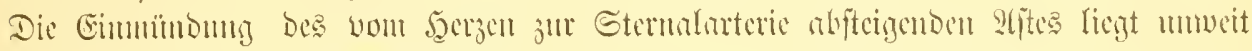

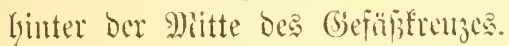

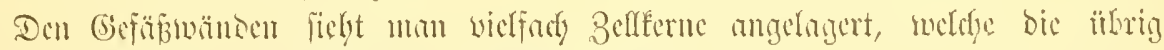

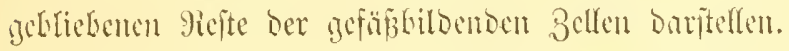

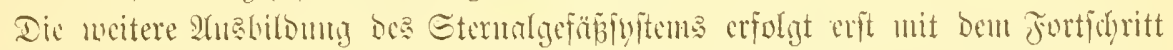

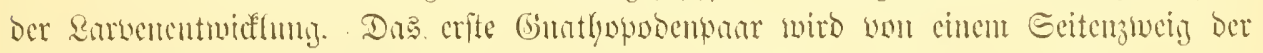

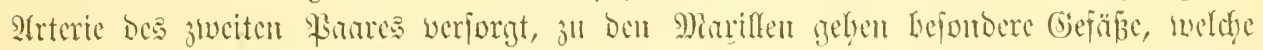

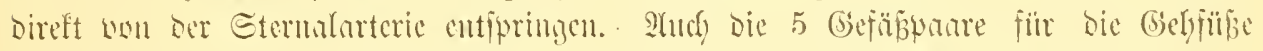

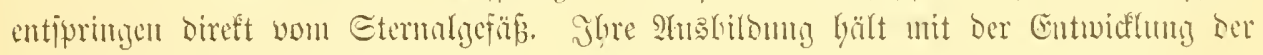

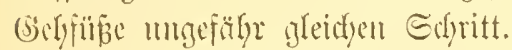

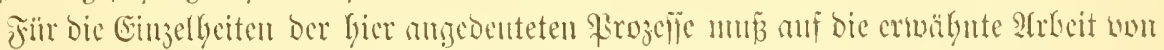

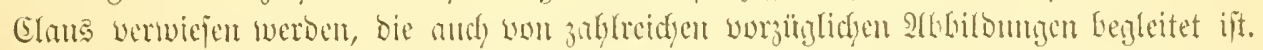

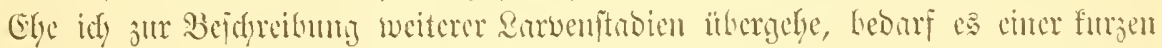
3cunctung barïter, in meldyer SBeife dic cinjelnen Etabien getwonnen mo gegen

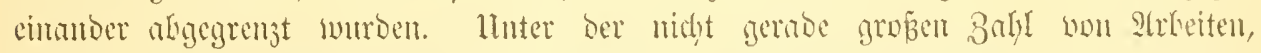

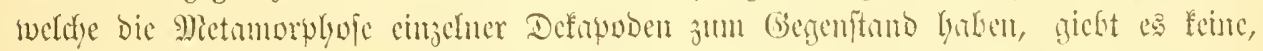

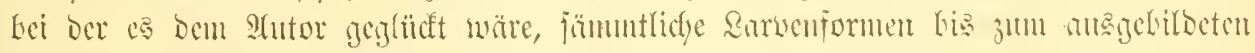

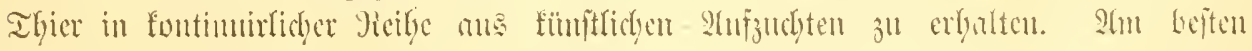

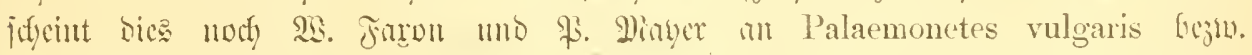

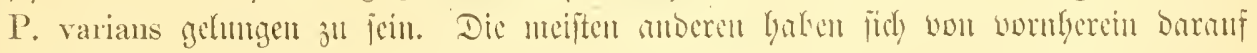

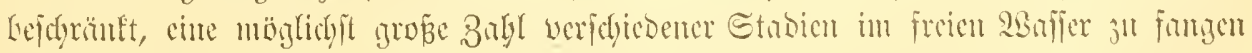

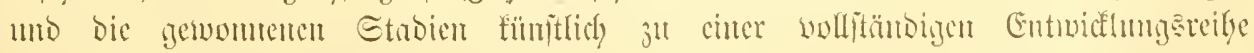

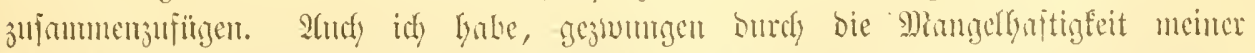

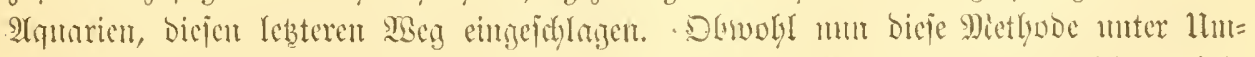

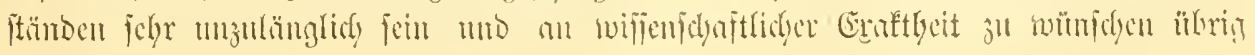




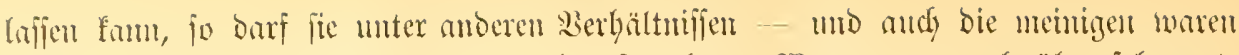

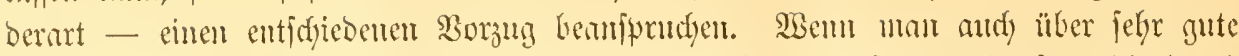

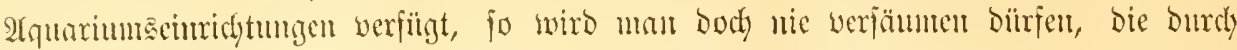

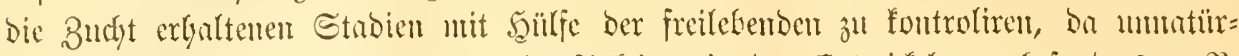

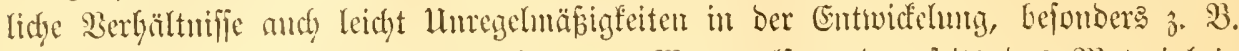

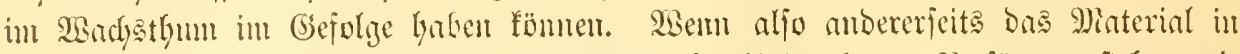

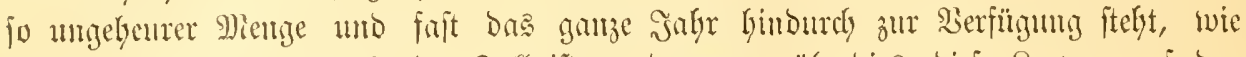
Das bei Crangon vulgaris ber Fall ift, und welun ittherbies bieje Rarvelt auf Dell

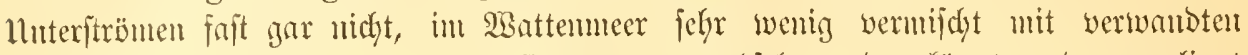
Sarvenformen auftreten, mit Denen fie etwa verwedffelt werben fönuten, onm getingt

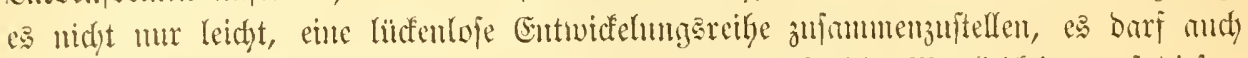

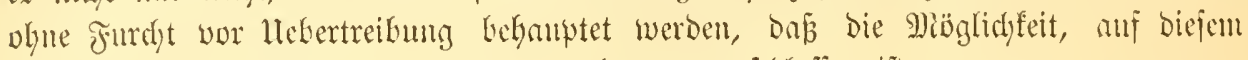

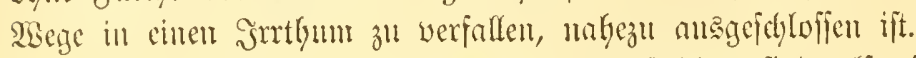

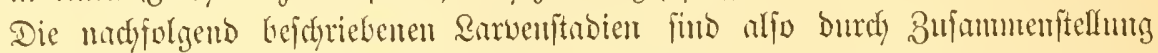

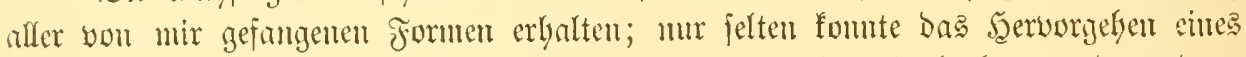

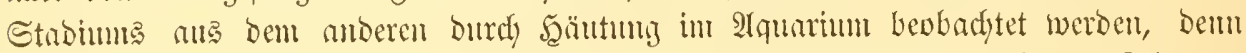

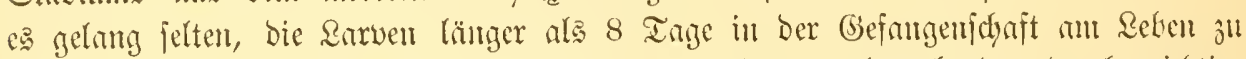

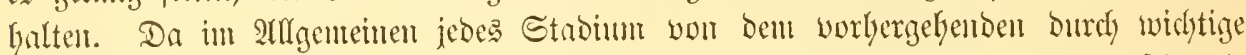

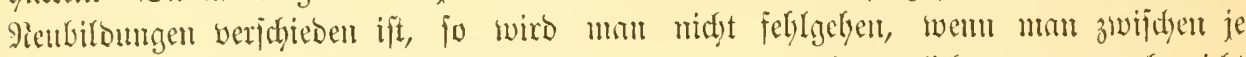

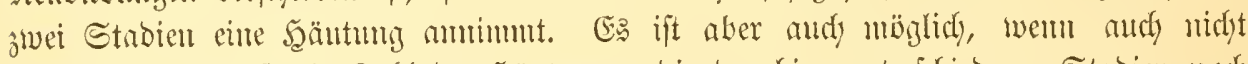

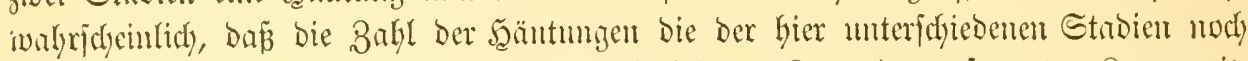

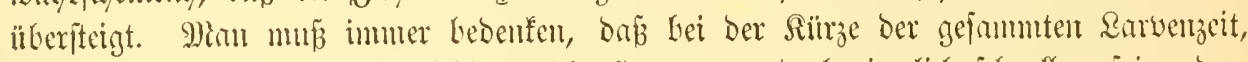

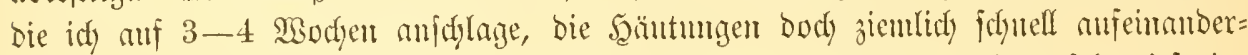

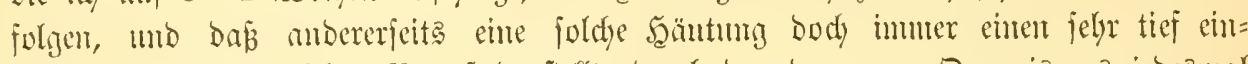

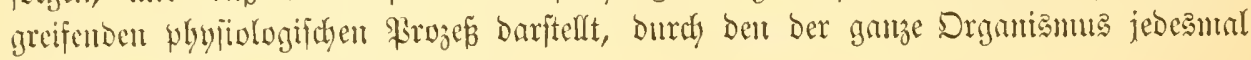
einen empfintolictyen Stóp erteibet.

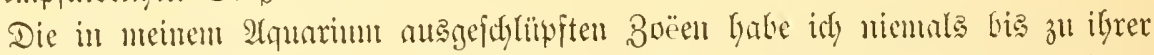

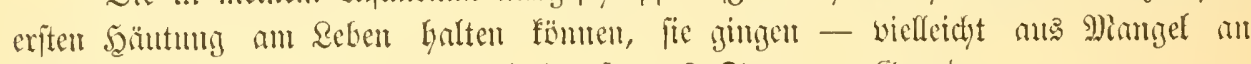

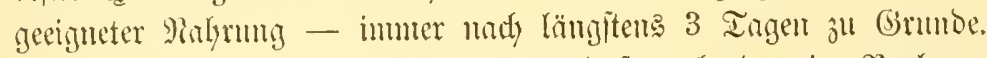

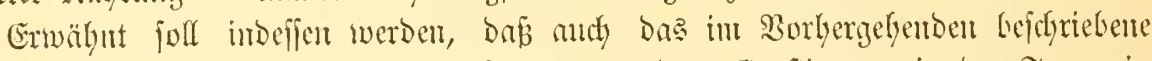
erfte Zoënftabium im freicu \$safier gefangen wurbe. Es ftimunte in ber Form in

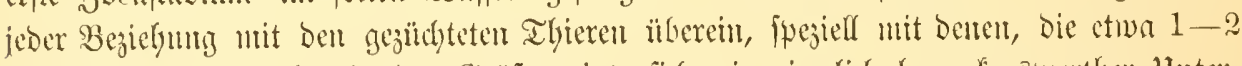

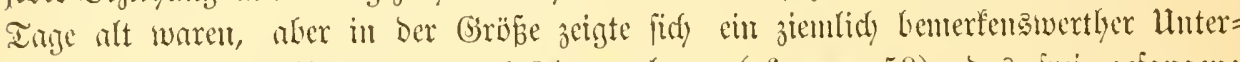
fafico. Das Buthttgier mar unr 1,84 mm lang (cf. pag. 59), Das frei gefangene

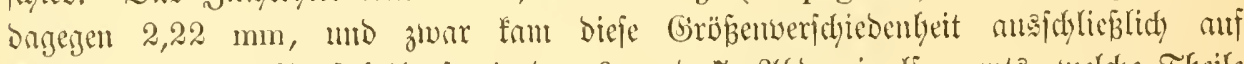

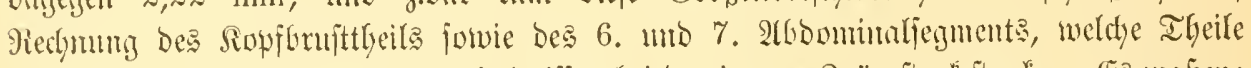

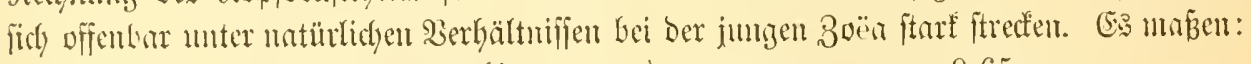
ant bem Aquarimmsthier frei gefangenten Thier

bณร 6.41110 Der Ropforufttgeil $0,65 \mathrm{~mm}$ 0,82 $0,56 \mathrm{~mm}$. 0,73

\section{Zweite $\mathfrak{E} \mathfrak{a r u c u | t a d i u m . ~}$}

Die befter Renuzeiden ses 2. Saruentadiums find bas neue

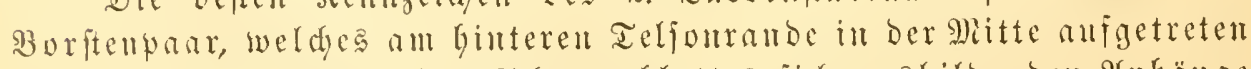

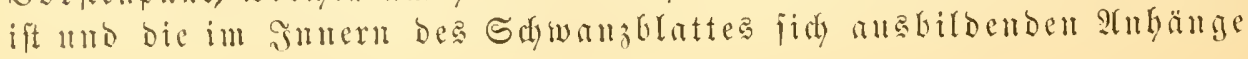




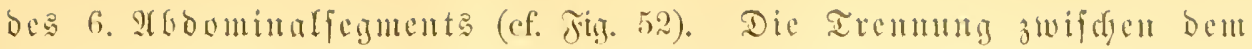

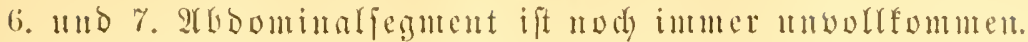

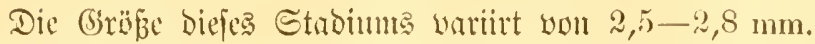

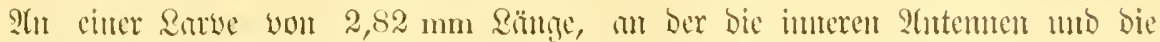

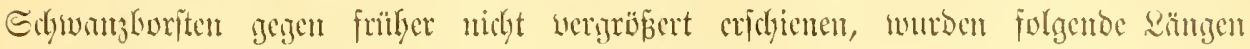
gemtejest:

Sopfrmittbeil bis jur Etimlunupibe. . . . . . . . . . . 0,98 mm 1.- - 4. Ifbominulfegment

5.

6. 11. 7.

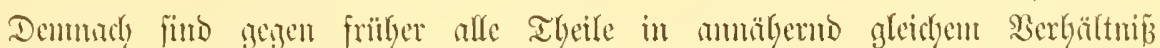
vergrïß̈ert.

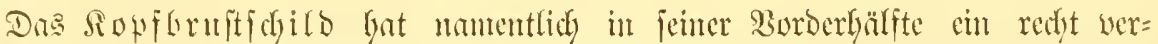

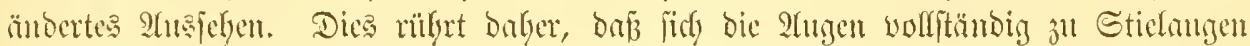

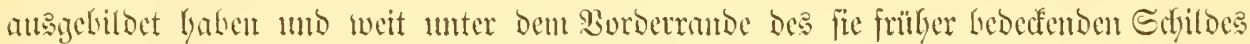

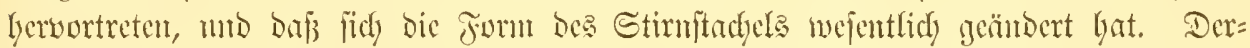

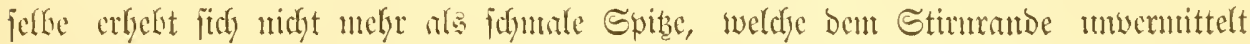
anfïbt (cf. Fig. 49), fonbern er ftellt jebt cine lägere Spibe Dar mit febr breiter

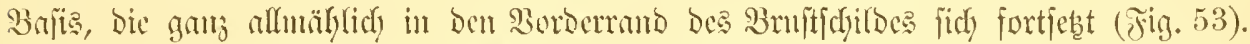

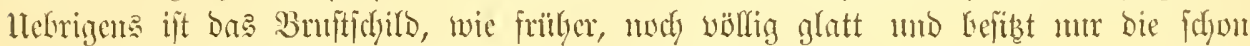

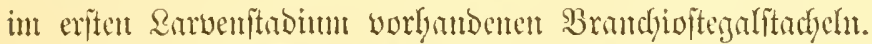

Dns erite Antemenpan ij jeb̧t im Stammtheil eimual gerlicbert, Der

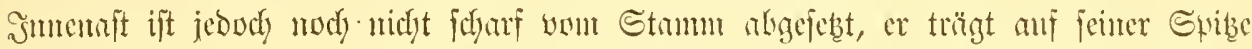

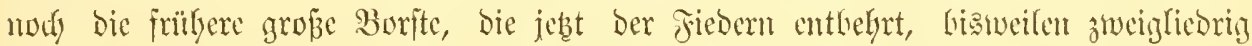

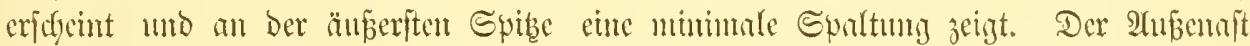

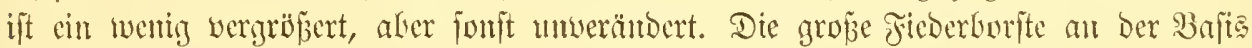

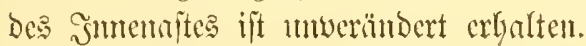

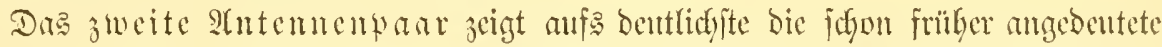

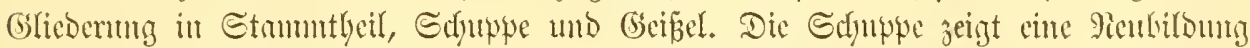
in Gejtalt des friftigen an Der laternlen worberen Sefe anftretenden Dorntes, der biejen

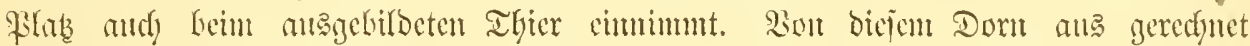

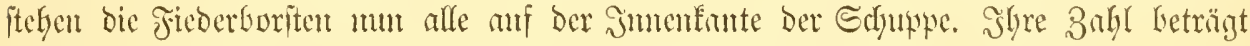
ctwa 9, 3 fleinere an Dor Epibe und 6 größzere weiter nady unten gerüdft.

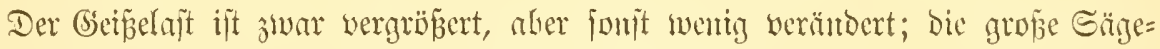
borite an feiner Epibe ift bereits in Sdymben begrifien.

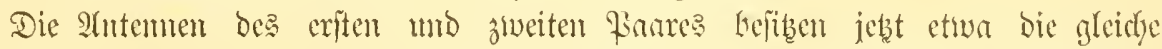

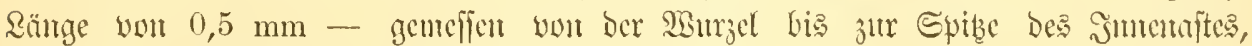
beju. bis zur Epitge der Exyuthe.

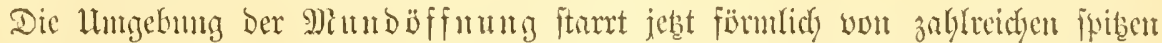

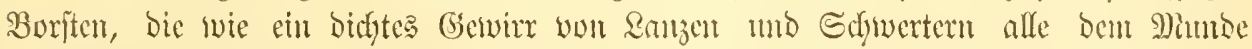
zugefïlyrten Rabrungstbcile zu Brei zu verarbeiten bereit find. Das fund Dic Dornen, Boriten un Ficberboriten, weldye die Mintlen und die endognatgen Pintien Der Rant= fïß̋e fröncu.

Die Mandifeln und Marillen zeigen fidy in Gröbe und Form wenig ver= ämbert. Die 2. Maxilfe bat fidy vou 0,162 anf $0,195 \mathrm{~mm}$ verlämgert; ilyr Scaphognatfit zeigt eine volffommener abgenmbete form und zu ben früferen 


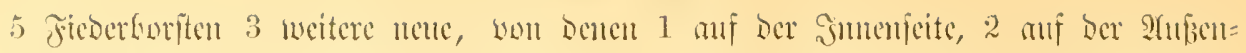
jute fteryen.

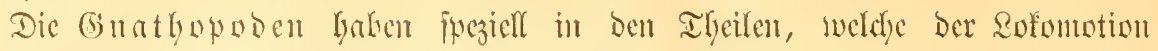

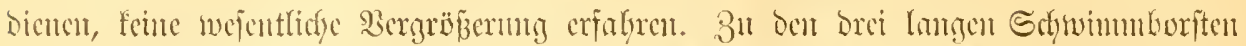

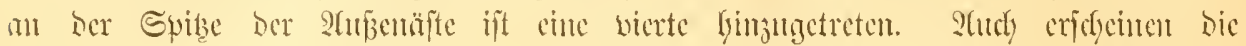

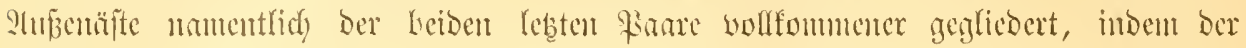

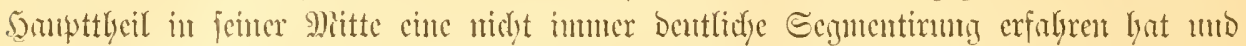

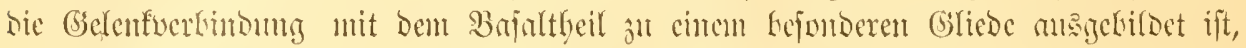

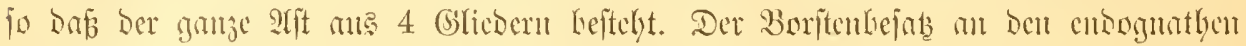

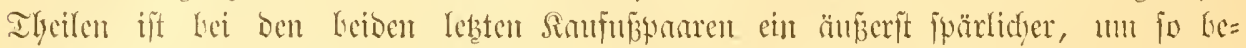

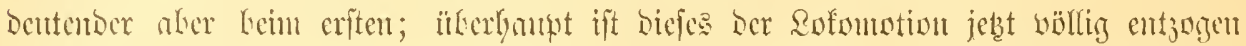

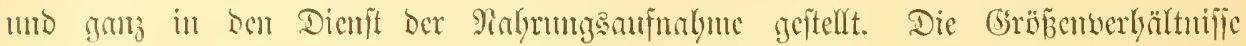

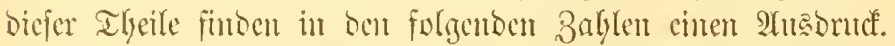

\begin{tabular}{|c|c|c|c|c|}
\hline $\mathrm{m}$ & $\begin{array}{l}\text { Bafaltbeil } \\
0,14\end{array}$ & $\begin{array}{l}\text { Smlenajt } \\
0,12\end{array}$ & 24uรenaft & $\begin{array}{l}\text { längite Schwwinmulbrite } \\
0,33 \mathrm{~mm}\end{array}$ \\
\hline $\mathrm{n}$ & 0,15 & 0,22 & 0,35 & $0,44=$ \\
\hline${ }_{1}$ & 0,10 & 0,35 & 0,35 & $0,45=$ \\
\hline
\end{tabular}

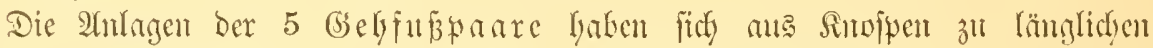

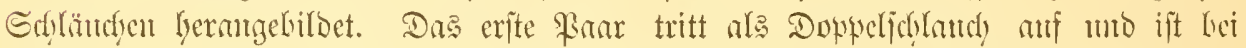

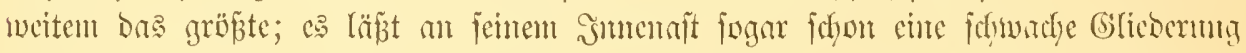

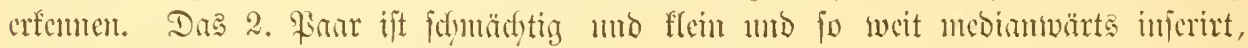

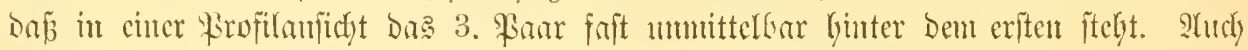

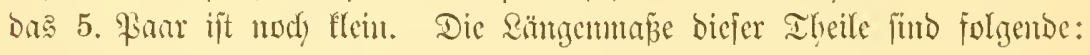

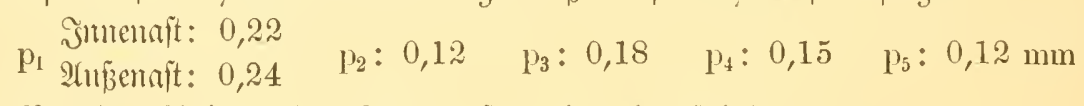

Mon Den SAlntagen ber Rienten ift nody nidyte fidytur.

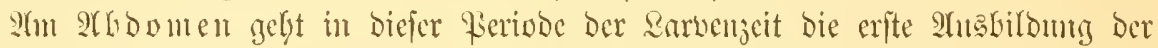

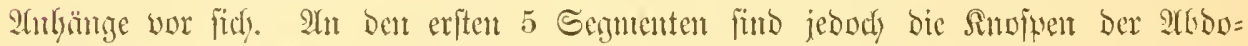

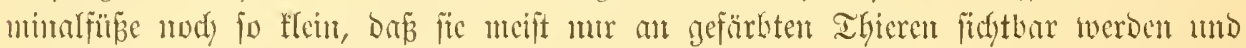

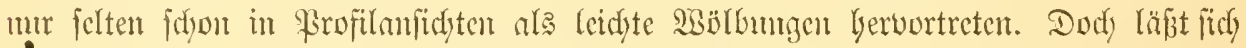

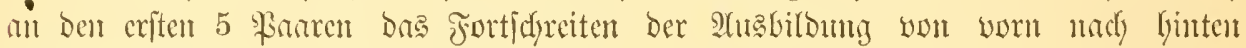

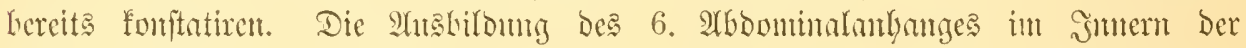

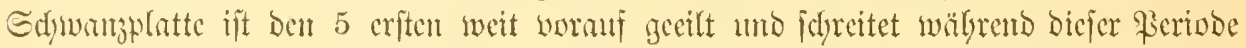

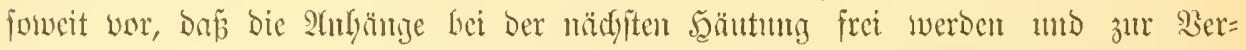

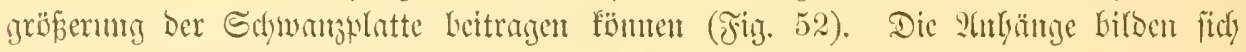

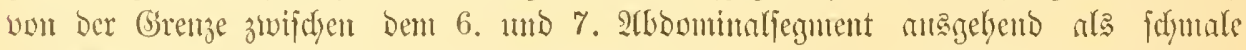

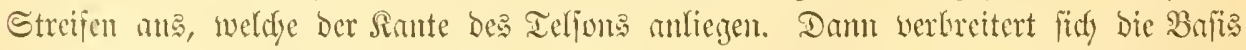

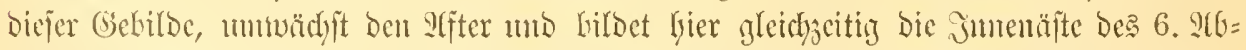

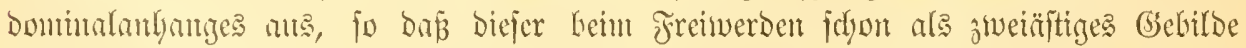

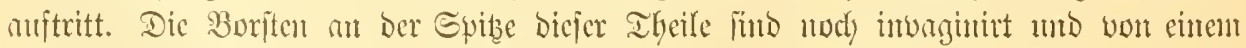

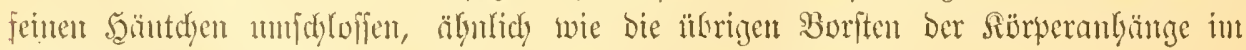

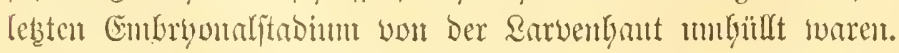

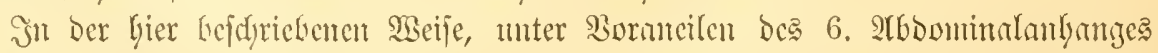

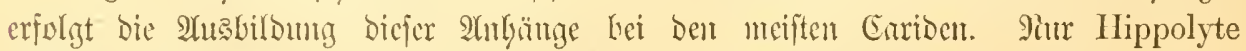

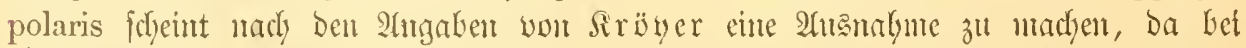

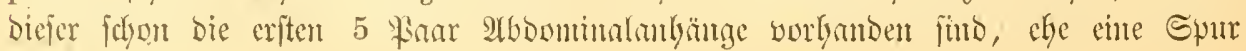




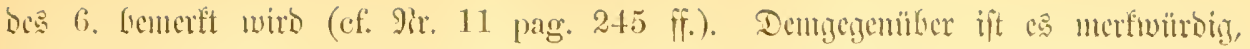

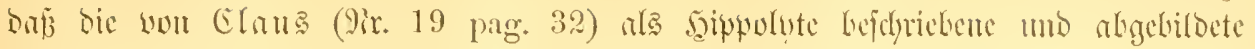

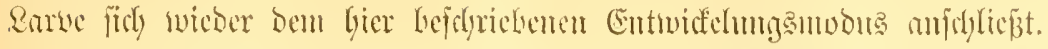

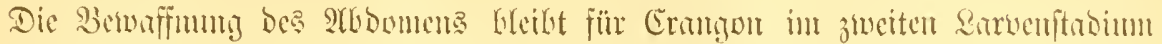

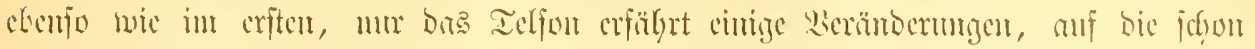

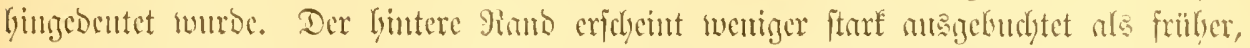

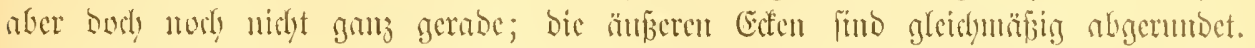

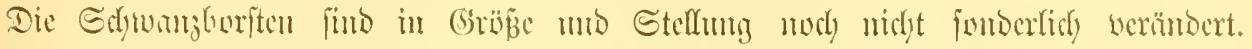

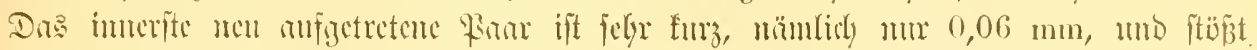

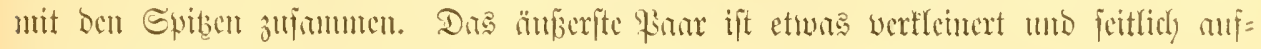
gerïltt (Jig. 52).

\section{Drittes Rarvenjtabium.}

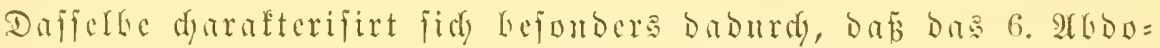

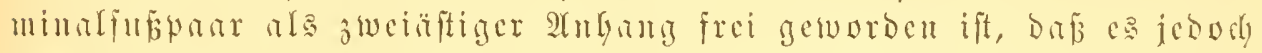

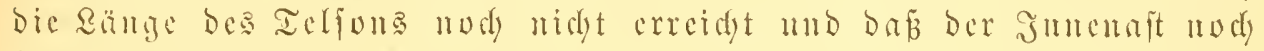
beimabe แn cin Drittel fürzer ift alz ber alubeuaft ub der Borften bis auf 2 ober 3 jelyr fleiue nody cutbelyt.

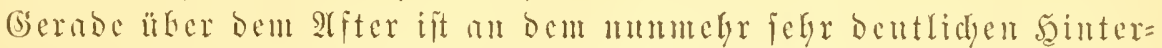

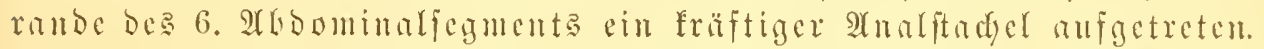

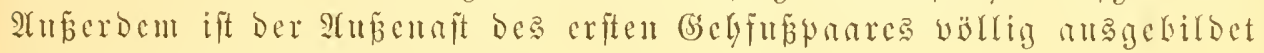
mub fungirt als $S_{d}$ wimmaft.

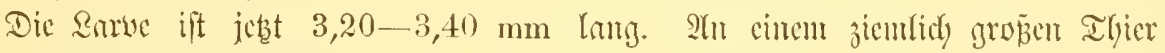
wurben folgende Dimenfiomen gefunden:

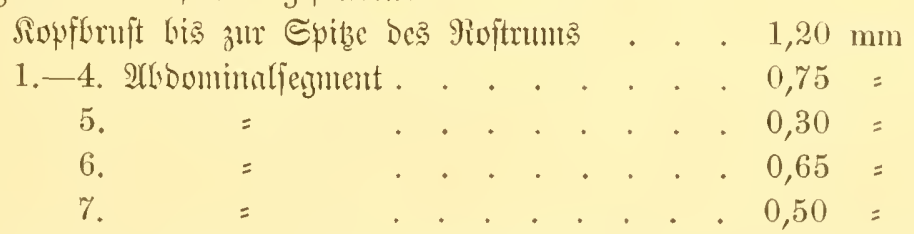

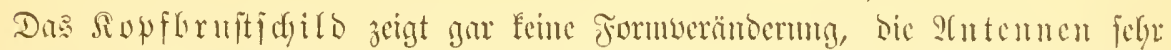

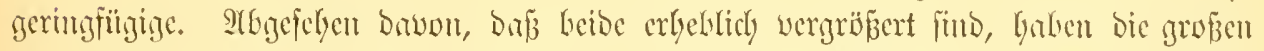

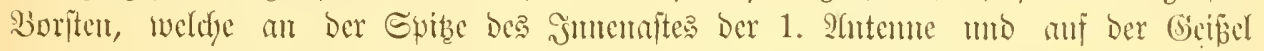

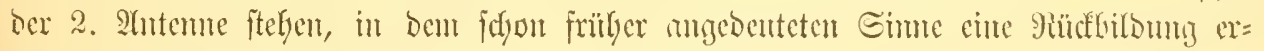

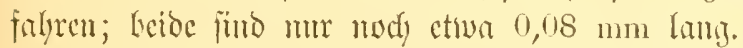

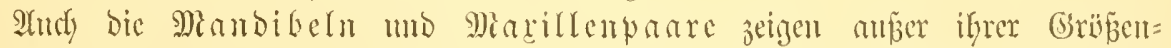

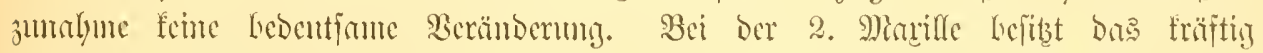

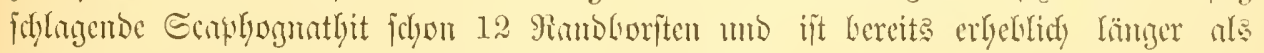
Der enbognatlge Theil, oer ülnigens umberïnbert ift.

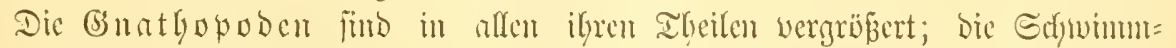

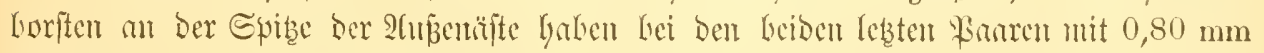

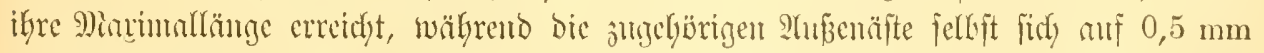

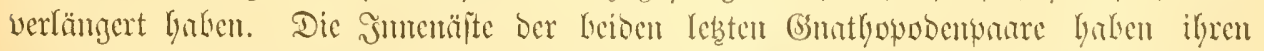

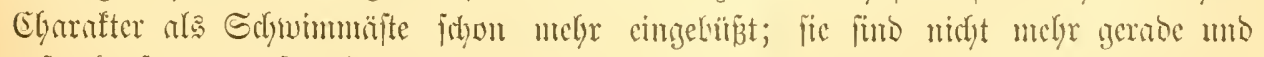
geftreft, fondent oftmals fdyou leidyt mady immen gefrümunt.

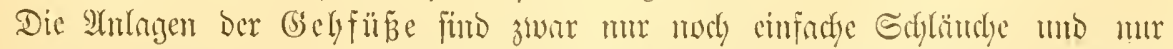

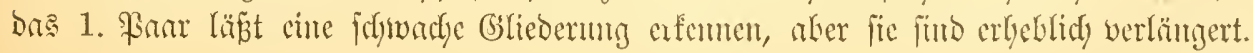




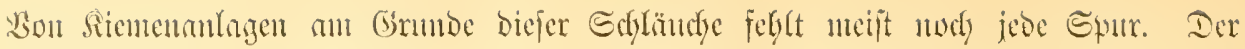

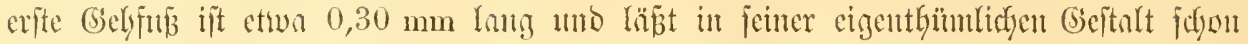

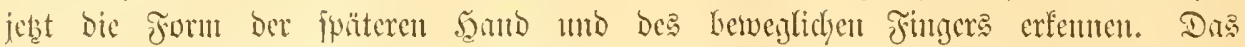

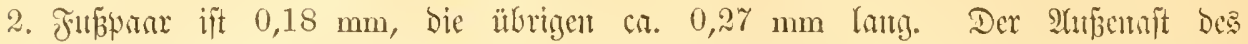

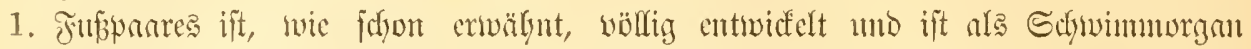
tbätig. Er ift ebenfo wie bie itbrigen Edywimmtäfte folyräg mady oben gejd)hgen, fo

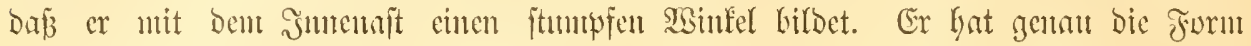
Der unbrigen Edywummä̈ite, ift jebod) erit $0,33 \mathrm{~mm}$ lang. Seinc Spibe ijt won

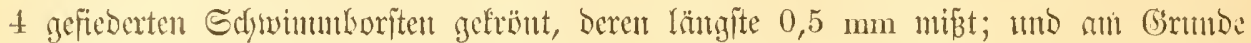

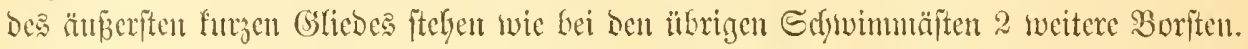

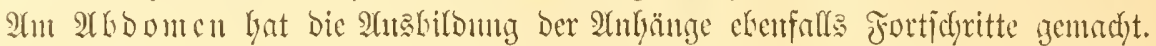

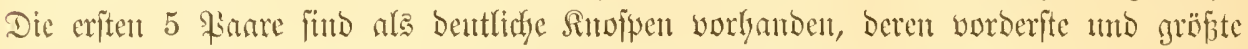

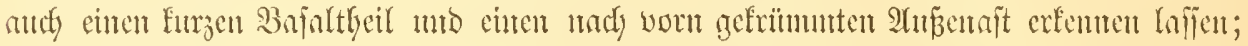

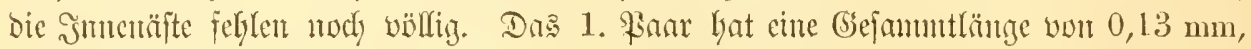

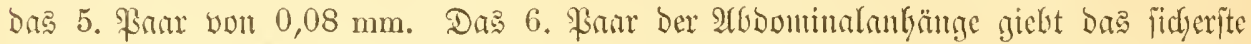

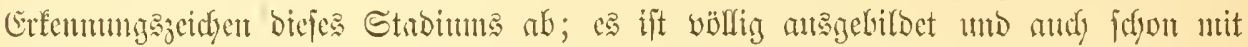

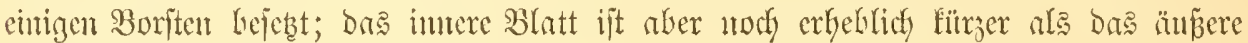

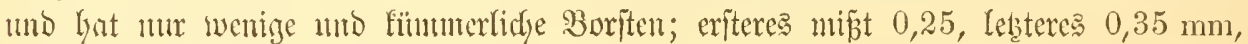
Der gemeinf(jaftlidye 3 bafaltyeil $0,10 \mathrm{~mm}$.

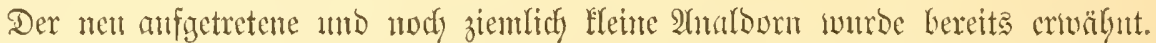

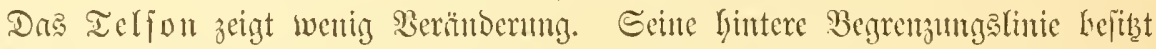

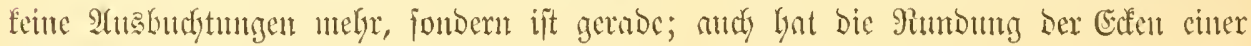

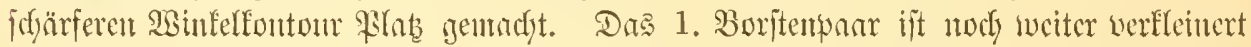

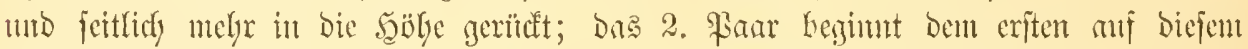

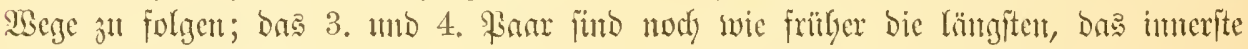
8. Fian bie fürzelten.

Das britte Rarbenftabiun verbient wegen ber fier in Funftion tretenden

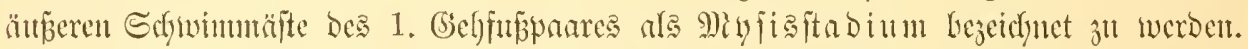

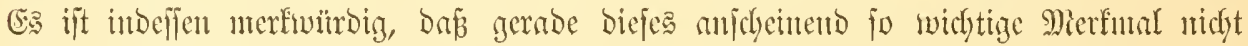

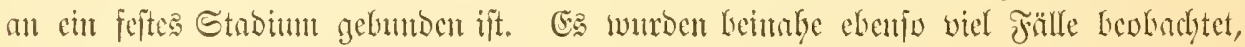

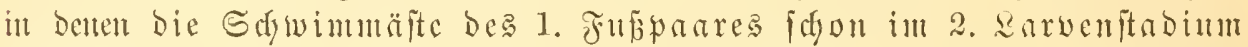

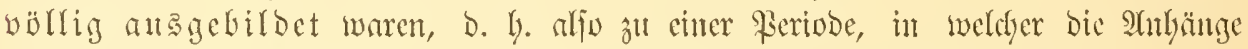

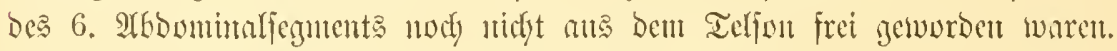

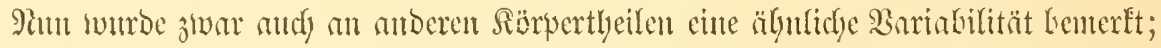

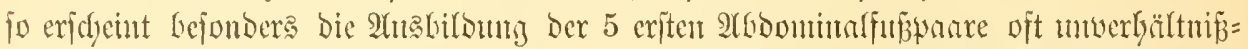

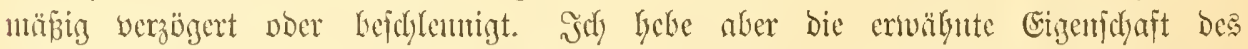

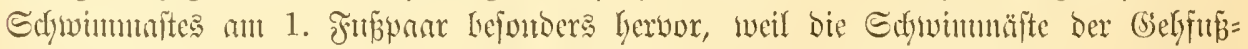

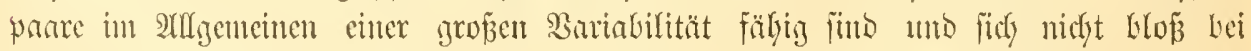

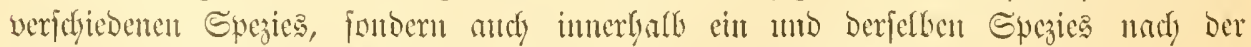

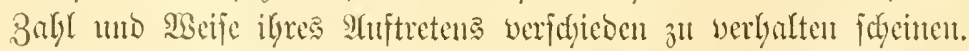

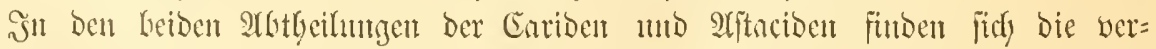

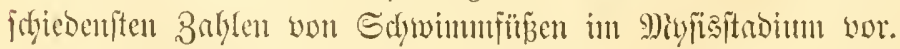

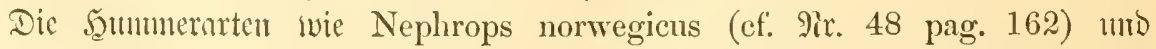

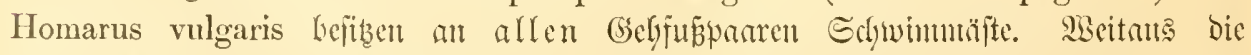

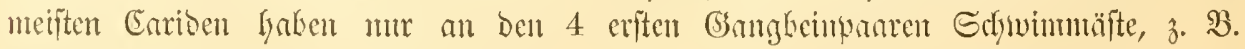
Palaemonetes vulgaris Stimpson (9ir. 41 pag. 317), Caridina Desmarestii ( $\Re$ r. 12 
pag. 71), Ilippolyte sp. (9r. 19 pag. 37) แ. a. Wui Gebia littoralis lisso Gat

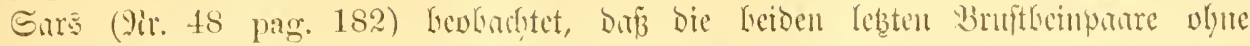

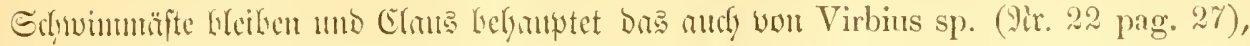

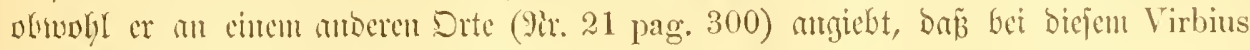

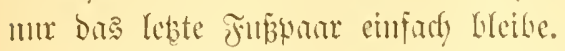

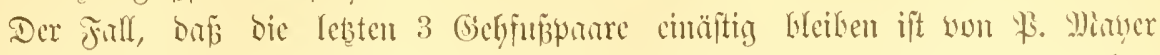

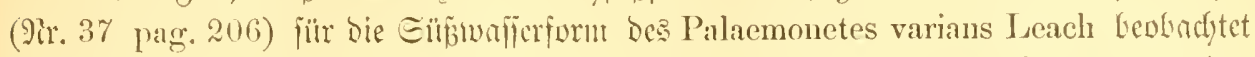

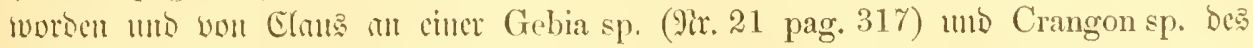

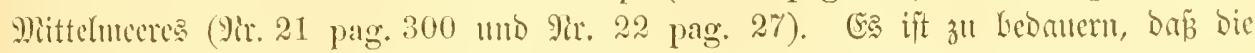

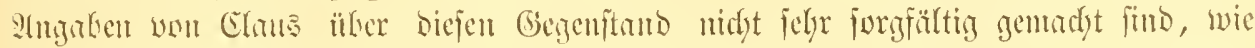

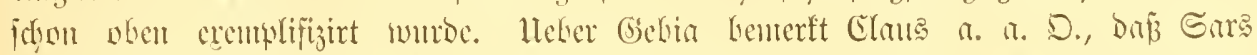

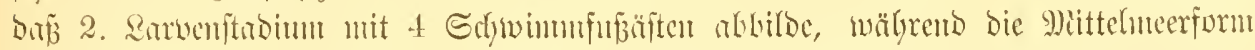

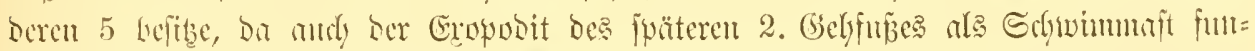

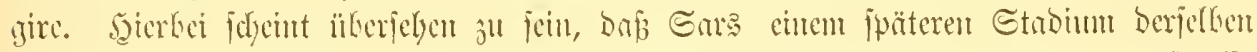

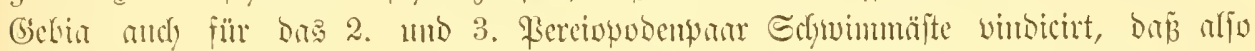

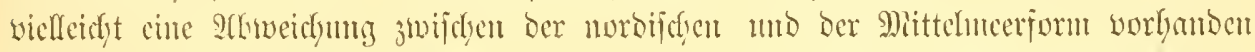

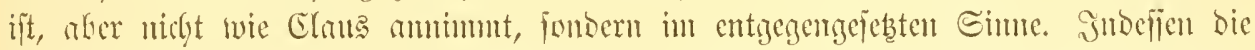

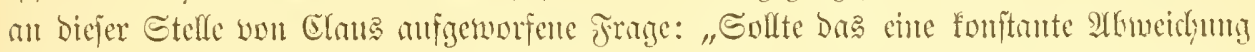

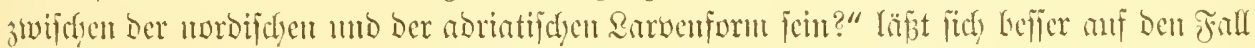

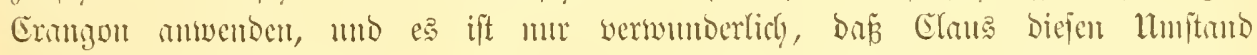

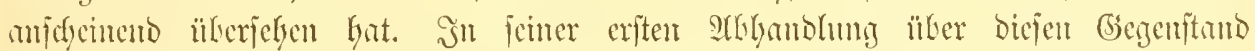

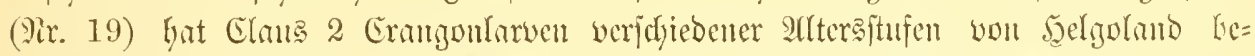

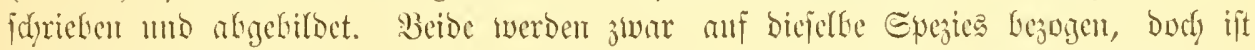

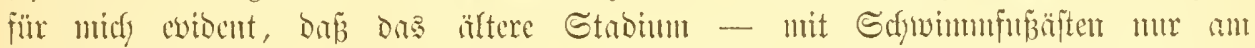

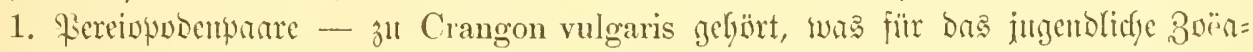

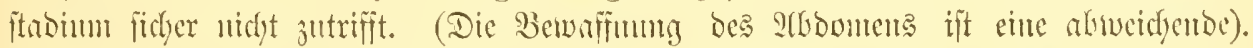

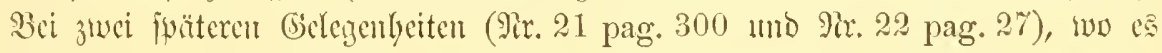

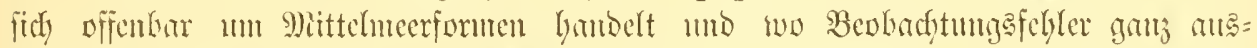

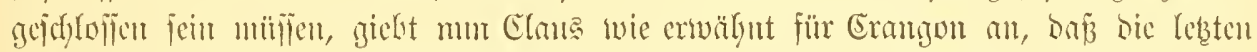

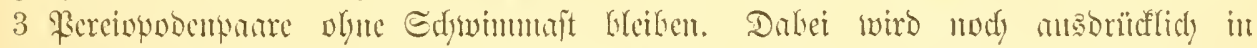

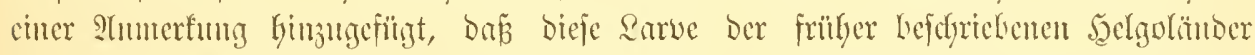

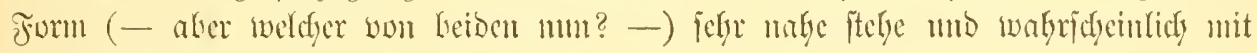
ifr zul derjelben Gjejies geböre.

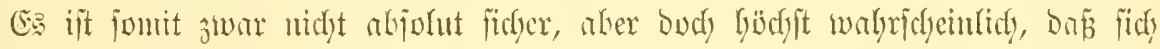

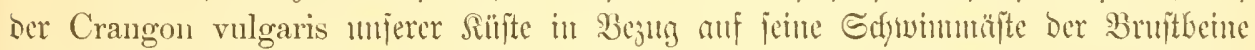

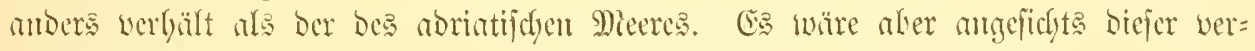

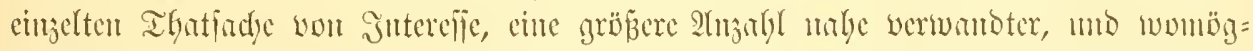

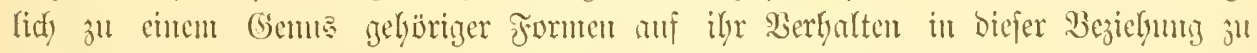
unterfudyeut.

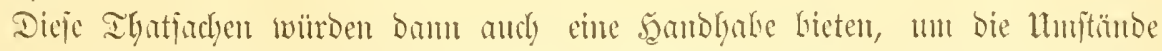

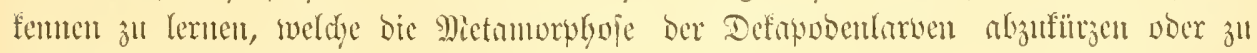
verlängern geeignet fund.

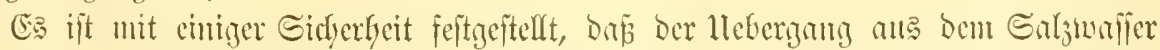

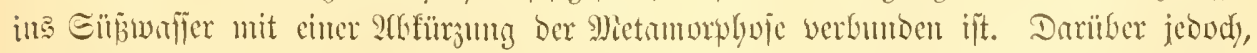

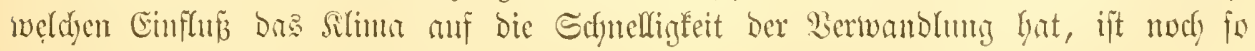
gut wie gar nicfite befinnt. 


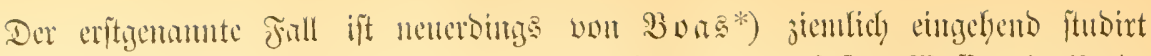
worben an Palaemonetes varians, weldyer in Stalien in rein jïfent \$saffer, in Miorb=

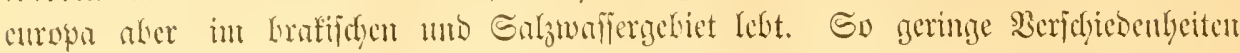

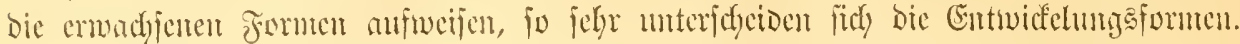

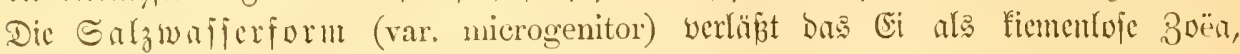

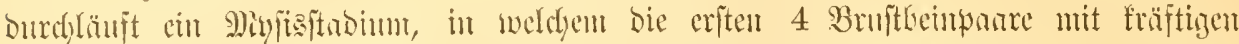

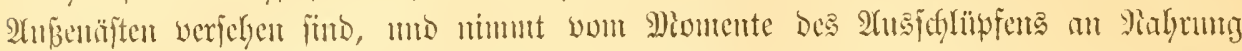

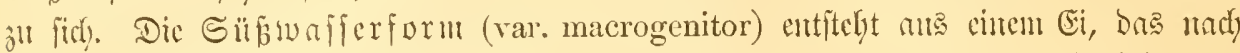

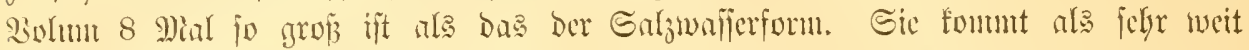

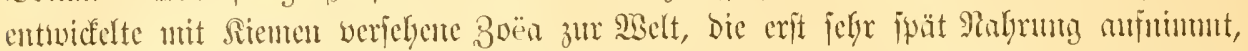

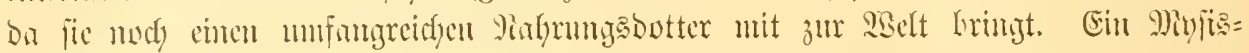

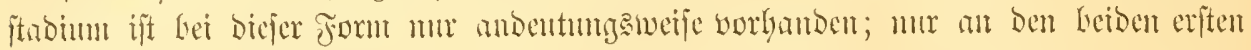

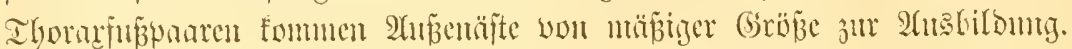

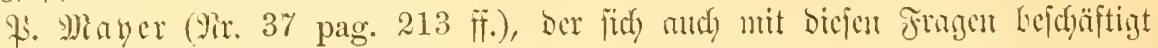

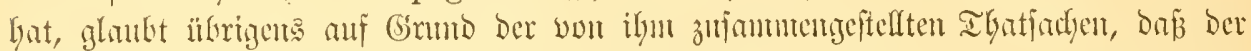

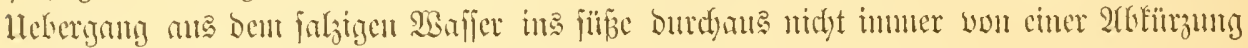

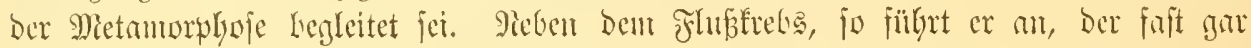

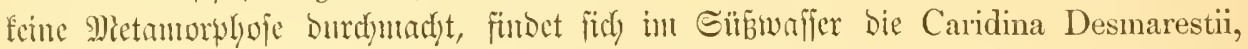

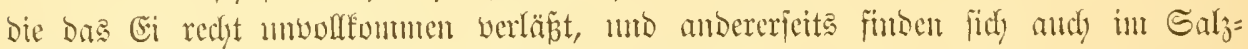
wriffer Formen wie Homarus vulgaris umb Hippolyte polaris, weldye alg jelyr woll=

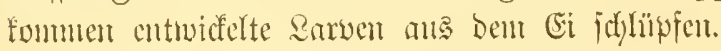

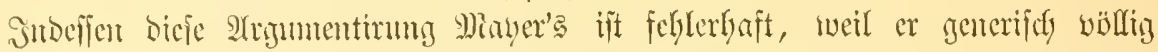

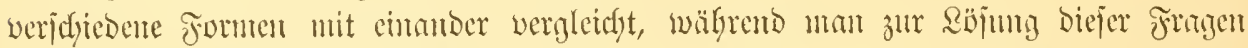

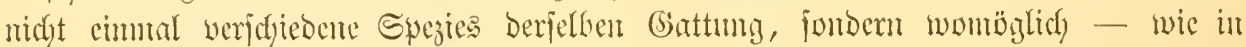

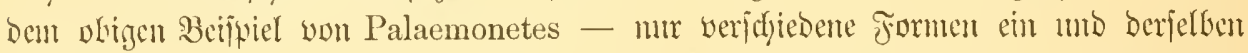

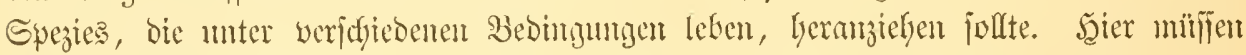

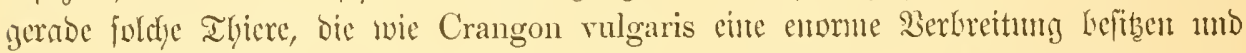

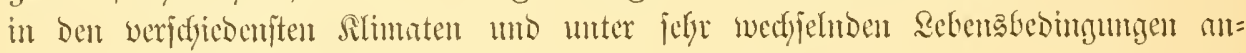

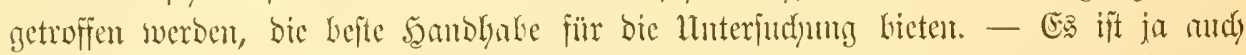

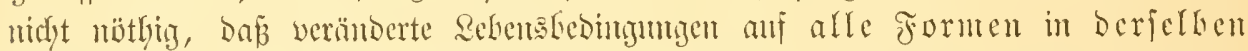

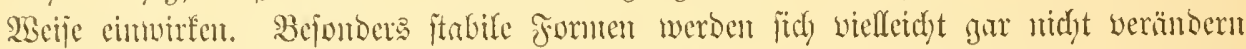
beim Llebergang ins füre

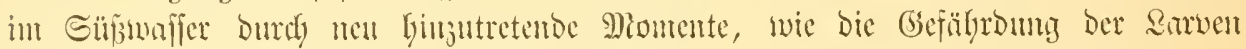

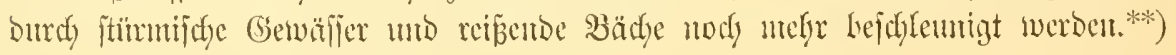

\section{Birertes Larucnitabium.}

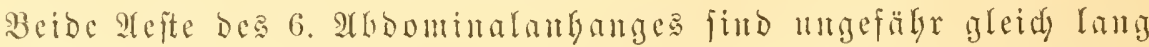
und faum fürjer als bas Teljon; ifre Ginteren un imeren Ränder

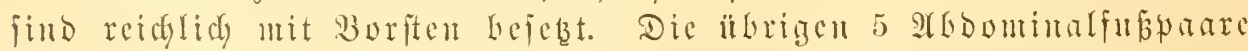
find ergebled verlängert ub zeigen die Anlage igrer jumenäte ala

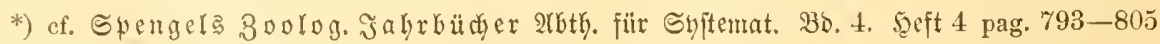
(m. 1. Taf.), Jena, 1889.

**) Bergl, ïber cinen foldjen Fall: Friţ Miüler, Palaemon Potiunna, cin Beijpicl ab= grfürzter "̈erivandung im 300\%. 2(nzeiger III pag. 152 uno 233. 1880. 


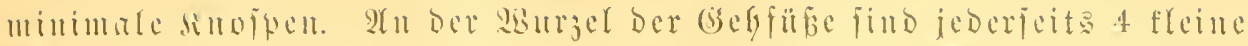

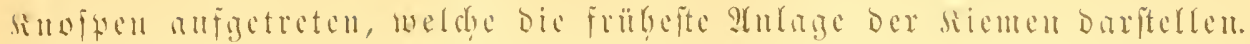

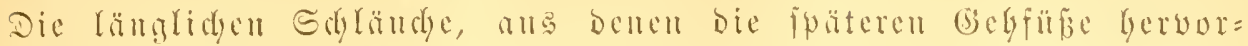

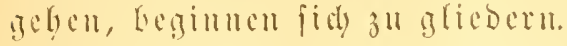

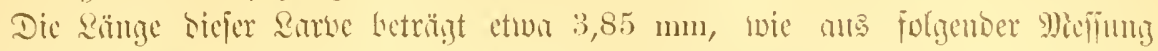
Gerworgelyt:

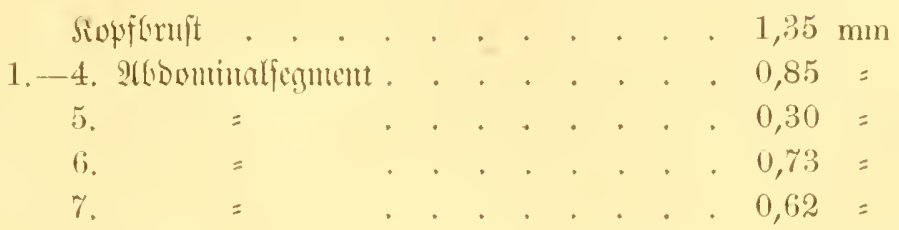

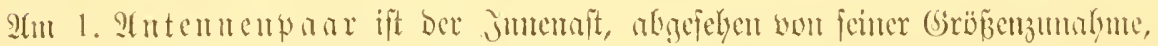

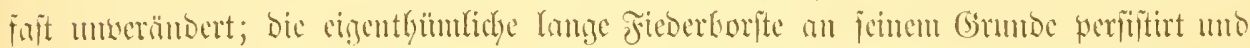

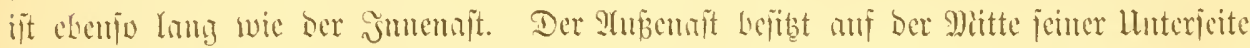

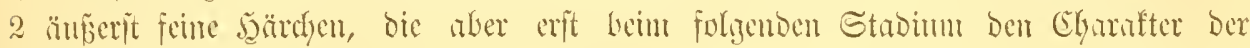
Tited lorften anmelymen.

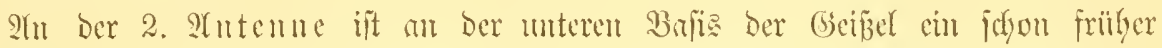

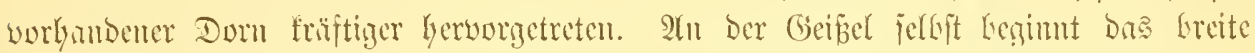

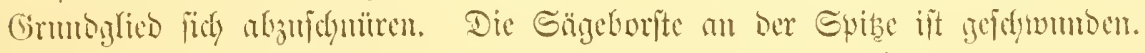

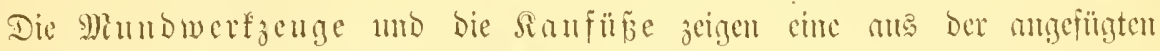

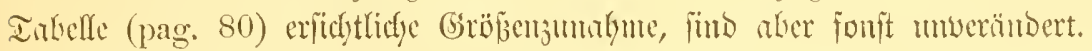

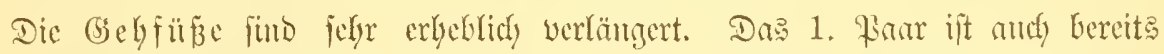
Dentlidy gegliebert mo befibt anf cunem zueigliebrigen Stammtheil neben Dem

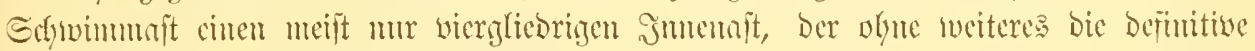

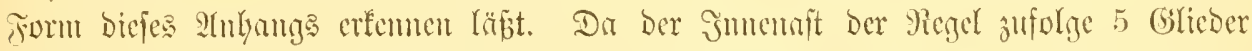

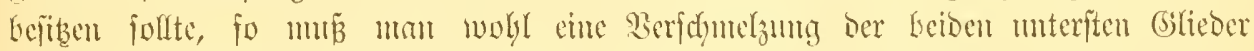
ammefmen, bic jedody nid)t regelner̈fin erfolgt, ba bic Grenge zwifdyen beiben oft ands

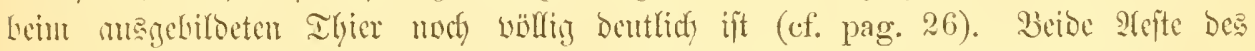

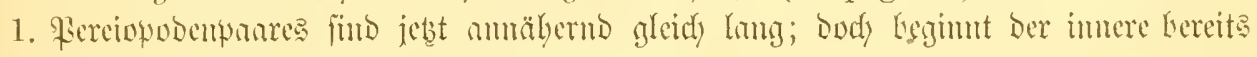
ben Edyvimmat in SBadystym zu riberbolen.

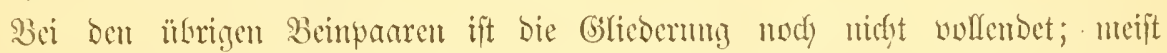
arfennt man mu 2-3 Dentlidye Segmentgrengen. Q4n Ränge fteben fie ben 1. Pinm

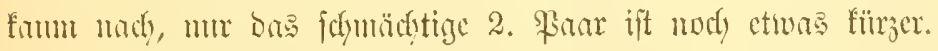

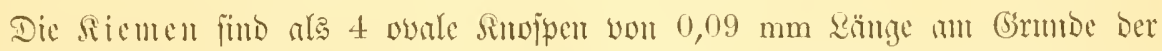

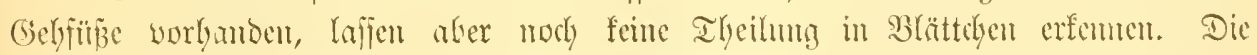

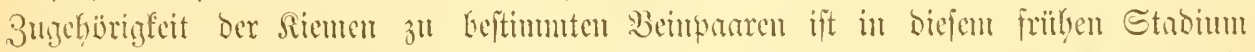
wenjomentị atsjumadyen wie beim am

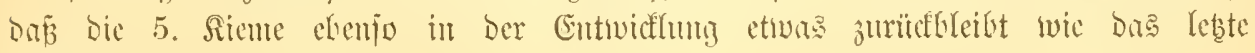
Bruftremparr.

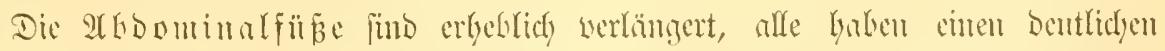

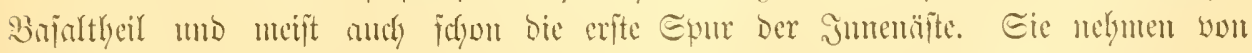

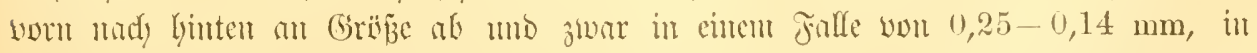

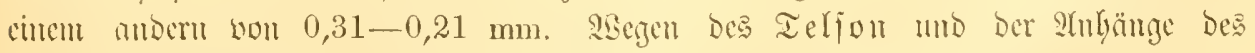

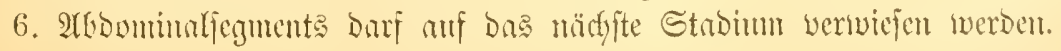




\section{Jüinftes Rarvenitndium (Jig. 53).}

Sinter ben eriten 4 Riementupipen ift bie 5. anfigetreten, weldye an

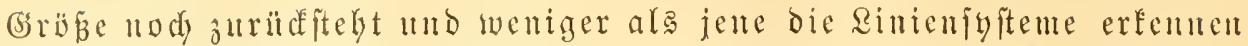

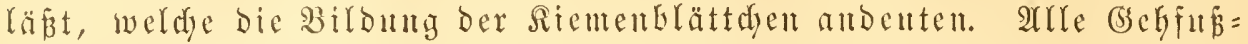
pare find voll entividelt, annäbernd gleidy lang mo wohl gegliebert.

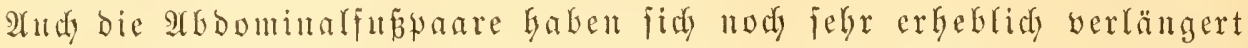

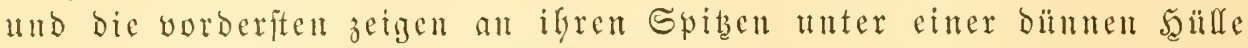
Die nody faft völlig invaginirten Boorten.

Die Fig. 53 giebt mur ciute jdywadye Borftelfung bavon, weldy eint Farben= pradyt Die jumge Rarve jeb̧t zut entfalten verntag. Der ganze Rörser ift ïberjäet mit

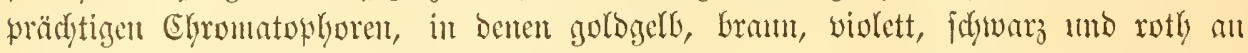

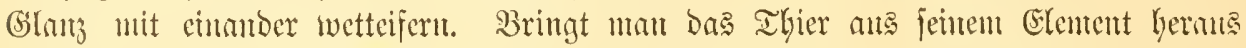

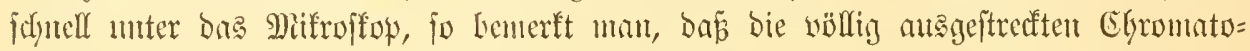
phoren faum ein Flectuen Der Rörweroberflädye frei lafjen. Arber bie Contraftion Der

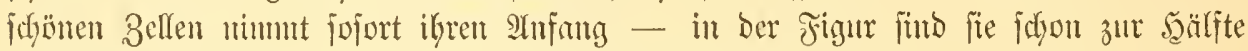

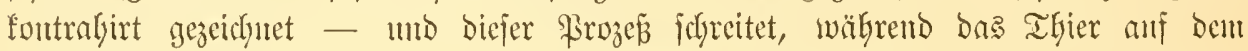
Drjeftträger liegt, foundl fort bis bie meiften Chromatoplyoren fids ju fehr fleinen

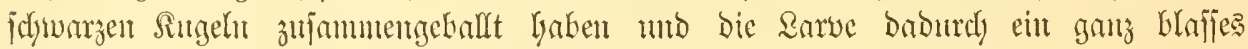
Ansteren getwomen bat.

Die Bewaffmug ber Sïrperoberfläd)e mit Dornen ift nody bicjelbe wie frillyer.

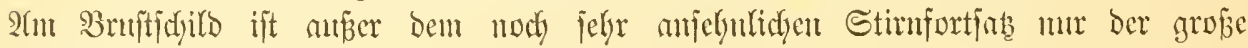

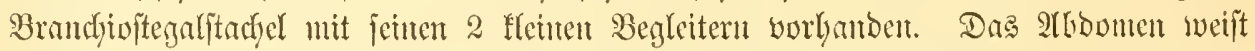

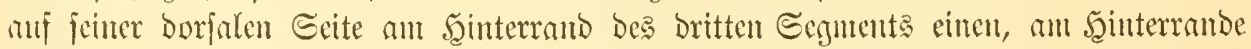

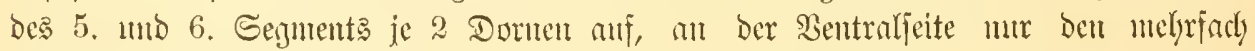

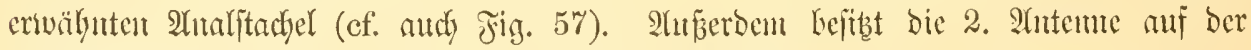
Ituterfeite an ber Spibe ibres Stanmutgeils eimen Dorn.

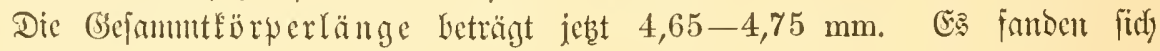
Die Räıgeı

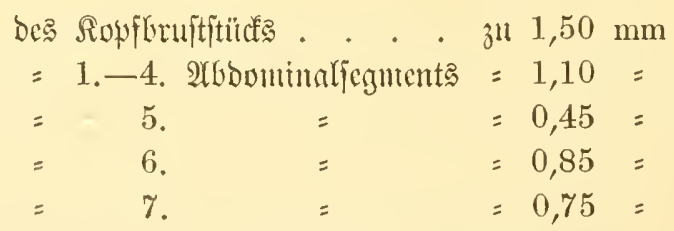

Dab 1. Antennenpara bat eine Gejanmtlänge won $1 \mathrm{~mm}$ erreidyt. 24u

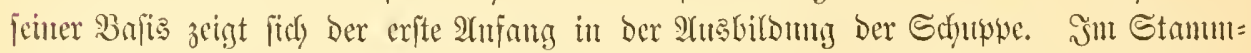

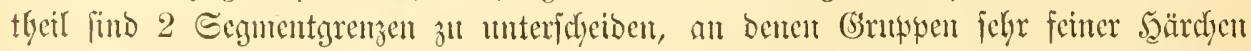
anftreten. Der Sonnenaft ift nody iumer nidyt gegen ben Stanum abgejdynürt uno

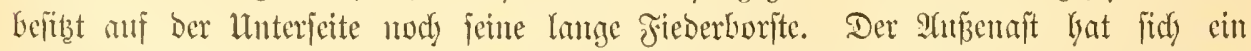

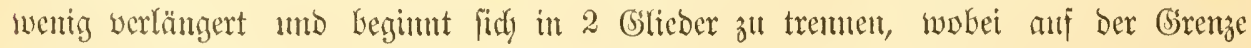

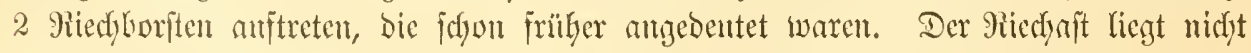

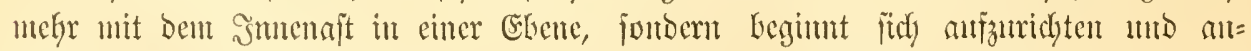

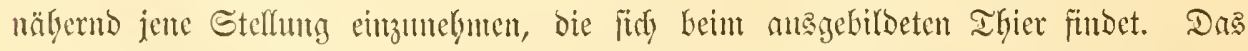

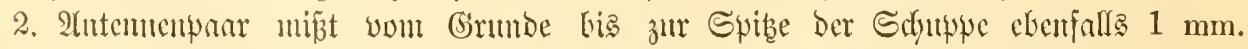

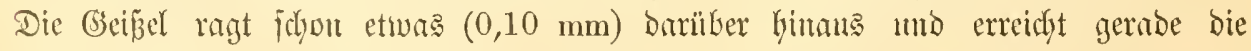

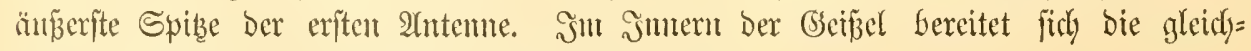
jeitige Alubbildung felyr zahlreidyer Segmuente bor. 


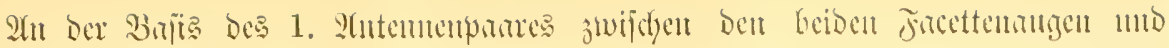

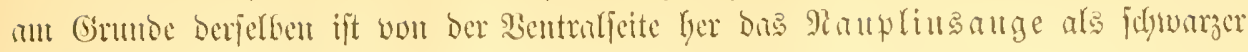

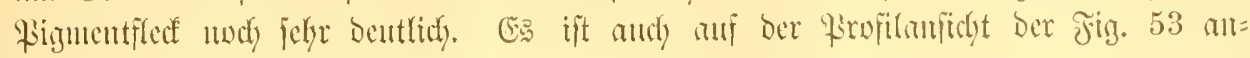
gebeutet.

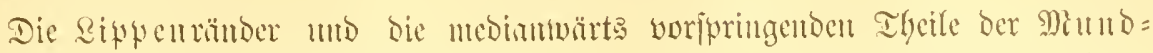

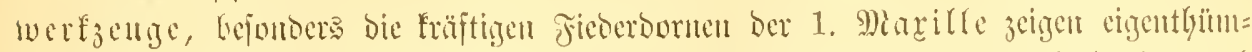

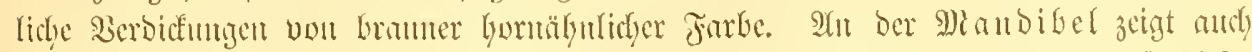

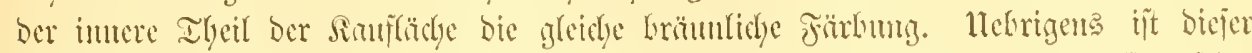

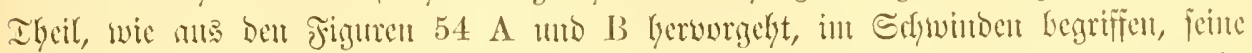

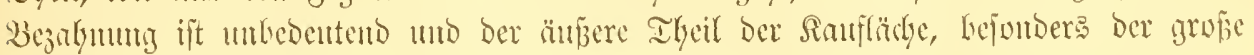

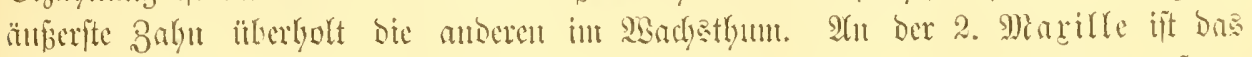

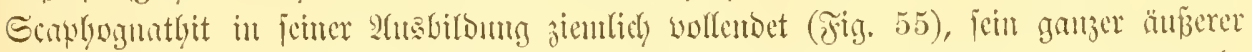

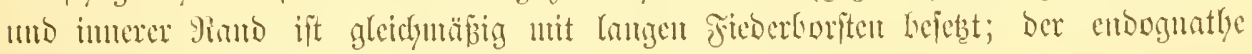
Theil ijt umberintocet.

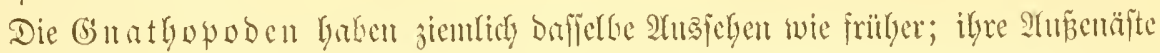

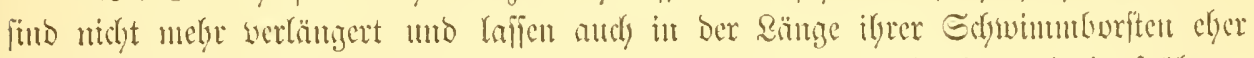

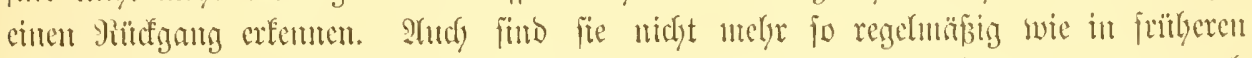

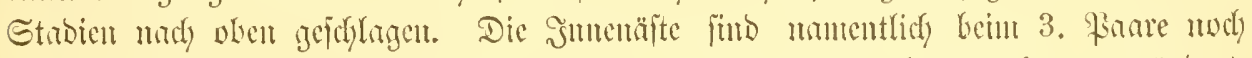

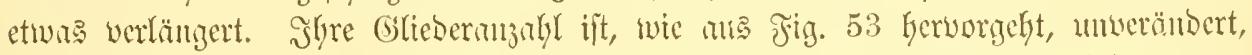

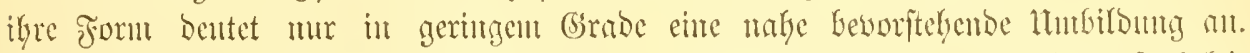

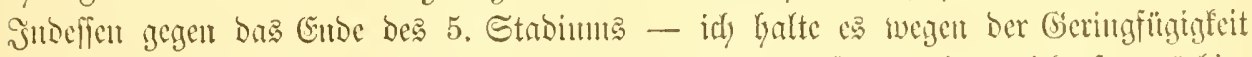

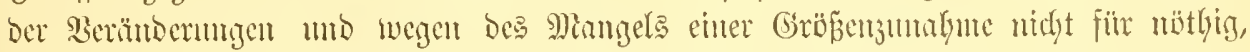

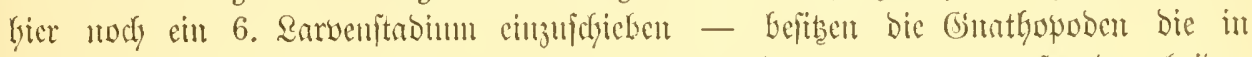

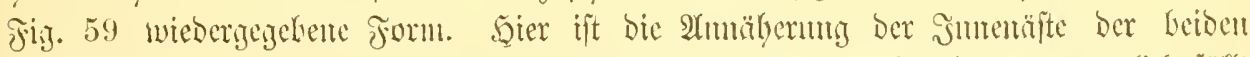

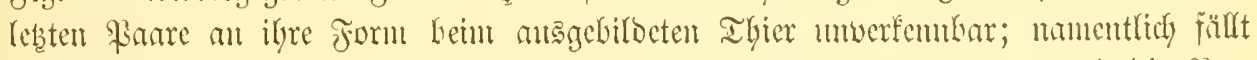

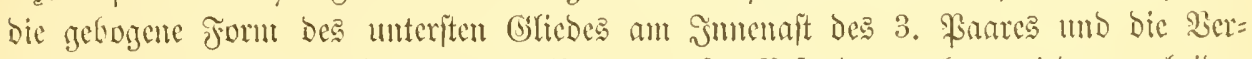

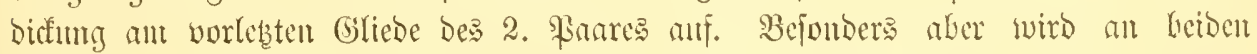

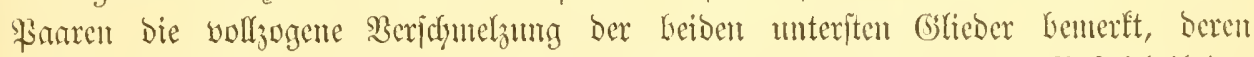

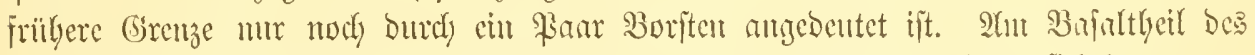

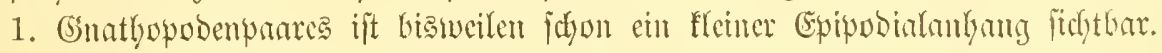

Die Gebfubpare find jebt alle wobl entwicfelt umb ctwa $0,85 \mathrm{~mm}$ lang.

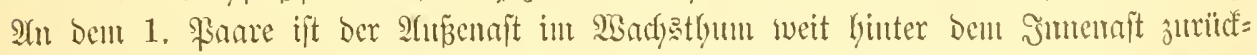
geblieben. Der lebtere befibt bereits ein beweglictyes Fingerglico, mo der flemert unbeweglidye Dormartige Finger ant immeren Rambe bes Gsliebes ift unter ber Chitiu=

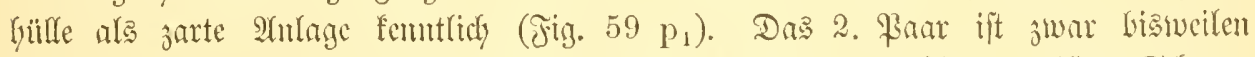

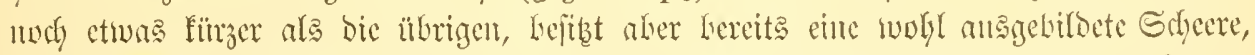
Deren Lemeglidyer Theil ebenjo wie ant 1. Panre von einer bereingelten Borite ge= fröıt ijt.

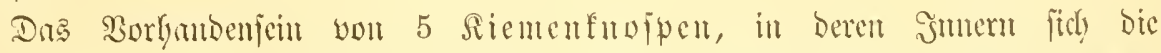

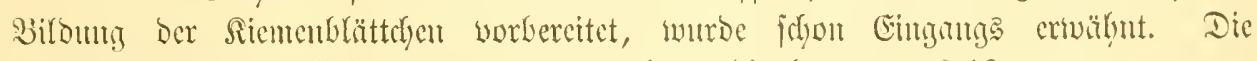
4 worderen Snopen find $0,18-0,22 \mathrm{~mm}$ lant, die lebete 4 tr $0,12 \mathrm{~mm}$.

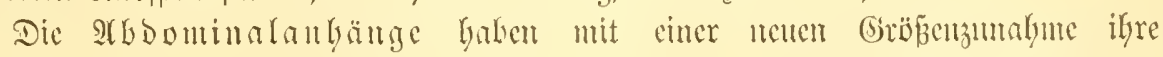

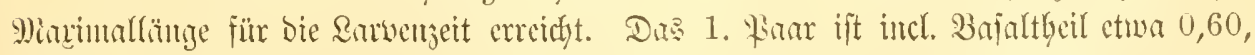

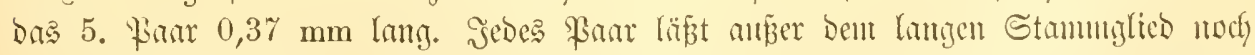

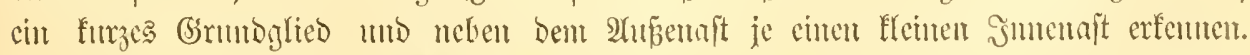

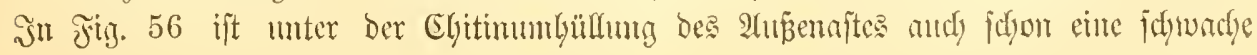




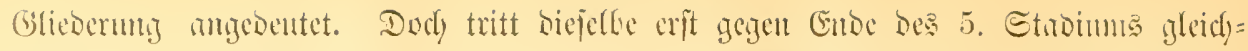

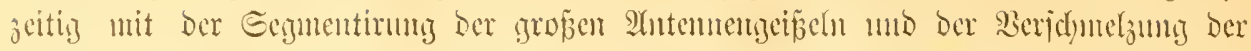

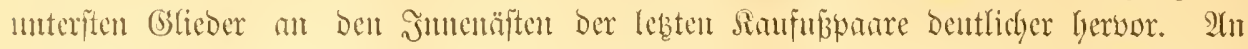

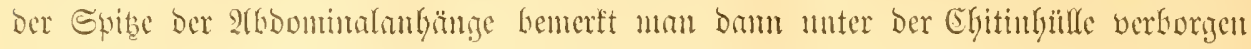

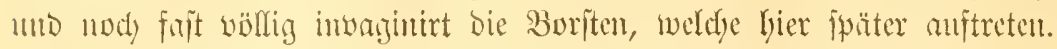

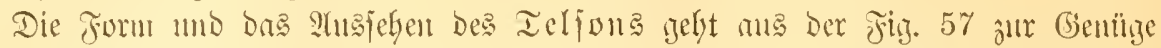

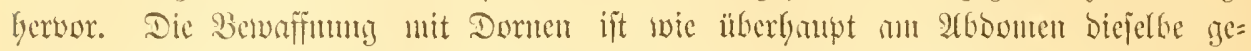
Wheben. Huter und Ginter Dem Analitadyel tritt Der 2 ffter Gerwor, ber nody immer

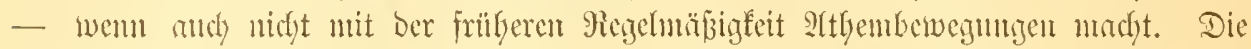

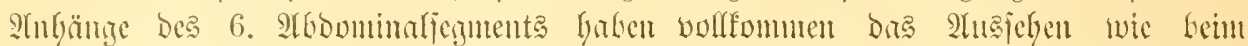

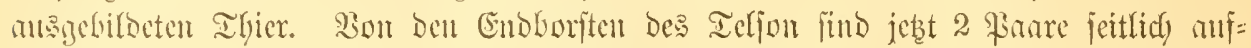

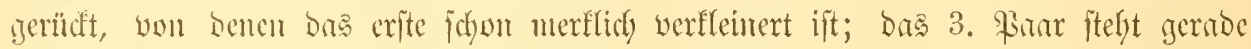

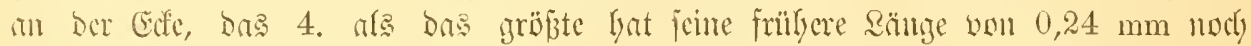

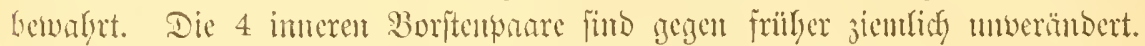

Salermit ift mu Da: Ende Der Rarecnjeit erreidyt.

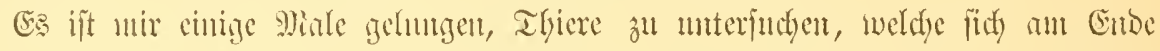

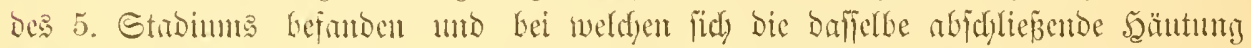

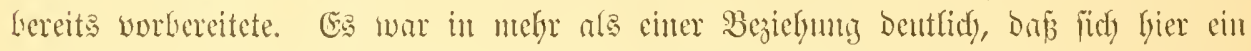

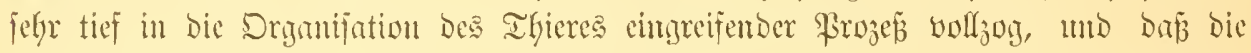

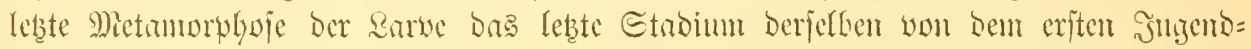

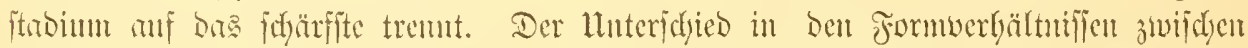

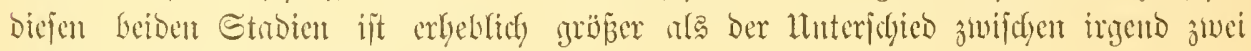
einumber folgenten früleren Strobien.

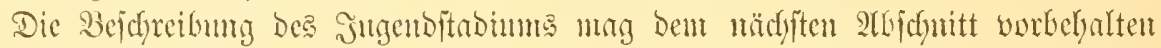

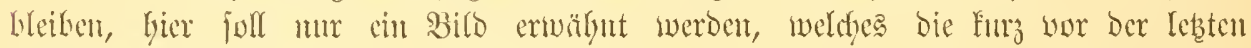

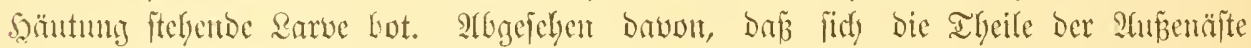

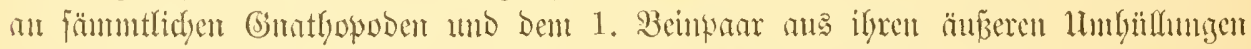

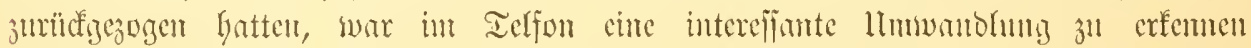

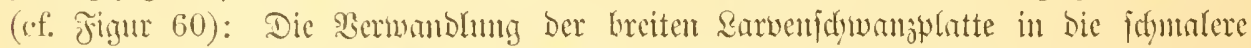

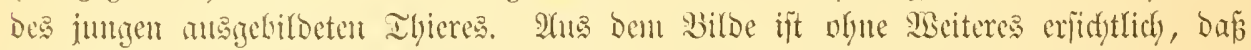

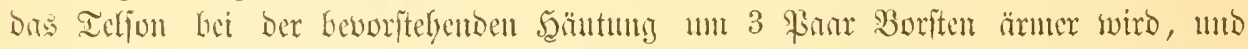

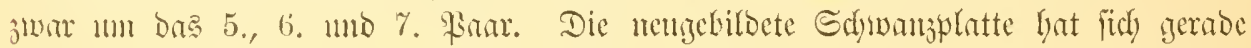

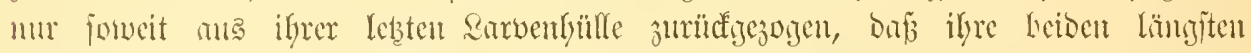

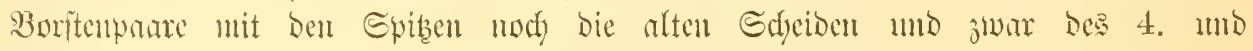
8. Fanres erreichen und ibr Serworgeben aus biejen fomit erfidftlidy ift.

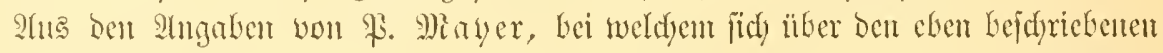

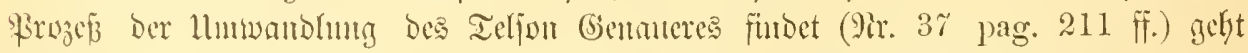

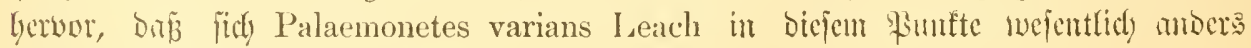
verbält, als Crangon rulgaris.

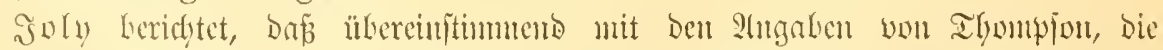

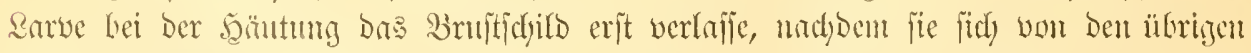
alten Jntegnmenten Gefreit babe (9ix. 12 pag. 76), wäbreno siseft wo od bies ala

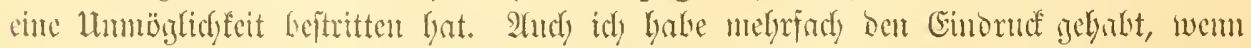

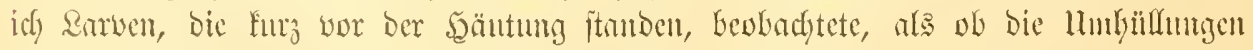

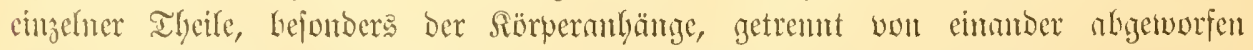

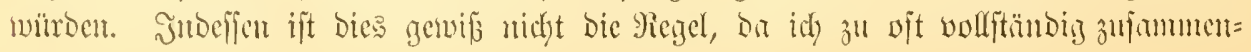




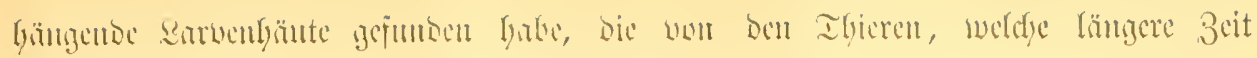

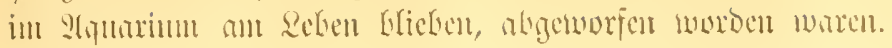

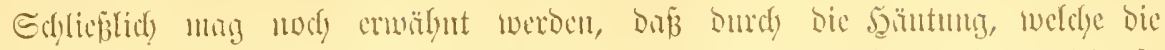

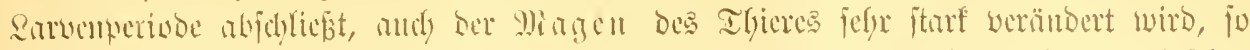

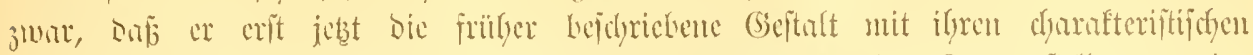

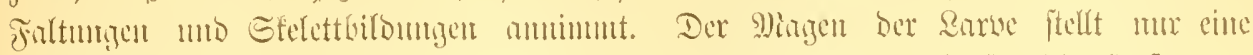

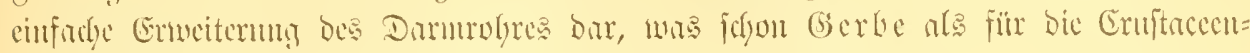

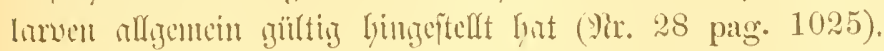

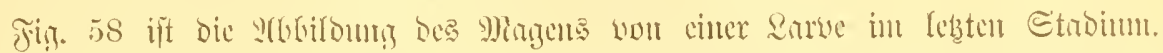

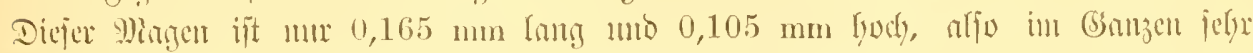

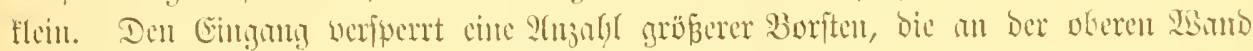

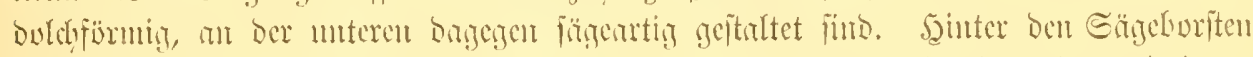

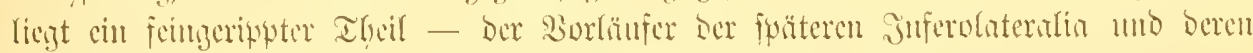

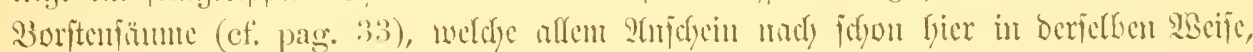

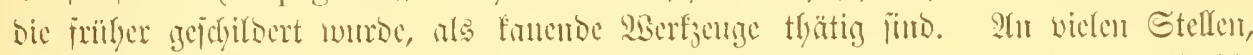

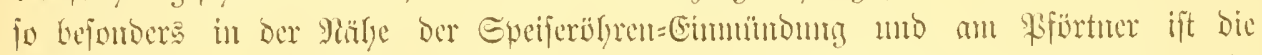

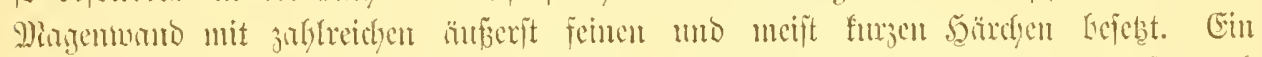

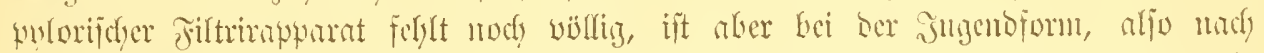

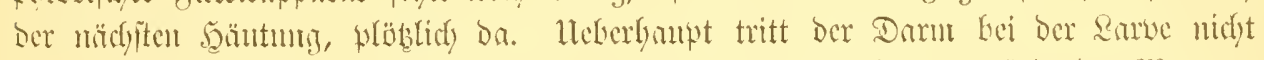

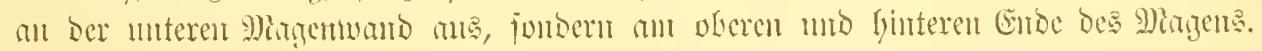

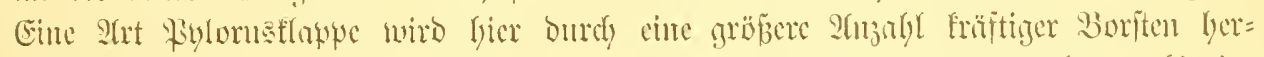

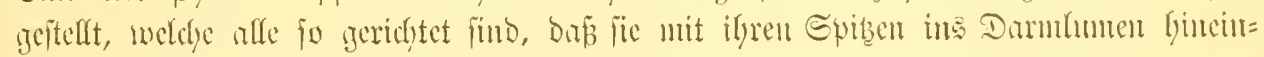

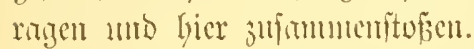

\section{Stadium - bic Iugcubform.}

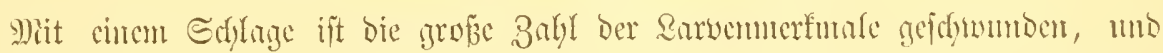

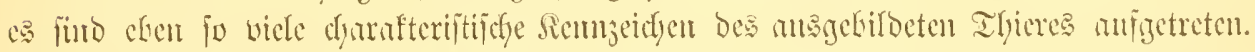

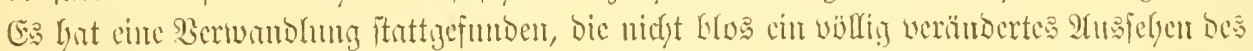

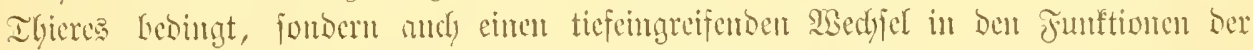

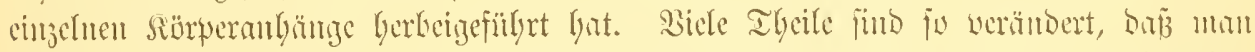

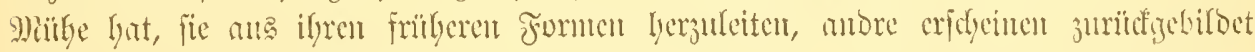

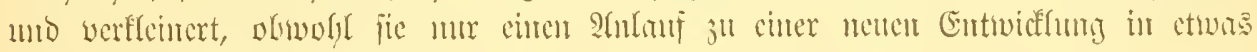
veritudorter Fidstumig nelynten.

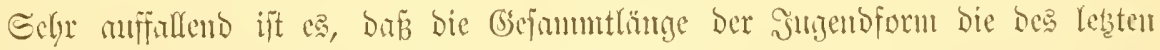

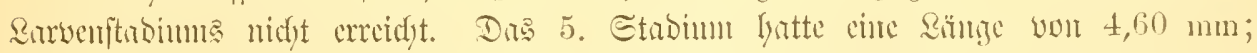

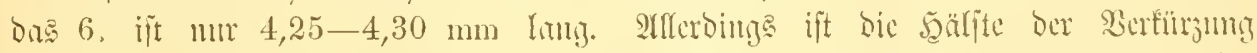

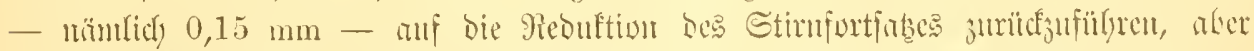

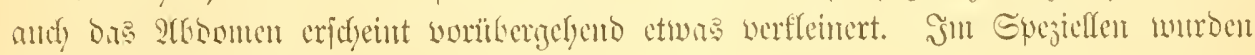
folyende Minß̈ gefunden:

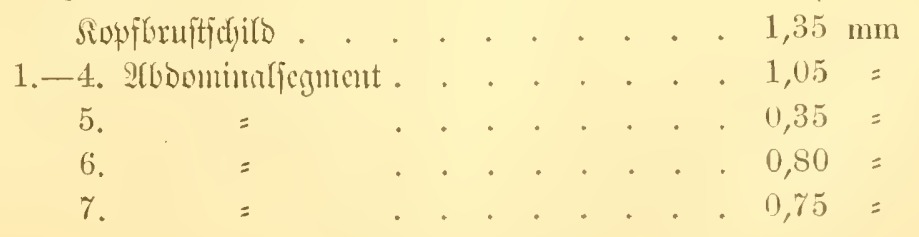


Die widftigiten un fidyerften Erfeunuggeiden ber Jugendform

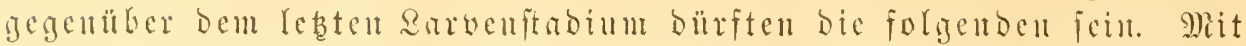

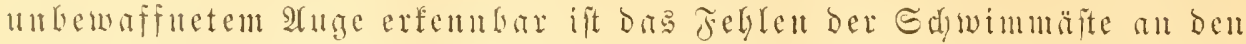

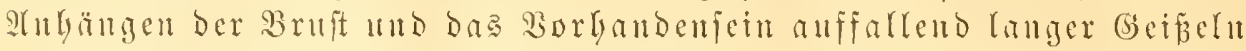

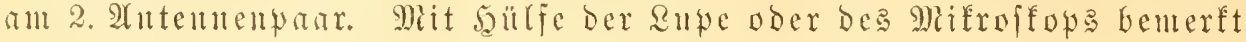
man weiter bie veränderte Bewaffung bes Sopfbruftidjilbes und bes AGDomens, befouders die Reduftion Des Stirufortiabes und Der Borfen

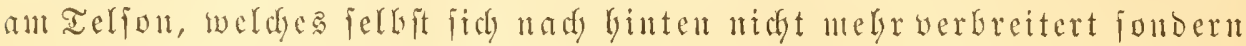
verfdymälert. Sämmtlide Mindtheile find eng an einander gerüd, die

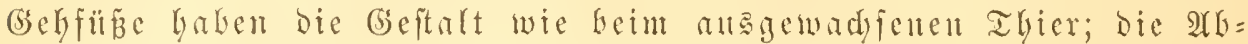
Dominalfübe find mit limgen Sdymumboriten bejebt.

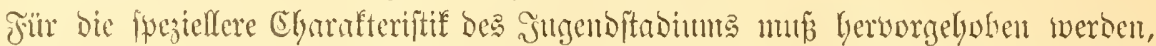

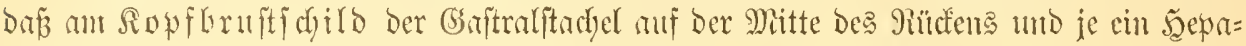
tifirlfadyel anf bent Seiten erft jeb̧t herworgetreten füb. Drifelte gilt wou bem febr

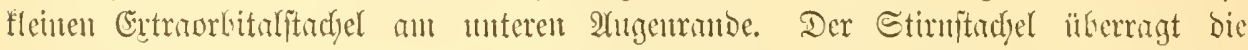

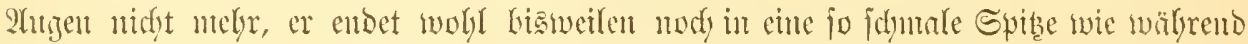

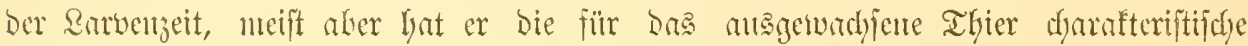

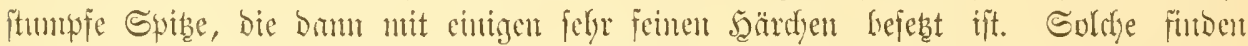

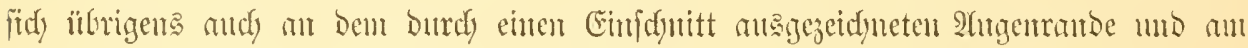

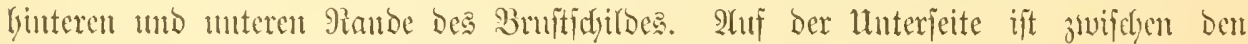
worderften Seinparen mudy ber Sternalitadyel berworgetreten.

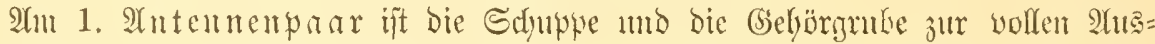
bilbung gelangt. Der gange 2Anfang ift wie viele andere gegen fritber etwas ver=

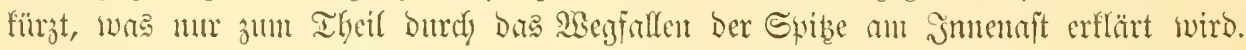

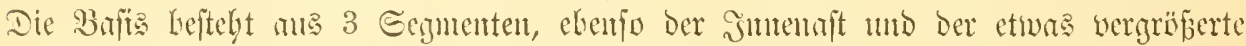

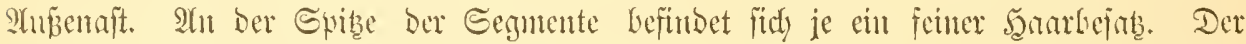

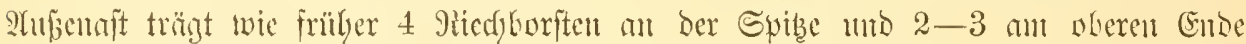

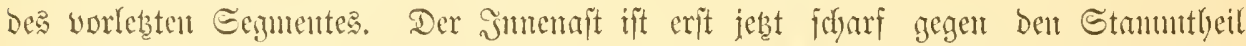

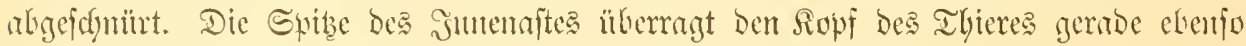
weit wie bie Epibe Der Sthuppe an 2. 2Untementaar.

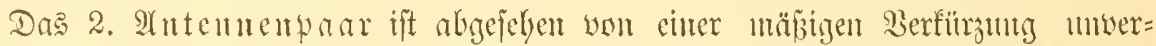

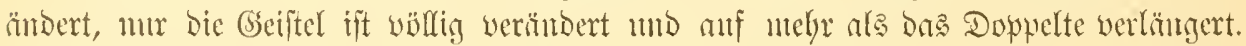

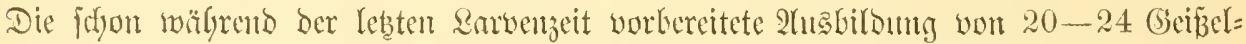

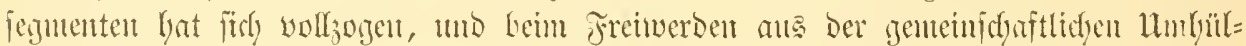

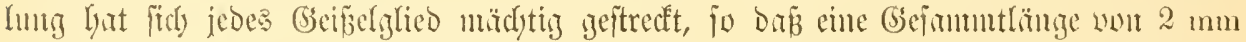

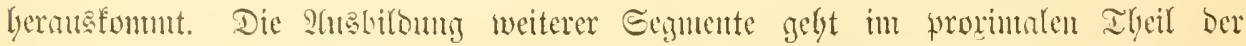

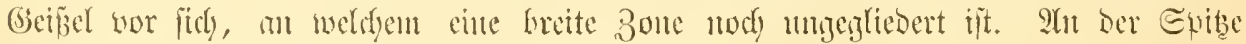

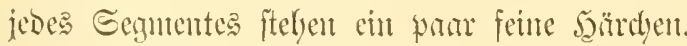

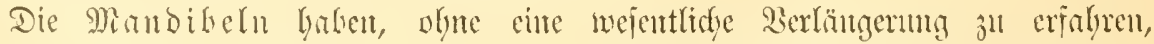

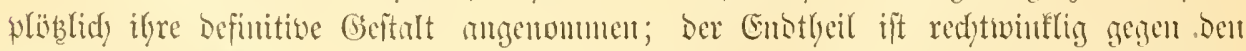

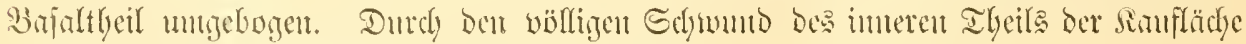
ijt bieje in ibren Dimenïmenen erbeblidy rebuzirt.

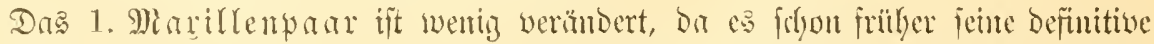

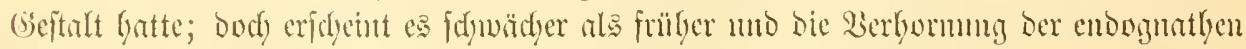
Iheile ift werfonmmben. Den Iafiter frönt mu nods eine Borfte, wie fem ams= genatsponen Ilsier. 


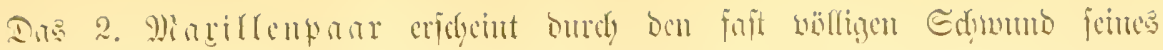

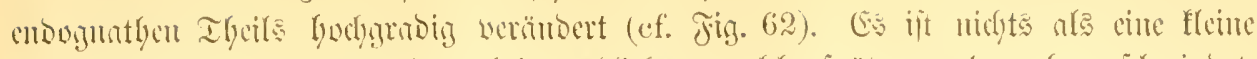

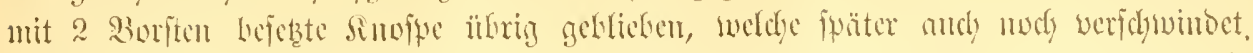

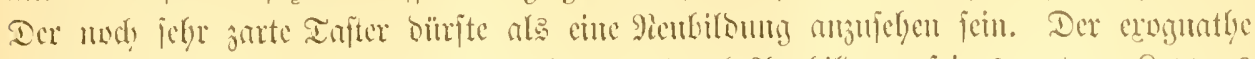

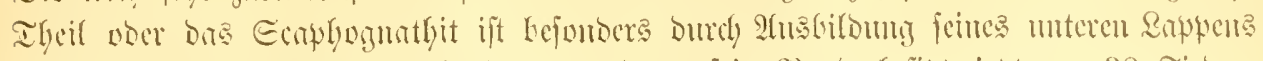

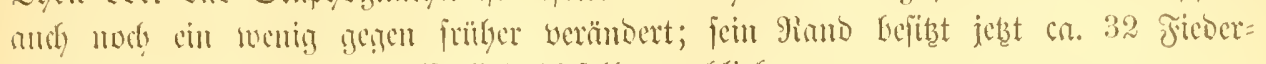

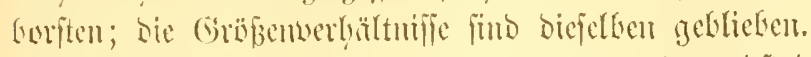

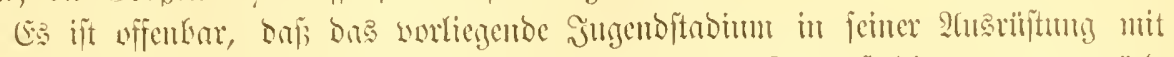

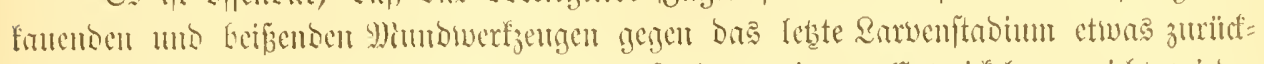

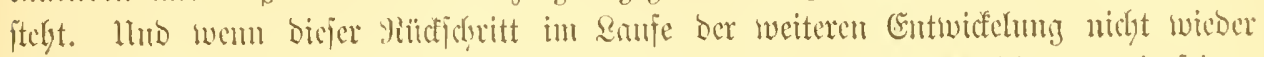

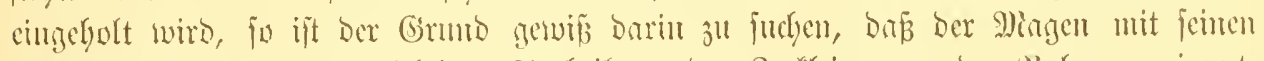

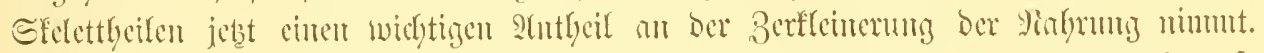

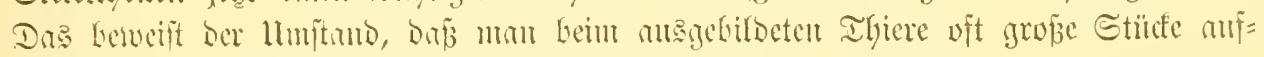

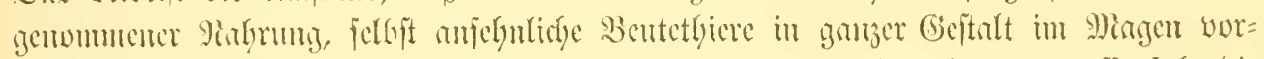

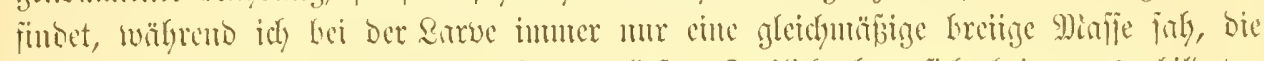

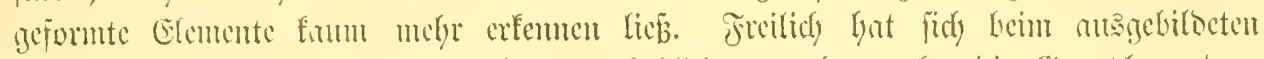

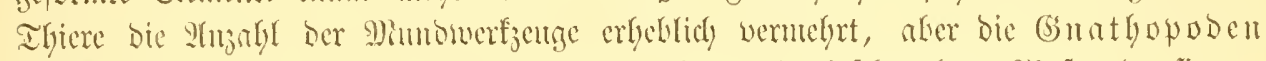

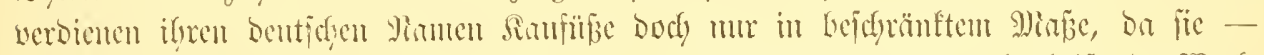

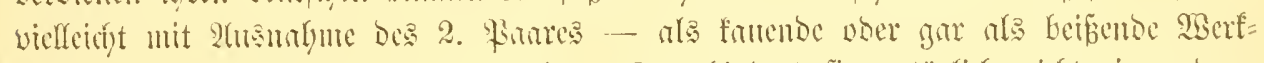

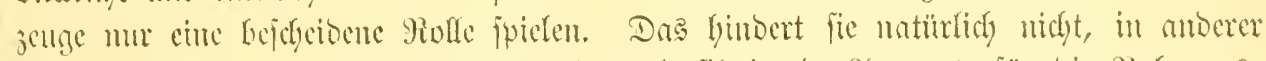

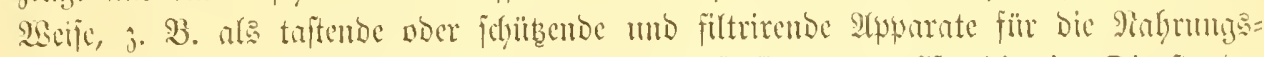

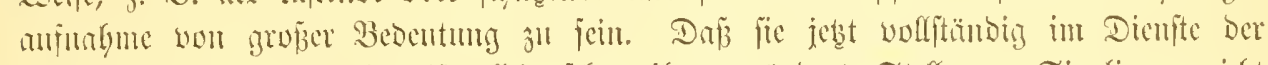

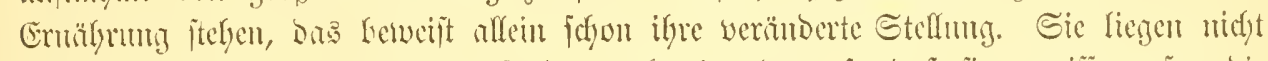

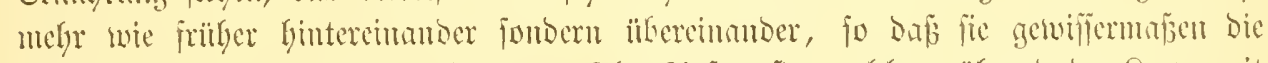

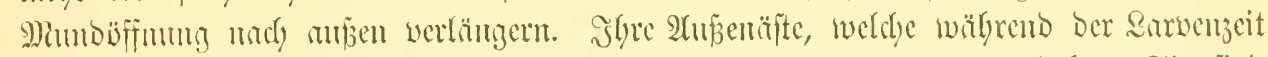

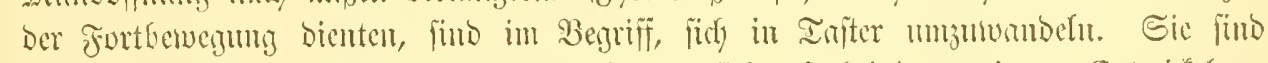

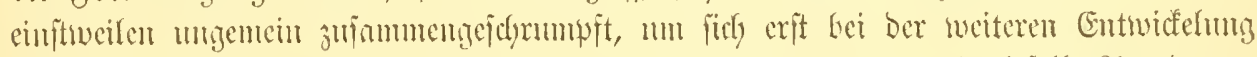

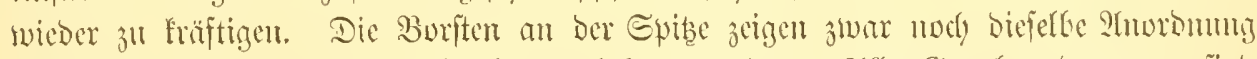

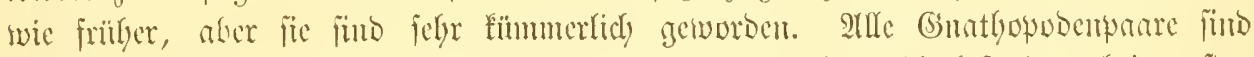

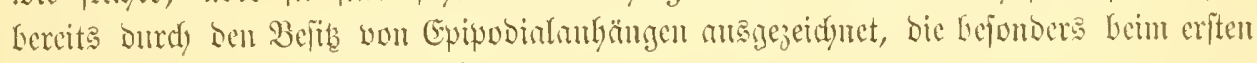
Prane cunc mélulidye Gröbe gaben.

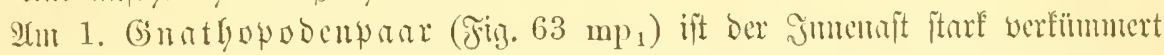

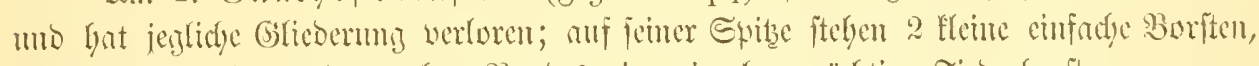

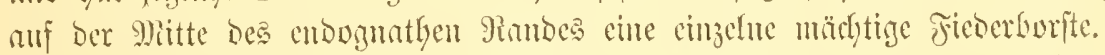

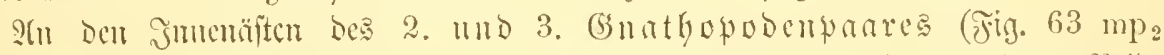

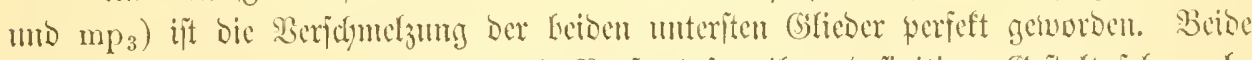

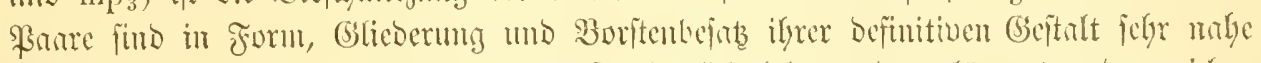

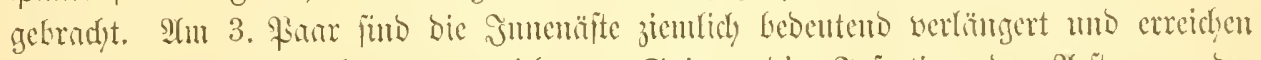

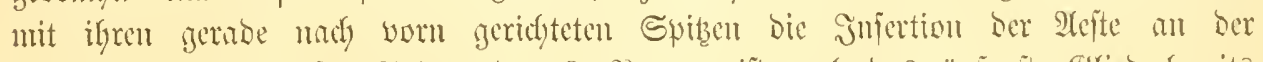

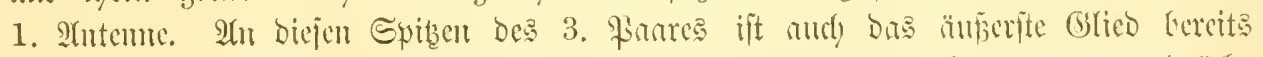

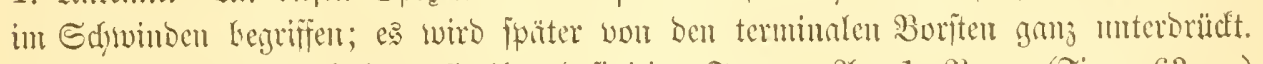

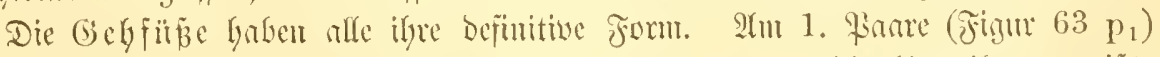

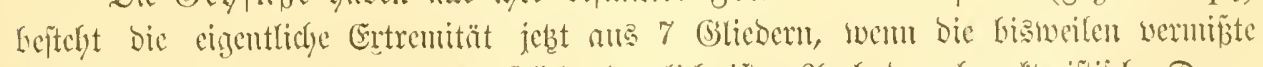

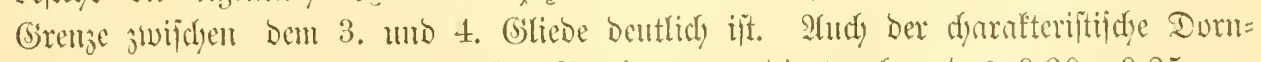

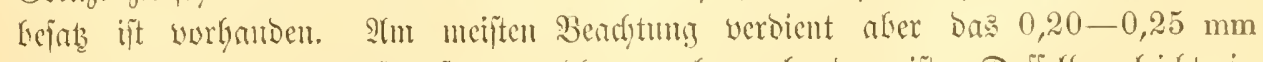

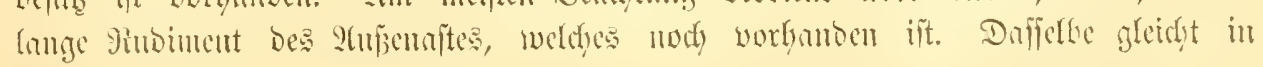


feiner Jorm ben Iaftern ber Mariflarfübe, cutbebrt aber ber Sorften faft ganz, unb

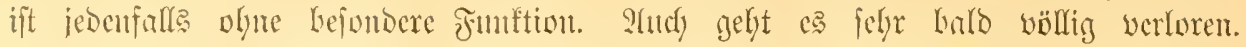

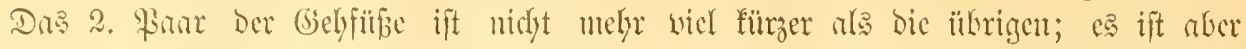

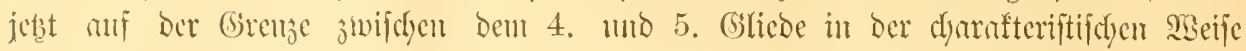

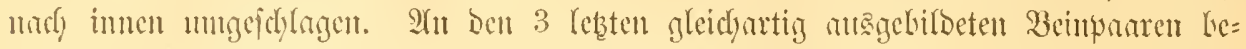

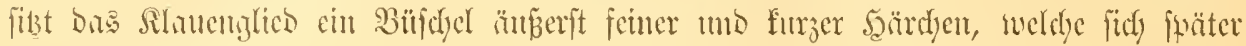
bald abjdileifen.

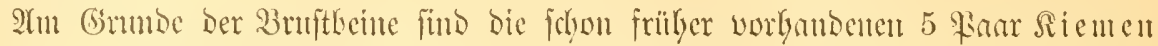

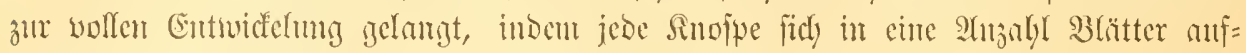

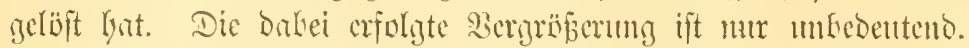

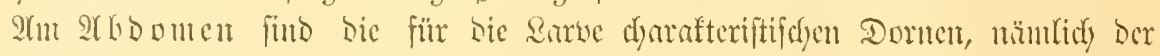
mebiane Dorn an bintern Dorfalrand Des 3. Eegments und bie lateralut an

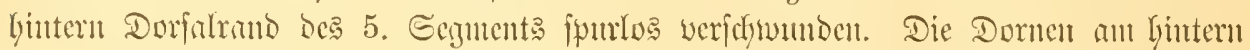

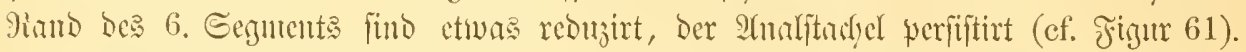

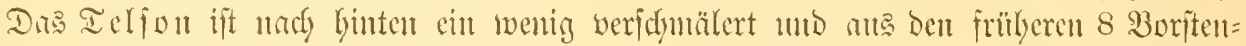

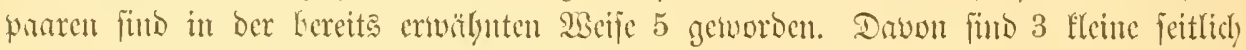

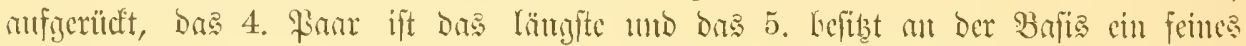

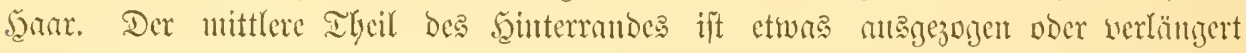

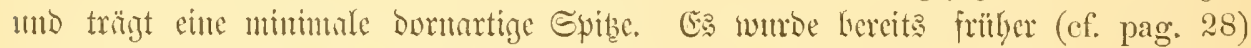

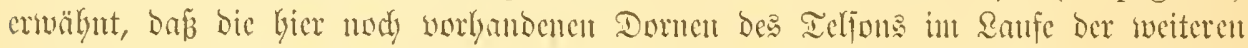

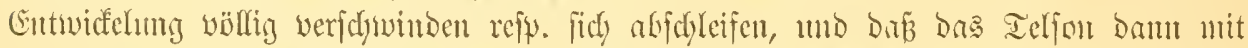

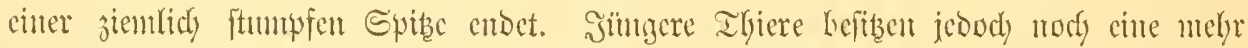

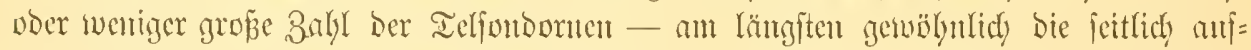

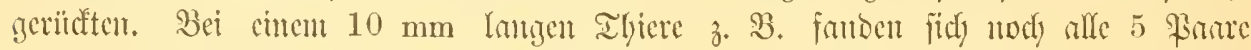

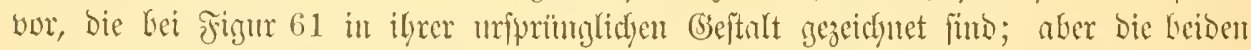

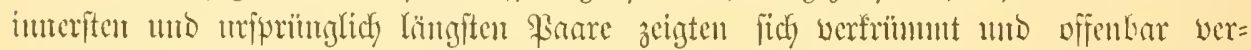

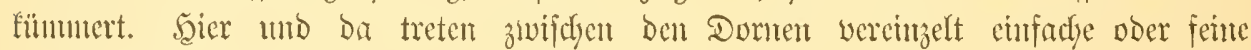
Jiederbanre alt.

Die 5 eriten $\mathfrak{A} D$ ominalfü̧panre Gaben, olyne fidd wefutlidy ju wergröpern,

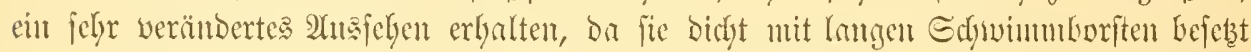

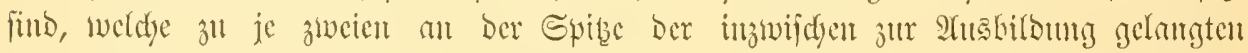
Geguncute ftelyen (cf. Figur 64). Ilebrigens ift mur der obere Ilycil bes 2fubentiftes

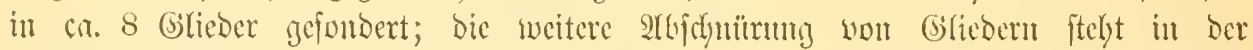

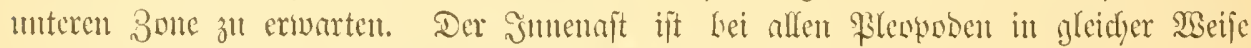
als einc rumbliche mit 2 Boriten luefebte Sinofpe ansgetilbet.

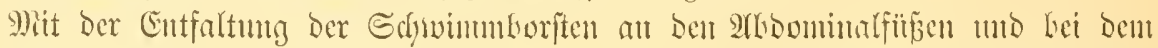

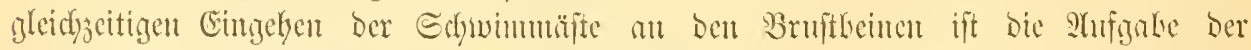

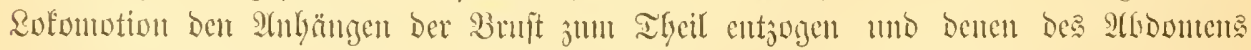

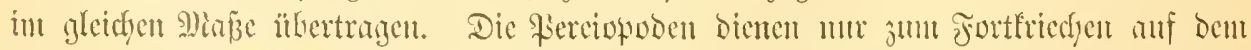

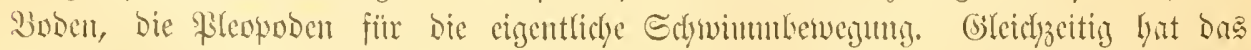
junge Ilyier bag tein pelagijobe Reben anfgegeben und bervegt fidh bald friecheno, unld jefwianuend.

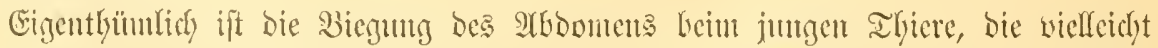

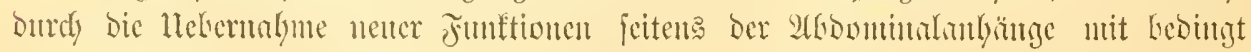

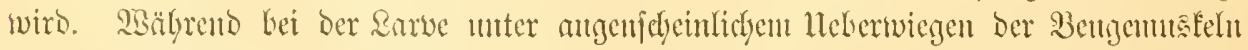

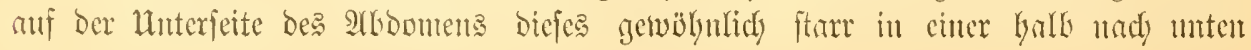




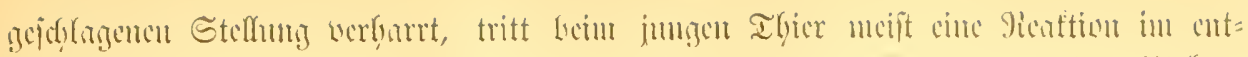

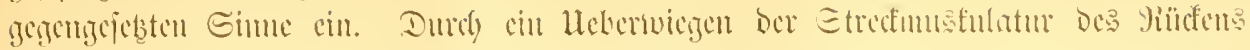

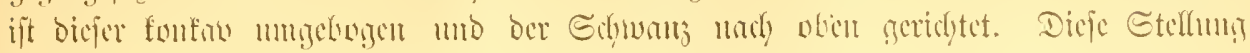

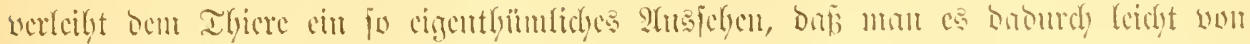

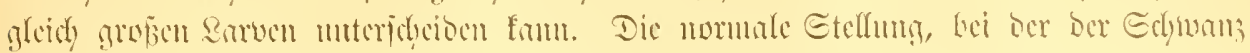

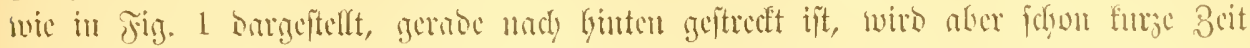
parter cintugenument.

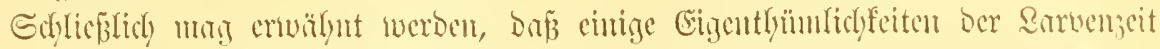

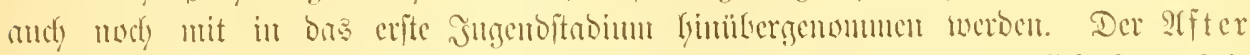

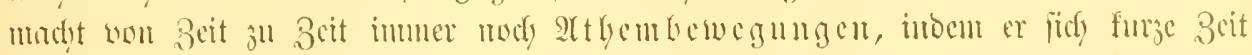

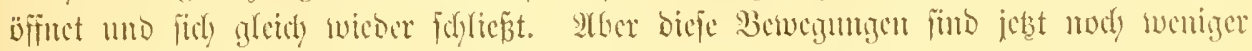

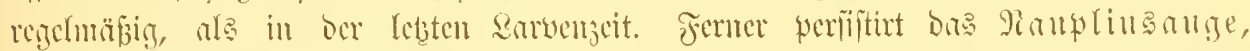

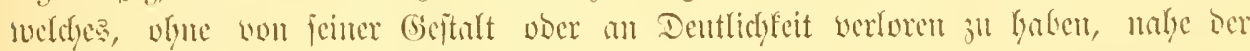

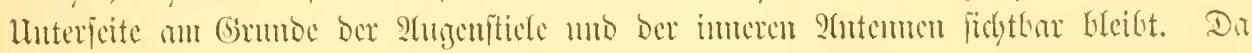

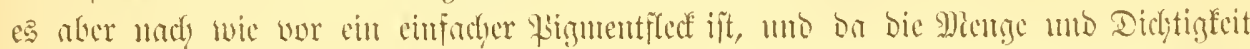

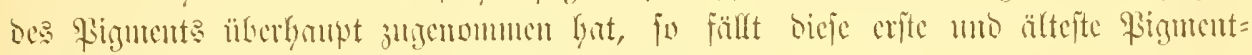
manumlung in feiner siscife bejonters ins atrige. 


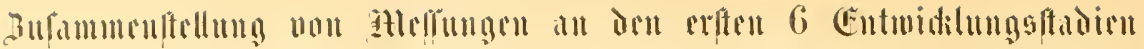 unu Crangon valgaris.}

(2lngaben in Millmetern.)

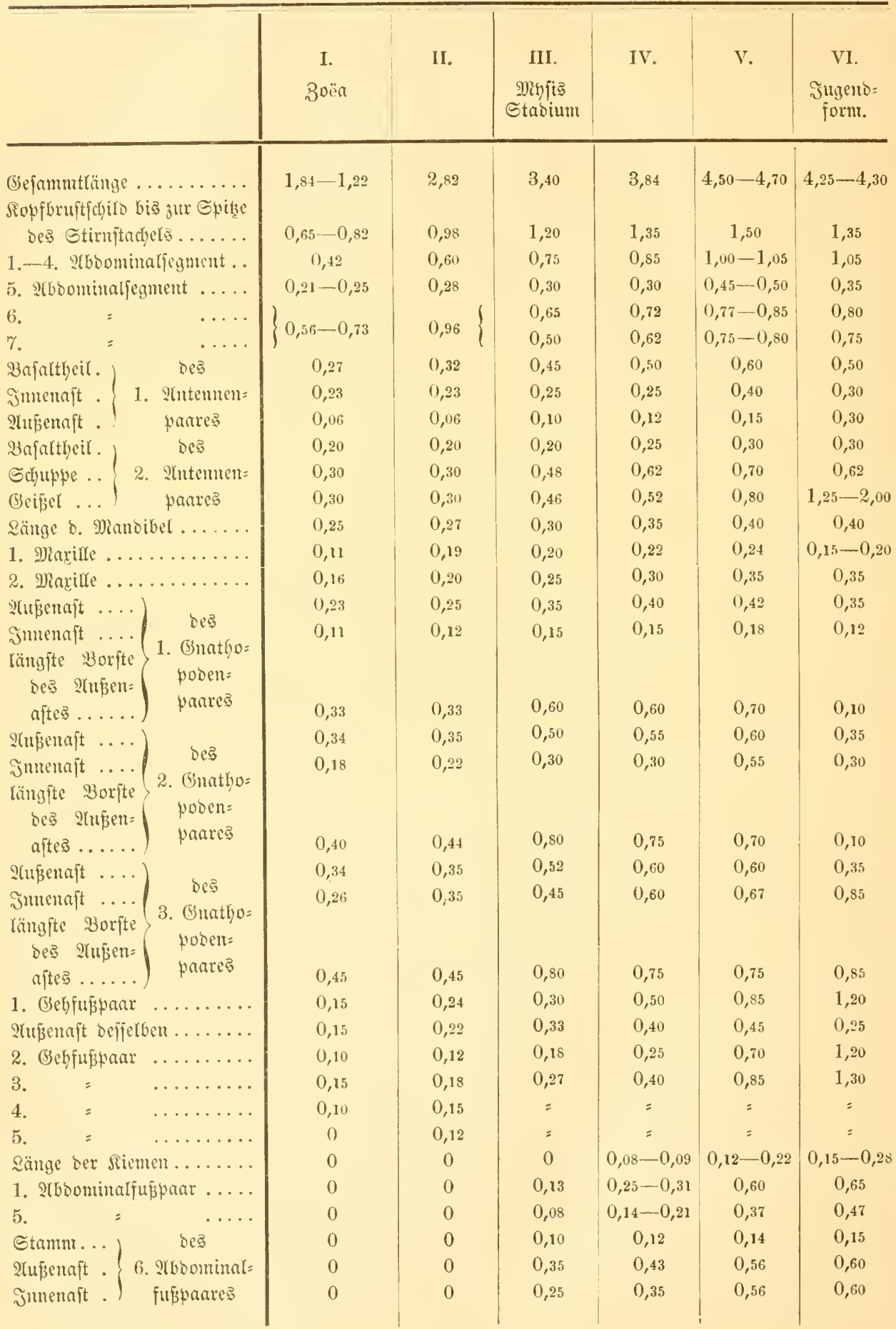


III. Sechensucije แnto Fantguergälttrijie.

6 


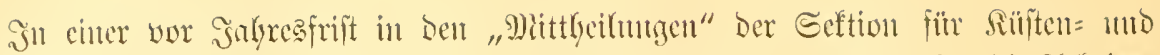

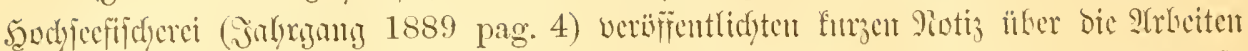

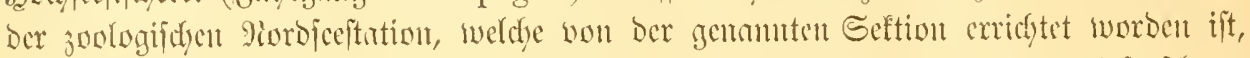

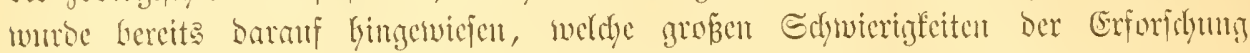

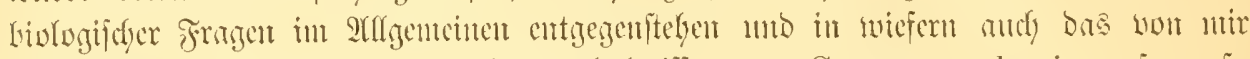

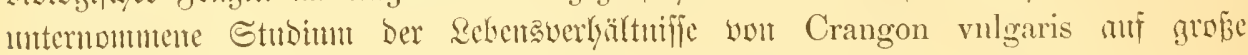

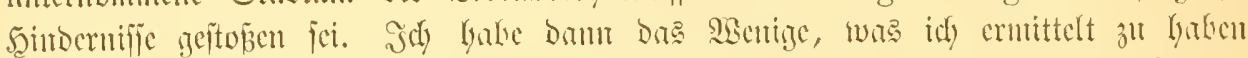

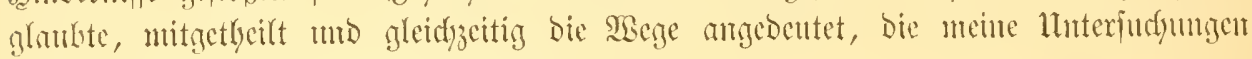
in ber nächiten Bcit einjolagen jollten.

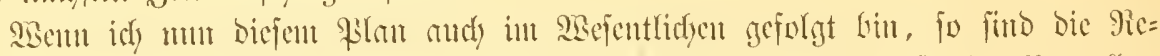

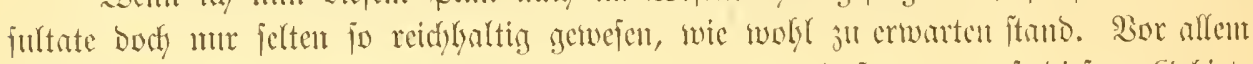

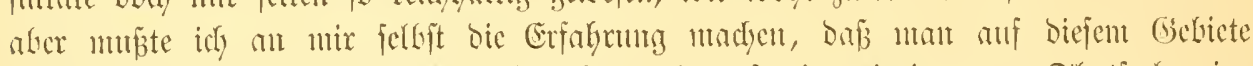

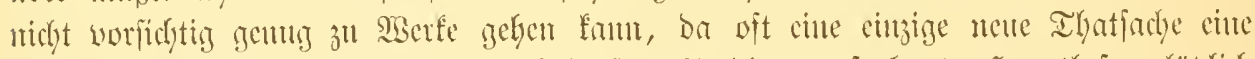

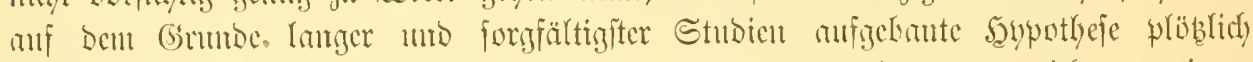

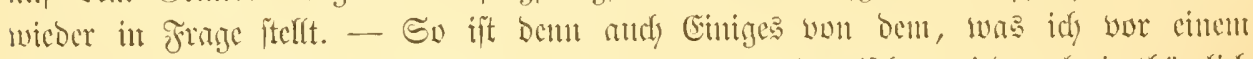

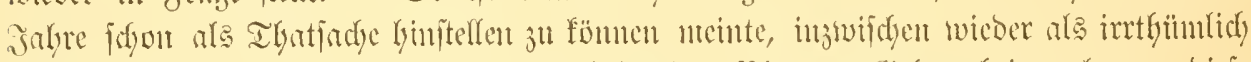

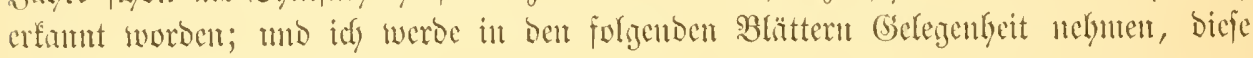
Srrtlyümer richtiog jull fteflest.

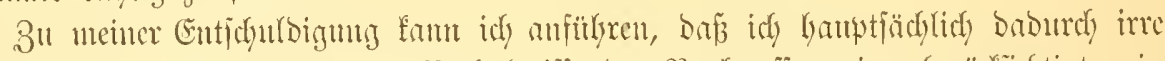

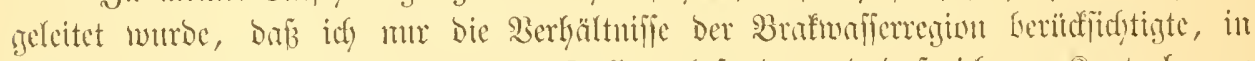

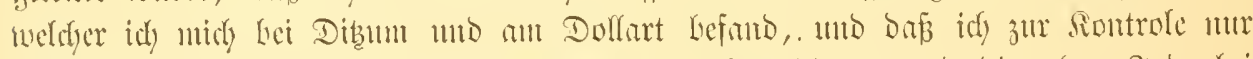

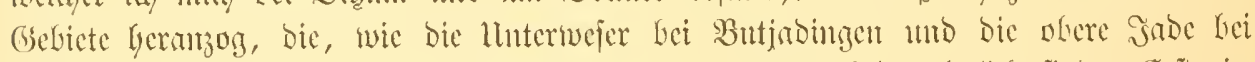

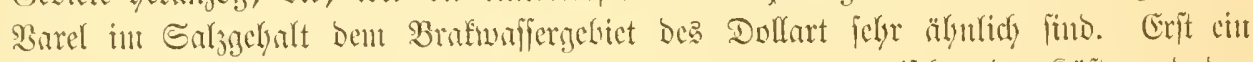

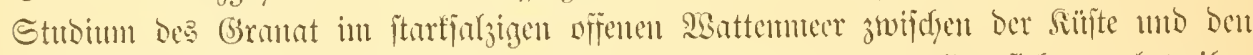

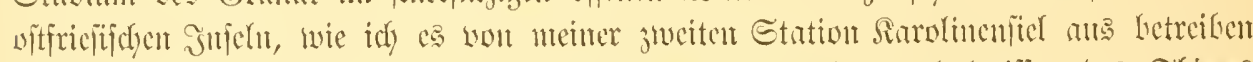

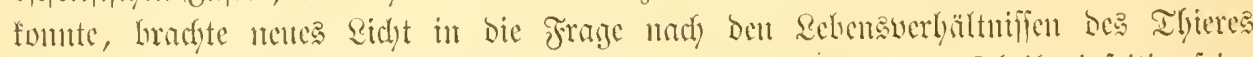

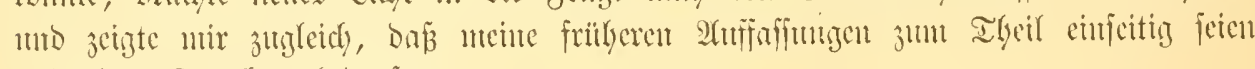
uno einer forreftur bedurften.

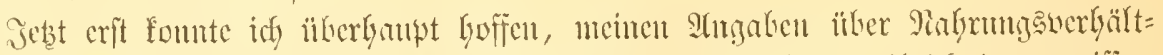

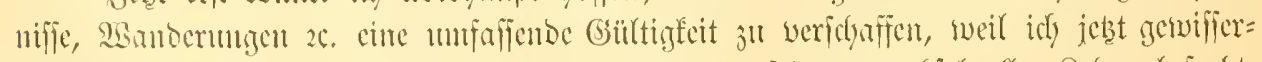

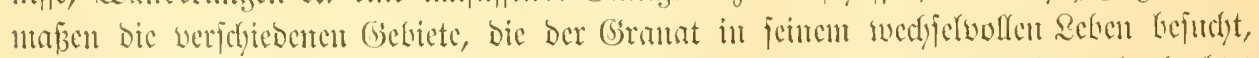

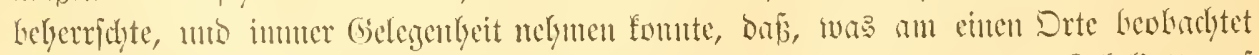
morben war, unter ben etwas weränderten Bebingunigu ciner andern Rofarität anf

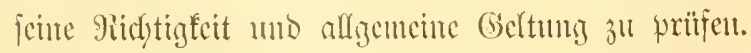

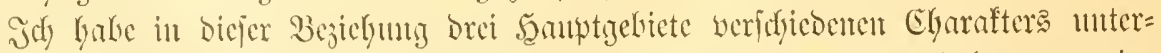

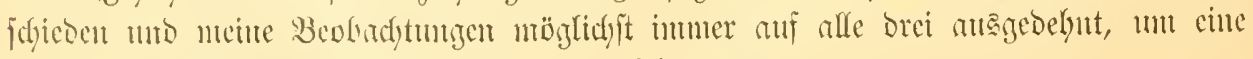
gute uno juverlaijitige siontrole zul Gaben. Dics waren: 


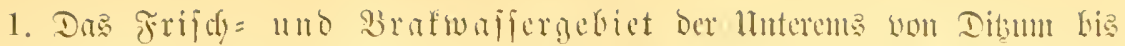

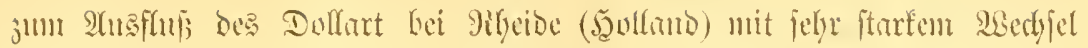
in Garjuglyalt won 0,3 bie 2,0 Prozent,

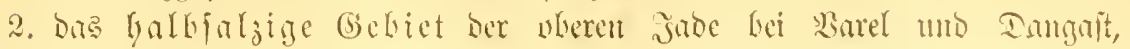

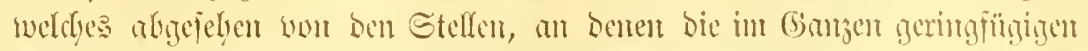

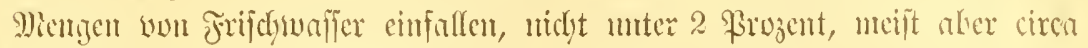
2,5 Prozent Gars anfucrit,

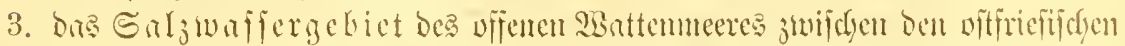

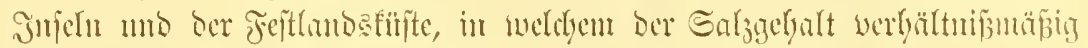

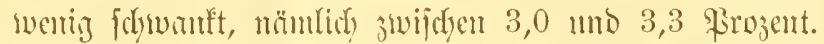

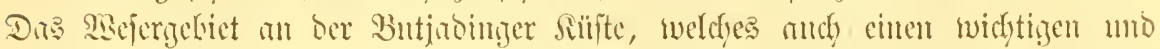

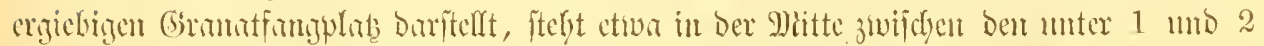

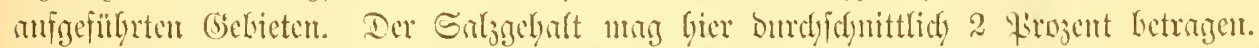

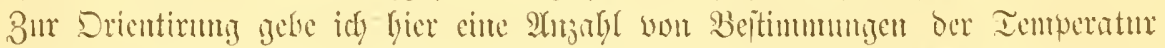

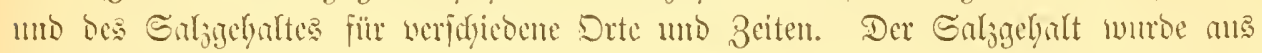

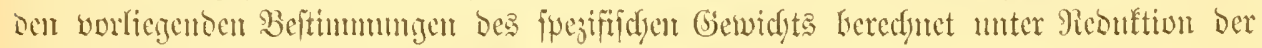
Iemperatur mif $17,5^{\circ} \mathrm{C}$.

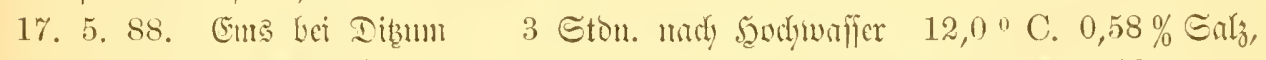
Ember Tutyrivafict in Dollart $12,0^{0}=1,13==$ ibid. (9)iüug. D. ?(i) $5==$

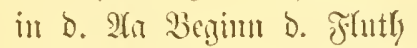

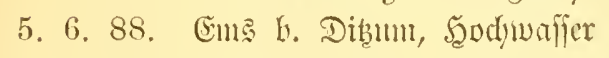

$11,8^{\prime \prime}=1,27==$

$12,6^{0}=1,15=$

$13,4^{0}=1,03=$

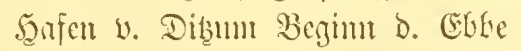

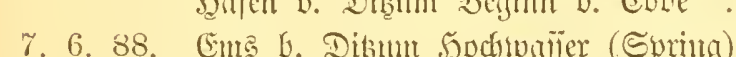

9.6.88. = = = Segim ๖. Fluth $=$ = Borffum 1 Stumbe Flutb.

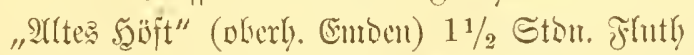
Baflontome (unterf. Embar) 2 Ston. Fluth Migciocrlyut (Eingang D. Dollart) 3 Gtou. Fluth Mitte D. Dollant $4 \frac{1}{2}$ ङton. Flutly.

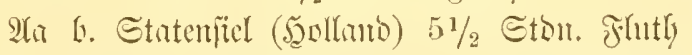

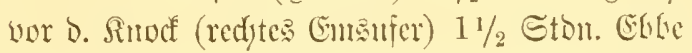

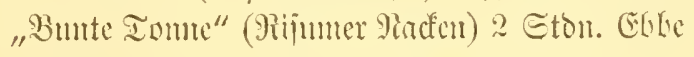
Duffe Gat b. D. Simmer Ionne 3 Find 5 Stbu. Ebtue Ember Falyrivanter griebrigunafier.

6. 7. S8. Ems 6. Sarjinm rebte Ebke. artes Sgift Miebrigmaffer.

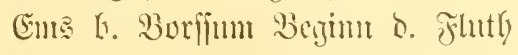
$13,6^{\circ}=1,26=$ $13,6^{0}=0,60=$ $13,7^{0}=1,5 \%=$ $15,2^{0}=0,28$ : $15,2^{0}=0,68=$ $15,4^{0}=1,15=$ $14,9^{0}=1,79=$ $14,7^{0}=2,06=$ $15,5^{0}=1,95=$ $16,9^{10}=1,81=$ $15,5^{0}=2,25=$ $15,1^{0}=2,44=$ $14,6^{\circ}=2,50=$ $16,3^{0}=1,91=$ $16,1^{\prime \prime}=1,06=$ $17^{\circ} 2^{\circ}=0, \pm 6=$ $17,0^{0}=0,67=$ $16,70=0,59=$ $=$ = Fosgum 1 巨tbe. Fluth.

17. 7. 88. Ember Fabrunafier 3 Stbu. Elute $16,8^{0}=0,46=$ Miljcioe (Doflart) $4=$

$15,0^{0}=1,73=$ "Polfatomi" (unterly. Dollart) $41 / 2$ Etom. Estue $15,1^{\prime \prime}=1,94=$ Ems 6. Delfjyl Riebrigwajier $15,0^{0}=2,10=$ b. Rheide in Dollartftrom 2 Gtout. Flutly $15,0^{0}=2,21=$ $15,0^{n}=2,07=$ 


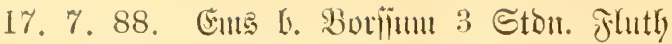

$15,2 \circ \mathrm{C} \cdot 1,00 \% \widetilde{\sigma a l}_{3}$,

4. 8. 88. Mienmuertshalje Niebrigunafier .

$15,6^{0}=2,97=$

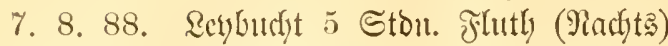

$14,4^{0}=2,95=$

8. 8. 88. "Bunte Tomme" 1 Stbe. Fluth .

$14,70=1,90=$

Geife (a. Dollart) 2 Ston. Flutl

$14,8^{0}=1,17=$

17. 8. 88. (uady andanemb ftarfen Regenfällen)

Ent: 6. Pognum 3 Ston. Ebbe

$16,6^{0}=0,30=$

Rlycide (Dollart) $4 \frac{1}{2}$ Stort. Ebbe

$15,70=0,75=$

Dterbum (oberly. Delfal) 6 Stbr. Gbbe

$15,70=0,75=$

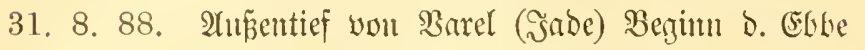

$14,6^{0}=2,46=$

ibid. (Antuenende) 1 Stbe. Ebbe

Ryede v. Wilkelmagafen 2 Stbu. Sube

$15,0^{0}=2,57=$

Solthöruer MBatt (Sabe) 4

$16,4^{0}=2,67=$

unterh. Bimenfenerjaiff (Gentubbant) lebte ebbe

$16,2^{0}=2,65=$

Ectivarderbörn (Sadc) 1 Stbe. Flutly

$16,5^{0}=2,67=$

$16,0^{0}=2,61=$

1. 9. 88. Rl. MBcjer b. B̈urlyaberjiel 1 Stbe. Erbe

$15,6^{0}=2,10=$

$16,20=2,25=$

13. 9. 88, 9ikeide (Dollart)

3 Gton. Ebbe

$14,2^{0}=1,45=$

Termynten (ફ口olland) $4 \frac{1}{2}=$

$14,3^{0}=1,51=$

Delfayl lebzte Ebfue

$14,6^{0}=1,61=$

Ent b. Pogum 3 Ston. Fluth .

26. 9. 88. Ditfriejiffes Gatje (Ems) 4 Ston. Ebbe

$15,2^{0}=0,60=$

Tome b. Butenemahörn Riebrigmaffer

Dufe Giat 1 Stbe. Flutly.

Bucfyt v. 2Batum (Euta) 2 Ston. Fluth

$14,3^{0}=2,24=$

$14,6^{\circ}=2,49=$

$14,0^{0}=2,83=$

$14,1^{0}=2,25=$

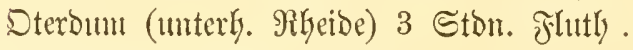

$14,6^{0}=2,08=$

Ribeiberbuf 4 Stbu. Fluth

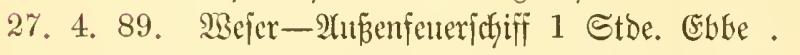

$14,0^{0}=1,81=$

2llte Şarle (Seegat) Şodjwaffer .

$6,8^{0}=3,30=$

$\mathrm{S}, 6^{0}=3,22=$

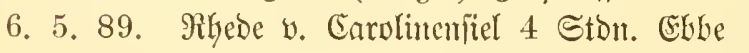

Saarle 5 Storr. Eblie

Saciterfalyrwafier (Caroliuenjiel) 1 Stbe. Fluth

$14,4^{0}=3,0=$

$13,0^{n}=3,28=$

$15,3^{0}=3,24=$

6. 6. 89. 2Unenticf v. Carolinentiel $1 \frac{1}{2}$ Stour. Ebbe

$19,8^{0}=2,11=$

ibid. Sopfluafe 2 Stou. Esble

Befterfahrivaficr v. Carolf. 3 Stbut. Ebthe

$18,2^{0}=3,26=$

Scïllylate b. Wangenoog 5 Ston. Ebbe

$18,1^{0}=3,28=$

$19,2^{0}=3,29=$

Diterfalyrwafier v. Carolj. 1 Stbe. Fluth .

$20,8^{0}=3,29=$

$19,9^{0}=3,28=$

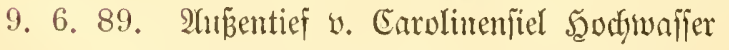

$19,5^{0}=3,29=$

SBangerooger Strant 4 Stbu. Ebbe

$20,3^{0}=3,07=$

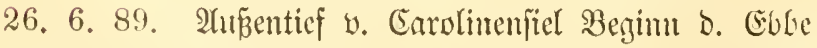

$19,5^{0}=3,35=$

16. 7. 89. Diterfahrio. v. Carolimenficl 3 ธton. Ebbe

$16,2^{0}=3,34=$

5. 10.89. anjacutief v. Carolj. (Sopfbafe) 1 Etbe. Ebre

$11,2^{0}=3,08=$

Diterfalyrm. v. Earotimentid 3 Ston. Sebe

$11,2^{0}=3,09=$

ibid.

$21 / 2$ Stbut. Ffutly

$11,4^{0}=3,03=$

10. 10. 89 .

ibid.

1

$10,0^{0}=2,92=$ 


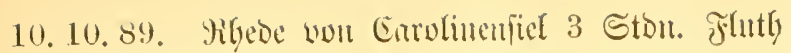

30. 10. 89. Diterfatim. 4 Stor. Ebte

SBangervoger Stramo Siedrigualier.

ahténtief 6. Earulf. (Sivpfbafe) 2 Ston. Fluth

26. 2. 90. Diterbalie 6. Cardinenitel 2 Etom. Eble

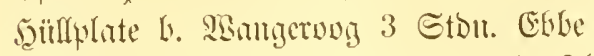

Diterfakruvajer v. Carulj. Segim D. Fluth

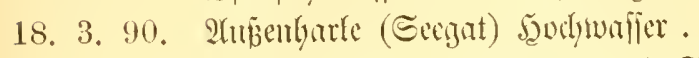

in Eee mürol. 2. Epictervoig 1 Etoc. Ebbe

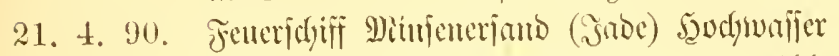
vkerh. v. Al. sgejerfeterictiff 2 Stom. Ebbe Bremer Reutfttguru 6 Stbu. Ebbe.

22. 4. 90. Everjand (28ejer) 4 Stbu. Este

ibid. Tiiebrigwafier

ibid. $1 \frac{1}{2}$ Eton. Fुhth

SBurter SBatt 2 Stou. Fluth

Remwerfer sisntt 5 Stbu. Ffutly)

ibid.

3 Stor. Eblue

23. 4. 90 .

ibid.

$1 \frac{1}{2}=$

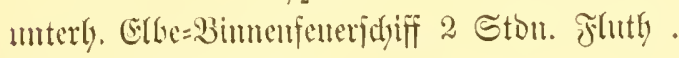

ribede v. Curbaven

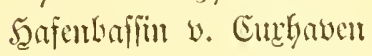

24. 4. 90. Elfe querab Eurfavent

Ellyämbe

Elbe eben oberh.

$3=$
$4=$
$11 / 2=$
$3=$
$5=$

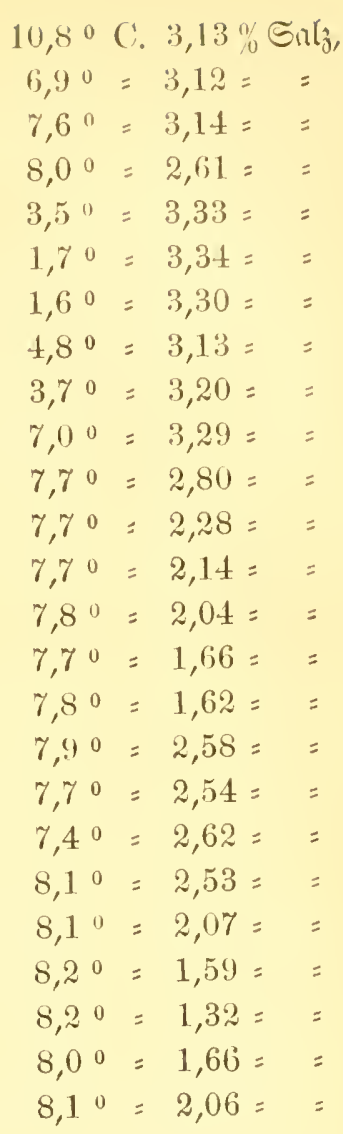

\section{Berioben ber Giablage, Eaidjetten.}

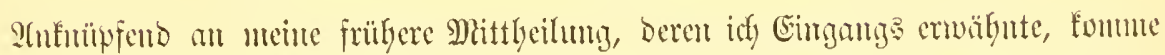

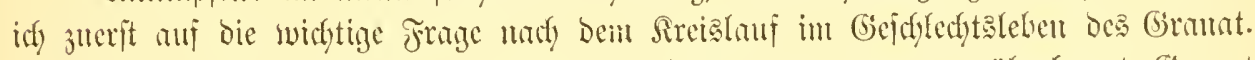

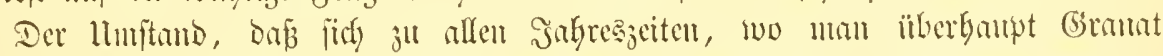

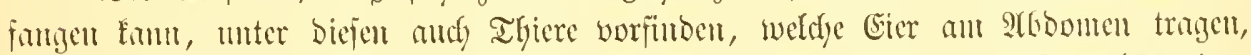

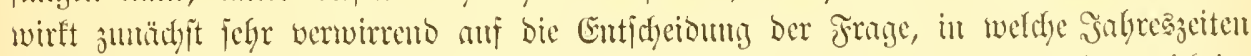

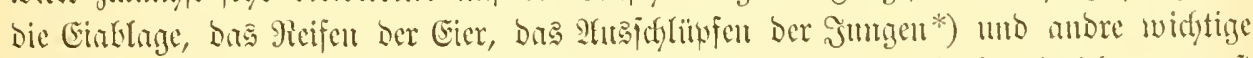

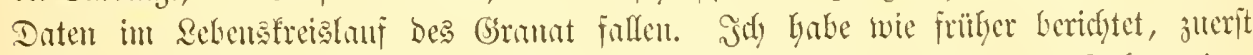

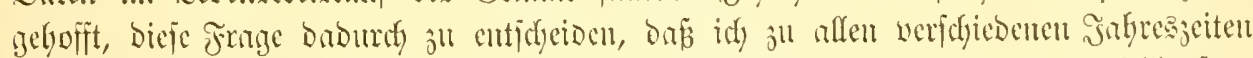

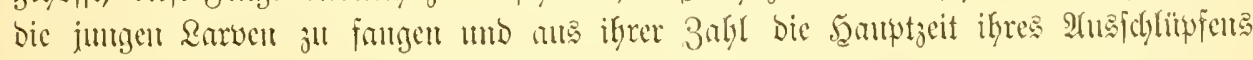
fejtzujtellen judyte.

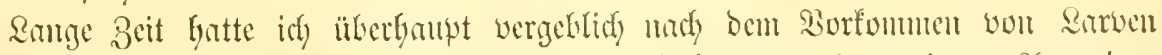

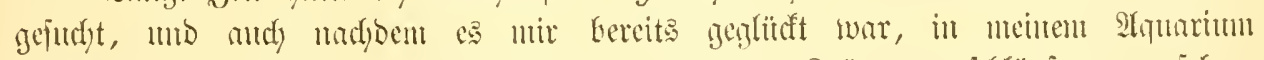

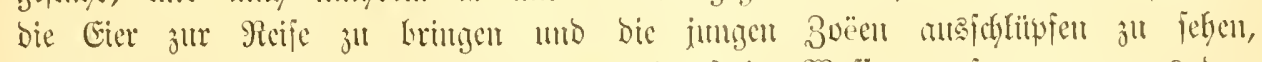
wollte

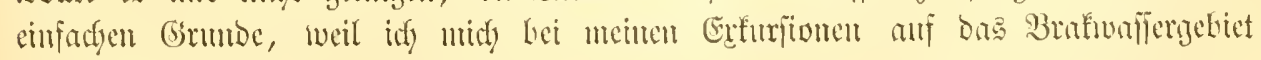

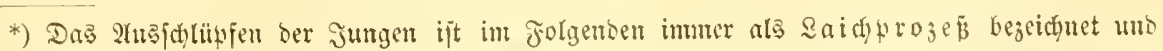

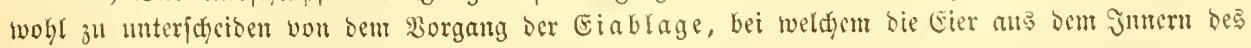
Rörpers hervortreten uno an bas Aboomen antgeheftet werben. 


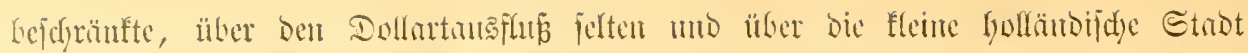

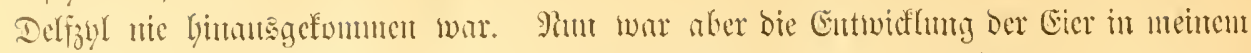

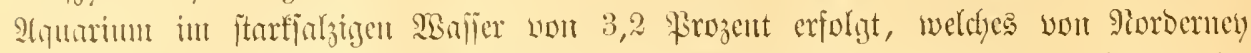

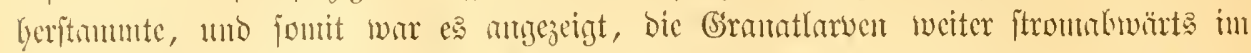

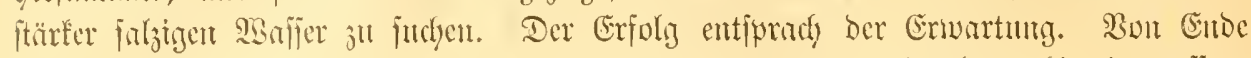

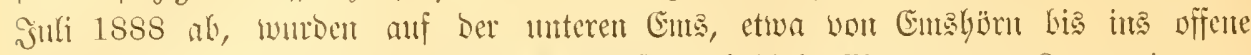

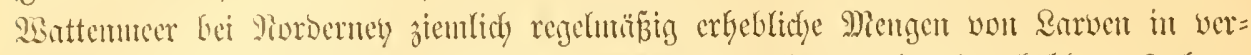

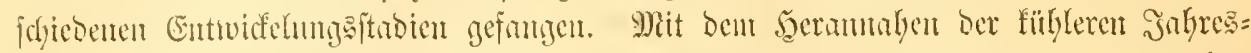

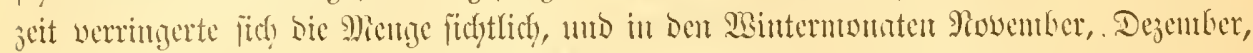

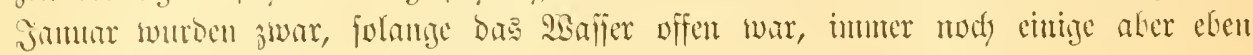
mur bereinjelte smoen gefmitgen.

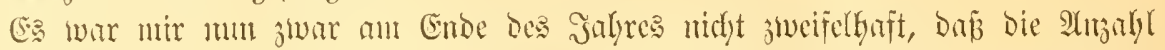

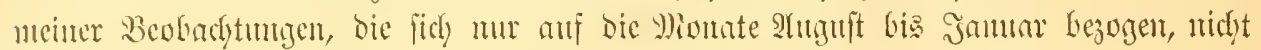

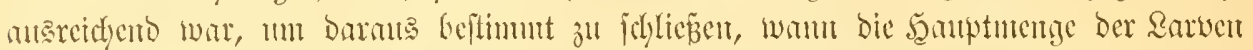

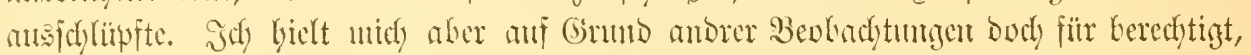

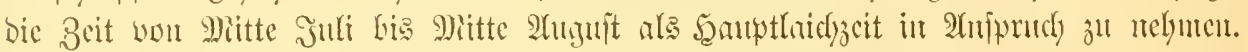

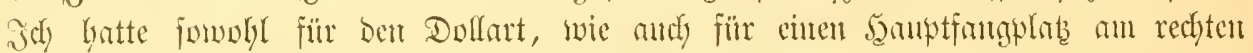

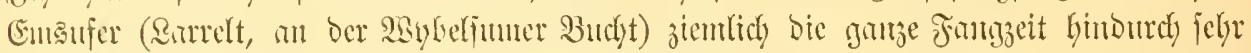

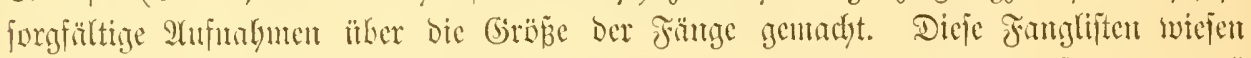

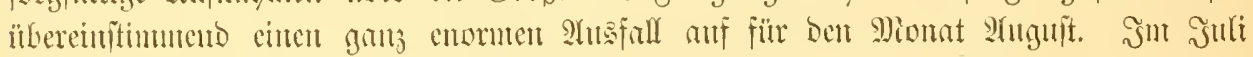
waren an Geiben Drten weit ïber Doppelt, un Geptember fogna brental fontel Granat

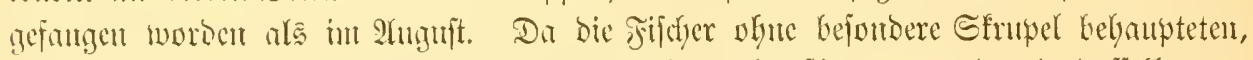

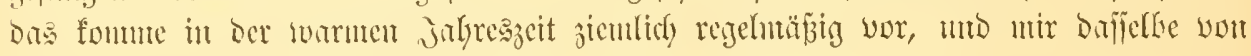

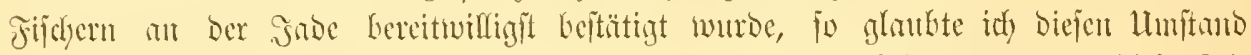

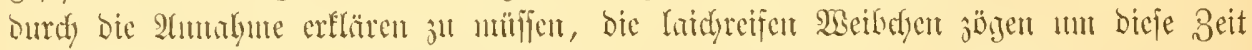

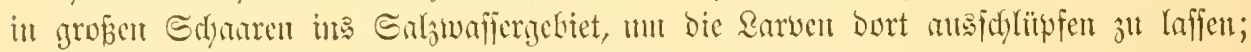

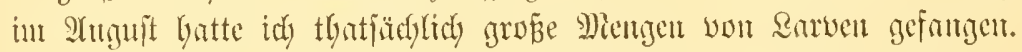

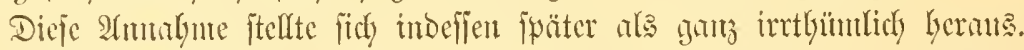

2(ls id) in Gommer 1889 jofort nnt Beginn bex Fangjeit Gegann bie Fang=

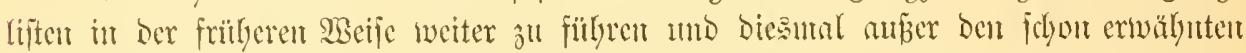

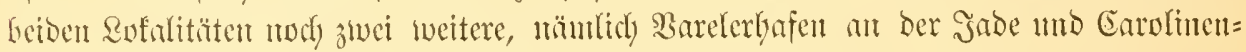

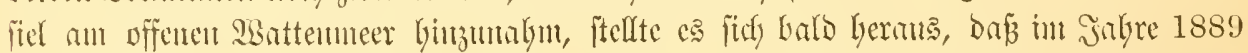

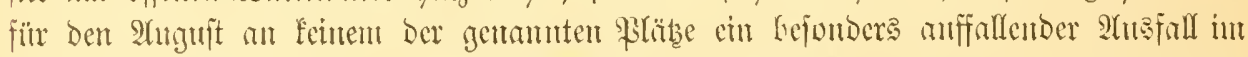

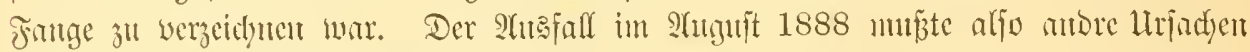

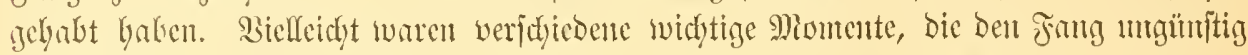

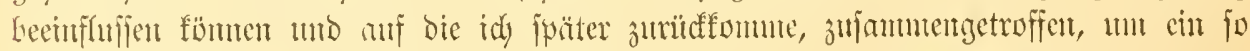

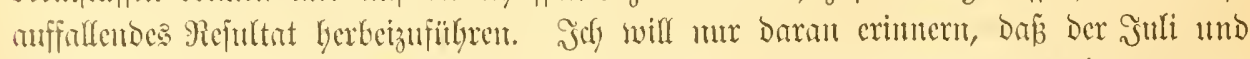

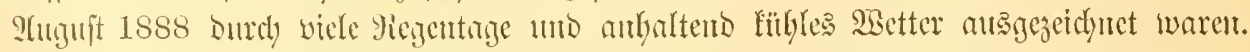

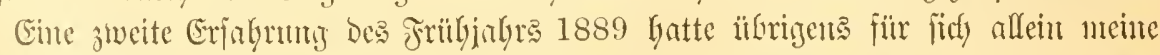

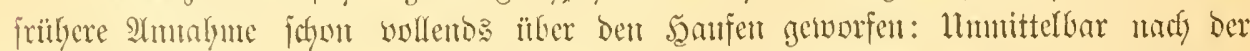

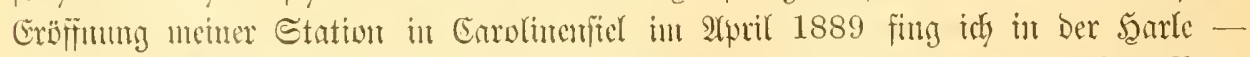

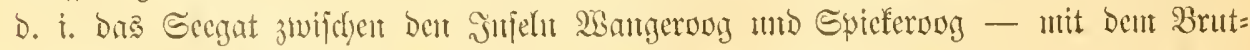

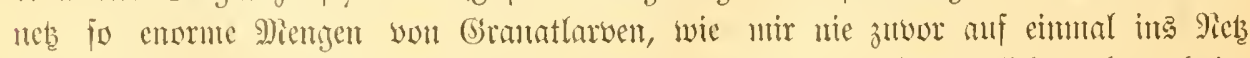

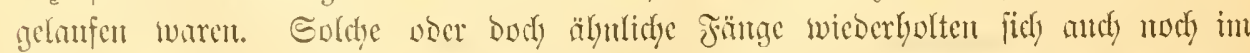

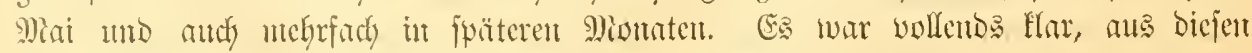

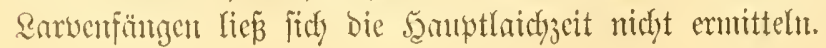




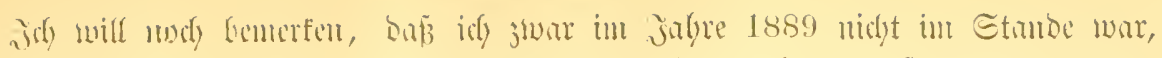

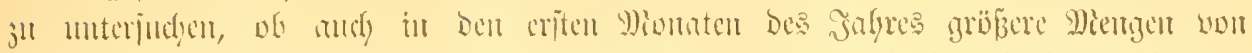

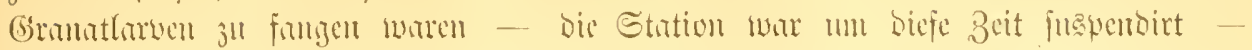

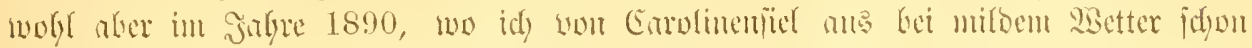

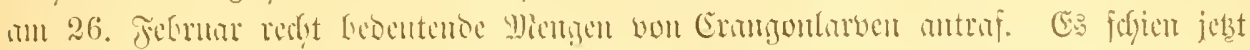

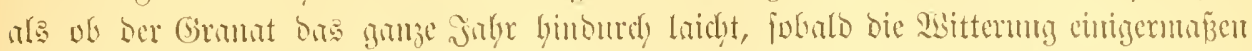

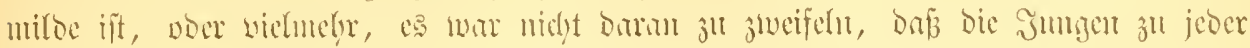

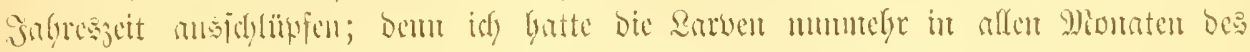

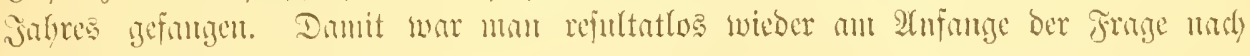
Der Ficriobijitit.

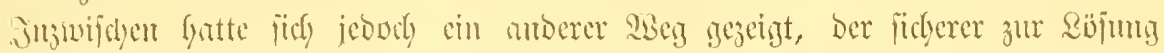
sor frimge fülyren munte.

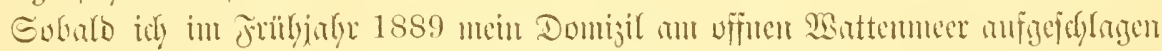

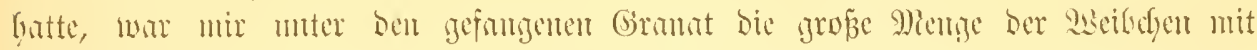

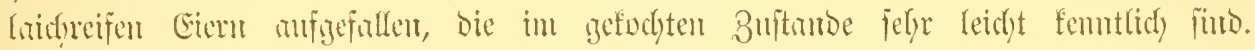

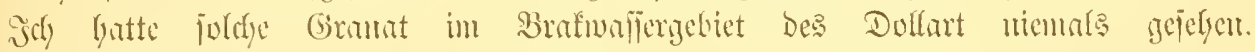

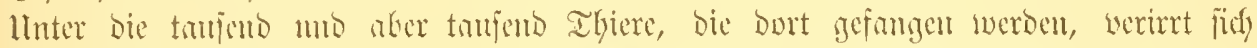

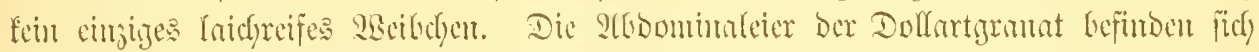

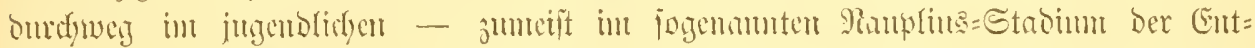

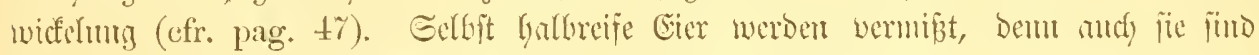

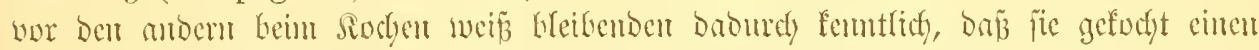
leidyt blänlidyen Edyummer erbalten, wälyend gauz reife Eier babei blau bie bumfel= violett umb fofwary werben.

Da alfo bie laidyreifen Tlyiere - juar weniger in frijdyen 3uftmbe - aber

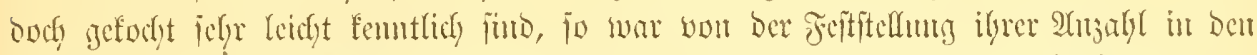

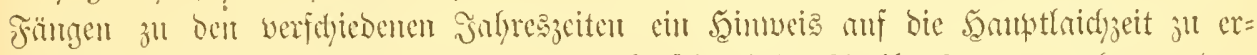

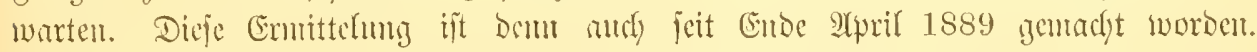

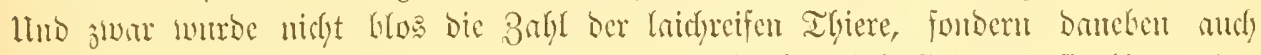

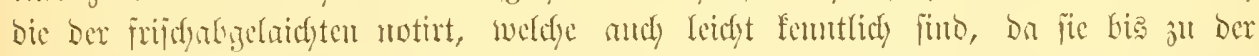

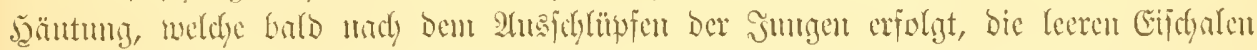

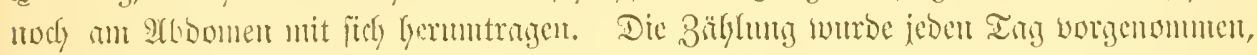

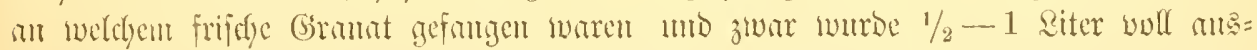

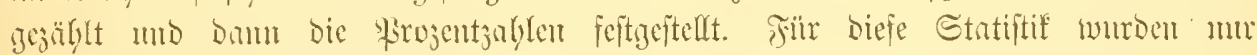

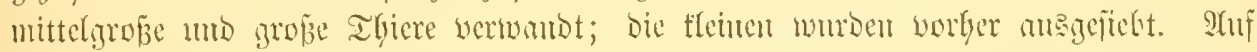

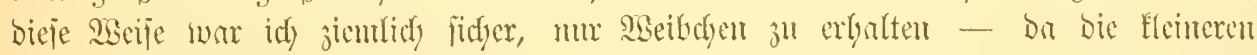

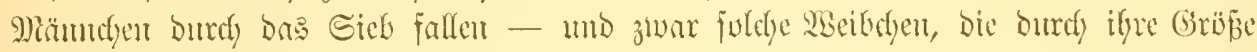

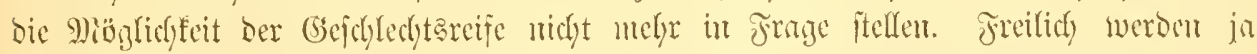

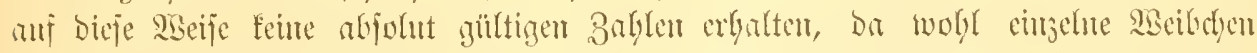

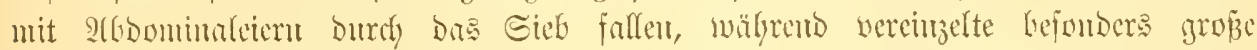

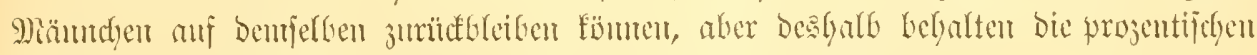

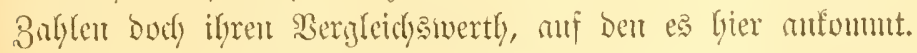

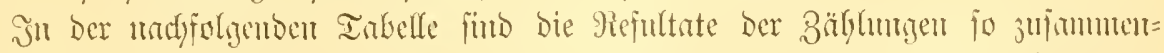

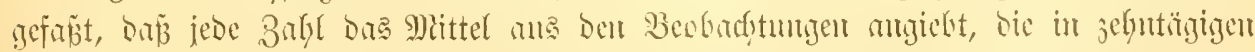

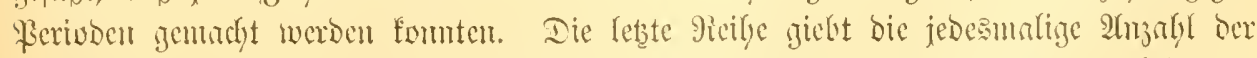

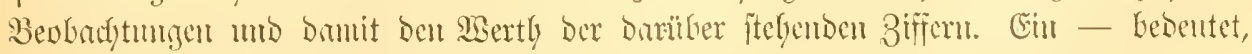
dä̈ Eeire Seokadytung worliegt. 


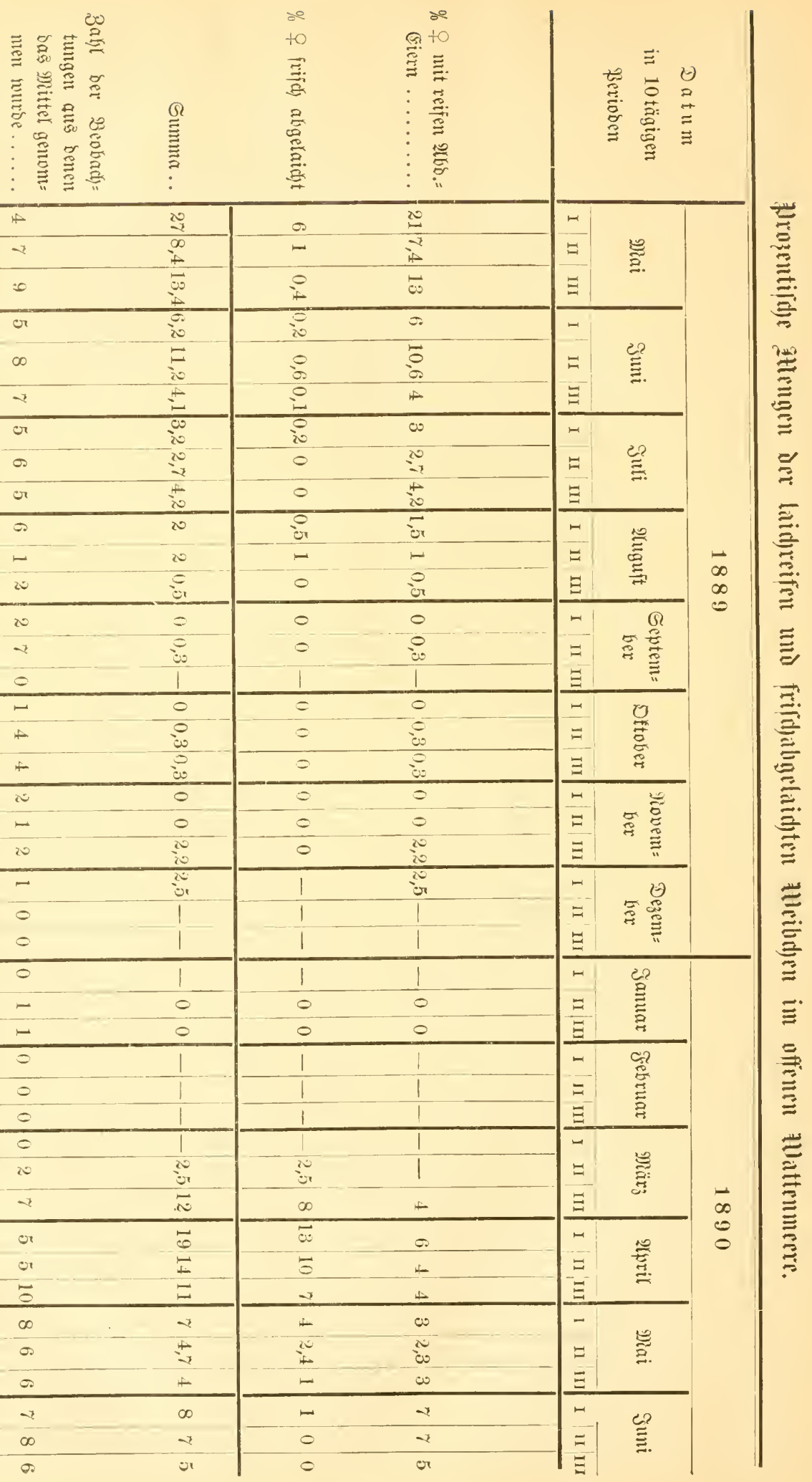




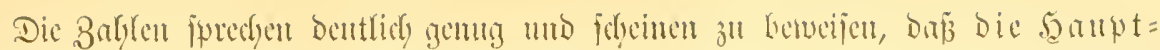

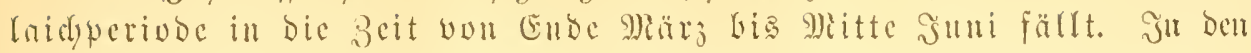

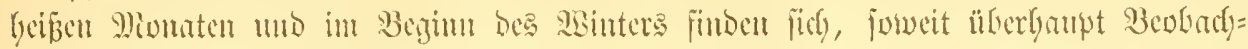
tungen worliegen, Durdywerg fleine 3 irlylen.

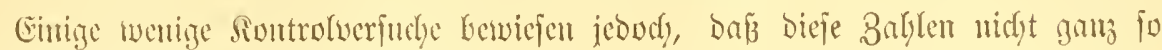

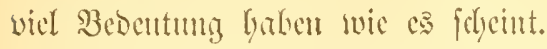

Die fïr bie Bühlungen verwertlyeten Fünge waren alfe an cin umb berjethen

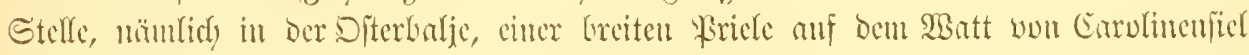

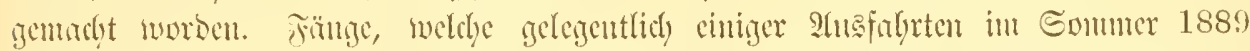

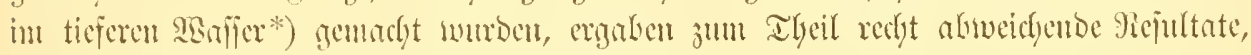
wic ans foligenoen Daten lectuorigetyt:

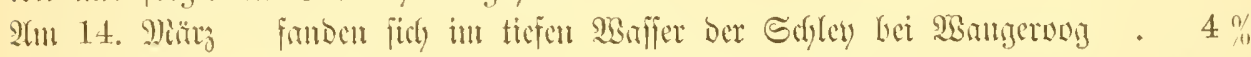

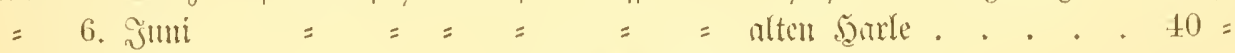

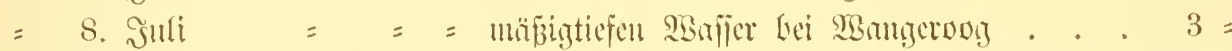

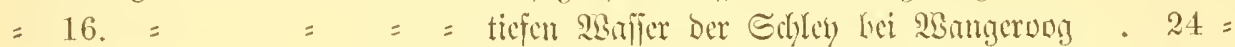

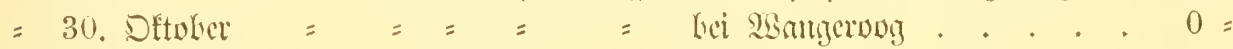

$=14$. Fiovemler $===\quad=$ Der STarle. . . . . $0=$

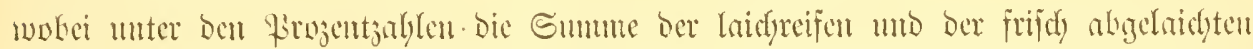

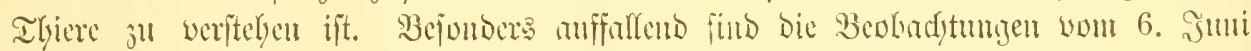

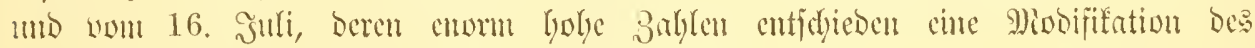
Rejultate verlangen, bas bic obrige Iabelfe ergiebt.

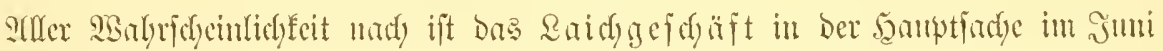

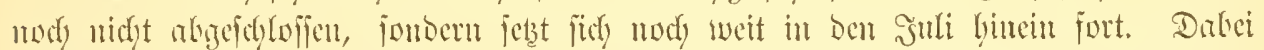

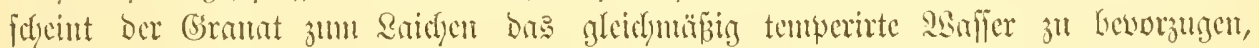

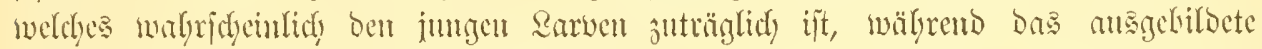

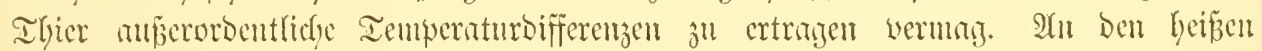

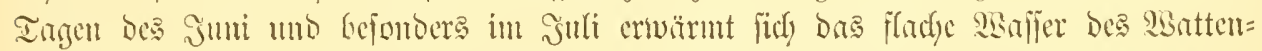

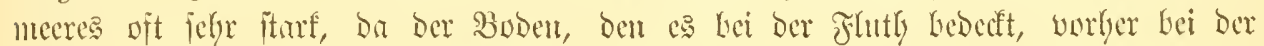

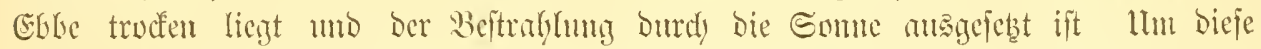
Beit findet bre saidyen wefentlid) mu nody in tieferen sisnifer itatt, weldyez geringeren Temperinturidjwanfungen unterworfen ift.

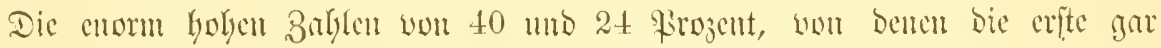

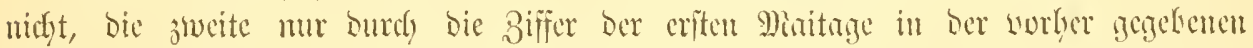

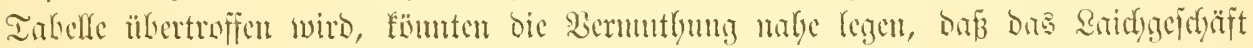

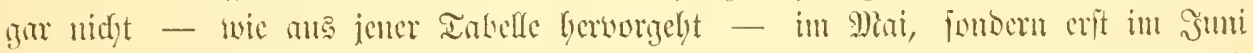

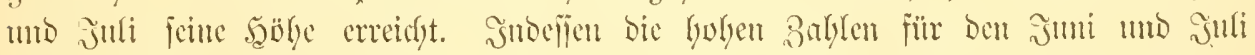

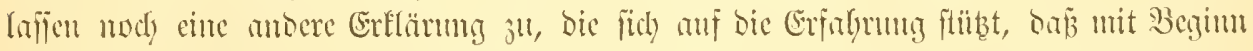

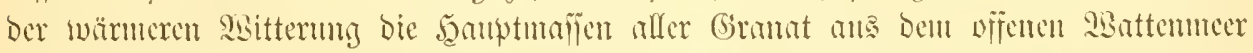

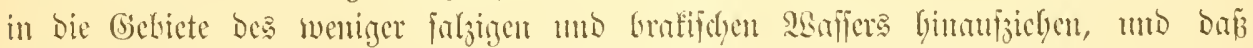

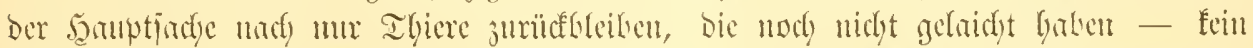

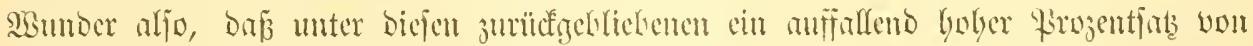
Inidyreifen unt frifdyabgelaidyten Thieren gefunden umurbe. -

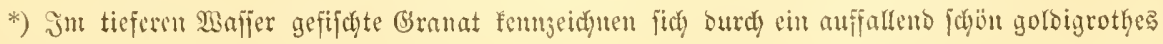
2tugenpigment. 


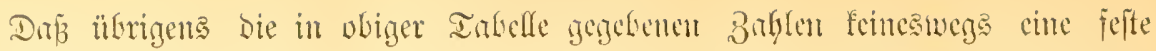

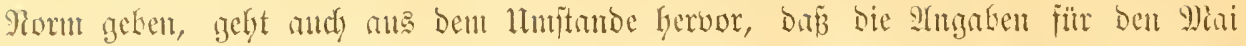

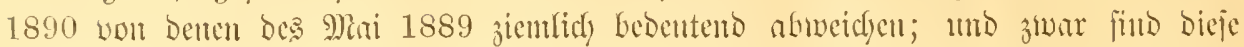

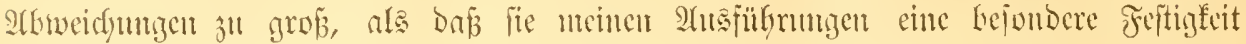

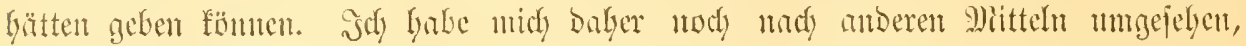

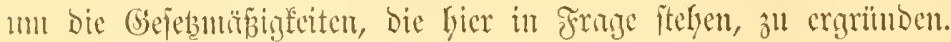

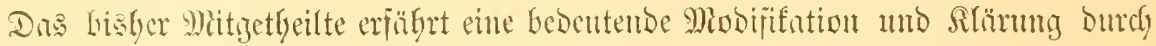

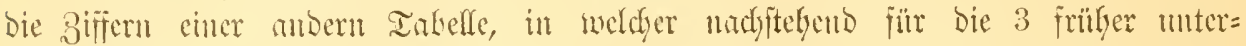

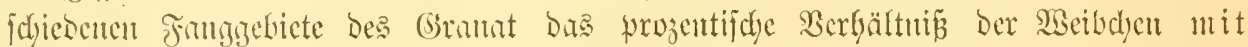

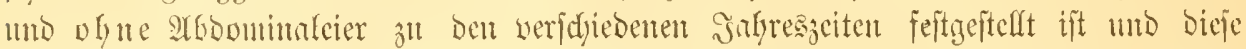

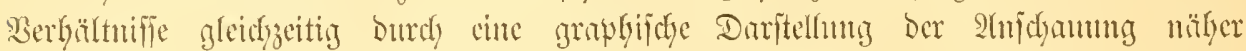

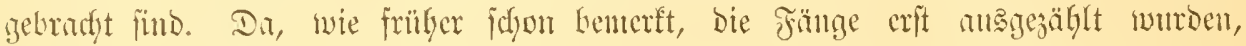

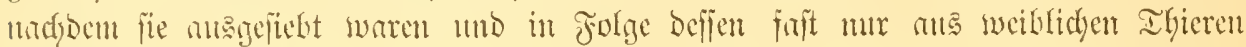

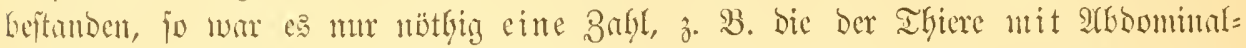

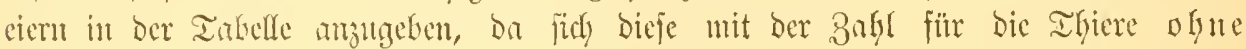
Eicr imuner ว̆ll 100 ergänzt.

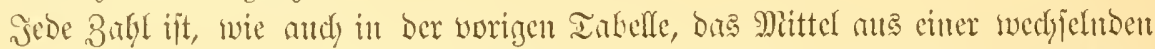

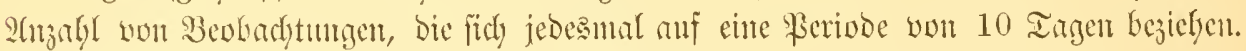

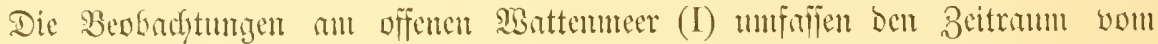

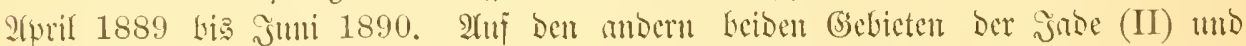
Des Dollart (III) wutroen mur in Der 3eit wom Mai fia Poventher 1889 Potizen

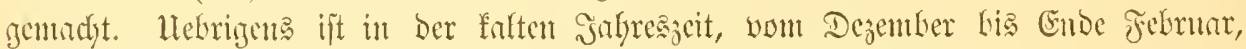

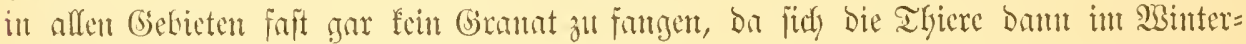
lager lefinton, bas fie mur felten werlafien.

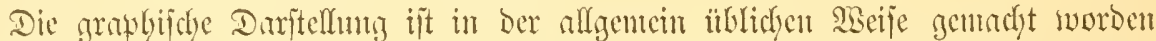

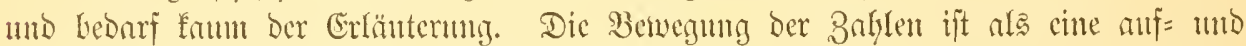

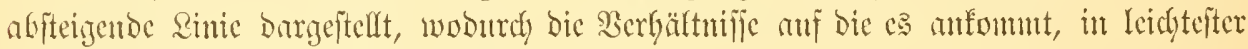

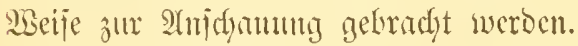

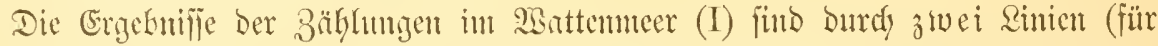

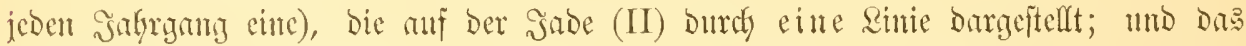

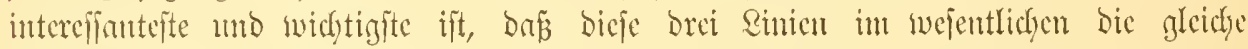

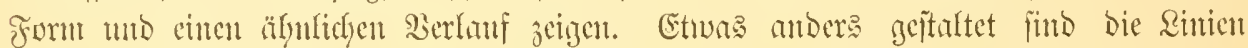

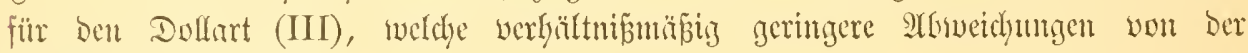
bูorizuntalen anfipeiju. 


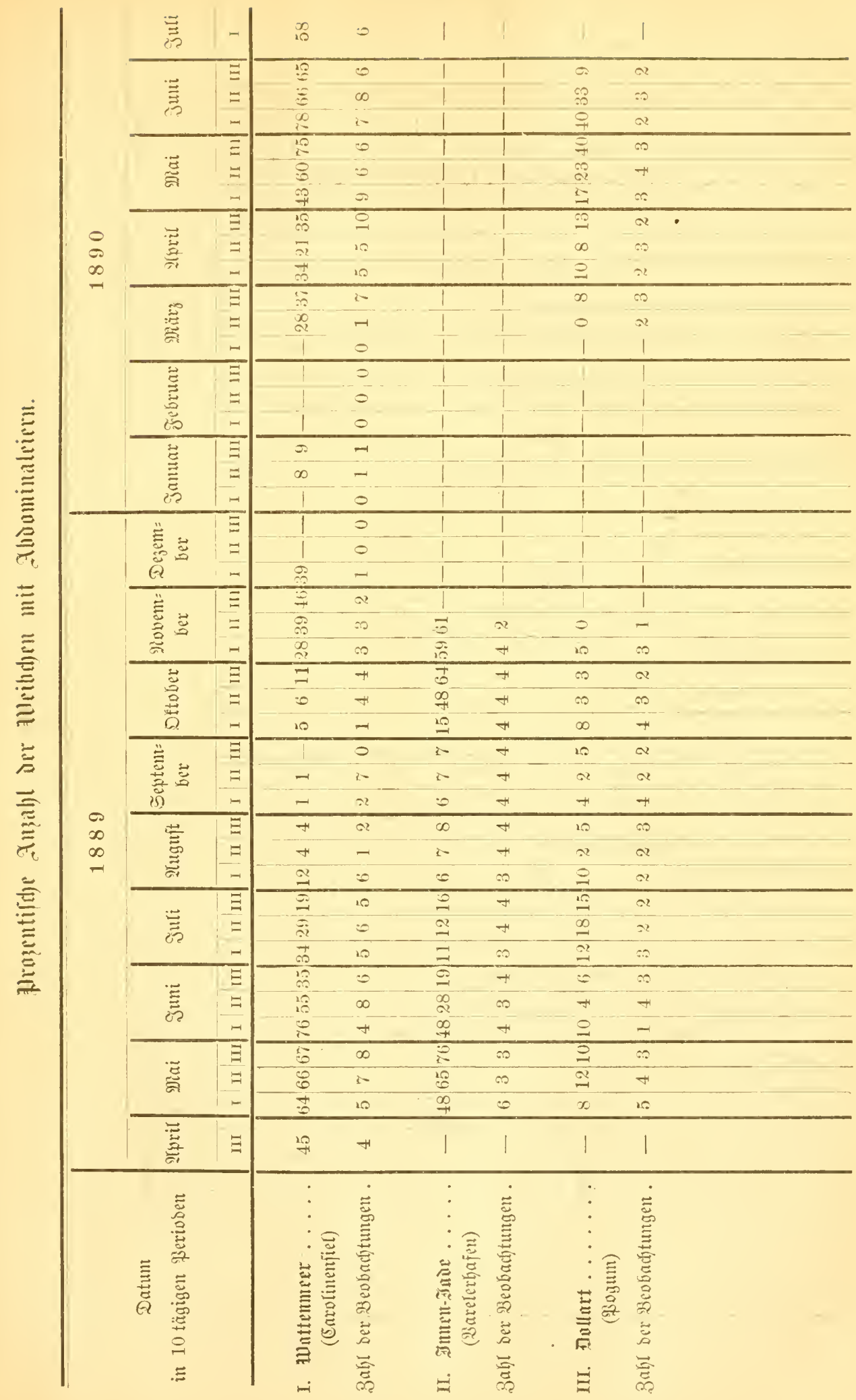




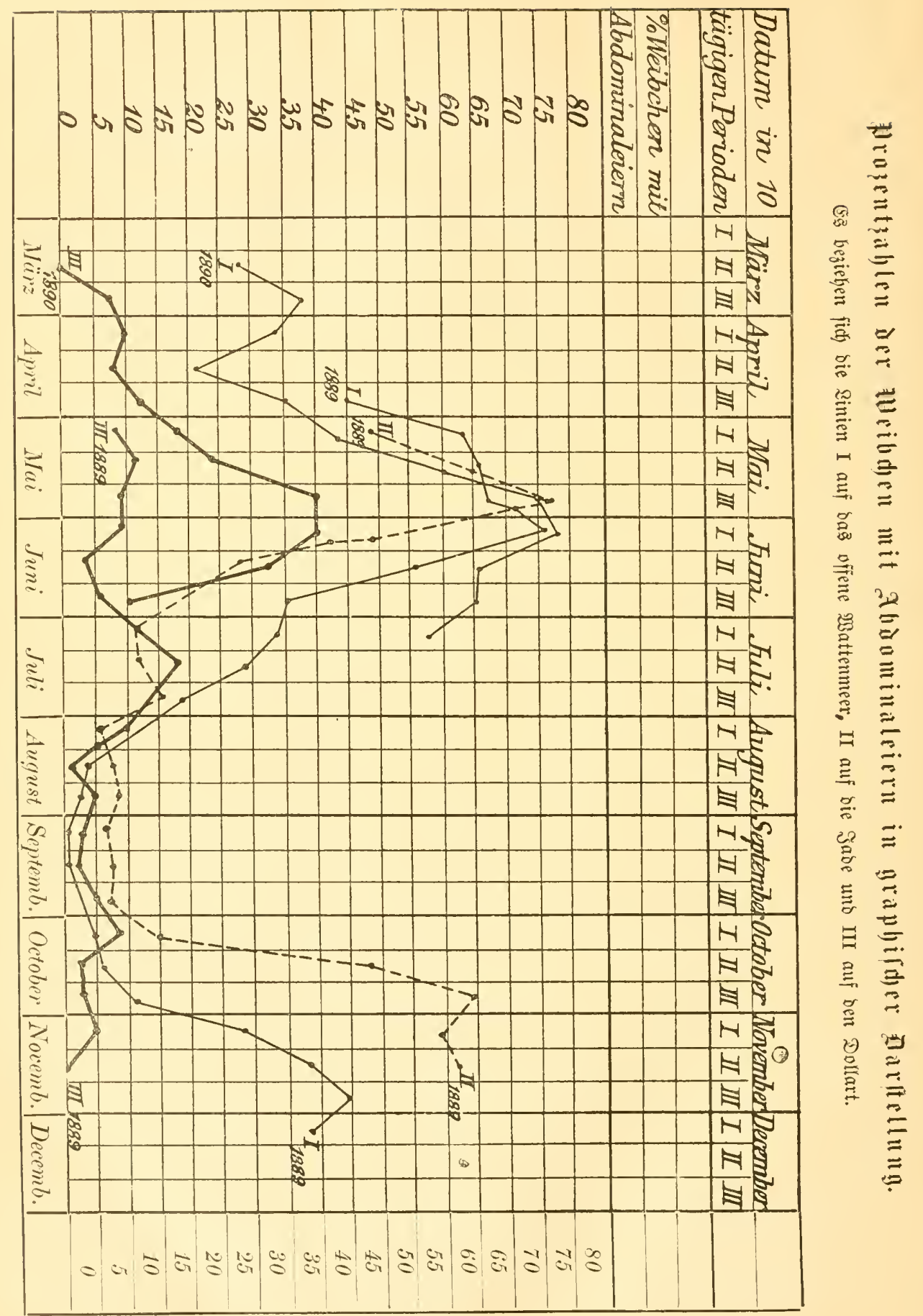




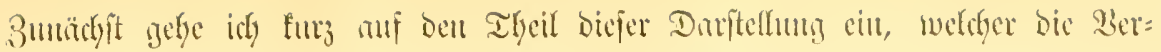

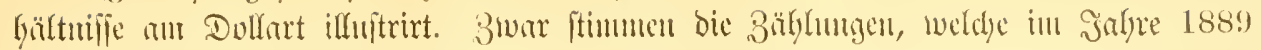

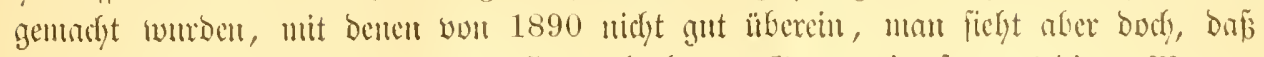

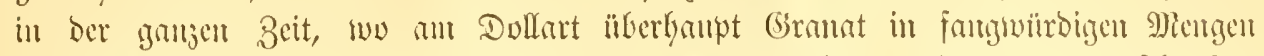

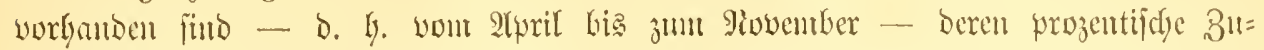

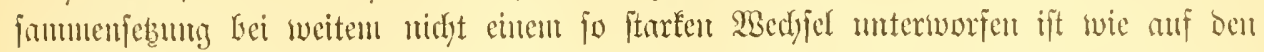

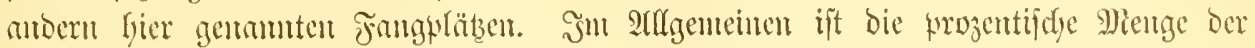

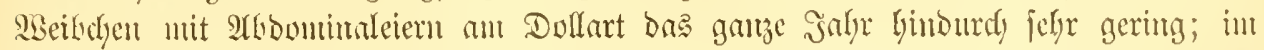

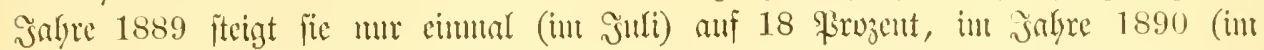

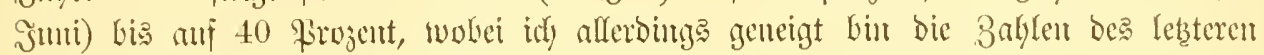

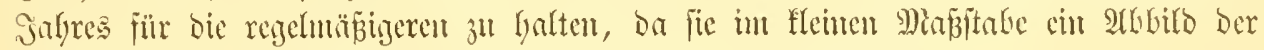
Berfältuifife anf ber Sabe mo in vifnen sBattemueer baritellen.

Giegt man einftweilen ab von biejer eimnaligen mo fidnelf voribergebenton

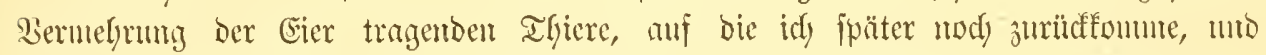

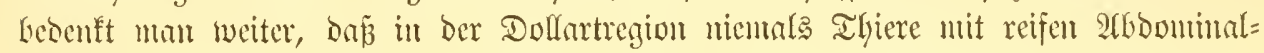

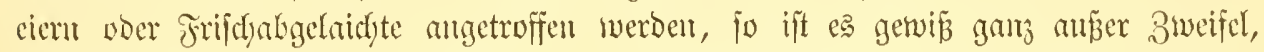

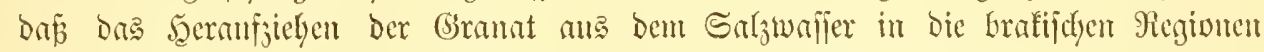

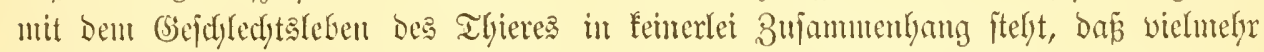

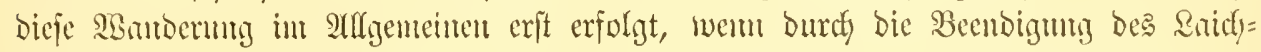

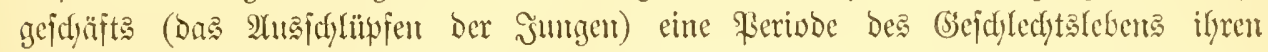

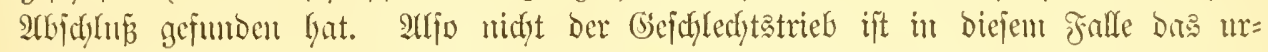

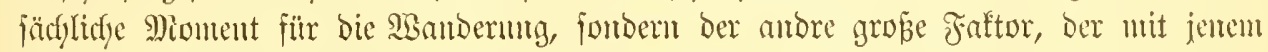

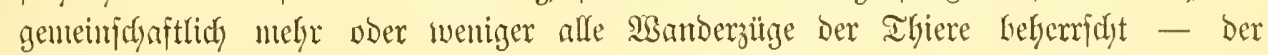
galyrumgetries.

Mährento bas Gorfgelegene fdywady falzige Dollartgebiet einen eigentartigen

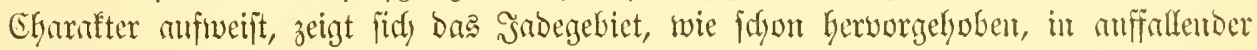

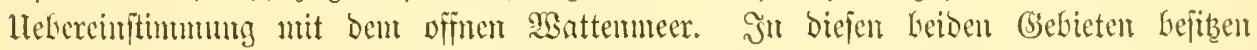

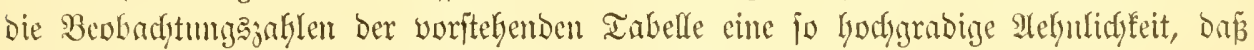

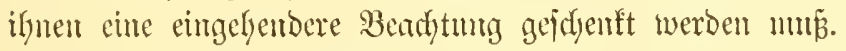

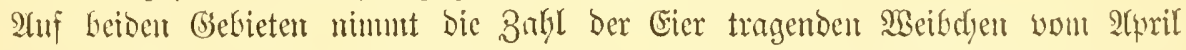

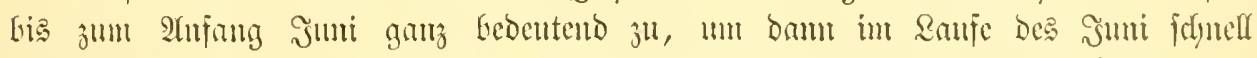

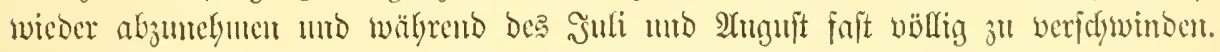

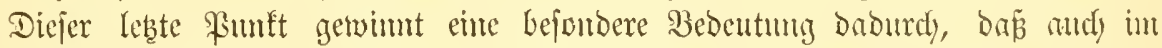

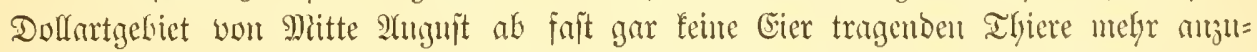

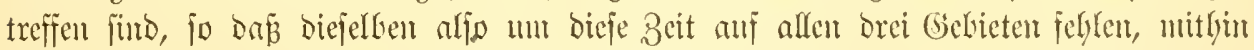

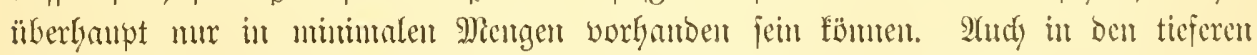

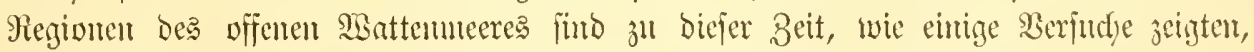

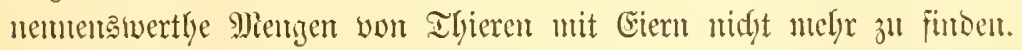

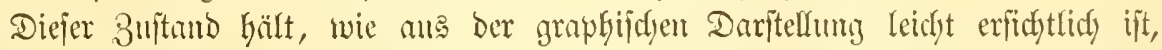
bis Ende Septenter und $\mathfrak{A n f a n g}$ Dftober an; Dam tritt wieder eine plöblidje Rentorutg ein.

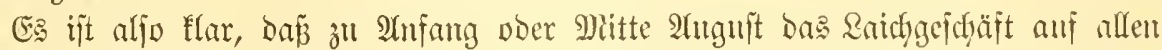

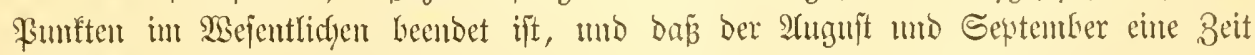

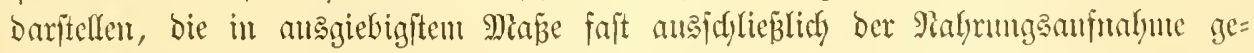

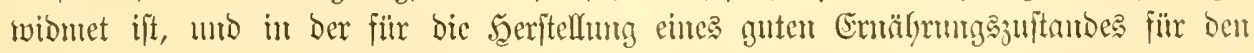
Begum des MButers Sorge getrigen wirs. - 


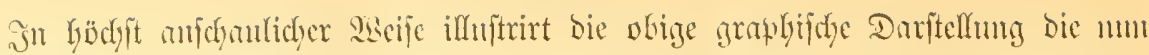

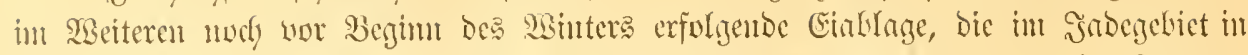

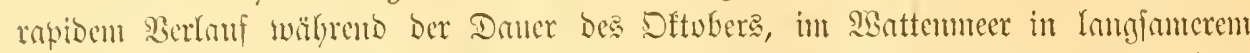

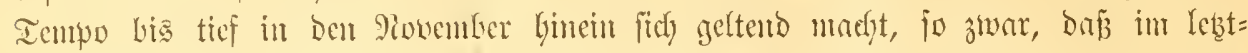

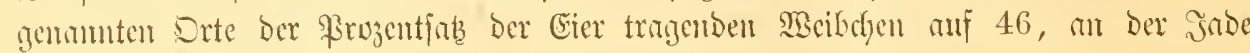

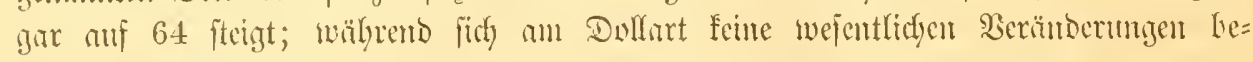
merfirar madyen.

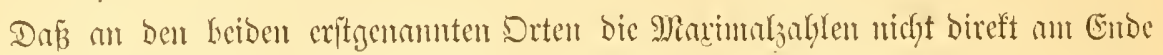

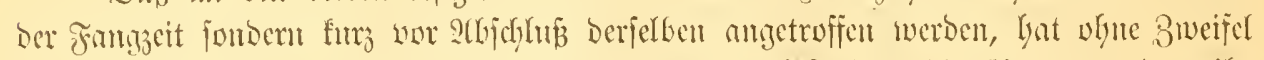

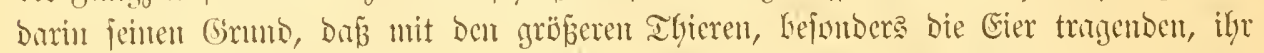

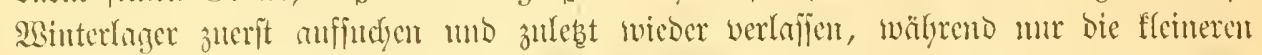

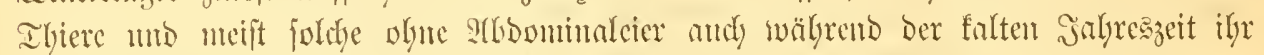

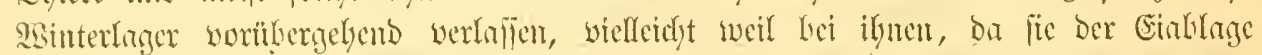

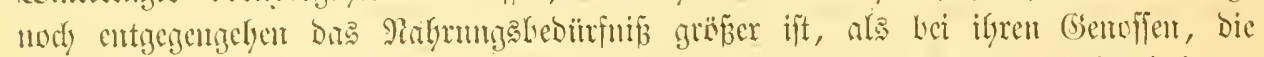
gejum beijulictoutten.

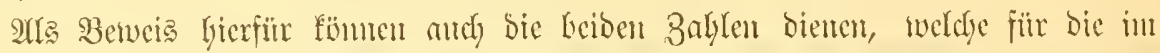

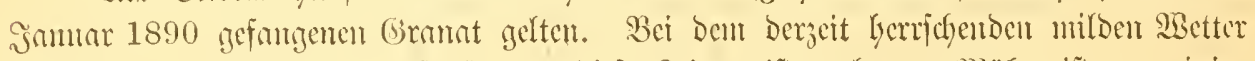

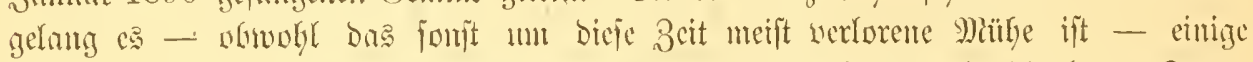

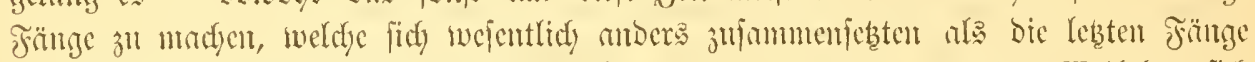

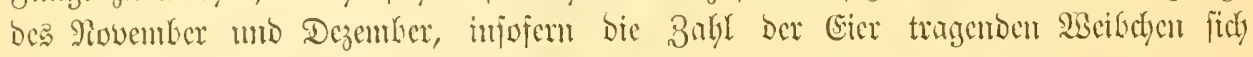
unr anf 8 แmb 9 Frozent belicf.

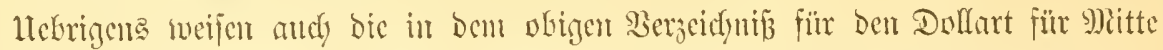

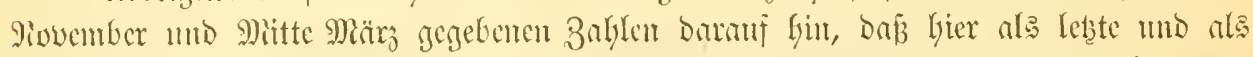

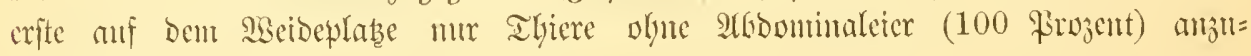
treffen fints.

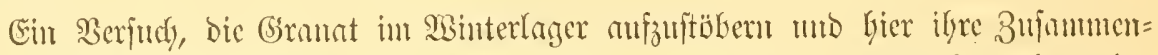

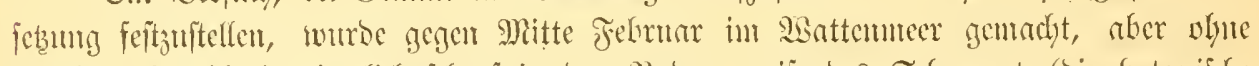

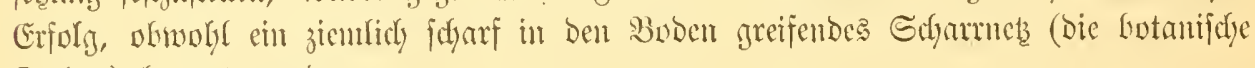
Dreoge) Genutit wurbe.

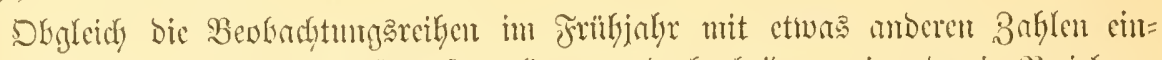

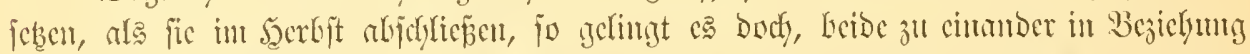

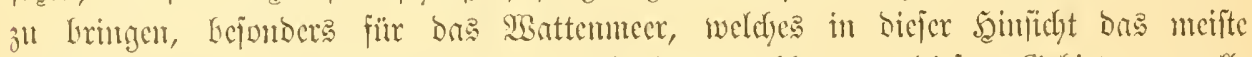

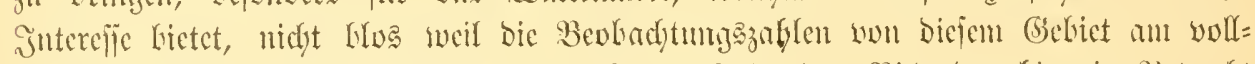

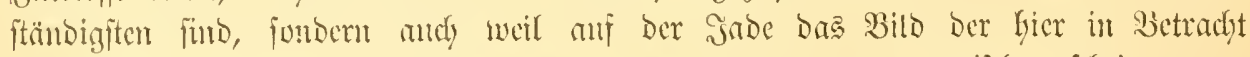

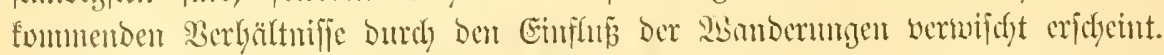

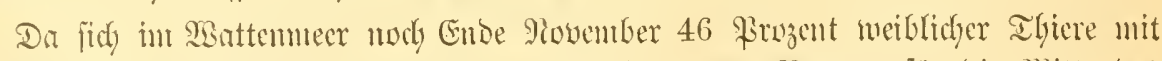

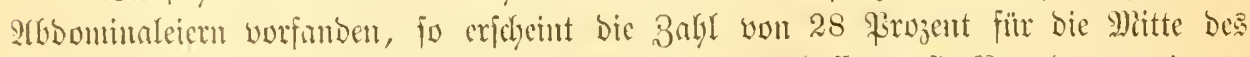

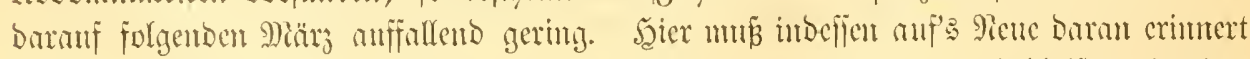

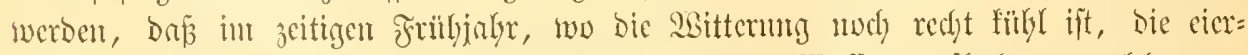

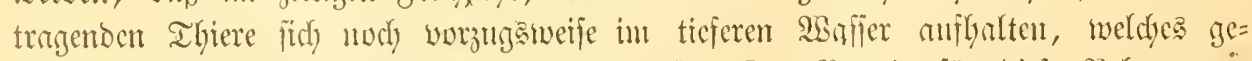

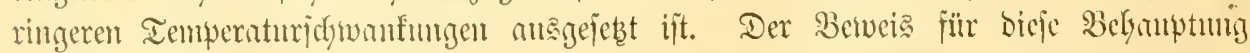

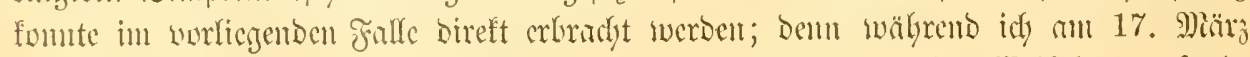

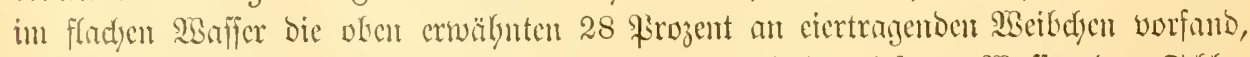

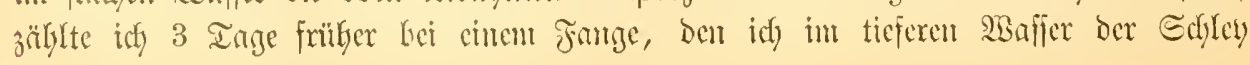




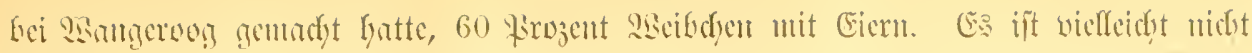

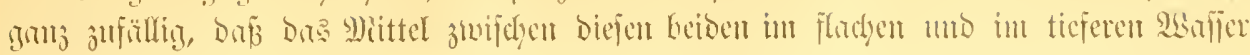

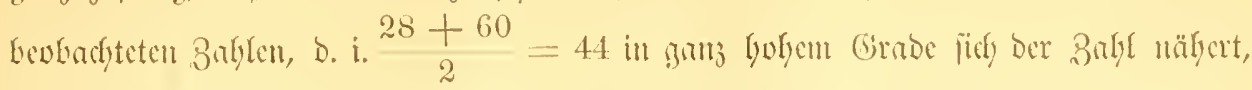

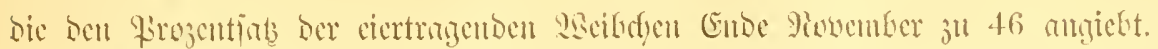

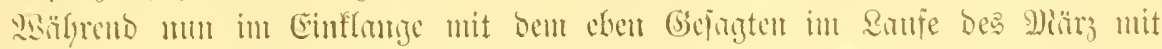

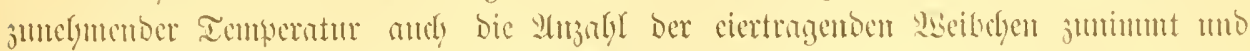

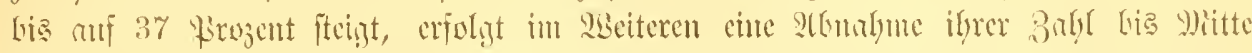

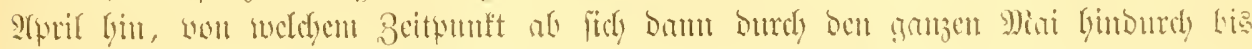

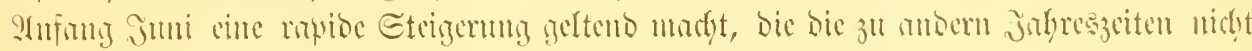

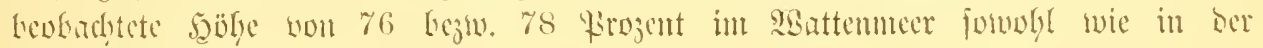
Sate erreidyt.

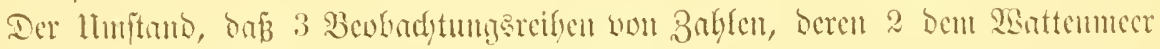

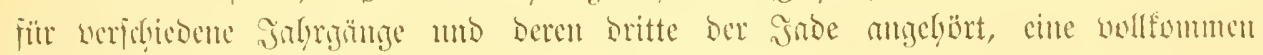

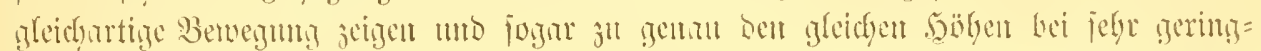

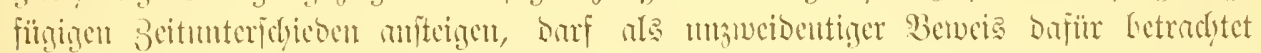

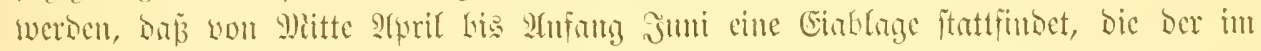

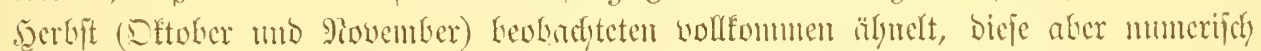

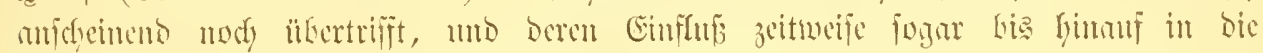

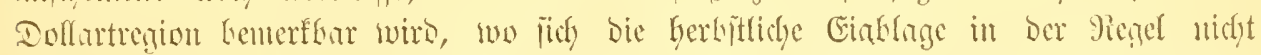

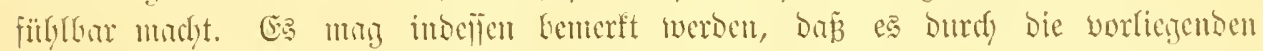

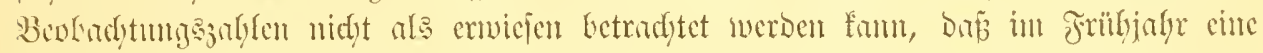

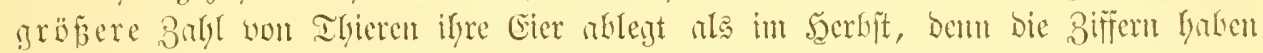

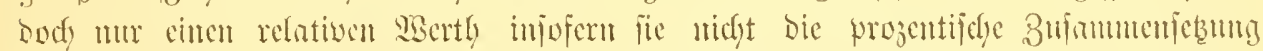

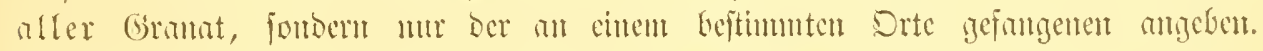

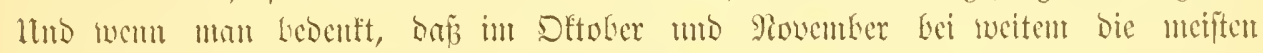

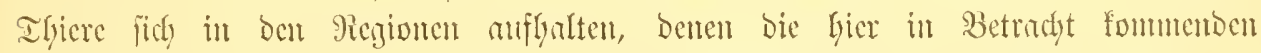

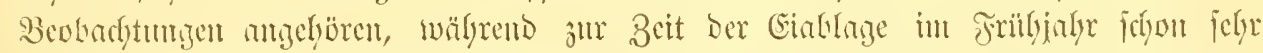

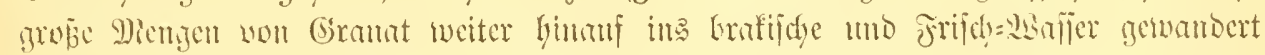

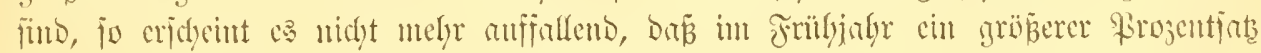

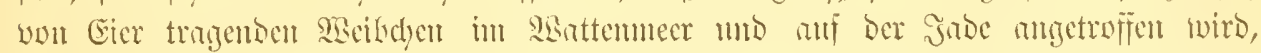

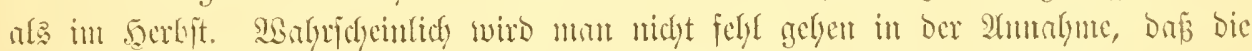

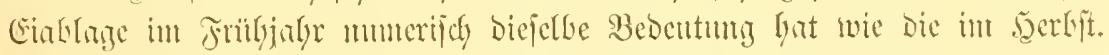

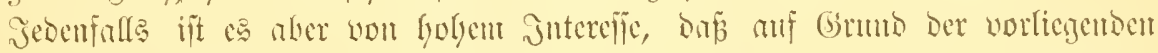

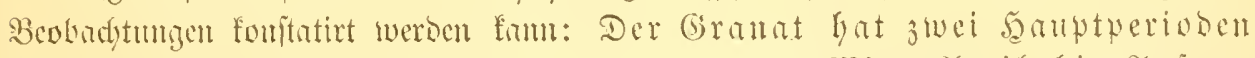

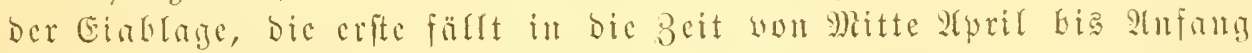
Suni, dic jueite in ben Dftofer mo Rivember.

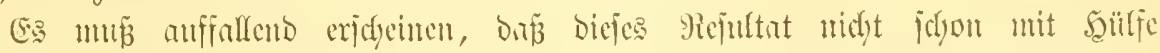

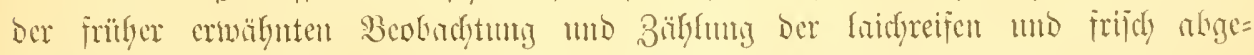

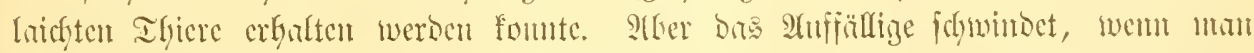

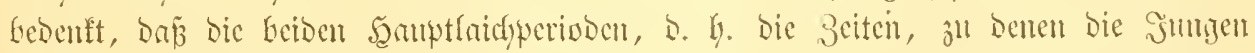

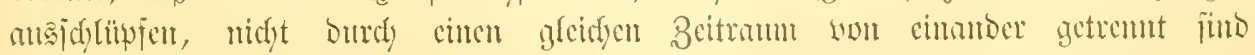

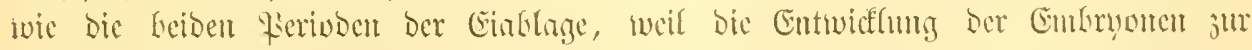

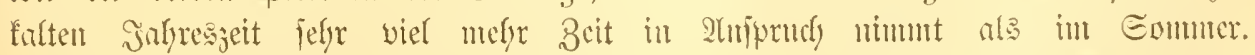

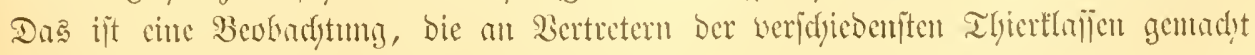
worden ift. 


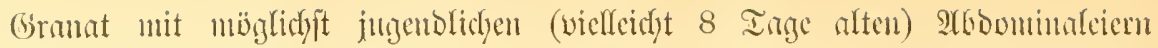

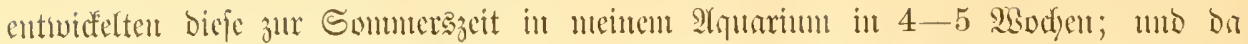

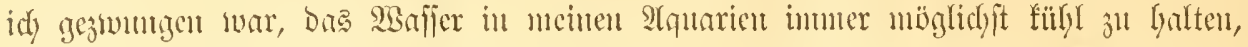

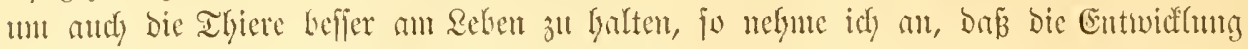

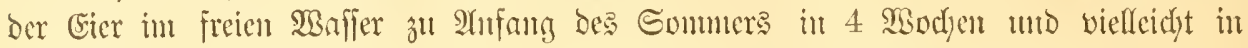
nod) Kürzerer 3eit verlünft. Freilid) barf nidyt wergeffen werbent, baj bie Grmat mit

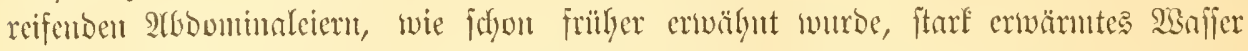

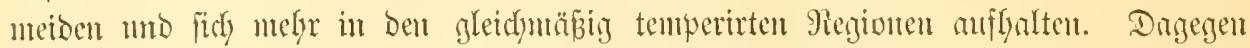

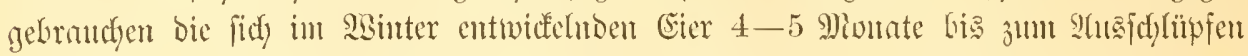

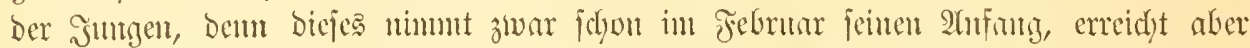

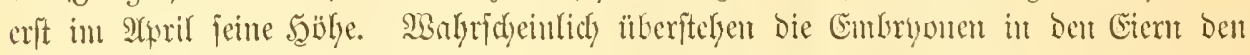

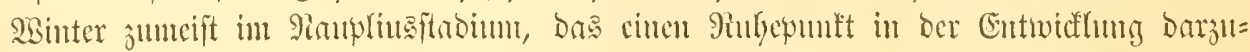

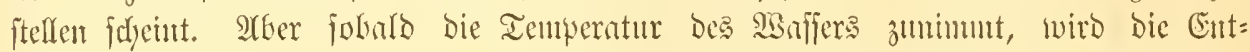

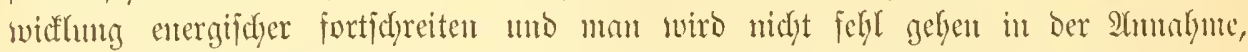

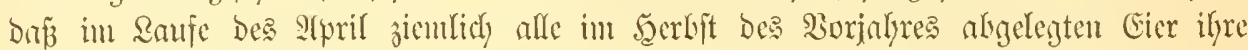
Entrinonen entlafjen lyaten.

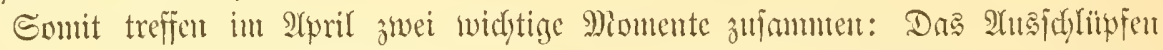

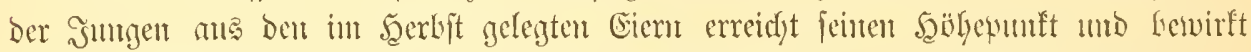

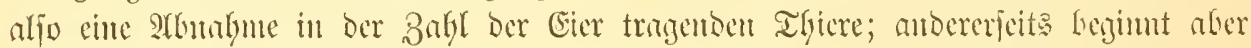

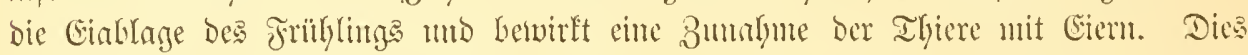

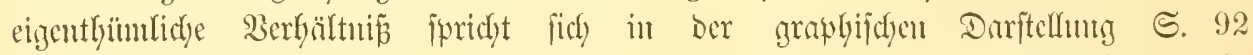

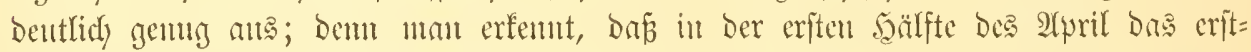

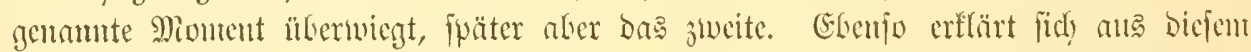

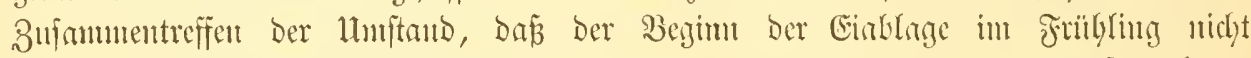

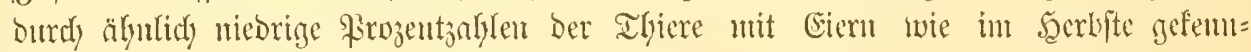
zeidjuet ift.

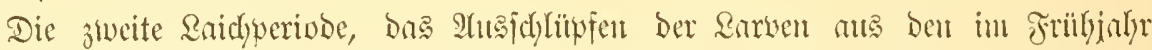

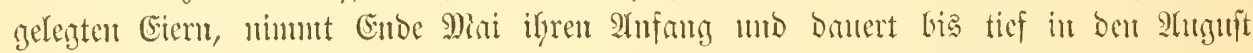

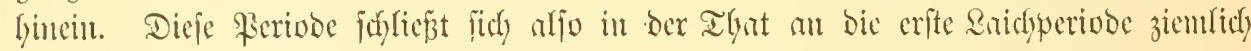

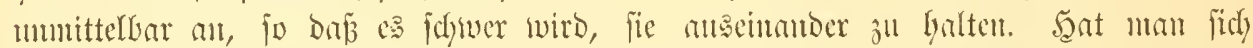

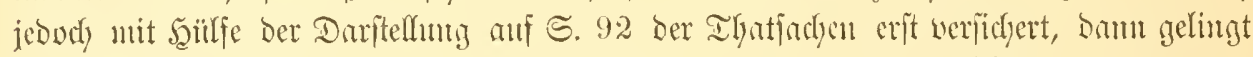

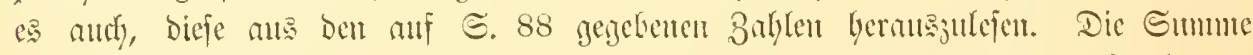

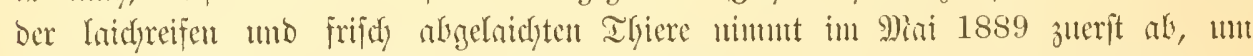

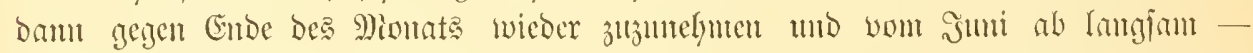

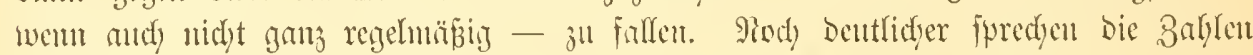

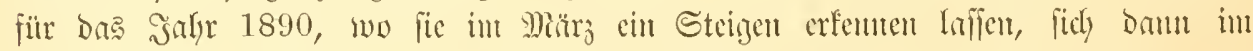

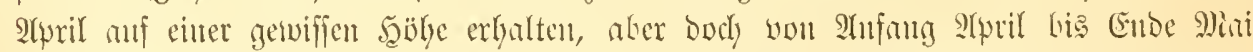

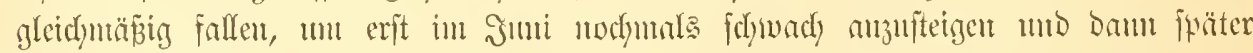

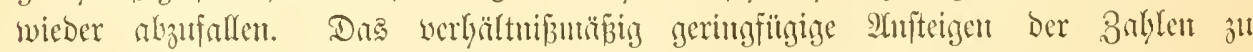

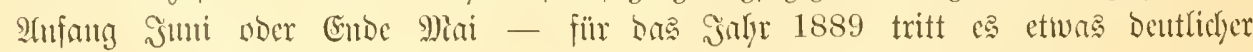

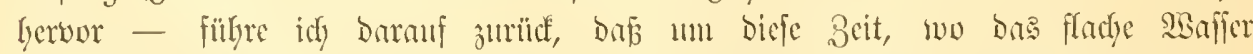

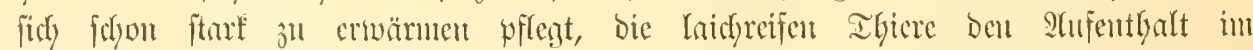

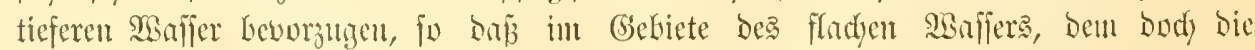

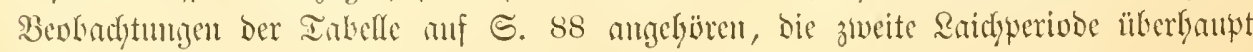
wenig bemerfbar wirb. 


\section{Lerfyulteu ber Miöund)u.}

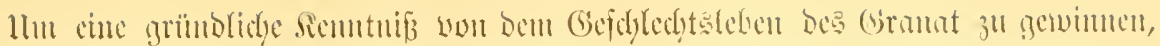

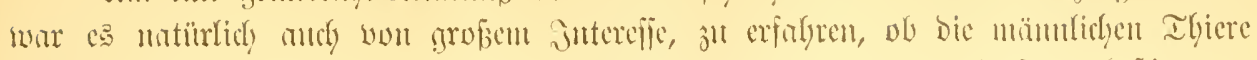

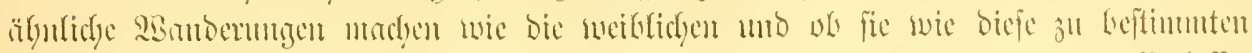

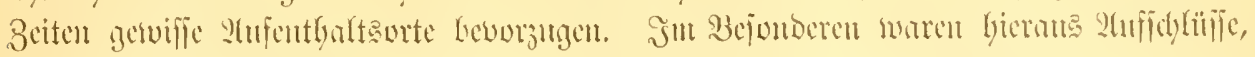

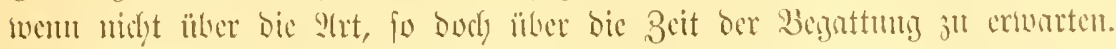

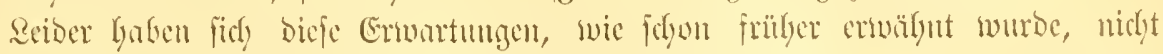

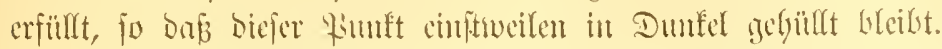

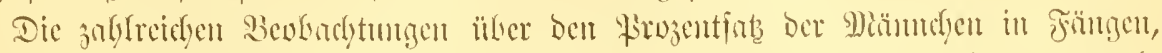

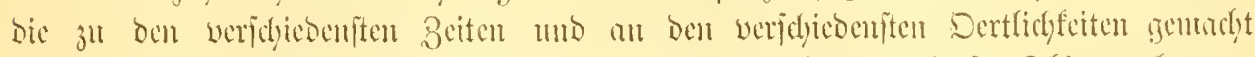

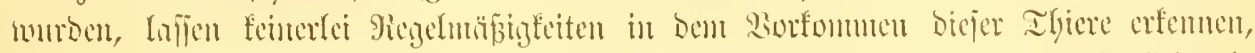

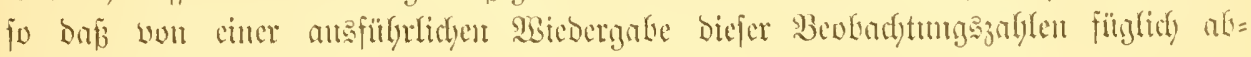
gejefyen werben fum.

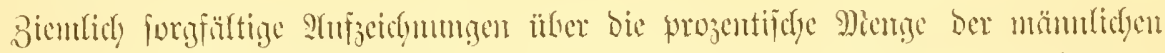

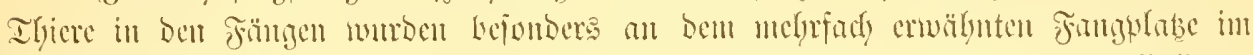

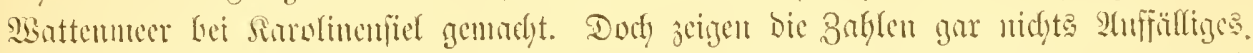

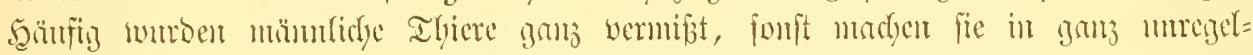

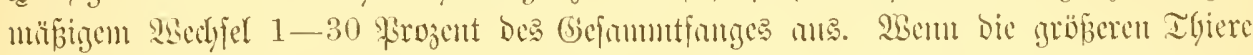

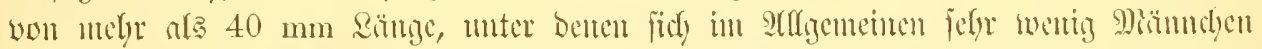

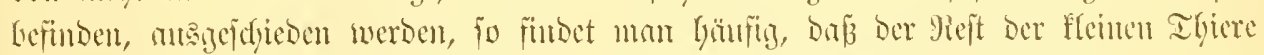

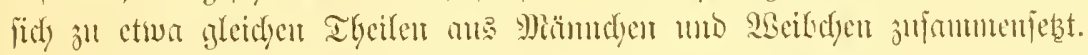

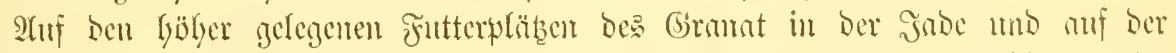

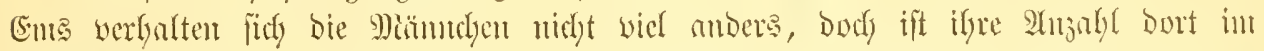

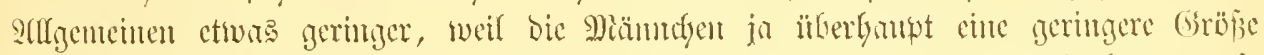

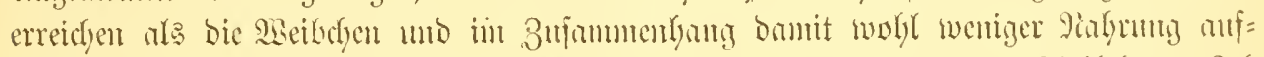

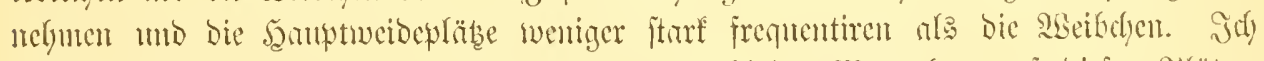

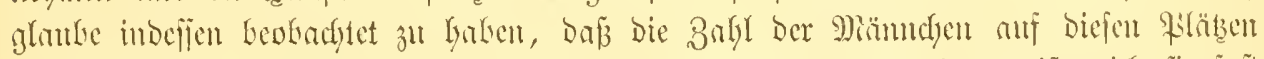

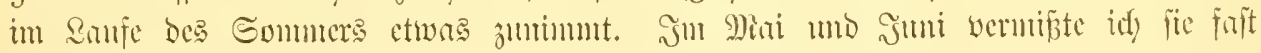

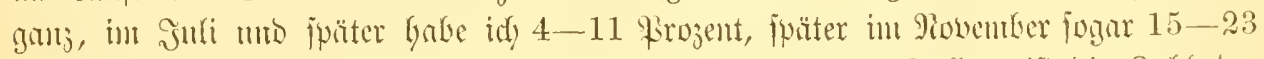

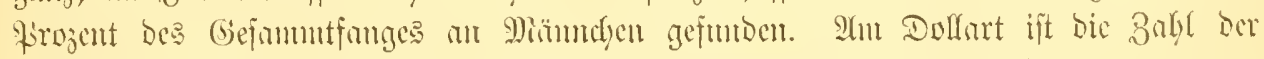

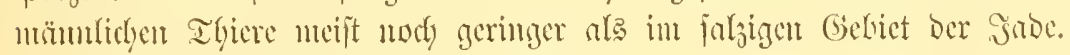

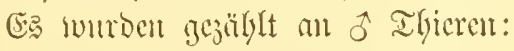

\begin{tabular}{|c|c|c|c|c|c|}
\hline & im Miẗrz & S̃ıni & Juli & Dftrber & Tiowember \\
\hline aun Doffart. & $0 \%$ & $0 \%$ & 4,1 น. $11 \%$ & $4,5 \%$ & $15 \%$ \\
\hline allf der Jatoc & - & - & $4,6 \%$ & $20 \%$ & $23 \%$ \\
\hline
\end{tabular}

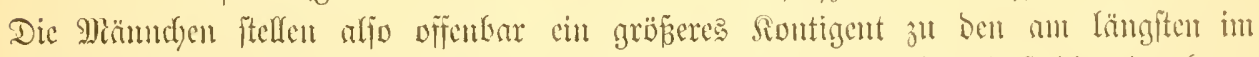

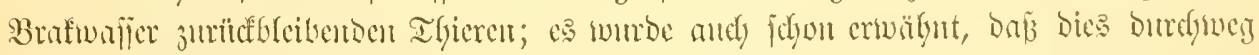
flemere Ifyiere finto.

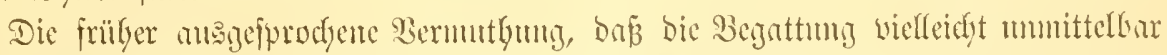

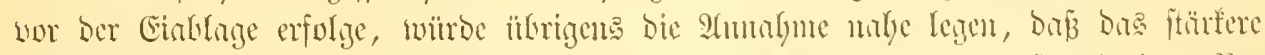

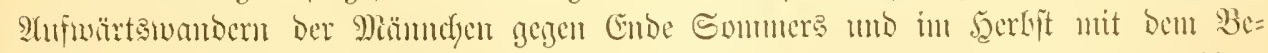

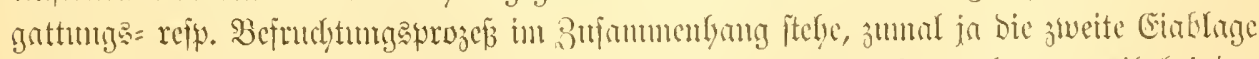

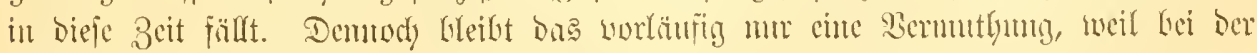

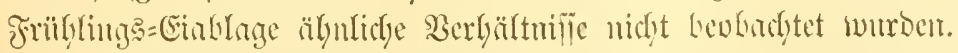

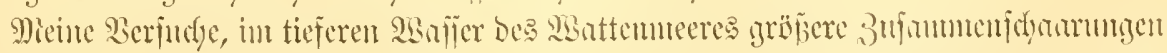

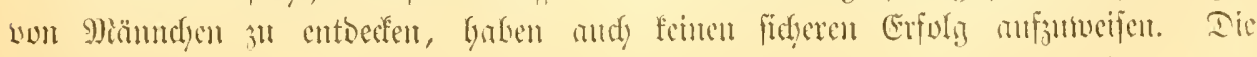




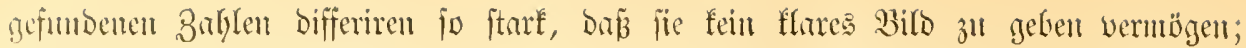

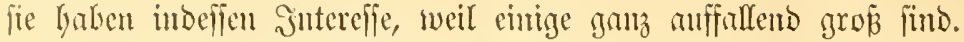

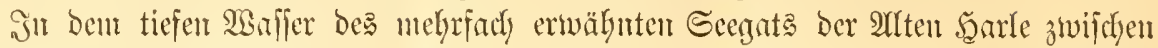

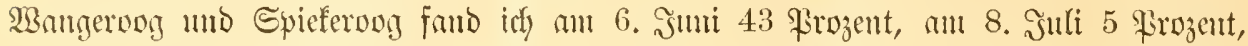
aur 30. Dftober 3 Frozent, an 14. Soventber 7 Frozent, und in ber bentablurten Schlesy ant 14. 9)iärz 11 Prozent, am 16. Juli 25 \$rozent bes Giejumntfanges an minmlicten Ifyeren. Stm 23. Suli aluer fand iff in cinem Fange, ben idy im füb=

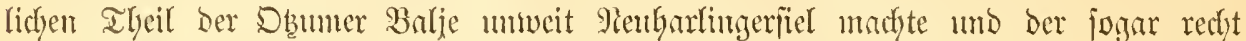
wiel groze ZGiere entbielt, bie enorme Menge won 70 Frozent Miämndyen. Diefe 3abl

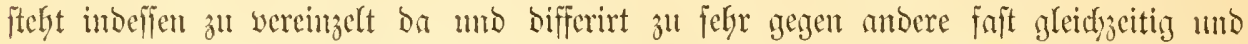

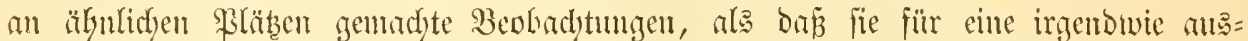

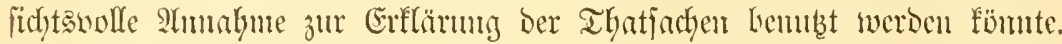

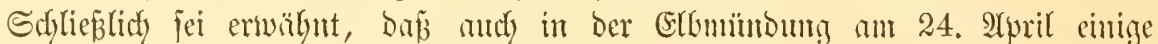

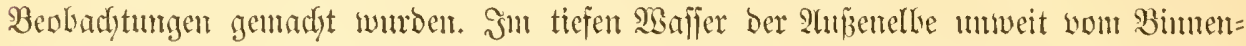

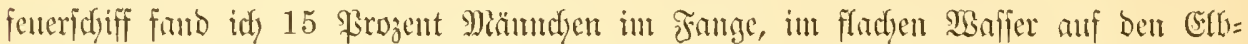
fämben querab Euthawen bagegen nur 8 Frojent. (Am criteru Drte fanden fidy auds

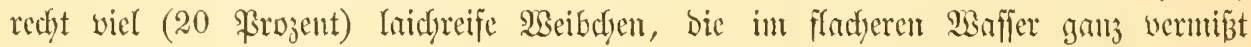
wurben.)

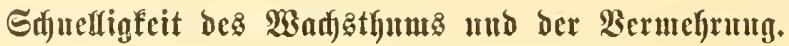

Rachben feftgeftellt worben war, bafz die Granat zjwei Raidyperioben baben, mo

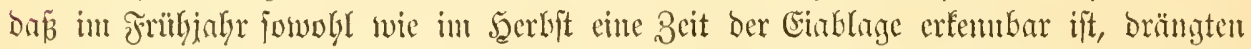

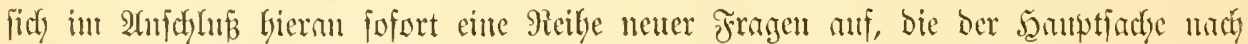

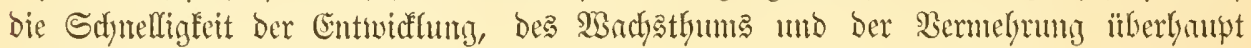
betreffert.

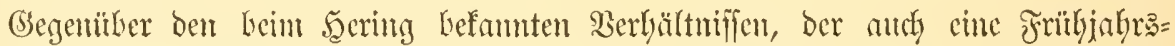

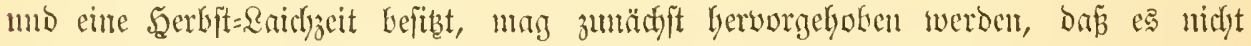
gelang, ztvijdyen Den Granat, die Der Cinblage im Serbft entfammen mo benen der Friibjabrs=Eiablage irgend weldye lluterfdyede aufufundem, audy midyt foldye, weldye

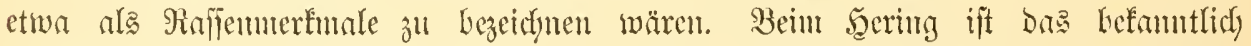

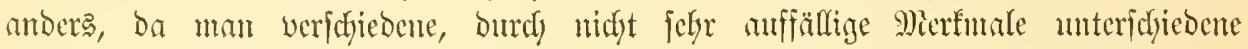

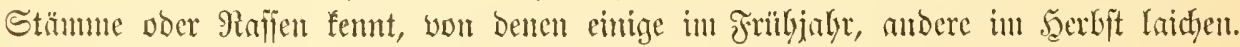

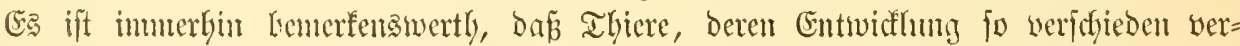
länft, wie beim Granat gezeigt werben fomnte, feine gröperen Ilnterjefrebe in Der

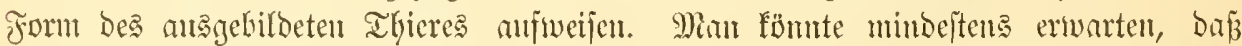

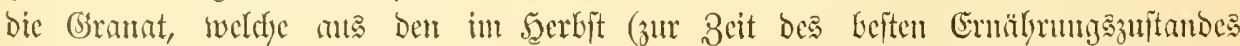

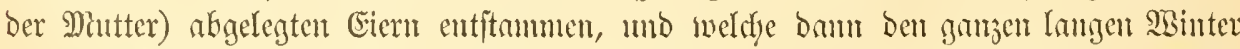

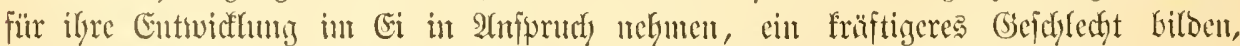
als biejenigen ifgrer Genoffen, weldye zwar zu einer wämneren umb beshalb wobl

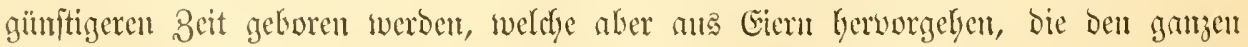

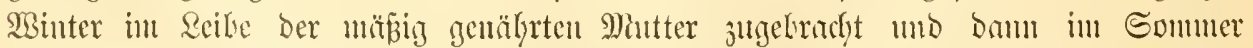

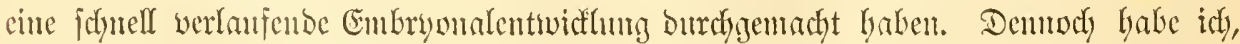
wie gejagt, feme Unterjcyiede lemerfen fümen umb glanke, daj die Granat ber

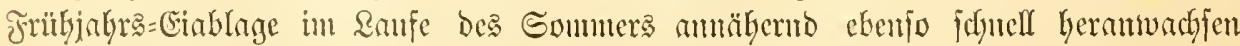
wie biejenigen, svelde ber Serbft=erablage bes 3orjabres entftammen. Sienan ge=

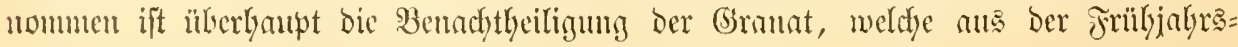




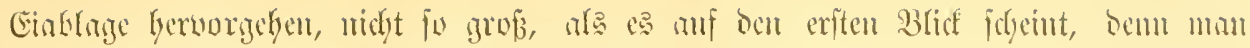

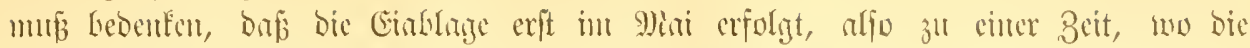

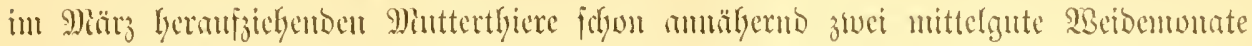
gehafit balen.

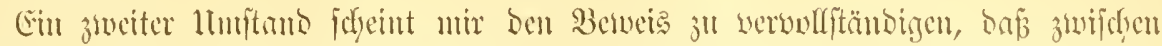

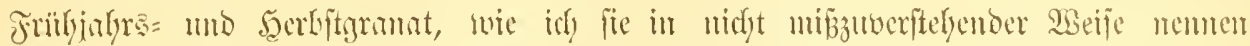

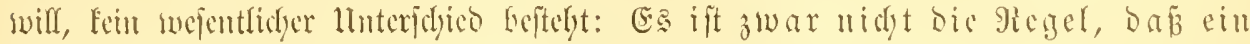

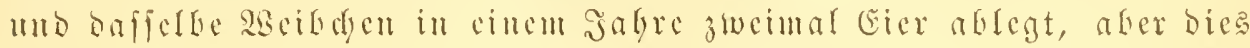

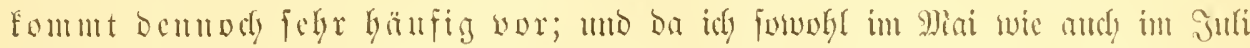

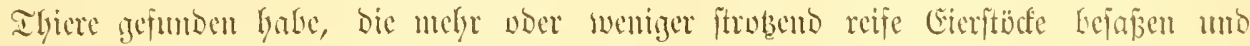

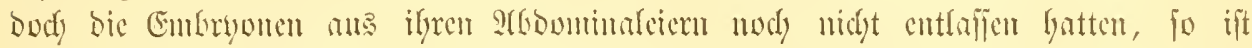

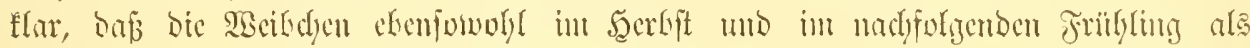

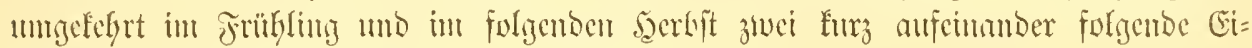
ablingen burtsyutadyen fömuch.

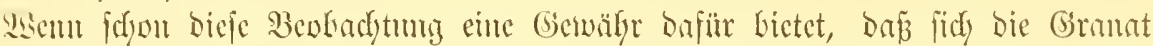

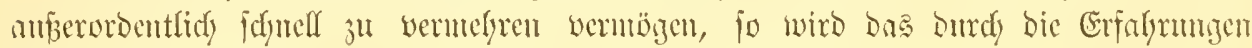
üfer bic Edyulligfeit Der Entwidflung und oce

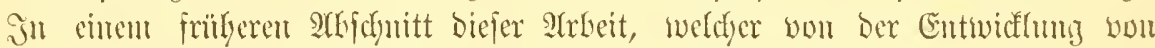

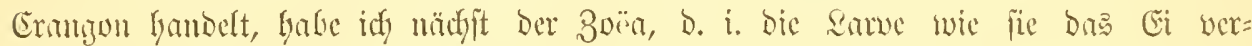

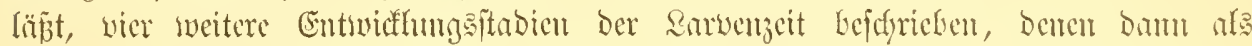

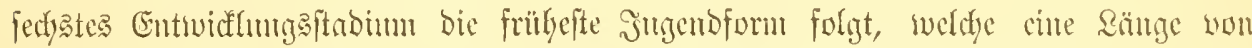

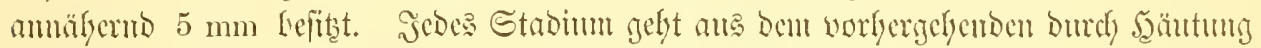

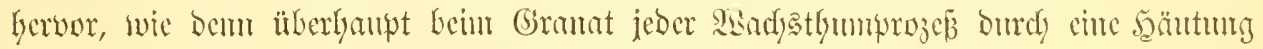
bernittelt wirb.

Dis Dauer ber Rarvenzeit genan anjugeben ift felyr folfwer; fie wiro etwa fünf

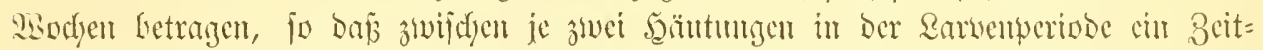

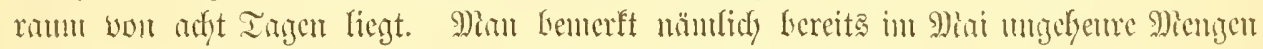

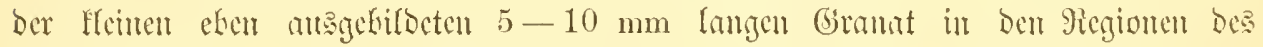

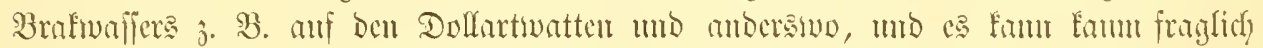

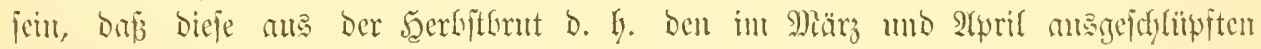

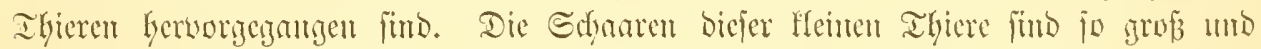

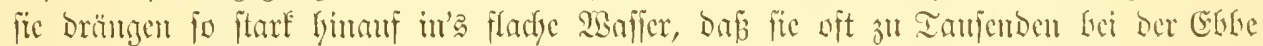

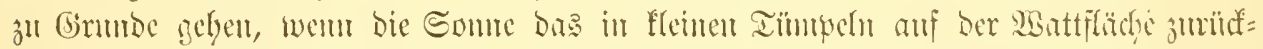

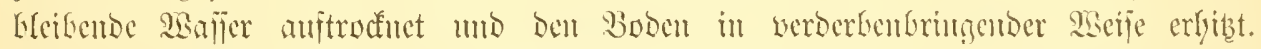

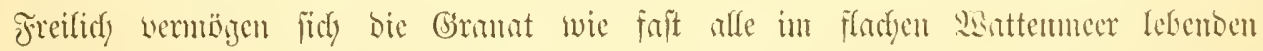

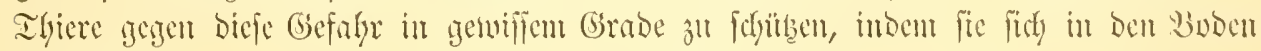
eingrafien.

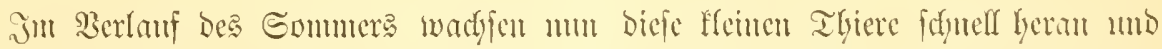

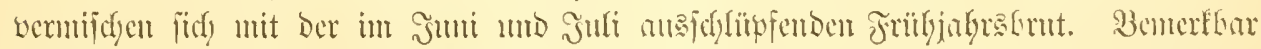

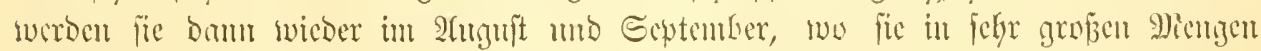

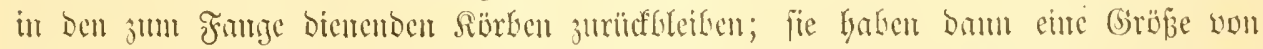
$20-30 \mathrm{~mm}$. 2Tus ben fpäter mitjutheilenden Frmigliften (cf. pag. 110) gefyt ber=

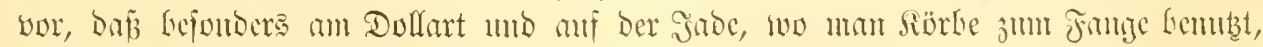

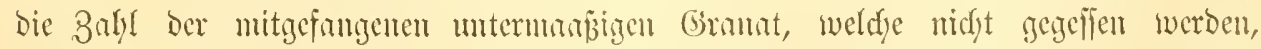

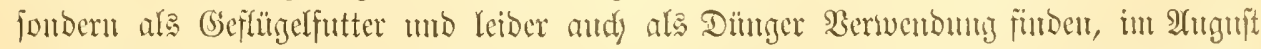

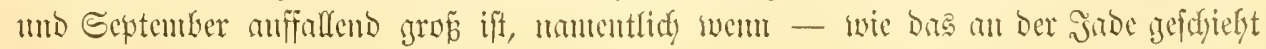




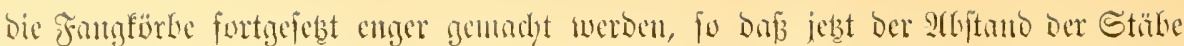
lidgt melgr ala $2 \mathrm{~mm}$ betrïgt.

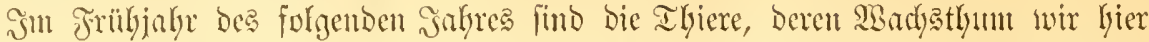

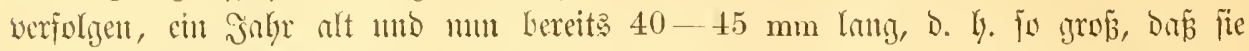

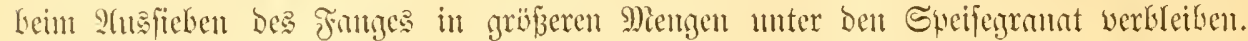

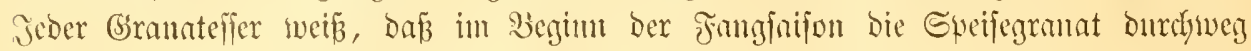

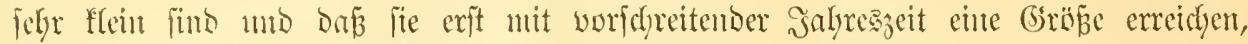

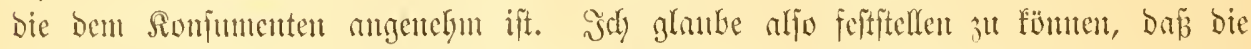

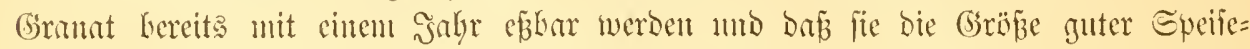
granat - 50 bis $60 \mathrm{~mm}$ - in 15 bis 18 Mionaten erreichen. Sdyon im gumeiten

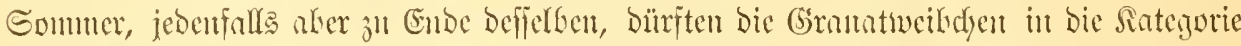

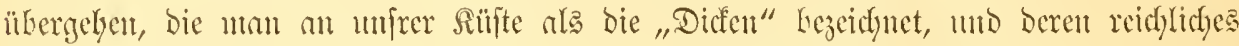

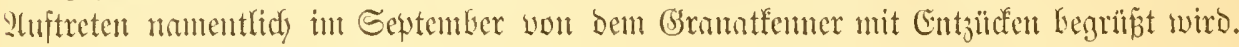

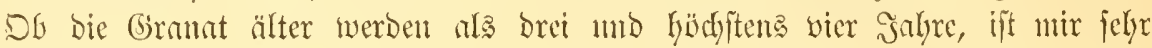

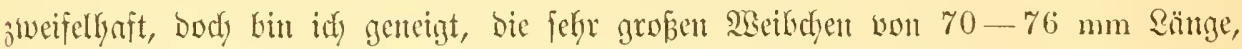

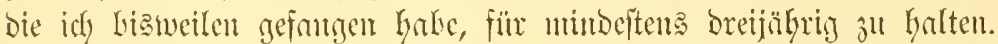

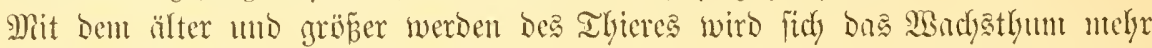

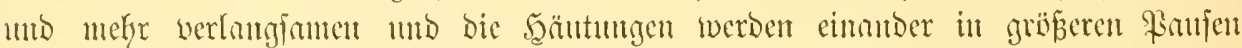

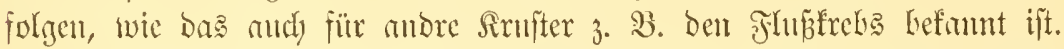

Da man fefre viel Granstweibdyen yon $40 \mathrm{~mm}$ Ränge antrifft, bic bereit?

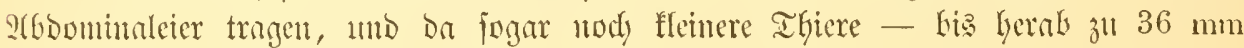
- jdyon mit abgelegten Eiem angetroffen werben, fo unterfiegt ce feinem 3iweifel,

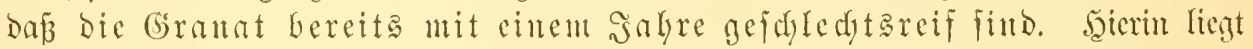

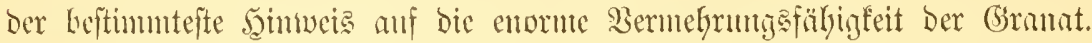

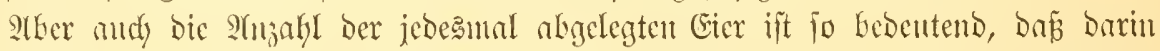

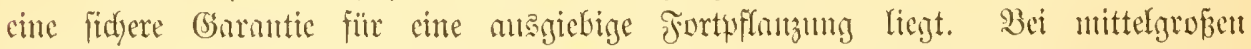

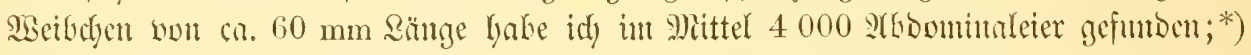
jüntgere Thiere werben vielfeidyt 3000 Eier legen; wenn man aher bebenft, bá̉ bei

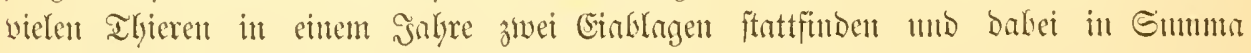
mindeftens 6-7000 Eier probucirt werben, fo wirb man nicht feht getyen, werut

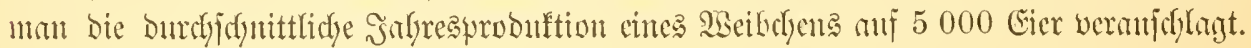

\section{รุäıtung.}

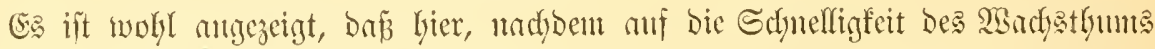

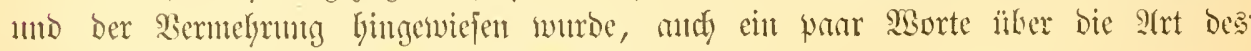

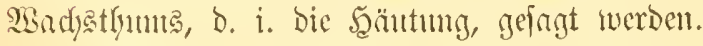

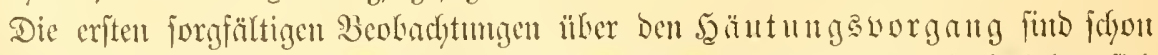

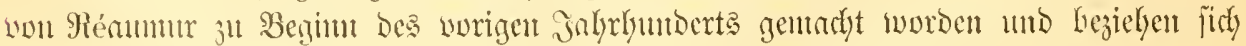

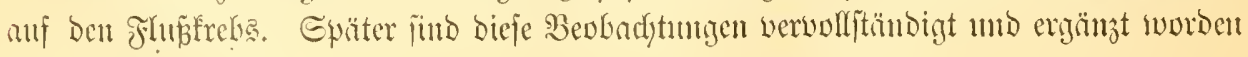
(wyl. TH. Şuthley, Der Sirebs).

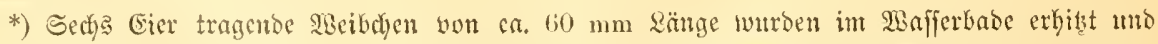

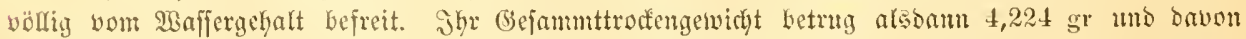

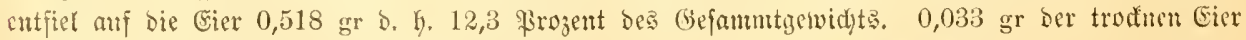

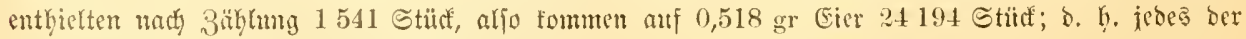

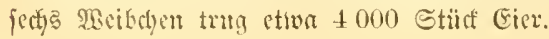




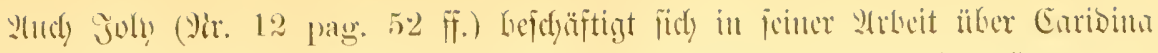

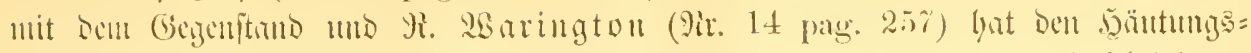

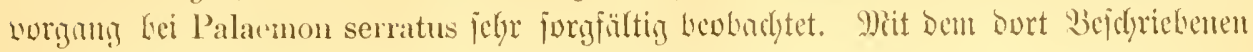

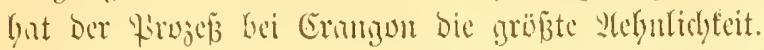

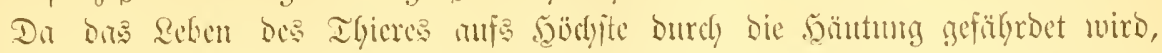

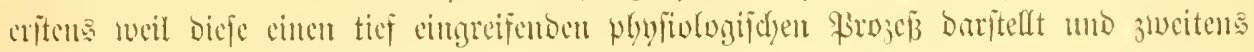

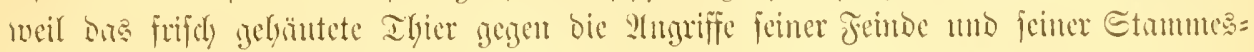

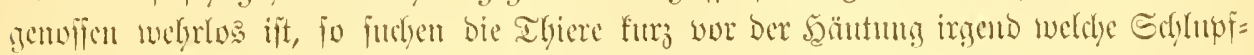

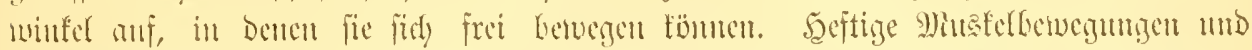

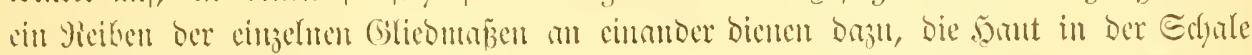

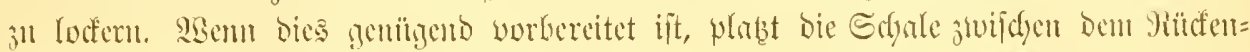

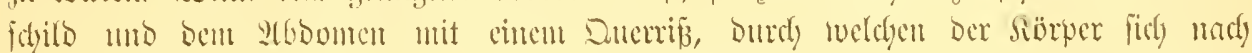

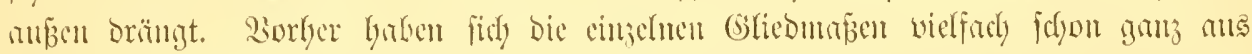

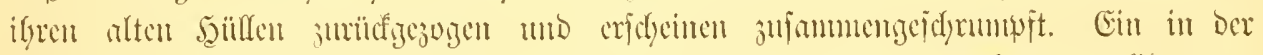

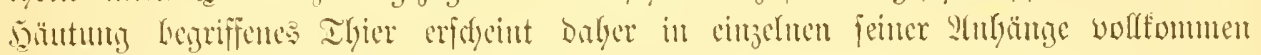

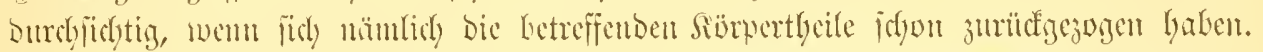

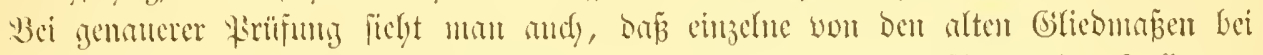

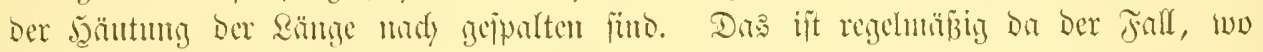

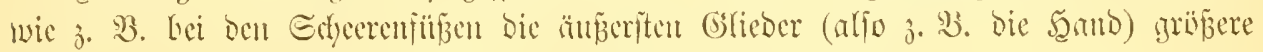

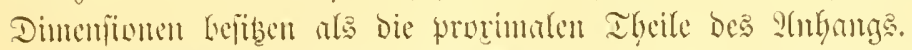

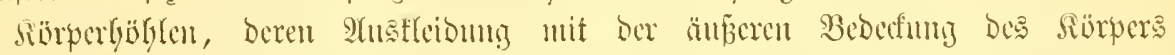

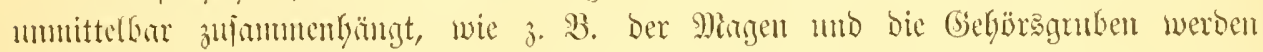

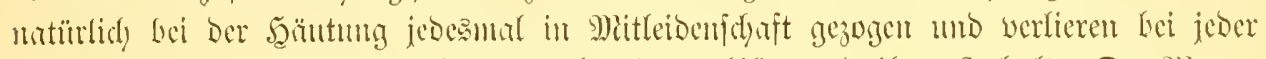

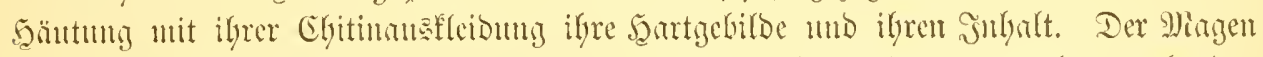

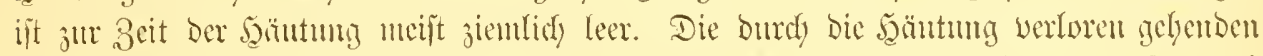

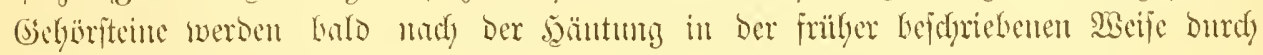
Die Bemïlyungen Des Thieres erietzt.

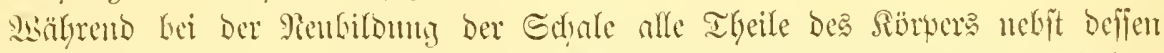

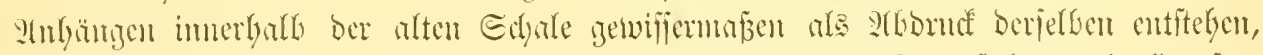

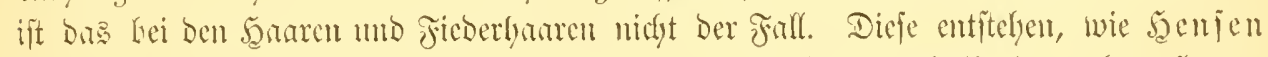

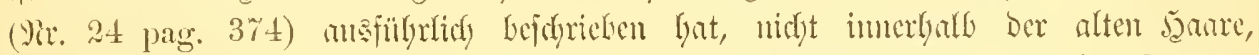

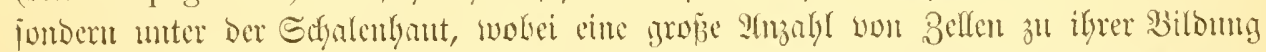

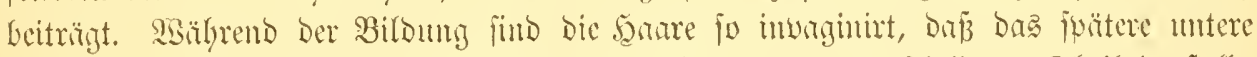

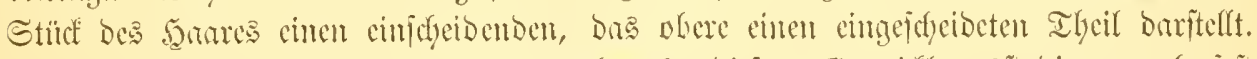

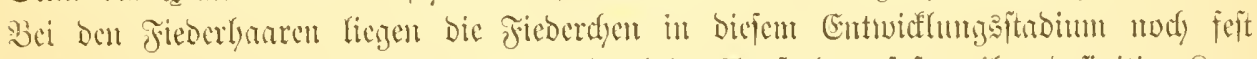

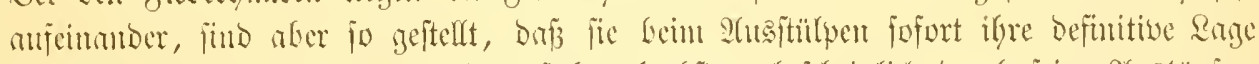

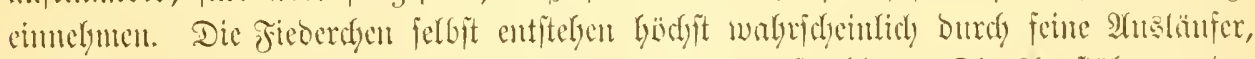

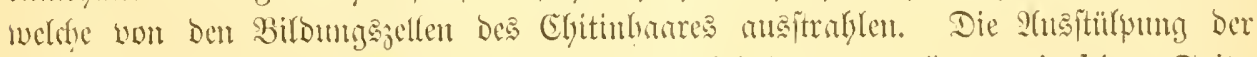

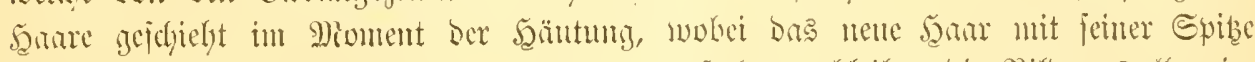

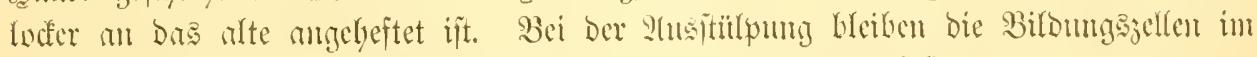

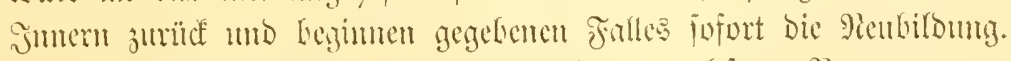

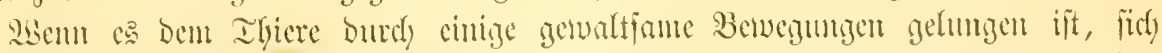

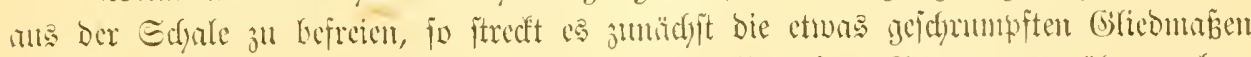

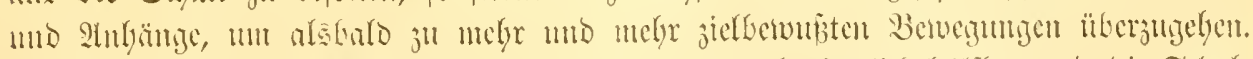

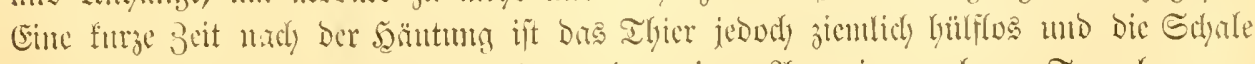

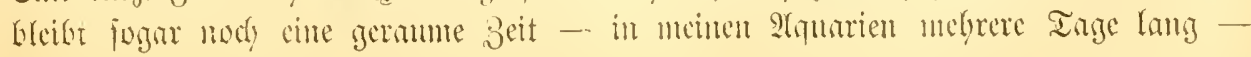




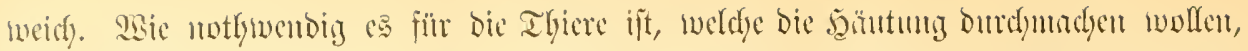

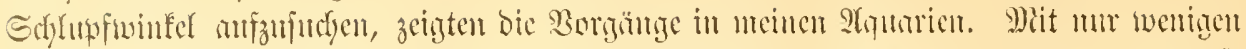

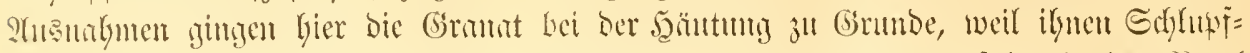

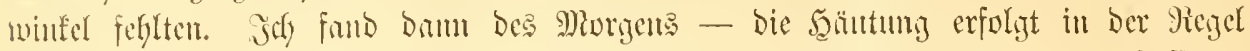

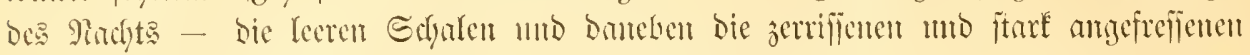

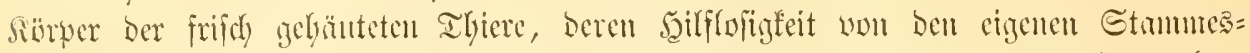

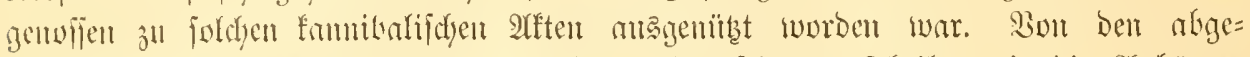

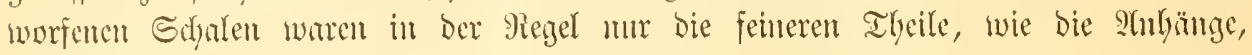
akgefreflen.

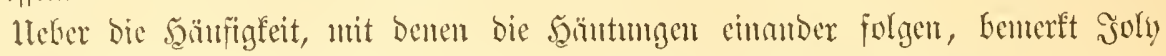
anf Grumb ziveier Beobadytumgen, bañ fids Caridina Desmarestii etwa alle 8-10

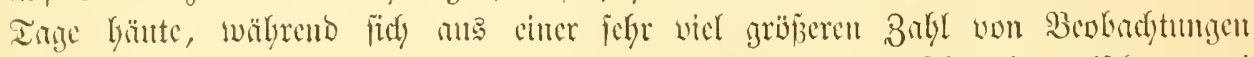

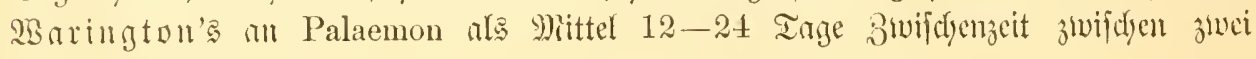
Sïutumigen ergeben.

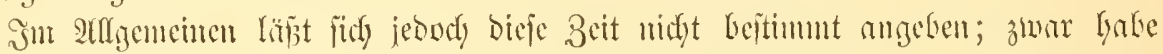

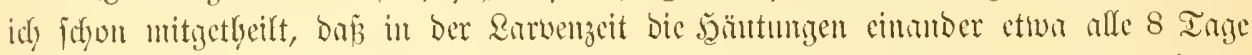

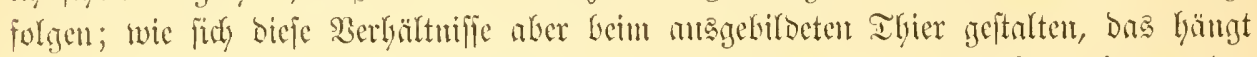

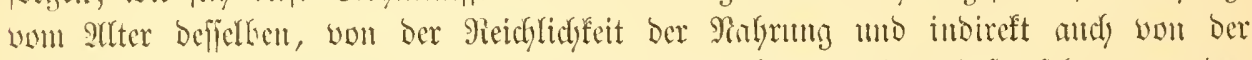

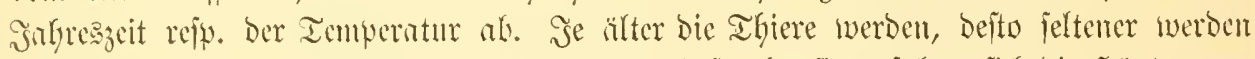

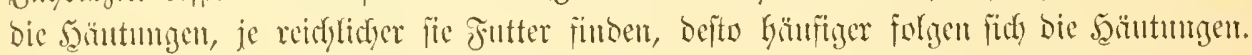

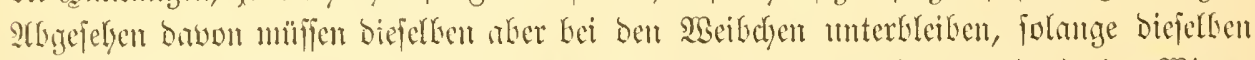

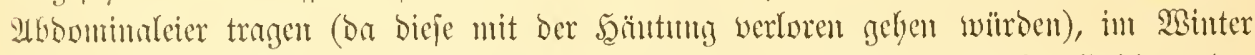

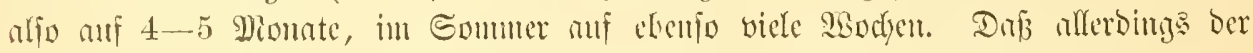

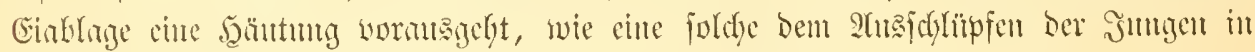

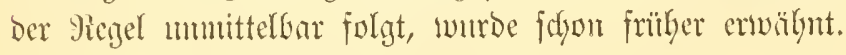

\section{(Er)altung Des Gramatbejtandes.}

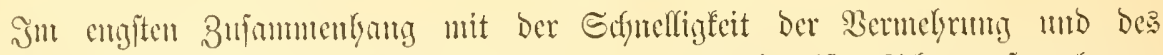

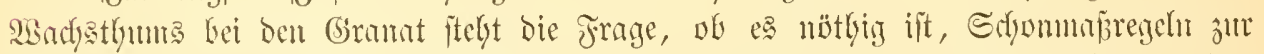

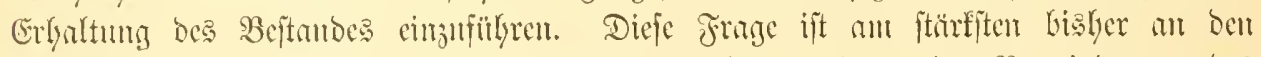

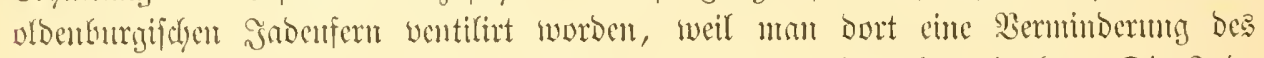

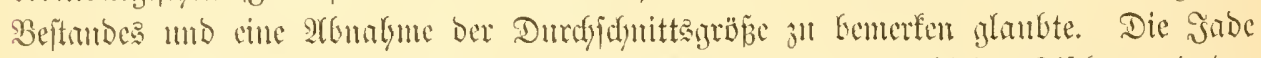

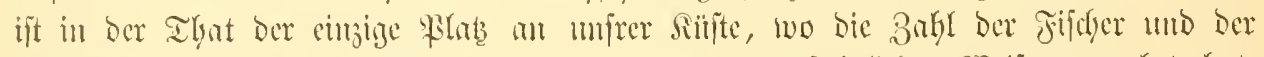

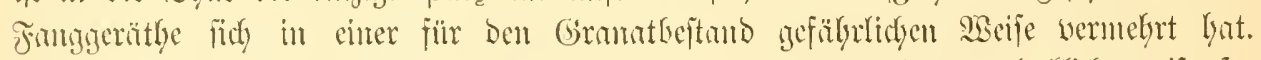

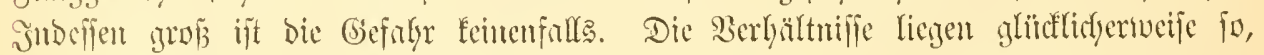

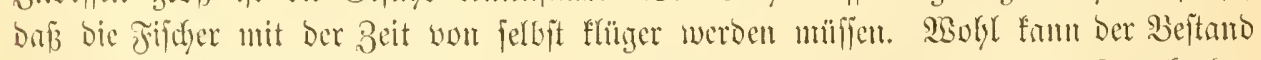

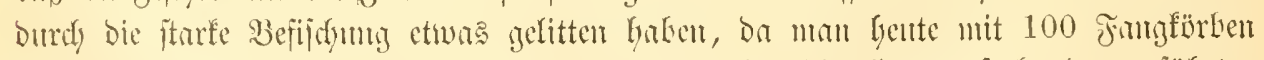

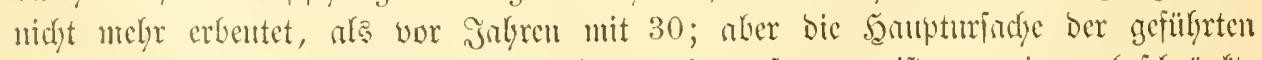

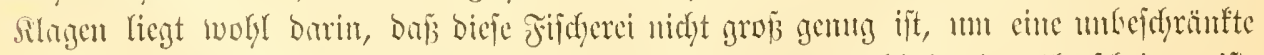

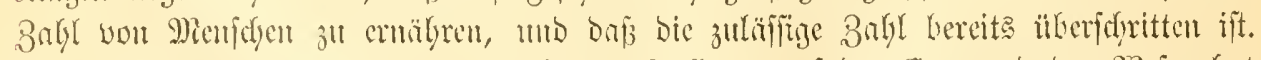

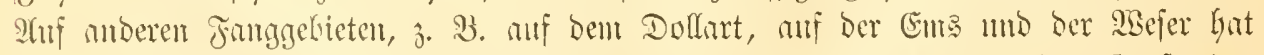

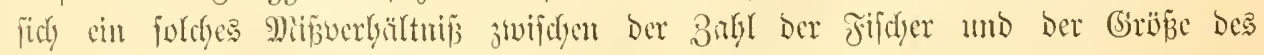
Beftanoes bisher nody midyt gelteno gemndyt.

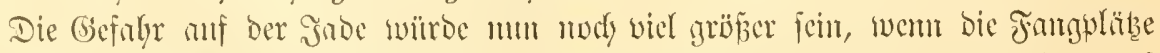

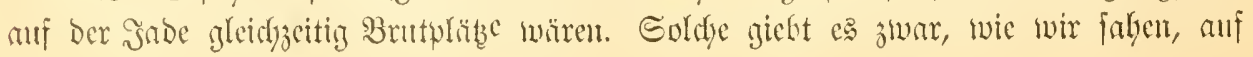




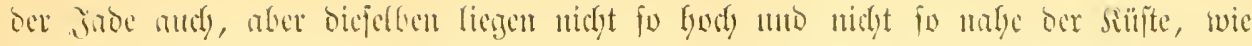

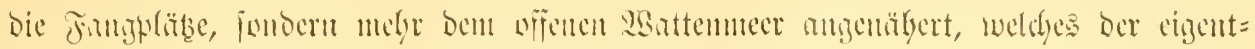

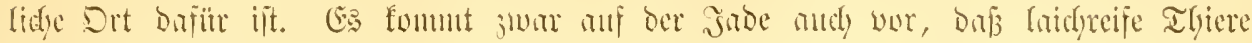

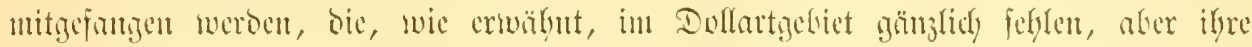

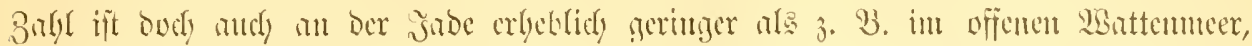

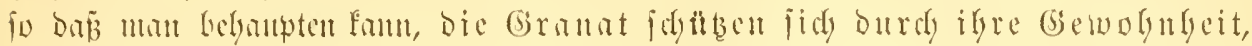

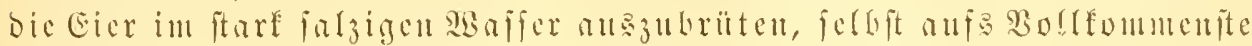

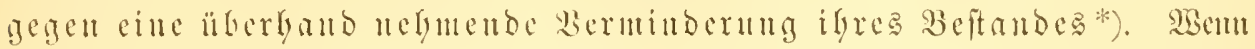

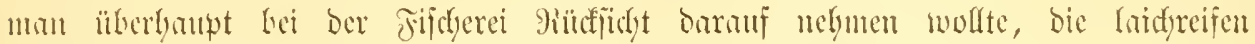

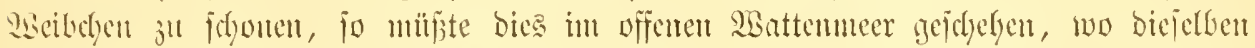

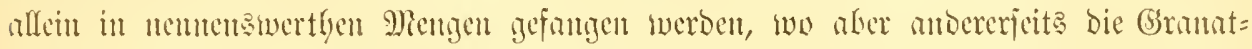

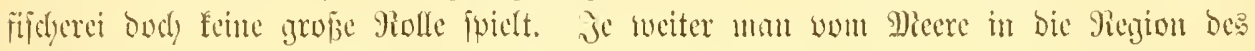

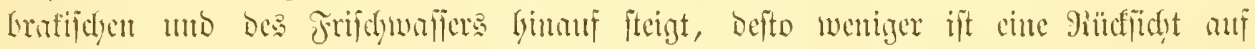

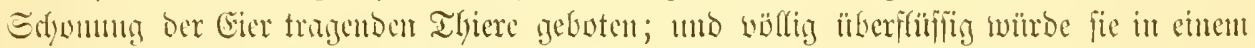

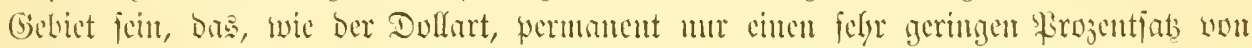

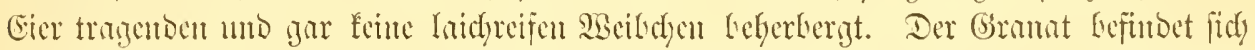

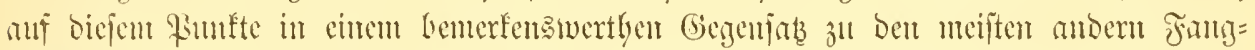

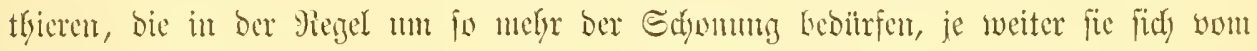
Miecre cutfernten.

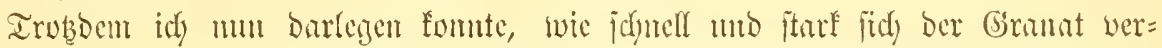

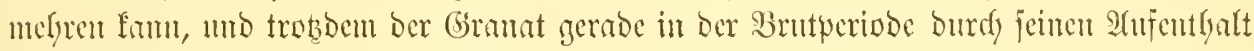

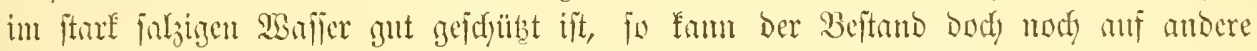

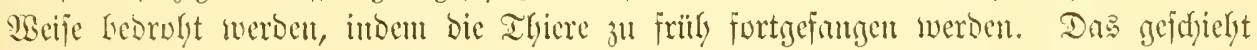

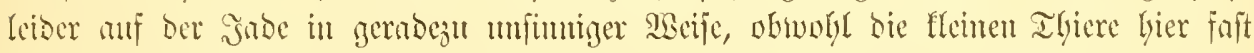

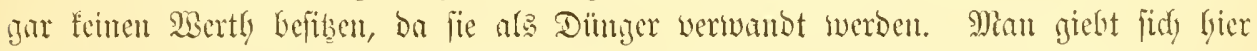
nidyt cimmal bie Miïlye, fie woie am Dollart ju Futter ju verarbeiten, wodurdy man

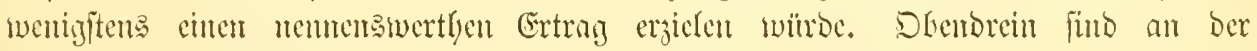
Sabe, wo an meiften ïfer Akralyme bes Beftandes gethgt wirb, bie engiten Fang= gerätlge - Sïrbe mit $2 \mathrm{~mm}$ Stabweite - in (Gebraud)!

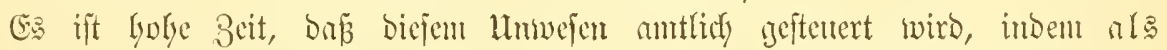

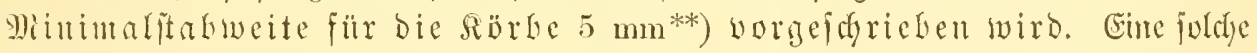

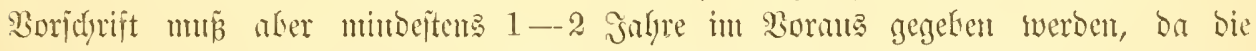

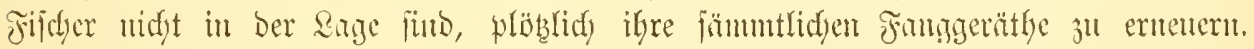
Shre Rörbe revräfentiven ein Rapital won $t-800$ Mart pro Fijder, uno wäbrend

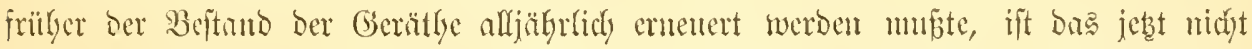

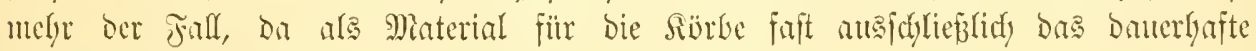
pitch-pine-乌ूolz werwant wirb.

Fïr Die Dollartfifder wïroc man vielleidyt bie sorjefrift mod) milder madjen

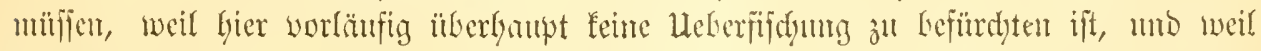

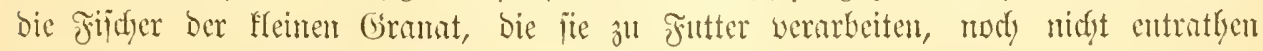

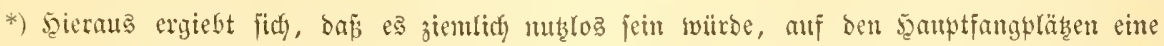
Sdyonzeit für bie Granatfiftherei eimzufiilyren, wie bas fürzlid von ber olbenfurgijdyen Regierung beabfititigt war.

**) Die Siebe, mit welchen man bie eppbaren Granat von ben fleinen fonbert, Gaben eine burdyfanittlidye Stabrueite von $7,5 \mathrm{~mm}$. 


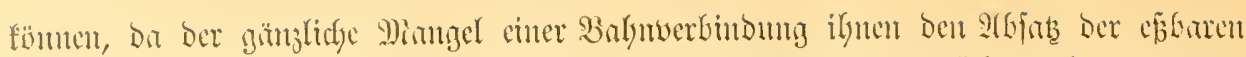

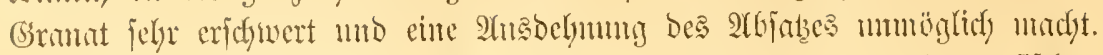

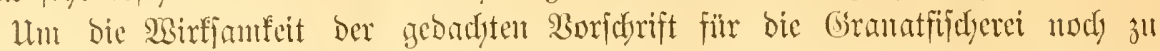
erböben, mübte es ftrenty verboten werben, Grauat in irgend einer Form

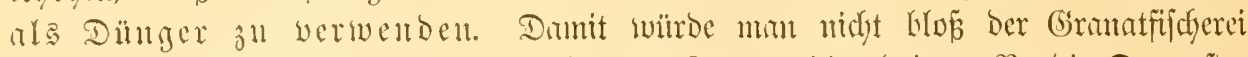
cunen Gefallen erweifen, jondern andy den Renten, die (wie 3. B. Die Dangafter

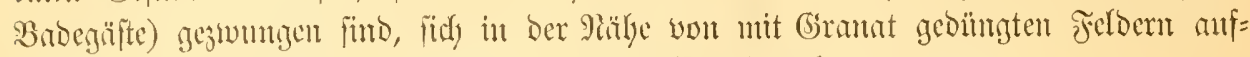

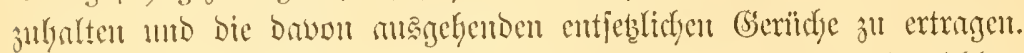

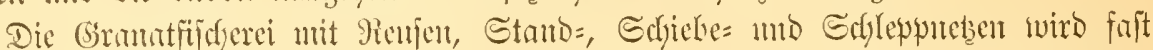

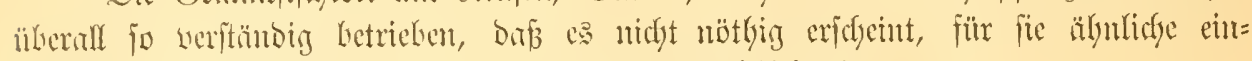

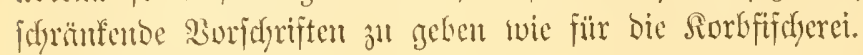

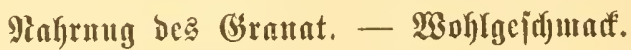

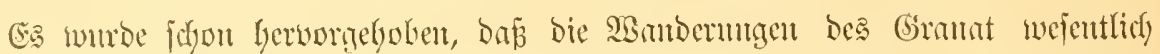

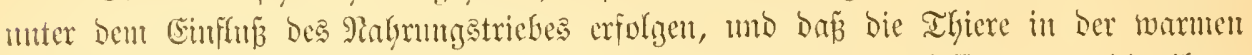

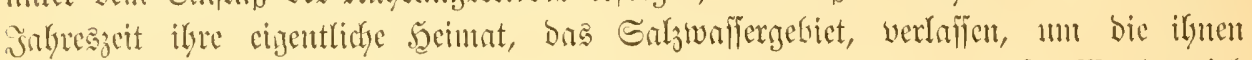

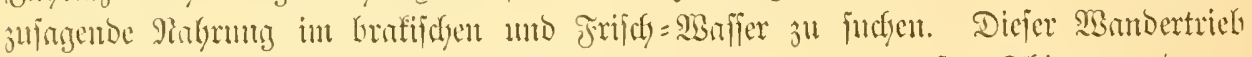

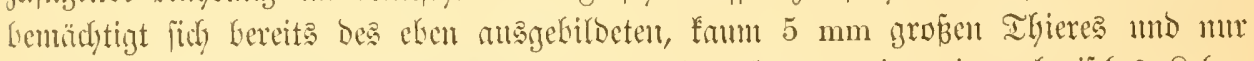

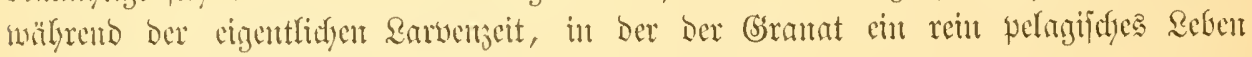
fülyrt, àtht u es vor, int Galjwaller ju verbleiben.

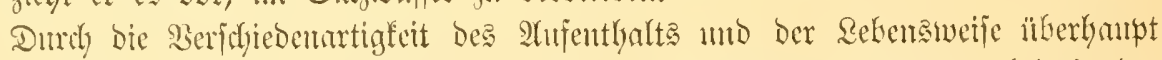

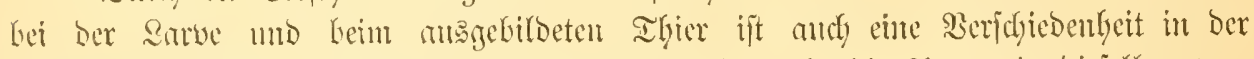

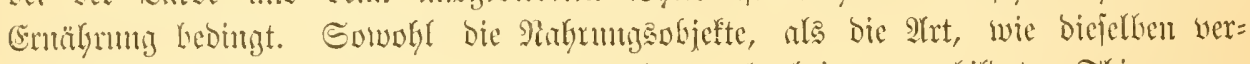

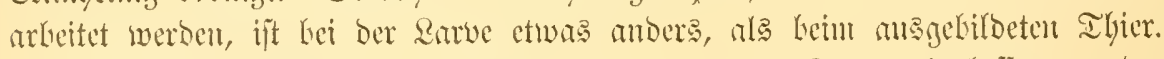

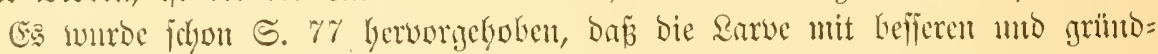

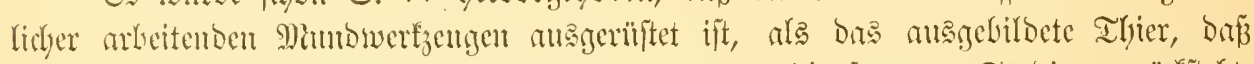

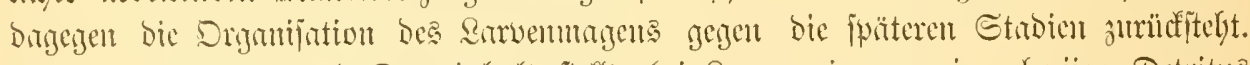

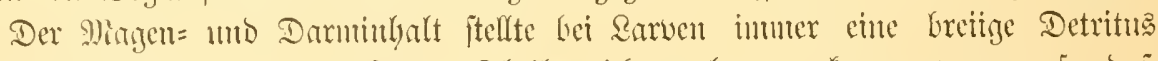

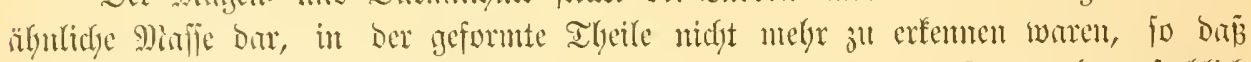

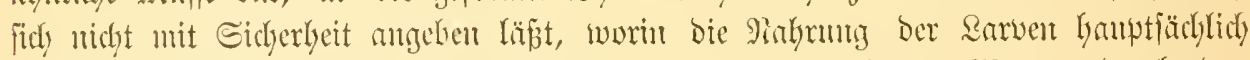

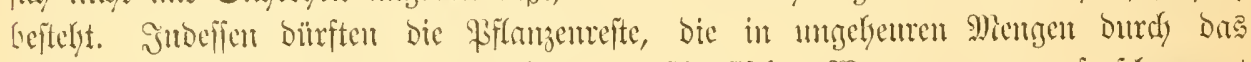

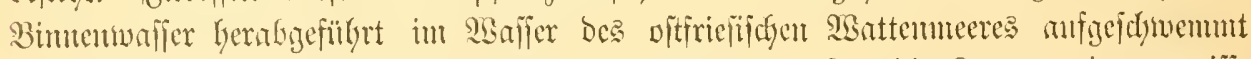

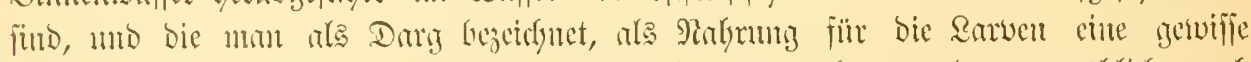

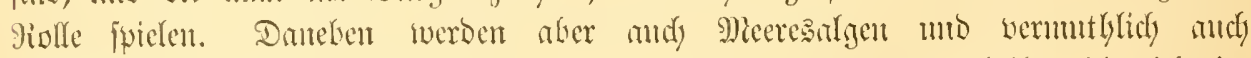

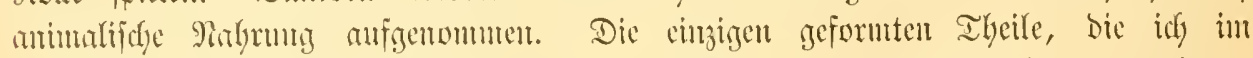

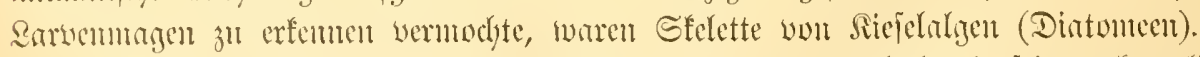

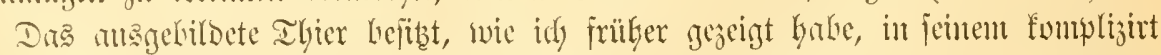

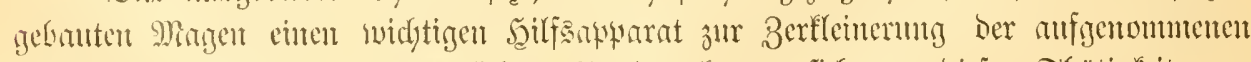

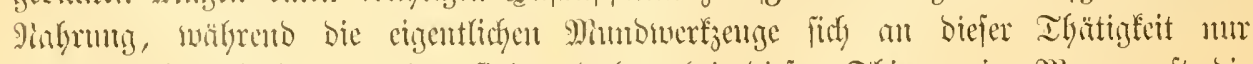

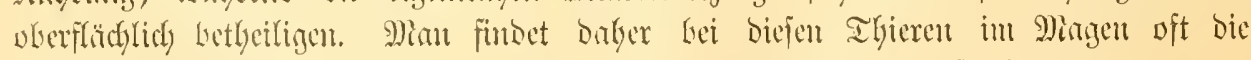

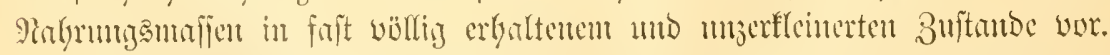

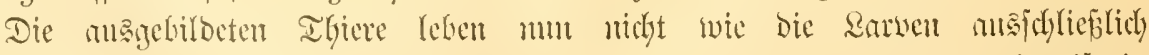

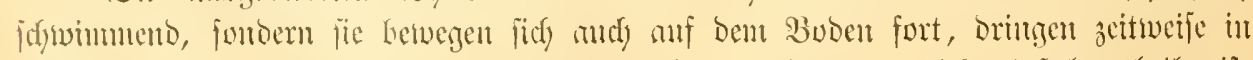

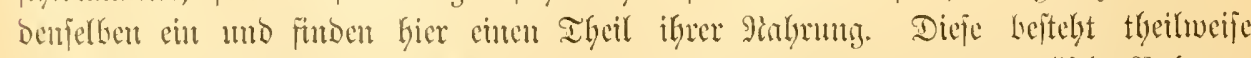

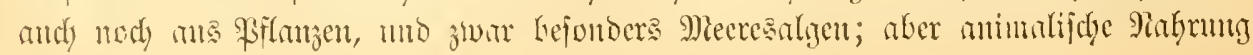




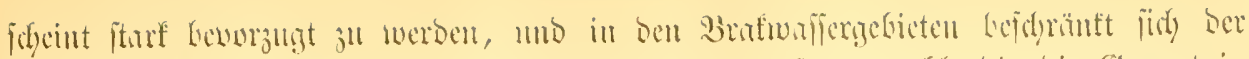

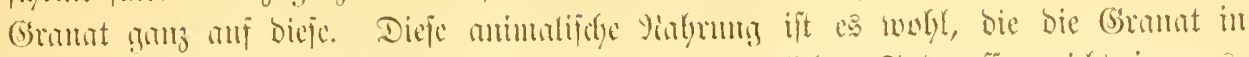

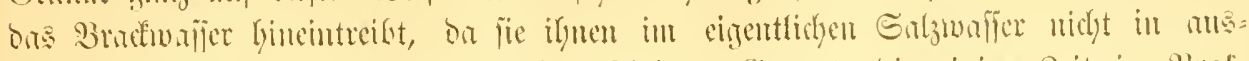

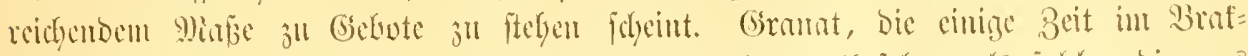

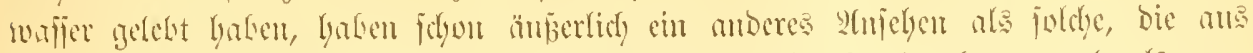

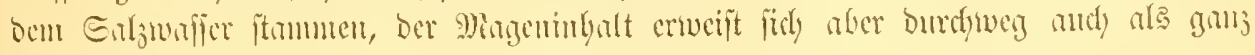
warficticts.

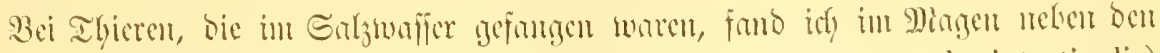

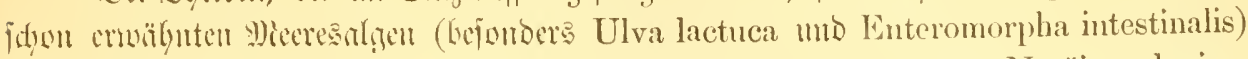

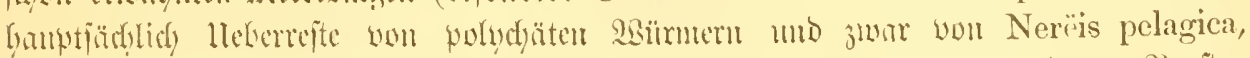

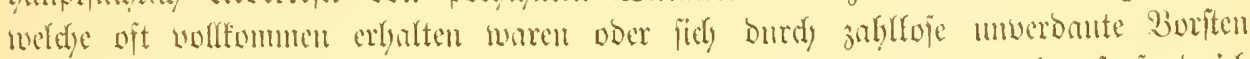

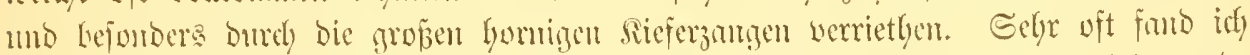

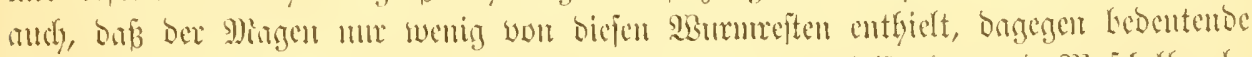

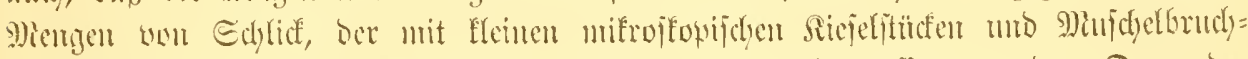

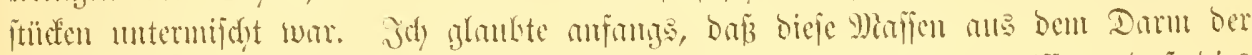

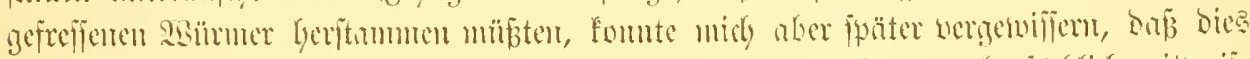

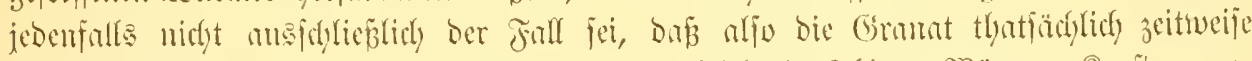

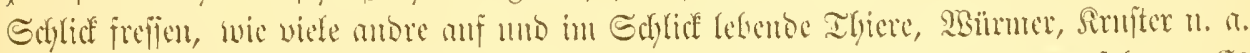

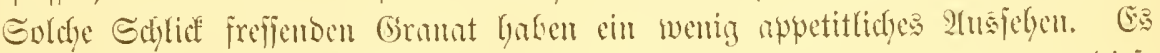

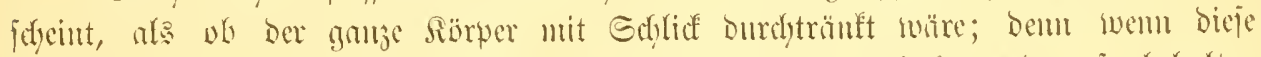

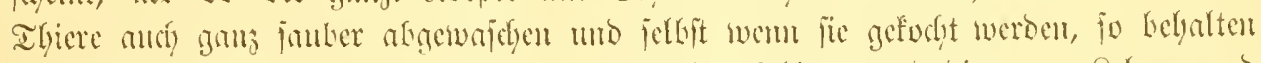

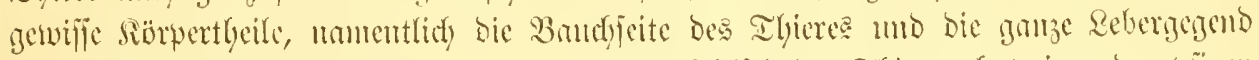

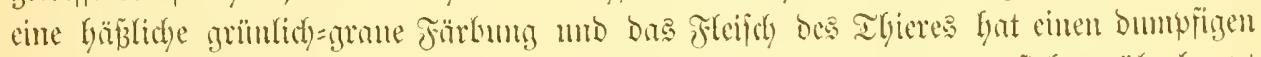

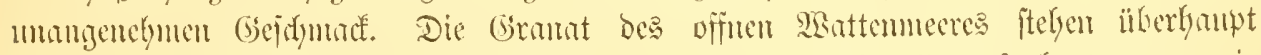

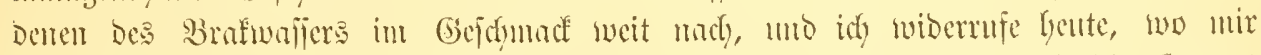

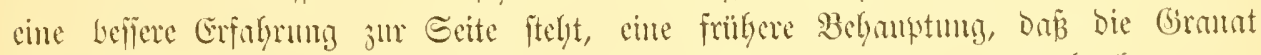

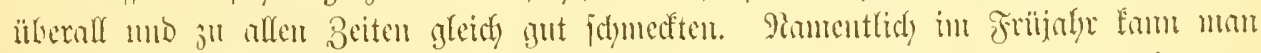

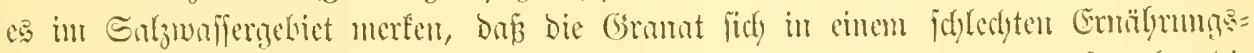

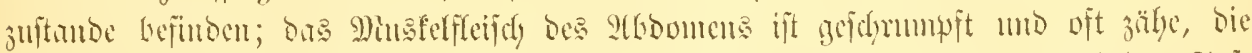

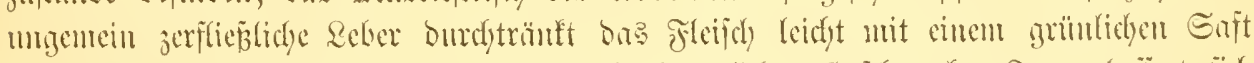

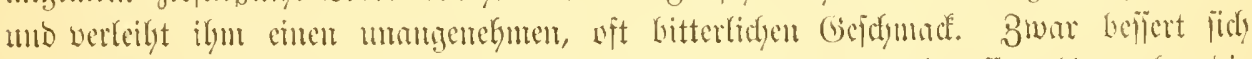

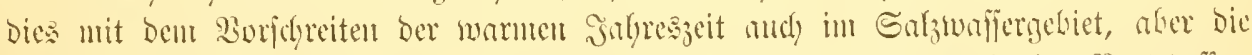

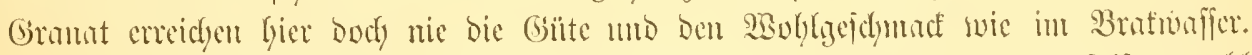

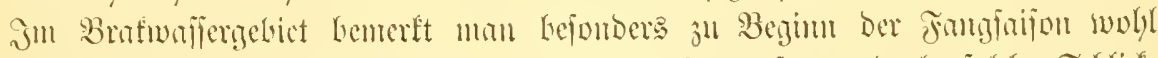

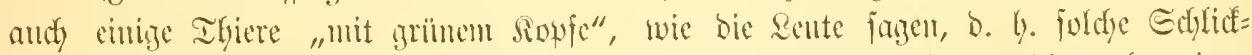

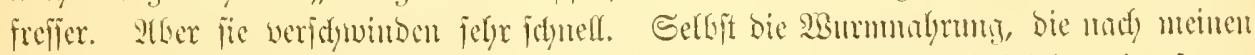

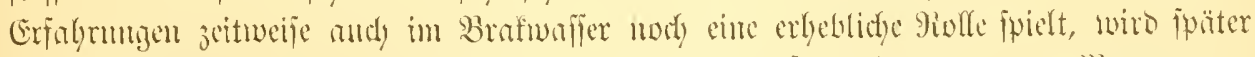

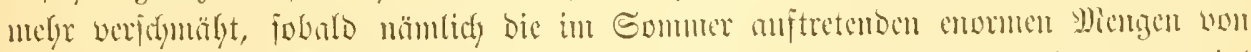

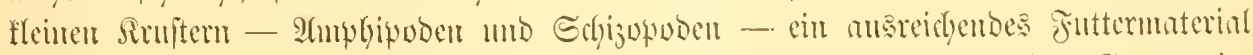

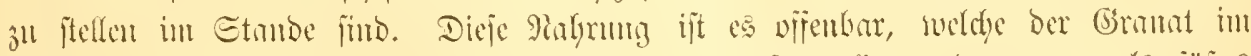

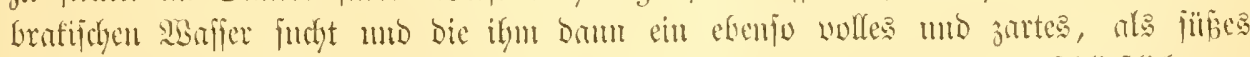

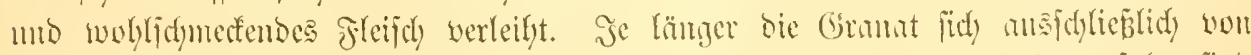

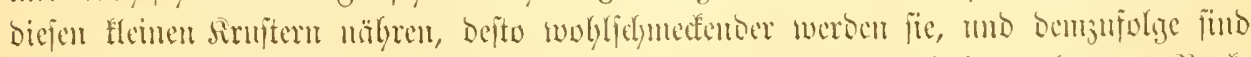

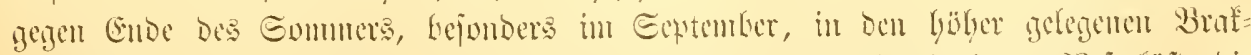

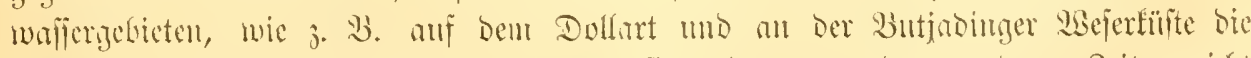

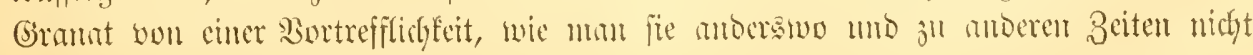




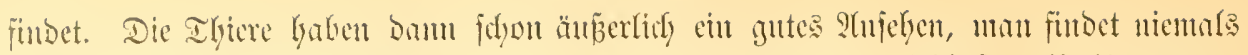

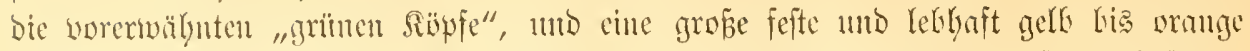

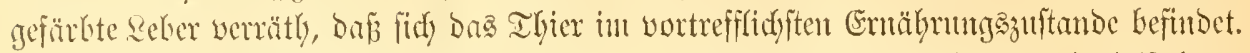

Itnter ben fleinen Sinffern, bie cine fo wejentlidye Boründermug Gerbeffübren,

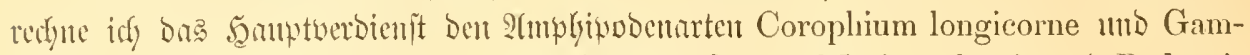
marus locusta jul, cin geringeres den Exfjizppodenformen Mysis vulgaris umb Podopsis

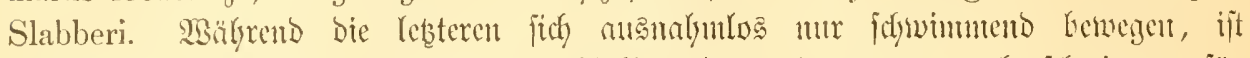

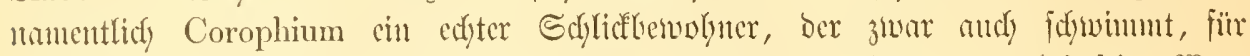

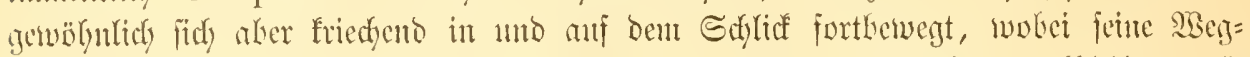

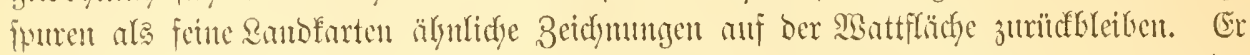

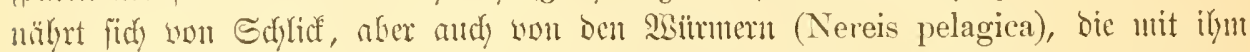

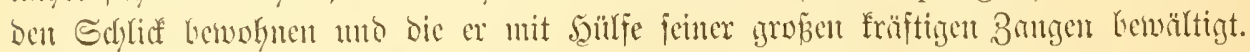

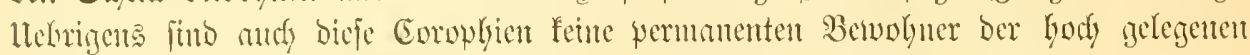

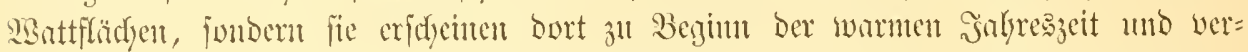

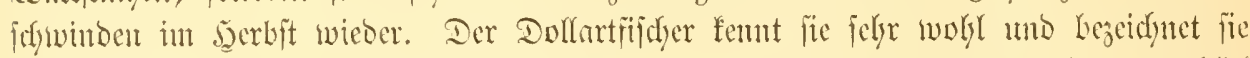

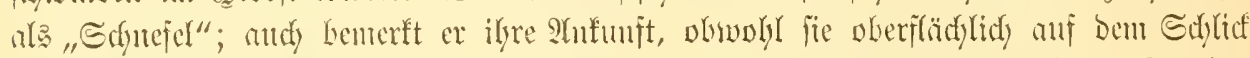

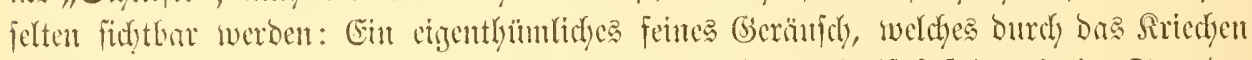

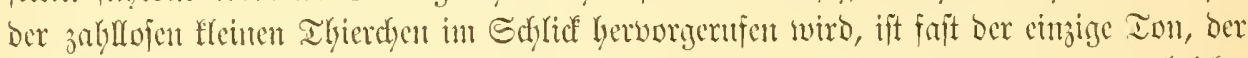

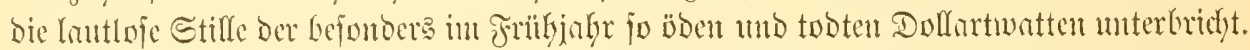

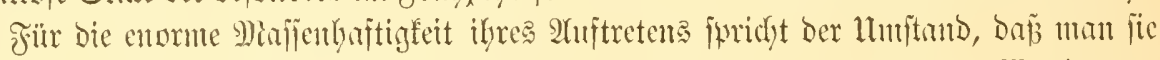

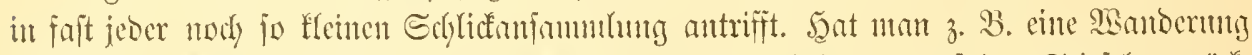

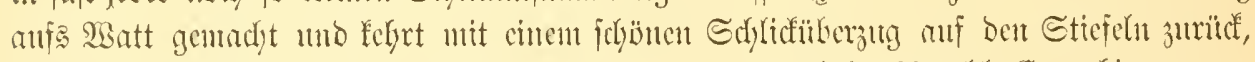

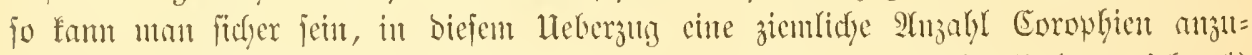

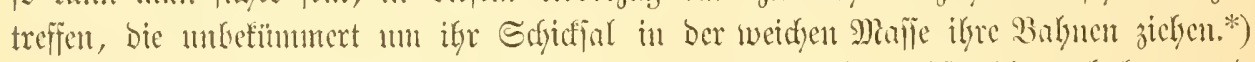

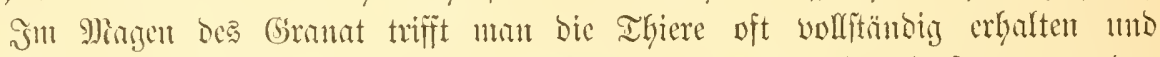

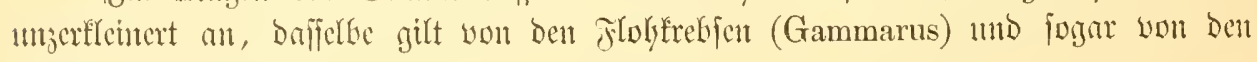

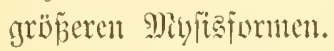

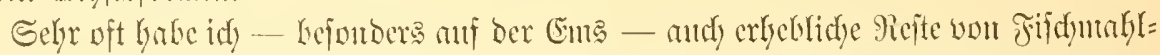

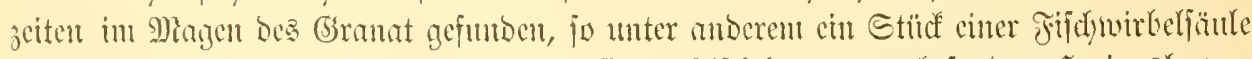

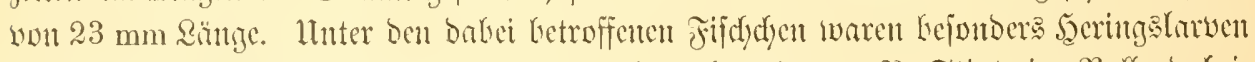

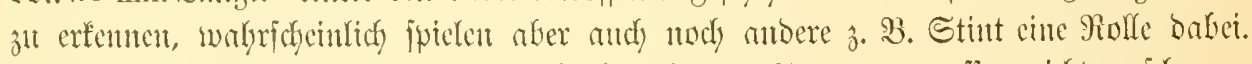

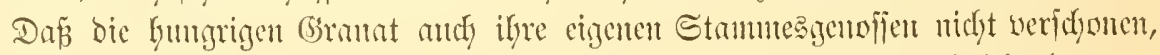

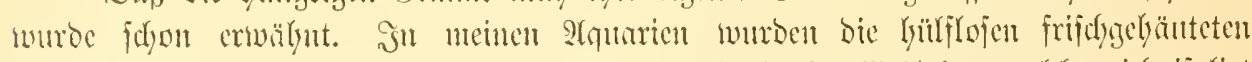

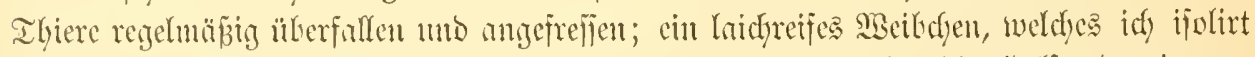

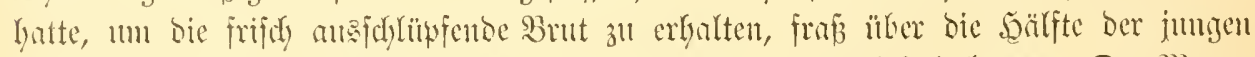

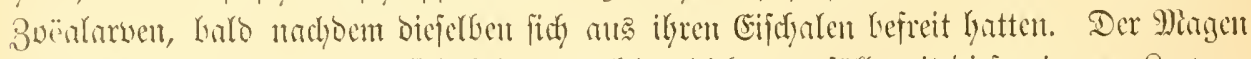

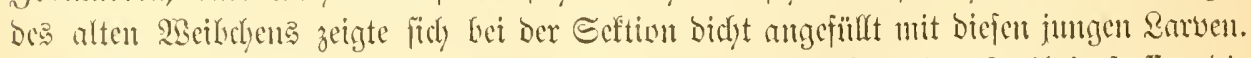

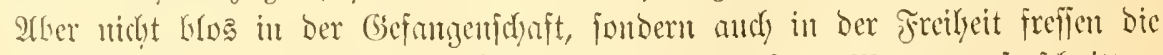

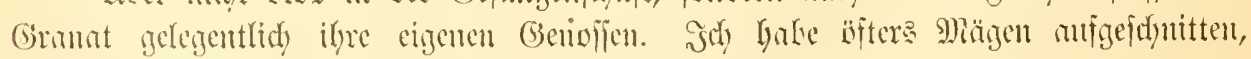

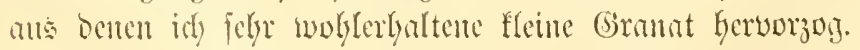

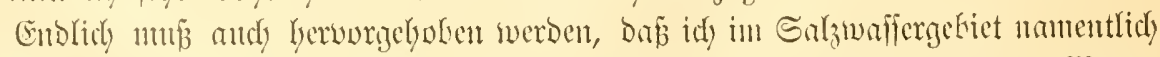

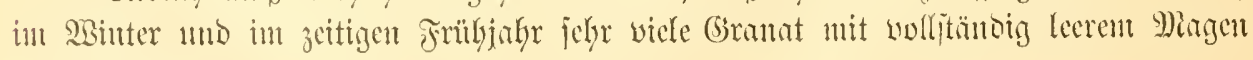
gefumben Gabe.

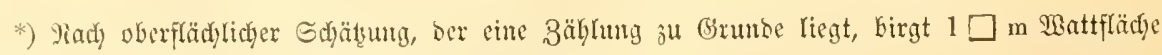
(Sdylidf) ca, 50000 Stütaf grope unb fleme Eorophien. 


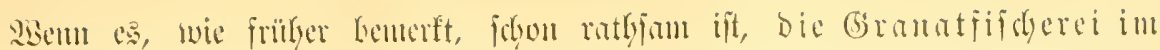

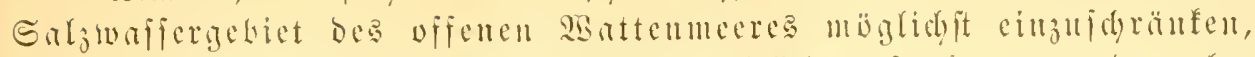

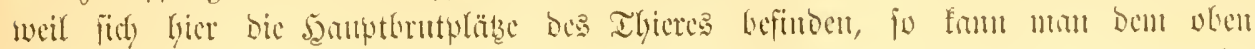

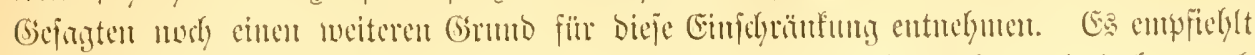

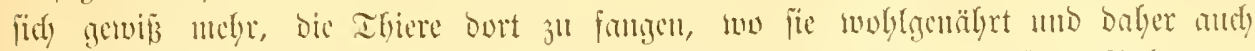

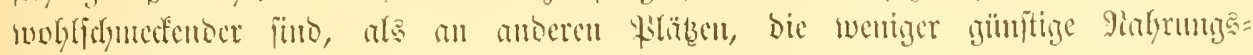
werbältnijịc ‘icten.

\section{Fanguerlÿ̈ltuiliןc.}

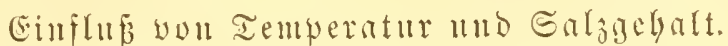

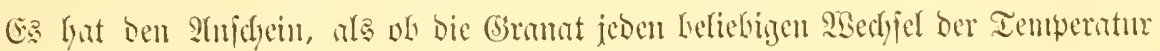

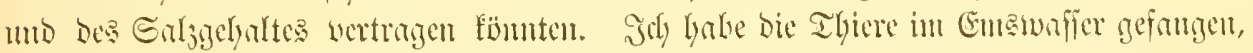

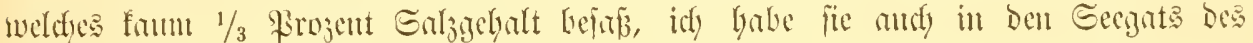

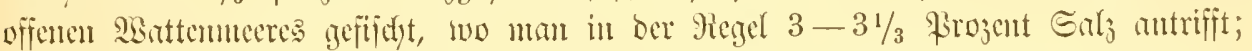

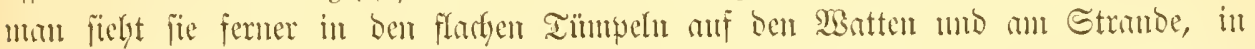

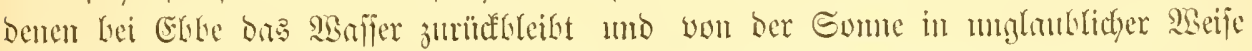

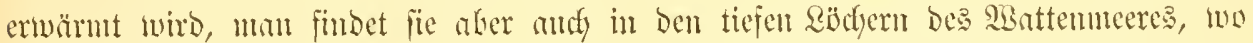

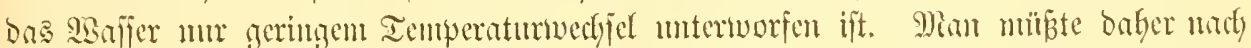

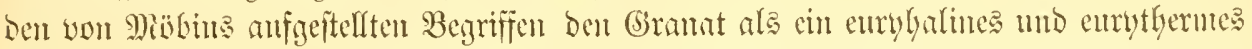

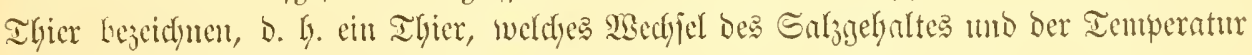
in jefyr weiten Gremjen jul ertragen vermag.

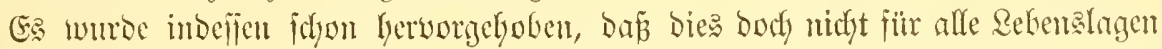

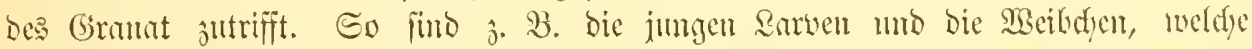

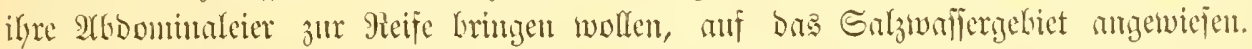
Sm Folgenten joll un and gezeigt werben, bá bie Temperntux poer alfgenteiner

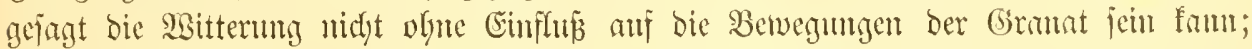

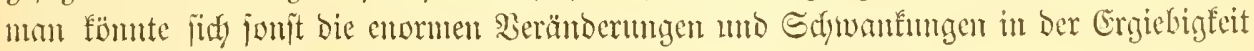
De马 Fannes frum erflüren.

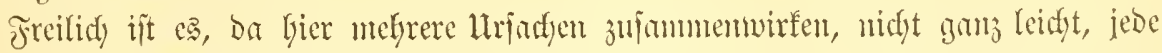
einzehe in ifyrer Beobutung ridjtig jul wïroigen.

Die Fifyer jelbit, bie im anfgemeinen mit Bermutbungen nidyt iparfant uno

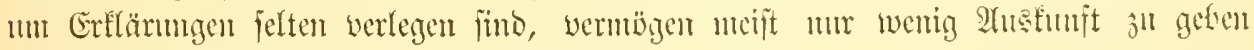
über bie Dinge, bie bon Fantg beeinflufien.

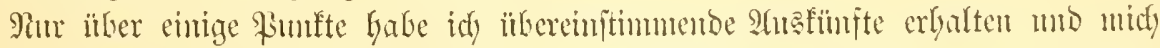

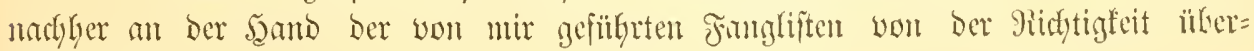
zeltgen föแler.

Der Fang ift bes gindte inmer befier als an Inge, bem ber Gromat ift ein

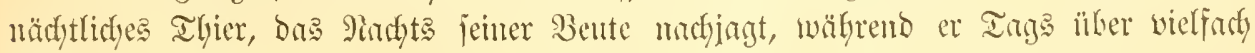

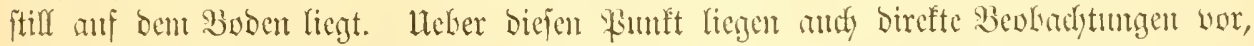

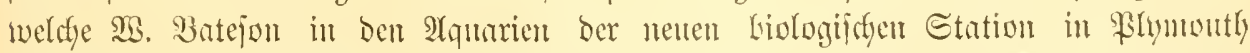

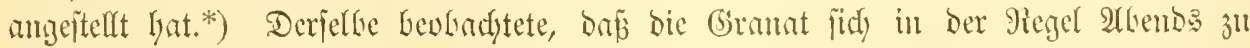
ciner bejtumnten Stmbe vom Soben erbeben unb bam auf bie Nabrumgajudje

*) Cfr. Journal of the Marine biological Association of the United Kingdom. New Ser. Vol. I No. 2 p. 211 f. London 1889. 


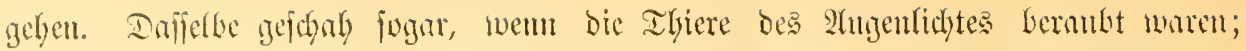

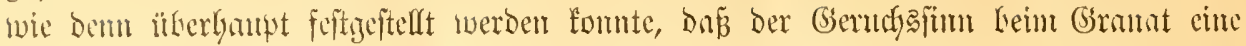

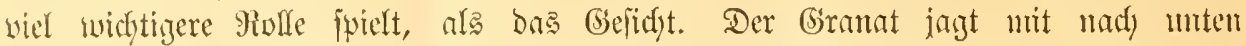
geridytetem Sivpf - Palnemwn bält ben Sopf nady ofen - offenthar, weil ex feime

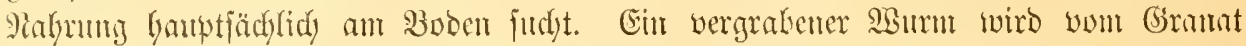
fofort gefunden, aud wern lesterer geblembet, voer gar ber immeren afutement beranbt

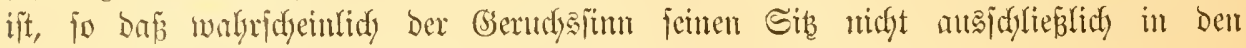

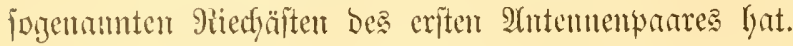

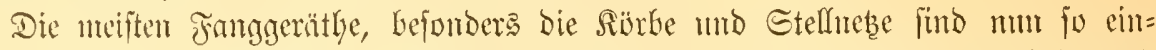

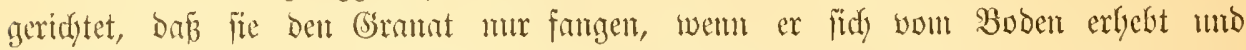

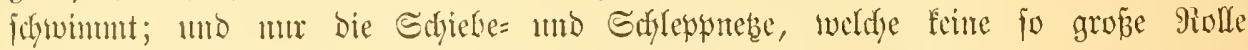

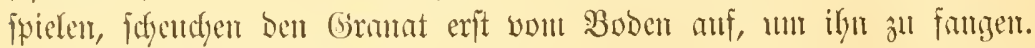

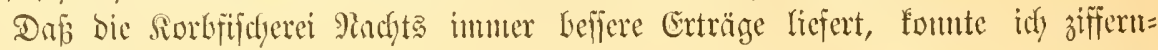
miñßig feittitellen.

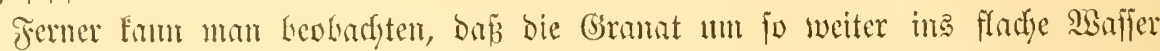

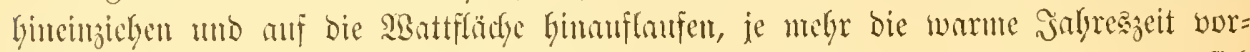

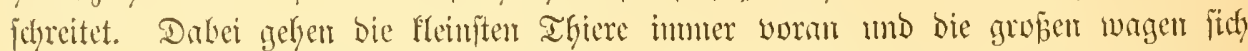

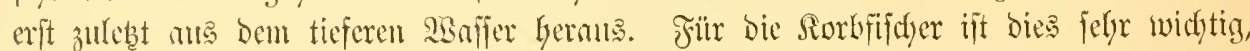

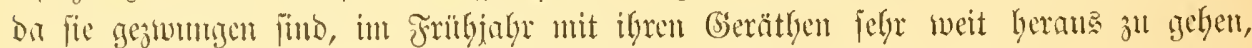

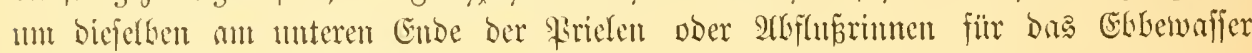

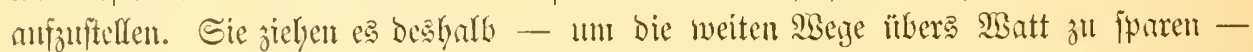

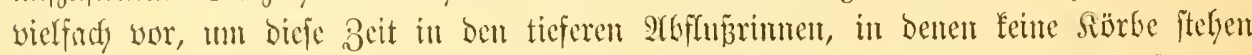

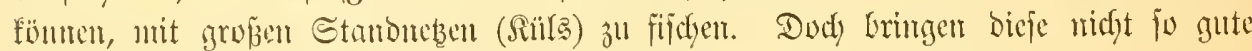

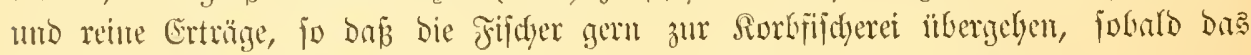

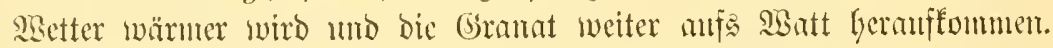

So leidyt es mun ift, bie eben gemamte Thatiadye are foldye feitzulteflen, fo

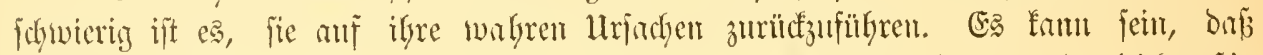

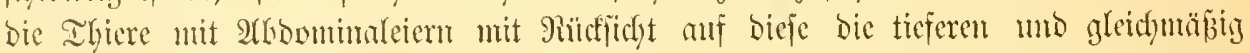
temperirten

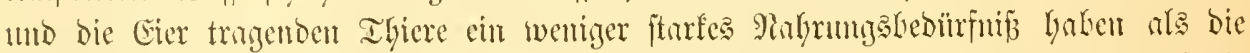

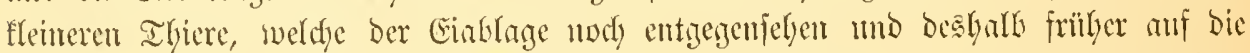

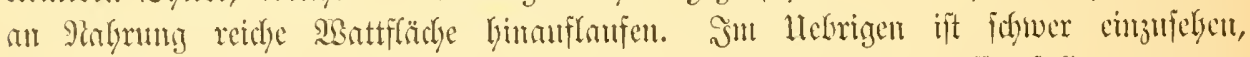
weshalb bie flemeten Thiere cinen ftärferen Temberaturwedfyel befler follten ertragen fümunen ala die grö̈ß̈ereı.

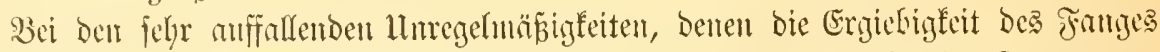

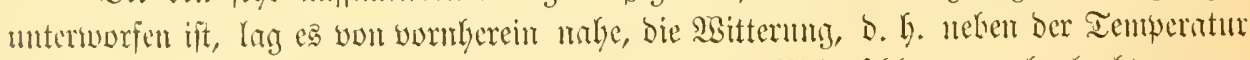

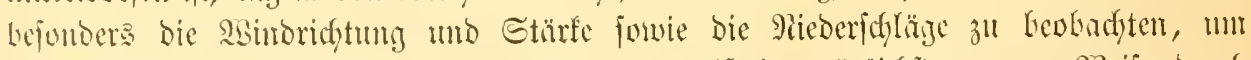

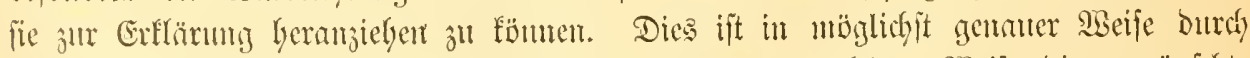

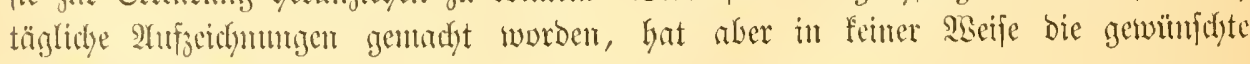
Silntbeit getradfl.

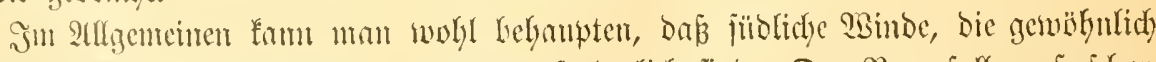

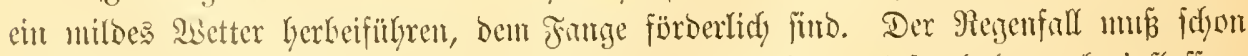

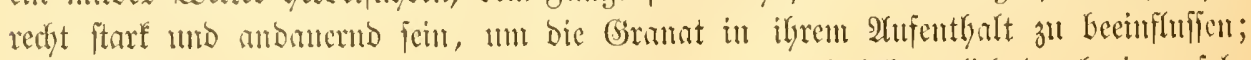

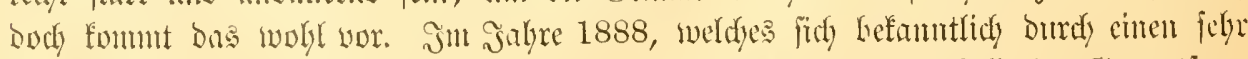

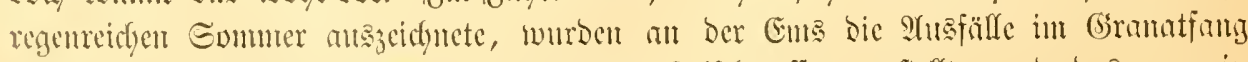

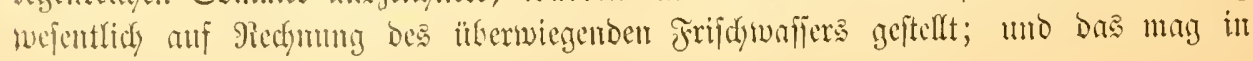




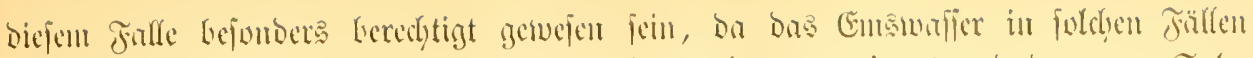

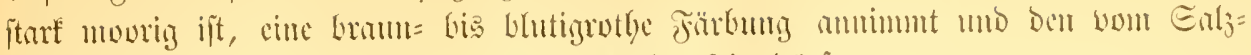

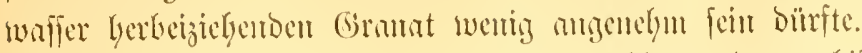

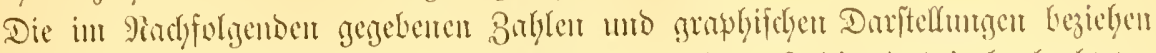

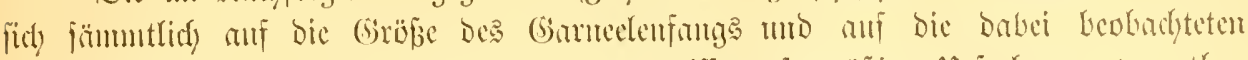

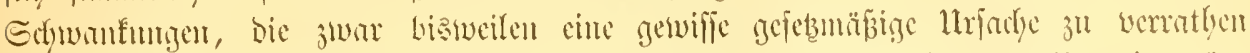

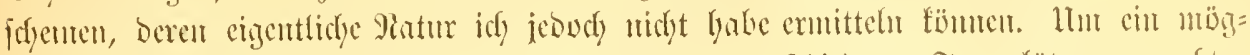

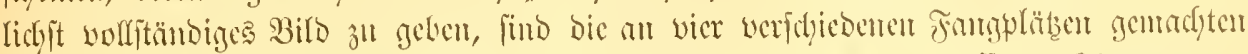

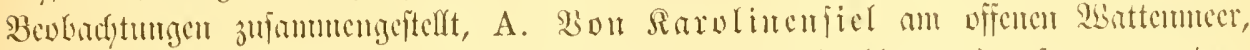

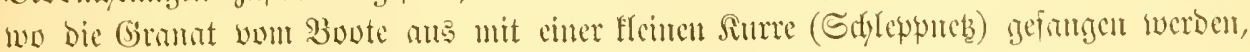
B. Bun \&arreft bei Emben an Der Ems, wo mit gropen Eteerthamen (Etand=

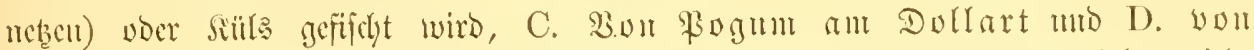
Barel an ber Sabe, an weldyen beiden Drten bie Fifdyerei mit fürben betrieben wiro.

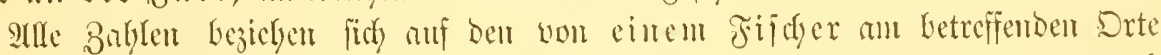

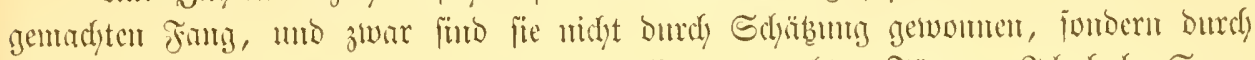

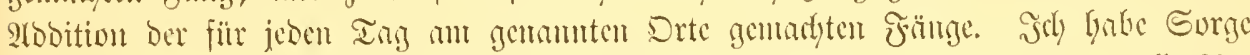

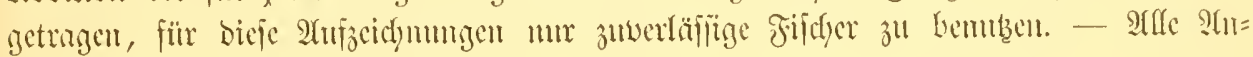
gatben find in Ritern gemadt. 


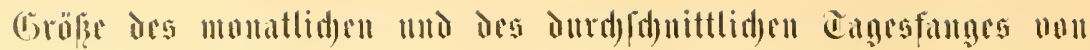

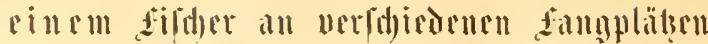

(in 2itern).

\begin{tabular}{|c|c|c|c|c|c|c|c|c|c|c|}
\hline \multirow{2}{*}{$3 \mathrm{eit}$} & \multicolumn{2}{|c|}{$\begin{array}{l}\text { A. Sitrenfifdere } \\
\text { Earolinenfiel }\end{array}$} & \multicolumn{2}{|c|}{$\begin{array}{l}\text { B. Rülfijdyerei } \\
\text { itl 2arrelt } \\
\text { a. o. Ens }\end{array}$} & \multicolumn{3}{|c|}{$\begin{array}{c}\text { C. Rorbfifdjerei } \\
\text { bei } \\
\text { Pogum auf o. Dollart } \\
40 \text { Siörbe }\end{array}$} & \multicolumn{3}{|c|}{$\begin{array}{l}\text { D. Rorbjifderei } \\
\text { bei } \\
\text { Sared auf b. Jabe } \\
130 \text { Rörbe }\end{array}$} \\
\hline & $\begin{array}{c}\text { wirflidjer } \\
\text { Fang } \\
\text { im } \\
\text { Monat }\end{array}$ & $\begin{array}{l}\text { Dourd }= \\
\text { fopnitta }= \\
\text { fang } \\
\text { pro Tag }\end{array}$ & $\begin{array}{c}\text { swirflider } \\
\text { nonat= } \\
\text { lidier } \\
\text { Zang } \\
\text { won } \\
3 \text { Sïls }\end{array}$ & $\begin{array}{l}\text { Durd)= } \\
\text { fdinittg= } \\
\text { faug } \\
\text { pro Tag }\end{array}$ & $\begin{array}{c}\text { Orfanmt }= \\
\text { fang } \\
\text { im } \\
\text { Plonat }\end{array}$ & $\begin{array}{l}\text { Davon } \\
\text { евbar }\end{array}$ & $\begin{array}{c}\text { Durd }= \\
\text { fdinitta }= \\
\text { fang } \\
\text { pro Iag }\end{array}$ & $\begin{array}{c}\text { Befaummt= } \\
\text { faulg } \\
\text { im } \\
\text { Mronat }\end{array}$ & $\begin{array}{l}\text { Davou } \\
\text { ép̧ar }\end{array}$ & $\begin{array}{l}\text { Durdf= } \\
\text { fditittg= } \\
\text { fang } \\
\text { pro Zag }\end{array}$ \\
\hline 1888 & & & & & & & & & & \\
\hline stpril . . . . & 64 & 32 & - & 一 & - & - & - & - & - & - \\
\hline Miai . . . . . & 1560 & 60 & 882 & 45 & 3000 & 346 & 100 & - & - & - \\
\hline 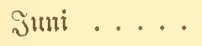 & 1638 & 63 & 2293 & 96 & 4680 & 1067 & 155 & - & - & - \\
\hline Juli ...... & 1386 & 63 & 2618 & 101 & 4480 & 1775 & 149 & - & - & - \\
\hline 2lugut & 336 & 84 & 1878 & 69 & 5710 & 760 & 193 & - & - & - \\
\hline September .. & 276 & 46 & 2430 & 97 & 12750 & 2235 & 425 & - & - & - \\
\hline Detuber.... & 1380 & 69 & 1615 & 60 & 7400 & 1600 & 233 & - & - & - \\
\hline Moucmber... & 84 & 42 & 335 & 84 & 650 & 160 & 130 & - & - & - \\
\hline Summa . . & 6724 & - & 12051 & - & 38670 & 7943 & - & 一 & - & - \\
\hline 1889 & & & & & & & & & & \\
\hline Märź . . . . & 66 & 33 & - & - & - & - & - & - & - & - \\
\hline 2lpril ..... & 1760 & 80 & 230 & 46 & 2460 & 88 & 190 & 3240 & 1640 & 108 \\
\hline Mai . . . . . & 1755 & 65 & 1970 & 73 & 7600 & 468 & 253 & 6110 & 2310 & 204 \\
\hline Suni ..... & 270 & 15 & 2825 & 118 & 5400 & 895 & 180 & 4167 & 567 & 139 \\
\hline $\mathfrak{J u l i} \ldots \ldots$ & 396 & 22 & 3190 & 118 & 10000 & 1185 & 333 & 7286 & 486 & 243 \\
\hline Iuguft & 442 & 34 & 2445 & 94 & 12150 & 1050 & 405 & 8405 & 705 & 280 \\
\hline Septentiber. & 252 & .42 & 1590 & 61 & 5750 & 887 & 192 & $50 \% 0$ & 1470 & 169 \\
\hline Dltober.... & 650 & 50 & 720 & 31 & 5650 & 840 & 188 & 3360 & 1460 & 112 \\
\hline November. . & 220 & 22 & 165 & 21 & 1660 & 265 & 110 & 1152 & 252 & 105 \\
\hline Summa . . & 5811 & - & 13135 & - & 50670 & 5678 & - & 38790 & 8890 & - \\
\hline
\end{tabular}




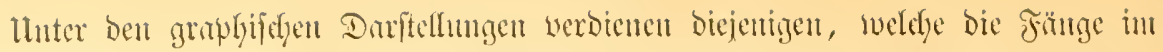

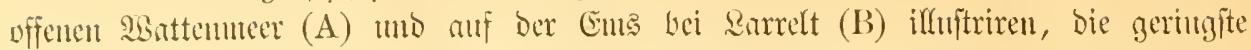

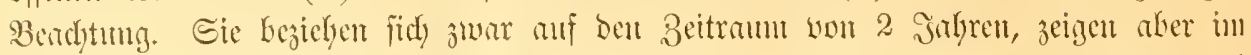

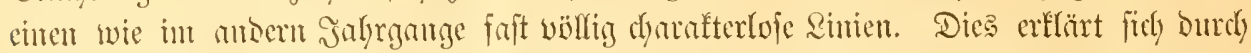

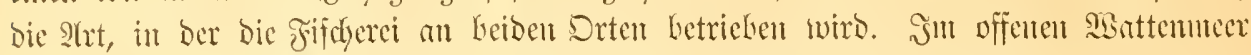

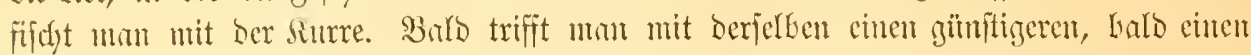

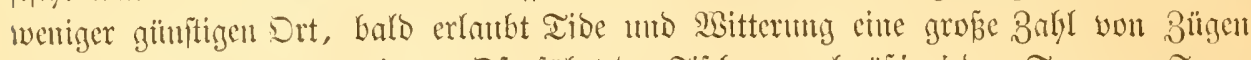

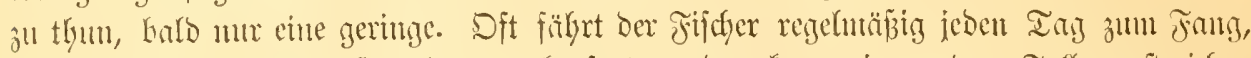

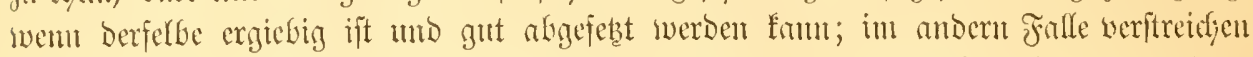

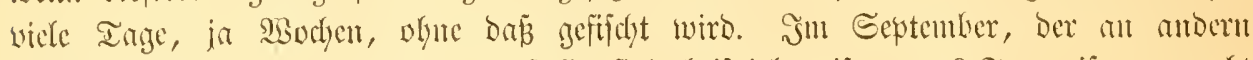

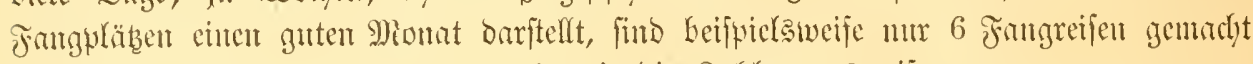
worben, iun 2luguft 1888 gar mur 4, wie bie Bahlen aušmeifen.

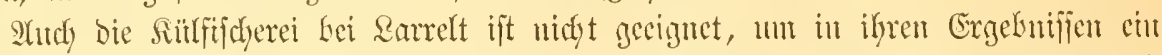

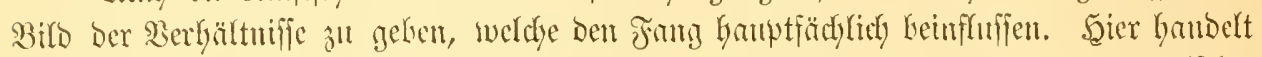

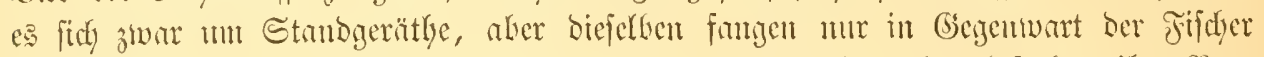

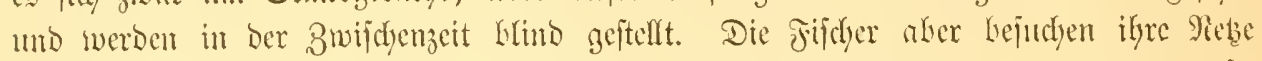

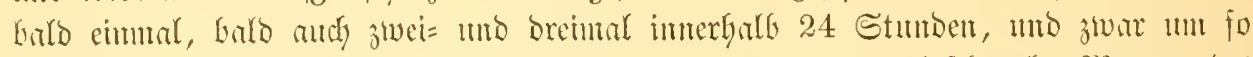

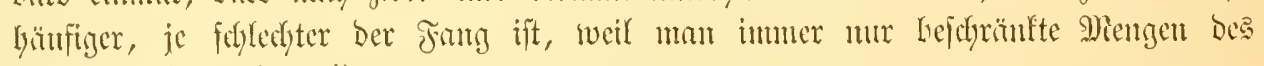
Fange abjeten kanm. *)

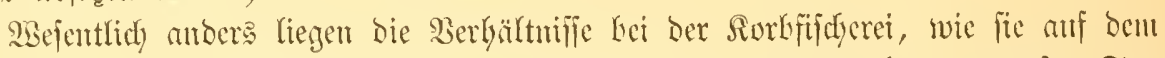

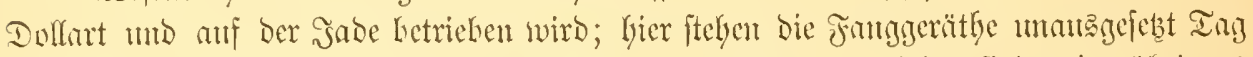

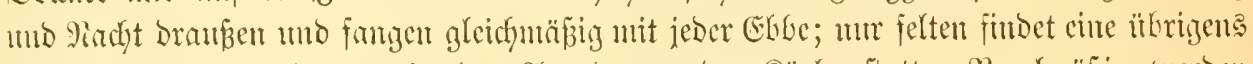

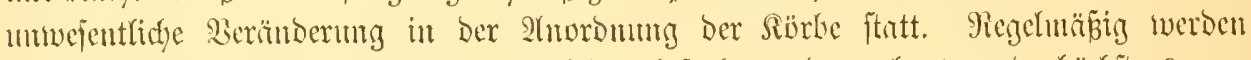

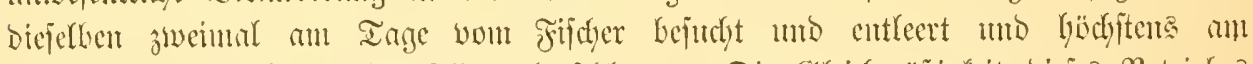

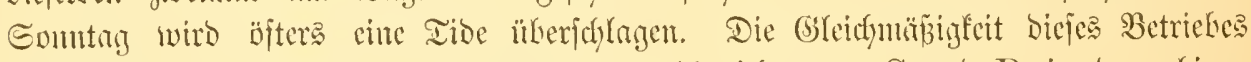
furidlyt fid benn and in Den Sinien nus, bie idf unter C mo D in ber obigen Darftellung geigeben batre.

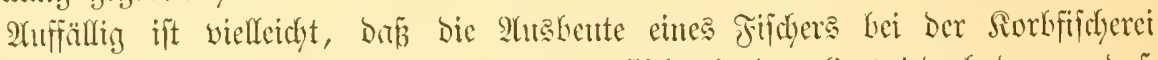

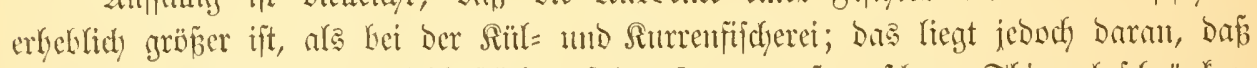

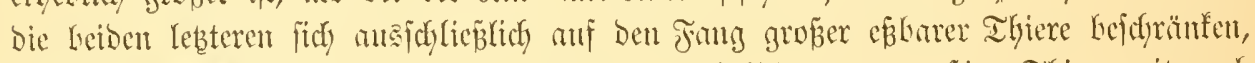

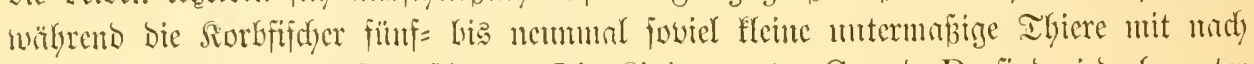

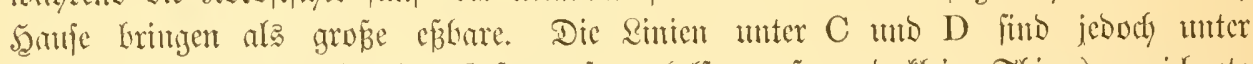

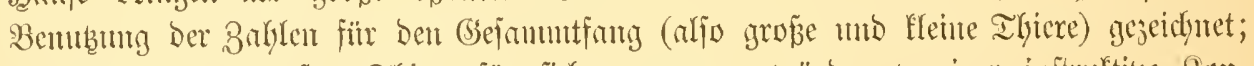

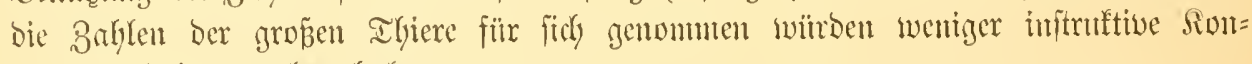
itruftionzlinien ergeten baten.

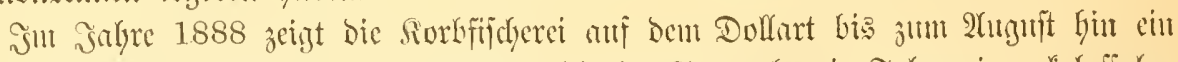
żienlitch gleidyunäpiges

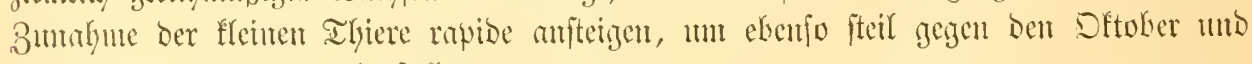
Sioventher biut wieder abzufallent.

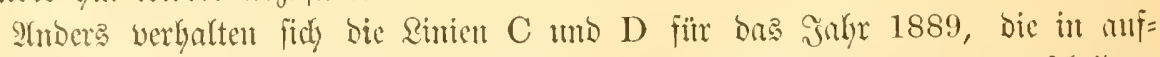

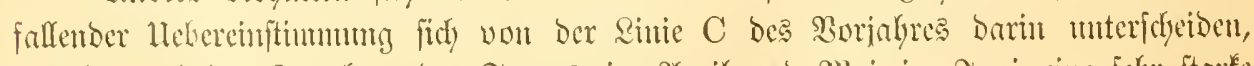

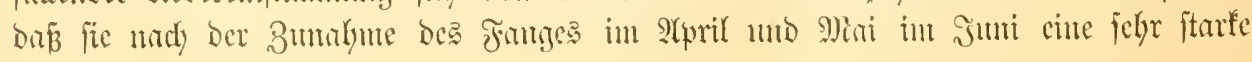

*) Mian vergleidge über biejen uns andere Betriebe menten 2rtifel über Garneelenffifcherei an

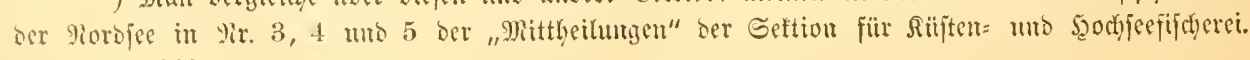
Jabrgang 1889. 
9)

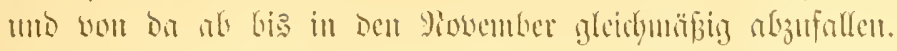

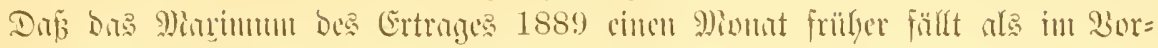

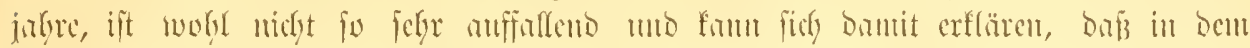

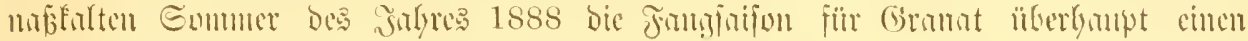

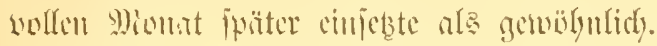

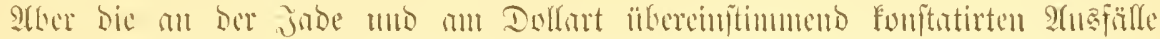

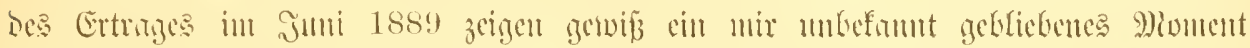

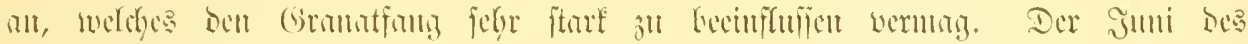

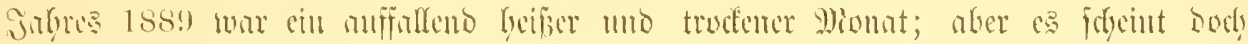

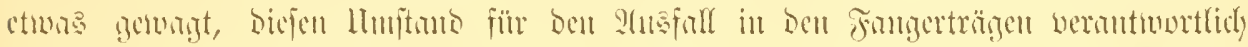

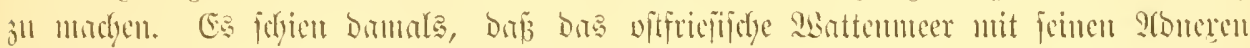

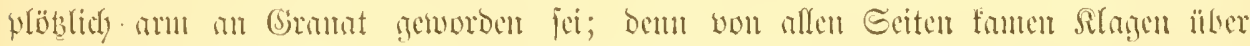

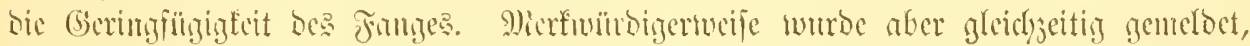

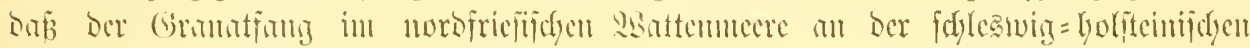

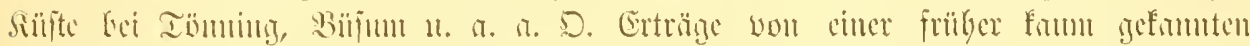

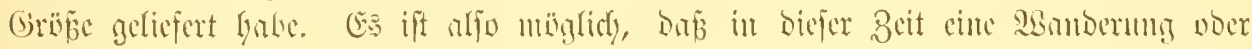

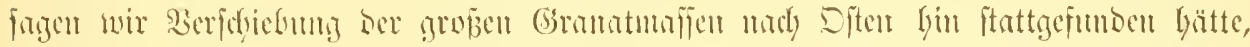

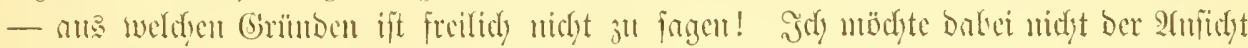

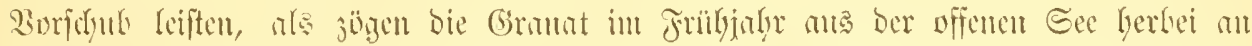

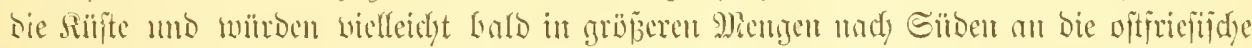

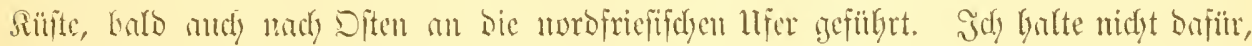

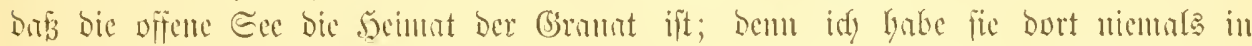

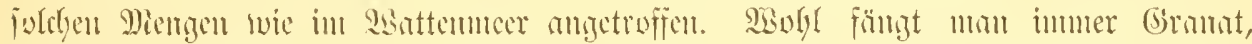

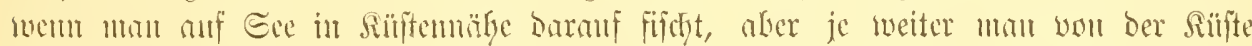

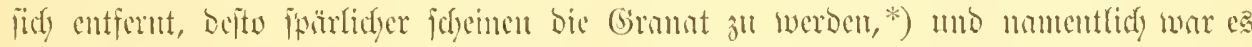

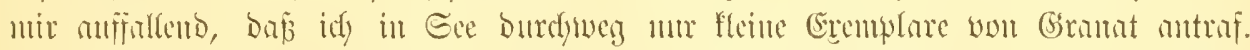

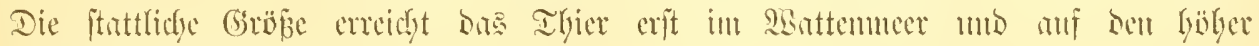

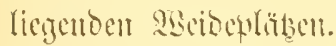

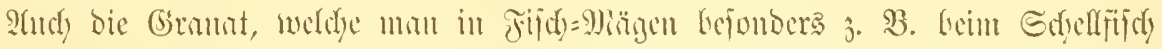

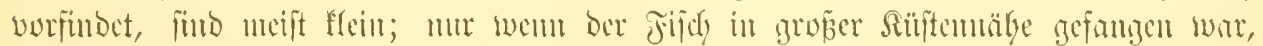

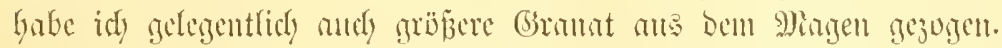

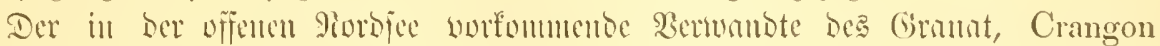

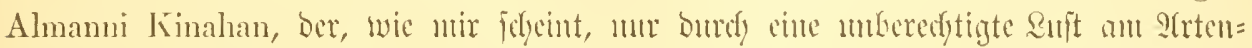

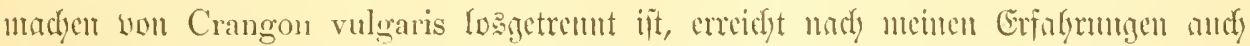

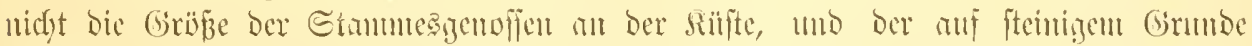

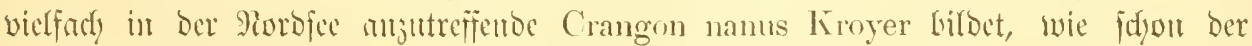

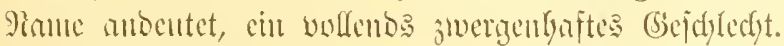

\section{Erträge ocr Girauatïijderci.}

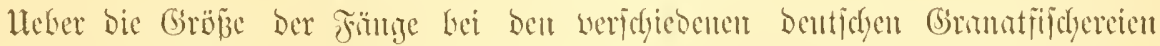

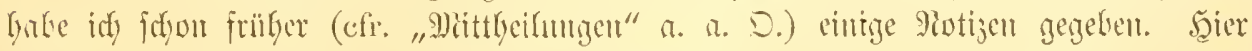

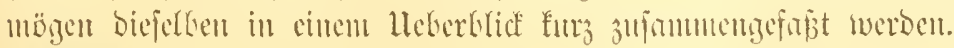

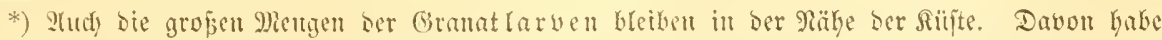

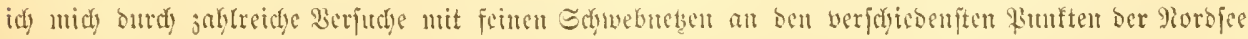
ïtergeugt. 


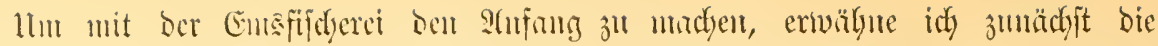

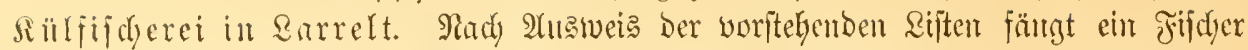

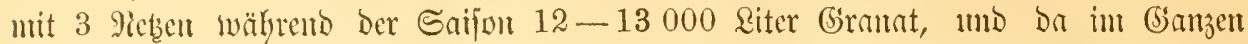

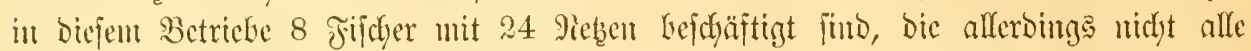

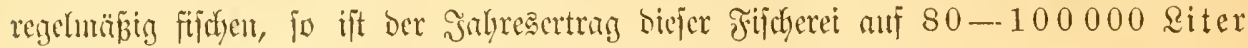
3u benteffen, Die cinen Mertly wou 7-8000 Miart repräjentiren.

Fïr bie Sorbfijdyerei am Dollart weifen in meiner Siffe bie Sarbre 1888

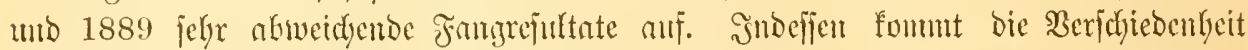

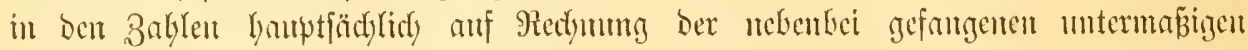

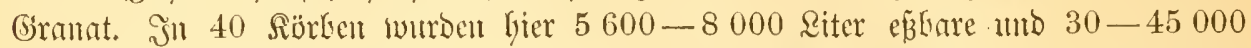

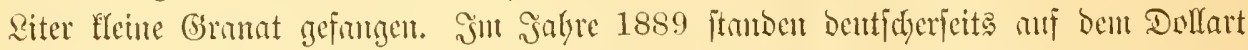

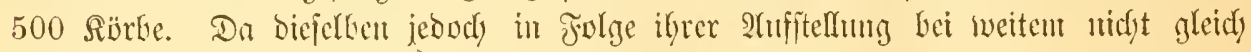

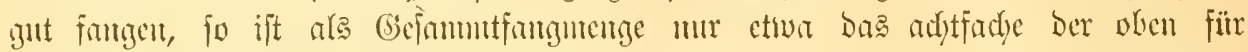

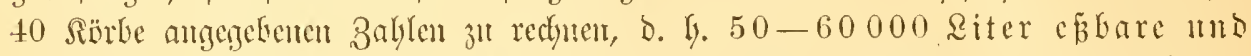

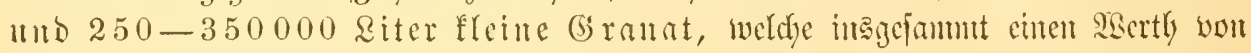
$16-22000$ Miart Garticu.*)

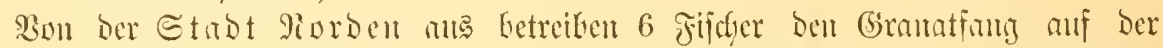

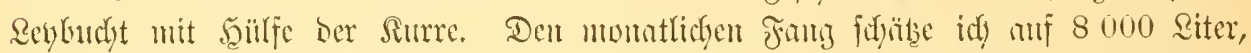

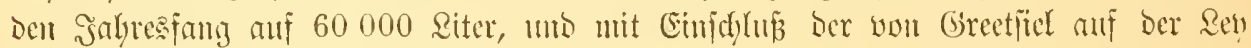

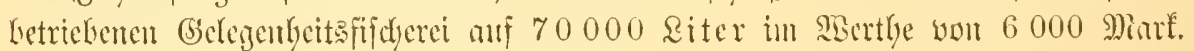

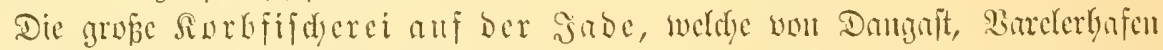

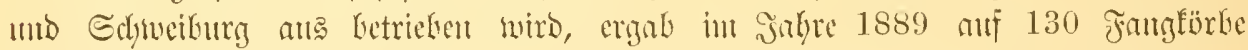

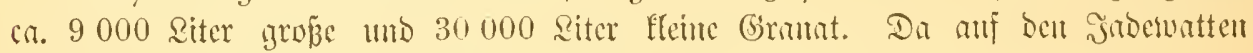

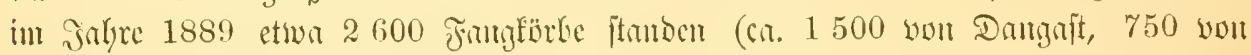

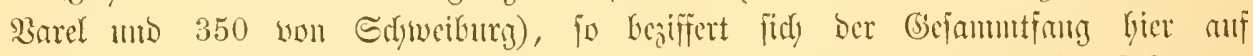

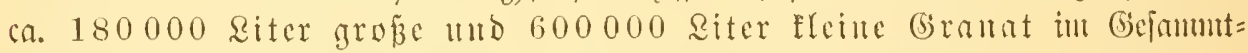

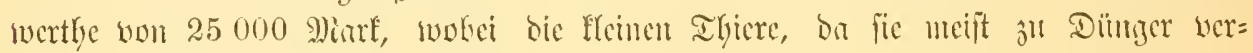

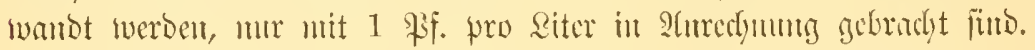

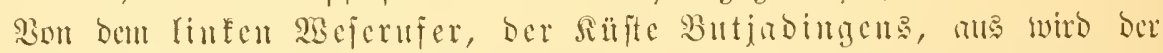

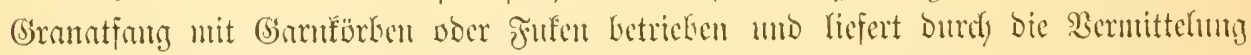

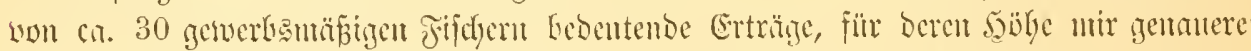

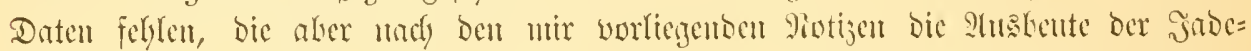

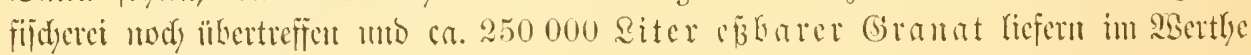
wou 25000 g) Mart.

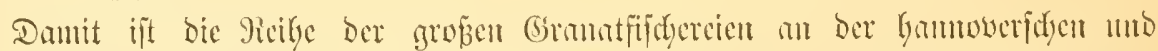

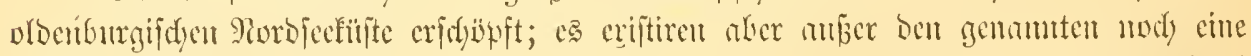

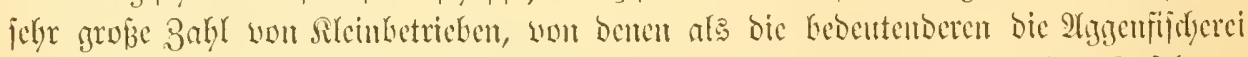

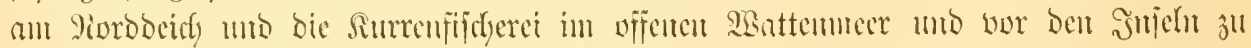

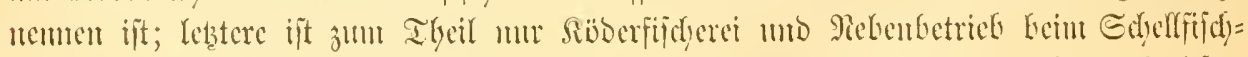

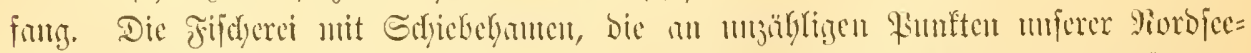

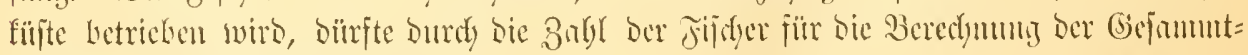
betrïge wou Sebentung merben.

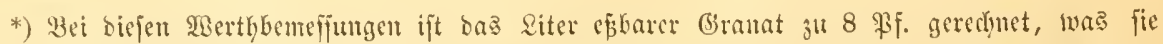

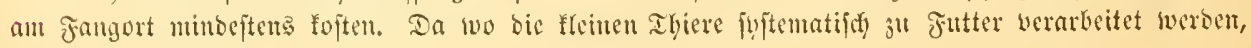
baben fie eiren $23 e r t h$ won ca. 5 \$j. pro Siter Rohiware. 


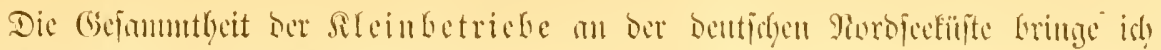
mit 250000 \&itern in Shredyumig.

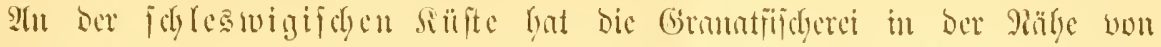

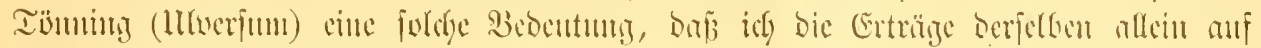
100000 Riter bermijolinge.

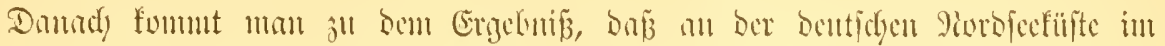

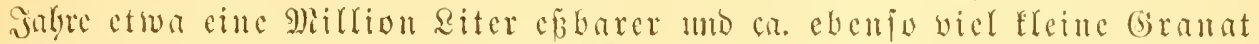
gefongen werben, wekdye zulammen cinen sgerty won 100-120 000 Miarf repräjentiren.

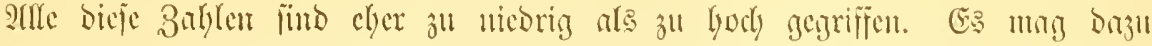

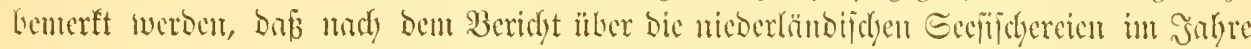

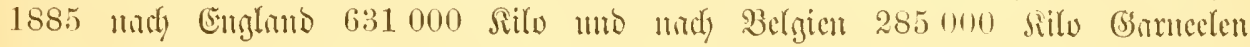

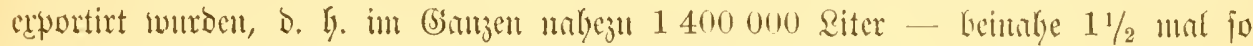
biel, ale an ben bentifyen Sinften überbant gefangen werden.

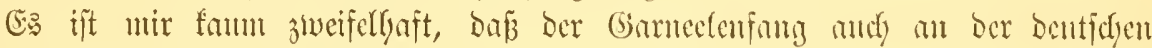

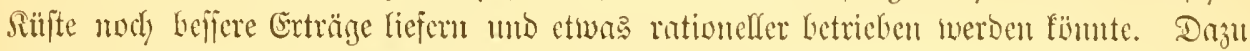

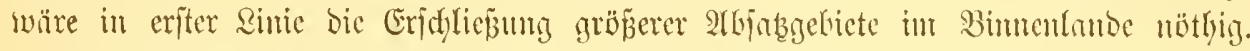

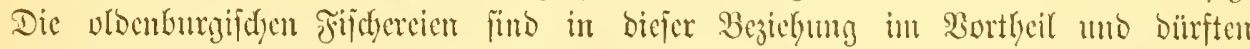

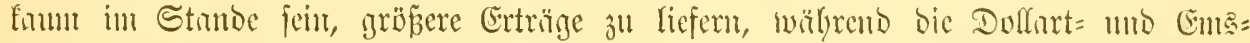

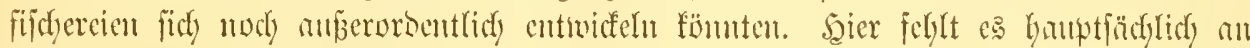

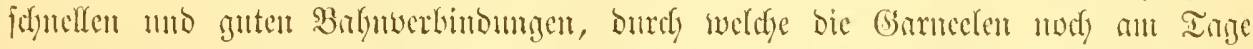

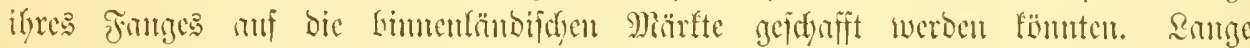

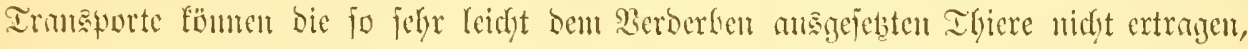

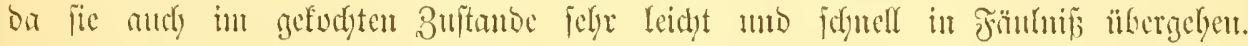

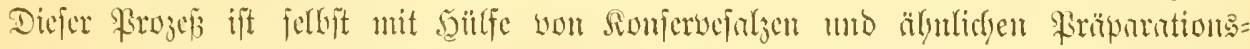

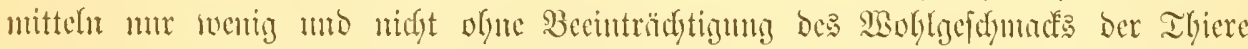

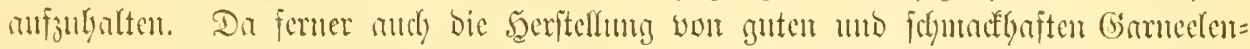

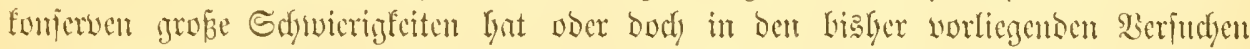

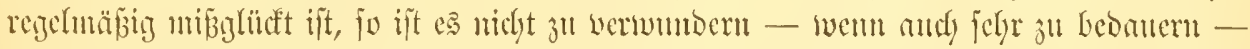

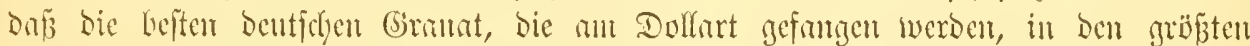

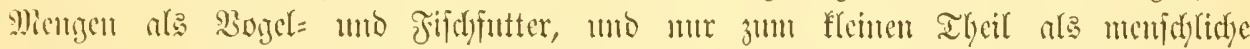

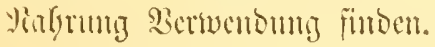




\section{Blitjaitg.}

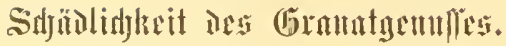

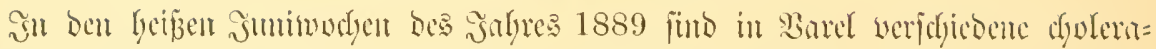

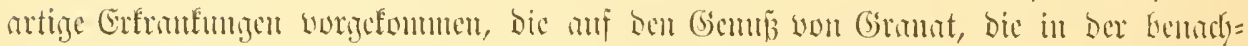

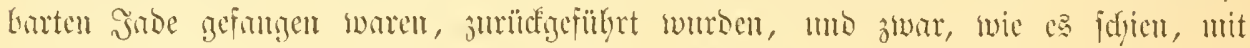

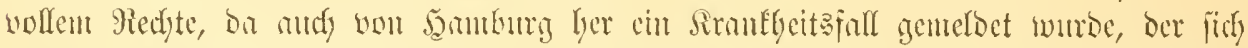

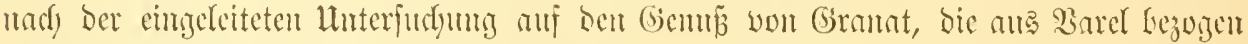
waren, zurïdffüilyren liej.

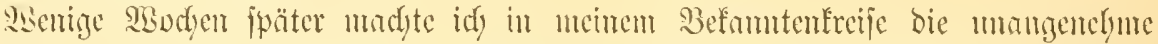

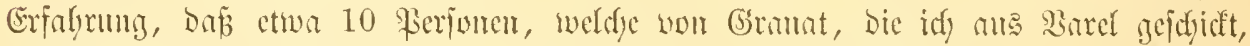

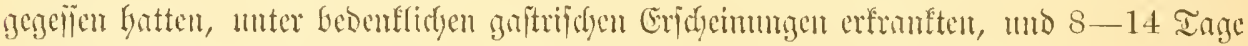

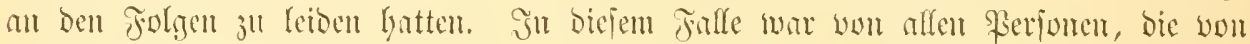

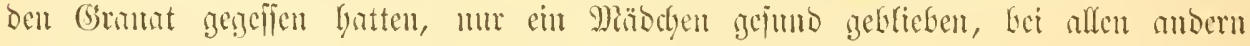

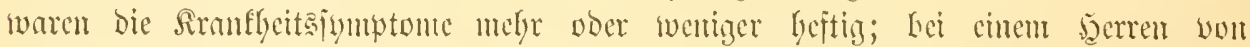

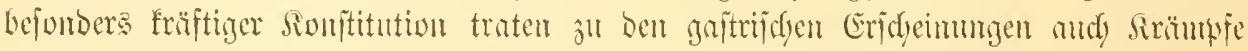
in ben GSliedern.

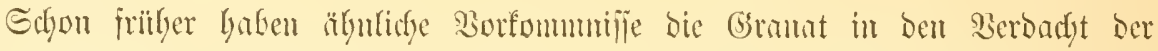

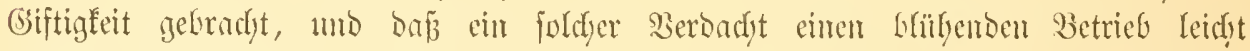

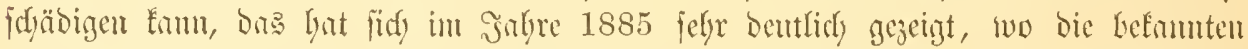

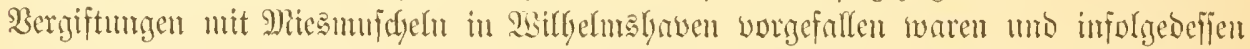

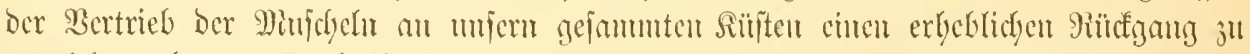

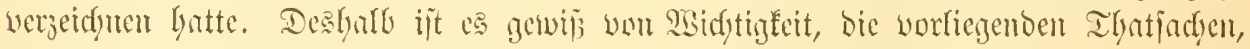

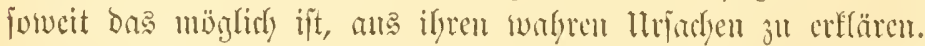

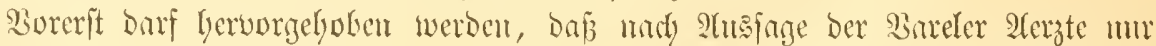

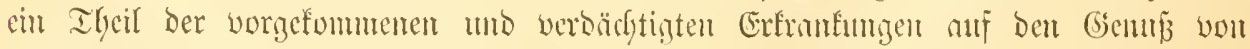

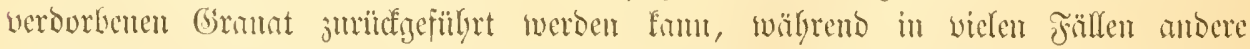

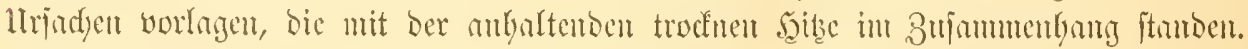

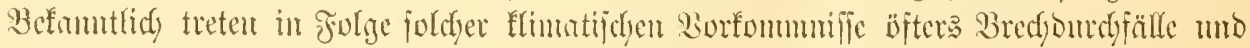

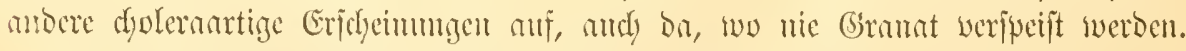

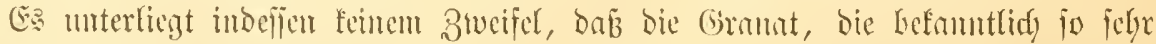

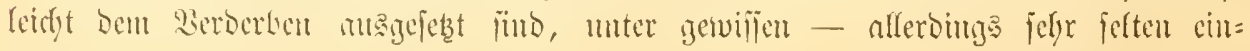




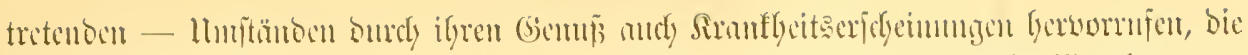

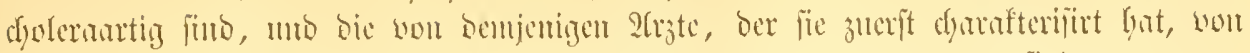

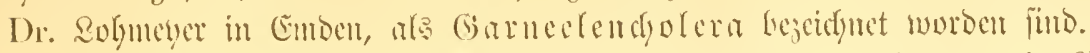

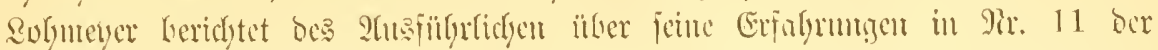

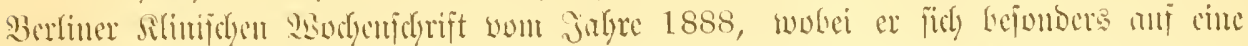

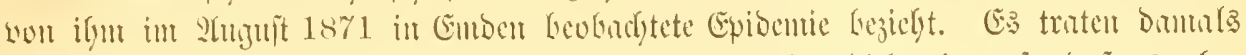

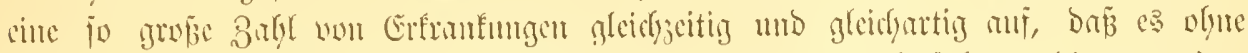

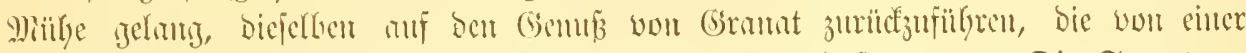

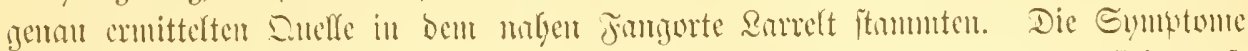

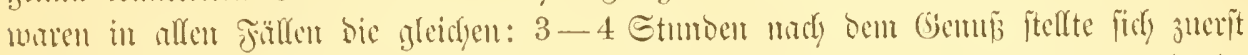

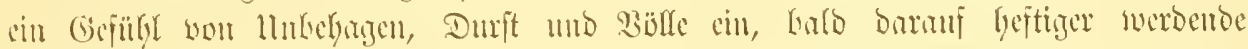

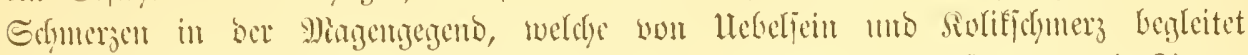

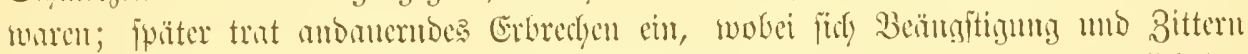

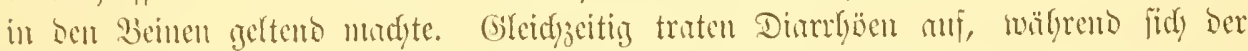

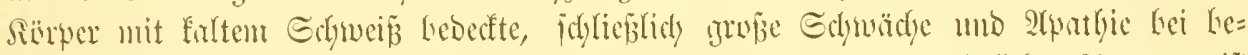
folylemtigter 9 th indefien offentsur jebr jelter.

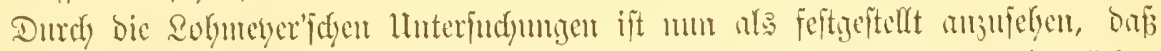

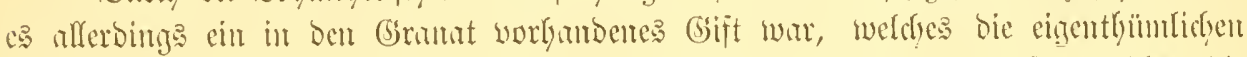

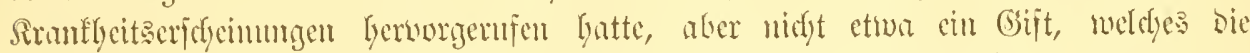

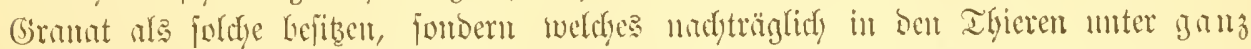

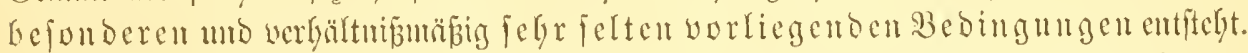

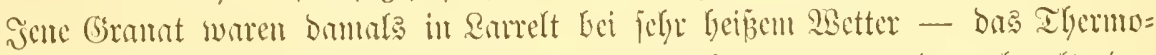
mater zeigte $24^{\circ} \mathrm{R}$. - gefangen unto geforfyt mo fomten unter ben blwaltensen

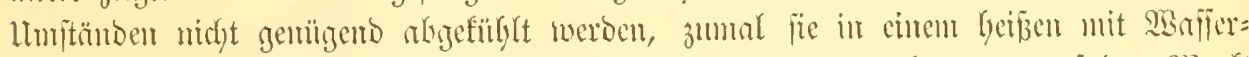

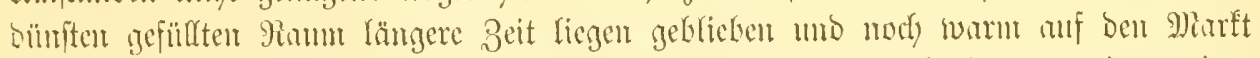

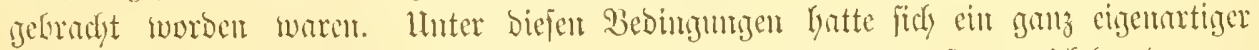

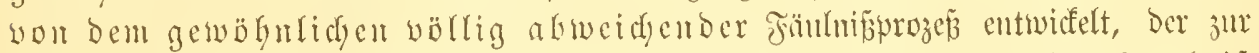

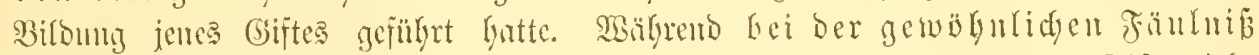

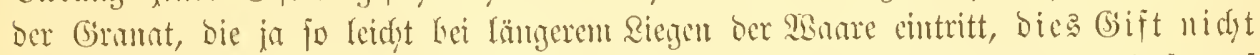

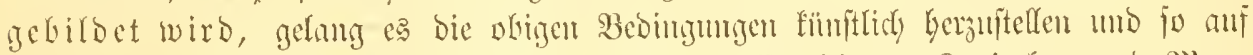

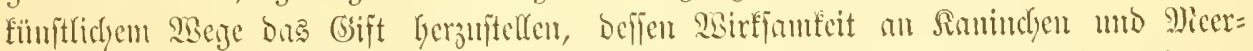

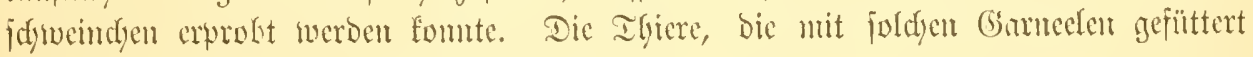
unurben, erfrumften poer gingen z̆l Grumbe.

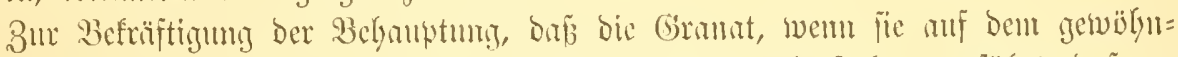

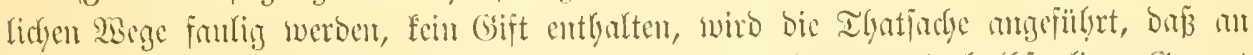

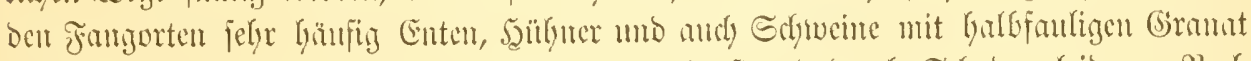

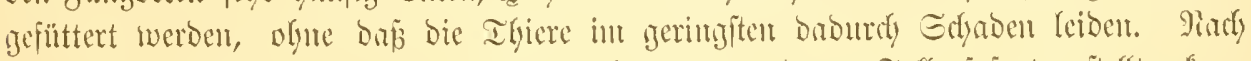

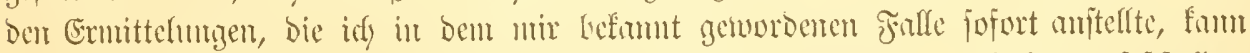

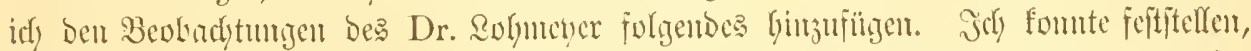

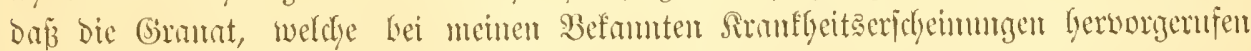

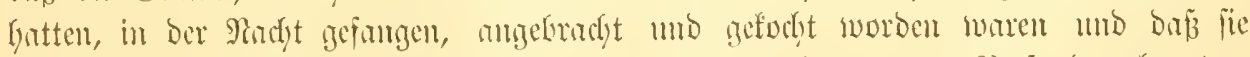

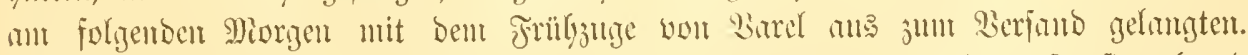

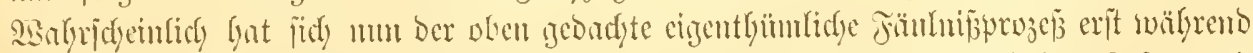

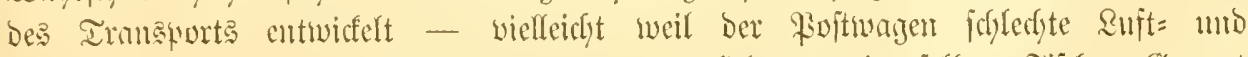

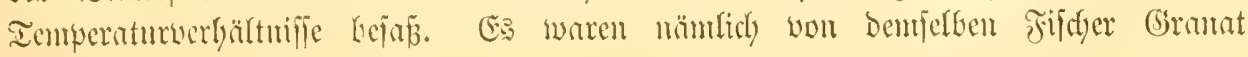




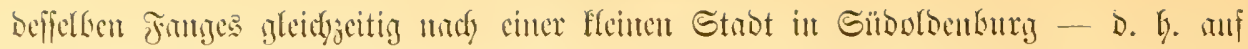
cine siel geringere Entfermung - edpebint worben mo waren, wie idy an Dit jelkft

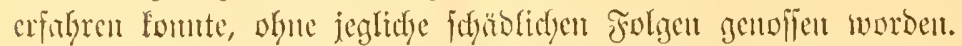

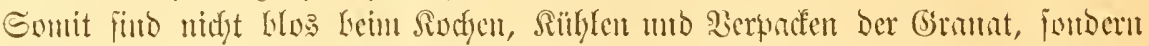

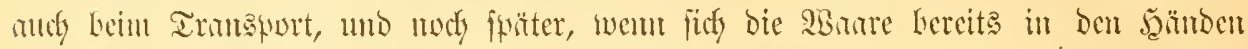

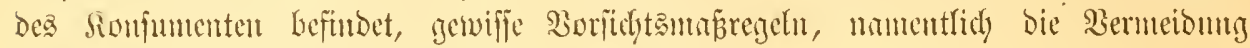

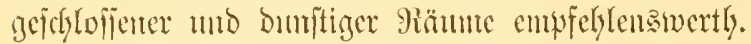

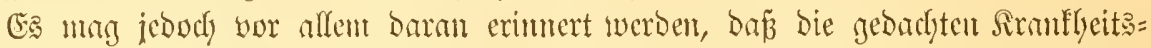

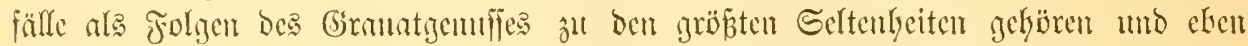

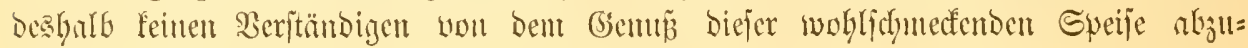
bilten Eratuchen.

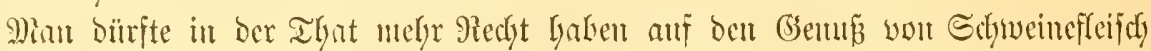

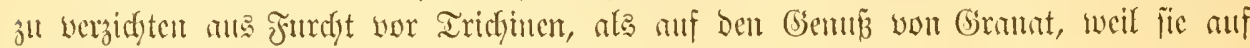
jue feltene siscije gifting geworben jein föntr.

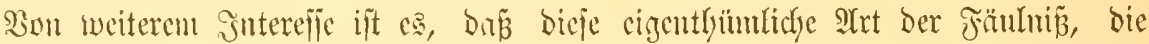

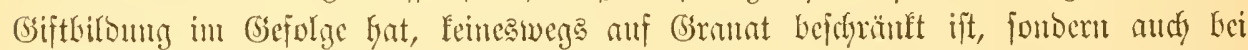

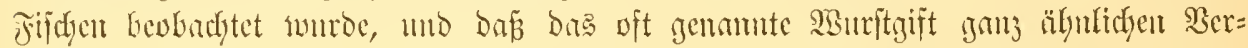

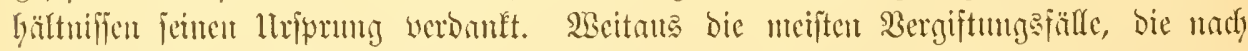

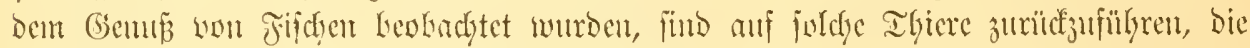

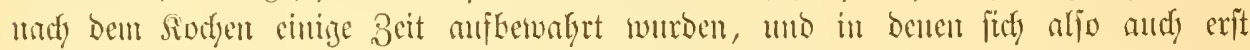

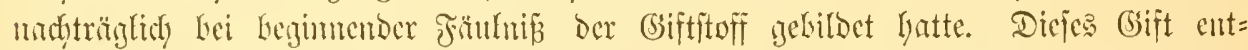

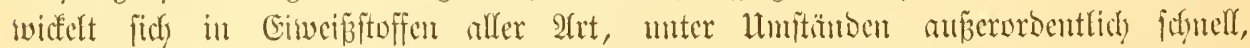

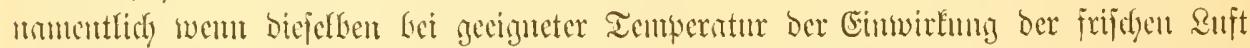

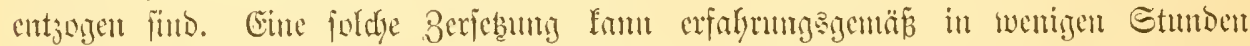

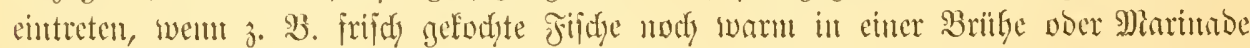

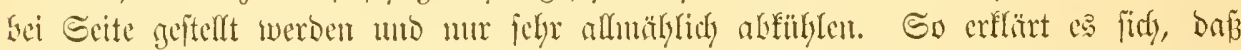

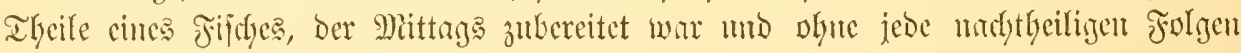

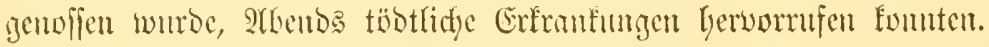

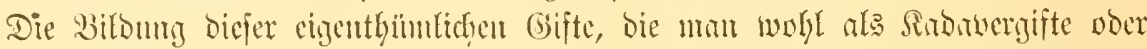

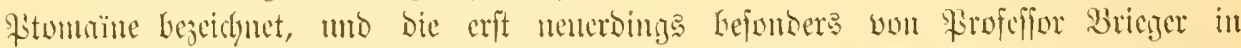

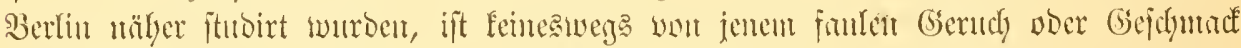

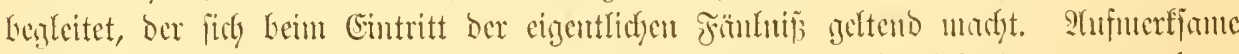

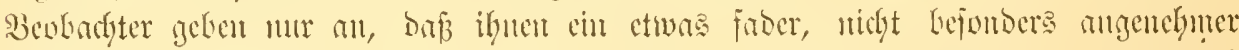

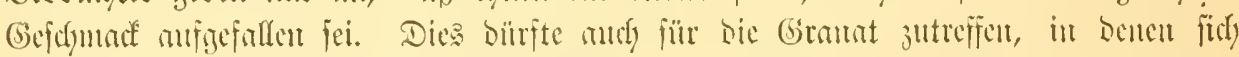

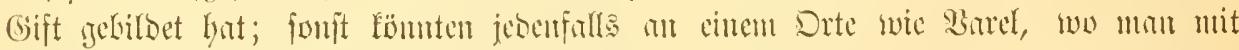

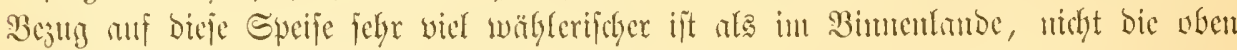
crwäbyten Bergiftungäfülle borigetounten fein. 


\section{fitterntur- Zlatzeidlutis.}

1. Fabricius, 3. Ch. Entomologia systematica. Tom II. Ropenfagen 1795.

Derjecbe. Supplementum entomologiae systematicae. 1798. (pag. 410).

2. Gcbn. Locupletissini rerum naturalinm thesauri accurata descriptio. 30. 1II. Thmiteroam 1734-65. (tab. 21, Jitg. 8.)

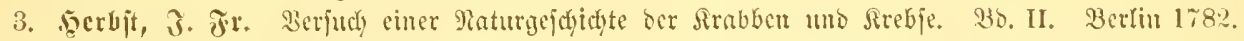
(pag. 57, tab. 29, زig. 3,4.)

4. Qcad), 23. Malacostraca podophthalmata Britanniae. Sondon 1815-17. (tab. 37, 3.)

5. Miifi, :I. Histoire naturelle des Crustacés des environs de Nice. 1816. (pag. 83.)

6. Miluc=0

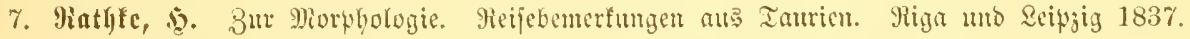

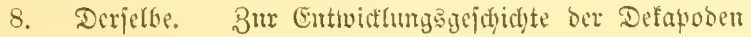

in 2trchio f. Yaturgefu. Jahtgg. 6. 1840. 3D. I. pag. 24I-49.

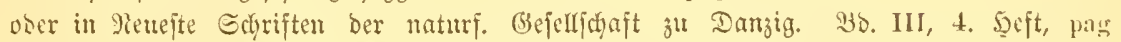
$23-55$ mit 3 Iafelr. Röntgäbrg 1835.

9. Du Crnte. Metamorplosis of Crustacea.

in Annals of nat. Hist. vol. 2, pag. 178 mit 2 Iajeln. Sonoon 1839.

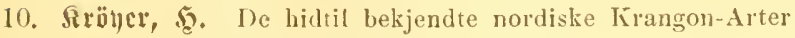

in Naturhist. Tidskrift. 1. Raekke 4. Bd. pag. 217 ff. mit Iafiln. Siöbenţaum 1842.

11. Derjelke. Monografisk fremstilling af Slaegten Hippolyte's nordiske Arter med Bidrag til Dekapodernes Udviklingshistorie

in Kongl. Danske Vidensk. Selsk. naturvid. og math. Afhandlinger IX. Deel pas. 209-360 mit 966. Rï̈benlyam 1842.

12. 3ofy, פgr. Etudes sur les meeurs, le développenent et les mitamorphoses diune petite Salicoque d'eau donce (Caridina Desmarestii)

iu Ann. des scieuc. natur. 2. Série 30. XIX. Faris 1843.

13. Berf, $\mathfrak{i f y}$. A History of the British stalk-eyed Crustacea. Qonoon 1853.

14. Rinriugtou, $\mathfrak{i}$. Observations on the natural history and habits of the common prawn (Palaemon serratus)

in Ann. of nat. list. 2. ser. 38. XV. pag. 247-52. Ronton 1855.

15. Bate, (c. Spcuce. On the development of dekapod Crustacea

in Philos. Transact. Roy. Soc. 3๖. 148. pag. 589-605 mit 2tbb. Qunton 1859.

16. Derfelbe. Report on the present state of our knowledge of the Crustacea

in Report Brit. Assoc. Adranc. Scienc. [1875 pag. 48. 1876 pag. 89. 1877 pag. 4. . 1878 pag. 7.] 1879 pag. 193. [1880 pag. 230.]

17. Dirfelbe. On the development of the Crustacean embryo and the variations of form exhibited in the larvae of 38 genera of Podophthalmia

in Proceed. Roy. Soc. 3.. 24. pag. 375-79 mit 2(b6. Ronbon 1876. 
18. Sars, 9). Bemaerkuinger over Crangoninerne med beskrivelse over to nye norske Arter in Forhandl. Vidensk. Selsk. Christiania pag. 179-18\%. 1861.

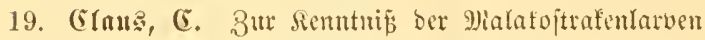

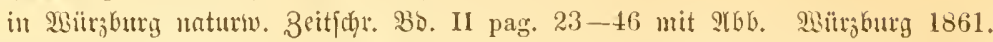

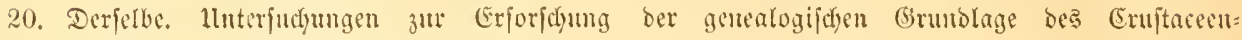
Sujtems mit 19 Tafelı. SEien 1876.

21. Derferbe. Zut Sentunip Der Sireislauforgane ber Sdjizopoden und Defapoden

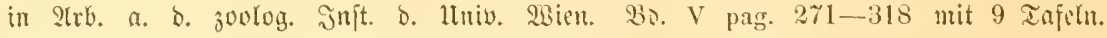
2sien 1884 .

22. Derfolbe. Meut Beiträge jur Mnowhologie ber Erujtaceen

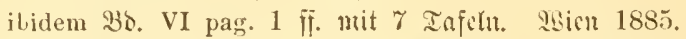

23. 5ecller. Dic Eruftaceen bes jüblidyen Europa. Wgien 1863.

24. 5enjen, 23. Studien über bas Gehörorgan der Defapoden

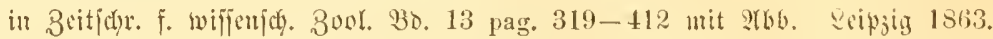

25. Miiller, Frits. Die Serwantumg Der Garmeelen

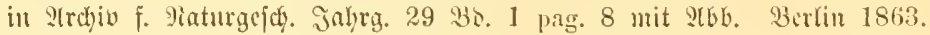

26. Derfalle. Jür Darwin. Leipzig 1864.

27. Riungan, $\mathfrak{I}$. $\mathfrak{i}$. Synopsis of the species of the families Crangonidae and Galatheidae which inliabit the seas around the British Isles

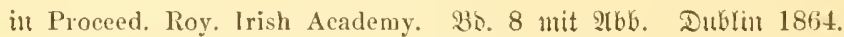

28. Gicrbc, Mi. 8. Metamorphoses des Crustacés marins

in Comptes rendus de l'Accad. d. Sci. 30. 62. pag. 1024. Raris 1866.

29. Enubcrs, YY. Notes on zoosperms of Crustacea

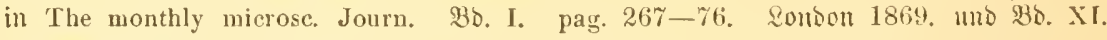
pag. 104-111. Zonbon 1874..

30. Dohra, ST. Beiträge jur Semntnif ber Malafojtrafen und igrer Earben

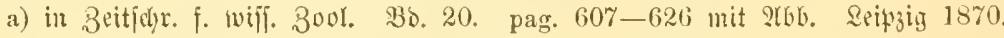

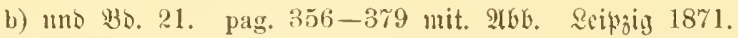

31. San Sicucben un Bcijels. Mémoire sur la formation du blastoderme chez les Amphipodes, les Lernéens et les Copépodes

in Mém. couron. et mém. d. sav. étr. publ. p. l'A cad. roy. d. Belg. 30. 34. Bruxelles $18 \% 0$.

32. Sturferg, Y. Karcinologiska iaktagelser.

in Ofversigt af Kongl. Vetenskaps Akademiens Förhandlingar. 13. Jahrg. Stoffyolm $1873-74$.

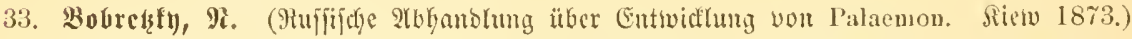

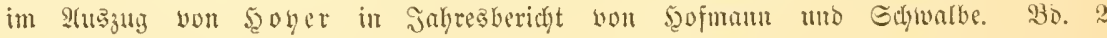
pag. $312-18.1875$.

34. Brocdji. Recherches sur les organes génitanx màles des Crustacés déliapodes

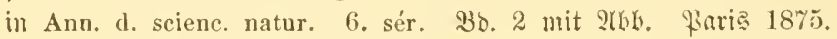

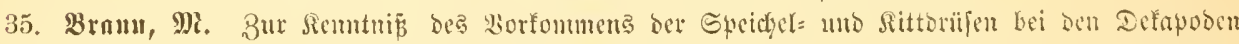

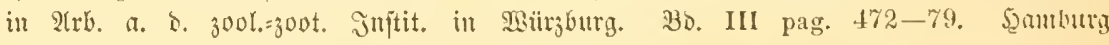
$1876-77$.

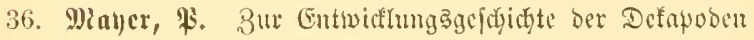

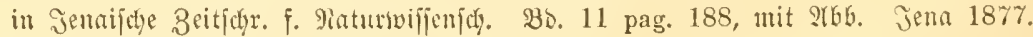

37. Derfacke. Earcinologifate Mittheilungen. (IX.)

in Mittlyeil. a. b. zool. Station zแ Teapel. 32. 2 pag. 197 mit 9r6b. Reipzig 1881.

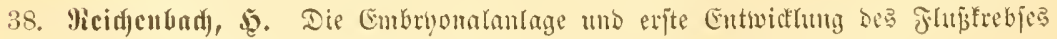

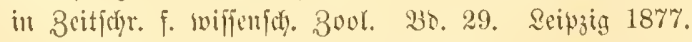

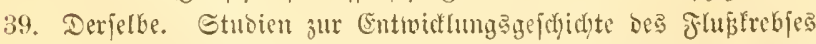

in Thhanol. D. Gentenberg. naturf. Gefellid). Frautfurt a/M). 1886.

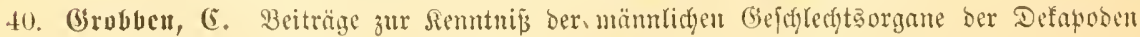

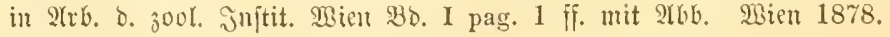

41. Fraton, 23. On the development of Palaemonetes rulgaris

in Bull. of the Museum of Comparative Zoology, Harrard College in Cambridge Mass. 30. 5 Jir. 15 mit ?lbb. Cambridge Mass. 1879. 
42. Derjeffe. On some points in the structure of embryonic Zö̈a, ibidem 93ठ. 6 9ir. 10, mit भLb. Cambridge Mass. 1880.

43. Boaz, オ. (5. ㄴ. Studier over Dekapodernes Slaegtskabsforhold

iu Dauske Vidensk. Selsk. Skrift. 6. Raekke. Naturvid. og math. Afd. I. 2. Rjüben= Gavit 1880.

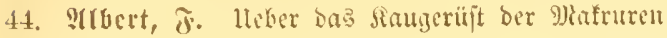
in Aeademia Göttingensia (Dissertat.) Göttingeu 1883.

45. Miocquarb, $\mho$. Recherehes anatomiques sur l'estomae des Crustacés podophthatmaires, mit thb. Limitis 1884.

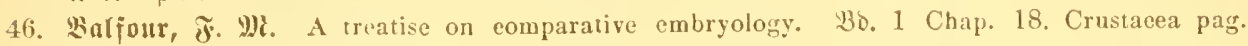
3.11 443. 20HDDII 1880.

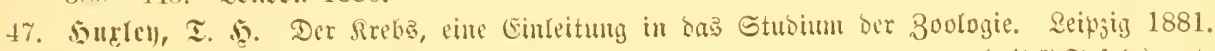

45. Sar?, (5) D. Bidrag til kundskaben om Dekapodernes forvandlinger. I (mit 7 Iafelu) IutD II iu Arehiv f. Mathem. og Naturvidensk. 20. 9 pag. 155-204. Iíristiania 1884 แแD 1888 pag. $133-201$.

49. Riugs(cy, $\mathfrak{3}$. . The Development of Crangon vulgaris

in Bulletin of the Essex Institute. BD. 18 pag. $99-1531887$ uno 30.21 pag. $1-421889$. 


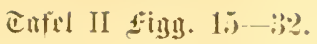

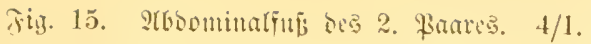

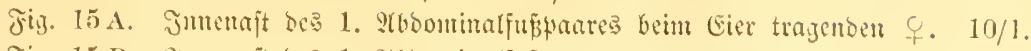

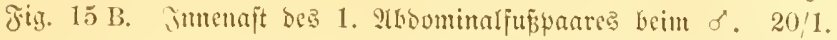

Fi3. 16. Frofilanildyt ber Eingeneibe in natïrlidyer Rage. $2 / 1$.
ne. Siagemumit.
s. Miagert.
h. Beber.
ov. Eierjtocf́ mit od., bem Eilciter.
i. Iarm.
c. Serry.

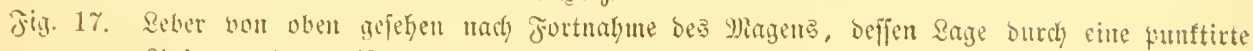
Sirie angebentet ift. 2/1.

i. Stustritt oç Darms ans Der Deber.

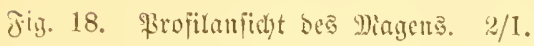
oе. Miagenmumo.
i. Darm.
ca. farbiafaler Ibit.
py. Whlorifcher Iheil.
pp. prizpllorifaler Theit.

Jis. 19. Die untere yiagentwaro von immen gejeken. 15/1.

Cifm. farbifales juferomedianm.

Coifl. farbiafale oberes Junferolaterale.

Cuifl. fartiafales unteres Jiffrolaterale.

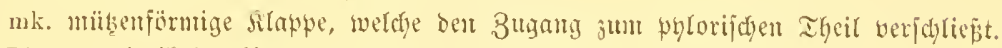

Phsm. pylorifales binteres Guperomedianum.

Plk. Bylorifalflapke. i. Darm.

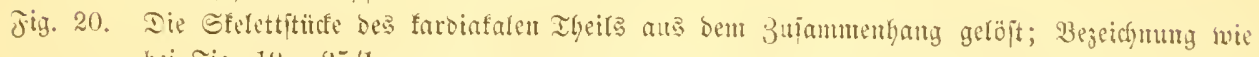
bei fig. 19. 25/1.

b. Borjte Des farbiafalen oberen Jnjerolaterale. $150 / 1$.

Jig. 21. Die unter ber mithenförmigen Rlappe liegende Jnjeromediantajcye. $30 / 1$.

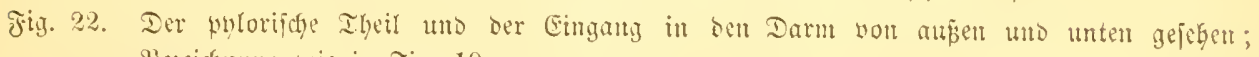
Begeidfunt wie in jig. 19.

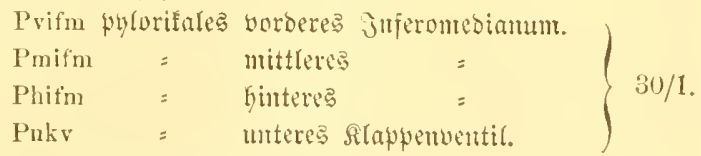

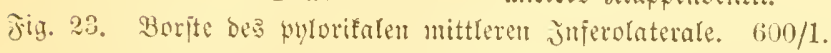

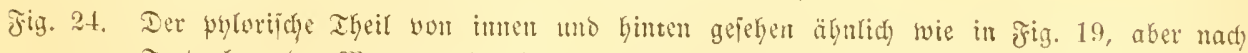

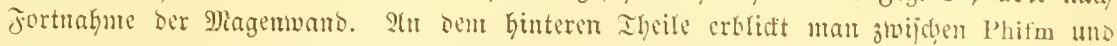

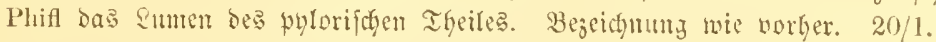

Phill pylorifales Ginteres Inferolaterate.

Phsm = Euperomedianum.

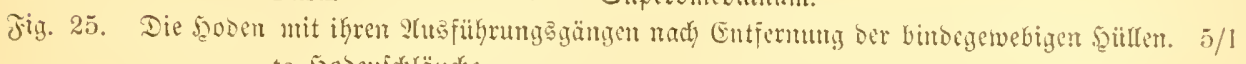
te 5rodenfduläuthe.

vd Buleitungsabidnitt bes vas deferens.

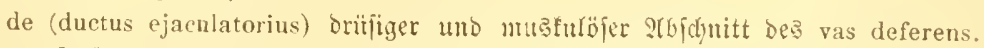

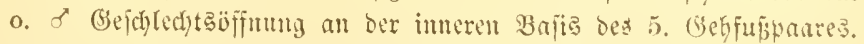

Jig. 26. A-E. Die Eamenzelle und ifre Entwidelung jum Santenfürperdfen. $12010 / 1$.

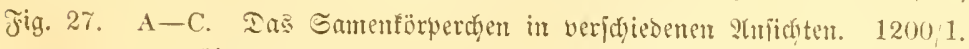

D. Ein Samenförperdyen mit Durd Förbung Deuttidy gemactsem Sicru.

Fig. 28. Eieritorf mit ben Eileitern. $2 / 1$.

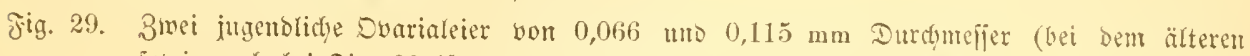
joivie audy hei fig. 30 ift bas Follifelepitgel fortgdafjent). 340,1 .

f. e. Jollifelepithet.

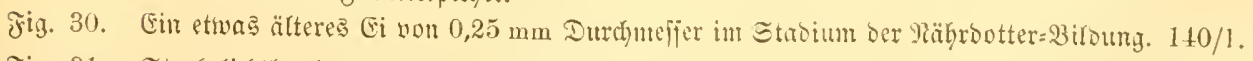

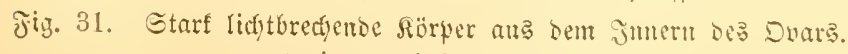

A. in gemeinfdaftlidjer 5ülle z̆ einer Gruppe bereinigt. $600 / 1$.

B. einjelte. $1200 / 1$. 
jig. 32. Eifegment mit ber Embryonalanlage im Mauplusftabium. 140/1.

eh. Chorion oder Eilyaut.

d. Dotterhaut (Mathłe's).

\section{Tnfel III fing. 33-43; 45-51.}

Trig. 33. Ein wentig älteres Starium von Der fräche gejelyen. $70 / 1$.

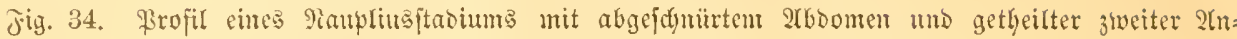
temle. $140 / 1$.

Jig. 35. Entbryo mit ber 2Yulage aller Earwengliebmaj̃en uns bem Entomoftrafenauge. 70/1.

Jig. 36. Formen Des Entomojtrafenanges. 200/1.

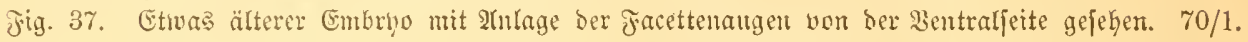

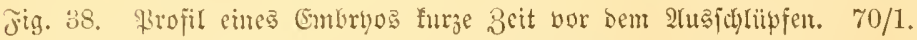

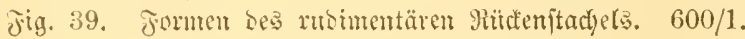

Jig. 40. Ein furz vor ber Meife aus dem Ei gepeflter Embryo in der ltmfürtung ber Rarben= lyaut. $100 / 1$.

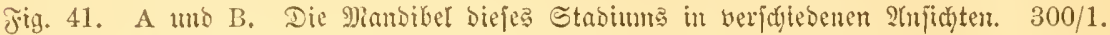

$\left.\begin{array}{l}\text { Jig. 42. Die erite Marilfe } \\ \text { Jig. 43. Die smeite Marille }\end{array}\right\}$ Diefes Stabiums. 200/1.

Jig. 45. Mandibel $(100 / 1)$

Jig. 16.*) Erite Marille (200/1) \} biejes Etabiums.

Tig. 47. 3weite Marille (200/1)

Jig. 48. Die Mumböffmung Der Zoen mit Den Sippen uno ben Mandibeln. 240/1.

ritg. 49. Die 2ugengegend Der 3oea mit Dem Stimfortfake. 125/1.

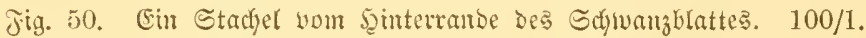

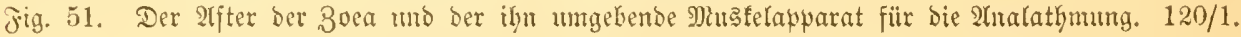

\section{Tafol IV 2 ing. 4t; $52-64$.}

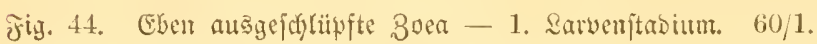

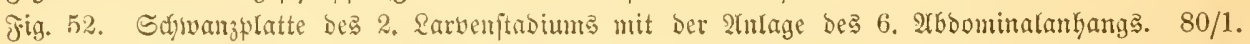

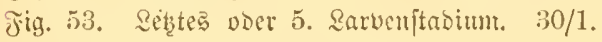

Fुig. 54. A. und B. Die Miandibel Deffelben in verjofiedenen 2Tnjidyten. 80/1.

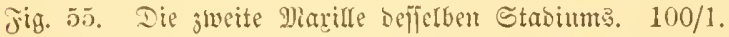

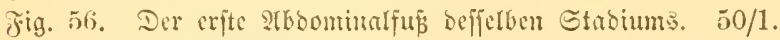

Fig. 57. Die Sdywanjplatte mit Dem 6. 2tbonminalfuppaar defjelben Stabiums. 30/1.

Jig. 58. Der Miagen befferben Stabiums. 200/1. Bezeidymung wie in Fig. 18.

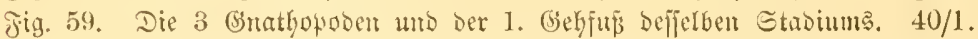

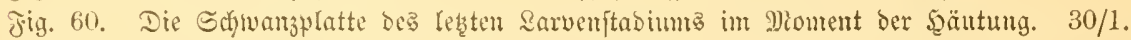

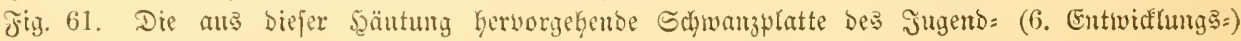
Stabiumb. 40/1.

Jig. 62. Die jweite Marille bes Jugenditabiums. 10n/1.

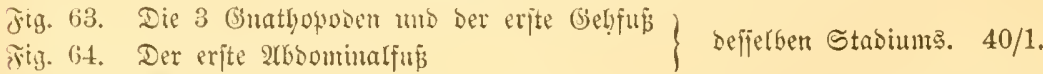

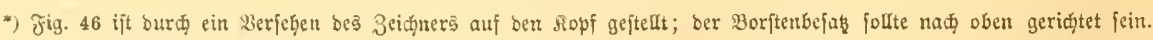




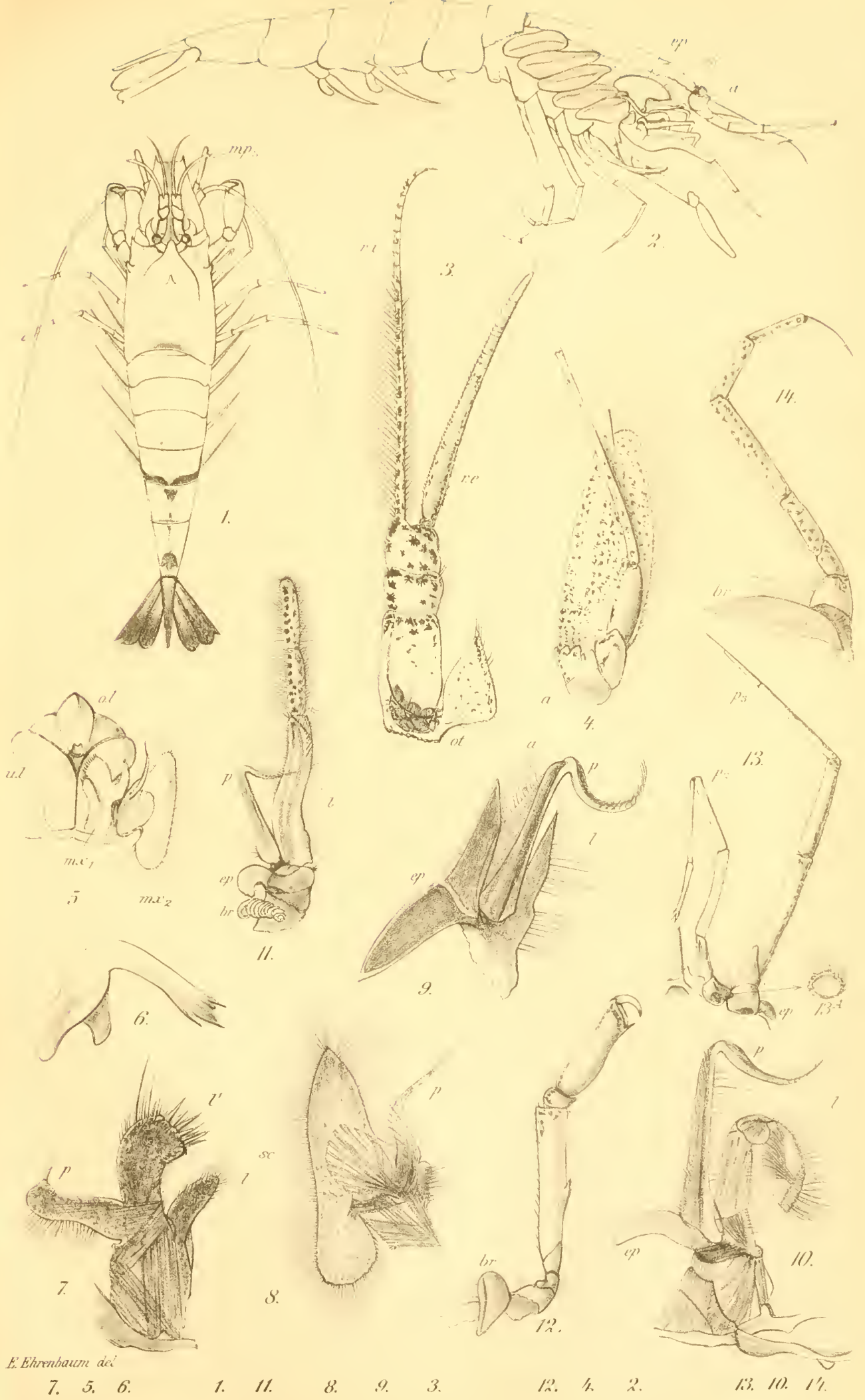





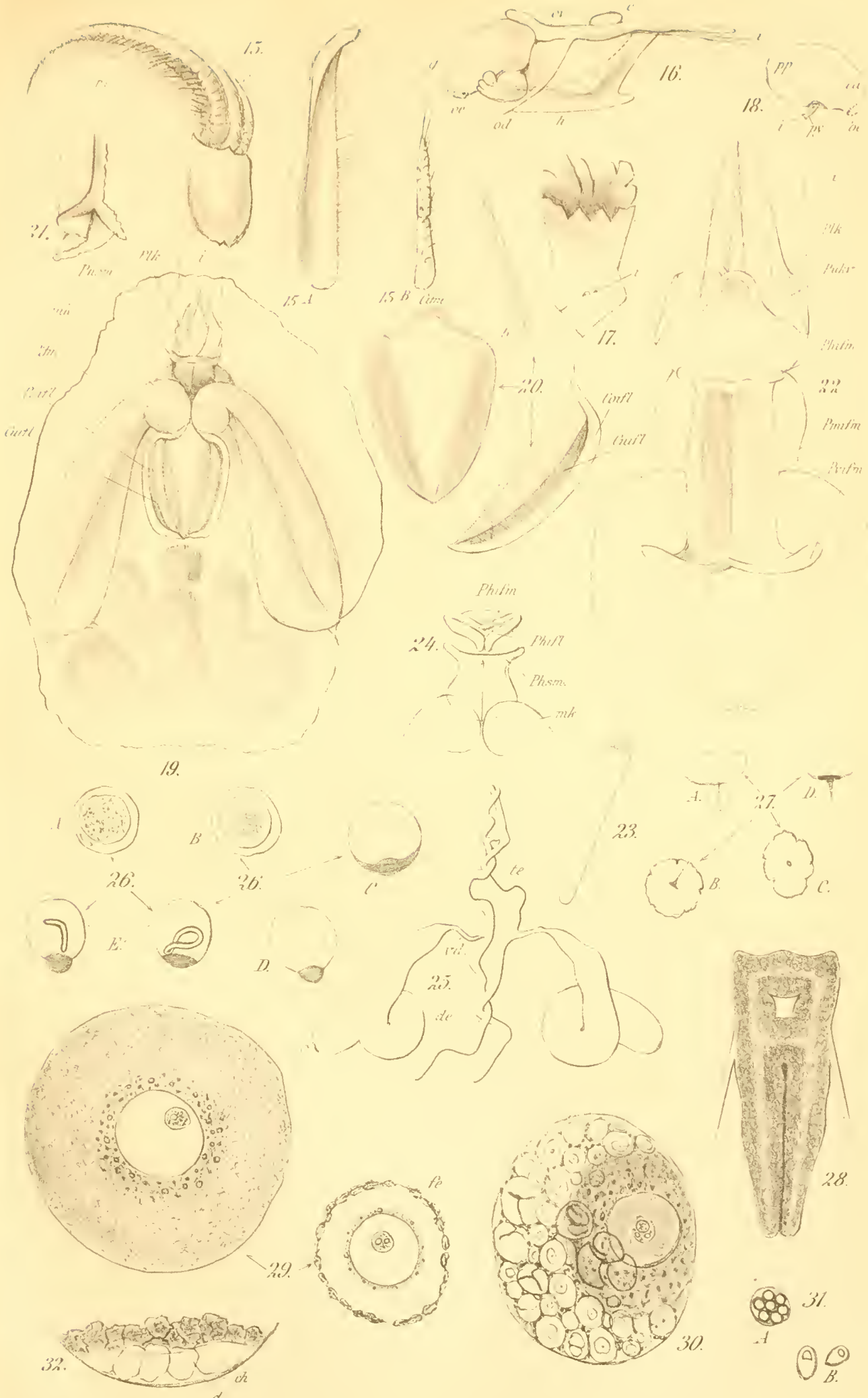




\section{.}




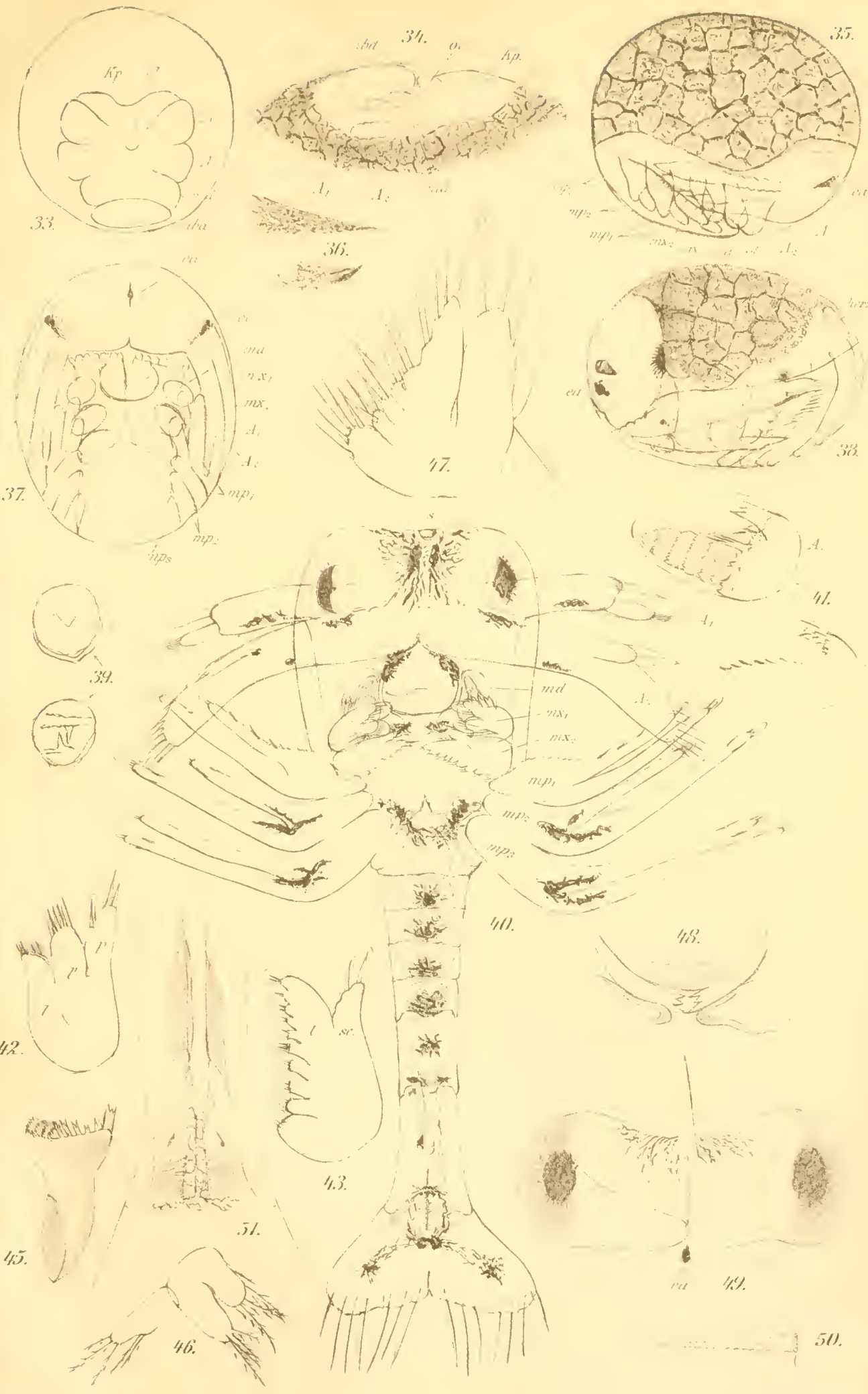





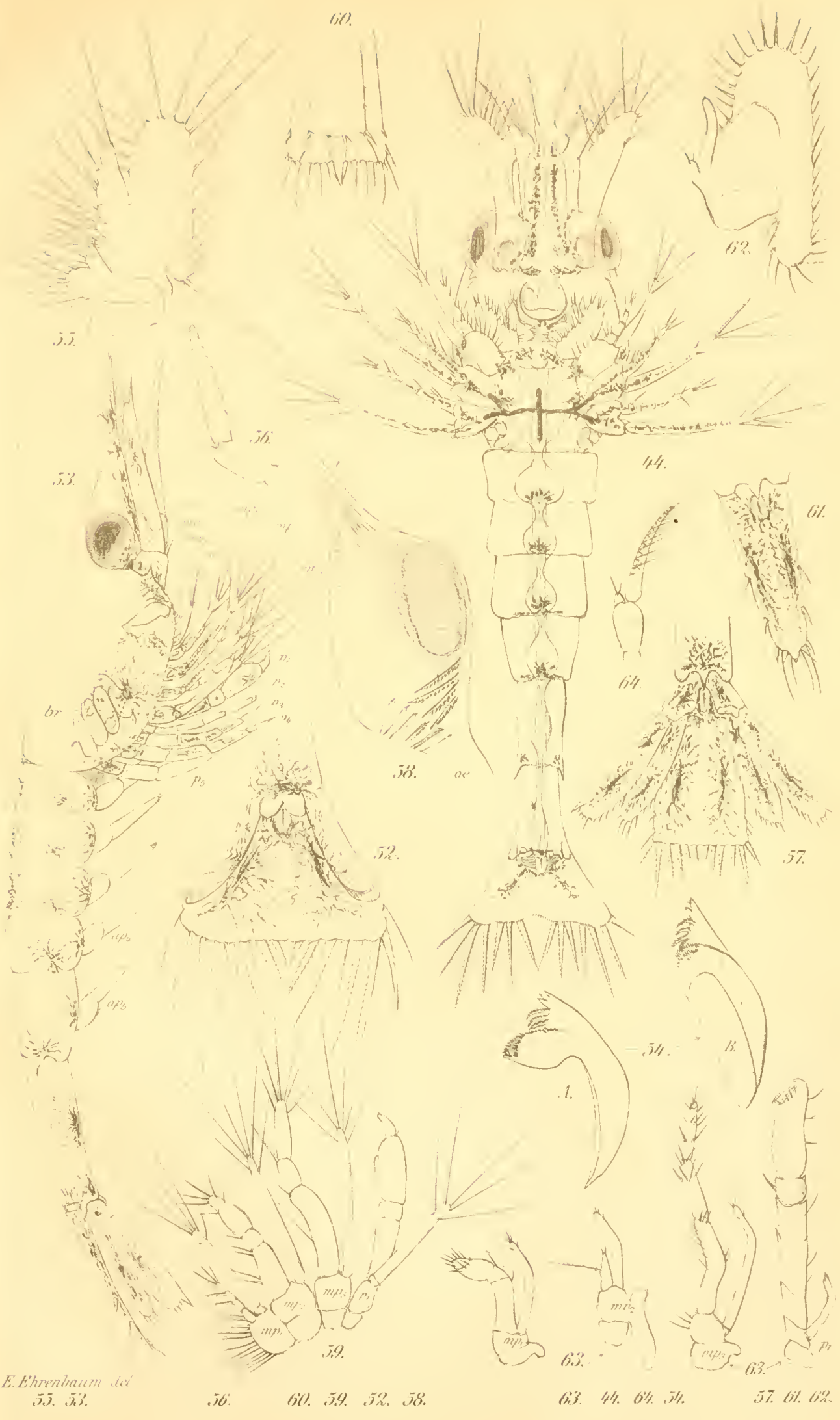








\section{•}




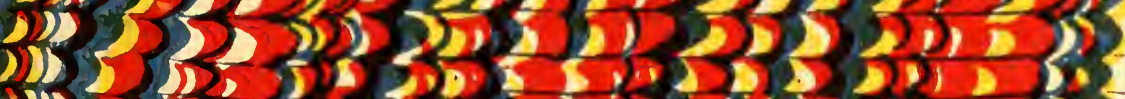

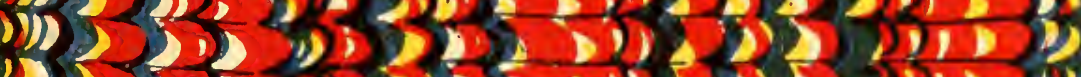

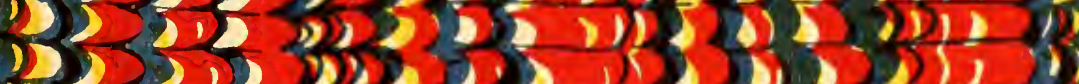

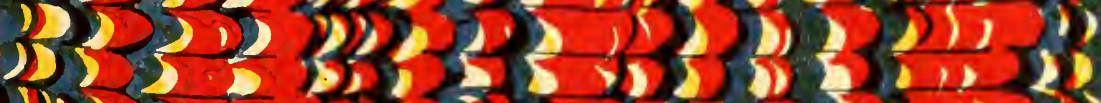

(1) 150

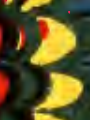

\section{$\{2(2) 1,2$}

$T_{1}(2,1)$

1) 2132

\section{1}

(2) 12

$\{, 5\} 2,21$

35

$(3)$

$2 \sqrt{2} 21$

Di, $25,2(2)$

Di) $1 \geqslant 12(2) 2$

2) 21

2,123

201 DD

D) 122 1))

12)

\section{) (1) 202}

252,20125

2312 2123252

212020212

D) 2,25013

1)

58

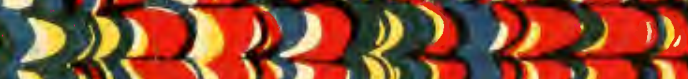

D) 235

1)

\section{3) $2(1,1)$} $32532+31535$

).

\section{1) 525013 , ग)}

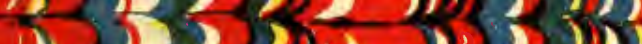

1) $212 !$

2) $22(2) 2$

1)

) 1)

2

()

\section{2}

$2, \frac{1}{25}$

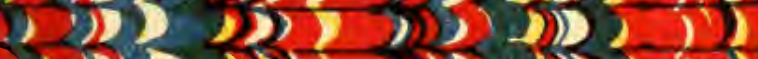

1), (2)

-
(D) D) (3) 2) 2015

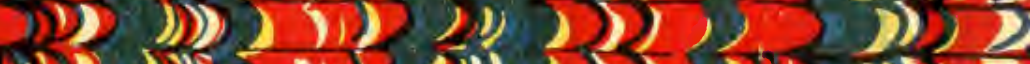

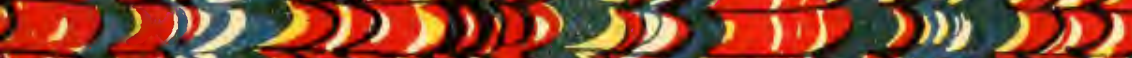

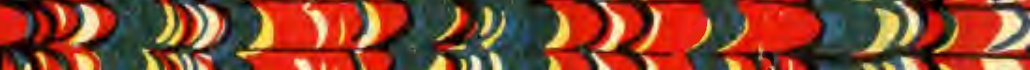

Dij) 2012 ?

D) 2 2)

(1)

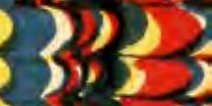

2032 2013

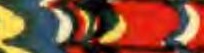

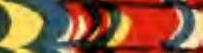
$2 \sqrt{D})$ D) $21,510,212$

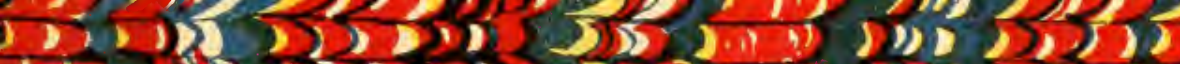

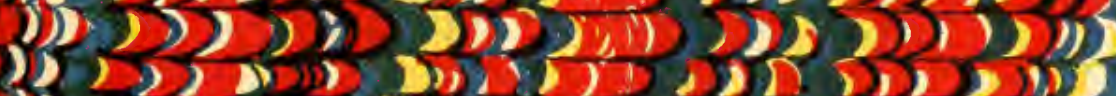


